\title{
GEAP 10371
}

AEC RESEARCH AND

DEVELOPMENT PROGRAM

JUNE 1971

\section{ZIRCALOY-CLAD $\mathrm{UO}_{2}$ FUEL ROD EVALUATION PROGRAM FINAL REPORT NOVEMBER 1967 - JUNE 1971}

F. H. MEGERTH

C. P. RUIZ

U. E. WOLFF 


\section{DISCLAIMER}

This report was prepared as an account of work sponsored by an agency of the United States Government. Neither the United States Government nor any agency Thereof, nor any of their employees, makes any warranty, express or implied, or assumes any legal liability or responsibility for the accuracy, completeness, or usefulness of any information, apparatus, product, or process disclosed, or represents that its use would not infringe privately owned rights. Reference herein to any specific commercial product, process, or service by trade name, trademark, manufacturer, or otherwise does not necessarily constitute or imply its endorsement, recommendation, or favoring by the United States Government or any agency thereof. The views and opinions of authors expressed herein do not necessarily state or reflect those of the United States Government or any agency thereof. 


\section{DISCLAIMER}

Portions of this document may be illegible in electronic image products. Images are produced from the best available original document. 


\section{ZIRCALOY.CLAD UO ${ }_{2}$ FUEL ROD EVALUATION PROGRAM}

\section{Final Report}

November 1967-June 1971
F. H. Megerth
C. P. Ruiz
U. E. Wolff

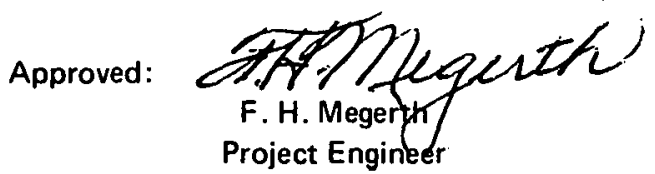

Approved:

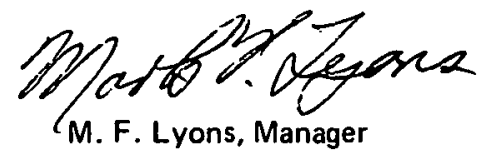

Fuel Development--Water Reactors

Prepared for

U. S. Atomic Energy Commission

Contract AT(04-3)-189

Project Agreement 41

NUCLEAR FUEL DEPARTMENT • GENERAL ELECTRIC COMPANY

SAN JOSE, CALIFORNIA 95125 


\section{NOtICE}

This report was prepared as an account of work sponsored by the United States Government. Neither the United States nor the United States Atomic Energy Commission, nor any of their employees, nor any of their contractors, subcontractors, or their employees, makes any warranty, express or implied, or assumes any legal liability or responsibility for the accuracy. completeness or usefulness of any information, apparatus, product or process disclosed, or represents that its use would not infringe privately owned rights. 


\section{TABLE OF CONTENTS}

ABSTRACT . . . . . . . . . . . . . . . . . . . . . . . 1

1. INTRODUCTION ........................... 1

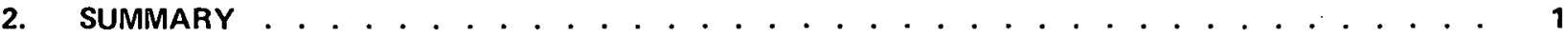

3. DESCRIPTION OF FUEL . . . . . . . . . . . . . . . . . . . . . . . . . . . . . . . . 4

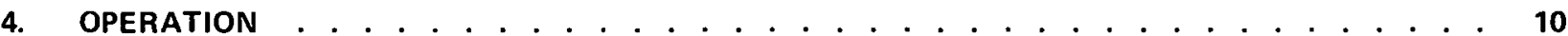

4.1 VBWR . . . . . . . . . . . . . . . . . . . . . 10

4.2 Dresden Unit No. 1 . . . . . . . . . . . . . . . . . . . . . . . . . . . . . . . 18

5. EXAMINATIONS AND ANALYSES OF THE SA-1 FUEL . . . . . . . . . . . . . . . . . . . . 27

5.1 Fuel Rod Performance Evaluation . . . . . . . . . . . . . . . . . . . . . . . . . 27

5.2 Irradiated $\mathrm{UO}_{2}$ Characterization Studies . . . . . . . . . . . . . . . . . . . . . . . 151

5.3 Fuel Burnup and Isotopic Composition Analyses . . . . . . . . . . . . . . . . . . . . 175

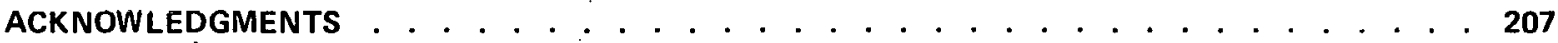

REFERENCES ........................... 208

\section{APPENDICES}

A. LIST OF REPORTS ISSUED . . . . . . . . . . . . . . . . . . . . . . . . . . . . . . 209

B. VBWR OPERATING DATA ON SA-1 RODS . . . . . . . . . . . . . . . . . . . . . . 211

C. DRESDEN REACTOR WATER CHEMISTRY . . . . . . . . . . . . . . . . . . . . . 219

D. DISTRIBUTION OF FISSIONS AMONG URANIUM AND PLUTONIUM ISOTOPES . . . . . . . . . . 223

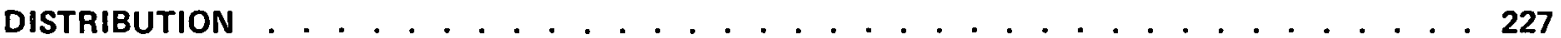

This. report was prepared as an account of work
sponsored by the United States Government. Neither
the United States nor the United States Atomic Energy
Commission, nor any of their employees, nor any of
their contractors, subcontractors; or their employees,
makes any warranty, express or implied; or assumes any
legal liability or responsibility for the accuracy, com-
plcteness or ustuluess uf any infiuinitintion, apporotuo;
product or process disclosed, or represents that its use
would not infringe privately owned rights.




\section{LIST OF ILLUSTRATIONS}

Figure 1

Title

Exploded View of Fuel Rod. . . . . . . . . . . . . . . . . . . . . . . . . . . . . 6

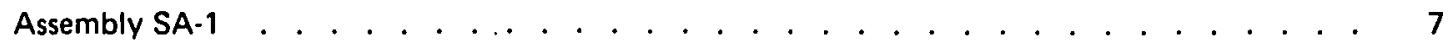

SA-1 Subassembly . . . . . . . . . . . . . . . . . . . . . . . . . . . . . . . 8

Bottom of Subassembly . . . . . . . . . . . . . . . . . . . . . . . . . . . . . 8

Top of Subassembly . . . . . . . . . . . . . . . . . . . . . . . . . . . . . . . . . . . . . . . . . . . . 8

Assembly Nosepiece and Stand . . . . . . . . . . . . . . . . . . . . . . . . . . 9

Handle Holddown Assembly . . . . . . . . . . . . . . . . . . . . . . . . . . . 9

Top of Channeled Assembly . . . . . . . . . . . . . . . . . . . . . . . . . . . . . 10

VBWR Core, Showing Initial Locations of Type J Assemblies . . . . . . . . . . . . . . . . 12

Fuel Centerline Temperature Versus Circumferential-Average Rod Surface Heat Flux . . . . . 13

Gamma Scan of Fuel Rod 11J-R1D71 at End of VBWR Irradiation . . . . . . . . . . . . 14

Approximate Axial Power Distribution for Assembly SA-1 at the Beginning of Dresden Operation. 20

Relative Radial Powers for Various Subassembly Rod Locations in Assembly SA-1 at the

Beginning of Dresden Operation . . . . . . . . . . . . . . . . . . . . . . . . . . 21

Locations of SA-1 and Types of Surrounding Fuel Assemblies in Cycle No. 3 (57-14),

Cycle No. 4 (54-16), and Cycle No. 5 (53-11) . . . . . . . . . . . . . . . . . . . . . 22

Location of SA-1 and Types of Surrounding Fuel Assemblies in Cycle No. 6 . . . . . . . . . . 23

SA-1 Fuel Rod Patterns During Dresden Cycles 3 and $4(a)$ and 5 and 6 (b) . . . . . . . . . 25

Irregular Parterris on Surface of Rod 14J 12 (SA-1, Rod A 18) . . . . . . . . . . . . . . . . . . 28

Severe Fretting Wear at Single-Layer Wire Spacer Contacts . . . . . . . . . . . . . . . . . . 28

Subassembly B-1 at End of Irradiation . . . . . . . . . . . . . . . . . . . . . . . . . . . 29

Typical Speckled Surface Film (Fuel Rod A46) . . . . . . . . . . . . . . . . . . . . 31

Surface Appearance of SA-1 Fuel Rods at Midlength (Rods A8, A15, A22, and A29 in

Subassembly A-1). . . . . . . . . . . . . . . . . . . . . . . . . . . . . . . 32

Rough Surfaces on Rods B64, B78, and B85 at Bottom Spacer of Subassembly B-1 . . . . . . 32

Bandlike Surface Pattern on Rod A15 . . . . . . . . . . . . . . . . . . . . . . . 33

Long End Plug and Plenum Regions of Rods B57, B64, B71, B78, and B85 . . . . . . . , . 33

Cracks in Crud Layer on Fuel Rod B53 . . . . . . . . . . . . . . . . . . . . . . . . . . . 34

Areas of Crud Spalling on Rod B56 at Various Distances from the Short End Plug . . . . . . . 35

Areas of Crud Spalling on Rod B56 at Various Distances from the Short End Plug . . . . . . . 36

Flaky Crud Buildups at Spacer Locations on (a) Rod B51 and (b) Rod B60 . . . . . . . . . 37

Crud Flakus at Dottom Edgo of Spacer Band (Rnds A8, A15, A22, and A29 at

Second Spacer from Topl . . . . . . . . . . . . . . . . . . . . . . . . . . . . 38

Spalling and Cracking of Crul oin Rods B51, B52, B53, and B54 at Bottom Spacer Band Locations 38

Brown Ring and Spots on Rod A11 Between $17.5 \mathrm{~cm}(6-7 / 8 \mathrm{in}$.$) and 28.1 \mathrm{~cm}(11-1 / 16 \mathrm{in}$.$) from$ Short End Plug . . . . . . . . . . . . . . . . . . . . . . . . . . . . 40 White Film on Bottom of Rods B51, B52, and Adjacent Corner Angle . . . . . . . . . . . . . 41 Fine Longitudinally Oriented Lines on (a) $\operatorname{Rod} A 18$. . . . . . . . . . . . . . . . . . . 41

(Continued) Fine Longitudinally Oriented Lines on (b) Rod A23, (c) Rod A43. . . . . . . . . 42 


\section{LIST OF ILLUSTRATIONS (CONTINUED)}

Rough Surface on Rod B50 After Crud Had Been Chemically Removed . . . . . . . . . . . 48

Peak Burnup Region of Rod A37 After Crud Removal . . . . . . . . . . . . . . . . . . 49

Surface Appearance of Rod A37-84 to $87 \mathrm{~cm}$ (33 to 34 in.) from Short End Plug Shoulder . . . 49

Smooth Rings at Pellet-Length Intervals on Rod A7 . . . . . . . . . . . . . . . . . . 50

Subassembly Spacer Markings at (a) 36-cm (14-in.) Location of Fuel Rod B70 and at

(b) 67.9-cm (26-3/4-in.) Location of Fuel Rod B50 . . . . . . . . . . . . . . . . . . . . . . . 51

VBWR Spacer Regions After Crud Removal on (a) Rod B70 and (b) Rod B50 . . . . . . . . 53

Fine, Linear Penetrations in Surface of Rod B50 . . . . . . . . . . . . . . . . . . . . . . . . 54

Pit in Surface of Fuel Rod A9-71.4 cm (28-1/8 in.) from Short End Plug Shoulder . . . . . . 54

Neutron Radiographs of Short End Plug Portions of Rods A43, B52, and A9. Dark Grey Spot on Cladding of Rod A9 Is Indicated. . . . . . . . . . . . . . . . . . . . . . . . . . 55

Neutron Radiographs of Short End Plug. Portions of Six SA-1 Rods. Fuel. Column Gaps and: Pellet Cracking Are Indicated . . . . . . . . . . . . . . . . . . . . . . . . . . . 55

Diameter Profiles of Fuel Rod A7 . . . . . . . . . . . . . . . . . . . . . . . . . 60

Diameter Protiles of Fuel Rod A9 . . . . . . . . . . . . . . . . . . . . . . . . . . 61

Diameter Profiles of Fuel Rod A22 . . . . . . . . . . . . . . . . . . . . . . . . . . . . . . . . . 62

Diameter Profiles of Fuel Rod A37 . . . . . . . . . . . . . . . . . . . . . . . . . . . . . . . . 63

Diameter Profiles of Fuel Rod A49 . . . . . . . . . . . . . . . . . . . . . . . . . . . 64

Diameter Profiles of Fuel Rod B50 . . . . . . . . . . . . . . . . . . . . . . . . . . 65

Gouge or Possible Crack in $\operatorname{Rod} A 40$. . . . . . . . . . . . . . . . . . . . . . . . 68

Group of Fine Cracks $92.7 \mathrm{~cm}$ (36-1/2 in.) from Short End Plug Shoulder of Rod A40 . . . . . 68

Crack in the Surface of Rod A43 Near Spacer Spring Contact Point $3.8 \mathrm{~cm}$ (1-1/2 in.) from

Short End Plug . . . . . . . . . . . . . . . . . . . . . . . . . . . . . . . . 69

Small Pit or Gouge and Discolored Area Located about $64 \mathrm{~cm}$ (25 in.) from Short End Plug of Rod A38 . . . . . . . . . . . . . . . . . . . . . . . . . . . . . . . . . . . . 69

Diameter Profiles of Fuel Rod A11 . . . . . . . . . . . . . . . . . . . . . . . . . 70

Cladding Microstructure of Transversely-Oriented Specimen No. 9957 from Fuel Rod A41 . • $\quad 80$

Cladding Microstructure of Longitudinally-Oriented Specimen No. 9956 from Fuel Rod A41. . $\quad 81$

Cladding Microstructure of Transversely-Oriented Specimen No. A580 from Rod A37 . . . . . 82

Cladding Microstructure of Transversely-Oriented Specimen No. A594 from Rod A49 . . . . . . 83

Example of Corrosion of Outside Cladding Surface, (a) Rod B50 (Specimen No. A609),

(b) Rod B57 (Specimen A613) . . . . . . . . . . . . . . . . . . . . . . . . . . . . . . 84

$\mathrm{ZrO}_{2}$ Layer on Outside Cladding Surface of Specimen No. A611 of Rod B83, (a) Octant No. 8 ,

(b) Octant No. 4 . . . . . . . . . . . . . . . . . . . . . . . . . . . . . . . . 85 


\section{LIST OF ILLUSTRATIONS (CONTINUED)}

Macrograph of Specimen No. 9954 from Rod A13 (As-Ground- 6X Magnification). Locations of Micrographs and Octants (Listed in Table 13) are Indicated. . . . . . . . . . . . . . . . 87 Oxide Weight Gain for SA-1 Cladding as a Function of Fuel Rod Operating Time . . . . . . . 99 Portion of Rod B56 Cladding Showing Thick Crud and External $\mathrm{ZrO}_{2}$ (Specimen No. A624). . . 101 Macrograph of Specimen No. 9960 (As-Ground-10X Magnification) . . . . . . . . . . . . 102 Thick $\mathrm{ZrO}_{2}$ Layer on Cladding in Spacer Spring Contact Area (Rod B70, Specimen No. 9960) . . 103 Macrograph of Specimen No. 9961 (As-Ground $\sim 4 \mathrm{X}$ Magnification). External $\mathrm{ZrO}_{2}$ Thickness in Various Locations is Shown . . . . . . . . . . . . . . . . . . . . . . . . . . 104 Highly Corroded Groove Worn into Cladding of Rod B70 by VBWR Spacer Wire (Specimen No. 9961) . . . . . . . . . . . . . . . . . . . . . . . . . . . . . . 105 Thick External $\mathrm{ZrO}_{2}$ Layer in Region d of Specimen No. 9961. Diameter Profile Traces Over Part of Rod A41 at 0-180-degree and 90-270-degree Orientations. The Location of Metallography Specimen No. 9956 is Indicated . . . . . . . . . . . . . . 106 Macrograph of Specimen No. 9956 (As-Ground-5X Magnification). Thickness of Patch-Type and Even-Film-Type $\mathrm{ZrO}_{2}$ on External Cladding Surface is Shown in Microns . . . . . . . . . . 107 Fuel Particles Attached to Thick Interior $\mathrm{ZrO}_{2}$ Film-Specimen No. 9954 . . . . . . . . . . . . 109 Fuel Particles Attached to Inside Cladding Surface and/or Thin Interior $\mathrm{ZrO}_{2}$ FilmSpecimen No.9958 . . . . . . . . . . . . . . . . . . . . . . . . . . . . . . . 109 Layer of Fuel Attached to Thick Interior $\mathrm{ZrO}_{2}$ Film and Intermediate Darker Phase . . . . . . 110 Area Shown in Figure 77 with Fuel in Etched Condition. . . . . . . . . . . . . . . . . 110 $\mathrm{UO}_{2}$ Microstructures of (a) Specimen No. A580 (Rod A37) and (b) Specimen No. A581 (Rod B62) (Fuel Etched) . . . . . . . . . . . . . . . . . . . . . . . . . . . . . 111 $\mathrm{UO}_{2}$ Microstructure of Specimen No. A582 from Rod A11 (Fuel Etched) . . . . . . . . . . 112 $\mathrm{UO}_{2}$ Microstructure of Specimen No. 9954 from Rod A13 (Fuel Etched). Area Later Examined by Replication Electron Microscopy is Outlined (See Subsection 5.2.1) . . . . . . . . . . . . 113 $\mathrm{UO}_{2}$ Microstructures of (a) Specimen No. 9957 and (b) Specimen No. 9958-Fuel Etched 45 reconds . . . . . . . . . . . . . . . . . . . . . . . . . . . . . 114 Unirradiated SA-1 (Fuel Cycle Program) Archive Cladding Material. . . . . . . . . . . . 116 SA-1 Fuel Rod Cladding Exposed to Approximately $5 \times 10^{21} \mathrm{nvt}>1 \mathrm{MeV}$. . . . . . . . . 117 Schematic Diagram of Tensile Specimens Obtained from SA-1 Fuel Cladding . . . . . . . . . 124 Appearance of Irradiated Longitudinal Coupon Specimens Tested at Various Temperatures . . . . 127 Ring Specimens and Mandrels After Testing at Room Temperature: (a) Specimen A41-14 (Side View), (b) Specimen A13-25 (Side View), (c) Specimen A13-25 (Top View) . . . . . . . 130 Specimen A41-13 After Testing at $343^{\circ} \mathrm{C}\left(650^{\circ} \mathrm{F}\right)$ : (a) Side View, and (b) Top View, Shown with an.Unirradiated Specimen That Has Not Been Tested . . . . . . . . . . . . . . . . . . 131 Specimen A41-16 After Testing at $343^{\circ} \mathrm{C}\left(650^{\circ} \mathrm{F}\right)$ with Grooved Mandrel . . . . . . . . . . . . 132 Specimen A41-4 After Testing at $454^{\circ} \mathrm{C}\left(850^{\circ} \mathrm{F}\right)$. . . . . . . . . . . . . . . . . . . . . . 133 Unirradiated Sample Positioned in Open Shroud Tube Prior to Burst Testing . . . . . . . . . 135 SA-1 Cladding Samples After Burst Testing (See Table 21 for Key to Sample Designation) . . . . 137 Burst Samples Tested at Room Temperature . . . . . . . . . . . . . . . . . . . 138 


\section{LIST OF ILLUSTRATIONS (CONTINUED)}

Burst Samples Tested at $\sim 343^{\circ} \mathrm{C}\left(650^{\circ} \mathrm{F}\right)$ : Unirradiated Sample No. 3 (left); Irradiated Sample A47D-2 (right) . . . . . . . . . . . . . . . . . . . . . . . . . . . 139

Burst Samples Tested at $\sim 399^{\circ} \mathrm{C}\left(750^{\circ} \mathrm{F}\right)$ : Unirradiated Sample No. 6 (left); Irradiated Sample B98C-1 (right) . . . . . . . . . . . . . . . . . . . . . . . . . . . . 140 Burst Samples Tested at $\sim 454^{\circ} \mathrm{C}\left(850^{\circ} \mathrm{F}\right)$ : Unirradiated Sample No. 9 (left, top); Irradiated Samples B50A-2 (left, bottom) and B96C-2 (right)

Values of $\left(D_{f}-D_{i}\right) / D_{i} \times 100$ at Various Points Along Samples Tested at a Nominal Temperature of $343^{\circ} \mathrm{C}\left(650^{\circ} \mathrm{F}\right)$. (Two determinations 90 degrees apart were made at each axial location indicated.)

Values of $\left(D_{f}-D_{j}\right) / D_{i} \times 100$ at Various Points Along Samples Tested at a Nominal Temperature of $399^{\circ} \mathrm{C}\left(750^{\circ} \mathrm{F}\right)$

Values of $\left(D_{f}-D_{j}\right) / D_{i} \times 100$ at Various Points Along Samples Tested at a Nominal Temperature of $454^{\circ} \mathrm{C}\left(850^{\circ} \mathrm{F}\right)$

Typical Array of Diamond Pyramid Hardness Indentations (Specimen No. 9957)

Center Region of Irradiated Fuel After Standard Etch, Showing Some Precipitates and Light Grain Boundary Attack. [0.36 cm (0.14 in.) from Pellet Periphery] (Specimen No. 9954) . . . . . .

Ring Region $0.30 \mathrm{~cm}$ (0.12 in.) from Pellet Periphery. Note Numerous Precipitates. (Specimen No. 9954) . . . . . . . . . . . . . . . . . . . . . . . . . . . . . . . . . 152

Ring Region $0.24 \mathrm{~cm}(0.09$ in.) from Pellet Periphery (Specimen No. 9954) . . . . . . . . . . 153

Outside of Ring Region $0.18 \mathrm{~cm}$ (0.07 in.) from Pellet Periphery. Note Lack of Precipitates.

(Specimen No. 9954) . . . . . . . . . . . . . . . . . . . . . . . . . . . . . . 153

$0.13 \mathrm{~cm}$ (0.05 in.) from Pellet Periphery, Where Increased Grain Boundary Attack Appears

(Specimen No. 9954) _. . . . . . . . . . . . . . . . . . . . . . . . . . . . . . 154

$0.06 \mathrm{~cm}$ (0.02:in.) from Pellet Periphery, Where Large Precipitates Start to. Appear.

(Specimen No. 9954)“ . . . . . . . . . . . . . . . . . . . . . . . . . . . . . . 154

Fuel-Cladding Interface Region. Note Numerous Large Precipitates in $\mathrm{UO}_{2}$ (Specimen. No. 9954) . 155

Large Intragranular Precipitates of Figure 107 Shown at Higher Magnification. Note

Orientation . . . . . . . . . . . . . . . . . . . . . . . . . . . . . . . . . 155

Irradiated $\mathrm{UO}_{2}, 8 \times 10^{20}$ Fissions $/ \mathrm{cm}^{3} 1.3 \pm 0.7 \mathrm{~mm}$ from Cladding . . . . . . . . . . . . 157

Irradiated $\mathrm{UO}_{2}, 8 \times 10^{20}$ Fissions $/ \mathrm{cm}^{3} 0.2_{-0.2}^{+0.7} \mathrm{~mm}$ from Cladding . . . . . . . . . . . . 158

Irradiated $\mathrm{UO}_{2}, \sim 0.2 \mathrm{~mm}$ from Cladding. Platelet Precipitates in Matrix . . . . . . . . . . . . . 159

Irradiated $\mathrm{UO}_{2}, \sim 1.3 \mathrm{~mm}$ from Cladding . . . . . . . . . . . . . . . . . . . . . . 160

Irradiated $\mathrm{UO}_{2}, \sim 1.3 \mathrm{~mm}$ from Cladding . . . . . . . . . . . . . . . . . . . . . . . . 161

Irradiated $\mathrm{UO}_{2}$, Near Fuel Center . . . . . . . . . . . . . . . . . . . . . . . . . . 162

Plastic Mold for Replicating Resin . . . . . . . . . . . . . . . . . . . . . . . . . 163

Replication Stages with Technovit, Replica No. 7 . . . . . . . . . . . . . . . . . . . 164

Schematic Representation of Replication. . . . . . . . . . . . . . . . . . . . . . . 166

Technovit Replica No. 16 . . . . . . . . . . . . . . . . . . . . . . . . . . . . 167

Technovit Replica No. 18 . . . . . . . . . . . . . . . . . . . . . . . . . . . . 168

Carbon Replica No. 7 from Near Fuel-Cladding Interface . . . . . . . . . . . . . . . . 169

Carbon Replica No. 7 . . . . . . . . . . . . . . . . . . . . . . . . . . . . . . 170 


\section{LIST OF ILLUSTRATIONS (CONTINUED)}

Carbon Replica No. 16 Showing Grain Boundary Surfaces : . . . . . . . . . . . . . . . 171

Carbon Replica No. 18 from Center of Fuel . . . . . . . . . . . . . . . . . . . . . 172

Carbon Replica No. 18 . . . . . . . . . . . . . . . . . . . . . . . . . . . . . 173

Carbon Replica No.18 . . . . . . . . . . . . . . . . . . . . . . . . . . . . . 174

Technovit Replicas in Molds with Embedded $\mathrm{UO}_{2}$ Particles Extracted From Fuel Section A584 176

Appearance of Portion of Fuel Rod B70 After Samples Had Been Removed from Different

Radial Locations . . . . . . . . . . . . . . . . . . . . . . . . . . . . . . . . 178

Locations of Burnup and Isotopic Composition Samples from Rods A37 and B62 in Terms of Distance from the Bottom of the Reactor Active Fuel Zone . . . . . . . . . . . . . . . 185

Schematic Drawing of $\mathrm{Ge}(\mathrm{Li})$ and Nal(TI) Gamma Scanning Systems . . . . . . . . . . . . 186

Typical Gamma Ray Spectrum Obtained with the $40 \mathrm{cc}$ Ge(Li) Detector on a 1024 Multichannel Analyzer . . . . . . . . . . . . . . . . . . . . 187

Gross Axial Gamma Profile of Rod A13 . . . . . . . . . . . . . . . . . . . . . . . 190

Gross Axial Gamma Profile of Rod B97 . . . . . . . . . . . . . . . . . . . . . . . 191

Gross Axial Gamma Profile of Rod A37 . . . . . . . . . . . . . . . . . . . . . . . 192

Comparison of Relative Burnups at Various Axial Locations by Cs-137 from the Rod Scan with Values Obtained by Nd-148 Method for Rod A37 . . . . . . . . . . . . . . . . . . 193

Comparison of Relative Burnups at Various Axial Locations by Cs-137 from the Rod Scan with Values Obtained by Nd-148 Method for Rod B62 . . . . . . . . . . . . . . . . . . . 194

Gamma Scan of Rod B86 for Cs-137 . . . . . . . . . . . . . . . . . . . . . . 195

Comparison of Relative Burnups by Cs-137 from Rod Gamma Scan Data at Specific Axial Locations with Those Obtained by the Nd-148 Method at the Same Locations for Subassembly A-1. Data are Normalized to the Sample Point from Rod A37

Comparison of Relative Burnups by Cs-137 from Rod Gamma Scan Data at Specific Axial Locations with Those Obtained by the Nd-148 Method at the Same Locations for Subassembly B-1. Data are Normalized to the Sample Point from Rod A37 . . . . . . . . . . 197 Gamma Scan of Rod A37 for Ru-106 . . . . . . . . . . . . . . . . . . . . . . . . 198 Gamma Scan of Rod B86 for Ru-106 . . . . . . . . . . . . . . . . . . . . . . . . 199 Gamma Scan of Rod A37 for $\operatorname{Pr} 144$. . . . . . . . . . . . . . . . . . . . . . . . 200 Gamma Scan of Rod 886 for Pr-144 . . . . . . . . . . . . . . . . . . . . . . . . 201

Gamma Scan of $\operatorname{Rod} \mathrm{A} 37$ for $\mathrm{Zr} / \mathrm{Nb}-95 \ldots \ldots 202$

Gamma Scan of Rod B86 for Zr/Nb-95 . . . . . . . . . . . . . . . . . . . . . . . 203

Relative Rod-Average Fission Product Activity Values Obtained from Rods from

Subassembly A.1 (Bottom) . . . . . . . . . . . . . . . . . . . . . . . . . . . 204

Relative Rod-Average Fission Product Activity Values Obtained from Rods from Subassembly B-1 (Top) : . . . . . . . . . . . . . . . . . . . . . . . . . . . . 205

Comparison of the Ru-106/Ce-144 Ratio for an Estimate of the Pu/(U + Pu) Fission Ratio for Rod A37 During Its Most Recent Exposure History . . . . . . . . . . . . . . . . . 206 


\section{LIST OF TABLES}

Table

Characteristics of Type J Fuel Rods Selected for Assembly SA-1 . . . . . . . . . . . . . . . . 5

Operational Data on the SA-1 Fuel Rods . . . . . . . . . . . . . . . . . . . . . . 15

DNPS Unit No. 1 Reactor Operating Data . . . . . . . . . . . . . . . . . . . . . . 19

SA-1 Thermal Performance History in Dresden . . . . . . . . . . . . . . . . . . . . . 26

Rods Selected for Diameter Profile Measurements . . . . . . . . . . . . . . . . . . . 57

Crud Thickness by Profilometry . . . . . . . . . . . . . . . . . . . . . . . . . . 58

Rod Diameter After Decrudding . . . . . . . . . . . . . . . . . . . . . . . . . . . . . 59

Post-Irradiation Rod Length . . . . . . . . . . . . . . . . . . . . . . . . . . . 72

Calculated Axial Interference in SA-1 Rods . . . . . . . . . . . . . . . . . . . . . 73

Rod Bow . . . . . . . . . . . . . . . . . . . . . . . . . . . . . . . . . . . 75

Gas Composition and Release . . . . . . . . . . . . . . . . . . . . . . . . . . . 76

Isotopic Analysis of Krypton and Xenon by Mass Spectrometry . . . . . . . . . . . . . . . . 77

Thickness of Crud and $\mathrm{ZrO}_{2}$ on the Cladding of Transverse Metallography Specimens . . . . . 88

Thickness of $\mathrm{ZrO}_{2}$ on the Cladding of Longitudinal Metallography Specimens . . . . . . . . . 97

Chromatographic Analysis of Gases Evolved from Fuel Rod Cladding Samples . . . . . . . . 119

Chromatographic Analysis of Gases Evolved from Fuel Rod Cladding Samples . . . . . . . . 120

Tritium Content of Cladding Samples . . . . . . . . . . . . . . . . . . . . . . . 122

Rod Operating Data . . . . . . . . . . . . . . . . . . . . . . . . . . . . . 123

Tensile Tests on Longitudinal Coupon Cladding Specimens . . . . . . . . . . . . . . . 126

SA-1 Cladding Ring Tests . . . . . . . . . . . . . . . . . . . . . . . . . . . 129

Burst Tests on SA-1 Cladding Samples . . . . . . . . . . . . . . . . . . . . . . 142

Microhardness of SA-1 Cladding . . . . . . . . . . . . . . . . . . . . . . . . . 146

Chemical Analysis of Crud Solutions . . . . . . . . . . . . . . . . . . . . . . . 149

Fast and Thermal Neutron Fluence . . . . . . . . . . . . . . . . . . . . . . . . 150

Lattice Parameter of Irradiated $\mathrm{UO}_{2}$. . . . . . . . . . . . . . . . . . . . . . . . 177

Burnups and Uranium and Plutonium Isotopic Compositions of Full Cross Section Samples . . . 180

Abundances of U-232, Np-237, Pu-236, Pu-238, Am and $\mathrm{Cm}$ Isotopes in Full Cross Section

Fuel Samples . . . . . . . . . . . . . . . . . . . . . . . . . . . . . . 181

Fission Product Analyses on Full Cross Section Fuel Samples . . . . . . . . . . . . . . . 182

Analyses of Fuel Samples from Different Radial Locations, Fuel Rod A13 . . . . . . . . . . . 183

Analyses of Fuel Samples from Different Radial Locations, Fuel Rod B70 . . . . . . . . . . . 184

Ratios of Axial Peak to Rod-Average Gamma Ray Intensities . . . . . . . . . . . . . . . . . 189

VBWR Operating Data on SA-1 Rods . . . . . . . . . . . . . . . . . . . . . . . . 212

Dresden Reactor Water Chemistry . . . . . . . . . . . . . . . . . . . . . . . . 220

Distribution of Fissions Among Uranium and Plutonium Isotopes for Full Cross-Section Fuel

Samples . . . . . . . . . . . . . . . . . . . . . . . . . . . . . . . 224

Distribution of Fissions Among Uranium and Plutonium Isotopes for Fuel Samples From Different Radial Locations Rod A13 . . . . . . . . . . . . . . . . . . . . . . . . 225

Distribution of Fissions Among Uranium and Plutonium Isotopes for Fuel Samples From

Different Radial Locations Rod B70 . . . . . . . . . . . . . . . . . . . . . . . . 226 


\begin{abstract}
The Zircaloy-clad $\mathrm{UO}_{2}$ pellet fuel rods in Assembly SA-1 received their initial irradiation in the VBWR, and were subsequently exposed in Dresden-1 to an estimated average burnup of $8.2 \times 10^{20}$ fissions $/ \mathrm{cm}^{3}(29,800 \mathrm{MWd} / \mathrm{tU})$. The peak and maximum rod. average burnups were $10.4 \times 10^{20}$ fissions $/ \mathrm{cm}^{3}(37,900 \mathrm{MWd} / \mathrm{tU})$ and $9.3 \times 10^{20}$ fissions $/ \mathrm{cm}^{3}(33,900 \mathrm{MWd} / \mathrm{tU})$, respectively. The total operating time in both reactors was 1827 days. Local peak powers of $14 \mathrm{~kW} / \mathrm{ft}$ were attained by some rods early in operation. No full-wall cladding penetrations were detected.

The average external corrosion weight gain shown by the fuel rod cladding at the end of operatlon was $480 \mathrm{mg} / \mathrm{dm}^{2}$, and the maximum hydrogen content measured was $146 \mathrm{ppm}$. Burst samples exposed to about $7 \times 10^{21}$ nvt $>1 \mathrm{MeV}$ showed hoop stresses at rupture of $5100 \mathrm{~kg} / \mathrm{cm}^{2}(72 \mathrm{kpsi})$ at $343^{\circ} \mathrm{C}\left(650^{\circ} \mathrm{F}\right)$ and $4400 \mathrm{~kg} / \mathrm{cm}^{2}(62 \mathrm{kpsi})$ at $454^{\circ} \mathrm{C}$ $\left(850^{\circ} \mathrm{F}\right)$. Strains to fracture of 2 to 8 percent were obtained with no clear temperature dependence indicated. Maximum fission gas release was less than 1 percent. The irradiated $\mathrm{UO}_{2}$ was examined by light and electron microscopy and by $x$-ray diffraction. Full cross-section and radially variant fuel samples were measured for burnup, uranium and plutonium isotopic composition, neptunium, americium, curium, and certain fission products. Relatively high levels of U-232, Pu-236, and Pu-238 were measured on some samples.
\end{abstract}

\title{
1. INTRODUCTION
}

At the time of the final shutdown of the Vallecitos Boiling Water Reactor (VBWR) and the termination of the AEC Fuel Cycle Program (Contract AT(04-3)-189, Project Agreement 11), the leading Zircaloy-2-clad UO ${ }_{2}$ fuel rods of the program's Type $J$ basic assemblies had attained rod average exposures as high as $3 \times 10^{20} \mathrm{fissions} / \mathrm{cm}^{3}$ $(10,000 \mathrm{MWd} / \mathrm{tU})$.

To demonstrate at the earliest possible time the capability of Zircaloy-clad fuel to achieve average burnups of at least $6 \times 10^{20}$ fissions $/ \mathrm{cm}^{3}\left(20,000 \mathrm{MWd} / \mathrm{tU}^{*}\right)$ and to take advantage of the available lead time in achieving these burnup targets, 98 of the higher exposure Fuel Cycle Program rods were incorporated in a special assembly designated as SA-1 and inserted in Unit No. 1 of the Commonwealth Edison Company's Dresden Nuclear Power Station for additional irradiation. The assembly consisted of two $7 \times 7$ subassemblies, stacked one on top of the other in a channel of standard dimensions for the Dresden reactor. Assembly SA-1 was operated continuousty from June 1964 to September 1969, with the exception of reactor shutdowns for refueling and maintenance.

To investigate in detail. the performance of the SA-1 fuel rods and to determine the isotopic composition of the highly exposed fuel, a two-phase program of destructive examination and analysis was. drawn up. For the initial phase of the program, ten rods were removed from the assembly in January 1967, after 1200 days of VBWR and Dresden operation, and were shipped to the Vallecitos Nuclear Center. The remaining rods operated on the average, a total of 1827 days. The two 44-rod subassemblies were shipped to VNC in March 1970 for the final phase of the program.

The present report briefly reviews the design and fabrication characteristics of the SA-1 fuel, describes the conditions of operation, and gives a detailed account of the examination results.

Prior reports to the Atomic Energy Commission under the Zircaloy-Clad $\mathrm{UO}_{2}$ Fuel Rod Evaluation Program are listed in Appendix A.

\section{SUMMARY}

The 88 rods that operated in Assembly SA-1 to the end of Dresden Reactor Cycle No. 6 attained an estimated average terminal burnup of $8.2 \times 10^{20}$ fissions $/ \mathrm{cm}^{3}(29,800 \mathrm{MWd} / \mathrm{tU})$. The maximum rod-average burnup measured was $9.3 \times 10^{20}$ fissions $/ \mathrm{cm}^{3}(33,900 \mathrm{MWd} / \mathrm{tU})$ and the axial peak burnup measured was $10.4 \times 10^{20} \mathrm{fissions} / \mathrm{cm}^{3}$ $(37,900 \mathrm{MWd} / \mathrm{tU})$. These rods operated in Dresden 1468 days. The total days of operation, including those in the VBWR, then ranged from 1767 to 1846.

\footnotetext{
* Megawatt days per short ton of uranium
} 
All of the rods that were selected for incorporation in Assembly SA-1 were determined to be sound at the conclusion of their operation in the VBWR. The interim leak tests and examinations conducted during Dresden operation, as well as all tests and examinations performed at the conclusion of SA-1's operation, failed to detect any full-wall cladding penetration in any rod.

The assembly operated at an estimated peak heat flux of $117 \mathrm{~W} / \mathrm{cm}^{2}\left(372,000 \mathrm{Btu} / \mathrm{h}-\mathrm{ft}^{2}\right)$ early in Dresden operation and underwent a fairly continuous decrease in power level with increasing exposure. The estimated peak heat flux attained during the fourth and final cycle of operation was about one-half of that attained during the first cycle. Most of the rods operated in the VBWR, for relatively brief periods, at power levels above those attained in Dresden. The maximum peak heat flux attained in the VBWR by any of the rods is estimated to have been $137 \mathrm{~W} / \mathrm{cm}^{2}(435,000$ $B t u / h-\mathrm{ft}^{2}$ or $\left.14 \mathrm{~kW} / \mathrm{ft}\right)$. The estimated peak centerline temperature associated with this heat flux is $\sim 2050^{\circ} \mathrm{C}\left(3700^{\circ} \mathrm{F}\right)$.

The two subassemblies appeared to be in generally good condition at the end of operation. The corrosion product, or crud, film that was deposited on the rods during Dresden operation generally gave most of the surface area a coloration best described as bluish-gray with varied amounts of reddish-brown. The reddish-brown portion of the film frequently was distributed in the form of speckles, and in such cases the surface usually appeared somewhat rough in texture. There were no distinct differences in appearance between rods that operated two cycles in Dresden and those that operated four cycles.

Essentially all of the crud observed on the SA-1 rods was deposited during Dresden operation, inasmuch as most of the crud deposited during VBWR operation was wiped from the rods before they were selected for further irradiation. The crud film was quite adherent over most of the rod surface. This was particularly true of the bluish-gray portion of the film. Chemical analysis indicated that nickel, iron, copper, and chromium were the principal metallic elements present, with the nickel concentration amounting to between 65 and 75 percent of the total. The mean and maximum rod-average crud thicknesses measured on selected rods that had operated $\mathbf{8 4 0}$ days in Dresden were about $0.0009 \mathrm{~cm}(0.00035 \mathrm{in.})$ and $0.0012 \mathrm{~cm}(0.0005 \mathrm{in}$.$) , respectively. The corresponding values determined on a group of$ rods that had operated 1468 days were about $0.0012 \mathrm{~cm}(0.0005 \mathrm{in}$.$) and 0.0017 \mathrm{~cm}(0.0007 \mathrm{in}$.$) . The maximum$ circumferential-average crud thickness measured at any axial location of any rod was $0.0028 \mathrm{~cm}(0.0011 \mathrm{in}$.). One corner rod exhibited a rather extensive spalling of the crud layer but, generally, only minor amounts of spalling were observed.

The rough, blistered appearance of portions of the rod surfaces was found to be primarily a consequence of the type of cladding corrosion that typically occurred, i.e., the formation of a relatively thin and even $\mathrm{ZrO}_{2}$ film in combination with a pitting attack that resulted in intermittent thicker patches of $\mathrm{ZrO}_{2}$. Among rods that operated to the end of Cycle No. 6, the average thickness of the even film-type $\mathrm{ZrO}_{2}$ was $14 \mu(0.0006 \mathrm{in}$.$) and that of the$ patch-type was $68 \mu(0.0027$ in.). The circumferential-average corrosion weight gain determined from thickness measurements on metallography specimens had a mean value of $480 \mathrm{mg} / \mathrm{dm}^{2}$ for these rods. Rods that were removed from SA-1 at the end of Cycle No. 4 after an average total exposure time of approximately 1200 days showed a mean weight gain of $320 \mathrm{mg} / \mathrm{dm}^{2}$, while comparable rods that saw only VBWR operation ( 365 days) showed a mean weight gain of $125 \mathrm{mg} / \mathrm{dm}^{2}$. Thus the post-transition corrosion rate of the SA-1 cladding was approximately $0.24 \mathrm{mg} / \mathrm{dm}^{2} /$ day. It must be pointed out, however, that due to uncertain causes, the weight gains determined on some of the individual SA-1 rods deviated considerably from the mean value. A specimen from one rod that saw 1803 days of exposure showed a circumferential-average weight gain of about $1100 \mathrm{mg} / \mathrm{dm}^{2}$. In addition, abnormally thick, fairly even layers of $\mathrm{ZrO}_{2}$ were observed over 45 to 90 degrees of about 15 percent of the specimens examined. On one specimen the corrosion layer reached an average thickness of $119 \mu(0.0047 \mathrm{in}$.) over one octant of its circumference.

Some increase in corrosion occurred near some of the subassembly spacer spring contact locations and also in the vicinity of some of the wire-type spacers employed during VBWR irradiation.

Oxidation of the inside cladding surface also apparently increased throughout the period of operation. Most of the specimens from rods that operated to the end of Cycle No. 6 showed internal $\mathrm{ZrO}_{2}$ films 8 to $9 \mu$ thick.

In general, very few platelets of zirconium hydride were observed in the metallographic examination of the cladding, but those that were present were uniformly distributed. The hydrogen contents, determined on samples from selected rods by hot vacuum extraction followed by gas chromatography, ranged from 45 to $146 \mathrm{ppm}$. The average contents of samples from rods that operated in Dresden two cycles and four cycles were $66 \mathrm{ppm}$ and $92 \mathrm{ppm}$, respectively. The average pre-irradiation content was about $28 \mathrm{ppm}$. Hydrogen constituted 72 to 96 percent by volume of the gas evolved from the different samples. The gas also contained significant amounts of carbon monoxide and lesser amounts of carbon dioxide, nitrogen, oxygen, and methane. The carbon monoxide content ran as high as $\sim 20$ percent in some samples from rods that operated to the end of Cycle No. 6. 
Tritium analyses were performed on samples of cladding from some of the rods removed from the assembly at the end of Cycle No. 4. The tritium contents ranged from approximately 5 to 58 ppb, equivalent to about 2 to 16 percent of the tritium generated during operation.

Changes in outside diameter were determined on some of the fuel rods by comparing the results of postirradiation profilometer scans; made after the crud had been chemically removed from the rod surfaces, with preirradiation micrometer measurements. The rods showed diameter increases which, averaged over the rod lengths, ranged from $0.001 \mathrm{~cm}(0.0005 \mathrm{in}$.$) to 0.004 \mathrm{~cm}(0.0015 \mathrm{in}$.) and had a mean value of $0.003 \mathrm{~cm}(0.001$ in.). The results were nearly the same for rods removed at the end of Cycle No. 4 and those that operated to the end of Cycle No. 6. Some of the diameter increase was due to formation of $\mathrm{ZrO}_{2}$ on the rod surfaces. It is estimated that with the effect of corrosion taken into account the maximum "true" rod-average increase was between $0.001 \mathrm{~cm}(0.0005 \mathrm{in}$.) and $0.003 \mathrm{~cm}(0.001 \mathrm{in.})$.

Length measurements made on the rods removed from SA-1 for the initial phase of the examination program indicated increases over the pre-irradiation lengths which ranged from 0.08 to $0.24 \mathrm{~cm}(1 / 32$ to $3 / 32$ in.) and averaged $0.16 \mathrm{~cm}(1 / 16 \mathrm{in}$.$) , or 0.16$ percent. Similar measurements made during the final phase of the program showed increases that ranged from 0.15 to $0.33 \mathrm{~cm}(0.06$ to $0.13 \mathrm{in.})$ and averaged $0.23 \mathrm{~cm}(0.09$ in.), or 0.23 percent. However, uncertainties in the pre-irradiation lengths reduce the accuracy of the data, and there is some question as to whether the plenum support tubes inside the rods may have been a factor in the length increases.

Samples of irradiated fuel rod cladding that were burst tested at room temperature and at $343^{\circ} \mathrm{C}\left(650^{\circ} \mathrm{F}\right), 399^{\circ} \mathrm{C}$ $\left(750^{\circ} \mathrm{F}\right)$, and $454^{\circ} \mathrm{C}\left(850^{\circ} \mathrm{F}\right)$ showed respective hoop stresses at rupture of approximately $8000 \mathrm{~kg} / \mathrm{cm}^{2}(114 \mathrm{kpsi})$, $5100 \mathrm{~kg} / \mathrm{cm}^{2}(72 \mathrm{kpsi}), 4900 \mathrm{~kg} / \mathrm{cm}^{2}(69 \mathrm{kpsi})$, and $4400 \mathrm{~kg} / \mathrm{cm}^{2}(62 \mathrm{kpsi})$. Irradiation to estimated fast fluences of $6 \times 10^{21}$ to $7 \times 10^{21} \mathrm{nvt}\left(\mathrm{E}>1 \mathrm{MeV}\right.$ ) increased the stress values 1400 to $1800 \mathrm{~kg} / \mathrm{cm}^{2}$ (19 to $25 \mathrm{kpsi}$ ) above those of comparable unirradiated samples. The strain to fracture values ranged from 2 to 8 percent among the irradiated samples, and did not show any clear temperature dependence between $343^{\circ} \mathrm{C}$ and $454^{\circ} \mathrm{C}$. Longitudinally oriented cladding coupon specimens exposed to between $\sim 3.5 \times 10^{21}$ and $5 \times 10^{21}$ nvt showed ultimate tensile strengths generally somewhat lower than the ultimate hoop stresses of the above burst samples and total elongations also somewhat lower, in general, than the strain-to-fracture values of the burst samples. The difference in strengths increased and the difference in elongations decreased with increasing test temperature. The total elongations shown by the longitudinal specimens in $343^{\circ} \mathrm{C}$ tests were only approximately 1 percent.

Cladding "ring-on-mandrel" tests showed strains to fracture of 13 to 27 percent in room temperature tests and of 34 to 45 percent in tests at $454^{\circ} \mathrm{C}\left(850^{\circ} \mathrm{F}\right)$ on specimens exposed to an estimated fast fluence of approximately $5 \times 10^{21}$ nvt $>1 \mathrm{MeV}$. Specimens tested at $343^{\circ} \mathrm{C}\left(650^{\circ} \mathrm{F}\right)$ were strained as much as 69 percent without fracturing. In this type of test a narrow transverse section, i.e., the ring of cladding is centered on a metal cylinder somewhat taller than the ring width and is increased in diameter by compressing the ends of the cylinder. The high strains achieved are attributed to the suppression of localized necking through the development of shear forces which support the entire gage length of the specimen. The results are in marked contrast to those obtained in the coupon tensile and burst tests in which necking instabilities are not supported.

The free gas contained in selected fuel rods from both the initial and final phase groups was analyzed for fission gas release and composition. The percentages of fission-generated $\mathrm{Kr}-85$ that were released from the $\mathrm{UO}_{2}$ matrix to the internal void volume ranged from about 0.1 to 0.9 percent. There was little difference between the two rod groups with respect to release percentage. The compositions of the gas samples, determined by chromatographic analysis and mass spectrometry, in general, appeared normal.

The irradiated $\mathrm{UO}_{2}$ fuel was examined by light microscopy and by replication and transmission electron microscopy. Evidence of some equiaxed central grain growth was observed in some of the specimens. The maximum ratio of central-to-peripheral grain size was approximately 3 to 1.

All specimens showed platelet-shaped precipitates of uncertain identity within the grains of the etched fuel near the outside surfaces of the pellets. Intragranular precipitates were observed also at interior locations of most specimens. In some of these cases the precipitates were most pronounced near the pellet center, while in others the maximum concentration occurred at mid-radial locations. Inclusions that appeared to have the same size and shape as those observed by light and replication electron microscopy at the peripheral locations were observed in the same general location by transmission electron microscopy. Some second phase particles that did not have the same appearance as the intragranular precipltates were seen on grain boundary surfaces in examinations by replication electron microscopy.

Lattice parameter measurements made on $\mathrm{UO}_{2}$ samples from one of the most highly exposed fuel rods showed values that ranged from $5.475 \AA$ at the pellet center to $5.477 \AA$ at the periphery compared with a value of $5.470 \AA$ for an unirradiated control specimen. The average increase in lattice parameter, which is attributed to radiation damage, was 0.10 percent. No phases other than $\mathrm{UO}_{2}$ could be detected by $x$-ray diffraction analysis. 
Burnup and isotopic composition were determined on selected fuel samples in both the initial and final phases of the program by measuring $\mathrm{Nd}-148$ and the uranium and plutonium isotopes by mass spectrometry and applying the computer code BURNUP. Np-237, U-232, Pu-236, Pu-238, americium, curium, and some of the fission products also were measured on some of the above samples. The concentrations of U-232 relative to U-235 in four high exposure samples ranged from 400 to $500 \mathrm{ppb}$. The atom ratios of Pu-236 and Pu-238 relative to U-238 averaged $9 \times 10^{-10}$ and $2 \times 10^{-4}$, respectively.

Cs-137 was determined to be an adequate burnup monitor for use in gamma scanning. By providing data on relative rod-average burnups and traces of axial burnup profiles, the Cs-137 gamma scanning technique combined with the Nd-148 data allowed rapid, nondestructive determinations of absolute average and peak burnups on a significant fraction of the SA-1 rods. The possibility of using gamma scan data to measure the plutonium fission rate relative to that of uranium also was demonstrated.

The fast fluences were measured by two methods, one based on the analysis of fuel samples and the other on the analysis of cladding samples. Good agreement was obtained between the two sets of data.

In conclusion, the SA-1 fuel rods and other parts of the assembly operated satisfactorily to relatively high burnups and long exposures. As far as could be determined, no full-wall cladding penetrations occurred, and none of the few areas that were suspected of being defective during the early stages of examination could be confirmed as defective upon further examination. Furthermore, none of the observations or results of the examinations, tests, and analyses revealed any conditions indicative of imminent fuel rod failure.

However, the operating mode of the SA-1 fuel rods was not unfavorable to the attainment of relatively high exposure levels without cladding failure. The fuel rod heat ratings almost steadily decreased toward end-of-life from the initial peak value in Dresden reached immediately after installation. Had the end-of-life power levels been close to those attained earlier, the $\mathrm{UO}_{2}$ temperatures would have been much higher and, conceivably, conducive to enhanced fission product induced fuel swelling. This swelling in turn could lead to larger fuel-cladding interaction strains, i.e., strains approaching or exceeding the irradiation-impaired strain capability of the cladding. The ductility of the cladding, as measured by longitudinal tensile and burst test results was, of course, significantly reduced during operation. At the conclusion of VBWR operation the room temperature and $343^{\circ} \mathrm{C}\left(650^{\circ} \mathrm{F}\right)$ total elongation values of longitudinal coupon specimens had been decreased to 2 to 5 percent and 1 to 2 percent, respectively, after estimated fast fluence exposures of $1 \times 10^{21}$ nvt $>1 \mathrm{MeV}$. However, the room temperature strain-to-fracture values shown by burst specimens were still as high as 13 to 16 percent at the same exposure level: Additional exposure to $3.5 \times 10^{21}$ to $5 \times$ $10^{21}$ nvt changed the total elongations of the longitudinal specimens relatively little, but additional exposure to $6 \times$ $10^{21}$ to $7 \times 10^{21}$ nvt decreased the room temperature burst test results to approximately one-half the post-VBWR values, and the strains to fracture determined at elevated.temperatures were somewhat lower than the room temperature values.

It also should be noted that although the assembly power level underwent a rather continuous, significant decrease, the average external $\mathrm{ZrO}_{2}$ thickness increased at a constant rate. Hence, one would expect that had higher power levels been maintained, with the associated higher cladding temperatures, corrosion might have been a factor of much greater concern, particularly in such local areas as those that showed unusually thick oxide layers.

The relatively high levels of Pu-236 and Pu-238 must be considered in working with plutonium separated from high exposure fuel. It is noted also that the concentrations of U-232 measured in the fuel samples exceeded the current specification limit of $110 \mathrm{ppb} U-232$ relative to U-235 for reenrichment in all cases. However, the fact that the SA-1 fuel exceeded its design nuclear lifetime and thus contained somewhat less residual U-235 than one would normally expect for fuel operated to the same burnup levels was partly responsible for the high ratios.

\section{DESCRIPTION OF FUEL ${ }^{1,2}$}

The fuel rods in Assembly SA-1 were selected from a group of nearly 400 irradiated rods of the same design and fabrication characteristics, some of which are listed in Table 1 . The rods consisted of cold-pressed, sintered, and ground $\mathrm{UO}_{2}$ pellets clad with annealed Zircaloy-2 tubing. The nominal o.d. and wall thickness of the tubing, which was designed to be "free-standing," were $1.077 \mathrm{~cm}(0.424 \mathrm{in.})$ and $0.056 \mathrm{~cm}(0.022 \mathrm{in}$.$) , respectively. The nominal pellet-$ to-cladding gap was $0.010 \mathrm{~cm}(0.004 \mathrm{in.})$. The overall rod length was $103.4 \mathrm{~cm}(40.7 \mathrm{in}$.$) .$

The seamless tubing was fabricated by the cold drawing process. The inside and outside surfaces of the tubes were pre-filmed with oxide by autoclaving them in $105 \mathrm{~kg} / \mathrm{cm}^{2}(1500 \mathrm{psi}), 399^{\circ} \mathrm{C}\left(750^{\circ} \mathrm{F}\right)$ steam for 36 hours.

The cylindrical pellets were made from ceramic grade $\cup_{2}$ powder produced from $U F_{6}$ by the ammonium diuranate method. 


\section{Table 1 \\ CHARACTERISTICS OF TYPE J FUEL RODS SELECTED FOR ASSEMBLY SA-1}

\author{
Cladding Material \\ Condition of Cladding Material, as received \\ Cladding Thickness, $\mathrm{cm}$ (in.) \\ Cladding i.d., $\mathrm{cm}$ (in.) \\ Cladding o.d., nominal, $\mathrm{cm}$ (in.) \\ Total Rod Length, nominal, cm (in.) \\ Pellet Diameter, $\mathrm{cm}$ (in.) \\ Pellet Density, percent of theoretical \\ Active Fuel Length, nominal, $\mathrm{cm}$ (in.) \\ Plenum Length, nominal, $\mathrm{cm}$ (in.)" \\ Wall thickness of Plenum Support Tube, \\ nominal, $\mathrm{cm}$ (in.) \\ Initial Uranium Enrichment, weight \\ percent U-235
}

\author{
Zircaloy-2 \\ Annealed \\ $0.056 \pm 0.0056(0.022 \pm 0.0022)$ \\ $0.965 \pm 0.0041(0.380 \pm 0.0016)$ \\ $1.077(0.424)$ \\ $103.408(40.712)$ \\ $0.955+0.000\left(0.376_{-0.003}^{+0.000}\right)$ \\ $95 \pm 1$ \\ 94 (37) \\ $4.831(1.902)$ \\ $0.076(0.030)$
}

2.76, 3.20, and 3.49

\footnotetext{
The length of the plenum support tube in most rods is believed to have been $4.420 \mathrm{~cm}(1.740 \mathrm{in}$.$) .$ However, post-irradiation examination revealed two such tubes. (out of 18 from SA-1 rods that were actually, measured) that were $4.826 \mathrm{~cm}$ (1.900 in.) long:
}

An exploded view of a typical fuel rod is shown in Figure 1: The Zircaloy-2 wafer and stainless steel plenum support tube held the pellets in place and maintained a plenum space for the fission gases. The end plugs were welded to the cladding to provide closure at each end of the tube."

The assembly consisted of two $7 \times 7,105-\mathrm{cm}(41-1 / 4-i n$.$) long, subassemblies stacked one on top of the other in a$ channel of standard dimensions for the Dresden reactor. A sketch of the assembly viewed with a side of the channel removed is shown in Figure 2. One of the subassemblies is shown before irradiation with a load of dummy fuel rods in Figure 3. A removable lifting tool, partially in view, is attached to the top. The rods in each subassembly rested on a bottom grid, as shown in Figure 4, and were held in position by four spring-type spacers distributed axially along the length of the fuel. The fuel rod pitch was $1.511 \mathrm{~cm}(0.595 \mathrm{in}$.$) .$

The spacers were supported by corner angles which were attached to the bottom grid and extended the full length of the subassembly, to form an integral basket for the fuel rods. The corner angles were fastened at the top to a band which extended about $0.6 \mathrm{~cm}(1 / 4 \mathrm{in}$.) above the top of the fuel rods (see Figure 5).

The lower subassembly was supported by a stand attached to a standard Dresden assembly nosepiece with a partially cut out grid (see Figure 6). The second subassembly rested on the first. The fission gas plenums of the rods in the bottom subassembly were pointed toward the bottom grid, and those of the rods in the top subassembly were pointed toward the top band.

The SA-1 fuel column was approximately $192 \mathrm{~cm}(75-9 / 16 \mathrm{in.})$ long, which included an approximate $3 \mathrm{~cm}$ ( 1-1/4 in.) nonfueled gap between the subassemblies. The bottom of the total fuel column was $58.6 \mathrm{~cm}(23-1 / 16 \mathrm{in}$. above the bottom of the reactor active fuel zone and the top of the column was $28.7 \pm 4.4 \mathrm{~cm}(1)-5 / 16 \pm 1-3 / 4 \mathrm{in}$. helow the top of the reactor active fuel zone. The subassemblies were held down by a spring-loaded fixture attached to a clamp (Figure 7) which fitted into slots in the sides of the channel near the top. A standard-shape handle was attached to the clamp for lifting the assembly. The relative positions of the handle, clamp, and channel when the assembly was ready to be inserted in the reactor are indicated in Figure 8.

"The shanks of the shorter end plugs were cut oft betore the rods were inserted into the SA-1 subassemblies. 
GEAP-10371

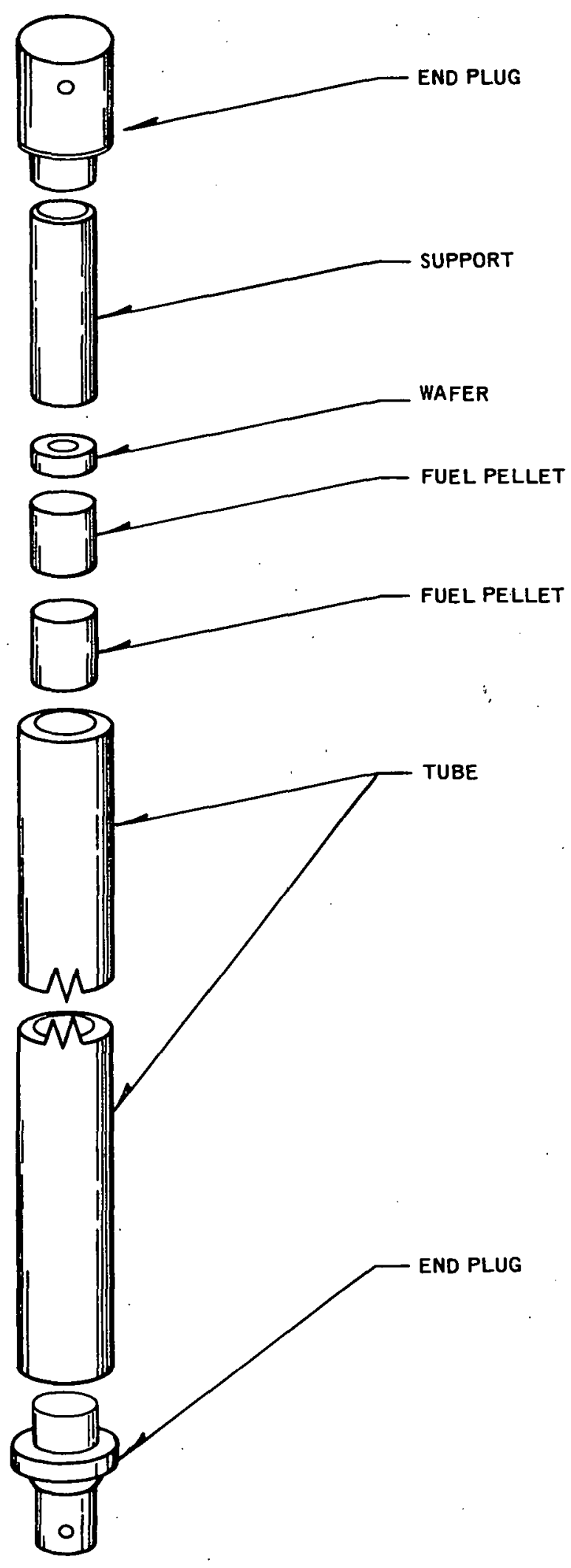

Figure 1. Exploded View of Fuel Rod 


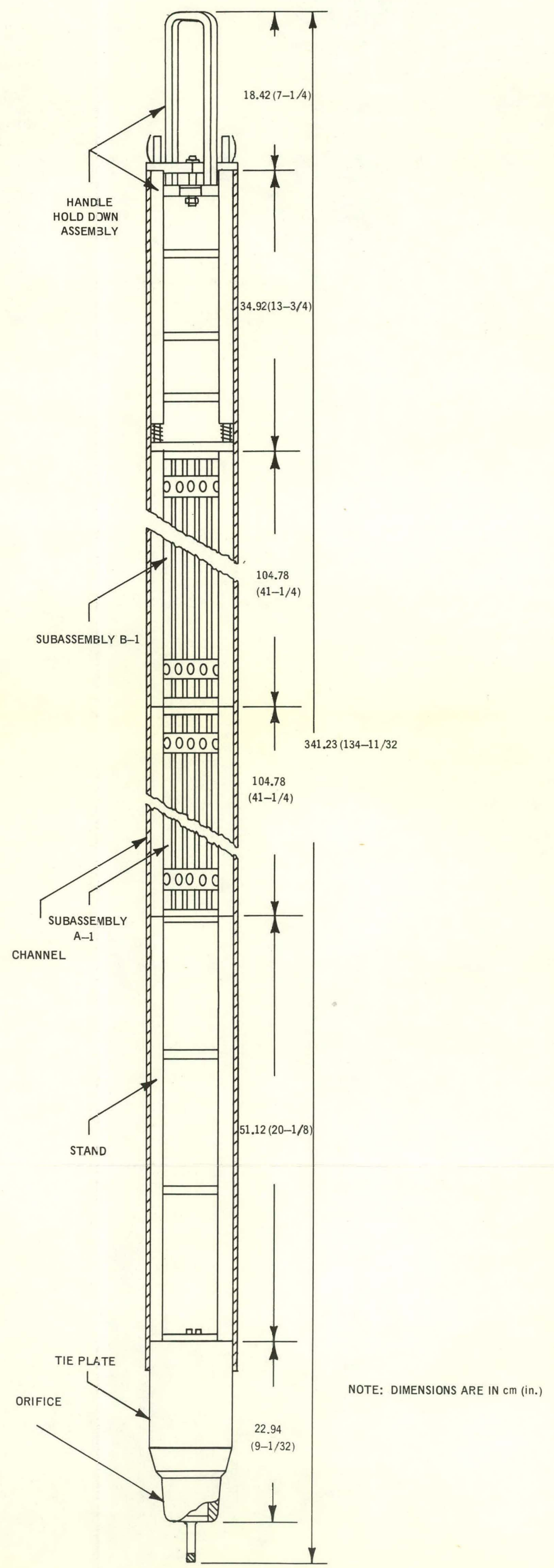



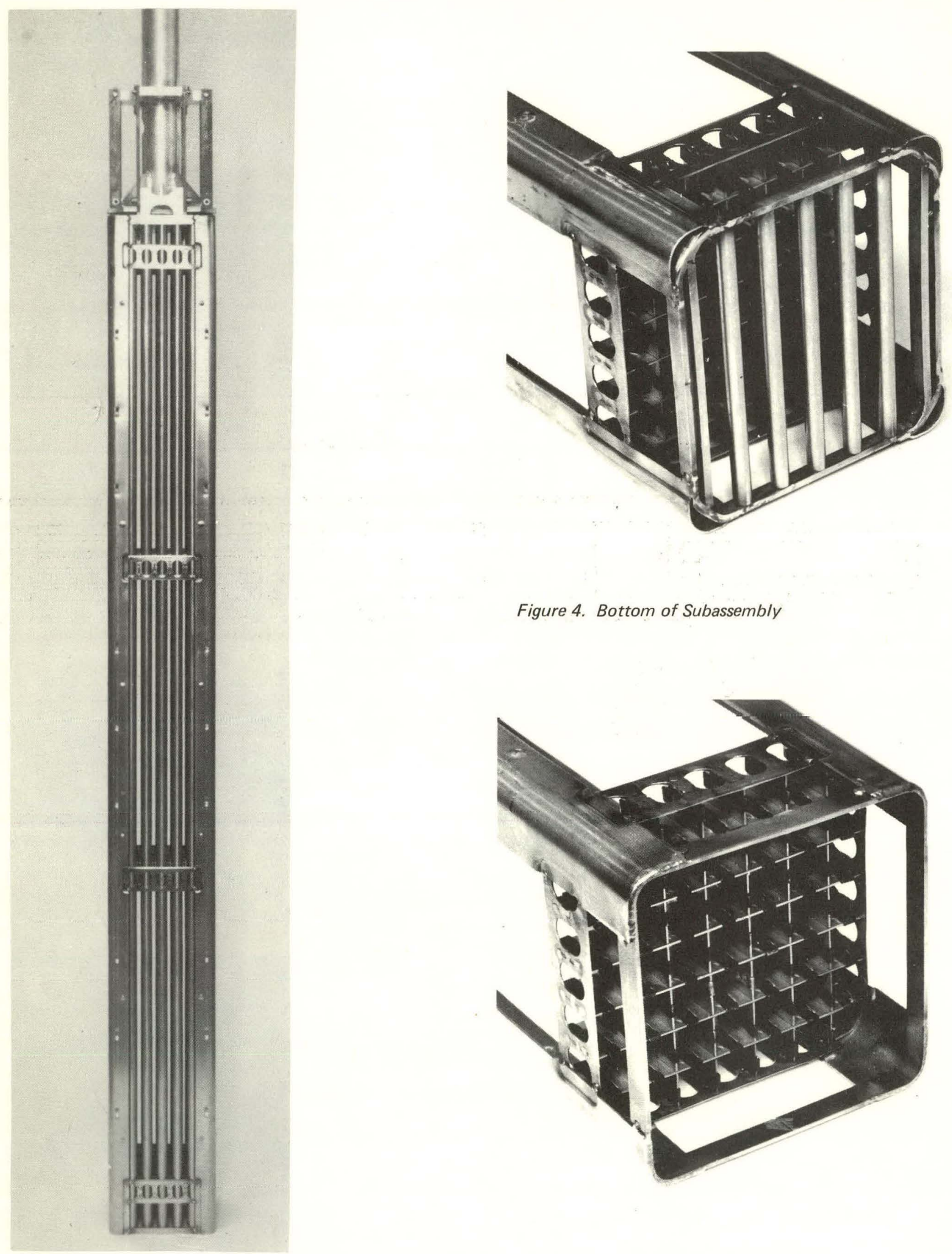

Figure 4. Bottom of Subassembly

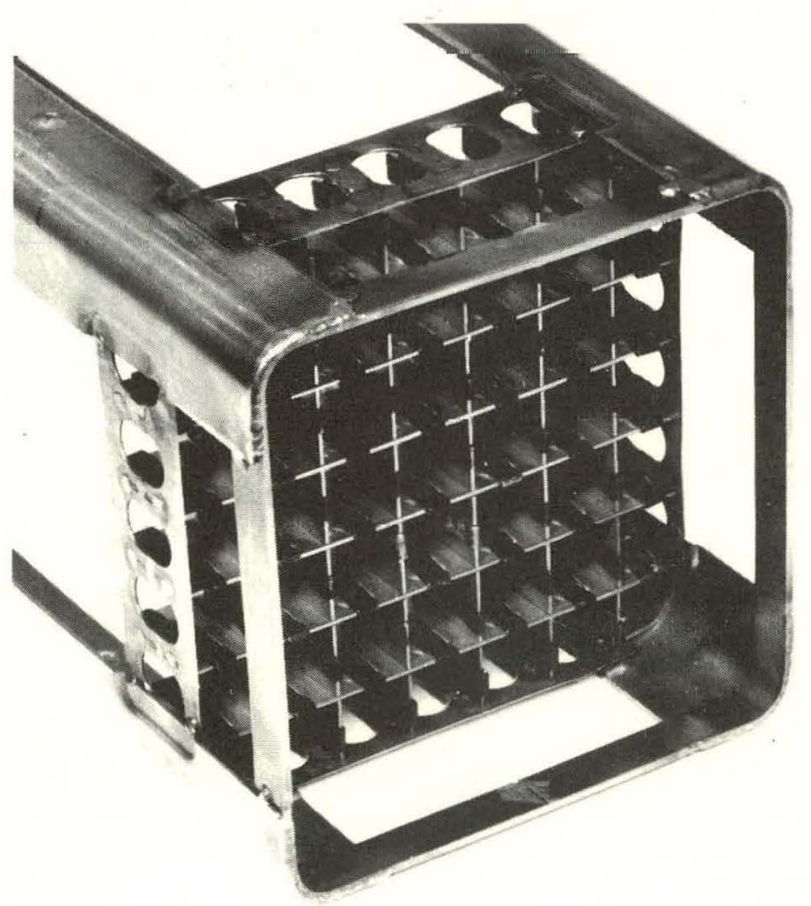

Figure 5. Top of Subassembly 


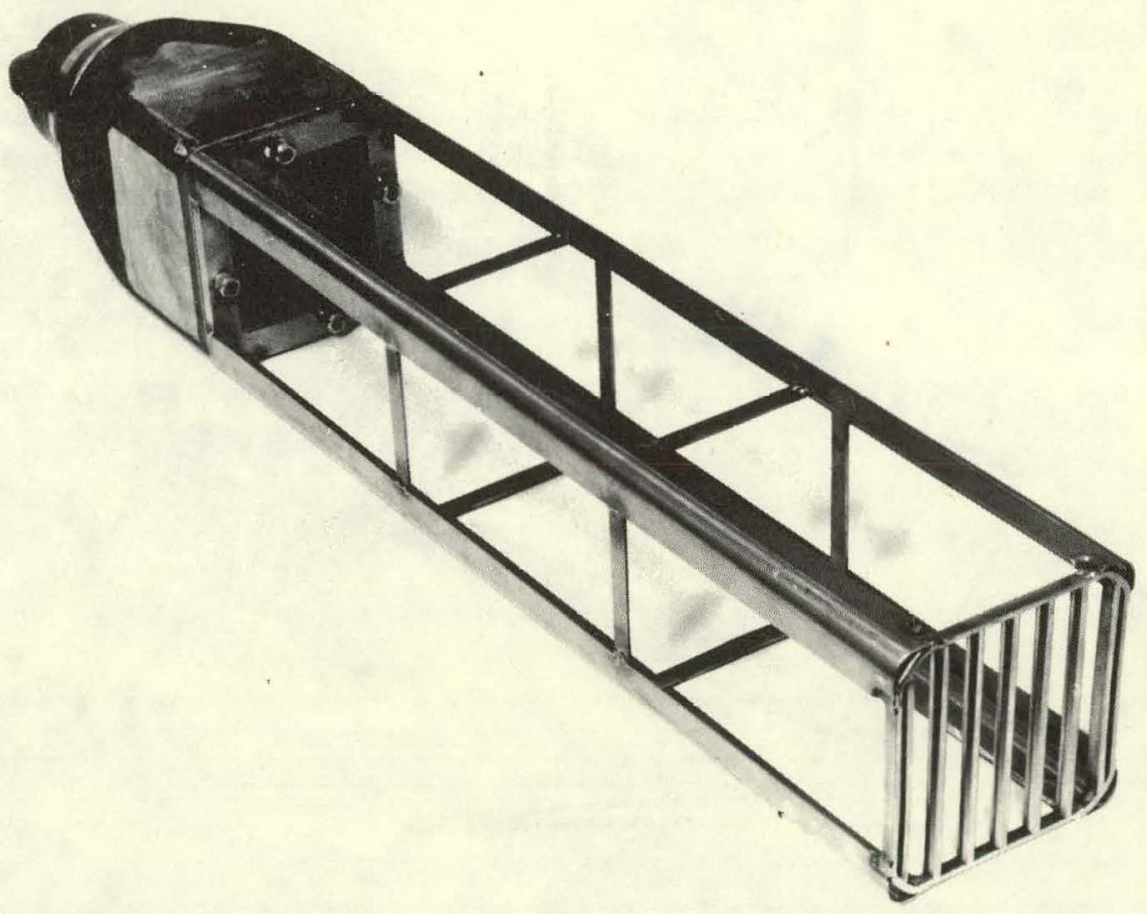

Figure 6. Assembly Nosepiece and Stand

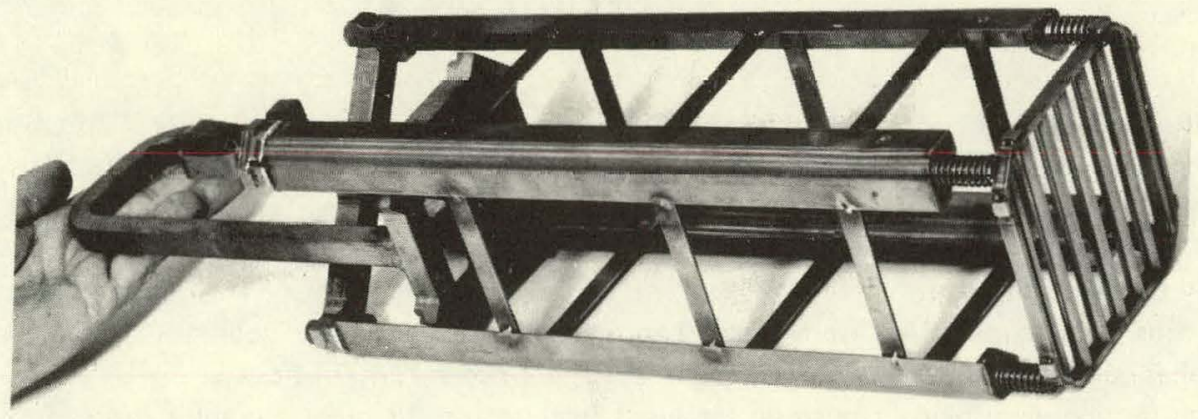

Figure 7. Handle Holddown Assembly 


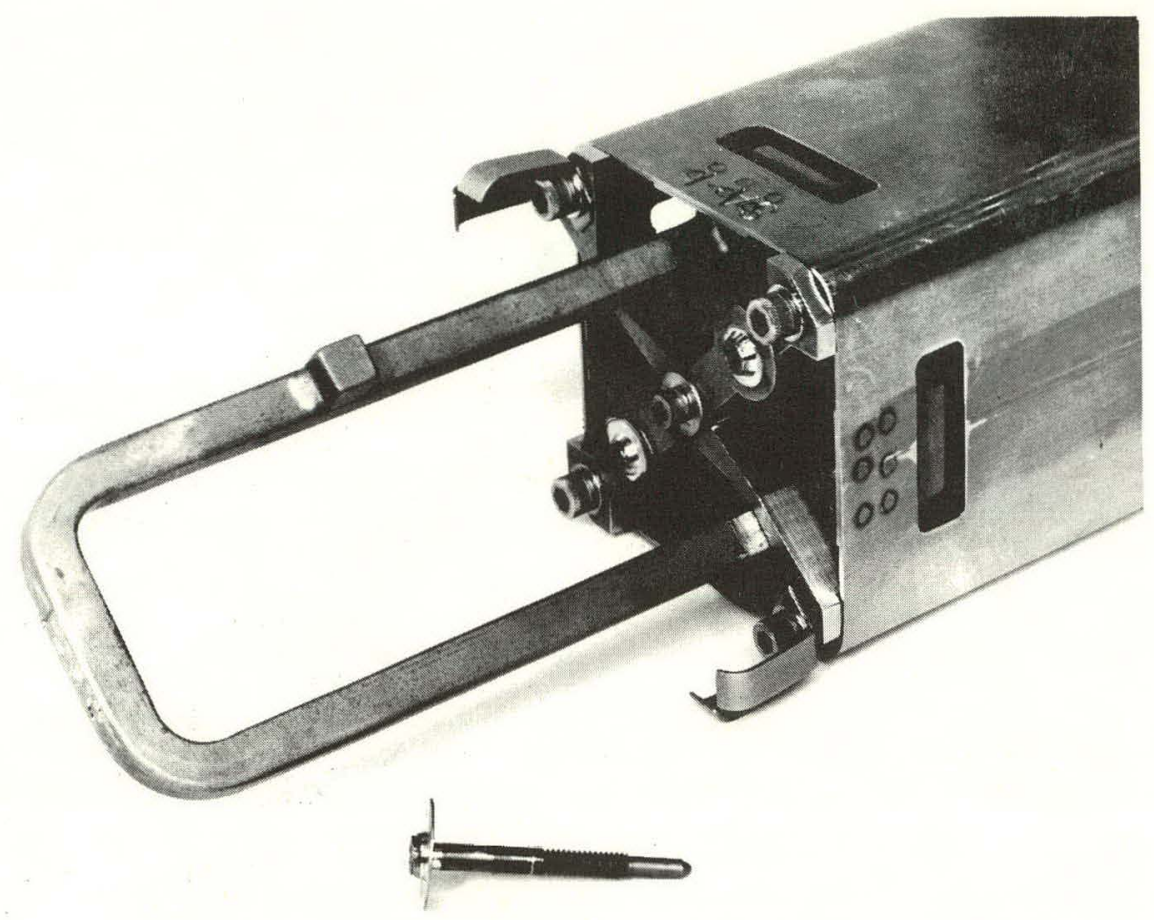

Figure 8. Top of Channeled Assembly

The spacer springs were made of Inconel " $X$," the leaf springs at the top of the assembly were made of Inconel " $X$ " 750, and the hold-down springs were made of Inconel "X." Except for the fuel rods, the rest of the assembly, including the channel, was Type 304 stainless steel.

\section{OPERATION}

\subsection{VBWR}

Most of the information contained in this section was extracted from GEAP-4597, "AEC Fuel Cycle ProgramExamination of Zircaloy-Clad $\mathrm{UO}_{2}$ Fuel Rods Operated in the VBWR to $10,000 \mathrm{MWd} / \mathrm{tU}$," by $\mathrm{H}$. E. Williamson, C. J. Baroch, J. P. Hoffmann, and D. T. Ikeuye. ${ }^{3}$

\subsubsection{Assembly Description}

The fuel rods in Assembly SA-1 were selected from 12 of the Fuel Cycle Program's Type J basic assemblies. Each of these assemblies contained sixteen rods arranged in a $4 \times 4$ array at center-to-center distances of $1.93 \mathrm{~cm}(0.760 \mathrm{in}$.$) .$ The rods in each bundle were held in position by a cast steel bottom tie plate, a combination wire spacer-top tie plate, and a single-layer wire spacer at mid-length. The longer end plugs and plenums of the rods were located at the top of every assembly.

\subsubsection{Reactor Environment and Operation}

The fuel assemblies were cooled by recirculating water at $70 \mathrm{~kg} / \mathrm{cm}^{2}(1000 \mathrm{psig})$ pressure. The water was subcooled about $10^{\circ} \mathrm{C}$ as it entered the bottom of each assembly. The heat transferred to the water as it passed upward through the assembly caused bulk boiling $\left(286^{\circ} \mathrm{C}\left[546^{\circ} \mathrm{F}\right]\right.$ saturation temperature) over most of the $94-\mathrm{cm}(37-\mathrm{in}$.) active fuel length.

The water was normally maintained at a $\mathrm{pH}$ of 7 at room temperature, and at a conductance of less than 1 micromho. The oxygen content of the steam phase was about $30 \mathrm{ppm}$. 
Samples of the VBWR water were analyzed daily, or more frequently when a buildup of impurities was indicated. The analysis included the measurement of the amount of crud, resistivity, and chloride ion content. Typically, the chloride ion content of the water was maintained at less than 0.02 ppm; however, on occasion it exceeded this level. Normally, the reactor power was reduced when the chloride ion level exceeded $0.15 \mathrm{ppm}$, and shut down when greater than $0.35 \mathrm{ppm}$. The insoluble corrosion products in the coolant generally contained from 1 to $100 \mathrm{ppb}$ (parts per billion) iron, 1 to $10 \mathrm{ppb}$ nickel, 1 to $50 \mathrm{ppb}$ copper, and 1 to $5 \mathrm{ppb}$ chromium.

VBWR operation was divided into a series of runs; most of which were of one to three weeks duration. The rather frequent shutdowns were required to allow the addition of new fuel assemblies, the changing of assembly core positions, and the removal of assemblies for examination, rod changes, etc., in order to satisfy the objectives of several different irradiation programs.

The reactor operated at maximum powers between 30 and $40 \mathrm{MWt}$ in most of the runs. One hundred seventynine power cycles and 300 thermal cycles occurred during the irradiation period of those Type $\mathrm{J}$ assemblies with the longest operating times. A power cycle was defined as a variation in reactor thermal power from less than $5 \mathrm{MW}$ to more than $20 \mathrm{MW}$ and back to less than $5 \mathrm{MW}$. A thermal cycle was defined as a reactor thermal power variation from zero to greater than $5 \mathrm{MW}$ and back to zero. The power and thermal cycles that each assembly underwent during each reactor run and the total numbers of such cycles are given in Appendix $B$.

\subsubsection{Assembly Operation}

Irradiation of the 12 assemblies began as early as June 1961 and continued until the reactor was shut down in December 1963. Figure 9 is a plot of the VBWR core which indicates the initial locations of the assemblies and also shows the locations of the flux trap-type control rods. Most of the assemblies were moved to other locations during the period of operation; one assembly (9J) operated in nine different locations. The location of each assembly during each reactor run is given in Appendix $B$.

\subsubsection{Exposure and Thermal Performance}

The rods that were later selected for continued irradiation in Dresden operated between 299 and 378 days ${ }^{*}$ in the VBWK to rod-average burnups of $1.3 \times 10^{20}$ to $2.6 \times 1 U^{20}$ tissions $/ \mathrm{cm}^{3}$ (48UU to YbUU MWd/tU). I he overall average VBWR burnup of the $98 \mathrm{SA}-1$ rods was $1.9 \times 10^{20}$ fissions $/ \mathrm{cm}^{3}(7100 \mathrm{MWd} / \mathrm{tU})$. The peak heat flux attained in the VBWR by any of the SA-1 rods was estimated to have been $137 \mathrm{~W} / \mathrm{cm}^{2}\left(435,000 \mathrm{Btu} / \mathrm{h}-\mathrm{ft}^{2}\right)$. The calculated centerline temperature at this heat flux is approximately $2050^{\circ} \mathrm{C}\left(3720^{\circ} \mathrm{F}\right)$. (See Figure 10.) The hours of operation and the average burnup and estimated peak heat flux attained in the VBWR are listed for each of the SA-1 rods in Table 2. The estimated peak heat flux values for the different rods for each VBWR run are given in Appendix B. The values of rod burnup and heat flux were based on values determined for the different assemblies by reactor physics analysis. The following approximation was employed:

Position in Assembly

Corner (4 rods)

Outside non-corner (8 rods)

Inside (4 rods)

\section{Burnup and Heat Flux}

$10 \%$ higher than assembly-average

Equal to assembly-average

$10 \%$ lower than assembly-average

Twenty-five of the SA-1 fuel rods operated in inside positions in the VBWR assemblies; the rest operated in outside non-corner positions. An indication of the variation in burnup along the axes of the rods was provided by scans of gross gamma ray activity made on four Type $\mathrm{J}$ fuel rods at the end of the VBWR operation. The ratios of peak activity to rod-average activity ranged from 1.42 to 1.50 and had an average value of 1.47 for these four rods. The points of peak activity were located 31 to $35 \mathrm{~cm}$ (12 to $14 \mathrm{in}$.) up from the bottom end plug shoulders. A scan of one of the rods is shown in Figure 11.

\footnotetext{
*Hours reactor thermal power $>5 \mathrm{MW} \div 24$.
} 


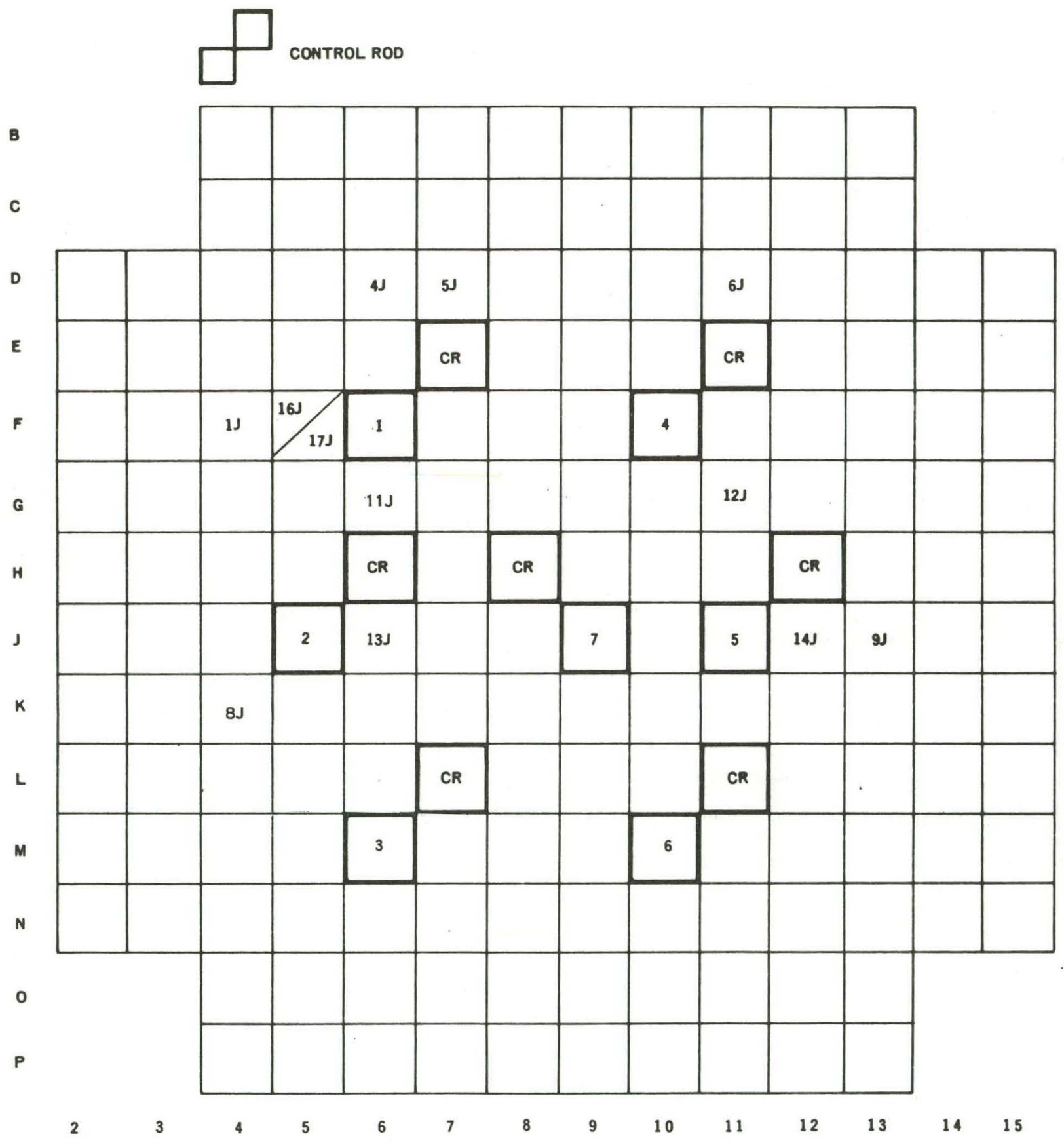

Figure 9. VBWR Core, Showing Initial Locations of Type J Assemblies 


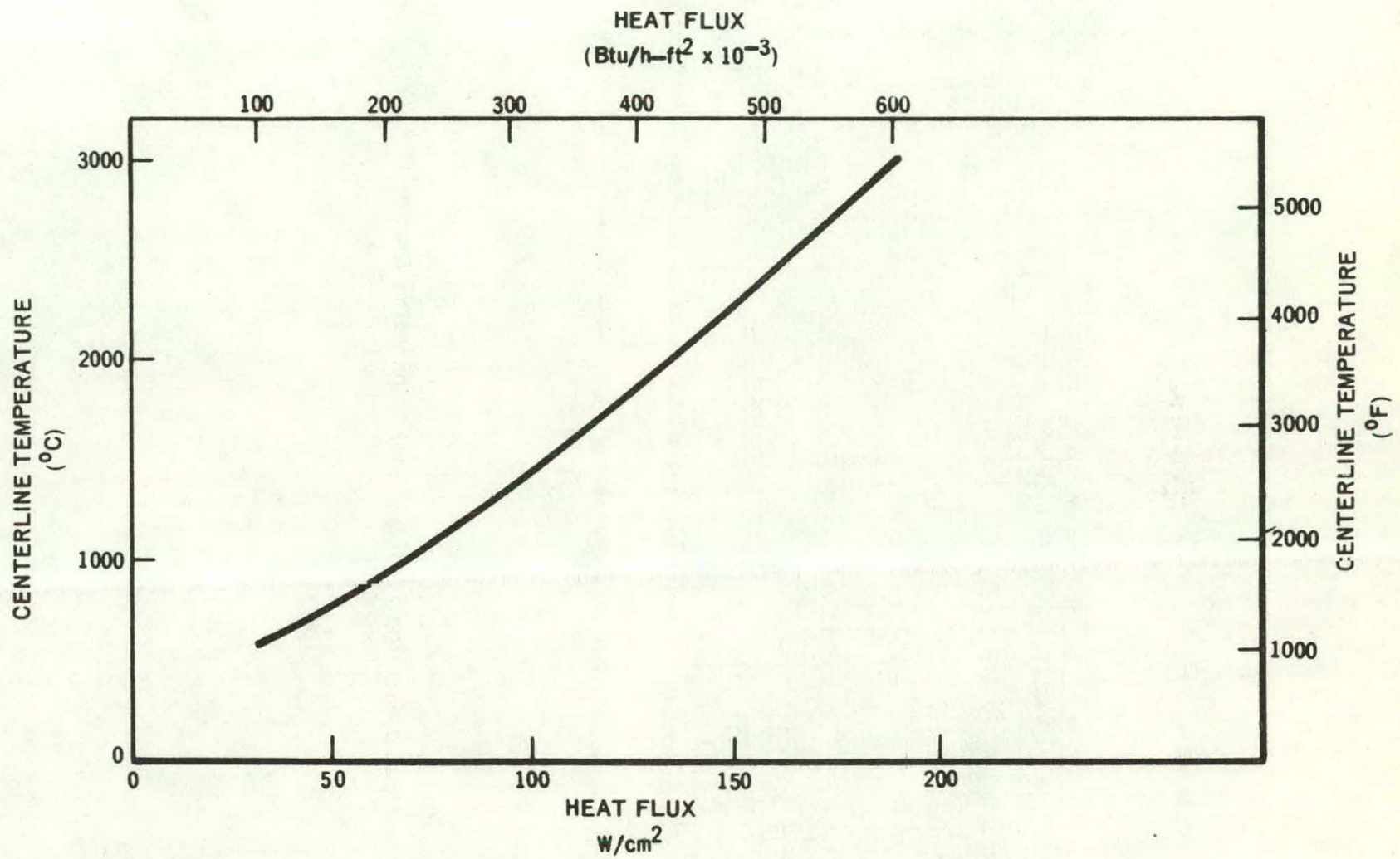

Figure 10. Fuel Centerline Temperature Versus Circumferential-Average Rod Surface Heat Flux 


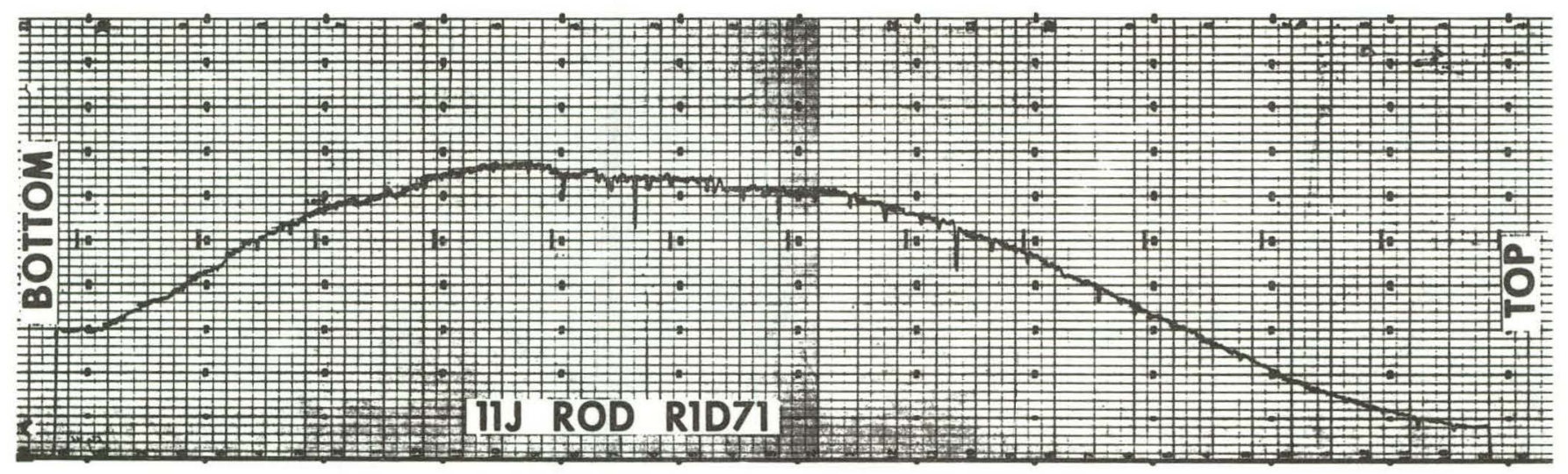

Figure 11. Gamma Scan of Fuel Rod 11J-R1D71 at End of VBWR Irradiation 
OPERATIONAL DATA ON THE SA-1 FUEL RODS

\begin{tabular}{|c|c|c|c|c|}
\hline \multirow{2}{*}{$\begin{array}{l}\text { SA-1 } \\
\text { Number }\end{array}$} & \multirow{2}{*}{$\begin{array}{c}\text { VBWR } \\
\text { Assembly } \\
\text { Designationa }\end{array}$} & \multicolumn{3}{|c|}{$\begin{array}{c}\text { Rod-Average Burnup } \\
\text { Fissions } / \mathrm{cm}^{3} \times 10^{-20}(\mathrm{MWd} / \mathrm{tU}) \\
\end{array}$} \\
\hline & & VBWR & Dresden & Total \\
\hline A1 & $5 J \cdot 6$ & $1.6(5,800)$ & $7.2(26,400)$ & $8.8(32,20$ \\
\hline A2 & $1 \mathrm{~J}-2$ & $1.5(5,400)$ & $6.7(24,600)$ & $8.2(30,000)$ \\
\hline A3 & $17 \mathrm{~J}-5$ & $1.5(5,500)$ & $6.5(23,900)$ & $8.0(29,400)$ \\
\hline $\mathrm{A}^{\mathrm{d}} \mathrm{d}$ & $17 \mathrm{~J} \cdot 8$ & $1.5(5,500)$ & $4.0(14,700)$. & $5.5(20,200)$ \\
\hline A5 & $4 \mathrm{~J}-15$ & $1.6(5,700)$ & $6.5(23,700)$ & $8,0(29,400)$ \\
\hline A6 & $16 J-11$ & $1.7(6,100)$ & $6.7(24,400)$ & $8.3(30,500)$ \\
\hline A7 & $16 \mathrm{~J} \cdot 2$ & $1.9(6,800)$ & $7.1(26,100)$ & $9.0(32,900)$ \\
\hline A8 & $1 \mathrm{~J}-3$ & $1.5(5,400)$ & $6.7(24,600)$ & $8.2(30,000)$ \\
\hline A9 & .12J.2 & $2.5(9,300)$ & $6.3(22,900)$ & $8.8(32,200)$ \\
\hline A10 & $8 \mathrm{~J} \cdot 9$ & $1.5(5,300)$ & $6.5(23,900)$ & $8.0(29,200)$ \\
\hline A11 & 13J-12 & $2.5(9,100)$ & $6.6(24,200)$ & $9.1(33,300)$ \\
\hline A12 & $8 \mathrm{~J}-2$ & $1.5(5,300)$ & $6.5(23,700)$ & $7.9(29,000)$ \\
\hline$A 13^{d}$ & $11 \mathrm{~J}-14$ & $2.6(9,500)$ & $4.4(16,100)$ & $7.0(25,600)$ \\
\hline A14 & $5 \mathrm{~J} \cdot 9$ & $1.8(6,400)$ & $6.3(23,200)$ & $8.1(29,600)$ \\
\hline A15 & $17 \mathrm{~J}-2$ & $1.5(5,500)$. & $6.6(24,300)$ & $8.2(29,800)$ \\
\hline A16 & $8 \mathrm{~J}-12$ & $1.5(5,300)$ & $6.1(22,300)$ & $7.6(27,600)$ \\
\hline A17 & $12 \mathrm{~J}-7$ & $2.3(8,400)$. & $6.5(23,700)$ & $8.8(32,100)$ \\
\hline A18 & $14 \mathrm{~J}-12$ & $2.2(8,200)$ & $6.5(23,700)$ & $8.7(31,900)$ \\
\hline A19 & $11 \mathrm{~J}-11$ & $2.3(8,500)$ & $6.3(23,200)$ & $8.7(31,700)$ \\
\hline A2U & yJ-8 & $1 . y(1,100)$ & & $\dot{8} . \dot{2}(2 \dot{y}, \dot{y} 0)$ \\
\hline A21 & $5 J-12$ & $1.8(6,400)$ & $6.2(22,500)$ & $7.9(28,900)$ \\
\hline A22 & $17 J-3$ & $1.5(5,500)$ & $6.6(24,300)$ & $8.2(29,800)$ \\
\hline A23 & 13J-14 & $2.5(9,100)$ & $6.7(24,400)$ & $9.2(33,500)$ \\
\hline A24 & $14 \mathrm{~J}-9$ & $2.2(8,200)$ & $6.3(23,200)$ & $8.6(31,400)$ \\
\hline A25 & $8 \mathrm{~J}-10$ & $1.3(4,800)$ & $6.0(21,900)$ & $.7 .3(26,700)$ \\
\hline A26 & 13J-8 & $2.5(9.100)$ & $6.2(22,800)$ & $8.7(31,900)$ \\
\hline A27 & $12 \mathrm{~J}-3$ & $2.5(9,300)$ & $6.3(23,200)$ & $8.9(32,500)$ \\
\hline A28d & $5 \mathrm{~J} \cdot 2$ & $1.8(6.400)$ & $4.0(14,800)$ & $5.8(21,200)$ \\
\hline A29 & $4 \mathrm{~J}-12$ & $1.6(5,700)$ & $6.3(23,200)$ & $7.9(28,900)$ \\
\hline A30 & $8 \mathrm{~J}-3$ & $1.5(5,300)$ & b.U $(21, y \dot{U})$ & $7.4(27,200)$ \\
\hline A31 & $11 \mathrm{~J}-6$ & $2.3(8,500)$ & $6.3(23,200)$ & $8.7(31,700)$ \\
\hline A32 & $13 \mathrm{~J}-9$ & $2.5(9,100)$ & $5.9(21,400)$ & $8.3(30,500)$ \\
\hline A33 & $9 \mathrm{~J}-10$ & $1.8(6.400)$ & $6.6(24,300)$ & $8.4(30,700)$ \\
\hline A34 & $9 \mathrm{~J}-12$ & $1.9(7,100)$ & $6.3(23,2>0)$ & $8.2(30,100)$ \\
\hline A35 & $5 \mathrm{~J} \cdot 5$ & $1.8(6,400)$ & $6.7(22,400)$ & $7.9(28,800)$ \\
\hline A36 & 16J-10 & $1.7(6 ; 100)$ & $6.3(23,000)$ & $8.0(29,100)$ \\
\hline A37 & $11 \mathrm{~J} \cdot 5$ & $2.6(9,500)$ & 6.7124, & $9.3(33,900)$ \\
\hline A38 & $9 \mathrm{~J}-9$ & $1.9(7,100)$ & $6.2(22,700)$ & $8.2(29,800)$ \\
\hline A39 & $13 \mathrm{~J} \cdot 2$ & $2.5(9,100)$ & $6.4(23,400)$ & $8.9(32,500)$ \\
\hline A40 & $9 \mathrm{~J}-2$ & $1.9(7,100)$ & $6.5(23,900)$ & $8.5(31,000)$ \\
\hline A4.1d & $11 \mathrm{~J}-15$ & $2.6(9,500)$ & $4.0(14,500)$ & $6.6(24,000)$ \\
\hline A42 & $6 \mathrm{~J}-15$ & $2.2(7,900)$ & $6.2(22,700)$ & $8.4(30 ; 600)$ \\
\hline A43 & $16 \mathrm{~J}-3$ & $1.9(6,800)$ & $6.4(23,400)$ & $8.3(30,200)$ \\
\hline A44 & $5 J-14$ & $1.8(6,400)$ & $5.9(21,400)$ & $7.6(27,800)$ \\
\hline A45d & $5\rfloor \cdot 15$ & $1.8(6,400)$ & $4.2(15,400)$ & $6.0(21 ; 800)$ \\
\hline A46d & $5 \mathrm{~J}-8$ & $1.8(6,400)$ & $4.3(15,600)$ & $6.0(22,000)$ \\
\hline
\end{tabular}

Final Peak

9.3 $(34.100)$

$6.5(23,800)$

$10.0(36,500)$

$9.6(35,100)$

$10.0(36,600)$

$8.1(29,700)$

$9.1(33,100)$

$-$

-

$8.9(32,500)$

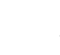

$9.5(34,800)$

$9.9(36,100)$

$6.6(24,000)$

$$
\text { - }
$$

$9.3(33,900)$

$8.8(32,200)$

$8.4(30,800)$

$10.2(37.300)$

$8.8(32,200)$

$9.8(35,100)$

$9.2(33,800)$

$7.8(28,500)$

$9.0(33,000)$

$8.8(32,000)$

$6.8(25,300)$

$6.9(25,300)$
Fissions/cmup $\times 10^{3} \times 0^{-20}$
Days of $\frac{\text { Operationb }}{\text { VEWR Total }}$ $\begin{array}{ll}378 & 1,846 \\ 378 & 1,846\end{array}$ 1,846
1,767
1,139 1,139
1,846

1,846
1,803
1,803

1,803
1,803

1,803
$.1,846$

1,846
1,832

1,774

1,832

1,774

1,204
1,846
1,767

1,767

1,832

1,832

1,832

1,832
1,848
1,846

1,846
$.1,767$

1,832

1,832
1,774
1,832

1.774
1,832

1,832

1,218

1,846

1,774
1,832
1,832

1,832

1,846

1,846
1,846

1,846

1,803 .

1,846
1,832

1,846

1,204

1,846

1,803

1,846

1,218

1,218
Estimated

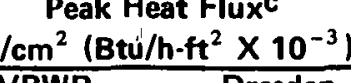

$80(284)$

$\begin{array}{ll}85(271) & 90(284) \\ 84(265) & 87(275)\end{array}$ $100(317) \quad 86(272)$ $100(317), \quad 88(278)$ $86(272) \quad 92(291)$ $93(294)$
$111(351) \quad 102(325)$ \begin{tabular}{rr}
$84(265)$ & $\quad 102(325)$ \\
\hline & $87(275)$
\end{tabular} 102 (3235) $\quad 102$ (32) $96(304)$ $27(402)$ $96(304)$ 95 (301) $95(301)$

$96(304)$

124 (392)

125 (396)

19 (376)

$99(314)$

00. (317)

$127(402)$

$86(274)$

$27(402)$

$137(435)$

$86(272)$

98 (304)

19 (376)

$89(283)$

$99(314)$

$95(301)$

32 (418)

$99(314)$
$127(402)$

99 (314)

$132(418)$

121 (385)

$95(301)$

$95(301)$

95 (301)
Time-Averaged Rod-Average Heat Fluxc $\frac{W / \mathrm{cm}^{2}\left(B t u / h \cdot \mathrm{ft}^{2} \times 10^{-3}\right)}{\text { VBWR }}$ 32 (102)

38 (121) $37(117)$ $\begin{array}{ll}36(113) & 35(110)\end{array}$ \begin{tabular}{ll}
$34(109) \quad 35(112)$ \\
\hline
\end{tabular} \begin{tabular}{l}
$37(117) \quad 38(119)$ \\
\hline
\end{tabular} $\begin{array}{lll}38(122) & 35(110) & 34(108) \\ 45(112) & 36(114)\end{array}$ $43(136) \quad 38(119) \quad 39(123)$ $30(96) \quad 35(112) \quad 34(108)$ $54(171) \quad 33(105) \quad 37(118)$ $\begin{array}{lll}37(117) & 35(110) & 35(111) \\ 53(167) & 35(110) & 38(121)\end{array}$ $37(117) \quad 34(109) \quad 35(110)$ $45(143)$ $39(123) \quad 35(112) \quad 34(114)$ $37(117) \quad 32(102) \quad 33(105)$ $48(153) \quad 34(108) \quad 37(118)$ $47(150) \quad 34(107) \quad 37(116)$ $49(156) \quad 33(105) \quad 36(115)$ $40(120) \quad 32(103) \quad 34(108)$ $36(115) \quad 33(104) \quad 33(106)$ $\begin{array}{lll}38(122) & 35(111) & 36(113) \\ 52(166) & 35(110) & 38(121)\end{array}$ $47(150) \quad 33(105) \quad 36(114)$ $33(106) \quad 32(100) \quad 32(101)$ $53(167) \quad 33(104) \quad 37(116)$ $54(115) \quad 33(120) \quad 38(119)$ $32(102) \quad 34(107) \quad 37(118)$ $37(116) \quad 31(99) \quad 32 \quad 3(102)$ $49(155) \quad 33(105) \quad 36(115)$ $35(115) \quad 35(112) \quad 35(111)$ $\begin{array}{lll}36(115) & 35(112) & 35(112)\end{array}$ $36(114) \quad 32(102) \quad 33(105)$ $38(122) \quad 33(105) \quad 34(108)$ $55(173) \quad 35(110) \quad 39(123)$ $40(127) \quad 33(104) \quad 34(109)$ $53(167) \quad 33(106) \quad 37(118)$ $\begin{array}{lll}40(127) & 35(110) & 36(113) \\ 55(174) & 36(115) & 42(133)\end{array}$ $44(141) \quad 32(103) \quad 35(111)$ $43(135) \quad 34(107) \quad 35(112)$ $36(114) \quad 31(98) \quad 32(101)$ $36(115) \quad 39(125) \quad 38(122)$ $40(126) \quad 39(123)$ 
SA-1
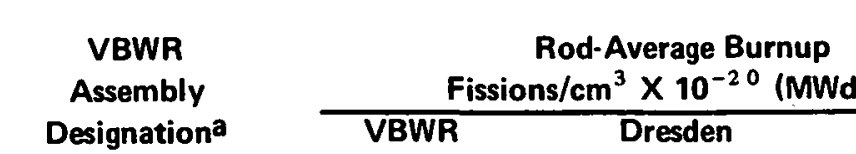

ions $/ \mathrm{cm}^{3} \times 10^{-20}$ (M)

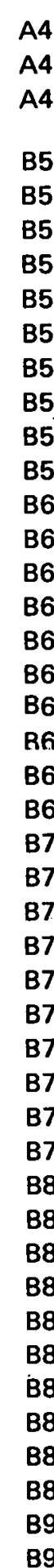

A47

A48

B56

558

559 6J-9 $2.0(7,200)$ $2.2(7,900)$ Total 1J.12 4J-2

5J-11

$8.3(30,200)$ $\begin{array}{ll}6.3(22,900) & 8.4(30,800) \\ 6.3(23,200) & 8.5(31,100)\end{array}$

$6.8(25,000)$

$6.7(24,400)$

$8.4(30,800)$

$6.3(23,200)$
$0.1(22,300) \quad 7.9(28,900)$

$\begin{array}{lll}1.7(6,100) & 6.1(22,300) & 7.7(28,100) \\ 2.0(22,100) & 7.7(28,200)\end{array}$

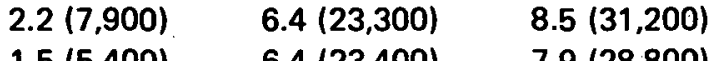

$\begin{array}{lll}2.5(5,400) & 6.4(23,400) & 7.9(28,800) \\ 2.5(9,300) & 6.0(21,900) & 8.5(31,200)\end{array}$

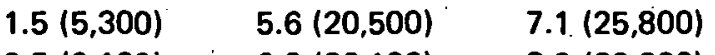

$6.3(23,100) \quad 8.6(27,800)$

$\begin{array}{lll}2.6(9,500) & 6.5(23,700) & 9.1(33,200)\end{array}$

$\begin{array}{lll}1.9(6,800) & 5.9(21.400) & 7.7(28,200) \\ 1.6(5,700) & 6.2(22,800) & 7.8(28,500)\end{array}$

$1.5(5,300) \div 6.2(22,800) \cdot 7.7(28,100)$

$22(8,200) \quad 61(22,300) \quad 8.3(30,500)$

$6.0(21,900) \quad 8.3(30,300)$

$\begin{array}{ll}1.8(6,400) & 5.9(21,600) \\ 1.7(28,000)\end{array}$

$\begin{array}{lll}1.9(6,800) & 3.7(13,400) & 5.5(20,200) \\ 1.6(5,700) & 6.1(22,300) & 7.7(28,000)\end{array}$

$2.3(8,500) \quad 6.3(23,000) \quad 8.6(31,500)$

$6.7(23,000)$
$-5.0(29,200)$

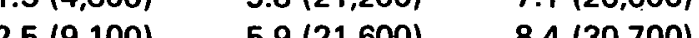

$5.6(13,100) \quad 0.1(22,400)$

$1.9(6,800) \quad 5.3(19,400) \quad 7.2(26,200)$

$\begin{array}{lll}1.6(5,700) & 6.0(22,100) & 7.6(27,800) \\ 1.5(5,300) & 6.1(22,300) & 7.6(27,600)\end{array}$

$\begin{array}{lll}2.3(8,400) & 6.1(22,300) & 7.6(27,600) \\ 2.5(21,900) & 8.3(30,300)\end{array}$

$\begin{array}{lll}2.5(9,100) & 6.0(21,900) & 8.5(31,000)\end{array}$

$\begin{array}{lll}1.9(7,100) & 5.9(21,700) & 7.9(28,800)\end{array}$

$2.0(7,200) \quad 5.3(19,400) \quad 7.3(26,600)$

$\begin{array}{lll}1.7(6,100) & 6.4(23,400) & 8.1(29,500) \\ 2.6(9,500) & 6.2(22,700) & 8.8(32,200) \\ 1.8(6,400) & 6.0(21,900) & 7.7(28,300)\end{array}$

$\begin{array}{lll}1.8(6,400) & 6.0(21,900) & 7.7(28,300)\end{array}$

$\begin{array}{lll}1.5(9,300) & 3.6(13,100) & 6.1(22,400)\end{array}$

$2.6(9,50)-0.9(21,400) \quad 7.8(28,500)$

$2.2(7,900)$
Table 2 (continued)

Final Peak

Fissions $/ \mathrm{cm}^{3} \times 10^{-20}$

(MWd/tU)

$9.1(33,100)$

$9.2(33,600)$

$9.5(34,800)$

$9.0(\overline{32}, 800)$

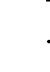

$9.5(34,900)$

$8.8(32,000)$
$9.9(36,200)$

$10.2(37,400)$

$8.4(30,600)$
$10.4(37,900)$

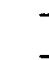

$-$

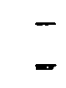

$6.9(25,300)$

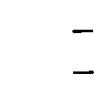

$8.0(29,100)$

-

-

$8.5(31,100)$

$9.0(33,000)$

$10.0(36,400)$

$7.7(28,000)$

$8.3(30,200)$

$10.3(37,500)$
$8.9(32.400)$
Estimated $\mathrm{W} / \mathrm{cm}^{2}\left(\mathrm{Btu} / \mathrm{h}-\mathrm{ft}^{2} \times 10^{-3}\right)$ $109(346) \quad 103(328)$ $121(385) \quad 105(334)$ $121(385) \quad 115(366)$ $86(272) \quad 86(272)$ $86(272) \quad 88(278)$ $85(271) \quad 92(291)$ $100(316) \quad 93(294)$ $121(385) \quad 102(325)$ $84(265)$
$137(435)$ $96(304) \quad 94(297)$ $127(402) \quad 100(316)$ $132(418) \quad 109(347)$ 111 (351) $100(316)$ $86(272) \quad 86(272)$ $96(304) \quad 94(297)$ $114(362) \quad 94(297)$ $126(306) \quad 05(300)$

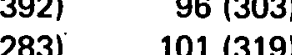
9
$99(313)$ $86(272) \quad 88(278)$ $119(376) \quad 100(316)$ $86(274) \quad 96(303)$ $127(402) \quad 102(322)$ $137(435)$ $86(272) \quad 92(291)$ 96 (304) 96 (300) $124(392) \quad 96(303)$ $127(402) \quad 102(322)$ $89(283) \quad 102(325)$ 99 (314) $\quad 103(328)$ $109(346) \quad 103(328)$ $100(316) \quad 93(294)$ $132(418) \quad 109(347)$ $89(283) \quad 101(319)$ $137(435) \quad 108(341)$ $99(314) \quad 103(328)$ $\begin{array}{ll}132(418) & 117(372) \\ 121(385) & 105(334)\end{array}$
Time-Averaged Rod-Average Heat Flux ${ }^{c}$ $\frac{W / \mathrm{cm}^{2}\left(B t u / h \cdot h \mathrm{t}^{2} \times 10^{-3}\right)}{\text { VBWR }}$

\section{$40(126) \quad 33(104) \quad 34(109)$} $44(140) \quad 33(104) \quad 35(111)$ $33(104) \quad 37(116) \quad 36(113)$ $30(96) \quad 35(111) \quad 34(108)$ $32(102) \quad 35(112) \quad 35(110)$ $32(102) \quad 34(107) \quad 33(106)$ $33(104) \quad 32(103) \quad 32(103)$ $38(122) \quad 32(101) \quad 33(105)$ $34(97) \quad 34(108) \quad 36(113)$ $54(170) \quad 31(99) \quad 36(113)$ $\begin{array}{lll}37(117) & 30(94) & 31(98)\end{array}$ $\begin{array}{lll}52(166) & 33(105) & 37(117)\end{array}$ $55(173) \quad 34(107)$ $43(136) \quad 31(98) \quad 33(105)$ $\begin{array}{lll}43(102) & 33(106) & 33(105)\end{array}$ $37(118) \quad 33(105) \quad 34(107)$ $47(150) \quad 33(105) \quad 36(114)$ $48(151) \quad 32(102) \quad 35(111)$ $49(154) \quad 32(100) \quad 35(111)$ $43(136) \quad 34(107) \quad 35(111)$ $32(101) \quad 32(103) \quad 32(102)$ $49(155) \quad 33(104) \quad 36(114)$ $\begin{array}{lll}33(105) & 30(96) & 34(107) \\ 51(97) & 31(98)\end{array}$ $\begin{array}{lll}53(167) & 31(98) & 35(111)\end{array}$ $\begin{array}{lll}53(135) & 33(104) & 39(124)\end{array}$ $32(102) \quad 32(102) \quad 32(102)$ $\begin{array}{lll}37(117) & 32(102) & 33(104) \\ 49(154) & 32(100) & 35(111)\end{array}$ $\begin{array}{lll}53(167) & 32(100) & 35(111) \\ 51(99) & 36(113)\end{array}$ $36(114) \quad 32(101) \quad 33(104)$ $40(127) \quad 32(100) \quad 33(105)$ $40(127) \quad 28(88) \quad 30(96)$ $38(122) \quad 34(107) \quad 35(110)$ $54(172) \quad 32(102) \quad 37(116)$ $36(114) \quad 32(100) \quad 32(103)$ $54(171) \quad 33(104) \quad 39(124)$ $40(127) \quad 31(98) \quad 33(104)$ $\begin{array}{lll}54(172) & 34(107) & 38(120) \\ 44(140) & 29(92) & 32(102)\end{array}$ 
Table 2 (Continued)

\begin{tabular}{|c|c|c|c|c|}
\hline \multirow{2}{*}{$\begin{array}{l}\text { SA.1 } \\
\text { Number }\end{array}$} & \multirow{2}{*}{$\begin{array}{c}\text { VBWR } \\
\text { Assembly } \\
\text { Designationa }\end{array}$} & \multicolumn{3}{|c|}{$\begin{array}{c}\text { Rod-Average Burnup } \\
\text { Fissions } / \mathrm{cm}^{3} \times 10^{-20}(\mathrm{MWd} / \mathrm{tU}) \\
\end{array}$} \\
\hline & & VBWR & Dresden & Total \\
\hline B92 & $6 \mathrm{~J}-11$ & $2.0(7.200)$ & $6.5(23,600)$ & $8.4(30,800)$ \\
\hline B93 & $16 \mathrm{~J} \cdot 12$ & $1.9(6,800)$ & $6.1(22,400)$ & $8.0(29,200)$ \\
\hline 894 & $16 \mathrm{~J}-14$ & $1.9(6,800)$ & $5.9(21,400)$ & $7.7(28,200)$ \\
\hline B95 & $16 \mathrm{~J}-15$ & $1.9(6,800)$ & $5.9(21,700)$ & $7.8(28,500)$ \\
\hline B96. & $6 \mathrm{~J}-7$ & $2.0(7,200)$ & $5.7(20,700)$ & $7.6(27,90$ \\
\hline B97d & $6 \mathrm{6J} 3$ & $2.2(7,900)$ & $3.9(14,300)$ & $6.1(22,200)$ \\
\hline B98 & $6 \mathrm{6J-8}$ & $2.2(7,900)$ & $5.6(20,500)$ & $7.8(28,400)$ \\
\hline
\end{tabular}

Final Peak

$\underset{\text { Fissions } / \mathrm{cm}^{3} \times 10^{-20}}{\text { Burnup }}$

(MWd/tU)

$9.8(35,700)$

$8.6(31,600)$

$8.8(32,100)$

$7.3(26,600)$

$9.1(33,200)$

\begin{tabular}{cc}
\multicolumn{2}{c}{ Days of } \\
Opperation \\
\hline VBWR & Total \\
& \\
378 & 1,846 \\
335 & 1,803 \\
335 & 1,803 \\
335 & 1,803 \\
378 & 1,846 \\
378 & 1,218 \\
378 & 1,846
\end{tabular}

Estimated

Peak Heat Flux

W/cm ${ }^{2}\left(B t u / h \cdot f^{2} \times 10^{-3}\right)$

$109(346) \quad 102(325)$

$111(351): \quad 100(316)$

$111(351)$ 99(313)

$111(351)$ 101 (319)

$109(346), \quad 103(328)$

$121(385): \quad 105(334)$

$121(385) \quad 115(366)$
Time-Averaged Rod-Average Heat Flux ${ }^{c}$ $\frac{\mathrm{W} / \mathrm{cm}^{2}\left(\text { Btu } / \mathrm{h} \cdot \mathrm{ft}^{2} \times 10^{-3}\right)}{\text { VBWR }}$

$40(127)$ Dresden

5 (112) $\quad 32(103) \quad 34(109)$ $\begin{array}{ll}43(136) & 33(105)\end{array}$ $43(136) \quad 31(99) \quad 33(106)$ $40(127) \quad 30(94) \quad 32(101)$ $\begin{array}{lll}44(141) & 36(114) & 38(122) \\ 44(140) & 29(93) & 32(102)\end{array}$

a) Rod is designated by assembly number (e.9., 5J) followed by position number as indicated below:

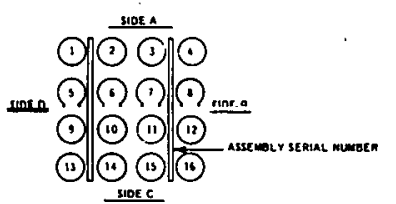

b) Days of operation in VBWR $=$ hours reactor thermal pówer $>5 \mathrm{MW} \div 24$. Davs of operation in Dresden $=$ hours of turbine-generator operation $\div 24$.

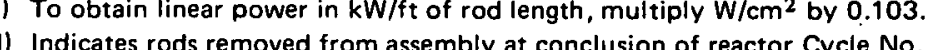

e) Indicates rod transilerred from Subassembly B-1 to Subassembly A-1 between reactor Cycle Nos. 4 and 5. 


\subsubsection{Leak Testing}

At the terminal shutdown of the VBWR, eleven of the fuel assemblies from which the SA-1 rods were selected were leak tested by a "wet sipping" technique. The sipping test is performed following a shutdown to detect assemblies in which the cladding has been penetrated, exposing $\mathrm{UO}_{2}$ fuel to the coolant. To perform this test the assembly was sealed in a can and, after it was allowed to soak for about 20 minutes, a 1 -liter water sample was withdrawn. The sample was analyzed for fission product iodine and the concentration compared with the concentration of fission product iodine in the surrounding pool water (background). A higher concentration of radioactive iodine was generally interpreted as being indicative of a fuel rod cladding failure.

From the results of the sipping tests, two of these assemblies (12J and 16J) were suspected of containing one or more rods with cladding defects. The signals were of relatively low levels, however, and when repeat tests were run on them. the: indications were too low to be conclusive. The one assembly (14J) that was not given a post-irradiation sip test was suspected of containing one or more failed rods on the basis of the activity release detected during earlier in-core monitoring.

During the subsequent visual examinations of the fuel rods, a full-wall fretting wear defect caused by the single-layer wire middle spacer was found in the cladding of one rod from Assembly 14J. The rest of the rods in this assembly and all of those in the other eleven assemblies appeared to be sound.

\subsection{DRESDEN UNIT NO. 1}

\subsubsection{Reactor Environment and Operation}

The reactor of the Dresden Nuclear Power Station Unit No. 1 is a dual cycle boiling water reactor that operates at a pressure of $71.5 \mathrm{~kg} / \mathrm{cm}^{2}$ or 1017 psia $\left(286^{\circ} \mathrm{C}\right.$ saturation temperature $)$. During the SA-1 operating period the reactor water had an average $\mathrm{pH}$ of 7.5 and an average conductivity of $0.44 \mu$ mho. The turbidity of the water averaged 5.5 APHA units, and the mean concentration of chioride was $0.040 \mathrm{ppm}$. A record of the reactor water chemistry data is given on a monthly basis in Appendix $C$.

Assembly SA-1. operated in Dresden throughout Cycles 3, 4, 5, and 6. During these cycles the station followed two basic patterns of operation. During the initial portions of $C_{y c l e s} 3$ and 4 , scheduled operation was on a daily load cycle to match the system demands. Generally speaking, this type of load schedule called for plant operation at approximately half power from about 11:00 p.m. to about 8:00 a.m. and at or near full power during the remainder of the day except for reductions to three-quarters power during the noon and late afternoon hours. This pattern was altered on Saturdays with a load reduction to half power from noon to early evening. Sunday operation was constant at half power. During most of the remainder of the four cycles the plant was base loaded. The power was more nearly constant with this type of operation than with the previously mentioned pattern. Although periods of operation below the base power level occurred, these reductions were generally less frequent, of smaller magnitude, and of shorter duration than the daily half- to full-power swings called for by the system demand following type of load schedule. The period and-number of days of operation and information on the reactor thermal power levels are given for each of the four cycles in Table 3.

\subsubsection{Assembly Operation}

\subsubsection{Calculated Operational Characteristics}

The approximate axial power distribution for Assembly SA-1 at the beginning of Dresden operation is depicted in Figure 12. The ratio of axial peak-to-average power without consideration of end pellet peaking is 1.23 . The end pellet factor is 1.15 . Since the location of the pellets adjacent to the short end plugs of the " $A$ " or bottom rods very nearly coincides with the previously mentioned peak, the overall axial factor becomes 1.41 .

The relative radial powers for the different subassembly rod locations at the beginning of Dresden operation are shown in Figure 13 for zero voids and for $40 \%$ voids. The relative power in the nonvoided region for the maximum power rod is 1.19 .

The overall power peaking factor for the assembly therefore is the product of the overall axial factor $(1.41)$ and the local radial factor (1.19) and equals 1.68 .

\subsubsection{Core Locations and Fuel Rod Patterns}

Assembly SA.1 operated continuously from June 1964 to September 1969 with the exception of shutdown periods for reactor refueling and maintenance. Figures 14 and 15 indicate where SA-1 was located in the reactor core and the types of fuel assemblies that surrounded it during its four cycles of operation. 
Table 3

DNPS UNIT NO. 1 REACTOR OPERATING DATA

\begin{tabular}{|c|c|c|c|c|c|c|c|c|c|}
\hline \multirow[b]{3}{*}{$\begin{array}{l}\text { Cycle } \\
\text { Number }\end{array}$} & \multirow{3}{*}{$\begin{array}{l}\text { Dates Cycle } \\
\text { Started and } \\
\text { Completed }\end{array}$} & \multirow{3}{*}{$\begin{array}{c}\text { Total Days } \\
\text { of Operationa }\end{array}$} & \multirow[b]{3}{*}{$\begin{array}{l}\text { Type of } \\
\text { Operation }\end{array}$} & \multirow[b]{3}{*}{ Period } & \multicolumn{4}{|l|}{ 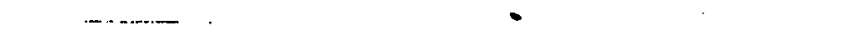 } & \multirow{3}{*}{$\begin{array}{l}\text { Number of } \\
\text { Times } \\
\text { Reactor } \\
\text { Power } \\
\text { Reduced } \\
\text { to Zeroc }\end{array}$} \\
\hline & & & & & \multicolumn{3}{|c|}{$\begin{array}{c}\text { Typical Reactor Thermal } \\
\text { Powers (MWt) } \\
\end{array}$} & $\begin{array}{l}\text { Peak } \\
\text { Power }\end{array}$ & \\
\hline & & & & & $\begin{array}{c}\text { Daily } \\
\text { Maximumb }\end{array}$ & $\begin{array}{l}\text { Daily } \\
\text { Average }\end{array}$ & $\begin{array}{c}\text { Daily } \\
\text { Minimumb }\end{array}$ & $\begin{array}{l}\text { Attained b } \\
\text { (MWt) }\end{array}$ & \\
\hline \multirow[t]{4}{*}{3} & $6 / 9 / 64-3 / 28 / 65$ & 281 & $\begin{array}{l}\text { System demand } \\
\text { following }\end{array}$ & 6/9/64-3/7/64 & $600-685$ & $\sim 500$ & $\sim 350$ & 690 & 3 \\
\hline & & & Base loaded & 9/8/64-1J/1/64 & 510 & 505 & 500 & 515 & 1 \\
\hline & & & Base loaded & $10 / 2 / 64-3 / 9 / 65$ & 460 & 460 & 460 & 475 & 1 \\
\hline & & & - & $3 / 9 / 65 \cdot 3 / 28 / 65$ & \multicolumn{3}{|c|}{ Gradual decrease to $\sim 415$} & - & 1 \\
\hline \multirow[t]{3}{*}{4} & $5 / 29 / 65-1 / 13 / 67$ & 559 & $\begin{array}{l}\text { System demand } \\
\text { following }\end{array}$ & $5 / 29 / 65-1 / 7 / 66$ & $650-685$ & $\sim 525$ & $\sim 350$ & 695 & 6 \\
\hline & & & Base loaded & $1 / 8 / 66-1 J / 4 / 66$ & $600-650$ & $590-640$ & $\sim 570$ & 700 & 9 \\
\hline & & & Base loaded & $10 / 9 / 66-1 / 13 / 67$ & $\sim 520$ & $505-520$ & $475-520$ & 675 & 1 \\
\hline 5 & $5 / 23 / 67-2 / 3 / 68$ & 214 & Base loaded & $5 / 23 / 67-2 / 3 / 68$ & $600-680$ & $590-675$ & $\geqslant 500$ & 695 & 7 \\
\hline \multirow[t]{6}{*}{6} & $6 / 2 / 68-9 / 5 / 69$ & 414 & Base loaded & $6 / 2 / 68-3 / 12 / 69$ & $625-675$ & $600-650$ & $550-650$ & 695 & 16 \\
\hline & & & $d$ & $3 / 13 / 69-5 / 12 / 69$ & $650-675$ & 525.625 & 350 & 700 & 3 \\
\hline & & & Base loaded & $5 / 13 / 69-5 / 27 / 69$ & $\sim 515$ & $\sim 505$ & - & - & 0 \\
\hline & & & Base loaded & 5/28/69-j/8/69 & $\sim 550$ & $\sim 535$ & - & 650 & 0 \\
\hline & & & Base loaded & $6 / 9 / 69-6 / 23 / 69$ & $\sim 580$ & $\sim 575$ & - & 630 & 0 \\
\hline & & & Base loaded & $6 / 24 / 69-3 / 5 / 69$ & $\sim 500$ & $\sim 495$ & - & 580 & 4 \\
\hline
\end{tabular}

\footnotetext{
a Hours of turbinegenerator operation $\div 24$.

b To obtain these walues, conversion factors calculated from corresponding values of electrical and thermal energy outputs,

were applied to the daily maximum and minimum electrical power levels. These data were obtained from the

Commonwealth Edison Company's daily reports on Unit Number 1 operation.

c Excludes end-of-cycle shutdowns.

d Special load schedule that called for $\sim 16$ hours of operation near full power and $\rightarrow 8$ hours of half-power operation per day.
} 


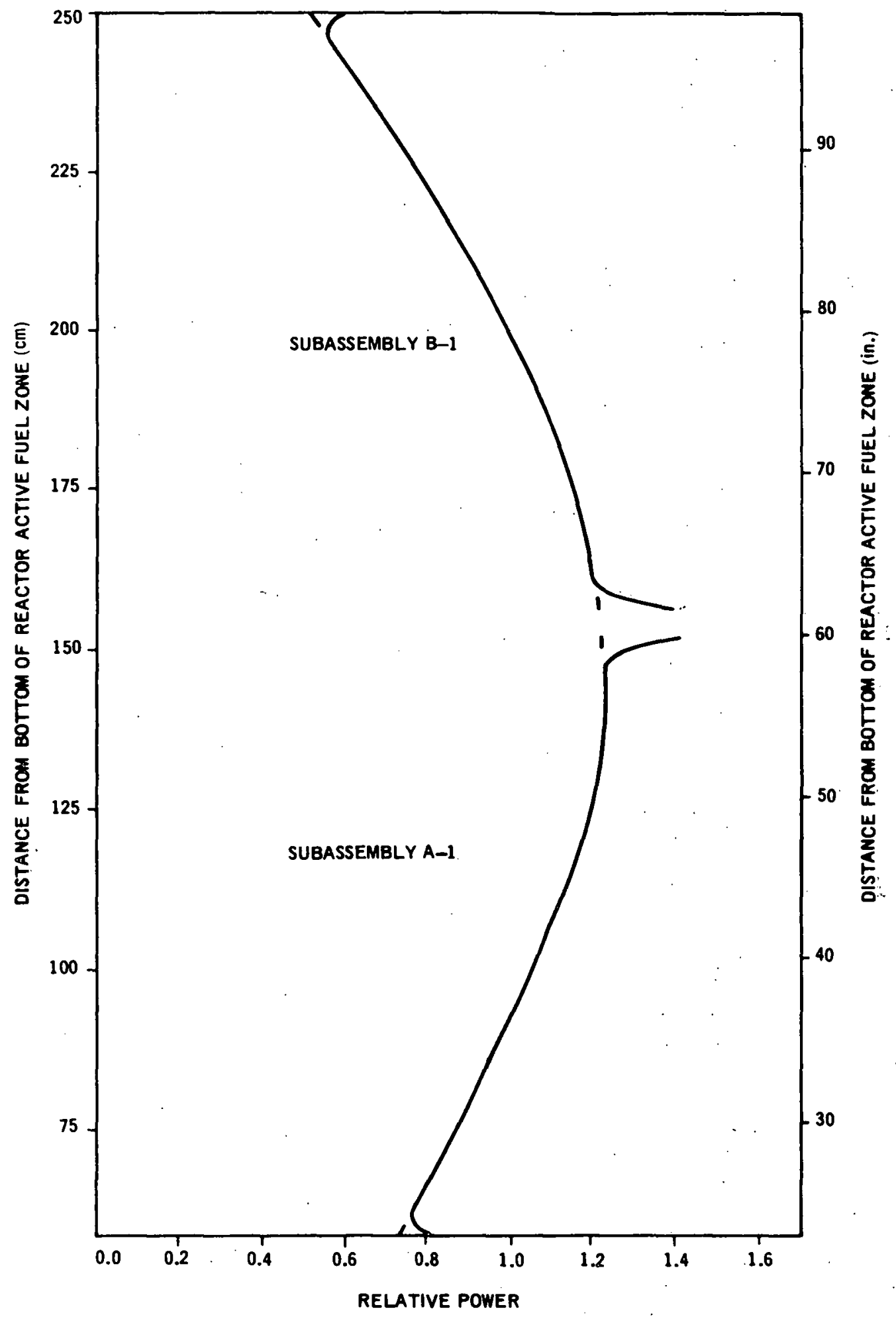

Figure 12. Approximate Axial Power Distribution for Assembly SA-1 at the Beginning of Dresden Operation 


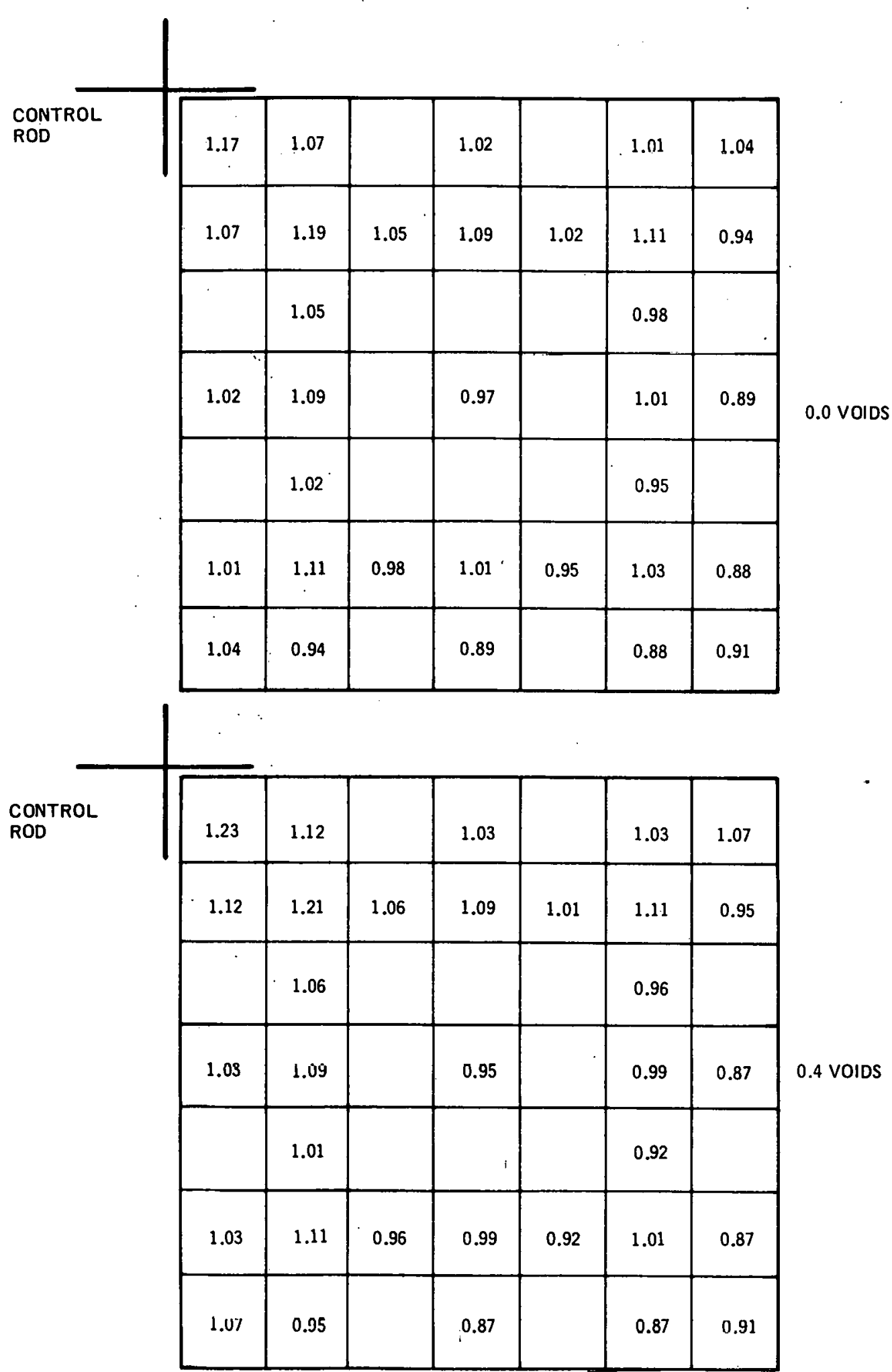

NOTE; Blanks indicate that value for location not specifically determined during in itial analysis

Figure 13. Relative Radlal Powers for Various Subassembly Rod Loactions in Assembly SA-1 at the Beginning of Dresden Operation 


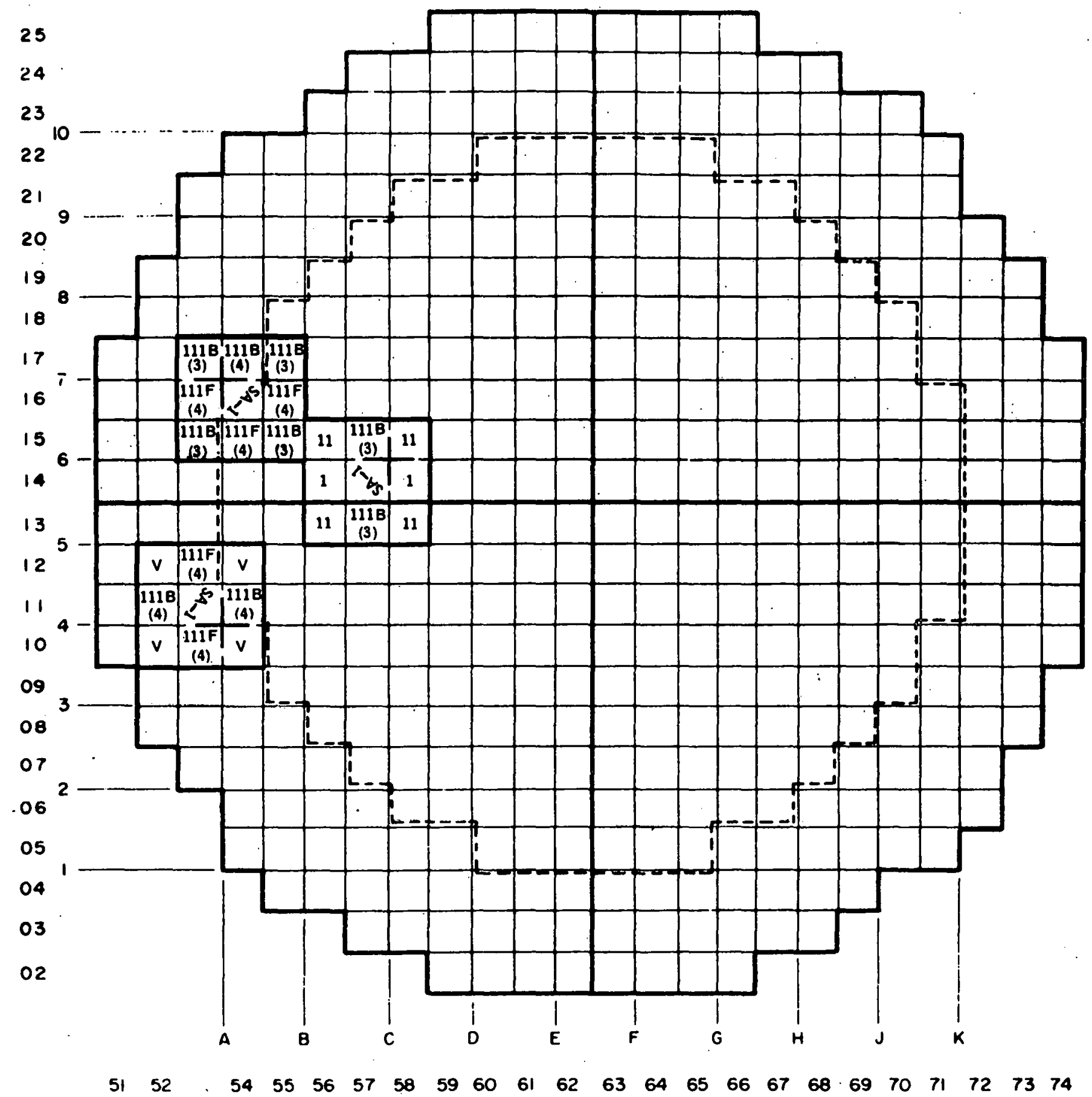

TYPE OF ASSEMBLY

11

$1118(3)$

1118 (4) \& $111 F(4)$

V

5455

STARTED OPERATION

JUNE 1960

MARCH 1963

JUNE 1964

MAY 1965

MAY 1967

Figure 14. Locations of SA-1 and Types of Surrounding Fuel Assemblies

in Cycle No. 3 (57-14), Crcle No. 4 (54-16), and Crcle No. 5 (53-11) 


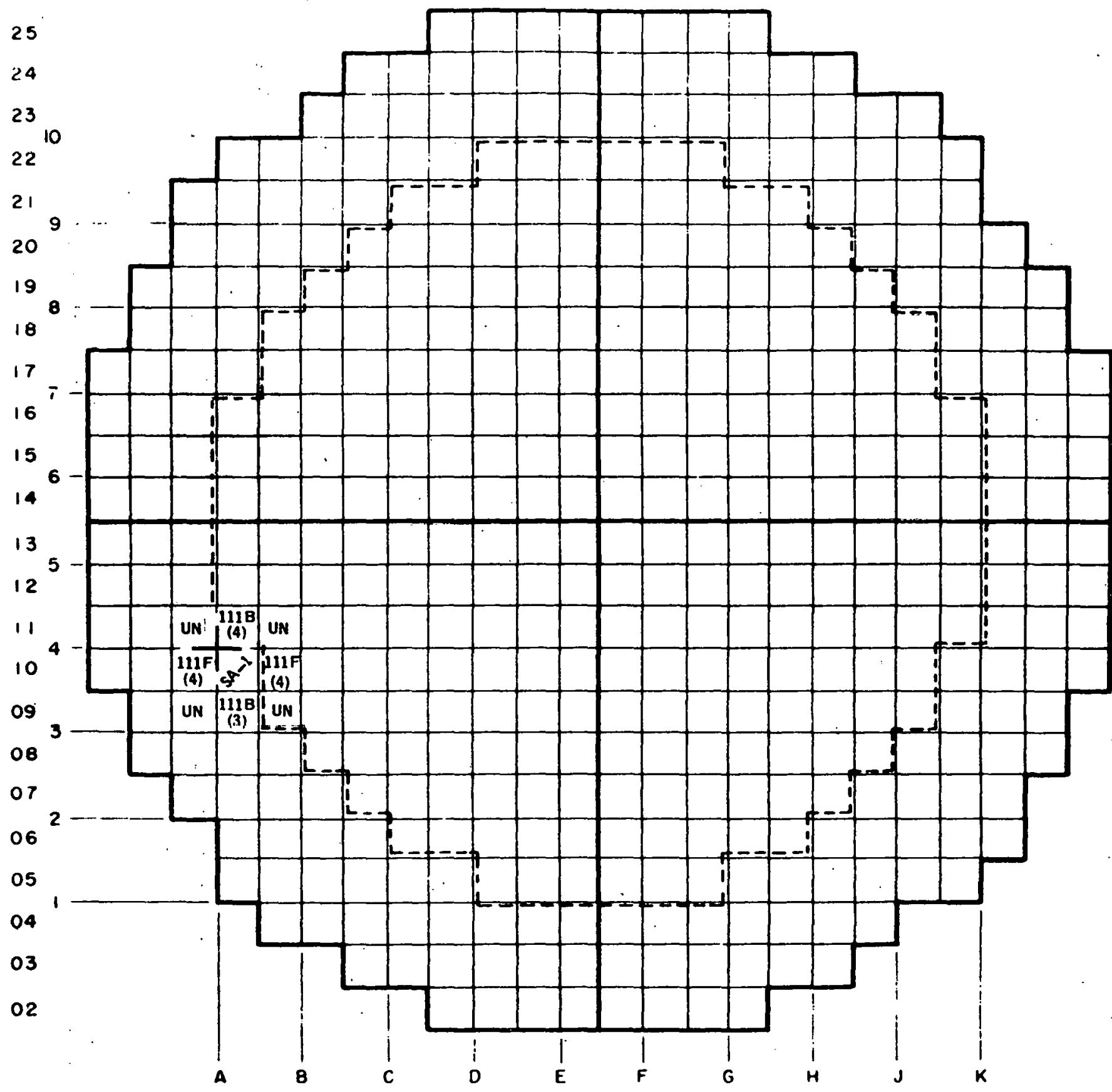

5152

TYPE OF ASSEMBLY 111B (3)

1118 (4) \& $111 F(4)$ UN
5354

5556 ZIRCALOY-2-CLAD THROUGH RODS - SECOND REFUELING ZIRCALOY-2-CLAO THROUGH RODS - FIFTH REFUELING
STARTED OPERATION

JUNE 1964

MAY 1965

JUNE 1968

Figure 15. Location of SA-1 and Types of Surrounding Fuel Assemblies in Cycle No. 6 
The locations of the fuel rods in the two subassemblies and the orientations of the subassemblies with respect to the adjacent control rod are shown in Figure 16. At the end of the assembly's second cycle of operation (reactor Cycle No. 4), the 10 rods indicated in Figure 16(a) were permanently removed for examination purposes.

To assure satisfactory power distribution and thermal-hydraulic characteristics in subsequent cycles, some of the 88 remaining fuel rods were rearranged, as shown in Figure 16(b), and the orientation of the assembly with respect to the adjacent control rod was changed by 180 degrees. The control rod at which SA-1 was located in each of the four cycles was, in every case, fully withdrawn throughout that particular cycle.

\subsubsection{Exposure and Thermal Performance}

Most of the SA-1 fuel rods operated 1468 days " in Dresden. The total days of operation for these rods, including VBWR exposure, ranged from 1767 days to 1846 days and averaged 1827 . The 10 rods that were removed from the assembly at the end of Cycle No. 4 operated 840 days* in Dresden and ranged from 1139 days to 1218 days in total exposure time.

The 88 rods that operated through four cycles received an average additional burnup in Dresden of.6.2 $\times 10^{20}$ fissions $/ \mathrm{cm}^{3}(22,800 \mathrm{MWd} / \mathrm{tU})$. The assembly-average burnup, including VBWR exposure, was $8.2 \times 10^{20} \mathrm{fissions} / \mathrm{cm}^{3}$ $(29,800 \mathrm{MWd} / \mathrm{tU})$. The terminal rod-average burnups ranged from $7.1 \times 10^{20}$ to $9.3 \times 10^{20}$ fissions/cm $3(25,800$ to $33,900 \mathrm{MWd} / \mathrm{tU})$, and the highest local peak burnup for any rod was $10.4 \times 10^{20}$ fissions $/ \mathrm{cm}^{3}(37,900 \mathrm{MWd} / \mathrm{tU})$. The exposure times and average burnups of all 98 SA-1 fuel rods and the peak terminal burnups of those rods that were gamma scanned at the end of operation are given in Table 2. The methods employed to analyze some of the rods for burnup are described in detail in Section 5.3. In brief, they were as follows: 51 rods, including the 10 that were removed from the assembly at the end of Cycle No. 4, were gamma scanned for Cs-137 with a Ge (Li) detector system to obtain both the axial burnup distribution for each rod and the relative rod-average burnups among these several rods. Fuel samples were taken from the peak burnup locations of 20 of these rods (25 to $30 \mathrm{~cm} \mathrm{[.10} \mathrm{to} 12$ in.] above or below the middle of the assembly) and analyzed for burnup by measuring the neodymium isotopes. These burnup values then were applied to the gamma scan results to obtain the average and peak burnups of all 51 rods. The average burnups of the remaining 47 were determined by estimating their burnups in.Dresden from the rods that were analyzed and taking the differences in VBWR burnups into consideration.

The power at which Assembly SA-1 operated was highest early in the first cycle (reactor Cycle 3) and decreased rather continuously. with increasing burnup. As Table 4 indicates, the local peak heat flux attained by the assembly was $117 \mathrm{~W} / \mathrm{cm}^{2}(372,000 \mathrm{Btu} / \mathrm{h}-\mathrm{ft})$, and the maximum assembly-average heat flux was $87 \mathrm{~W} / \mathrm{cm}^{2}\left(277,000 \mathrm{Btu} / \mathrm{h}-\mathrm{ft}^{2}\right)$. . $^{*}$. The time-averaged assembly-average heat flux for Dresden operation was $33 \mathrm{~W} / \mathrm{cm}^{2}\left(104,000 \mathrm{Btu} / \mathrm{h}-\mathrm{ft}{ }^{2}\right)$.

The peak heat flux attained and the time-averaged heat flux are given for each individual fuel rod in the assembly in Table 2. All rods, including those in the relatively lower power positions in the assembly. during the first two cycles, attained their maximum heat fluxes early in Dresden operation. With about $60 \%$ of the rods, that heat flux was lower than the local peak heat flux attained during VBWR operation. Among rods that operated through four Dresden.cycles; the maximum time-averaged rod-average heat flux for VBWR and Dresden operation combined was $39 \mathrm{~W} / \mathrm{cm}^{2}(123,000$ Btu/h-ft ${ }^{2}$ ).

\subsubsection{Leak Testing}

At the conclusion of each of the four Dresden cycles, Assembly SA-1 was transferred to the fuel building pool and leak tested by wet sipping in a manner similar to that employed on the VBWR assemblies. No indication of fuel rod failure was detected in any of these tests.

\footnotetext{
- Hours of turbine-generator operation $\div 24$.

* An overall peaking factor of 1.68 was used in all calculations of assembly peak heat flux given in Table 4 . The accuracy of this value becomes more doubtful with increase in exposure, particularly for operation after the second cycle when rods were removed and underwent changes of position, and the assembly orientation was changed. However, because of the relatively low assembly power levels toward the end of operation, attempting to "update" the peaking factor did not seem warranted.
} 

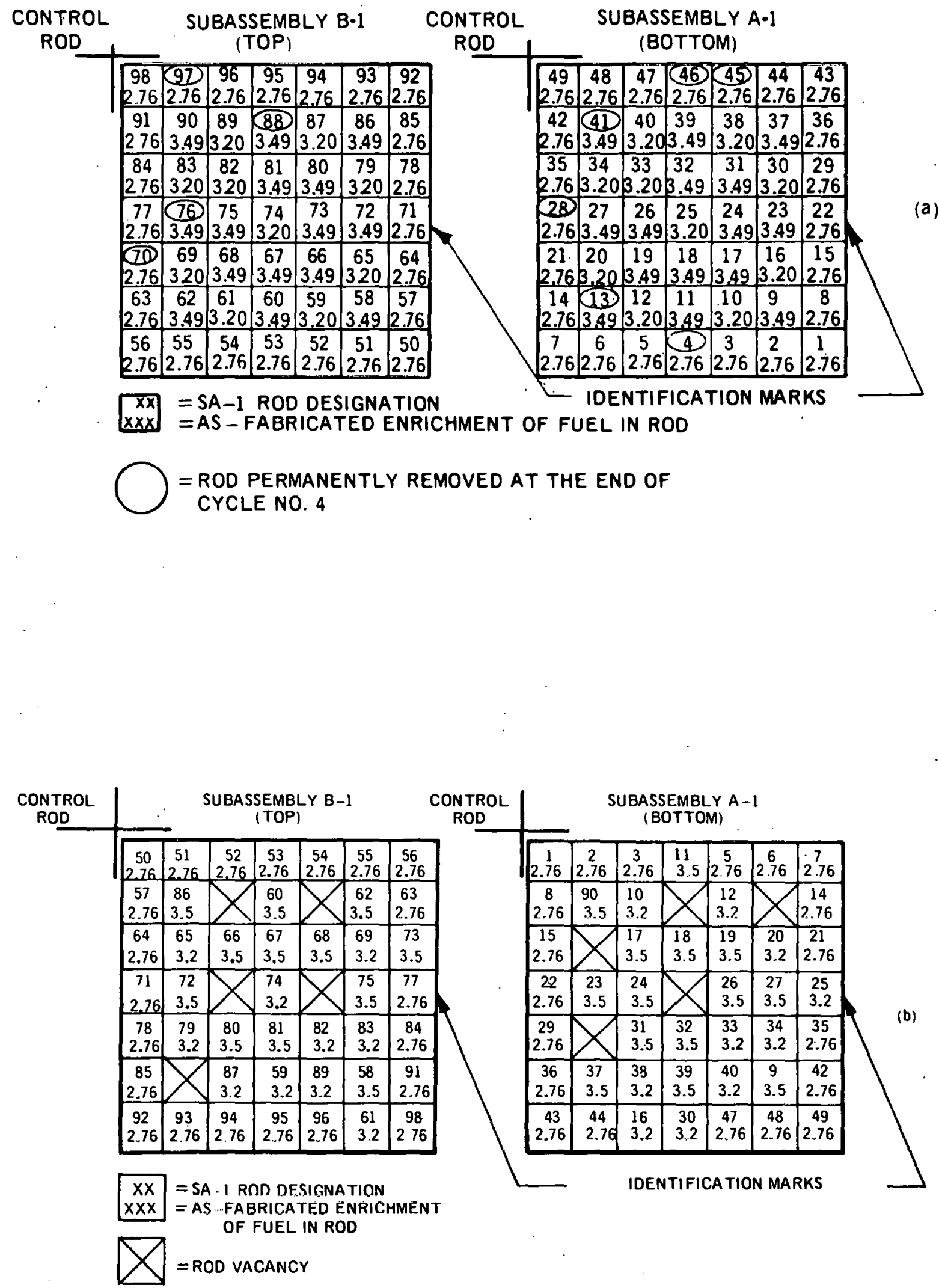

Figure 16. SA-1 Fuel Rod Patterns During Dresden Cycles 3 and 4 (a) and 5 and 6 (b) 
Table 4

SA-1 THERMAL PERFORMANCE HISTORY IN DRESDEN

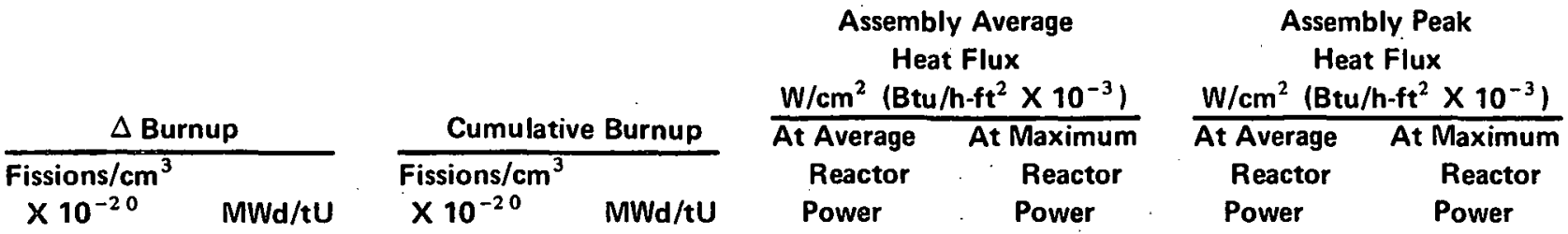

CYCLE NUMBER 3

$\begin{array}{rrrrrrrr}0.13 & 480 & 2.08 & 7,590 & 52(165) & 69(220) & 87(277) & 116(370) \\ 0.48 & 1.740 & 2.55 & 9,330 & 46(146) & 70(221) & 77(245) & 117(372) \\ 0.58 & 2.120 & 3.13 & 11,450 & 45(142) & 49(155) & 75(238) & 82(260) \\ 0.24 & 880 & 3.37 & 12,330 & 42(133) & 45(142) & 70(223) & 76(239) \\ 0.25 & 910 & 3.62 & 13,240 & 43(138) & 45(144) & 73(231) & 76(242)\end{array}$

\section{CYCLE NUMBER 4}

$\begin{array}{lllllllll}0.61 & 2,240 & 4.24 & 15,480 & 35(110) & 49(156) & 58(185) & 82(262) \\ 0.31 & 1,140 & 4.55 & 16,620 & 38(120) & 52(166) & 64(201) & 88(278) \\ 0.45 & 1,660 & 5.00 & 18,280 & 35(110) & 50(157) & 65(207) & 83(264) \\ 0.46 & 1,680 & 5.46 & 19,960 & 40(126) & 46(145) & 67(212) & 77(244) \\ 0.42 & 1,540 & 5.88 & 21,500 & 36(115) & 44(139) & 61(194) & 74(233) \\ 0.36 & 1,330 & 6.25 & 22,830 & 28(89) & 39(123) & 47(150) & 65(207)\end{array}$

CYCLE NUMBER 5

$\begin{array}{llllllll}0.08 & 280 & 6.31 & 23,050 & 16(49) & 20(62) & 26(82) & 33(104) \\ 0.16 & 600 & 6.47 & 23,650 & 21(68) & 30(94) & 36(114) & 50(158) \\ 0.16 & 580 & 6.63 & 24,230 & 22(69) & 25(79) & 37(117) & 42(134) \\ 0.11 & 420 & 6.74 & 24,650 & 23(72) & 27(85) & 38(121) & 45(142) \\ 0.13 & 490 & 6.88 & 25,140 & 23(73) & 26(84) & 38(122) & 44(141) \\ 0.04 & 140 & 6.92 & 25,280 & 20(64) & 26(84) & 34(108) & 44(141)\end{array}$

CYCLE NUMBER 6

$\begin{array}{rrrrrrrr}0.33 & 1,210 & 7.25 & 26,490 & 25(79) & 29(91) & 42(133) & 48(152) \\ 0.27 & 990 & 7.52 & 27,480 & 22(69) & 25(80) & 36(115) & 42(134) \\ 0.31 & 1,140 & 7.83 & 28,620 & 20(64) & 24(75) & 34(107) & 40(127) \\ 0.33 & 1,210 & 8.16 & 29,830 & 18(58) & 25(78) & 30(97) & 41(131)\end{array}$




\section{EXAMINATIONS AND ANALYSES OF THE SA-1 FUEL}

\subsection{FUEL ROD PERFORMANCE EVALUATION}

\subsubsection{Visual Examinations of Fuel Rods (G. P. Ferguson, F. H. Megerth)}

\subsubsection{Procedure and Scope}

The external surfaces of most of the SA-1 fuel rods were visually examined on several occasions during the course of operation. Interim pool examinations were performed with an underwater periscope on the Type $\mathrm{J}$ assemblies during scheduled shutdown periods between VBWR runs. At the conclusion of VBWR operation, all of the rods that were ultimately selected for incorporation in Assembly SA-1 were transferred to the hot cells of the Radioactive Materials Laboratory at VNC and examined individually. All of these rods were wiped down with a dry cotton pad at this time to remove most of the deposited corrosion products, or crud.

At the end of Dresden Reactor Cycle No. 4, all sides of the two SA-1 subassemblies were examined by means of both an underwater television camera and a borescope. Nineteen fuel rods were withdrawn from the subassemblies and individually inspected with the borescope, and ten of these were shipped to VNC where they were examined in-cell during the initial phase of the PA-41 examination program.

Finally, after the assembly had operated to the end of reactor Cycle No. 6, the two subassemblies were transported to VNC for the final phase of the examination program. The four sides of each subassembly were examined in the hot cells in order to determine the external surface appearance of some of the rods before they were removed from the subassembly structures and thus subjected to an unavoidable scraping of the surfaces by the spacer springs and bands. The conditions of the spacers and other parts of the subassembly structures also were of interest from the standpoint of the possible effects on fuel rod operation. Upon completing a subassembly examination, each rod was removed and examined. A Kollmorgen periscope was used in all of the hot cell work to examine the SA-1 fuel at magnifications between approximately $2 X$ and $4 X$.

Twelve rods were re-examined after dissolving the crud layers with hydrochloric acid. The details of the dissolution procedure used are described in Section 5.1.9 (Crud Analysis). Half of these rods (A4, A13, A28, A41, B70, and $B 76)$ were removed from $S A-1$ at the end of Cycle No. 4; the rest $(A 7, A 9, A 22, A 37, A 49$, and $B 50)$ operated to the end of C'ycle No. 6.

In carrying out the visual examinations, the axial positions of points of interest on the rod surfaces generally were defined in terms of distance from the shoulder of the shorter end plug, regardless of whether a rod was from the top (B-1) or bottom (A-1) subassembly. In both cases, the shorter plugs were located near the middle of the full SA-1 assembly, while the longer end plugs (and plenums) were located at the top and bottom. The radial orientations of points of interest on the 10 rods removed at the end of Cycle No. 4 were arbitrarily defined in terms of degrees from the identifying numbers stamped on the longer end plugs. With the other 88 rods, however, the 0-degree orientation was taken as that point on the circumference of a rod that was directed toward the "identification mark" side of its subassembly. (See Figure 16.)

\subsubsection{Results}

At the conclusion of VBWR operation the surfaces of the Type $J$ fuel rods were generally uniform in appearance and were evenly covered with deposited corrosion products, or crud. The crud was red-brown, soft, and easily removed by wiping with a dry cotton pad. The removal of the crud deposits revealed a reddish-black surface film which contained numerous shiny specks. About $5 \%$ of the rods inspected had some irregular surface patterns. An example of this mottling can be seen in Figure 17 on rod 14J-12, which later was selected for irradiation in SA-1 as rod A18. ${ }^{3}$

Evidence of fretting wear of the cladding caused by the single-layer wire spacers located at the middle of the VBWR assemblies was frequently noted. Some relatively severe cases of fretting wear are shown in Figure $18 .^{3}$ The depths of the wear grooves were measured with a special gauge. The grooves in approximately three-fourths of those rods selected for further irradiation in Assembly SA-1 were $\leqslant 0.0076 \mathrm{~cm}(0.003 \mathrm{in}$.) deep. Seventeen of the SA-1 rods had wear grooves $0.013 \mathrm{~cm}(0.005 \mathrm{in}$.) or more deep. The deepest grooves in any of the SA-1 rods were shown by rods A24 and A31. (0.025 cm or 0.010 in.). ${ }^{2}$

The two subassemblies appeared to be in generally good condition after four cycles of Dresden operation. An overall view of subassembly B-1, which was in the top position during operation, is shown in Figure 19. The spacing between visible outside rods was uniform in both subassemblies. The four corner rods in each subassembly were completely hidden from view, and the rods next to the corner rods were partially hidden by the staınless steel corner 


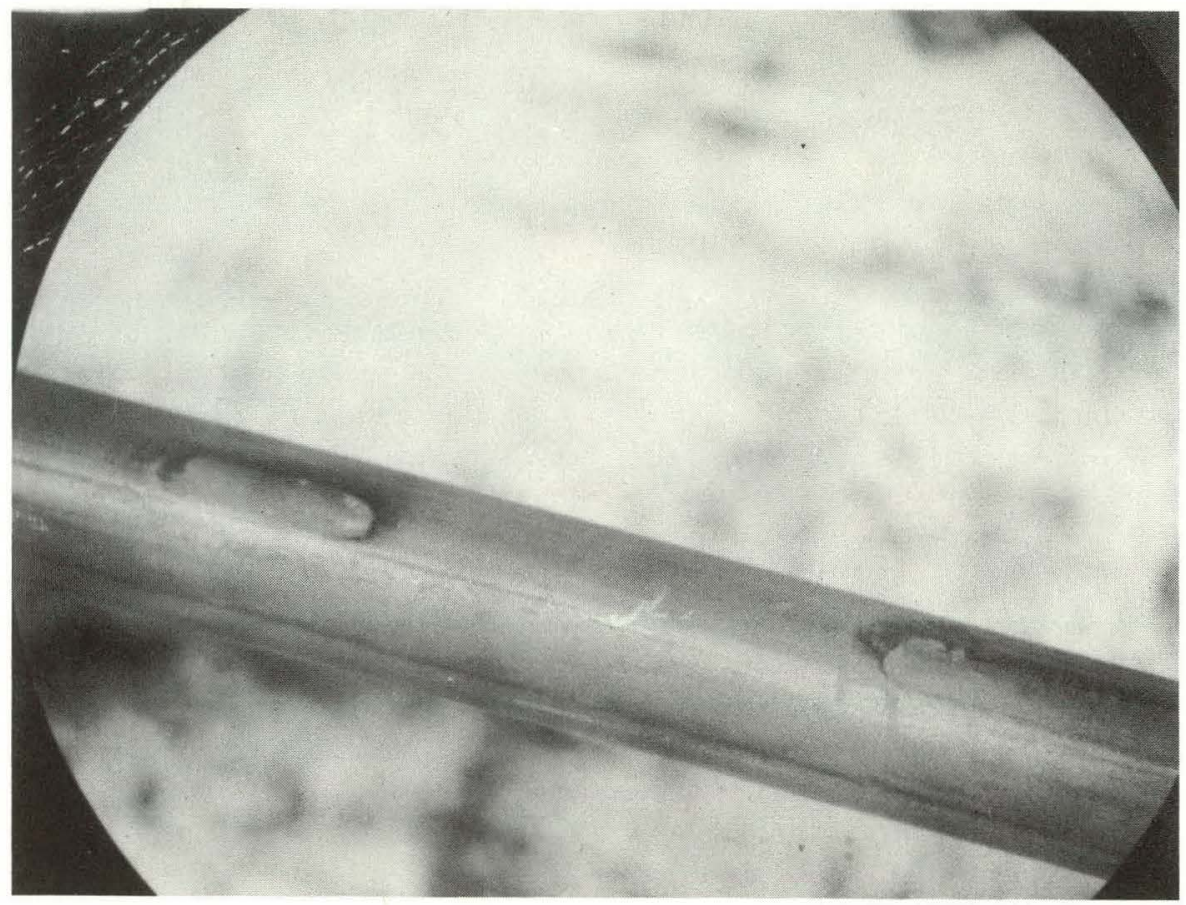

Figure 17. Irregular Patterns on Surface of Rod 14J-12 (SA-1, Rod A18)
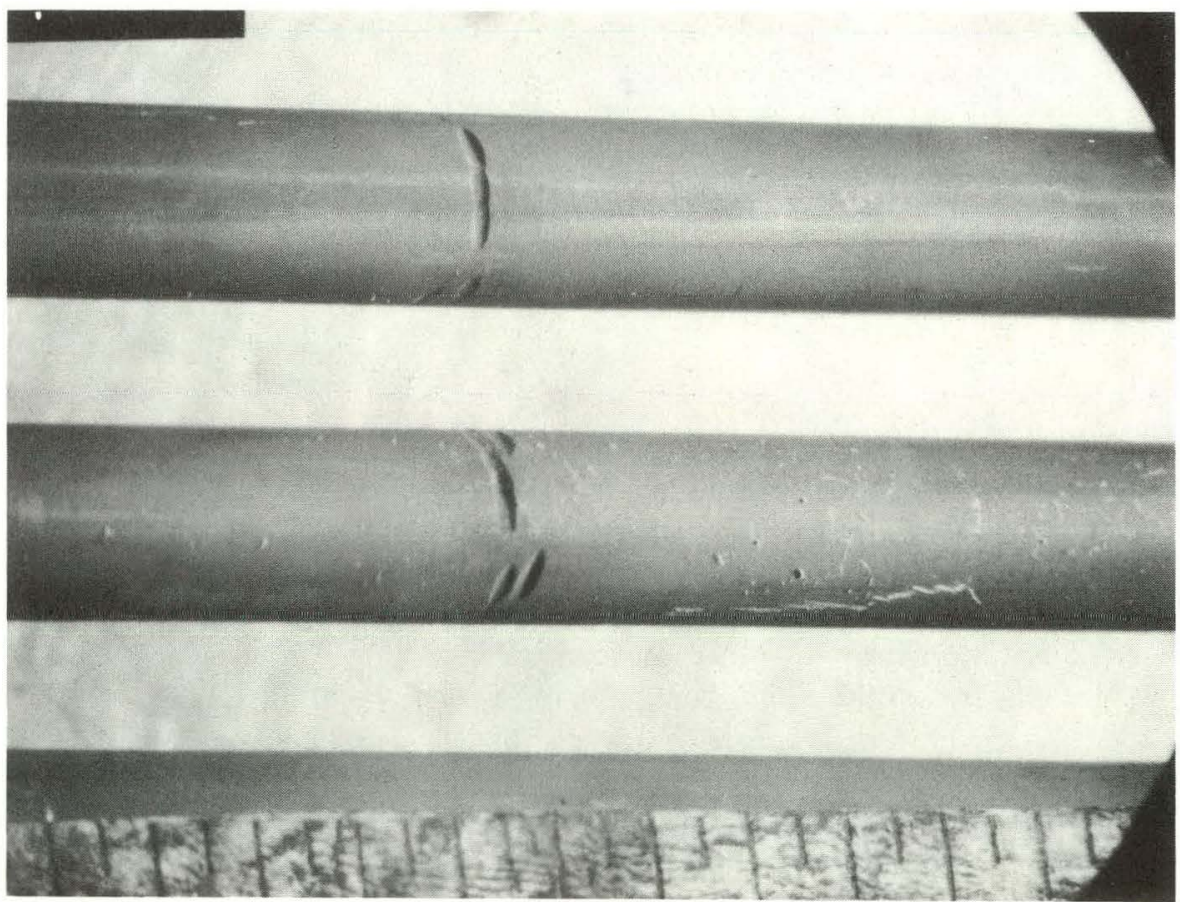

Figure 18. Severe Fretting Wear at Single-Layer Wire Spacer Contacts 


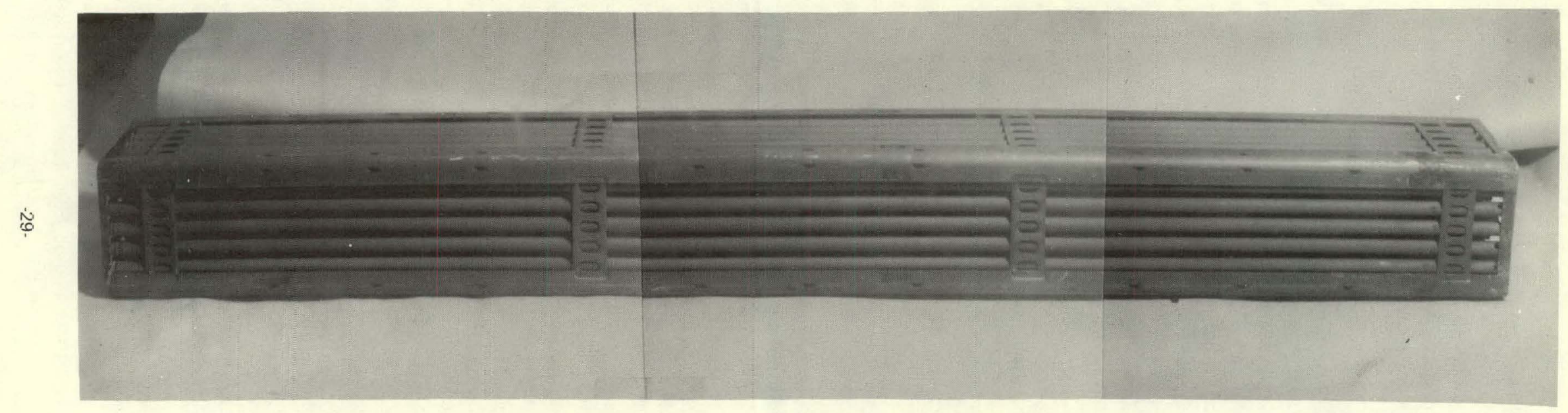


angles. No distortion in or significant damage to corner angles, bottom grids, top horizontal straps, or spacer bands was apparent. All band-to-angle and other weldments appeared to be in satisfactory condition. No damage to spacer cross members could be detected, and there was no apparent loss, damage, or misalignment of spacer springs.

Some blue and red discolored areas about $1 \mathrm{~cm}$ by $2 \mathrm{~cm} \mathrm{(} \mathrm{1/2} \mathrm{in.} \mathrm{by} 3 / 4 \mathrm{in}$.) were observed on the corner angles of subassembly A-1 just below the top spacer bands.

Subassembly B-1 showed $1 \mathrm{~cm}$ by $1 \mathrm{~cm}(\sim 1 / 2$ in. by $1 / 2 \mathrm{in.})$ areas of greater than normal wear on the corner angles just below the top spacer and about $10 \mathrm{~cm}(4 \mathrm{in}$.) below the second spacer from the top. Two corner angles of one side of this subassembly had rather deep, fresh scratches over the entire length.

During Dresden operation, a film of crud deposited on the fuel rods that generally gave most of the surface area a coloration best described as bluish-gray with varied amounts of reddish-brown. The reddish-brown portion of the film frequently was distributed in the form of speckles, and in such cases the surface usually appeared somewhat rough in texture. Examples of this type of surface are shown in Figures 20,21, and 22. Generally speaking, the appearance of the rods that had operated in Dresden for four cycles was similar to that of the ten rods that were permanently removed after two cycles of operation. The crud film seemed to be quite adherent over most of the rod surface. This was particularly true of the bluish-gray portion of the film. As Figures 21 and 22 show, the degree of speckling and roughness varied from rod to rod at a given elevation.

Practically all rods showed some roughness between the short end plugs, located at the middle of the assembly, and a location near the distant edge of the closest spacer, i.e., $5 \mathrm{~cm}$ to $8 \mathrm{~cm}$ ( 2 in. to $3 \mathrm{in.}$ ) away from the plugs (Figure 22). The roughness at this axial location generally extended completely around the rod. About three-fourths of the rods showed some roughness elsewhere along their lengths, and in somewhat over half of these cases the degree of roughness decreased in going from the center of the entire assembly to the upper and lower extremities, i.e., from relatively high- to low-power locations. Somewhat less than one-fourth of these rough rods showed rough-smooth axial patterns that varied from the one just described, and for a few within this group the relationship between roughness and power appeared to be reversed. For the rest of the rods, little if any axial variation in surface roughness could be detected over the fuel columns. Some variation around the peripheries was apparent on about three-fourths of those rods that exhibited any significant amount of roughness.

A bandlike pattern in the surface roughness and speckling was observed over 10 to $15 \mathrm{~cm}$ (4 to 6 in.) lengths of three " $\mathrm{A}$ " rods that had operated to the end of Cycle No. 6 (see Figure 23). This pattern occurred over the fuel column between the plenum and a point about $23 \mathrm{~cm}(9 \mathrm{in}$.$) from the plenum, and the smooth, unspeckled rings occurred at$ pellet-length intervals in each case. The long end plugs and plenum regions of the cladding generally were coated with a smooth reddish-brown film of crud (Figure 24).

Approximately ten rods showed spalling or cracking of the crud layer at locations between the subassembly spacers at the end of Cycle No. 6. In most cases, the spalling occurred as isolated, singular spots on the order of $0.3 \mathrm{~cm}$ (1/8 in.) across its largest dimension. Rod B53 showed intermittent, longitudinal cracks in the crud between 85.5 and $94.5 \mathrm{~cm}(33-3 / 4$ and $37-1 / 4 \mathrm{in}$.) from the short end plug (Figure 25).

Corner rod B56, which operated in the top assembly and was positioned at a wide-narrow water gap throughout its Dresden irradiation exhibited the greatest amount of crud spalling. The crud had spalled away down to a white $\mathrm{ZrO}_{2}$ surface in five separate locations from $\sim 2-1 / 2$ to $40 \mathrm{~cm}(\sim 1$ to $16 \mathrm{in.}$ ) above the bottom of the subassembly (Figures 26A and 26B). Most of the spalled areas were $1 / 2 \mathrm{~cm}$ wide by $1 / 2$ to $1 \mathrm{~cm}$ long, and some were larger. Their locations appeared to be associated, but not necessarily directly aligned, with spacers and corner angle recesses. It is quite possible, of course, that a significant amount of crud spalling took place during removal of the rod from the subassembly. On the other hand, the other seven corner rods showed relatively little or no spalling.

A relative increase in deposition of reddish-brown crud generally was observed on a rod at one or more of the subassembly spring type spacer locations. The deposits at these locations typically extended a centimeter or so $(\sim 1 / 2 \mathrm{in}$.) on either side of the apparent spring-rod contact point. The deposition was comparatively somewhat less at the topmost and bottommost spacers in the full assembly, which were located over the fuel rod plenums instead of over the fuel columns. A more localized and flaky appearing buildup of crud occasionally was observed on the rod surface at a spacer location. These localized buildups, examples of which are shown in Figure 27, were as large as approximately $0.3 \mathrm{~cm}(1 / 8 \mathrm{in}$.$) in diameter and were located 0.3$ to $0.6 \mathrm{~cm}(1 / 8$ to $1 / 4 \mathrm{in}$.) below the apparent spring-rod contact point.

Flakes of crud were observed clinging to the bottom edges of a few of the bottom subassembly spacer bands (Figure 28). The flakes were present on two sides of the second spacer from the top and on one side of the third spacer.

Spalling or cracking of the crud near spacer locations was noted on about ten rods. In most cases the spalling or cracking was limited to one spacer contact area per rod. Most of the spalled areas were $0.5 \mathrm{~cm}(\sim 3 / 16 \mathrm{in}$.$) in diameter$ or less. An example of spalled crud at a spacer band location is shown in Figure 29. 


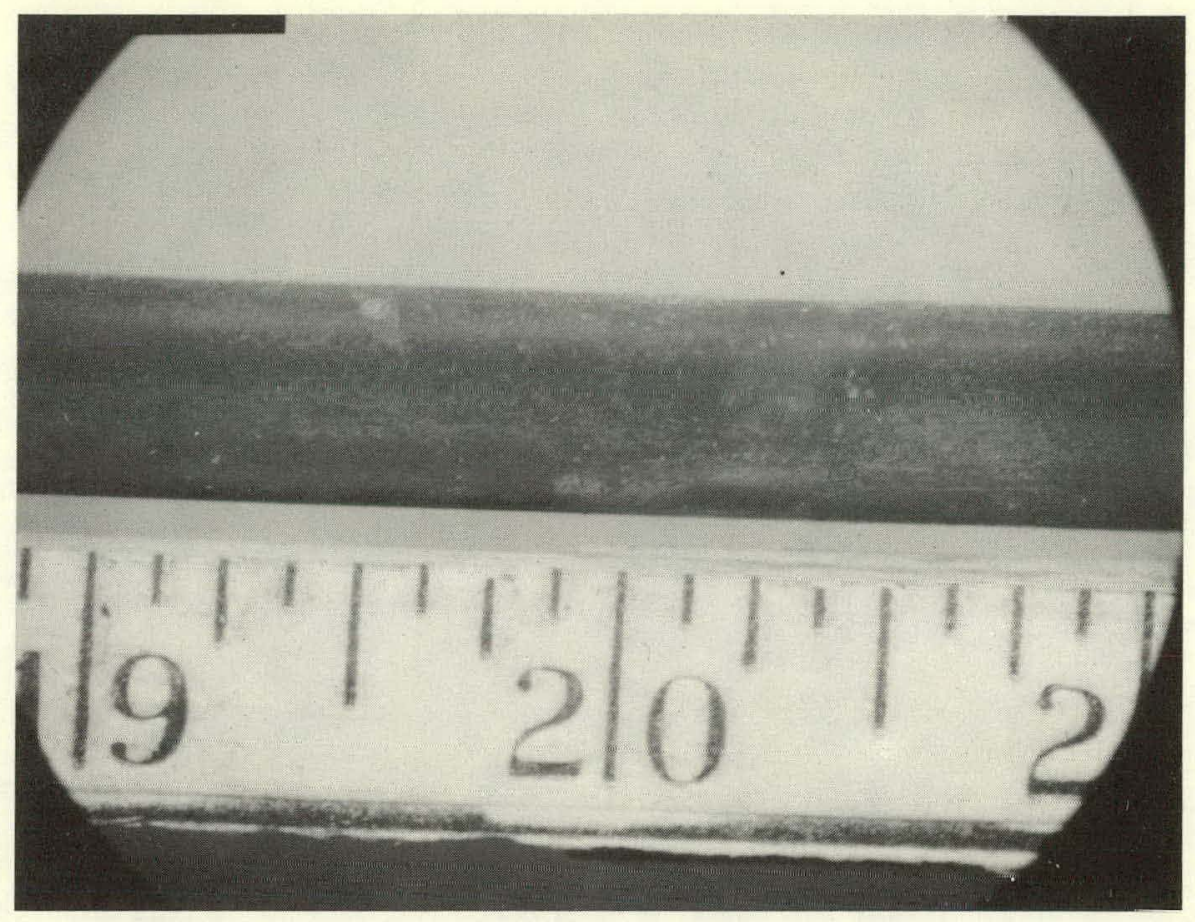

2XMAG.

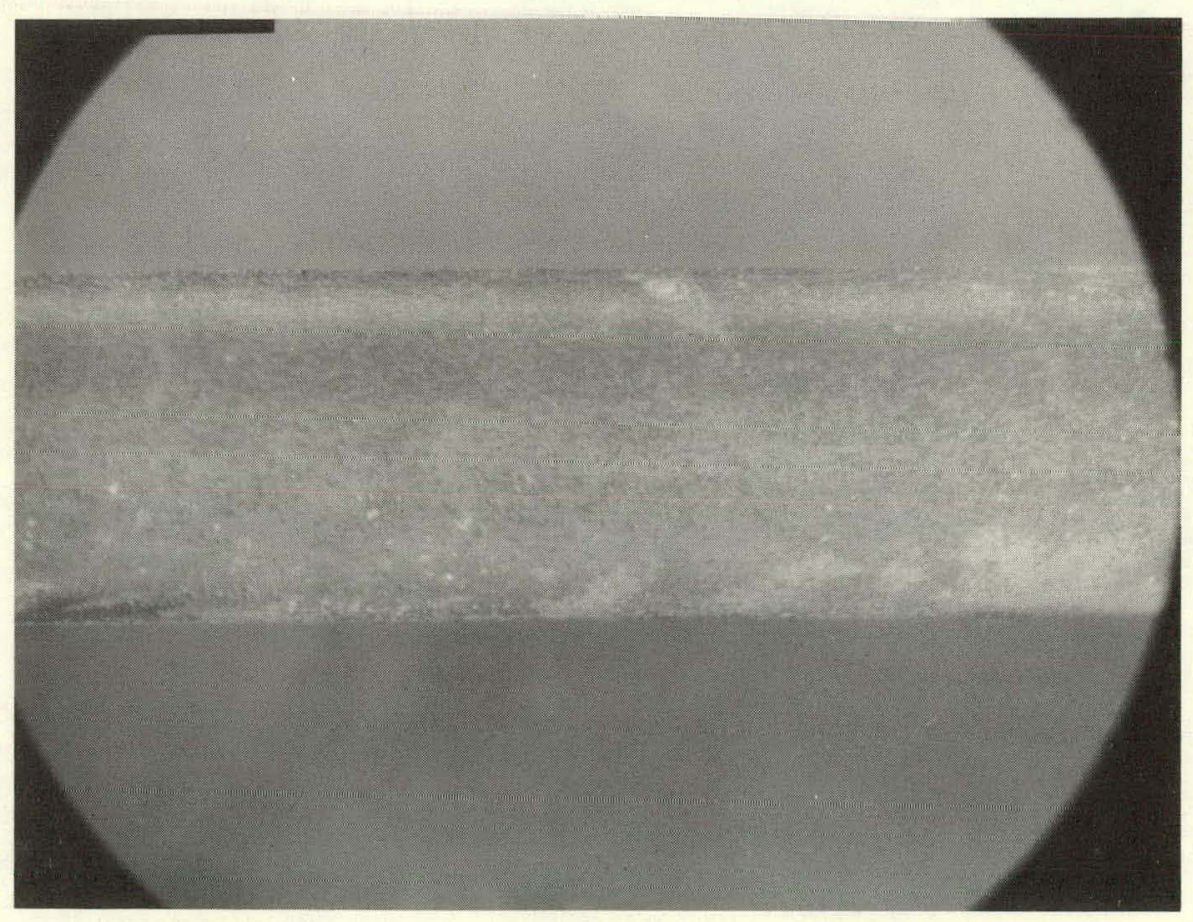

$\sim 3 \%$ MAG

Figure 20. Typical Speckled Surtace HIIm (Fuel Rod A46) 


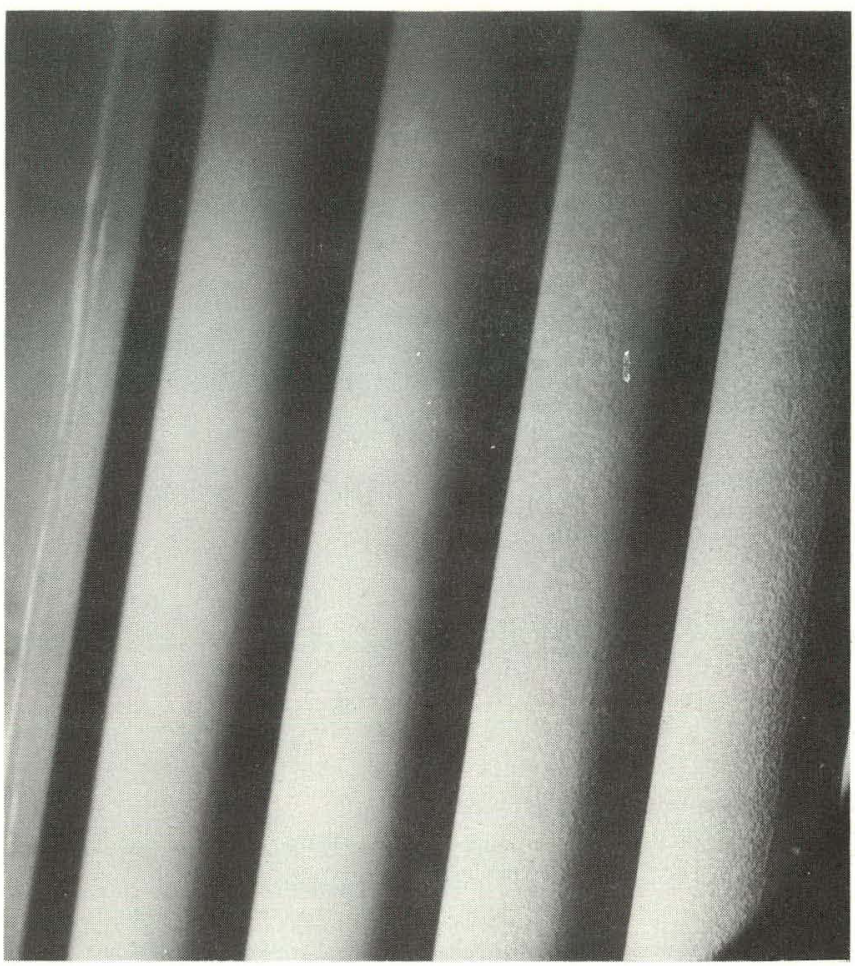

Figure 21. Surface Appearance of SA-1 Fuel Rods at Midlength (Rods A8, A15, A22, and A29 in Subassembly A-1)

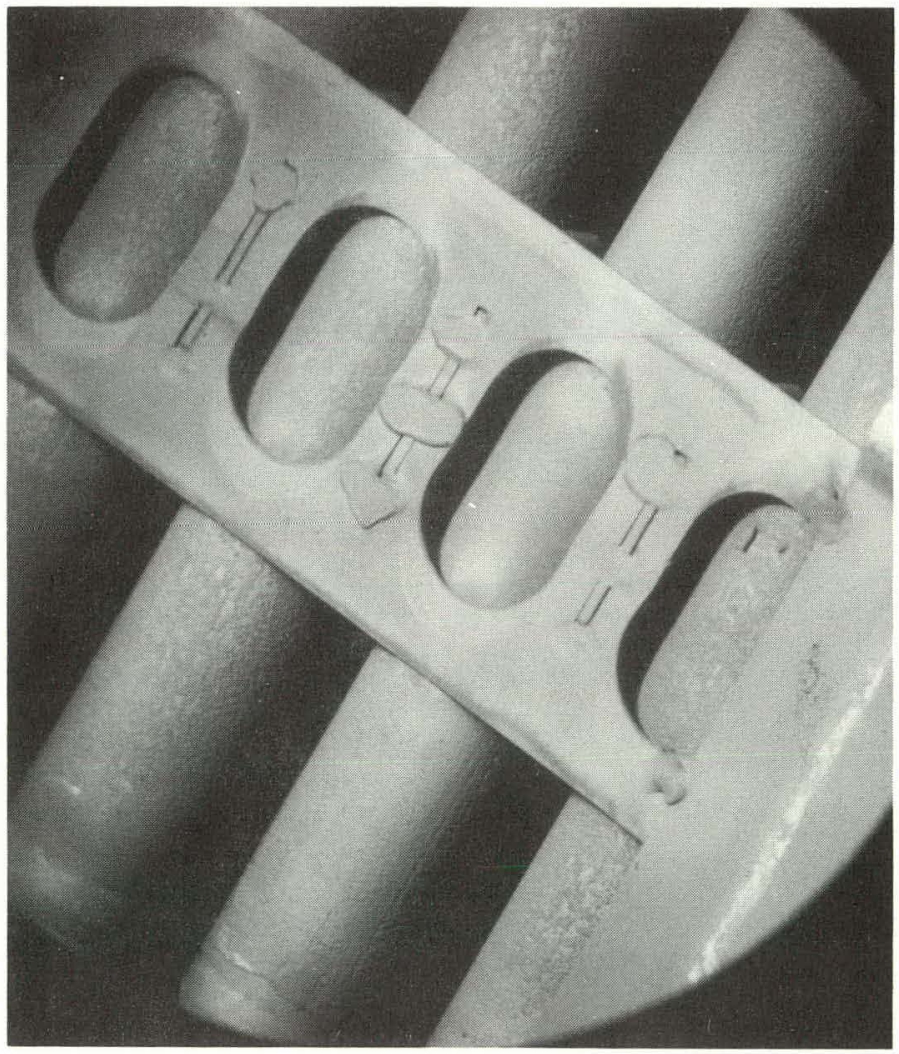

Figure 22. Rough Surfaces on Rods B64, B78, and B85 at Bottom Spacer of Subassembly B-1 


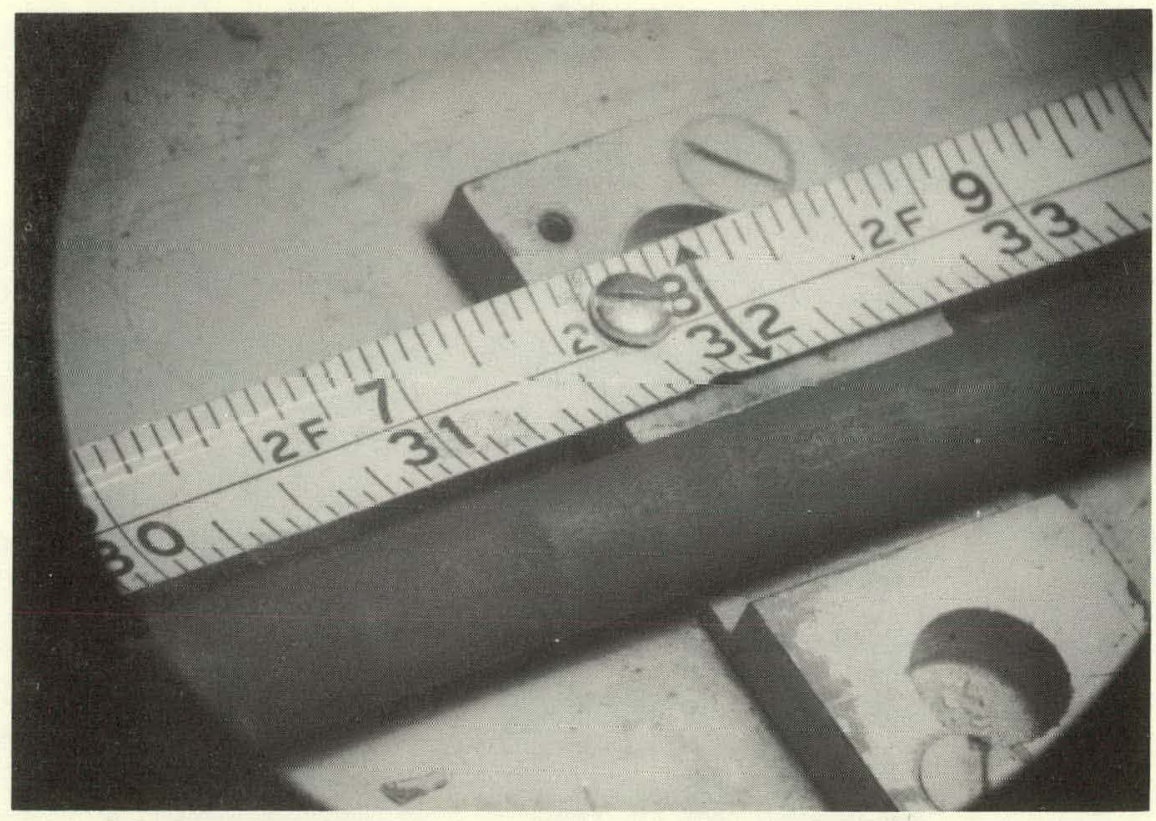

Figure 23. Bandlike Surface Pattern on Rod A15

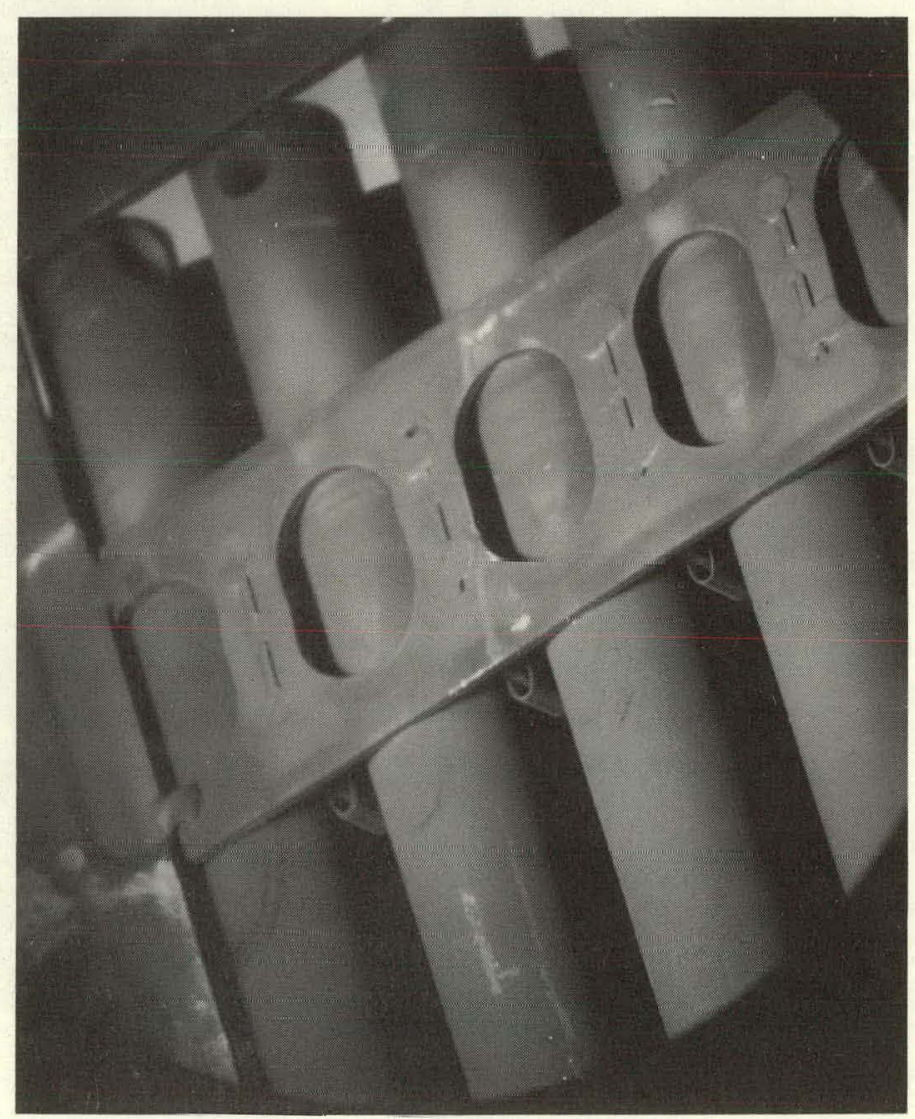

Figure 24. Long End Plug and Plenum Regions of Rods B57, B64, B71, B78, and B85 


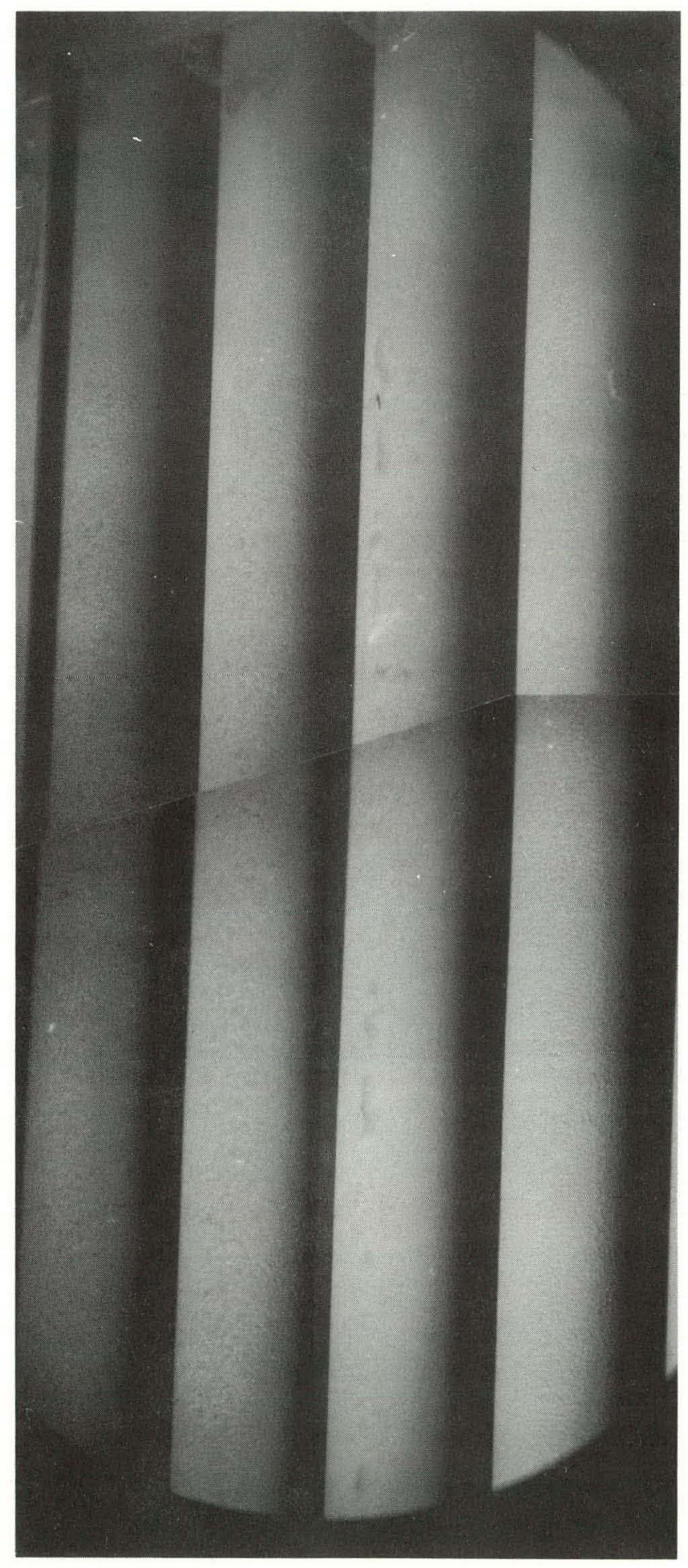

Figure 25. Cracks in Crud Layer on Fuel Rod B53 

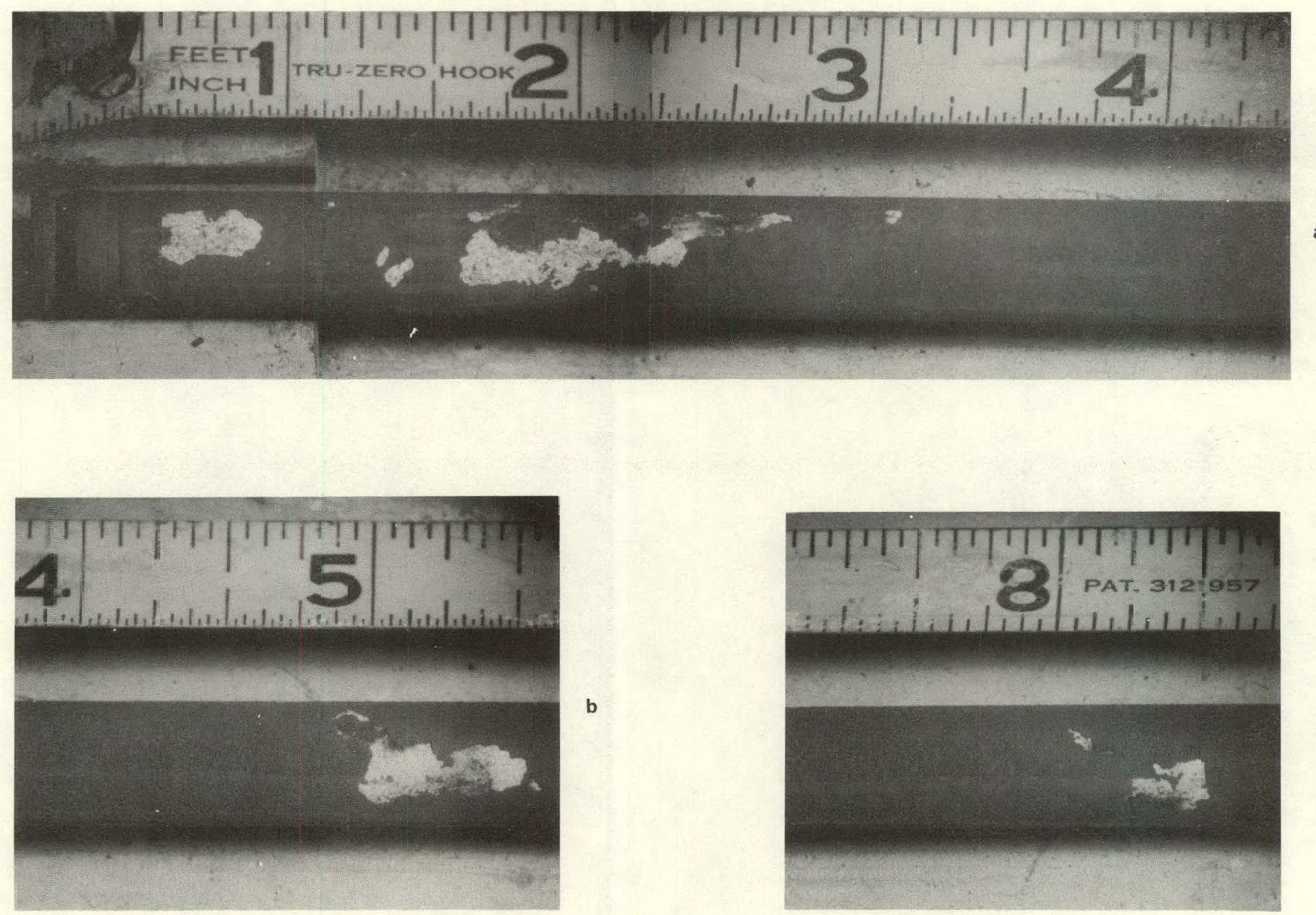

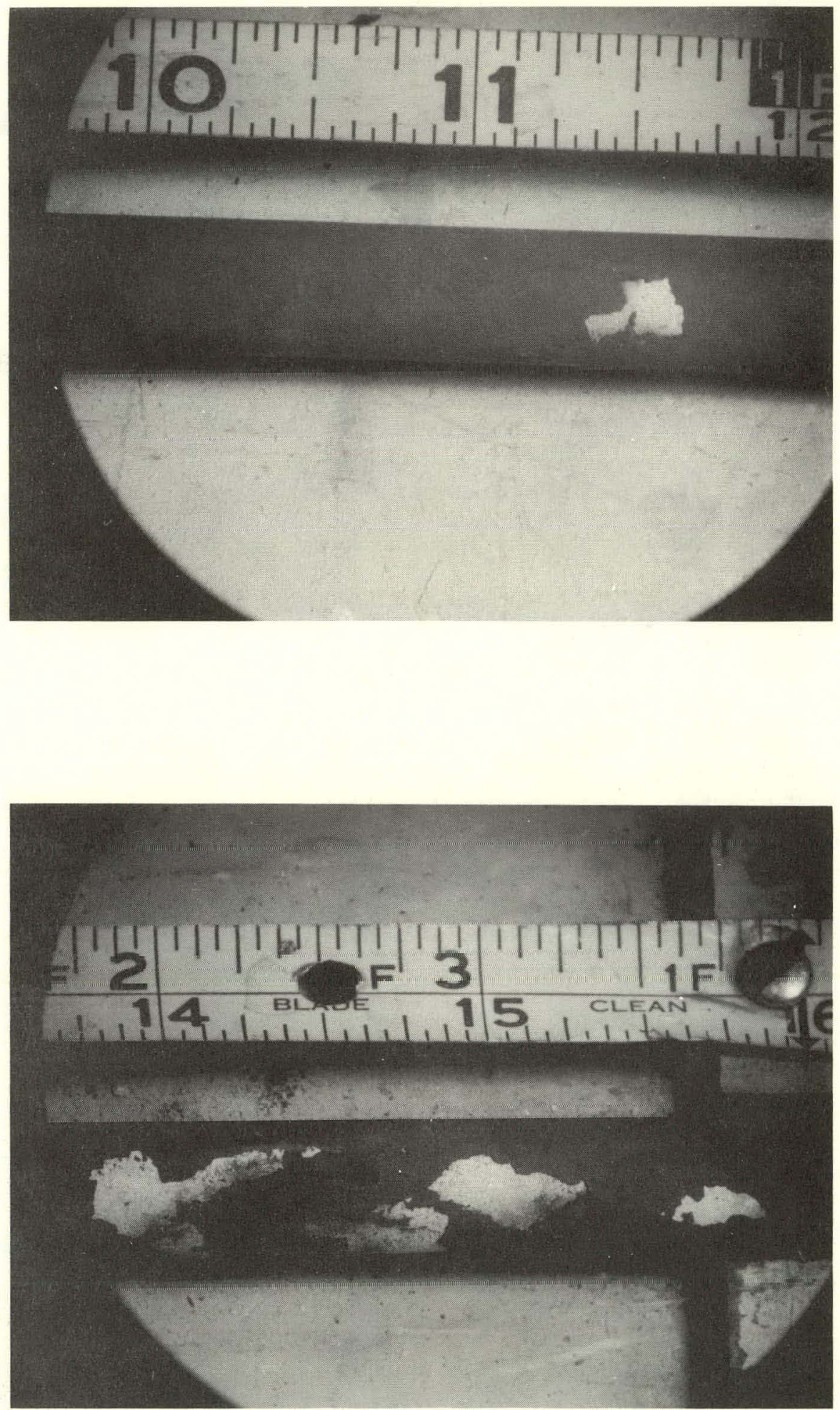

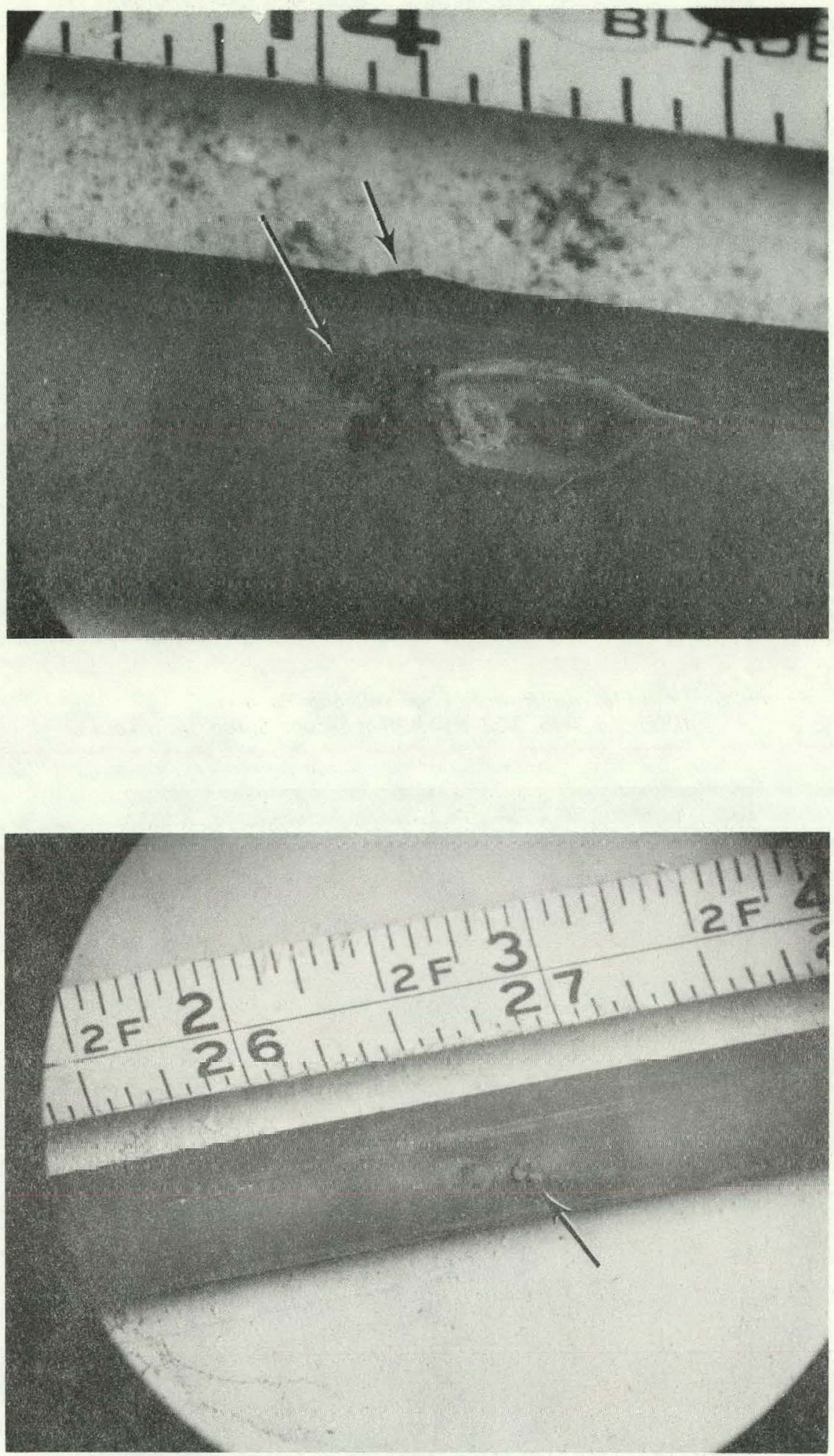


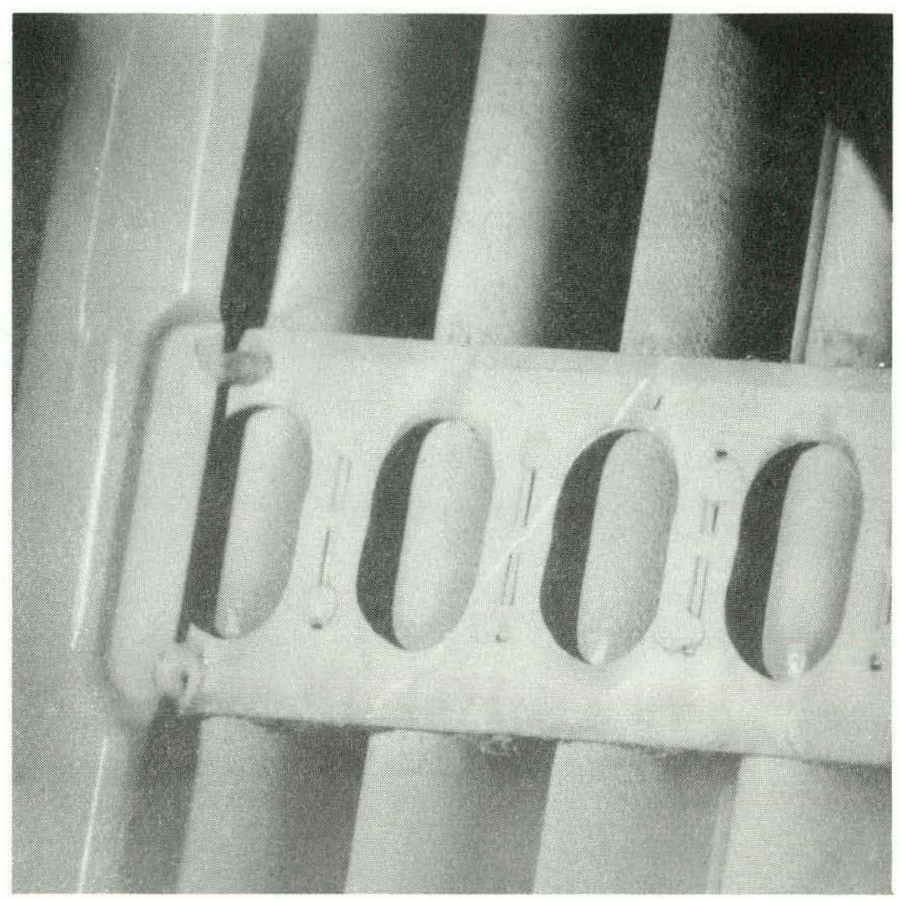

Figure 28. Crud Flakes at Bottom Edge of Spacer Band (Rods A8, A15, A22, and A29 at Second Spacer from Top)

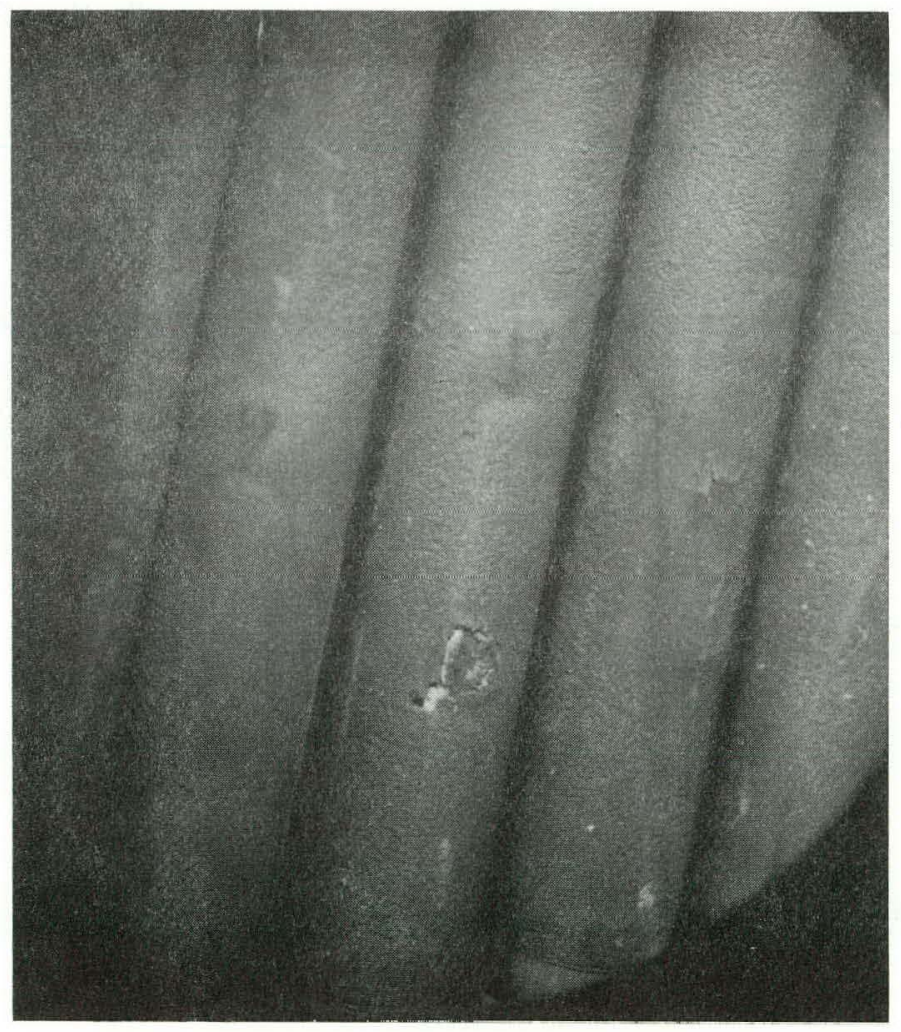

Figure 29. Spalling and Cracking of Crud on Rods B51, B52, B53, and B54 at Bottom Spacer Band Locations. (Rods Have Been Removed Somewhat from Normal Subassembly Position) 
Brown circumferential rings and/or circular brown spots like those shown in Figure 30 were noted on about seven rods. Thin white or light gray films in the forms of streaks and smeared regions, generally $2.5 \mathrm{~cm}$ (1 in.) long or less, were seen on various portions of eight rods. An example of some of this white material is shown in Figure 31 , where it is present at the short end plug regions of two " $\mathrm{B}$ " rods, as well as at the bottom of the adjacent corner angle. At least some of this material is probably aluminum oxide resulting from the abrasion and oxidation of portions of the cask liner.

Approximately 20 fuel rods were marked with fine longitudinally oriented lines which varied in length from less than $1 \mathrm{~cm}(\sim 1 / 2 \mathrm{in}$.) to greater than $20 \mathrm{~cm}$ ( $\sim 8 \mathrm{in}$.$) . Most of these lines appeared to be shallow surface penetrations$ that had resulted from handling (Figures 32a-d), but in some cases portions of the lines appeared to protrude from the surface (Figure 32e). As Figures $32 \mathrm{~d}$ and e indicate, these lines were observed on some of the outside rods before they were removed from the subassemblies.

In addition to the fine longitudinal marks, approximately five rods exhibited pitlike surface penetrations that were generally $0.2 \mathrm{~cm}(\sim 1 / 16 \mathrm{in}$.) or less across (Figure 33$)$, about ten rods contained small, rather jagged cracks or crack networks (Figure 34), and one or two rods showed $0.2 \mathrm{~cm}$ diameter blisterlike protrusions (Figure 35).

The exact natures of many of these anomalies and the depths of penetration could not be determined solely by visual inspection of the external surfaces, and further investigations covered in subsequent sections were carried out on some of these rods.

The wear grooves in the cladding, which had been caused by contact with the wire type spacers during VBWR operation, did not appear to have any deleterious effect on the operation of the rods in Dresden. Some increase in surface roughness typically was observed for 0.5 to $1 \mathrm{~cm}(\sim 1 / 4$ to $1 / 2 \mathrm{in}$.) on either side of the middle spacer wire contact points.

The surface appearance of some of the rods after the crud had been chemically removed from them is shown in Figures 36 through 39. A roughness similar to that shown by portions of nearly all rods in the "as-received" condition also was observed over portions of the decrudded heat transfer surfaces. This roughness had the appearance of small, closely spaced blisters, as shown in Figures $36 \mathrm{~b}$ and 37.

The surfaces of the six rods that had been removed from the assembly at the end of Cycle No. 4 were a solid black over both relatively smooth and relatively rough areas, except for a few areas of fine white or silvery speckling. Most of this speckling appeared to be associated with an abrasion of the rod surface. The surfaces of the six rods that had operated to the end of Cycle No. 6 were primarily white or light gray over some areas, particularly those that were comparatively rough. Other areas were a dark brownish color, sometimes in combination with fine, white speckling.

The roughness on a given rod generally varied somewhat with radial orientation, as exemplified by rod B76 in Figure 36, and usually showed some variation along the length. The roughness generally tended to decrease toward the longer end plug, i.e., toward the relatively low power region, of the rods that were removed at the end of Cycle No. 4 . However, the surfaces of most of the rods that operated throughout the life of SA-1 were about as rough at the low power ends as they were at the high power ends.

There were noticeable differences in the extent and degree of roughness among different rods in each six-rod group, although the average power ratings of most of the rods in each group were similar. The rods that operated to the end of Cycle No. 6 probably were, generally speaking, somewhat rougher in appearance than those that were removed two cycles earlier.

Rods A49 and B50, which were fabricated from the same tubing lot (CA-2) and were located in corner positions of their respective subassemblies, showed the roughest surfaces of all twelve rods. However, rod $A 9$, which was relatively smooth, was also fabricated from lot CA-2, and corner rod A7 was about average with respect to roughness; hence the rough surfaces of rods $A 49$ and B50 cannot be clearly attributed either to tubing lot or to some condition imposed by the proximity of the subassembly corner angles.

Four of the rods (A7, A22, A49, and B50) that had operated to the end of Cycle No. 6 showed smooth, dark brown circumferential rings spaced at pellet length intervals. The surface usually had a speckled light gray appearance between these rings (Figure 40). These rings were located between the 69-cm (27-inch) locations and the plenums; i.e., in relatively low power regions, on the " $A$ " rods, but they were located on the higher power half of rod B50.

Oval-shaped marks were observed on most of the decrudded fuel rods near some of those locations where the subassembly spacer springs had contacted the cladding surface. The most prominent of these were found on rods B50 and $B 70$, shown in Figure $41(a, b)$. As can be seen, at least some of the marks protruded from the cladding surface, particularly at their perimeters. 


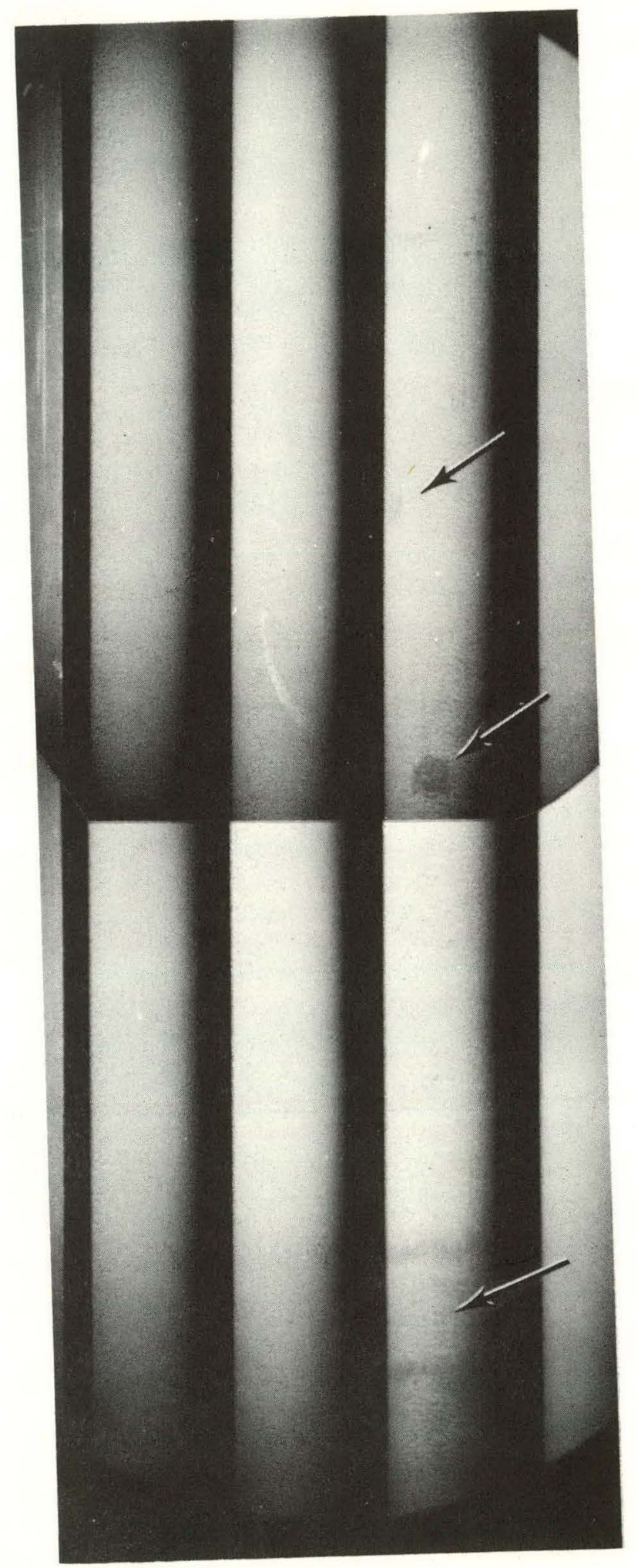

Figure 30. Brown Ring and Spots on Rod A11 Between $17.5 \mathrm{~cm}$ (6-7/8 in.) and $28.1 \mathrm{~cm}(11-1 / 16 \mathrm{in.})$ from Short End Plug 


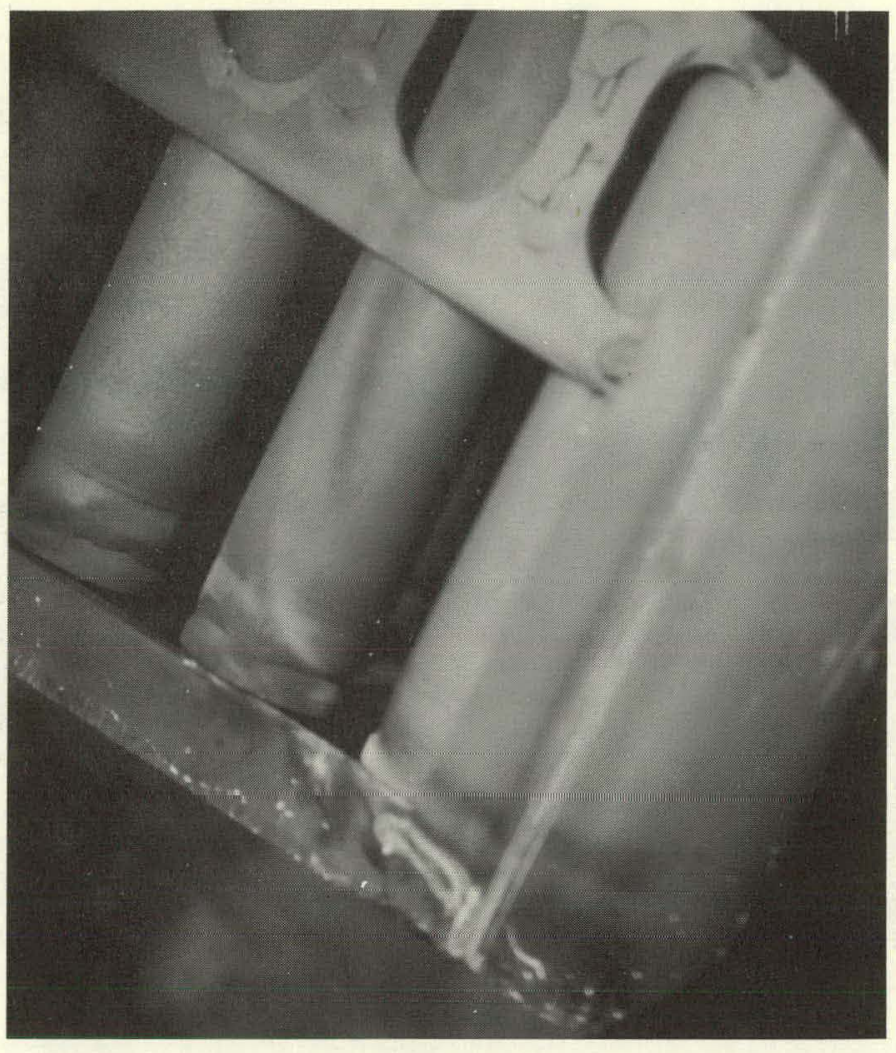

Figure 31. White Film on Bottom of Rods B51, B52, and Adjacent Corner Angle

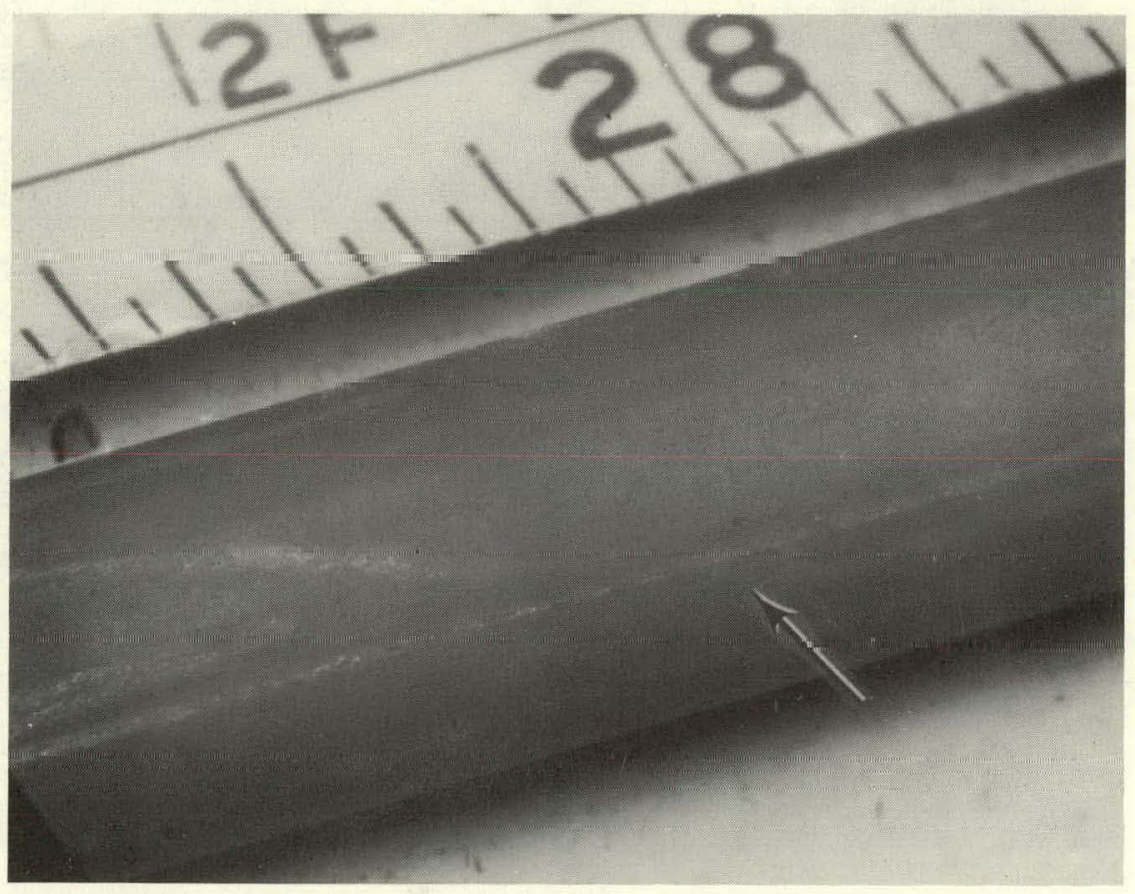

Figure 32. Fine Longitudinally Oriented Lines on (a) Rod A18 

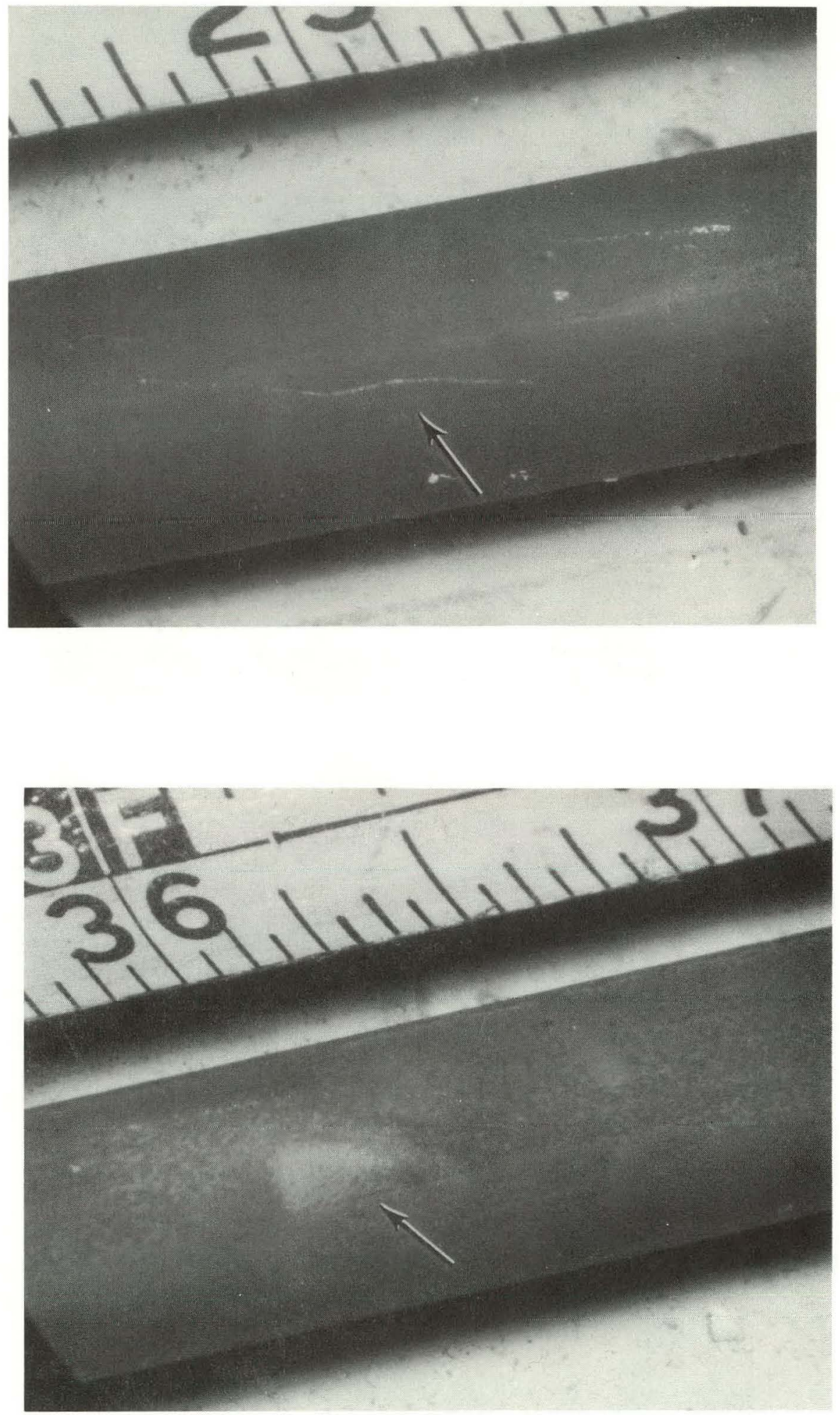

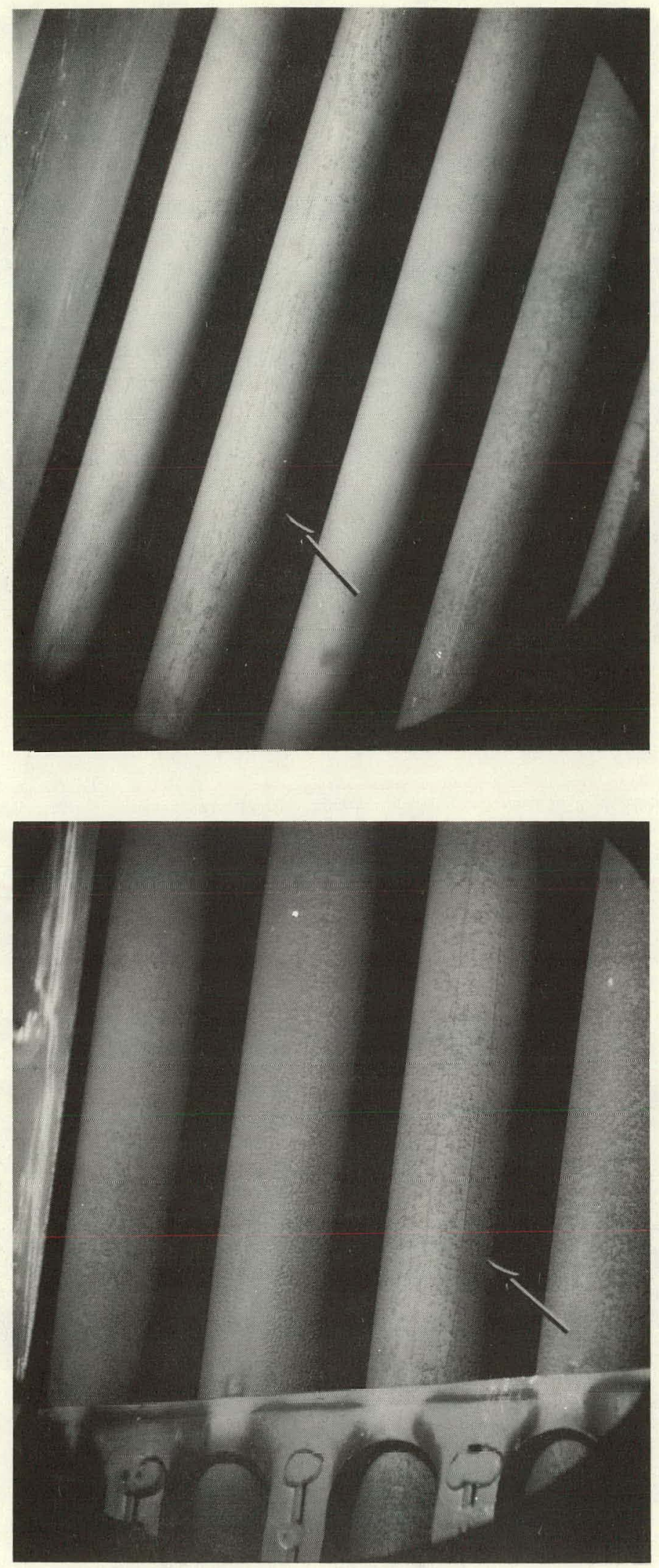

e

Figure 32 (Continued). Fine Longitudinally Oriented Lines on (d) Rod A 15 and (e) Rod B95 

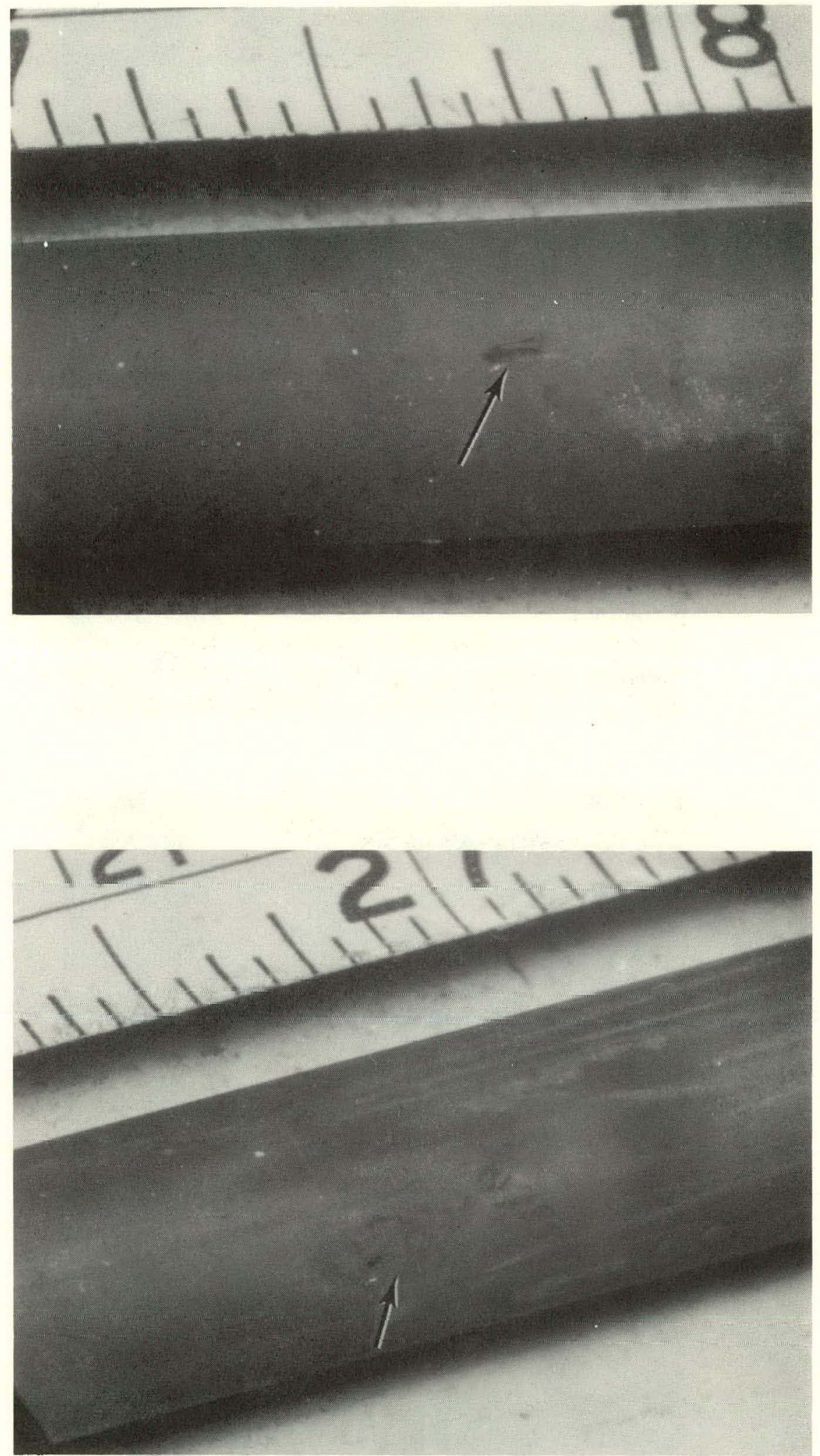

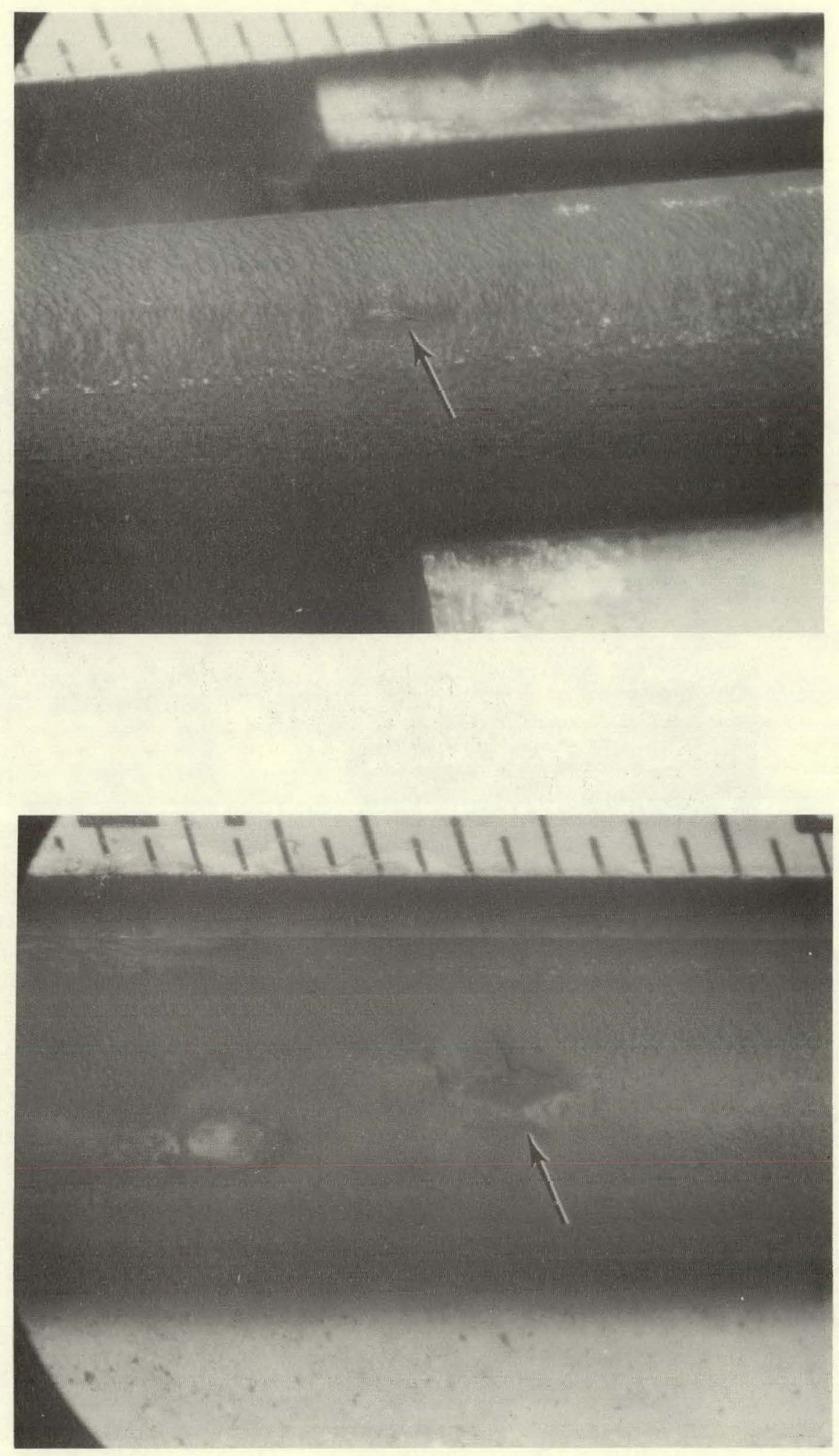

Figure 34. Small Cracks in Surface of Rod B52 at the (a) $80.3 \mathrm{~cm}(31-5 / 8 \mathrm{in}$.) Location and at (b) $69.8 \mathrm{~cm}$ (2/-1/2 in.) Near a Spacer Location 


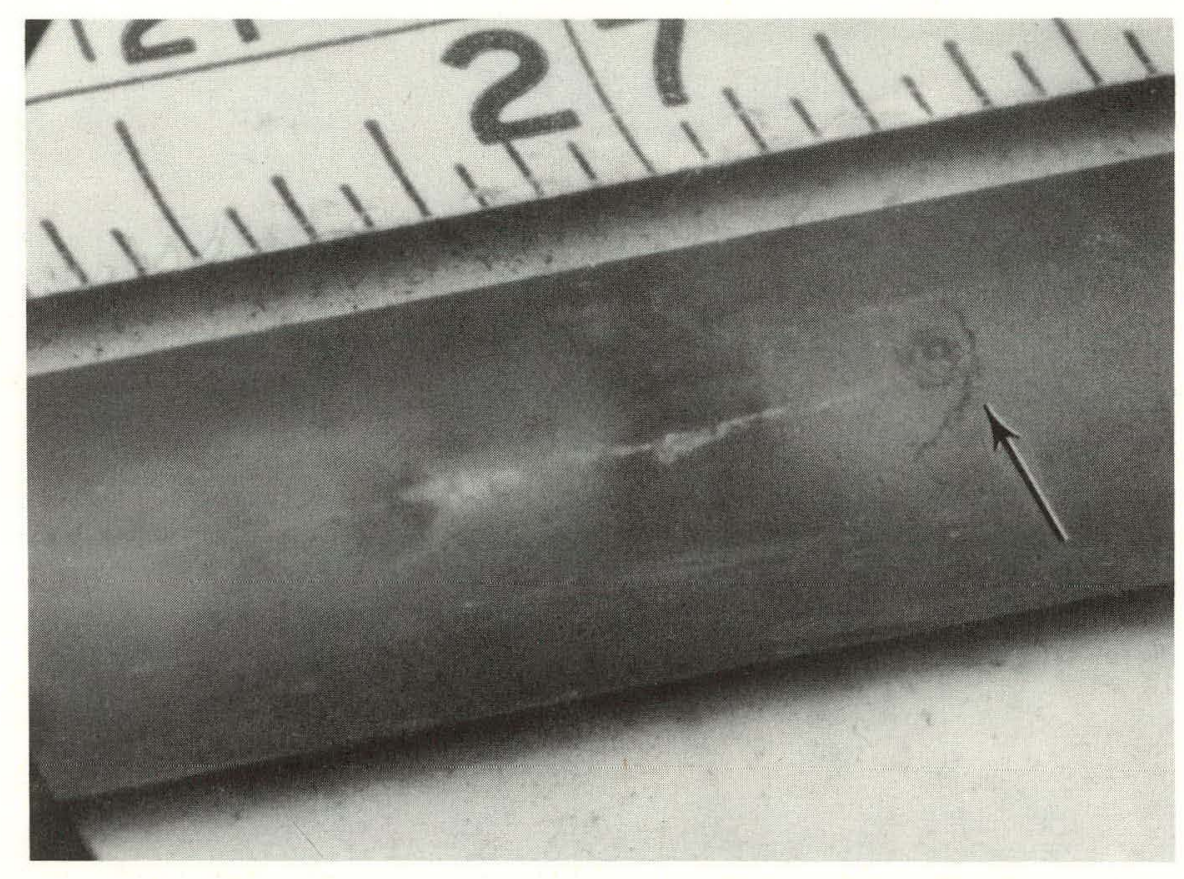

Figure 35. Small Blister and Irregular Circumferential Crack at the $69.2 \mathrm{~cm} \mathrm{(27-1/4} \mathrm{in.)} \mathrm{Location} \mathrm{of} \mathrm{Rod} \mathrm{A-1}$ 


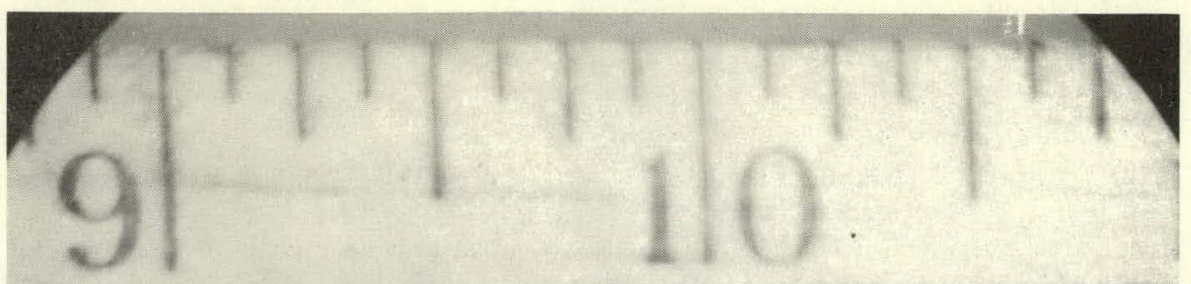

(a)

$90^{\circ}$

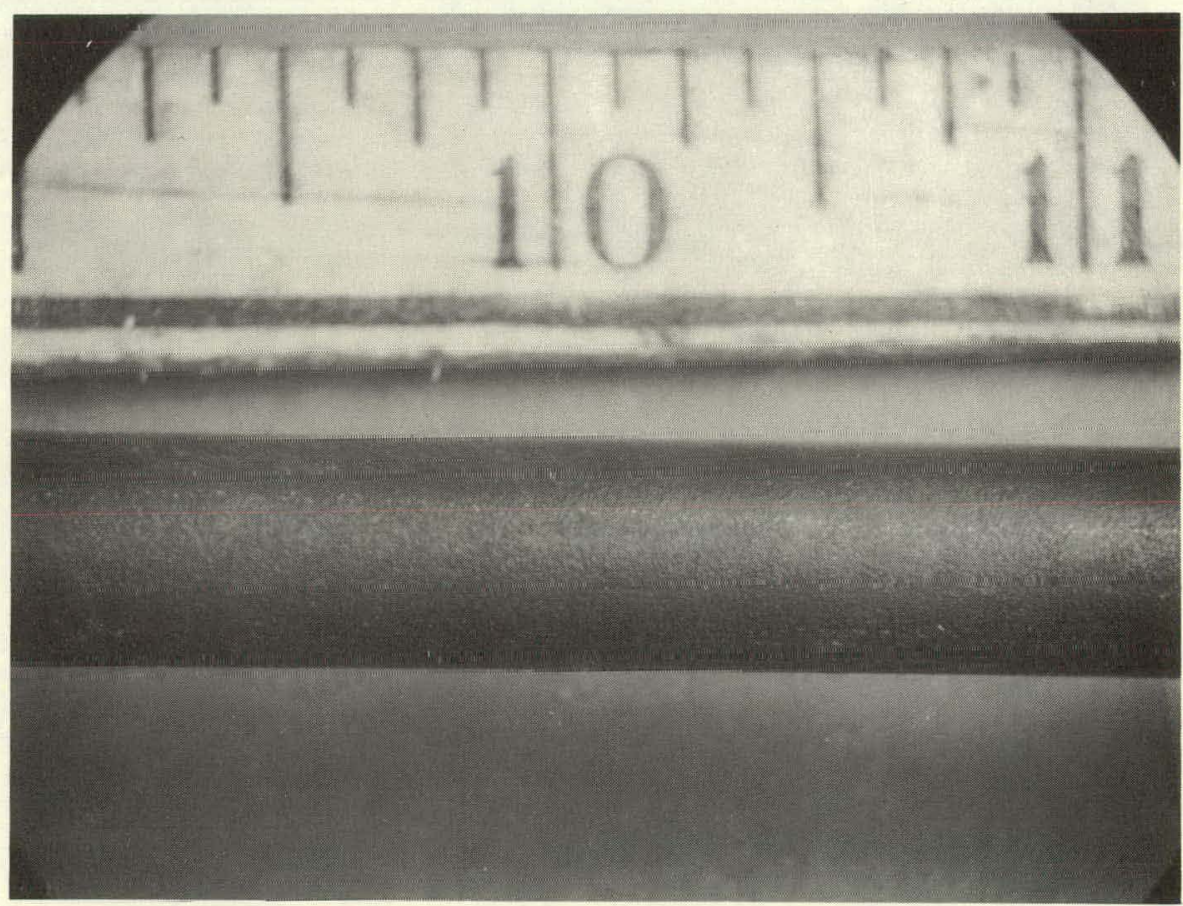

$270^{0}$

Figure 36. Fuel Rod B76 at 25-cm (10-in.) Location, After Chemically Removing Crud 


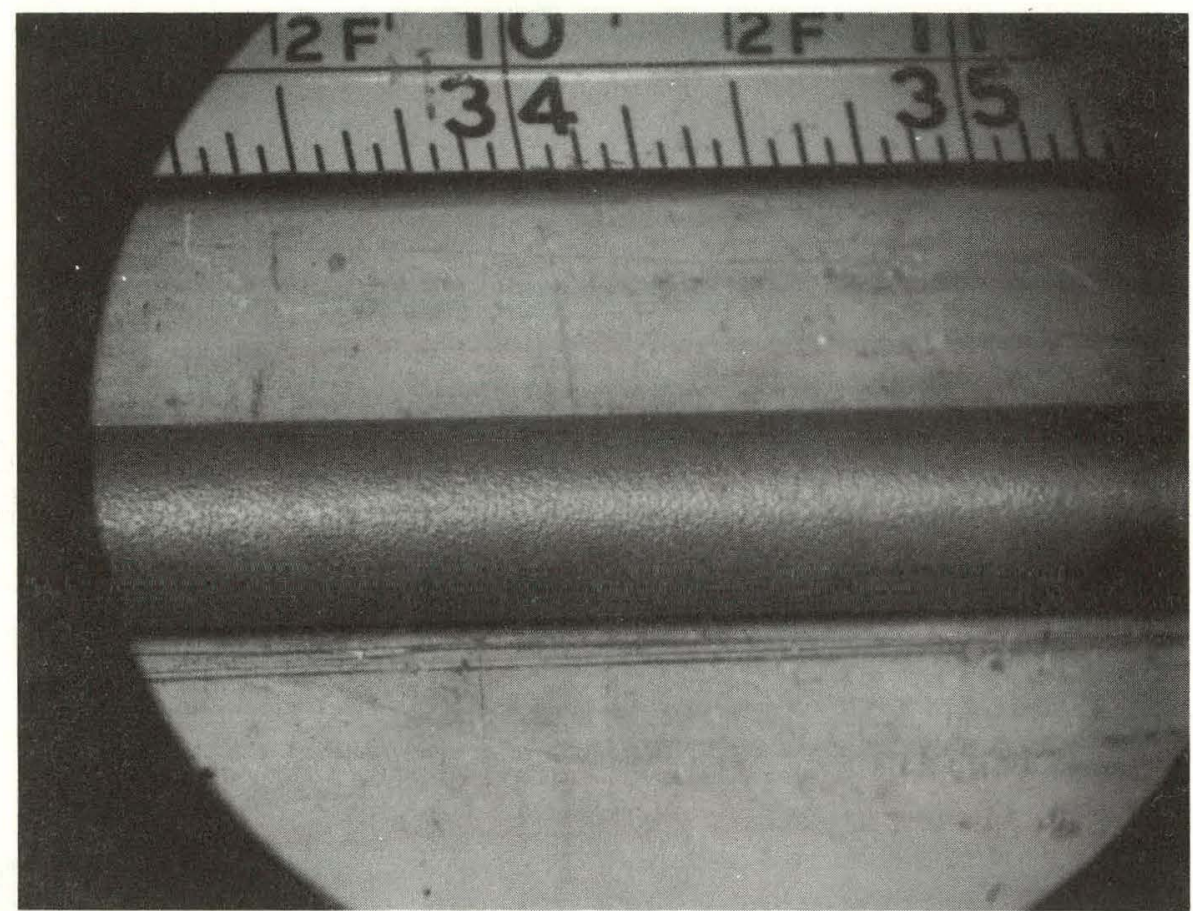

Figure 37. Rough Surface on Rod B50 After Crud Had Been Chemically Removed 


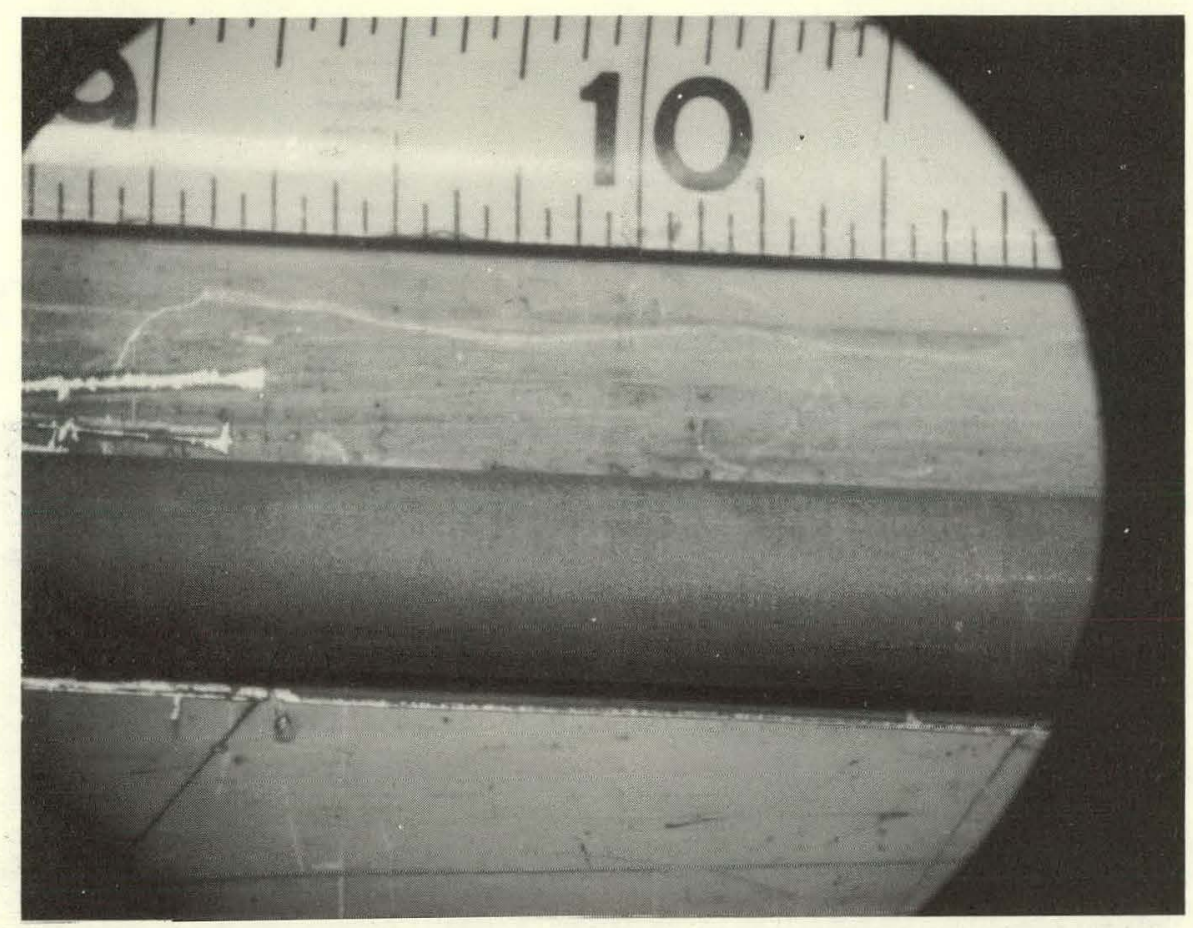

Figure 38. Peak Burnup Region of Rod A37 After Crud Removal

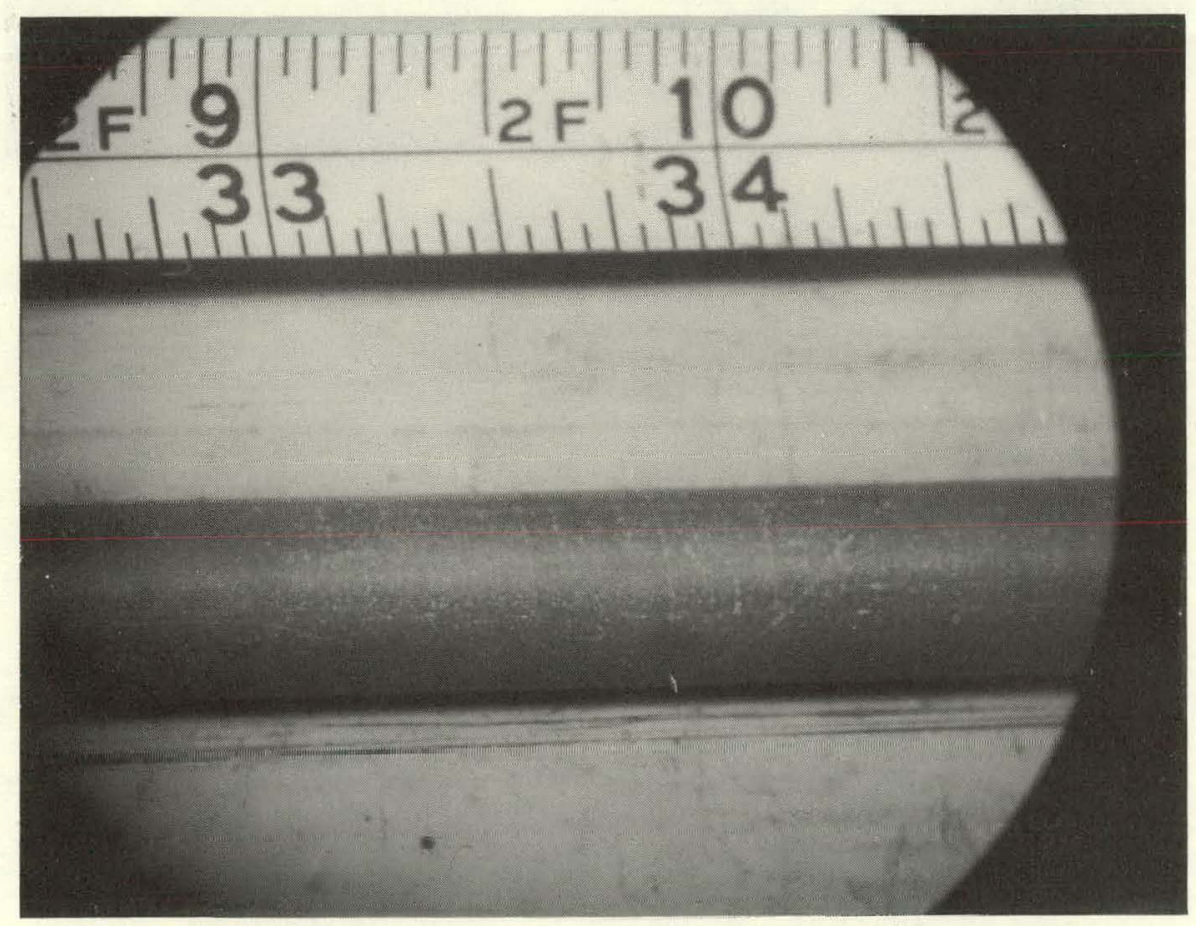

Figure 39. Surface Appearance of Rod A37-84 to $87 \mathrm{~cm}$ (33 to $34 \mathrm{in.}$ ) from Short End Plug Shoulder 


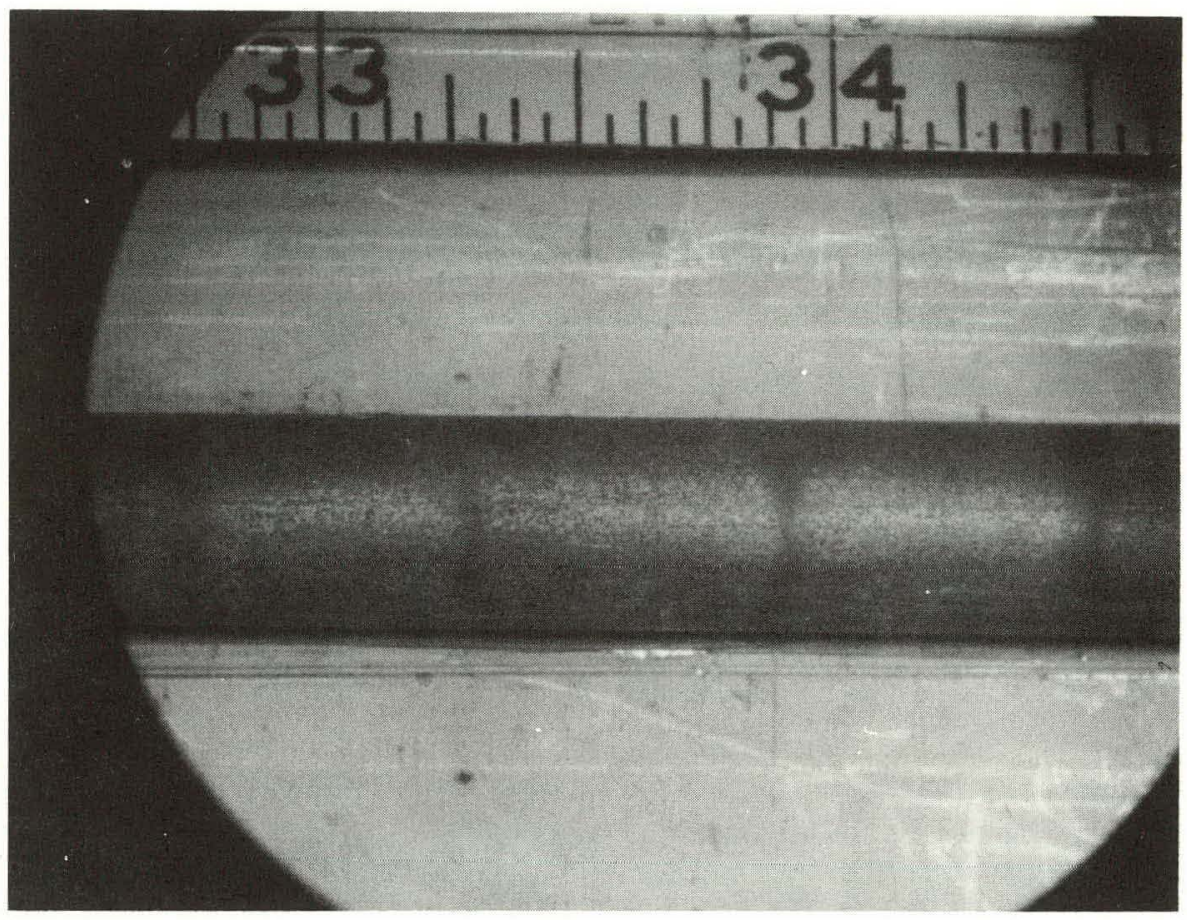

Figure 40. Smooth Rings at Pellet-Length Intervals on Rod A7 


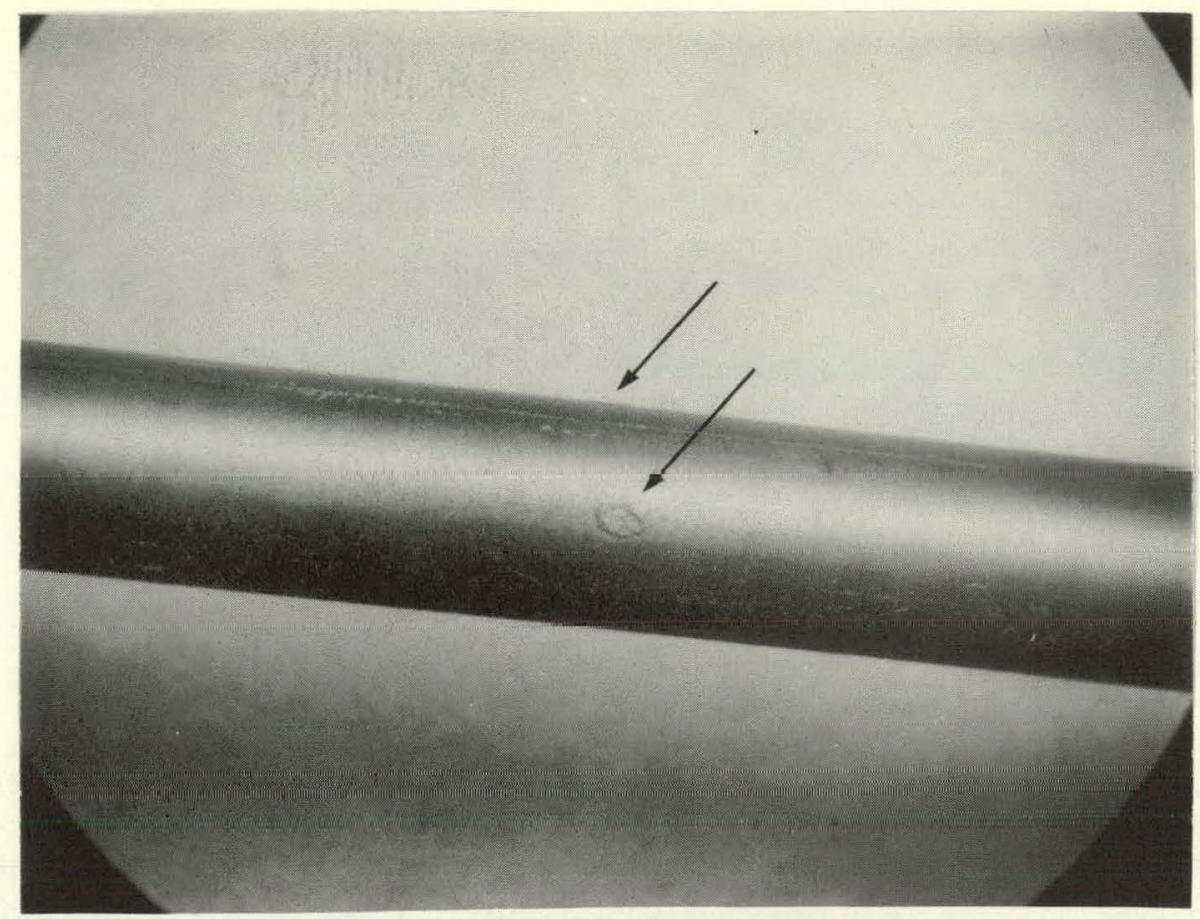

(a) ROD B70

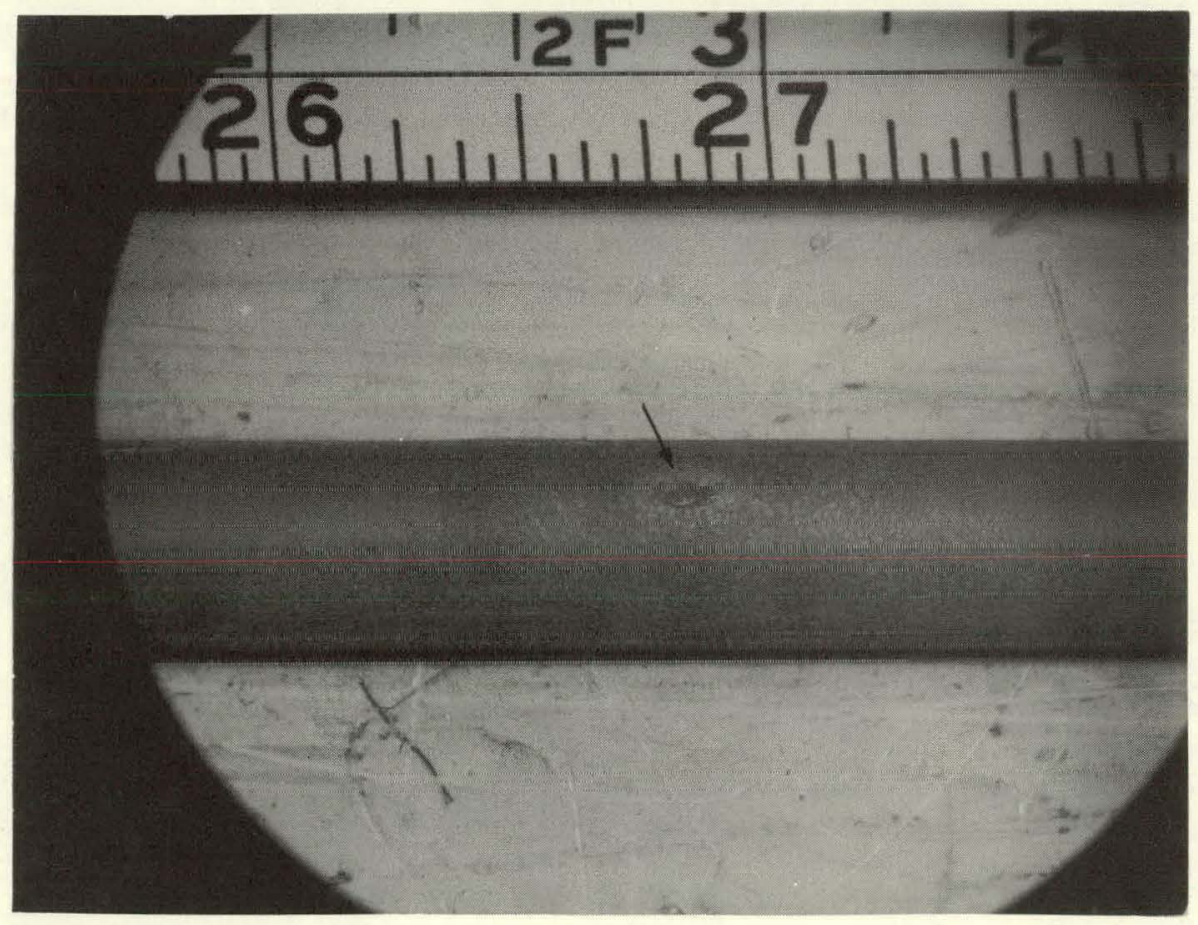

(b) ROD B50

Figure 41. Subassembly Spacer Markings at (a) 36-cm (14-in.) Location of Fuel Rod B70 and at (b) 67.9-cm (26-3/4-in.) Location of Fuel Rod B50 
A few of the rods showed localized increases in surface roughness near those points where the VBWR spacers contacted the rods (Figure 42a). The surfaces of two other rods (A49 and B50) were fairly smooth near the VBWR spacer locations, but they contained fine cracks around the wire-rod contact points. It appeared that the corrosion layer was unusually thick over areas that extended $\sim 1 \mathrm{~cm}$ or $1 / 2 \mathrm{in}$. on either side of these contact points (Figure $42 \mathrm{~b}$ ).

Most of the rods had linear markings, primarily of longitudinal orientation, on their decrudded surfaces. They varied in length from 0.2 to $0.3 \mathrm{~cm}(\sim 1 / 8 \mathrm{in}$.) to 10 to $20 \mathrm{~cm}(\sim 4$ to $8 \mathrm{in}$.). Most, if not all, of these markings appeared to be scratches that resulted from either fabrication or post-irradiation handling. Examples of this type of marking are shown in Figure 43.

The depth of an $\sim 0.05 \mathrm{~cm}$ by $0.025 \mathrm{~cm}(\sim 0.02$ by $0.01 \mathrm{in}$.) oval-shaped pit in rod A9 was determined after crud removal to be 0.010 to $0.012 \mathrm{~cm}(0.004$ to $0.005 \mathrm{in}$.) deep. The pit was located $71.4 \mathrm{~cm}(28-1 / 8 \mathrm{in}$.) from the short end plug shoulder (Figure 44).

Again, some of the previously mentioned surface characteristics noted in the visual examinations, such as roughness and spacer markings, were subsequently investigated by other techniques and will be discussed further in some of the following sections.

\subsubsection{Neutron Radiography of Fuel Rods (G. P. Ferguson, J. J. Haskins)}

\subsubsection{Procedure and Scope}

Fuel rods selected to be examined by neutron radiography were mounted vertically in an aluminum holder and transferred by cask from the hot cells to the neutron radiographic facility at the Nuclear Test Reactor (NTR).

The NTR facility utilizes horizontal neutron beams obtained from the physical center of the NTR's annular core. One beam is allowed to leave the reactor building via a shuttered, conical hole in the 1-1/2-meter (5-foot) thick north wall. On the outside of this wall a large stationary concrete receiving cask has been constructed. A hole in one side is in alignment with the beam hole in the reactor wall and allows the neutron beam to enter a central cavity in the cask. The central cavity is open at the top of the cask where a lead and steel transfer cask can be positioned to discharge radioactive objects down into the neutron beam. A stepped plug, mounted on wheels, penetrates the receiving cask on the opposite side of the cask from the beam entrance. Neutron radiographic transfer plates up to $13 \times 38 \mathrm{~cm}$ $(5 \times 15 \mathrm{in.})$ are positioned on the inside face of the plug and are changed only when the beam shutter is closed and the radioactive object is withdrawn into the transfer cask. ${ }^{4}$

Dysprosium transfer plates were used to produce neutrographs of the SA-1 rods. The neutron exposure time was 60 minutes. Three separate exposures were required to cover the full length of the rods. After irradiation the transfer plates were placed in contact with $\mathrm{x}$-ray film for approximately 16 hours. Positive prints were then made from the exposed film. A variation in contrast was obtained by using two different developing times in the printing process.

One of the principal values of neutron radiography in the examination of irradiated fuel is the ability to detect regions of high hydride concentration in the cladding, which may be indicative of a defective fuel rod. These regions show up as dark areas on positive prints produced from the exposed film.

Neutron radiographs were taken of six of the ten rods that were removed from the assembly at the end of reactor Cycle No. $4^{*}$ and of six rods that operated to the end of Cycle No. 6. The first six were selected at random, since no significant anomalies were observed during the visual examinations of the initial group of rods. Possible cracks, small pit-like penetrations, small blisters, or discolored areas were noted during visual examination of the external surfaces of the latter six rods [rods A1 (Figures 33 and 35), A9 (Figure 44), A11 (Figure 30), A18 (Figures 32 and 33 ), A43 (Figure 32), and B52 (Figure 34)] .

\subsubsection{Results}

Nothing that appeared significant was detected on the neutrographs in those regions that were believed to be possibly defective on the basis of visual examinations. The neutrograph of rod A9, however, did show an $\sim 0.1-\mathrm{cm}-(0.04-\mathrm{in}$.)-long, rather faint dark gray spot on the tube wall $29.8 \mathrm{~cm}(11-3 / 4-\mathrm{in}$.) from the short end plug shoulder, which suggested that the concentration of hydrogen might be somewhat higher than normal at that location (Figure 45).

Gaps in the fuel columns as large as 0.1 to $0.3 \mathrm{~cm}$ were noted in five or six instances in each group of six rods (Figure 46). Approximately 5 percent of the pellets in each group were fractured or showed marked cracking. However, whereas the pellet cracking detected during the initial phase occurred quite at random, 50 percent of the cracked pellets in the later rods were located within $10 \mathrm{~cm}$ (4 in.) of the short end plug shoulder and 85 percent were located within $40 \mathrm{~cm}$ (16 in.) of it. 


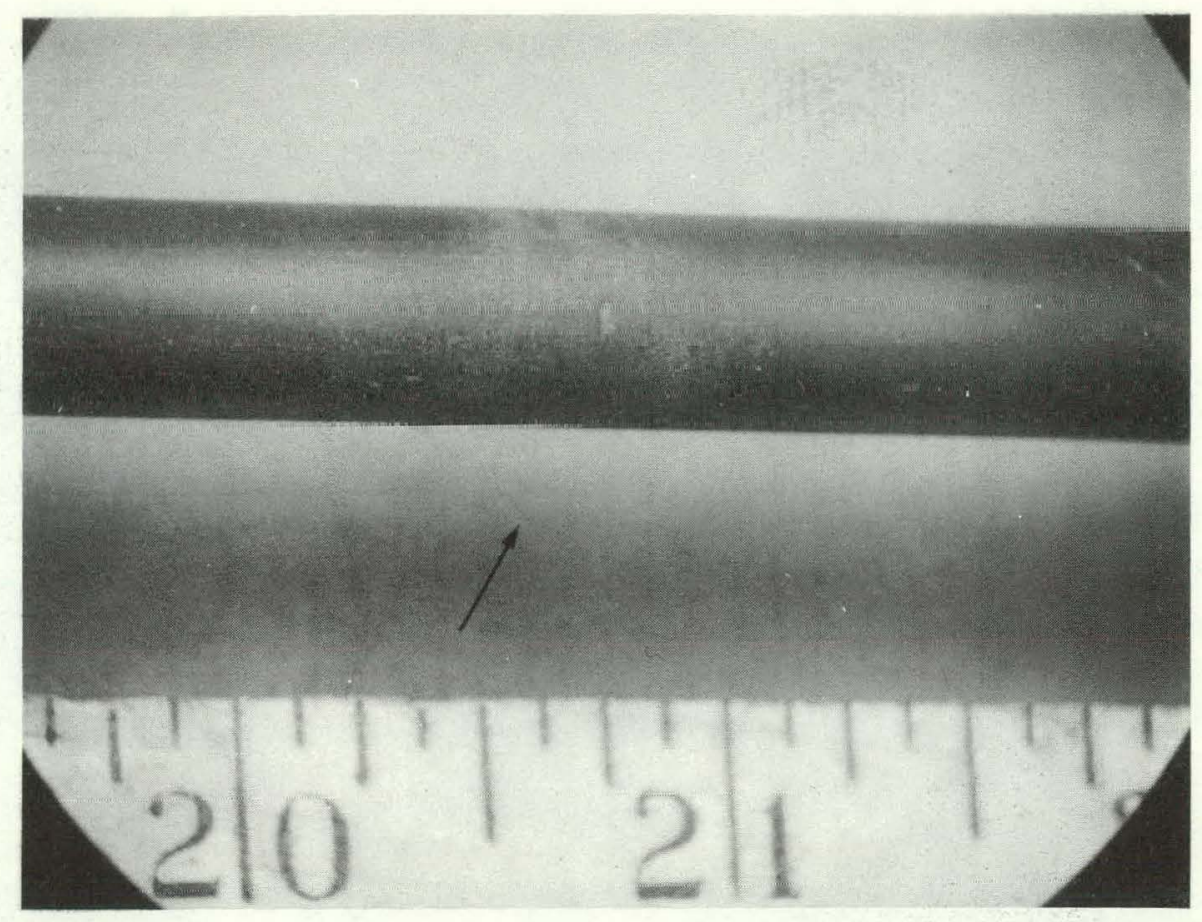

(a) ROD B70

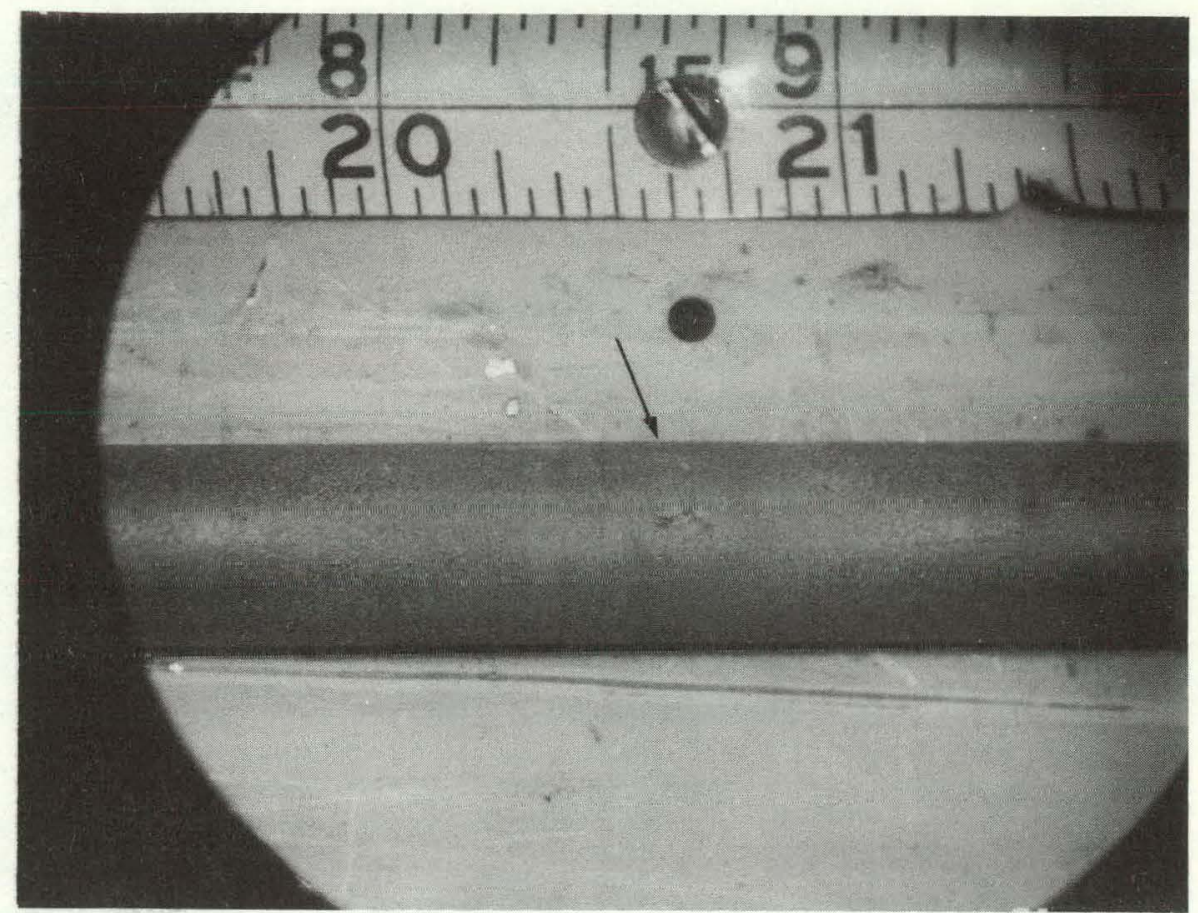

(b) ROD B50

Figure 42. VBWR Spacer Regions After Crud Removal on (a) Rod B7O and (b) Rod B50 


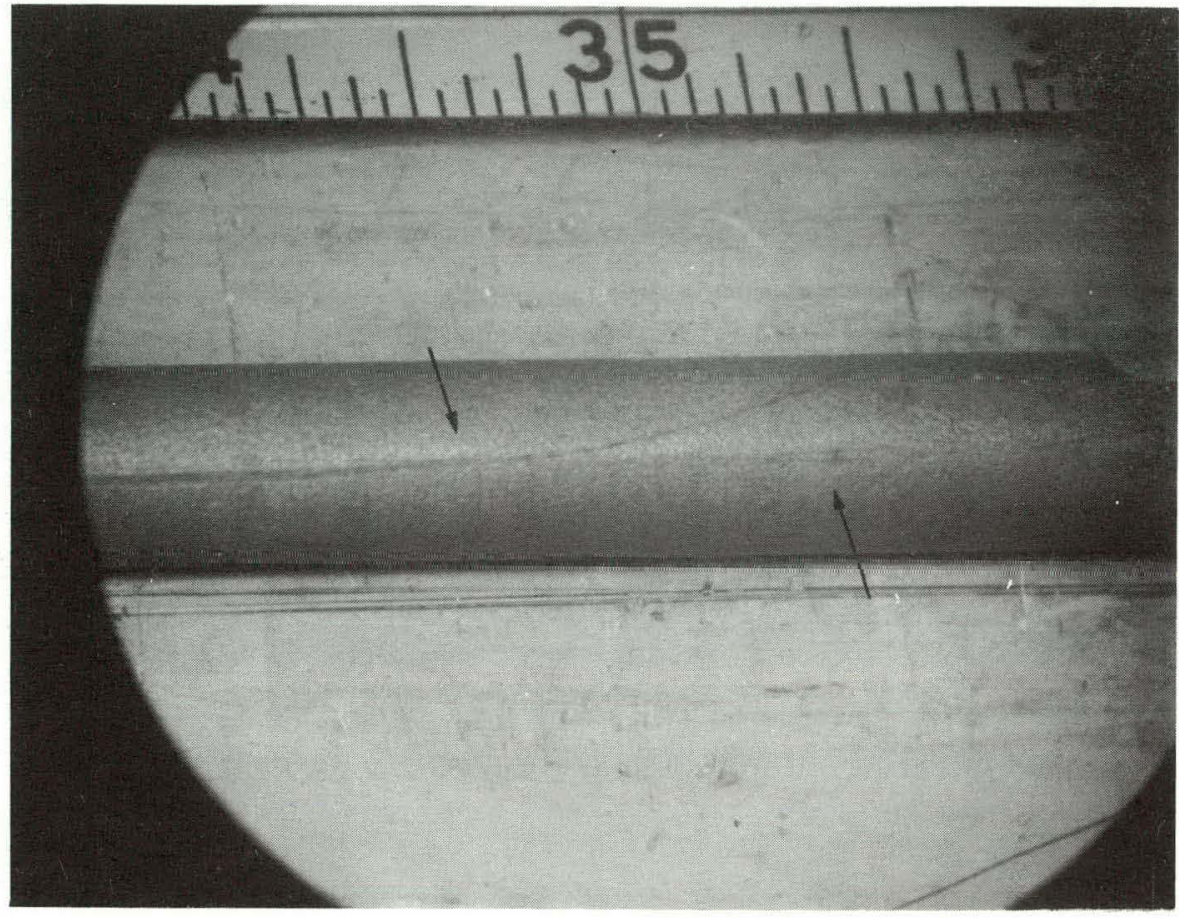

Figure 43. Fine, Linear Penetrations in Surface of Rod B50

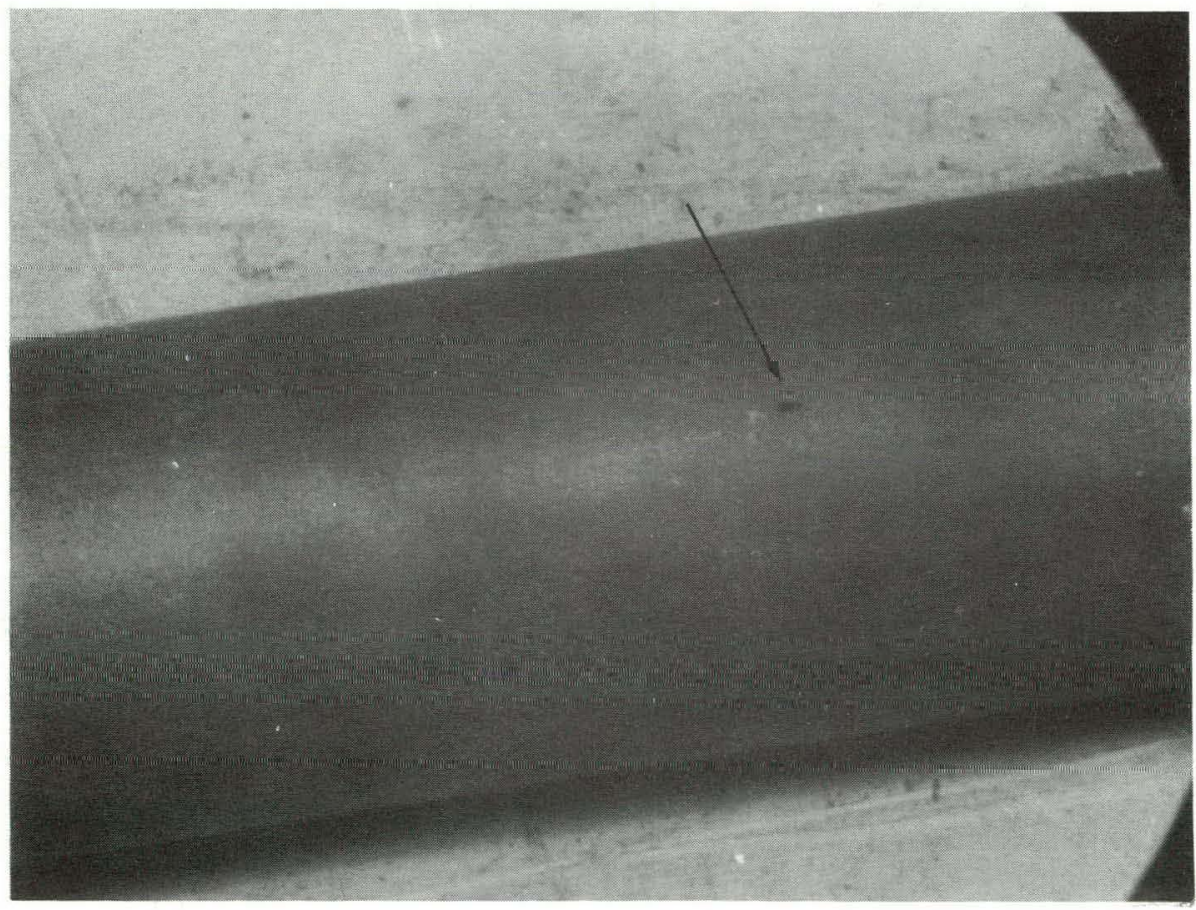

Figure 44. Pit in Surface of Fuel Rod A9-71.4 cm (28-1/8 in.) from Short End Plug Shoulder 


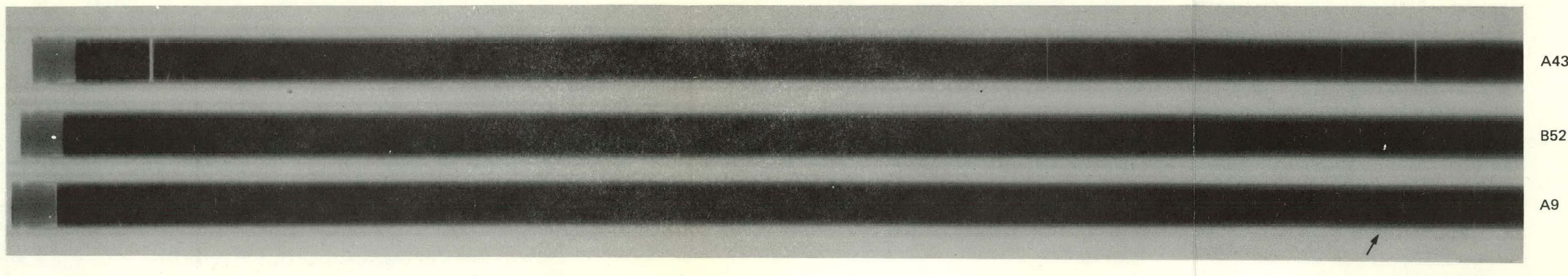

Figure 45. Neutron Radiographs of Short End Plug Portions of Rods A43, B52, and A9.
Dark Gray Spot on Cladding of Rod A9 Is Indicated.
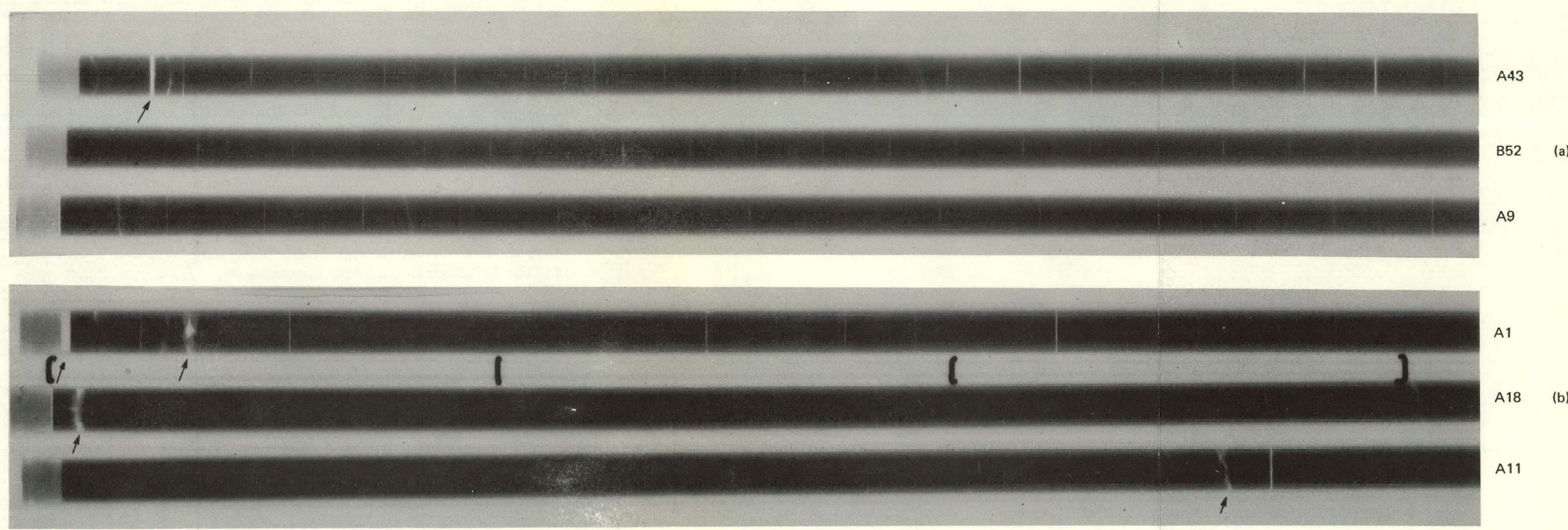

Figure 46. Neutron Radiographs of Short End Plug Portions of Six SA-1 Rods. Fuel Column Gaps and Pellet Cracking Are Indicated. 


\subsubsection{Rod Dimensional Measurements (G. P. Ferguson, F. H. Megerth)}

\subsubsection{Diameter}

\subsection{Procedure and Scope}

A hot cell profilometer was used to measure diametral variations along the length of the fuel rods. The fuel rod was scanned by a pair of probes bearing on diametrically opposed sides of the rod. Probe travel perpendicular to the axis of the fuel rod was converted to an electrical signal by transducers. The output voltage was directly proportional to the displacement of the probes; the signal was continuously recorded by an $x-y$ recorder. The instrument recorded the algebraic sum of the movement of the probes. The scans, therefore, showed the deviation from a standard diameter.

In general, each set of diameter measurements made on a rod consisted of three separate scans. One scan was made with the rod oriented to measure the diameter in the 0 - 180-degree plane; a second was made to measure the diameter in the 90 - 270-degree plane, and a third scan was made while the rod was rotating. The 0-degree orientation was defined in the preceding section on visual examinations. All scans were made from the shorter end plugs to the longer end plugs of the rods.

Ten rods were scanned in the "as-received" condition during each of the two phases of the examination program, and six rods in each group were rescanned after the crud had been chemically removed from them. The rods selected for diameter measurements are listed in Table 5 . Most of these rods had comparatively high combinations of exposure and fuel density, and thus would tend to demonstrate relatively high degrees of fission product-induced $\mathrm{UO}_{2}$ swelling. Prior to any irradiation, the diameter of each rod was measured to the nearest $\sim 0.001 \mathrm{~cm}(0.0005 \mathrm{in}$.) with a micrometer at the top, middle, and bottom; the exact locations of these measurements are not known. Diameter profiles were obtained on rods A11, A38, A40, and A43, which operated through Dresden Reactor Cycle No. 6, primarily to further investigate certain areas that were believed to be possibly defective.

\subsection{Results}

The general thickness of crud was determined on those rods, in both phases of the examination program, that were scanned before and after decrudding. The thickness determinations made in this manner are believed to be generally valid; however, it must be pointed out that some crud was removed from some areas of the rods during handling and shipping. Essentially, all of the crud measured at the end of Cycles $\mathrm{Nn} 4$ and $\mathrm{N} n \mathrm{f}$ mas depesited during Dresden operation, since most of the crud that was deposited during VBWR operation was wiped off. The six rods that operated in Dresden 840 days to the end of Cycle No. 4 showed an average crud thickness of about $0.0009 \mathrm{~cm}$ (0.00035 in.). The maximum thickness averaged over the length of any of these rods was $0.0012 \mathrm{~cm}(0.0005 \mathrm{in}$.). The diameter profiles of the six decrudded rods that operated in Dresden 1468 days to the end of Cycle No. 6 are shown in Figures 47 through 52.

As Table 6 indicates, the rod average thicknesses ranged from $0.00084 \mathrm{~cm}(0.00033 \mathrm{in}$.) for rod $\mathrm{A} 37$ to $0.00173 \mathrm{~cm}(0.00068 \mathrm{in}$.$) for rod B50. The mean crud thickness for this group was 0.00122 \mathrm{~cm}(0.00048 \mathrm{in}$.). Rod A7 showed a local maximum crud thickness of $0.0028 \mathrm{~cm}(0.0011 \mathrm{in}$.$) , which was the highest value among all rods. The$ thickest crud on most rods in each group was located between the short end plug and mid Icngth; i.e., on the higher power half of the rod.

As Table 7 indicates, all decrudded rods showed some diameter increase with respect to the pre-irradiation measurements. The rod-average increases ranged from $0.001 \mathrm{~cm}(0.0005 \mathrm{in}$.$) to 0.004 \mathrm{~cm}$ (0.0015 in.). Interestingly, the overall average increase of the group of rods removed at the end of Cycle No. 4 was as large as that of the group removed at the end of Cycle No. 6-0.003 cm (0.001 in.), and the maximum rod-average increase was the same for both groups $-0.004 \mathrm{~cm}$ (0.0015 in.).

If one considers full thirds of the rod length over the fuel column, most rods in the latter group showed the greatest average diameter increase over the section that includes the long end plug and plenum and which operated at a power somewhat below the average for a given rod. The lowest diameter increases took place over the middle thirds of the rods with the exception of rod A22. The earlier rods showed more variation with respect to the locations of greatest and least diameter increase.

It is of some interest to compare the preceding data with diameter measurements made on two Zircaloy-2-clad fuel rods, of the same type as those incorporated in Assembly SA-1, after they had operated 364 days in the VBWR to rod-average burnups of $2.24 \times 10^{20}$ fissions $/ \mathrm{cm}^{3}(8190 \mathrm{MWd} / \mathrm{tU})$ and $2.85 \times 10^{20}$ fissions $/ \mathrm{cm}^{3}(10,430 \mathrm{MWd} / \mathrm{tU})$. The measurements were made with a micrometer at several points along the length. The lower burnup rod, which was 
GEAP-10371

Table 5

RODS SELECTED FOR DIAMETER PROFILE MEASUREMENTS

\begin{tabular}{|c|c|c|c|c|c|c|}
\hline \multirow{3}{*}{$\begin{array}{c}\text { Rod } \\
\text { Number }\end{array}$} & \multirow{3}{*}{$\begin{array}{l}\text { Tubing } \\
\text { Lot }\end{array}$} & \multicolumn{2}{|c|}{ Burnup } & & \multicolumn{2}{|c|}{$\begin{array}{l}\text { As-Fabricated Fuel Density } \\
\text { (Percent of Theoretical) }\end{array}$} \\
\hline & & (Fissions $/ \mathrm{cm}^{3}$ & $[\mathrm{MWd} / \mathrm{tU}])$ & & \multirow[b]{2}{*}{ Smeared* } & \multirow{2}{*}{$\begin{array}{c}\text { Pellet"* } \\
\text { Average-Range }\end{array}$} \\
\hline & & Rod-Average & Peak & & & \\
\hline & & \multicolumn{2}{|c|}{ Initial Phase. } & . & & \\
\hline A4 & CA.5 & $5.5(20,200)$ & $6.5(23,800)$ & & 91.6 & $95.1(94.1-96.0)$ \\
\hline A13 & CA-2 & $7.0(25,600)$ & $8.1(29,700)$ & & 91.5 & $94.4(92.7-95.2)$ \\
\hline A28 & CA-2 & $5.8(21,200)$ & $6.6(24,000)$ & & 92.9 & $96.0(95.5-96.6)$ \\
\hline A41 & CA.4 & $6.6(24,000)$ & $7.8(28,500)$ & & 91.2 & $94.8(94.3-95.3)$ \\
\hline A45 & CA.2 & $6.0(21,800)$ & $6.9(25,300)$ & & 92.9 & $96.0(95.5-96.6)$ \\
\hline A46 & CA-2 & $6.0(22,000)$ & $6.9(25,300)$ & & 92.7 & $96.0(95.5-96.6)$ \\
\hline B70 & CA. 5 & $5.5(20,200)$ & $6.9(25,300)$ & & 91.6 & $95.1(94.1-96.0)$ \\
\hline B76. & CA-2 & $6.1(22,400)$ & $8.0(29,100)$ & & 91.2 & $94.4(92.7-95.2)$ \\
\hline B88 & $\mathrm{CA} \cdot 2$ & $6.1(22,400)$ & $7.7(28,000)$ & & 91.2 & $95.0(94.5-95.5)$ \\
\hline \multirow[t]{2}{*}{ B97 } & CA-2 & $6.1(22,200)$ & $7.3(26,600)$ & & 91.6 & $95.3(94.4-96.2)$ \\
\hline & \multicolumn{3}{|c|}{ Final Phase } & & & \\
\hline A7 & CA-5 & $9.0(32,900)$ & $10.0(36,500)$ & & 91.6 & $95.7(95.0-96.4)$ \\
\hline $\mathrm{A9}$ & CA-2 & $8.8(32,200)$ & $9.6(35,100)$ & & 91.6 & $94.7(94.2-95.3)$ \\
\hline A11 & CA-4 & $9.1(33,300)$ & $10.0(36,600)$ & & 90.7 & $94.0(92.7-95.2)$ \\
\hline A22 & CA.5 & $8.2(29,800)$ & $8.9(32,500)$ & & 91.3 & $95.1(94.1-96.0)$ \\
\hline A37 & $\overline{C A}-1$ & $9.3(33,900)$ & $10.2(37,300)$ & & 90.8 & $94.1(92.3-95.3)$ \\
\hline A38 & CA-3 & $8.2(29,800)$ & $8.8(32,200)$ & & 92.1 & $95.2(94.0-96.6)$ \\
\hline A40. & CA-3 & $8.5(31,000)$ & $9.2(33,800)$ & & 92.1 & $95.2(94.0-96.6)$ \\
\hline A43 & CA-5 & $8.3(30,200)$ & $8.8(32,000)$ & & 91.4 & $95.7(95.0-96.4)$ \\
\hline A49 & $\mathrm{CA}-2$ & $8.5(31,100)$ & $9.2(33,600)$ & & 91.5 & $95.3(94.4-96.2)$ \\
\hline $\mathrm{B} 50$ & CA-2 & $8.4(30,800)$ & $9.5(34,800)$ & & 92.7 & $96.0(95.5-96.6)$ \\
\hline
\end{tabular}

Weight $\mathrm{UO}_{2}$ in rod $(\mathrm{gm}) \times 100$

"Smeared density (percent of theoretical) is defined as: $\frac{\left.\left.\text { Weight } \mathrm{UO}_{2} \text { in rod (gm) } \times 100 \text { (cladding ID in } \mathrm{cm}\right)^{2} \times \text { (fuel column length in } \mathrm{cm}\right) \times 10.97}{\pi / 4 \times}$

- Water immersion density on sampling of approximately 2 percent.

Listed below are the average and median pre-irradiation inside diameters of tubing from the various lots, based on measurements made on samples from these lots. The measurements were within a range of 0.965 to $0.968 \mathrm{~cm}(0.380$ to 0.381 in.).

\begin{tabular}{lll}
$\begin{array}{l}\text { Tubing } \\
\text { Lot }\end{array}$ & \multicolumn{2}{c}{ Inside Diameter (cm [in.]) } \\
\cline { 2 - 3 } CA-1 & \multicolumn{1}{c}{ Median } & Average \\
CA-2 & $0.9671(0.38075)$ & $0.9671(0.38075)$ \\
CA-3 & $0.9665(0.3805)$ & $0.9662(0.3804)$ \\
CA-4 & $0.9658(0.38025)$ & $0.9660(0.3803)$ \\
CA-5 & $0.9665(0.3805)$ & $0.9667(0.3806)$ \\
& $0.9665(0.3805)$ & $0.9665(0.3805)$
\end{tabular}

The nominal pre-irradiation pellet diameter was $0.955_{-0.008}^{+0.000} \mathrm{~cm}(0.376+0.000$ in.). The diameter of each pellet in rode $B 70$ and $\mathrm{A} 22$ was moasurcd bcfore it was loaded into the tube.

In rod B70, one pellet was $0.947 \mathrm{~cm}(0.373 \mathrm{in.}), 44$ pellets were $0.950 \mathrm{~cm}(0.374 \mathrm{in}$.$) , and 17$ pellets were $0.952 \mathrm{~cm}$ (0.375 in.) in diameter. In rod A22, 4 pellets were $0.945 \mathrm{~cm}(0.372 \mathrm{in}$.$) to 0.947 \mathrm{~cm}, 39$ were $0.950 \mathrm{~cm}$, and 18 were $0.952 \mathrm{~cm}$ (Reference 2). 
Table 6

CRUD THICKNESS BY PROFILOMETRY

(Rods That Operated in Dresden through the End of Cycle No. 6)

\section{Rod} Number

A7

A9

in

\begin{tabular}{cc}
\multicolumn{2}{c}{$\begin{array}{c}\text { Circumferential-Average } \\
\text { Crud Thickness } \\
\text { (cm [in.]) }\end{array}$} \\
\hline Rod-Average & Naximum * \\
0.00140 & 0.0028 \\
$(0.00055)$ & $(0.0011)$ \\
0.00099 & \\
$(0.00039)$ & 0.0020 \\
& $(0.0008)$
\end{tabular}

$$
\begin{aligned}
& \text { Location(s) of } \\
& \text { Thickest Crud } \\
& \text { (cm [in.] from } \\
& \text { Short End Plug) }
\end{aligned}
$$

\section{1 to 51 (16 to 20 )}

23 to 30 (9 to 12 )

13 to $20(5$ to 8$)$

58 to 76 (23 to 30$)$

$\begin{array}{cc}0.00127 & 0.0018 \\ (0.00050) & (0.0007)\end{array}$

$\begin{array}{ccc}\text { A37 } & 0.00084 & 0.00165 \\ & (0.00033) & (0.00065) \\ \text { A49 } & 0.00112 & 0.0020 \\ & (0.00044) & (0.0008) \\ & & \\ \text { B50 } & 0.00173 & 0.0024 \\ & (0.00068) & (0.00095)\end{array}$

10 to 23 (4 to 9 )

\section{Remarks}

Only 0.0008 to $0.001 \mathrm{~cm}(0.0003$ to 0.0004 in.) over most of that part of rod between mid-length and long end plug.

Decreases toward long end plug. Only 0.0005 to $0.0008 \mathrm{~cm}$ ( 0.0002 to 0.0003 in.) over most of that part of rod between mid-length and long plug.

Fairly uniform thickness over full length with most values between 0.0010 and $0.0015 \mathrm{~cm}(0.0004$ and 0.0006 in.); however, crud is slightly thicker at indicated location than elsewhere on rod.

Gradually decreases to 0.00025 to $0.0005 \mathrm{~cm}$ (0.0001 to 0.0002 in.) toward long end plug.

Ranges from about 0.0013 to $0.0020 \mathrm{~cm}(0.0005$ to 0.0008 in.) in fairly random manner between short plug and mid-length. Drops off to about $0.0005 \mathrm{~cm}(0.0002 \mathrm{in}$.) over rest of rod.

Tends to decrease somewhat toward long end plug, but thickness is still 0.00165 to $0.0019 \mathrm{~cm}(0.00065$ to 0.00075 in.) in some places near long plug. 
Table 7

\section{ROD DIAMETER AFTER DECRUDDING}

\begin{tabular}{|c|c|c|c|c|}
\hline \multirow[b]{2}{*}{$\begin{array}{l}\text { Rod } \\
\text { Number }\end{array}$} & \multirow{2}{*}{$\begin{array}{l}\text { Distance from Short } \\
\text { End Plug Shoulder } \\
\text { (cm [in.]) }\end{array}$} & \multicolumn{3}{|c|}{ Rod Diameter (cm [in.]) } \\
\hline & & $\begin{array}{l}\text { Post-Irradiation } \\
\text { (Average) }\end{array}$ & Pre-Irradiation & Change \\
\hline \multicolumn{5}{|c|}{ Initial Phase } \\
\hline A4 & $\begin{array}{c}0.95-30.5(0.375-12) \\
30.5-63.5(12-25) \\
63.5-94.0(25-37) \\
\text { Average }\end{array}$ & $\begin{array}{l}1.0765(0.4238) \\
1.0744(0.4230) \\
1.0747(0.4231)\end{array}$ & $\begin{array}{l}1.072(0.422) \\
1.072(0.422) \\
1.074(0.423)\end{array}$ & $\begin{array}{r}+0.005(0.002) \\
+0.003(0.001) \\
0.000(0.000) \\
+0.003(0.001)\end{array}$ \\
\hline A13 & $\begin{array}{c}0.95-30.5(0.375-12) \\
30.5-63.5(12-25) \\
63.5-94.0(25-37) \\
\text { Average }\end{array}$ & $\begin{array}{l}1.0838(0.4267) \\
1.0838(0.4267) \\
1.0843(0.4269)\end{array}$ & $\begin{array}{l}1.081(0.4255) \\
1.082(0.426) \\
1.082(0.426)\end{array}$ & $\begin{array}{l}+0.003(0.001) \\
+0.001(0.0005) \\
+0.003(0.001) \\
+0.003(0.001)\end{array}$ \\
\hline A28 & $\begin{array}{c}0.95 \cdot 30.5(0.375 \cdot 12) \\
30.5 \cdot 63.5(12-25) \\
63.5-94.0(25-37) \\
\text { Average }\end{array}$ & $\begin{array}{l}1.0866(0.4278) \\
1.0846(0.4270) \\
1.0856(0.4274)\end{array}$ & $\begin{array}{l}1.081(0.4255) \\
1.082(0.426) \\
1.082(0.426)\end{array}$ & $\begin{array}{l}+0.006(0.0025) \\
+0.003(0.001) \\
+0.004(0.0015) \\
+0.004(0.0015)\end{array}$ \\
\hline A41 & $\begin{array}{c}0.95-30.5(0.375-12) \\
30.5-63.5(12-25) \\
63.5-94.0(25-37) \\
\text { Average }\end{array}$ & $\begin{array}{l}1.0785(0.4246) \\
1.0772(0.4241) \\
1.0775(0.4242)\end{array}$ & $\begin{array}{l}1.078(0.4245) \\
1.076(0.4235) \\
1.076(0.4235)\end{array}$ & $\begin{array}{r}0.000(0.000) \\
+0.001(0.0005) \\
+0.001(0.0005) \\
+0.001(0.0005)\end{array}$ \\
\hline $\mathrm{B} 70$ & $\begin{array}{c}0.95-30.5(0.375-12) \\
30.5-63.5(12-25) \\
63.5-94.0(25-37) \\
\text { Average }\end{array}$ & $\begin{array}{l}1.0798(0.4251) \\
1.0790(0.4248) \\
1.0805(0.4254)\end{array}$ & $\begin{array}{l}1.080(0.425) \\
1.078(0.4245) \\
1.074(0.423)\end{array}$ & $\begin{aligned} & 0.000(0.000) \\
+ & 0.001(0.0005) \\
+ & 0.006(0.0025) \\
+ & +0.003(0.001)\end{aligned}$ \\
\hline B76 & $\begin{array}{c}0.95-30.5(0.375-12) \\
30.5-63.5(12-25) \\
63.5-94.0(25-37) \\
\text { Average }\end{array}$ & $\begin{array}{l}1.0848(0.4271) \\
1.0841(0.4268) \\
1.0841(0.4268)\end{array}$ & $\begin{array}{l}1.082(0.426) \\
1.080(0.425) \\
1.080(0.425)\end{array}$ & $\begin{array}{l}+0.003(0.001) \\
+0.005(0.002) \\
+0.005(0.002) \\
+0.004(0.0015)\end{array}$ \\
\hline \multicolumn{5}{|c|}{ Final Phase } \\
\hline A7 & $\begin{array}{c}0.95-30.5(0.375-12) \\
30.5-63.5(12-25) \\
63.5-94.0(25-37) \\
\text { Average }\end{array}$ & $\begin{array}{l}1.0752(0.4233) \\
1.0726(0.4223) \\
1.0744(0.4230)\end{array}$ & $\begin{array}{l}1.073(0.4225) \\
1.072(0.422) \\
1.071(0.4215)\end{array}$ & $\begin{array}{l}+0.003(0.001) \\
+0.001(0.0005) \\
+0.004(0.0015) \\
+0.003(0.001)\end{array}$ \\
\hline A9 & $\begin{array}{c}0.95-30.5(0.375-12) \\
30.5-63.5(12-25) \\
63.5: 84.0(26-37) \\
\text { Average }\end{array}$ & $\begin{array}{l}1.0825(0.4262) \\
1.0825(0.4262) \\
1.0828(0.4263)\end{array}$ & $\begin{array}{l}1.080(0.425) \\
1.082(0.426) \\
1.080(0.425)\end{array}$ & $\begin{array}{r}+0.003(0.001) \\
0.000(0.000) \\
+0.004(0.0015) \\
+0.003(0.001)\end{array}$ \\
\hline A22 & $\begin{array}{c}0.95-30.5(0.375-12) \\
30.5-63.5(12-25) \\
63.5-94.0(25-37) \\
\text { Average }\end{array}$ & $\begin{array}{l}1.0795(0.4250) \\
1.0787(0.4247) \\
1.0772(0.4241)\end{array}$ & $\begin{array}{l}1.077(0.424) \\
1.077(0.424) \\
1.077(0.424)\end{array}$ & $\begin{array}{c}+0.003(0.001 \\
+0.001(0.0005) \\
0.000(0.000) \\
+0.001(0.0005)\end{array}$ \\
\hline A37 & $\begin{array}{c}0.95-30.5(0.375-12) \\
30.5-63.5(12-25) \\
63.5-94.0(25-37) \\
\text { Average }\end{array}$ & $\begin{array}{l}1.0792(0.4249) \\
1.0795(0.4250) \\
1.0790(0.4248)\end{array}$ & $\begin{array}{l}1.078(0.4245) \\
1.080(0.425) \\
1.077(0.424)\end{array}$ & $\begin{array}{c}+0.001(0.0005) \\
\text { n.nกn }(0.0 n n) \\
+0.003(0.001) \\
+0.001(0.0005)\end{array}$ \\
\hline A49 & $\begin{array}{c}0.95-30.5(0: 375-12) \\
30.5-63.5(12-25) \\
63.5-94.0(25-37) \\
\text { Aver dye }\end{array}$ & $\begin{array}{l}1.0828(0.4263) \\
1.0803(0.4253) \\
1.0851(0.4272)\end{array}$ & $\begin{array}{l}1.080(0.425) \\
1.078(0.4245) \\
1.080(0.425)\end{array}$ & $\begin{array}{l}+0.004(0.0015) \\
+0.003(0.001) \\
+0.005(0.002) \\
10.004(0.0015)\end{array}$ \\
\hline$B 50$ & $\begin{array}{c}0.95-30.5(0.375-12) \\
30.5-63.5(12-25) \\
03.5=94.0(25=37) \\
\text { Average }\end{array}$ & $\begin{array}{l}1.0846(0.4270) \\
1.0823(0.4261) \\
1.0051(0.4272)\end{array}$ & $\begin{array}{l}1.080(0.425) \\
1.080(0.425) \\
1.000(0.425)\end{array}$ & $\begin{array}{l}+0.005(0.002) \\
+0.003(0.001) \\
10.005(0.002) \\
+0.004(0.0015)\end{array}$ \\
\hline
\end{tabular}


AS-RECEIVED
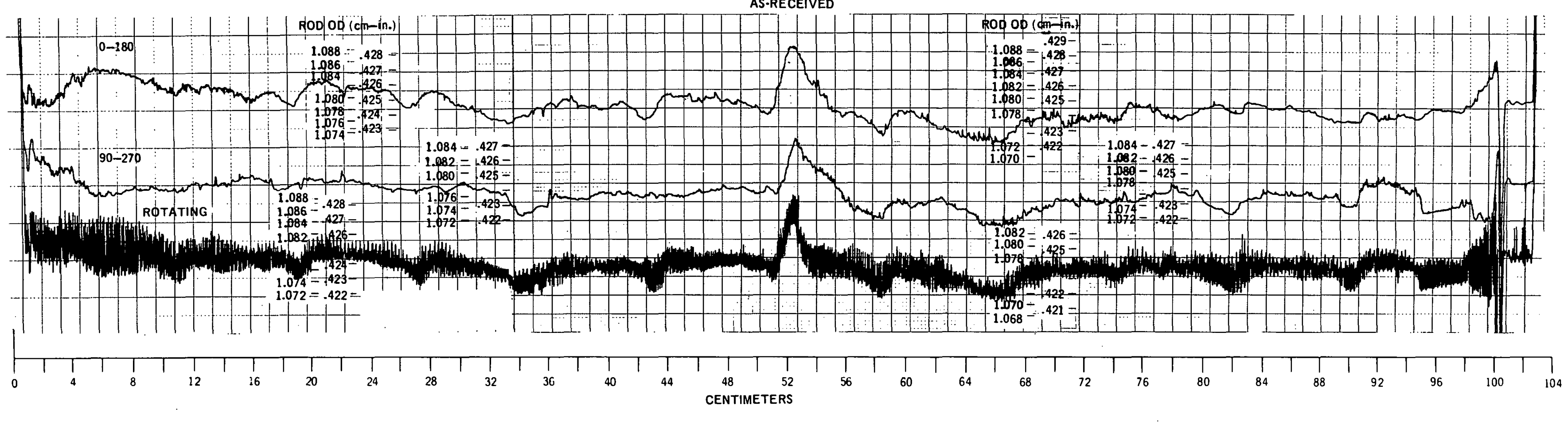

DISTANCE FROM SHORT END PLUG SHOULDER

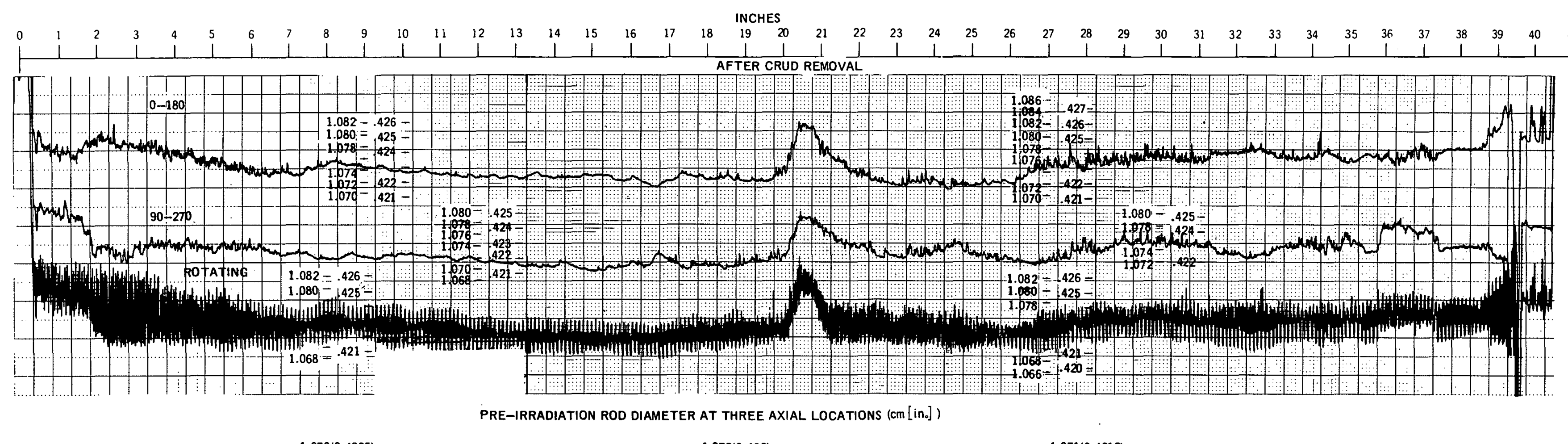

$1.073(0.4225)$

1.072(0.422)

$1.071(0.4215)$

Figure 47. Diameter Profiles of Fuel Rod A7 

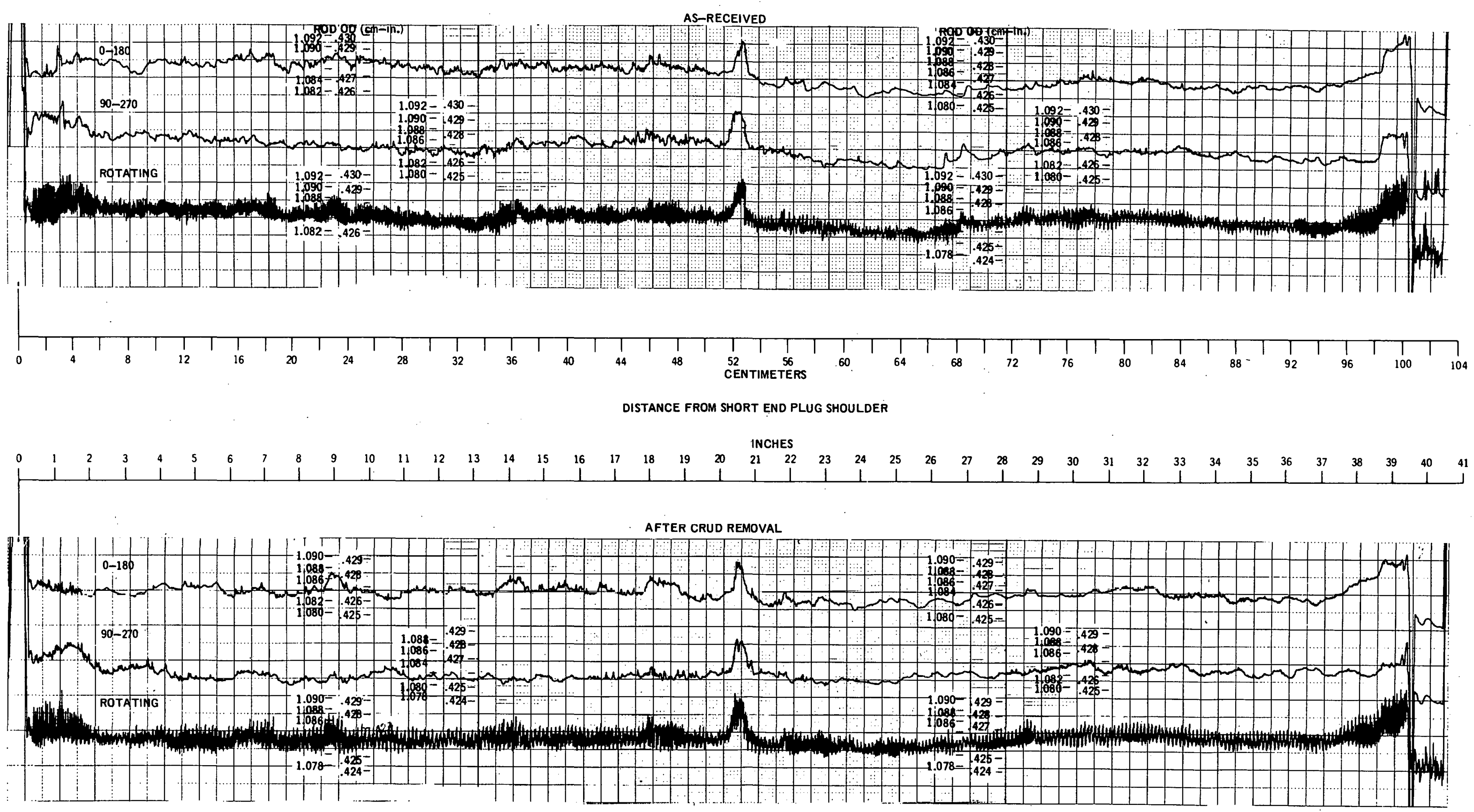

$1.080(0.425)$

PRE-IRRADIATION ROD DIAMETERS AT THREE AXIAL LOCATIONS (cm[ in.] )

$1.082(0.428)$

$1.080(0.425)$

Figure 48. Diameter Profiles of Fuel Rad A9 

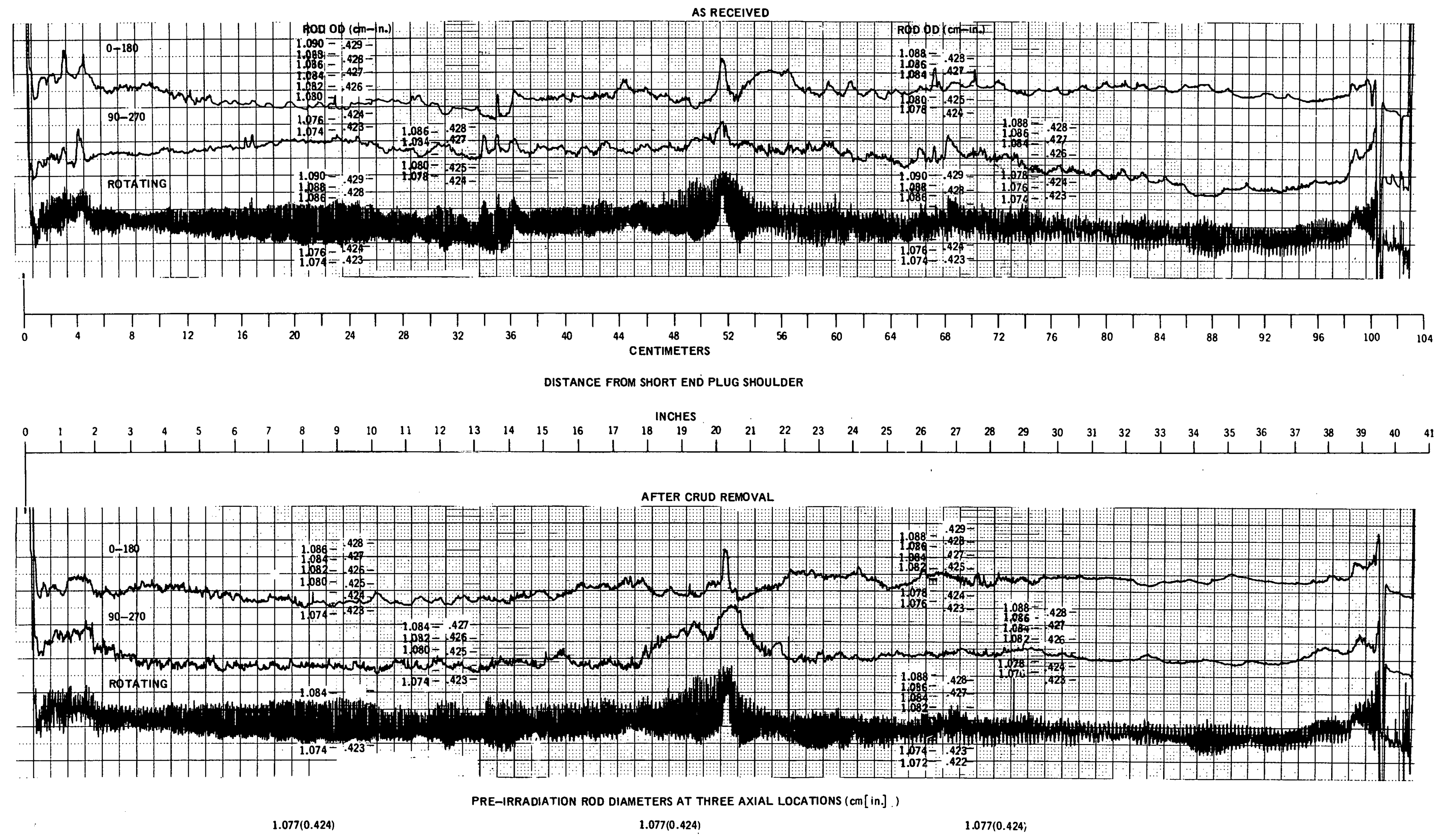

Figure 49. Diameter Profiles of Fuel Rod A22

1.077(0.424)

$1.077(0.424 ;$ 
AS-RECEIVED



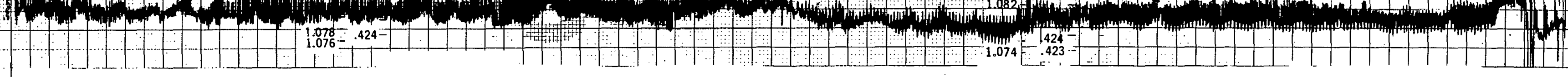

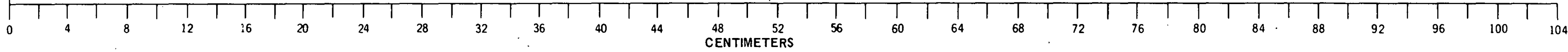

DISTANCE FROM SHORT END PLUG SHOULDER

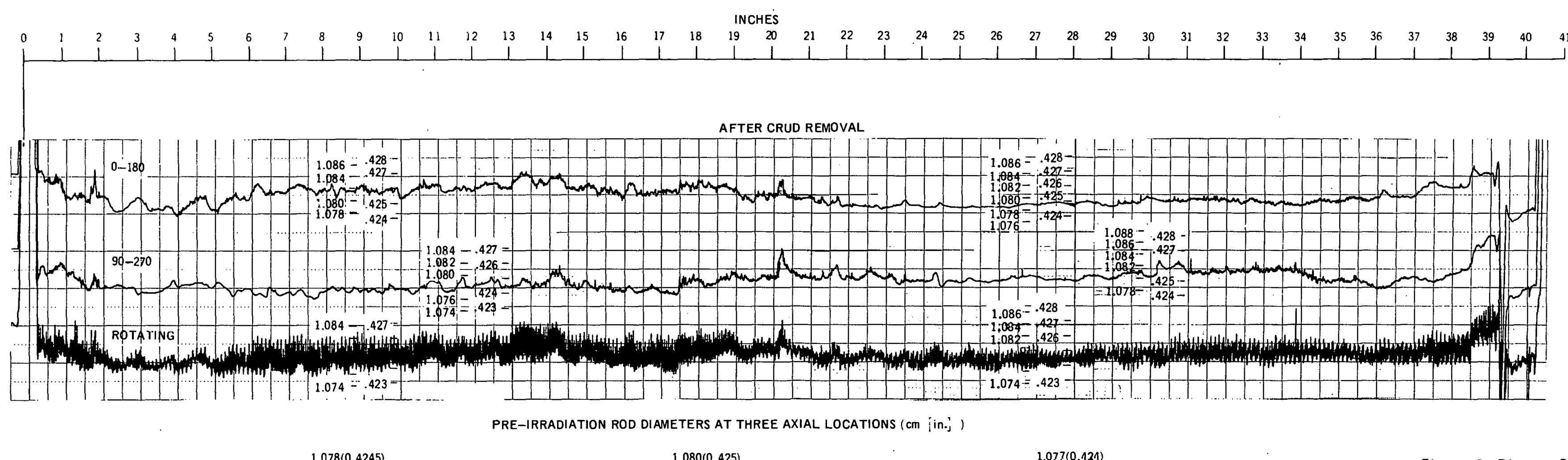

1:078(0.4245)

$1.08 n(0425)$

Figure 50. Diameter Profiles of Fuel Rod A37 



DISTANCE FROM SHORT END PLUG SHOULDER

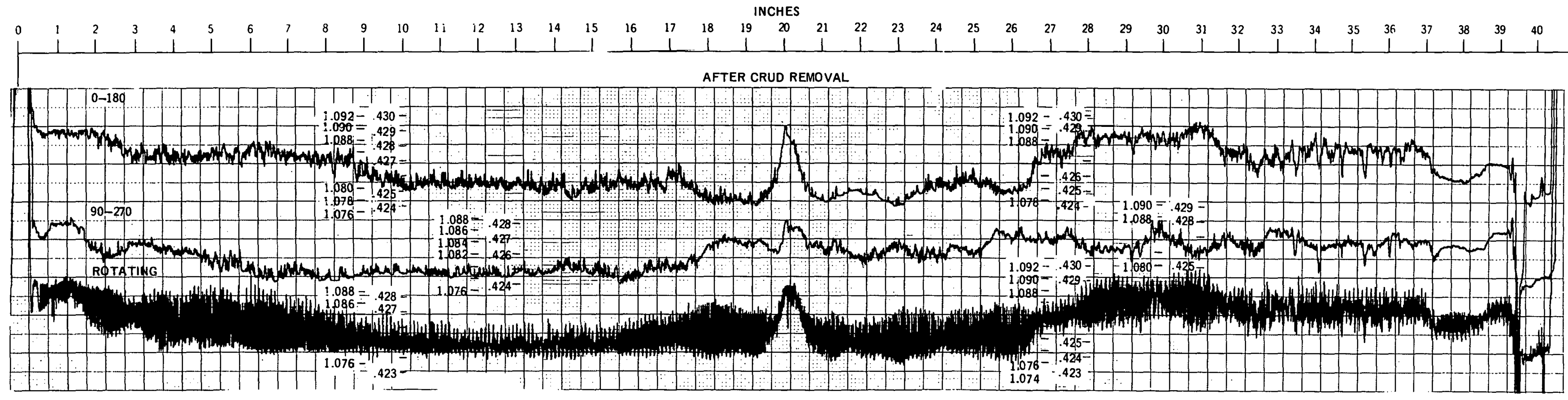
PRE-IRRADIATION ROD DIAMETERS AT THREE AXIAL LOCATIONS (cm [in.] )

.078(0.4245)

$1.080(0.425)$

$1.080(0.425)$ 

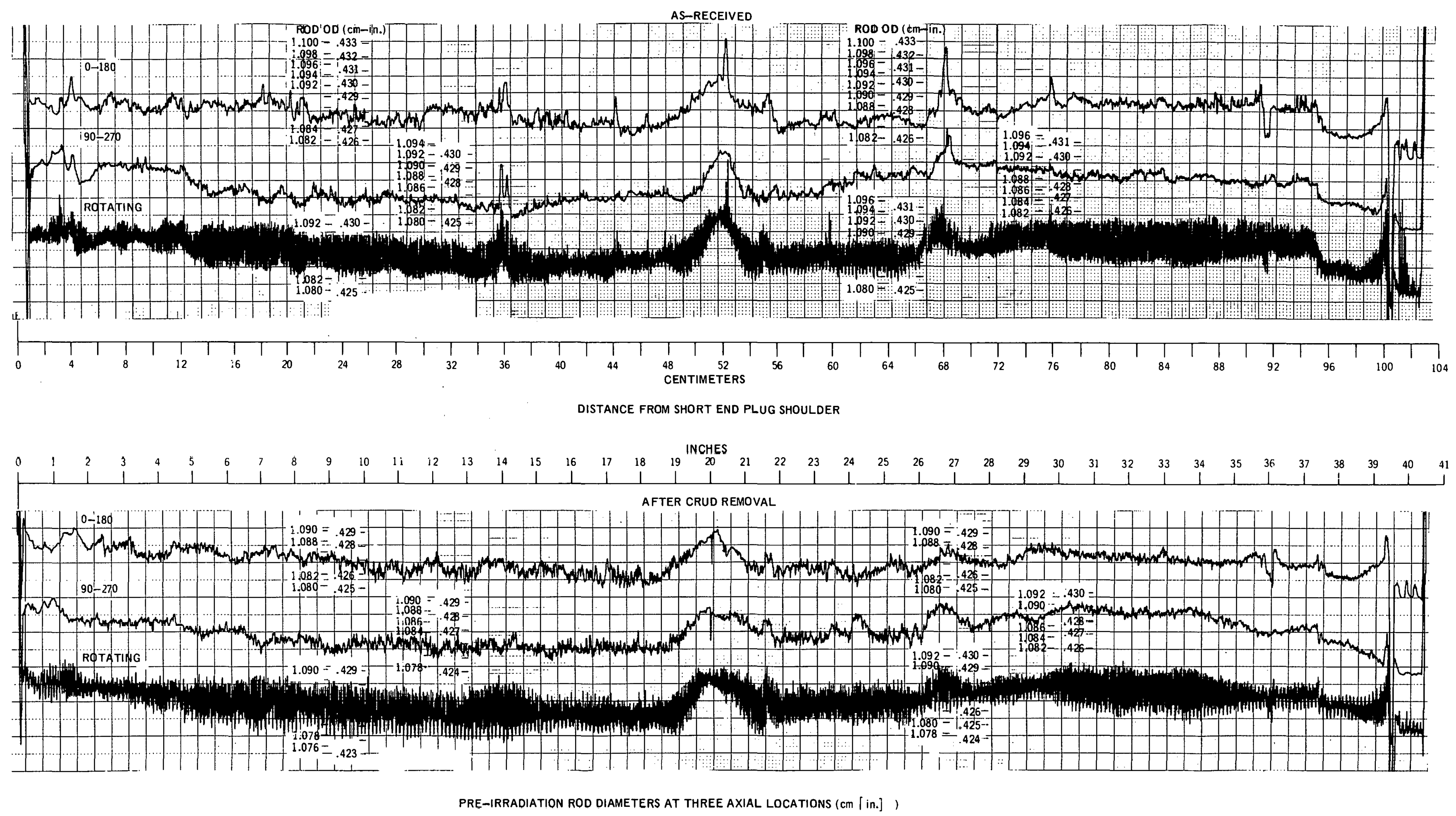

$1.080(0.425)$ 
clad with lot CA-4 tubing and had smeared and average pellet densities of 90.6 and 94.3 percent of theoretical, showed diameter increases within the range of 0 to $0.001 \mathrm{~cm}(0.0005 \mathrm{in}$.). The other rod, which was clad with lot CA-2 tubing and had smeared and average pellet densities of 90.2 and 93.8 percent of theoretical, showed diameter increases that ranged from 0.003 to $0.004 \mathrm{~cm}(0.001$ to $0.0015 \mathrm{in}$.), i.e., as large as the overall average increase shown by the twelve rods that received additional irradiation in Dresden. ${ }^{3}$

The difference between the maximum diameter and the minimum diameter at a given point along the rod axis (o.d. $\max -$ o.d. $\min$ ) was as large as 0.0075 or $0.010 \mathrm{~cm}(0.003$ or $0.004 \mathrm{in}$.) at some locations of some SA-1 rods, both among those that were removed after two cycles of Dresden operation and among those that operated four cycles. The general magnitude of this difference varied considerably among different rods (for example, compare rod 850 in Figure 52 with rod A9 in Figure 48). In general, the rods located at inside positions of the subassemblies showed lower values of o.d. max $-0 . d_{\text {min }}$ than the outside rods measured. The portion of a rod where $0 . d_{\text {.max }} \cdot 0 . d_{\text {min }}$ was greatest varied from rod to rod. For instance, this difference was largest over the short-end-plug, high-power half of rod A22 (Figure 49), but on rod A49 o.d. $\max -0 . d_{\text {min }}$ was low between $\sim 25$ and $40 \mathrm{~cm}(\sim 10$ and 16 in.) from the short end plug, near the peak burnup location, in comparison with almost any other location. The " $A$ " rods measured in the initial phase of the program did tend to show their largest o.d. $\max -{ }^{-0 . d .}$ min values either toward the short end plug or near the mid-length. Two of the " $B$ " rods in this group showed the largest values of o.d.max - o.d.min near the short end plug, but with the other two the magnitude of this difference was greatest near the long end plug.

Chemical removal of the crud generally did not markedly change the amount of or the pattern of this" "apparent ovality." However, some portions of rods $\mathrm{B} 50$ and $\mathrm{A} 22$ between the plenum region and mid-length showed decreases in o.d.max ${ }^{-0 . d .}$ min, up to approximately $0.0025 \mathrm{~cm}(0.001 \mathrm{in}$.) on the former rod and about $0.0012 \mathrm{~cm}(0.0005 \mathrm{in}$.) on the latter, and in other cases decrudding resulted in increases in $0 . d$.max $-0 . d_{\text {.min }}$ up to nearly $0.0025 \mathrm{~cm}$ over portions of rod A7.

In addition to the general increase in diameter that occurred during operation, local peaks in rod diameter often were present near spacer locations. The SA-1 subassembly spacer springs contacted the rods at approximately $3.8 \mathrm{~cm}$ (1-1/2 in.), $35.7 \mathrm{~cm}$ (14-1/16 in.), $67.6 \mathrm{~cm}$ (26-5/8 in.) and $99.7 \mathrm{~cm}(39-1 / 4 \mathrm{in}$.$) from the short end plug shoulder. The$ VBWR spacer wires were located about $51.4 \mathrm{~cm}(20-1 / 4 \mathrm{in}$.) from the short plug.

All of the rods exhibited local increases in diameter at the $3.8 \mathrm{~cm}$ subassembly spacer location and less frequently at the other subassembly spacer locations. These peaks were generally 0.0025 to $0.005 \mathrm{~cm}(0.001$ to $0.002 \mathrm{in}$.) above the typical rod diameter in the vicinity; however, a few were in the 0.008 to $0.010 \mathrm{~cm}(0.003$ to 0.004 in.) range. Those near the $99.7 \mathrm{~cm}$ location were 0.005 to $0.008 \mathrm{~cm}(0.002$ to $0.003 \mathrm{in.}$ ), but a force fit between the long end plug and tube may be responsible for at least some of the diameter peaking noted near this location. Chemical removal of the crud from the rods decreased the rod diameter at the spacer peaks in most cases. The 3.8-cm, 35.7-cm, and 67.6-cm locations showcd dccrcases as large as 0.006 to $0.008 \mathrm{~cm}$ in about five instances among the twelve decrudded rods. Thus, the maximum thickness of crud on some part of a rod might have been as much as $0.008 \mathrm{~cm}$ or as little as one-half of this value depending upon the evenness of the crud layer around the rod. The average diameter decrease at these three spacer locations was $0.0018 \mathrm{~cm}(0.0007 \mathrm{in}$.) among rods removed at the end of Cycle No. 4 and $0.0030 \mathrm{~cm}$ $(0.0012 \mathrm{in.}$ ) among rods removed at the end of Cycle No. 6 . Thus, it appears that on the average the crud was not significantly thicker at spacer locations than elsewhere on the heat transfer surfaces.

Crud removal did not necessarily climinatc a local diameter increase, or even decrease it; some peaks at subassembly spacer locations were relatively more prominent on the profiles that were run after crud removal. Local increases in diameter could still be seen on these profiles at most of the $3.8-\mathrm{cm}$ spacer locations and at some of the other subassembly spacer locations as well. The differences between diameters at the spacer peaks and those of the corresponding adjoining regions on these profiles were as large as 0.005 to $0.008 \mathrm{~cm}$ at five spacer locations on rods removed at the end of Cycle No. 4 and at the 3.8-cm location on rod A7 (Figure 47).

All rods showed peaks in their diameter profiles at the VBWR spacer locations. Such peaks were 0.005 to $0.008 \mathrm{~cm}$ high on the diameter on most of the rods in each exposure group. Decrudding the rods somewhat increased the prominence of the VBWR spacer peak more often than not; hence, the crud was usually thinner at the spacer location than it was on either side of that location.

The stationary. "decrudded" diameter profiles of some rods in both groups showed peaks. at pellet-length intervals. The profiles of rod $A 37$ show sùch peaks $\sim 2.2 \mathrm{~cm}(\sim 7 / 8 \mathrm{in.}$ ) apart between 28 and $38 \mathrm{~cm}(11$ and $15 \mathrm{in})$. from the short end plug shoulder and between the 56- and 61-cm (22- and 24-in.) locations (Figure 50). The difference in diameter between these peaks and the corresponding troughs is typically $0.0012 \mathrm{~cm}(0.0005 \mathrm{in}$.) to $0.0019 \mathrm{~cm}$ $(0.00075 \mathrm{in.})$ and has a maximum value of about $0.0025 \mathrm{~cm}(0.001 \mathrm{in}$.). The profiles of rod A22 showed some similar peaks at pellet-length intervals of about $1.5 \mathrm{~cm}(0.6 \mathrm{in.})$ between the short end plug and mid-length and also between 
the 69- and 74-cm (27- and 29-in.) locations (Figure 49). The average height of such peaks on this rod are somewhat greater than $0.0012 \mathrm{~cm}$, and the maximum is $0.0019 \mathrm{~cm}$. A few scattered and rather ill-defined peaks are shown by the profiles of rod A9 over the short end plug half of the rod (Figure 48), and a few small peaks are barely discernible within the same region of rod A7 (Figure 47). The length of the pellets in the former rod is $\sim 2.2 \mathrm{~cm}$ and in the latter $\sim 1.5 \mathrm{~cm}$. The 0 - 180-degree and 90 - 270-degree profiles of rods A49 and B50 are so jagged that it is difficult to tell whether or not there is any particular diameter peaking at pellet-length intervals on these rods. The profiles of rod A41, which was one of the rods removed after two cycles in Dresden, showed peaks at pellet-length intervals between the $8-\mathrm{cm}$ (3-inch) and 36-cm (14-inch) locations and between the 56-cm (22-in.) and 61-cm (24-in.) locations. The magnitude of the peaking was comparable to that shown by rod A37, discussed above. The profiles of most of the other rods in the initial group showed some degree of this type of peaking. However, the locations where such peaks could be identified were generally less frequent and more scattered than in the case of rod A41. The roughness of the surface of some of these rods may have decreased the definition of some peaks.

The rod A49 traces show some sharp and easily discernible troughs at pellet-length intervals, particularly hetween the 84- and 91-cm (33- and 36-in.) locations (Figure 51). Some of these troughs are as deep as 0.004 to $0.005 \mathrm{~cm}$ ( $\sim 0.0015$ to 0.002 in.). Other troughs that are somewhat less well defined can be observed between the 74- and 84-cm (29- and 33-in.) locations and between the 14- and 24-cm (5-1/2- and 9-1/2-in.) locations. The troughs between the 84and $91-\mathrm{cm}$ locations correspond with the locations of the smooth circumferential rings observed on this rod. This correspondence suggests that the rings may be localized areas of relatively low cladding corrosion. It should be pointed out, however, that no rings were noted on rod A49 at other trough locations, and no well-defined troughs can be detected on the diameter profiles of rods $A 7, A 22$, and $B 50$ where rings were observed during the visual examinations.

Rather pronounced local decreases in diameter can be seen on the as-received profile traces of rods A7 and A49 near some of the points of contact with the subassembly corner angle recesses. These recesses were centered at 3.8 , $11.7,19.7,27.6,35.8,43.7,51.6,59.5,67.7,75.6,83.5$, and $91.4 \mathrm{~cm}(1-1 / 2,4-5 / 8,7-3 / 4,10-7 / 8,14-3 / 32,17-3 / 16$, $20-5 / 16,23-7 / 16,26-21 / 32,29-3 / 4,32-7 / 8$, and 36 in.) from the short end plug shoulders. The profile traces run after the rods were decrudded presented no evidence of depressions of this sort on rod A7, and only a few of relatively lower prominence could be seen on rod A49.

The diameter profiles of rod A9 appeared quite normal at the location of the pit observed visually (Figure 44) and at the location of tho dark gray spot noted on the neutruy aplı ul llie iud (Fiyure 45 ).

During the visual examinations of rods $A 40, A 43, A 38$, and $A 11$, areas were noted that were believed to be possibly defective. The main reason for obtaining diameter profiles on these rods then was to detect any sharp diameter changes in these areas as, for example, might be caused by a bulge. These rods were not decrudded before profiling.

Rod A40 contained a rather deep-appearing gouge or possible crack $0.6 \mathrm{~cm}(1 / 4 \mathrm{in}$.) long and longitudinally oriented $56.2 \mathrm{~cm}(22-1 / 8 \mathrm{in}$.) from the short end plug (Figure 53) and an $\sim 0.3-\mathrm{cm}$ (1/8-in.) diameter group of fine cracks of uncertain depth located $92.7 \mathrm{~cm}$ (36-1/2 in.) from the short end plug (Figure 54). Corner rod A43 showed a 0.6-cm (1/4-in.) long, longitudinally oriented apparent crack at the 91.8-cm (36-1/8-in.) location near the area where a recess in the subassembly corner angle contacted the rod (see Figure $32 \mathrm{c})$. A $0.6-\mathrm{cm}(1 / 4-\mathrm{in}$.) $\times 0.3-\mathrm{cm}(1 / 8-\mathrm{in}$.) area where the crud was cracking and lifting up also was noted at the 3.8-cm (1-1/2-in.) location (Figure 55). The surface appcarance suggested that sume claddiıy peıtılıation might have taken place. As mentioned in the preceding section, however, a neutrograph taken of this rod did not show anything indicative of a defect. Rod A38 had a $0.08-\mathrm{cm} \times 0.04-\mathrm{cm}(1 / 32$-in. $\times 1 / 64$-in.) pit or gouge (possibly a small area where the crud had spalled away), $64.1 \mathrm{~cm}$ (25-1/4 in.) from the short end plug shoulder, and an $\sim 0.3-\mathrm{cm}(1 / 8-\mathrm{in}$.$) diameter discolored area at the 63.5-\mathrm{cm}(25-\mathrm{in}$. location (Figure 56).

Rod A11 showed four brown circular spots of $\sim 0.3-\mathrm{cm}(1 / 8-i n$.$) diameter 17.5 \mathrm{~cm}, 19.7 \mathrm{~cm}, 21.6 \mathrm{~cm}$ and $23.8 \mathrm{~cm}$ (6-7/8 in., 7-3/4 in., 8-1/2 in., and 9-3/8 in.) from the short end plug and two brown circumferential rings about $1.1 \mathrm{~cm}$ (7/16 in.) apart at the 27.6-cin (10-7/8-in.) lucation (see Figure 30). The general rod coloration was dark gray in the vicinity of the rings and spots, which probably came about from variations in crud deposition, It was believed that such variations might indicate localized differences in rod diameter. On the other hand, nothing was observed on the neutrograph of this rod to suggest that it might be defective.

With the remotely possible exception of rod A11, the diameter profiles of the four rods in question did not reveal anything to indicate they might be defective. The profiles tend to indicate that those surface features previously regarded as possible cracks were either handling gouges or cracks that extended no deeper than the $\mathrm{crud}$ or $\mathrm{ZrO}_{2}$ layers.

Diameter profiles of rod A11 run with the rod held in the 0 - to 180-degree and 90- to 270-degree orientations are shown in Figure 57. Series of peaks and troughs can be seen on the two profiles in the vicinity of the circular spots, but the profiles are rather flat near the brown rings. The maximum difference between any peak and a corresponding 


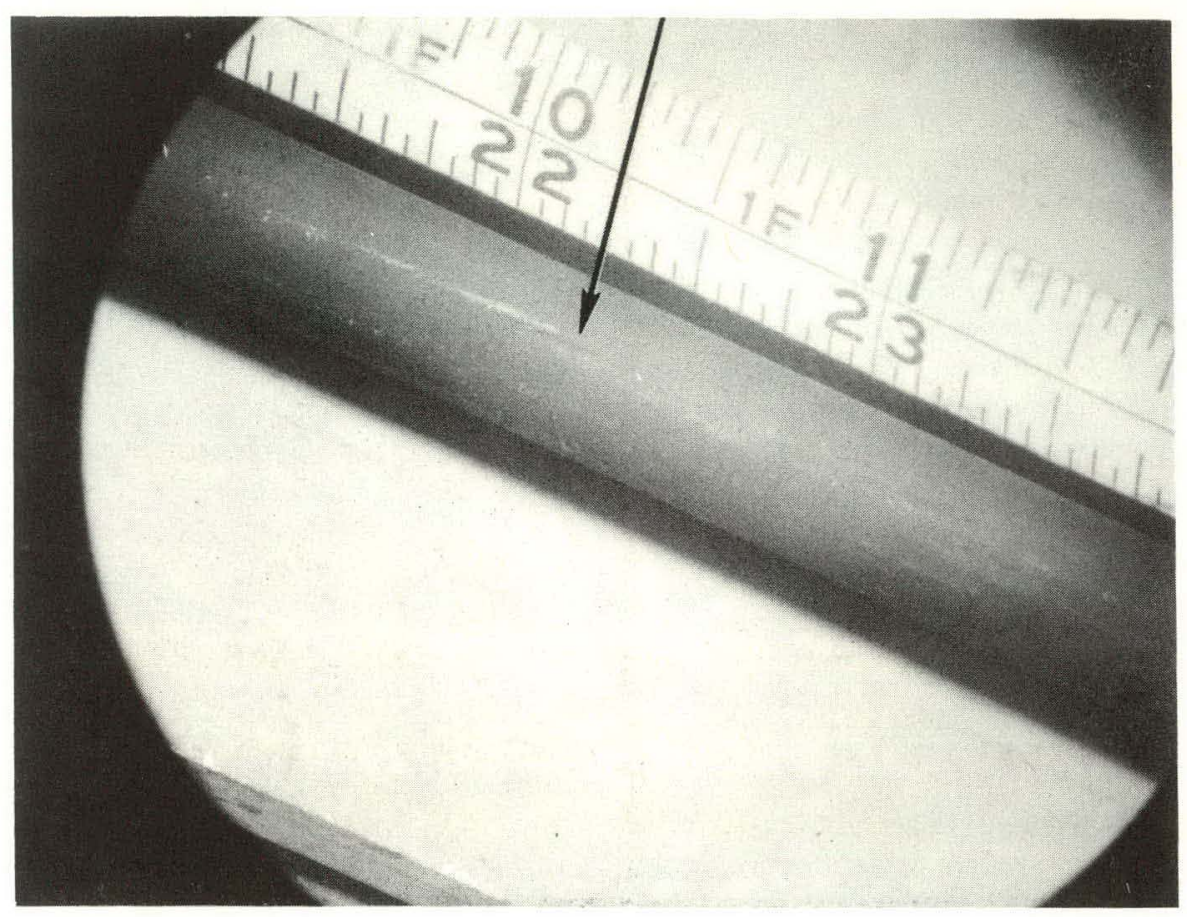

Figure 53. Gouge or Possible Crack in Rod A4O

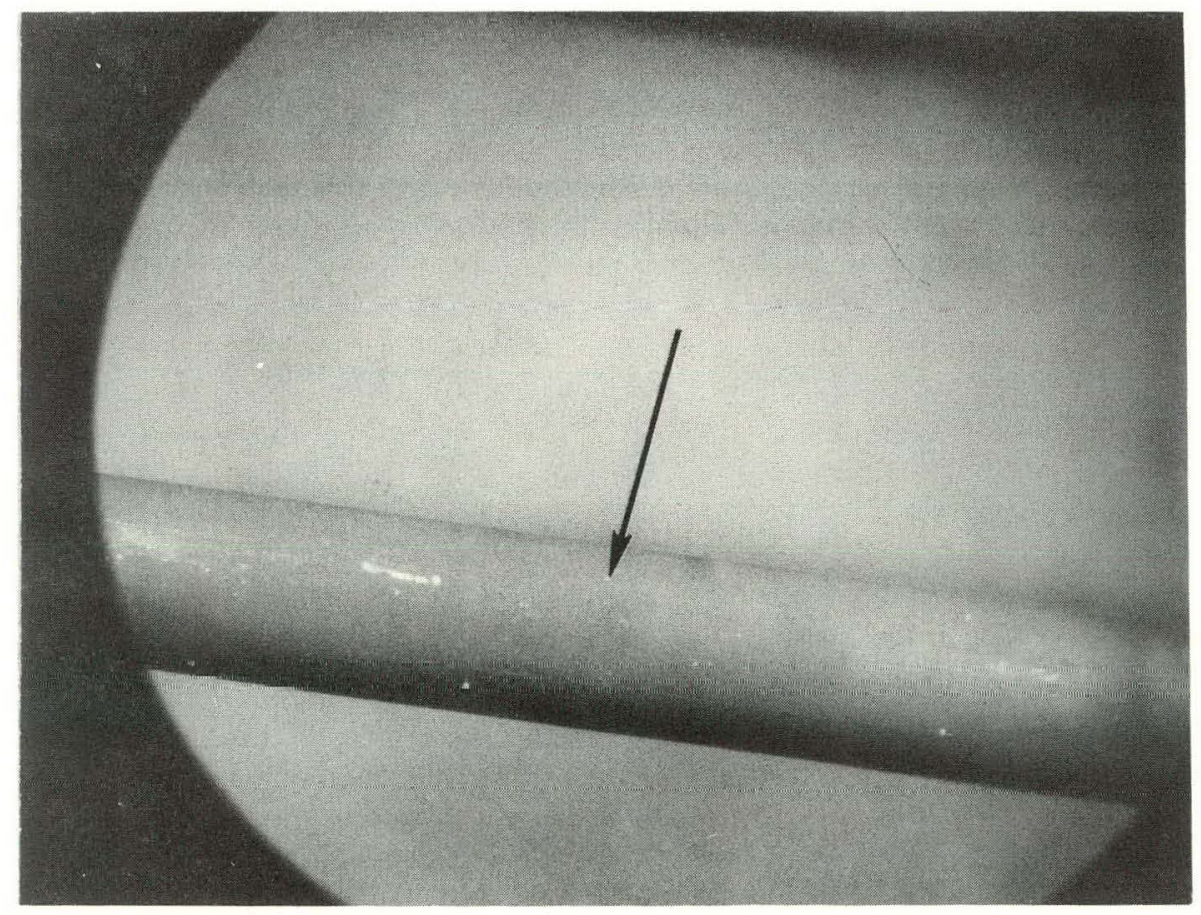

Figure 54. Group of Fine Cracks $92.7 \mathrm{~cm}(36-1 / 2 \mathrm{in.})$ from Short End Plug Shoulder of Rod A4O 


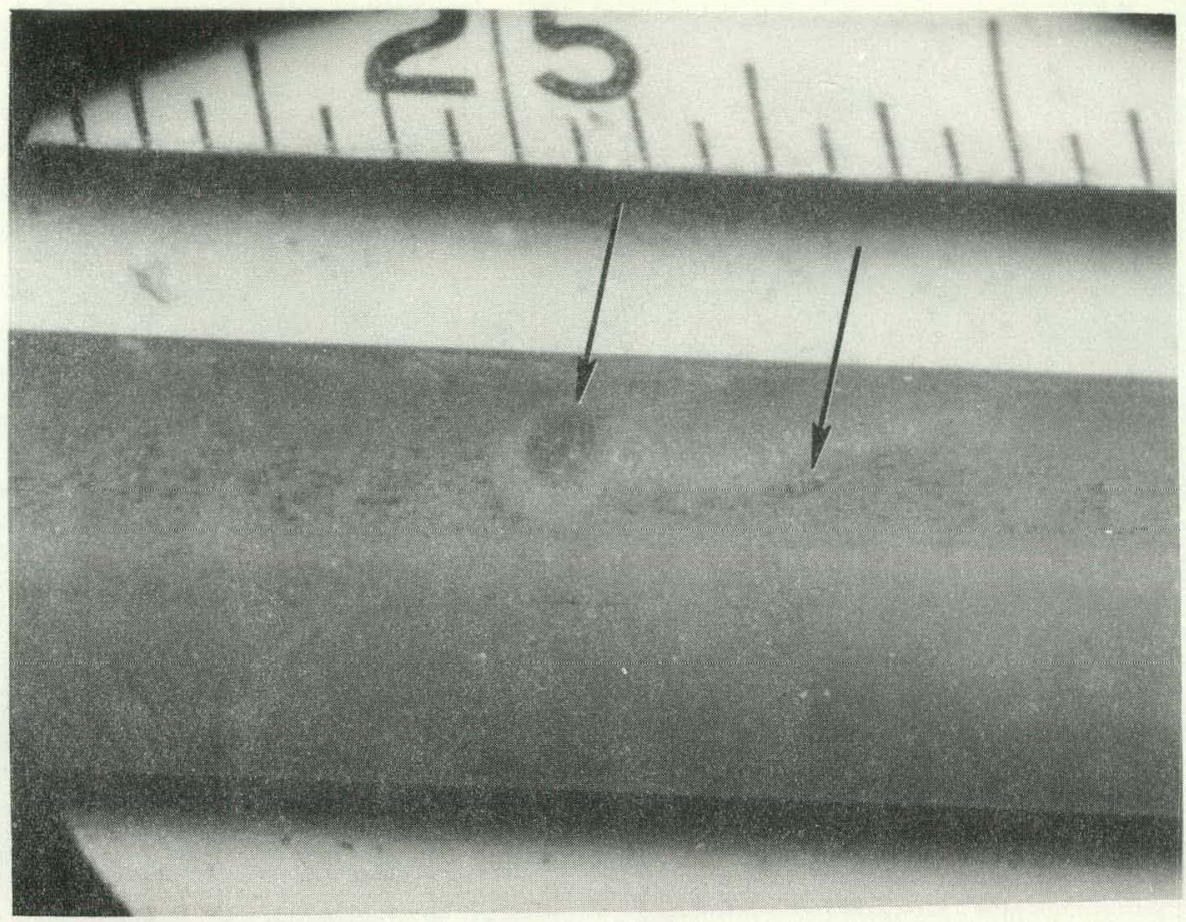

Figure 55. Crack in the Surface of Rod A43 Near Spacer Spring Contact Point $3.8 \mathrm{~cm}(1-1 / 2 \mathrm{in}$.) from Short End Plug

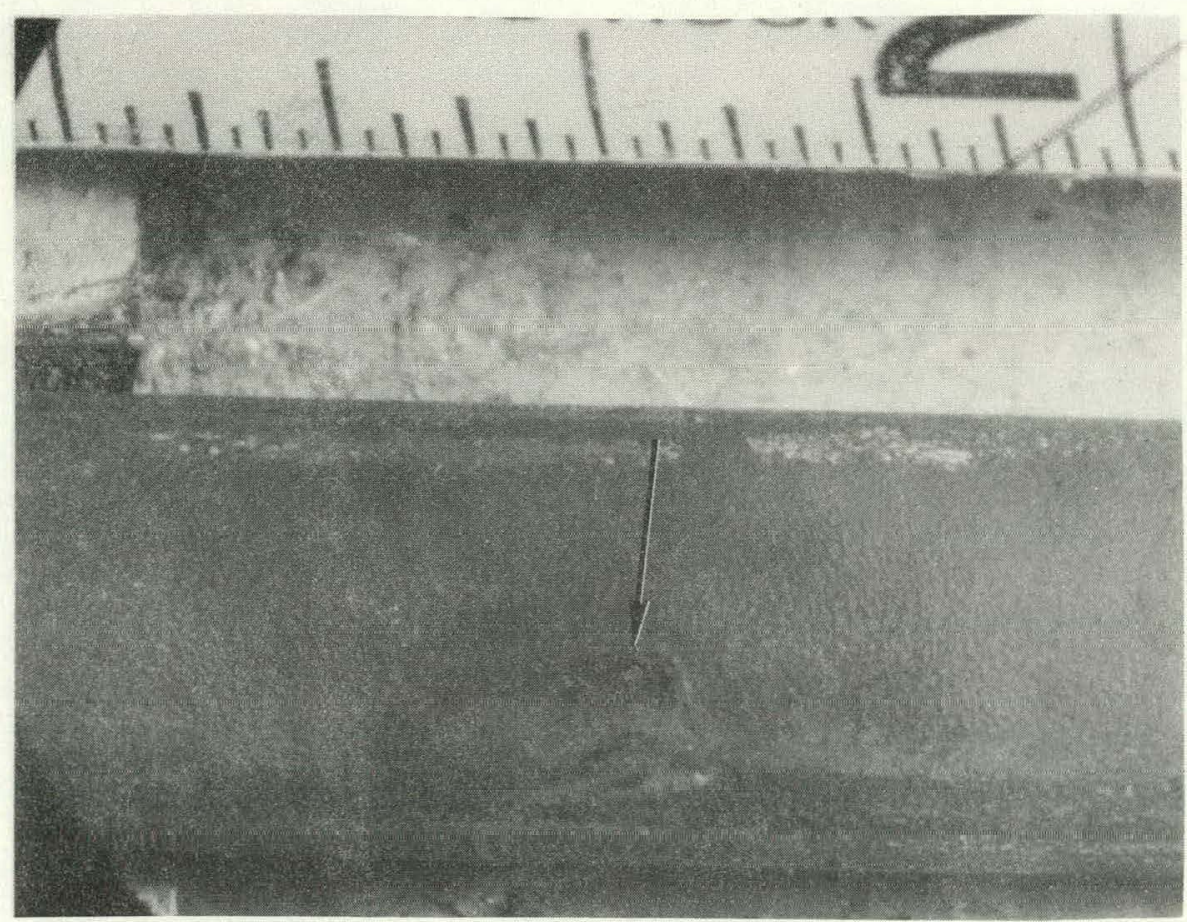

Figure 56. Small Pit or Gouge and Discolored Area Located about $64 \mathrm{~cm}$ (25 in.) from Short End Plug of Rod A38 


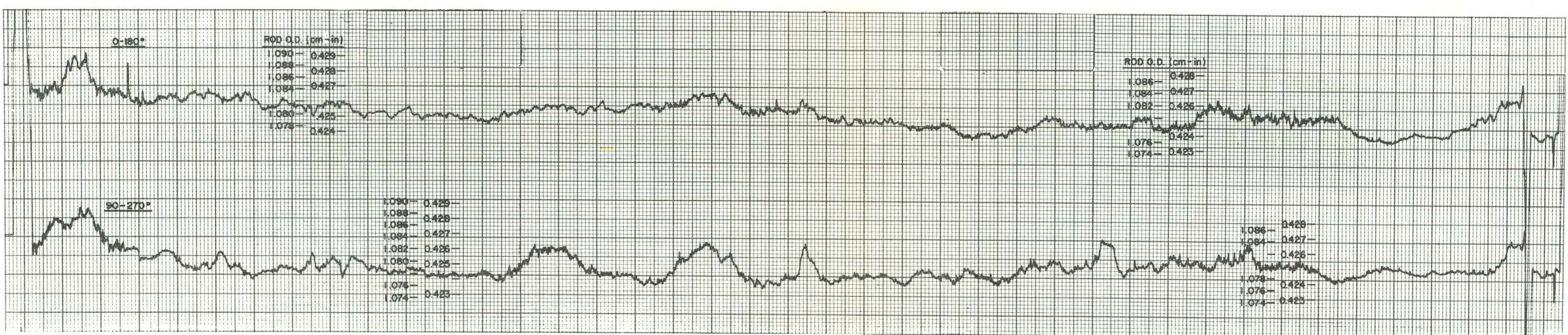
$\begin{array}{lllllllllllllllllllllllllllllllllllllllllllllllllllllll}1 & 1 & 1 & 1 & 1 & 1 & 1 & 1 & 1 & 1 & 1 & 1 & 1 & 1 & 1 & 1 & 1 & 1 & 1 & 1 & 1 & 1 & 1 & 1 & 1 & 1 & 1 & 1 & 1 & 1 & 1 & 1 & 1 & 1 & 1 & 1 & 1 & 1 & 1 & 1 & 1 & 1 & 1 & 1 & 1 & 1 & 1 & 1 & 1 & 1 & 1 & 1 & 1 \\ 0 & 2 & 4 & 6 & 8 & 10 & 12 & 14 & 16 & 18 & 20 & 22 & 24 & 26 & 28 & 30 & 32 & 34 & 36 & 38 & 40 & 42 & 44 & 46 & 48 & 50 & 52 & 54 & 56 & 58 & 60 & 62 & 64 & 66 & 69 & 70 & 72 & 74 & 76 & 78 & 80 & 82 & 84 & 86 & 88 & 90 & 92 & 94 & 96 & 98 & 100 & 102 & 104 & \end{array}$ $\begin{array}{lllllllllllllllllllllllllllllllllllllllllllll}1 & 1 & 1 & 1 & 1 & 1 & 1 & 1 & 1 & 1 & 1 & 1 & 1 & 1 & 1 & 1 & 1 & 1 & 1 & 1 & 1 & 1 & 1 & 1 & 1 & 1 & 1 & 1 & 1 & 1 & 1 & 1 & 1 & 1 & 1 & 1 & 1 & 1 & 1 & 1 & 1 & 1 \\ 0 & 1 & 2 & 3 & 4 & 5 & 6 & 7 & 8 & 9 & 10 & 11 & 12 & 13 & 14 & 15 & 16 & 17 & 18 & 19 & 20 & 21 & 22 & 23 & 24 & 25 & 26 & 27 & 28 & 29 & 30 & 31 & 32 & 33 & 34 & 35 & 36 & 37 & 38 & 39 & 40 & 41\end{array}$ DISTANCE FROM SHORT END PLUG SHOULDER [cm (in.)]

PRE-IRRADIATION ROD DIAMETER AT THREE AXIAL LOCATIONS [cm(in.)] 
trough is about $0.0035 \mathrm{~cm}(0.0014$ in.). Comparing the profiles with the neutrographs showed a reasonably good correspondence between the peak locations and pellet interfaces. Although at least some of the surface discolorations observed may have been due to differences in crud deposition associated with variations in diameter, these variations did not appear to be indicative of a defective rod.

The 90 - 270-degree profile of this rod also shows peaks at $35 \mathrm{~cm}$ (14 in.), $45 \mathrm{~cm}$ (18 in.), $52 \mathrm{~cm}(20.5 \mathrm{in}$.), and $72 \mathrm{~cm}(28.5 \mathrm{in}$.) from the short end plug shoulder. The peaks at $35 \mathrm{~cm}$ and $52 \mathrm{~cm}$ are typical of those frequently seen on other rods at subassembly and VBWR spacer locations. The other two peaks, however, are more unusual. Although there was some variation in surface roughness along the length, nothing specific was noted during the visual examinations or on the neutrographs that would give rise to these peaks. It is possible that, for some unknown reason, the crud deposition and/or cladding corrosion was unusually heavy in these regions.

\subsubsection{Length}

\subsection{Procedure and Scope}

The distance between the two end plug shoulders (i.e., the overall rod length) was measured on each of the ten rods removed after two cycles of operation in Dresden and on twelve rods that operated four cycles. The lengths of the rods in the initial group were measured to $\pm 0.04 \mathrm{~cm}( \pm 1 / 64 \mathrm{in.})$ with a steel rule. The lengths of those in the second group were measured to $\pm 0.013 \mathrm{~cm}( \pm 0.005 \mathrm{in}$.) with dial indicator calipers. The dial indicator was zeroed with a reference rod of a length similar to the lengths of the SA-1 fuel rods. The as-fabricated lengths. of the SA-1 rods, which were purposely made on a production line basis, were recorded as being accurate to $\pm 0.08 \mathrm{~cm}( \pm 1 / 32 \mathrm{in}$.$) . The$ fabrication records indicate that all rods were $103.35 \mathrm{~cm}(40-11 / 16 \mathrm{in}$.$) long.$

The fast fluence exposures of the rods in both groups were estimated on the basis of analyses of cladding and fuel samples from rods that operated to the end of Cycle No. 6. These analyses are described in Section 5.1.10.

\subsection{Results}

The results of the above measurements are given in Table 8. The lengths of the rods that were removed from SA-1 at the end of Cycle No. 4 showed increases over the pre-irradiation lengths of 0.08 to $0.24 \mathrm{~cm} \mathrm{(1/32} \mathrm{to} 3 / 32 \mathrm{in}$.). The average increase in length was $0.16 \mathrm{~cm}$ (1/16 in.) or 0.16 percent, based on the 100.23-cm (39.462-in.) nominal tube length. The increases in length shown by the rods that operated to the end of Cycle No. 6 ranged from 0.15 to $0.33 \mathrm{~cm}$ $(0.06$ to $0.13 \mathrm{in.}$ ) and averaged $0.23 \mathrm{~cm}(0.09 \mathrm{in}$.$) . The estimated rod-average fast fluence exposures (E>1 \mathrm{MeV})$ were approximately $4 \times 10^{21}$ nvt for the first group of rods and $5.5 \times 10^{21}$ to $6 \times 10^{21}$ nvt for the second. Length measurements made under the Fuel Cycle Program on a Zircaloy-2-clad rod and on a Zircaloy-4-clad rod at the end of VBWR irradiation indicated respective increases of $0.13 \mathrm{~cm}(0.05 \mathrm{in}$.$) and 0.10 \mathrm{~cm}(0.04 \mathrm{in}$.$) relative to the as-$ fabricated dimensions. The rods were estimated to have been exposed to fast fluences of about $1 \times 10^{21}$ and $0.6 \times 10^{21}$ nvt. The accuracy of the length increase reported for any individual rod is, of course, in doubt because of the uncertainties in the pre-irradiation data.

In addition, a feature of the SA-1 fuel rod design may have had an effect on some of the post-irradiation lengths. The fission gas plenum of each rod contains a stainless steel support tube with a $0.076 \mathrm{~cm}(0.030 \mathrm{in}$.) thick wall. With a support tube $4.42 \mathrm{~cm}$ (1.74 in.) long, the design length of fuel column (93.98 cm or $37 \mathrm{in}$.) plus support tube plus interjacent Zircaloy wafer is only $0.41 \mathrm{~cm}(0.16 \mathrm{in}$.) less than the design distance between the internal faces of the two end plugs. If the tube is $4.83 \mathrm{~cm}(1.90 \mathrm{in}$.$) long these two dimensions are equal. Since the axial thermal expansion of the fuel$ column and support tube was greater than that of the cladding, it is very likely that "interference," which would have applied an axial tensile stress to the tubing, occurred in some rods at times during operation.

The lengths of the fuel columns were measured during rod fabrication, ${ }^{2}$ and the lengths of the plenum support tubes in most of the rods listed in Table 8 were measured either directly or from neutrographs after irradiation. By applying these lengths to the nominal design dimensions for the plug-to-plug distance, the unirradiated room temperature clearance was calculated for each rod (Table 9). For comparison, the total axial gaps after irradiation were estimated for those rods that had been neutrographed. These total gap values, in general, are probably on the low side since only the relatively larger individual gaps were taken into account. However, in the case of rod B97, the total gap shown by the neutrograph is larger than the calculated gap.

The magnitude of interference was calculated for each rod during operation at its estimated maximum heat flux. The values range from negative quantities (clearances) to nearly $0.5 \mathrm{~cm}(0.2 \mathrm{in}$.), which amounts to 0.5 percent of the tube length. The length increases and interference values do not show a clear relationship. For example, three rods that operated to the end of Cycle No. 6 and showed an average increase in length for that group $(0.23 \mathrm{~cm}$ or 0.09 in.) had 
GEAP-10371

Table 8

POST-IRRADIATION ROD LENGTH

Estimated

Rod

Number

A4

A13

A28

A41

A45

A46

B70

B76

B88

B97

A1.

A7

A9

A11

A22

A37

A40

A43

A49

B50

B52

B62
Fast Fluence Exposure of Cladding ( $E>1 \mathrm{MeV}$ )

nvt $\times 10^{-21}$

\author{
Post-Irradiation \\ Length \\ (cm [in.])
}

Initial Phase

$103.46(40-47 / 64)$
$103.46(40-47 / 64)$
$103.43(40-23 / 32)$
$103.50(40-3 / 4)$
$103.50(40-3 / 4)$
$103.50(40-3 / 4)$
$103.50(40-3 / 4)$
$103.55(40-49 / 64)$
$103.58(40-25 / 32)$
$103.50(40-3 / 4)$

Final Phase

$103.49(40.745)$

103.54 (40.7.65)

$103.61(40.790)$

103.59 (40.785)

$103.52(40.755)$

103.59 (40.785)

103.57 (40.775)

$103.61(40.790)$

$103.57(40.775)$

$103.50(40.750)$

103.57 (40.775)

103.67 (40.815)

\section{Pre-Irradiation Length \\ (cm [in.])}

Change

(cm [in.])

\begin{tabular}{|c|c|c|c|}
\hline \multirow{10}{*}{\multicolumn{3}{|c|}{$103.35(40-11 / 16)$}} & $+0.12(3 / 64)$ \\
\hline & & & $+0.12(3 / 64)$ \\
\hline & & & $+0.08(1 / 32)$ \\
\hline & & & $+0.16(1 / 16)$ \\
\hline & & & $+0.16(1 / 16)$ \\
\hline & & & $+0.16(1 / 16)$ \\
\hline & & & $+0.16(1 / 16)$ \\
\hline & & & $+0.20(5 / 64)$ \\
\hline & & & $+0.24(3 / 32)$ \\
\hline & & & $+0.16(1 / 16)$ \\
\hline
\end{tabular}

$+0.15(0.06)$

+0.20 (0.08)

+0.25 (0.10)

$+0.25(0.10)$

$+0.18(0.07)$

$+0.25(0.10)$

$+0.23(0.09)$

$+0.25(0.10)$

+0.23 (0.09)

$+0.15(0.06)$

$+0.23(0.09)$

$+0.33(0.13)$ 
Table 9

CALCULATED AXIAL INTERFERENCE IN SA-1 RODS

Rod Number

A4

A13

A28

A41

A45

A46

B70

B76

B88

B97

A1

A7

A9

A11

A22

A37

A40

A43

A49

B50

B52

B62

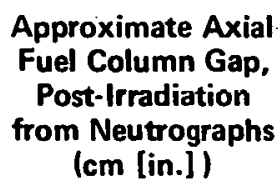

Approximate Axial Fuel Column Gap, Post-Irradiation from Neutrographs (cm [in.])

Fuel Column Gap. Pre-Irradiation at Room Temperature (cm [in.])

(a)

$0.33(0.13)$

$0.41(0.16)$

$0.48(0.19)$

$0.33(0.13)(\mathrm{b})$

$0.33(0.13)(b)$

$0.25(0.10)$

$0.48(0.19)$

$0.33(0.13)(b)$

$0.00(0.00)$

$0.64(0.25)$

$0.25(0.10)$

$0.41(0.16)$

$0.25(0.10)$

(a)

$0.48(0.19)$

$0.64(0.25)$

$0.33(0.13)$

$0.08(0.03)$

$0.33(0.13)$

$0.25(0.10)$

$0.25(0.10)$
Interference at Maximum Rod-Average Heat Flux (cm [in.])

\begin{tabular}{|c|c|}
\hline $0.30(0.12)$ & $+0.30(0.12)$ \\
\hline $0.10-0.20(0.04-0.08)$ & $+0.10(0.04)$ \\
\hline \multirow[t]{3}{*}{$0.41(0.16)$} & $+0.15\{0.06)$ \\
\hline & $+0.15(0.06)$ \\
\hline & $+0.15(0.06)$ \\
\hline $0.20(0.08)$ & $+0.23(0.09)$ \\
\hline \multirow[t]{2}{*}{$0.30(0.12)$} & $+0.18(0.07)$ \\
\hline & $+0.33(0.13)$ \\
\hline $0.20(0.08)$ & $+0.36(0.14)(c)$ \\
\hline \multirow[t]{2}{*}{$0.51(0.20)$} & $-0.20(0.08)$ \\
\hline & $+0.23(0.09)$ \\
\hline $0.10-0.20(0.04-0.08)$ & $+0.25(0.10)$ \\
\hline \multirow[t]{3}{*}{$0.20(0.08)$} & $+0.41(0.16)$ \\
\hline & $+0.15(0.06)$ \\
\hline & $-0.15(0.06)$ \\
\hline \multirow[t]{3}{*}{$0.30(0.12)$} & $+0.15(0.06)$ \\
\hline & $+0.48(0.19)$ \\
\hline & $+0.10(0.04)$ \\
\hline \multirow[t]{2}{*}{$0.10(0.04)$} & $+0.15(0.06)$ \\
\hline & $+0.36(0.14)$ \\
\hline
\end{tabular}

\footnotetext{
(a) Not determined.

(b) Assumed to have $4.42 \mathrm{~cm}$ (1.74 in.) plenum support tube since fuel column was greater than $93.98 \mathrm{~cm}$ ( 37 in.) long.

(c) Value based on axlal gaj shown by neutrograph.
} 
calculated interferences ranging from $-0.15 \mathrm{~cm}(-0.06 \mathrm{in.})$ to $+0.48 \mathrm{~cm}(+0.19 \mathrm{in}$.$) . The interference values in Table 9$ do not take into account the possible additional effect of $\mathrm{UO}_{2}$ swelling from fission products, although any contribution to axial interference by an increasing volume of fission products would have been counteracted to some extent by the rather continuous decrease in power at which the rods operated in Dresden.

\subsubsection{Bow}

\subsection{Procedure and Scope}

The maximum deviation from straightness, or bow, was measured on the ten rods that were removed from SA-1 after two cycles of operation. The measurements were made by supporting the rod at the ends in a horizontal position and determining the largest positive and negative deflections with a dial indicator as the rod was rotated.

\subsection{Resuits}

The maximum bow is given for each of the ten rods in Table 10. The measurements range from 0.020 to $0.056 \mathrm{~cm}(0.008$ to $0.022 \mathrm{in}$.) and have an average value of $0.033 \mathrm{~cm}(0.013 \mathrm{in}$.$) .$

\subsubsection{Gas Analysis and Fission Gas Release (D. E. Rey, M. M. Csicsery)}

\subsubsection{Procedure and Scope}

A gas sample was taken from a fuel rod by vacuum sealing a drilling fixture to the rod, drilling a hole into the plenum region, and allowing the released gas to expand into the pre-evacuated gas measurement and sampling system. Total gas volumes in each rod were determined by measuring the gas system equilibrium pressure after the rod puncture with a Zimmerli vacuum gauge, and calculating the gas volume (at STP) from the measured pressure and pre-calibrated vacuum system-sample container volumes.

To measure the internal void volume, the drilled and evacuated rod was back purged with argon to a positive pressure in the rod. The rod was allowed to achieve equilibrium at atmospheric pressure. It was rotated 180 degrees from the original position, and the drilling fixture was resealed to it. The system was again evacuated, and the rod was redrilled. The void volume of the rod was then calculated from the initial rod pressure, i.e., atmospheric, and the volume and equilibrium pressure of the system.

Precision aliquots of the gas samples were analyzed by gamma counting, gas chromatography, and mass spectrometry.

With the counting technique, the $0.52 \mathrm{MeV}$ gamma rays associated with $\mathrm{Kr}-85$ decay were counted, and the $\mathrm{Kr}-85$ concentration in terms of atoms $/ \mathrm{cm}^{3}$ was calculated. The total number of $\mathrm{Kr}-85$ atoms collected from a fuel rod was then compared with a calculated value of the total atoms of Kr-85 generated during the fuel's exposure to gain an indication of the total fission gas release percentage.

Total composition was determined by gas chromatography techniques. In analyses carried out during the initial phase of the program, the following combinations of column material and carrier gas were employed to determine the amounts of the various components:

(1) Helium carrier gas-Molecular Sieve column

$$
\mathrm{O}_{2} / \mathrm{Ar}, \mathrm{N}_{2}, \mathrm{CO}, \mathrm{CH}_{4}, \mathrm{Kr} \text {, and } \mathrm{Xe}
$$

(2) Argon carrier gas-Molecular Sieve column

$$
\mathrm{He}, \mathrm{H}_{2} \text { and } \mathrm{O}_{2}
$$

(3) Helium carrier gas-Silica gel column

$$
\mathrm{CO}_{2} \text { ethane, ethylene, and acetylene }
$$

In the final phase of the program, most of the components were determined from scans obtained by temperature programming a $6.1-\mathrm{m}(20-\mathrm{ft})$ Porapak $\mathrm{QS}$ column from $-60^{\circ} \mathrm{C}$ to $+75^{\circ} \mathrm{C}$, using helium as carrier gas. A molecular sieve column with argon carrier gas was used to analyze for $\mathrm{He}$ and $\mathrm{H}_{2}$.

The isotopic abundancies of $X e$ and $K r$ and the ratio of $X e$ to $X e+K r$, as well as a qualitative analysis of total composition, were determined with a time-of-flight mass spectrometer.

.The free gas was collected from five fuel rods that operated to the end of Cycle No. 4 and nine rods that operated to the end of Cycle No. 6. The gas from each of the first five rods and that from selected rods in the second group were analyzed by the different techniques. The void volumes of the first five rods also were determined. Rods A1, A9, A1.1, 
Table 10

ROD BOW

\begin{tabular}{|c|c|c|}
\hline $\begin{array}{l}\text { Rod } \\
\text { Number }\end{array}$ & $\begin{array}{l}\text { Maximum Deviation } \\
\text { from Straightness } \\
\text { (cm [in.]) }\end{array}$ & $\begin{array}{l}\text { Axial Location of } \\
\text { Maximum Deviation } \\
\text { (cm [in.] from Short } \\
\text { End Plug Shoulder) }\end{array}$ \\
\hline A4 & $0.028(0.011)$ & $84(33)$ \\
\hline$A 13$ & $0.025(0.010)$ & $46(18)$ \\
\hline A28 & $0.020(0.008)$ & $84(33)$ \\
\hline A41 & $0.051(0.020)$ & $38(15)$ \\
\hline A45 & $0.033(0.013)$ & $23-30(9-12)$ \\
\hline A46 & $0.020(0.008)$ & $23(9)$ \\
\hline B70 & $0.056(0.022)$ & $53(21)$ \\
\hline B76 & $0.023(0.009)$ & $53(21)$ \\
\hline B88 & $0.038(0.015)$ & $46(18)$ \\
\hline B97 & $0.041(0.016)$ & $.53-61(21-24)$ \\
\hline
\end{tabular}

A18, A35, and B52 from the second group contained what were believed to be possible defects based on visual examination of heir external surfaces, neutron radiographic examination, or irregularities in a diameter protile, and the gas collection operation afforded an additional method of determining whether or not these rods were sound.

\subsubsection{Results}

No difficulties urere enrouıteren in maintaining a vasuum on any of tho rods; whioh foot tends to indicatc that they contained no full-wall cladding penetrations. The total free gas contents of the different rods ranged from 4.7 to $12.5 \mathrm{~cm}^{3}\left(0.29\right.$ to 0.76 in. $\left.^{3}\right)$, and the void volumes of the five rods on which these measurements were made were between 3.4 and $3.8 \mathrm{~cm}^{3}\left(0.21\right.$ and $\left.0.23 \mathrm{in.}^{3}\right)$.

The compositions of the eight samples analyzed by chromatography, in general, appear fairly normat (Table 11 ). Some of the rods in the initial group show rather high $\mathrm{N}_{2}$ and $\mathrm{O}_{2}$ contents, which may have resulted from leakage of air into the system. The normal compositions of the samples from rods $A 9$ and $A 11$ provide additional evidence that these rods were sound. The compositions of the gas from the five rods removed after two cycles of Dresden operation and from rods $\mathrm{A} 9$ and $\mathrm{B} 90$ of the second group also were qualitatively determined by mass spectrometric analysis. Additional constituents detected in the earlier samples were $\mathrm{Ar}$ in all five samples, $\mathrm{CO}_{2}$ in samples froms rods $\mathrm{A} 41$ and $B 70$, and $\mathrm{H}_{2} \mathrm{O}$ in all samples except that from rod $A$ 13. Analyses for $\mathrm{CO}_{2}$ were performed by chromatography only on the samples from $A 13$ and $A 46$ in the initial phase of the prograrn. No species were detected in the samples from rods $A 9$ and $B 90$ in addition to those listed in Table 11.

The percentage of fission-generated $\mathrm{Kr}-85$ that was released from the $\mathrm{UO}_{2}$ matrix to the internal void volume is given for ten rods in Table 11. The values range from 0.06 to 0.93 percent. On the average, there is little difference between the two groups of rods with respect to relcasc percentages. The highest percentage was shown by rod $A 41$ in the lower exposure group. Rods A1, A18, A35, and B52 were punctured and evacuated primarily as a means of determining their integrity. However, by comparing the total volumes of gas contained in these rods with the amounts of gas contained in rods A7, A9, A11, A37, and B90, a reasonably accurate estimate of fission gas release can be obtained. One would expect the release values for rods $A 1, A 35$, and $B 52$ to be about the same as that for rod $\wedge 7$ and the release value for rod $A 18$ to be between those for rods $A 9$ and $A 11$.

The rods that operated at the relatively higher peak heat fluxes generally show greater than average gas release values: however. most of these same rods alsn rnntained pellets nf medium tn lnum rensity The pellets in rọds $\Delta . \mathbf{1}, \Delta .7$, A35, A46, B52, and B70 (average density 95.1 to 96.0 percent of theoretical) were $\sim 1.5 \mathrm{~cm}(0.6 \mathrm{in}$.) long, while those in the other rods (averaye density 93.8 to 94.8 percent of theoretical) were $\sim 2.3 \mathrm{~cm}(0.9 \mathrm{in}$.) long.

The isotopic compositions of the krypton and xenon released from seven rods and the $\mathrm{Xe} /(\mathrm{Xe}+\mathrm{Kr})$ ratios, determined by mass spectrometry, are given in Table 12. 
Table 11

GAS COMPOSITION AND RELEASE

\begin{tabular}{|c|c|c|c|c|c|c|c|}
\hline $\begin{array}{l}\text { Fuel Rod } \\
\text { Number }\end{array}$ & $\begin{array}{l}\text { Total U in } \\
\text { Unirradiated } \\
\text { Rod } \\
\text { (gm) }\end{array}$ & $\begin{array}{l}\text { Average } \\
\text { Burnup } \\
\text { Fissions/cm } / \mathrm{cm}^{3} \times 10^{-20} \\
(\mathrm{MWd} / \mathrm{tU})\end{array}$ & 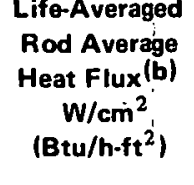 & $\begin{array}{c}\text { Estimated } \\
\text { Peak Heat Flux (b) } \\
\text { W/cm } \\
\left(B+\mathrm{cm}^{2}\right. \\
\left(\mathrm{Btu} / \mathrm{h} \cdot \mathrm{ft}^{2}\right)\end{array}$ & $\begin{array}{l}\mathrm{UO}_{2} \\
\text { Powder } \\
\text { Lot }\end{array}$ & $\begin{array}{l}\text { As-Fabricated } \\
\text { Pellet Density } \\
\text { Percent of } \\
\text { Theoretical }\end{array}$ & $\begin{array}{c}\text { Total Volume of } \\
\text { Gas Collected (ST } \\
\mathrm{cm}^{3} \\
\left(\text { (in. }^{3}\right)\end{array}$ \\
\hline & & & & & & & Initial Phase \\
\hline A13 & 611 & $\begin{array}{c}7.0 \\
(25,600)\end{array}$ & $\begin{array}{r}45.1 \\
(143,000)\end{array}$ & $\begin{array}{c}132 \\
(418,000)\end{array}$ & $\begin{array}{l}\text { JO1DD/ } \\
\text { J02DD }\end{array}$ & 94.4 & $\begin{array}{c}7.7 \\
(0.47)\end{array}$ \\
\hline A41 & 607 & $\begin{array}{c}6.6 \\
(24,000)\end{array}$ & $\begin{array}{c}41.9 \\
(133,000)\end{array}$ & $\begin{array}{c}132 \\
(418,000)\end{array}$ & JO1DD & 94.8 & $\begin{array}{c}9.5 \\
(0.58)\end{array}$ \\
\hline A46 & 619 & $\begin{array}{c}6.0 \\
(22,000)\end{array}$ & $\begin{array}{c}38.8 \\
(123,000)\end{array}$ & $\begin{array}{c}101 \\
(319,000)\end{array}$ & JO5HB & 96.0 & $\begin{array}{c}4.7 \\
(0.29)\end{array}$ \\
\hline B70 & 612 & $\begin{array}{c}5.5 \\
(20,200)\end{array}$ & $\begin{array}{c}35.0 \\
(111,000)\end{array}$ & $\begin{array}{c}111 \\
(351,000)\end{array}$ & ЈОЗНB & 95.1 & $\begin{array}{c}4.7 \\
(0.29)\end{array}$ \\
\hline \multirow[t]{2}{*}{ B76 } & 608 & $\begin{array}{c}6.1(a) \\
(22,400)\end{array}$ & $\begin{array}{c}39.1 \\
(124,000)\end{array}$ & $\begin{array}{c}137 \\
(435,000)\end{array}$ & $\begin{array}{l}\text { JO1DD/ } \\
\text { J02DD }\end{array}$ & 94.4 & $\begin{array}{c}7.1 \\
(0.43)\end{array}$ \\
\hline & & & & & & & Final Phase \\
\hline A1 & 611 & $\begin{array}{c}8.8(\mathrm{a}) \\
(32,200)\end{array}$ & $\begin{array}{c}36.9 \\
(117,000)\end{array}$ & $\begin{array}{c}90 \\
(284,000)\end{array}$ & Јознв. & 95.4 & $\begin{array}{c}5.3 \\
10.321\end{array}$ \\
\hline A7 & 611 & $\begin{array}{c}9.0^{(a)} \\
(32,900)\end{array}$ & $\begin{array}{r}38.8 \\
(123,000)\end{array}$ & $\begin{array}{c}111 \\
(351,000)\end{array}$ & ЈUзн世 & $\overline{9} \overline{5} . \overline{7}$ & $\begin{array}{c}5.9 \\
(0.34)\end{array}$ \\
\hline A.9 & 610 & $\begin{array}{c}8.8 \\
(32,200)\end{array}$ & $\begin{array}{c}37.2 \\
(118,000)\end{array}$ & $\begin{array}{c}137 \\
(435,0000)\end{array}$ & $\begin{array}{l}\text { JO10D/ } \\
\text { J02DD }\end{array}$ & 94.7 & $\begin{array}{c}7.6 \\
10.461\end{array}$ \\
\hline A11 & 605 & $\begin{array}{c}9.1 \\
(33,300)\end{array}$ & $\begin{array}{c}38.2 \\
(121,000)\end{array}$ & $\begin{array}{c}127 \\
(402,000)\end{array}$ & JO1DD & 94.0 & $\begin{array}{c}9.8 \\
(0.60)\end{array}$ \\
\hline A18 & 606 & $\begin{array}{c}8.7 \text { (a) } \\
(31,900)\end{array}$ & $\begin{array}{c}36.6 \\
(116,000)\end{array}$ & $\begin{array}{c}125 \\
(396,000)\end{array}$ & $\begin{array}{l}\text { JO1DD/ } \\
\text { J02DD }\end{array}$ & 94.2 & $\begin{array}{c}8.9 \\
10.541\end{array}$ \\
\hline A35 & 611 & $\begin{array}{c}7.9 \text { (a) } \\
(28,800)\end{array}$ & $\begin{array}{c}33.1 \\
(105.000)\end{array}$ & $\begin{array}{c}103 \\
(328,000)\end{array}$ & ЈозНВ & 95.4 & $\begin{array}{c}5.3 \\
(0.32)\end{array}$ \\
\hline A37 & 603 & $\begin{array}{c}9.3 \\
(33,900)\end{array}$ & $\begin{array}{c}38.8 \\
(123,000)\end{array}$ & $\begin{array}{c}132 \\
(418,000)\end{array}$ & $\begin{array}{c}122360-6 / \\
\text { JO1DD }\end{array}$ & 94.1 & $\begin{array}{l}11.5 \\
10.70)\end{array}$ \\
\hline 852 & 621 & $\begin{array}{c}\mathbf{8 . 2 ( a )} \\
(29,800)\end{array}$ & $\begin{array}{c}34.7 \\
(110.000)\end{array}$ & $\begin{array}{c}86 \\
(272,000)\end{array}$ & JO5HB & 96.0 & $\begin{array}{l}5.1 \\
(0.31)\end{array}$ \\
\hline 890 & 600 & $\begin{array}{c}9.1 \text { (a) } \\
(33,200)\end{array}$ & $\begin{array}{c}37.8 \\
(120,000)\end{array}$ & $\begin{array}{c}132 \\
(418,000)\end{array}$ & $\begin{array}{c}122360-6 / \\
\text { JO1DD }\end{array}$ & 93.8 & $\begin{array}{c}12.5 \\
(0.76)\end{array}$ \\
\hline
\end{tabular}

Rod Void
Volume
$\mathbf{c m}^{\mathbf{3}}$
$\left(i n .^{3}\right)$

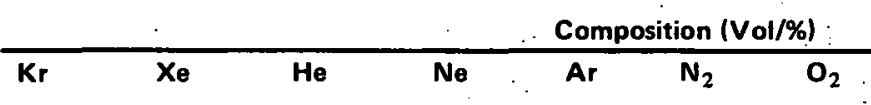

Kr-85
Release

Phase

$\begin{array}{cccccccccccccc}7.7 & 3.8 & 6.49 & 32.7 & 59.9 & \text { NA }(c) & \text { ND } & 2.59 & 1.61 & \text { ND(d) } & \text { ND } & 0.11 & \text { ND } & 0.58 \\ (0.47) & 10.23) & & & & & & & & & & & & \end{array}$

9.5

4.7
$(0.29)$

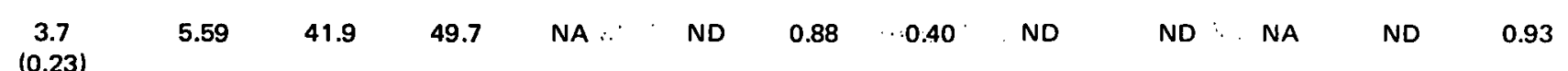

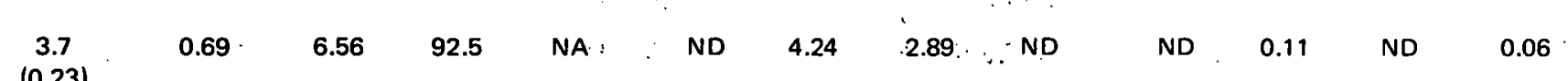

$\begin{array}{ccccccccccccc}3.7 & 0.93 & 6.94 & 91.6 & \text { NA } & \text { ND } & 1.14 & 0.93 & \text { ND } & \text { ND } & \text { NA } & \text { ND } & 0.08\end{array}$

7.1

$\begin{array}{ccccccccccccc}3.4 & 3.93 & 30.8 & 63.7 & \text { NA } & \text { ND } & 0.97 & 0.77 & \text { ND } & \text { ND } & \text { NA } & \text { ND } & 0.50\end{array}$

5.3

3.9
$(0.34)$

7.6
$0.46 i$

9.8
$(0.60)$

8.9

5.3
$0.32)$

11.5
$10.70)$

5.1

12.5
$(0.76)$

\begin{tabular}{|c|c|c|c|c|c|c|c|c|c|c|c|c|}
\hline NA & NA & NA & NA & NA & NA & NA & ${ }^{N A}$ & NA & NA & NA & NA & NA \\
\hline NA & NAA & INA & $P \mathrm{NA}_{\mathrm{A}}$ & NA. & NAA & PJA & NA & $\mathrm{NA} \mathrm{A}^{\circ}$ & $P A A$ & PHA & $\mathrm{PAA}$ & 0.10 \\
\hline NA & 3.70 & $\begin{array}{c}29.31 \\
\vdots\end{array}$ & 65.01 & 0.08 & 0.04 & 0.31 & 0.03 & 0.01 . & 0.03 & .0 .02 & 0.03 & 0.25 \\
\hline NA & 5.07 & 39.98 & 55.56 & 0.05 & 0.03 & 0.24 & 0.02 & 0.01 & 0.02 & 0.02 & 0.02 & 0.43 \\
\hline NA & NA & NA & NA. & NA. & NA. & $\mathrm{NA}$ & NA & NA & NA & NA & NA. & NA \\
\hline NA & $\mathrm{NA}{ }^{\circ}$ & NA & $N A$ & NA & NA & $\mathrm{NA}$ & NA & NA. & NA" & NA & NA & $N A$ \\
\hline NA & NA & NA & NA & NA & -NA & NA & NA & NA. & NA & NA & NA. & 0.51 \\
\hline NA & NA & NA & NA & NA & $\mathrm{NA}$ & NA & NA & NA & NA & NA. & NA & NA \\
\hline NA & 5.74 & 49.10 & 45.16 & 0.05 & 0.02 & 0.40 & 0.02 & 0.01 & 0.27 & 0.01 & 0.02 & 0.69 \\
\hline
\end{tabular}

(a) Values were obtained from $\mathrm{Cs}-137$ gamma scan data.
(b) To obtain linear power in $\mathrm{kW} / \mathrm{ft}$ of rod length, multiply $\mathrm{W} / \mathrm{cm}^{2}$ by 0.103 .

(b) To obtain linear power in kW/ft of rod length, multiply $\mathrm{W} / \mathrm{cm}^{2}$ by 0.103 .
(c) $\mathrm{NA}=$ not analyzed.
(d) $\mathrm{ND}=$ Below the limits of detection $\left\langle 00.05 \%\right.$. Furthermore, $\mathrm{C}_{2} \mathrm{H}_{6}, \mathrm{C}_{2} \mathrm{H}_{4}$, and $\mathrm{C}_{2} \mathrm{H}_{2}$ were not detected in any of the samples. 
Table 12

ISOTÓPIC ANALYSIS OF KRYPTON AND XENON BY MASS SPECTROMETRY

Rod

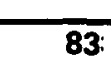

Krypton (Atom Percent) 84
85

86

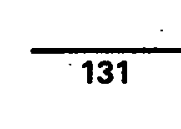

Initial Phase

$\begin{array}{lrlll}\text { A13 } & 9.62 \pm 0.59 & 33.26 \pm 1.08 & 5.15 \pm 0.23 & 51.97 \pm 0.92 \\ \text { A41 } & 9.12 \pm 0.30 & 33.48 \pm 0.70 & 5.54 \pm 0.27 & 51.85 \pm 0.67 \\ \text { A46 } & 12.05 \pm 0.95 & 30.46 \pm 1.18 & 6.68 \pm 0.70 & 50.61 \pm 1.08 \\ \text { B70 } & 11.80 \pm 1.06 & 31.63 \pm 1.58 & 5.47 \pm 0.41 & 51.10 \pm 1.26 \\ \text { B76 } & 10.93 \pm 0.23 & 32.00 \pm 0.74 & 5.60 \pm 0.41 & 51.47 \pm 0.75\end{array}$

\section{$7.43 \pm 0.10$}

$7.37 \pm 0.13$

$8.80 \pm 0.42$

$9.01 \pm 0.22$

$8.18 \pm 0.12$

$21.44 \pm 0.32$

$21.53 \pm 0.10$

$20.66 \pm 0.49$

$20.58 \pm 0.42$

$21.05 \pm 0.12$

Final Phase

$\begin{array}{lll}\text { A9 } & 8.16 \pm 0.26 & 34.69 \pm 0.41\end{array}$

B90 $8.80 \pm 0.24 \quad 34.25 \pm 0.25$
$4.74 \pm 0.12$
$52.41 \pm 0.47$
$4.96 \pm 0.12 \quad 51.99 \pm 0.42$

$6.67 \pm 0.08$

$22.51 \pm 0.12$

$7.21 \pm 0.11$

$22.19 \pm 0.14$
Xenon (Atom Percent)

134

$\begin{array}{ll}29.61 \pm 0.38 & 41.53 \pm 0.31 \\ 29.48 \pm 0.28 & 41.62 \pm 0.32 \\ 28.90 \pm 0.65 & 41.63 \pm 0.67 \\ 28.76 \pm 0.36 & 41.64 \pm 0.36 \\ 29.20 \pm 0.29 & 41.57 \pm 0.18\end{array}$

$29.14 \pm 0.16$

$28.91 \pm 0.14$
$41.68 \pm 0.18$

$41.69 \pm 0.21$
Atoms $X_{e}$

Atoms $\mathrm{Kr}+\mathrm{Xe}$
136 $\ldots$

0.882
0.871
0.893
0.893
0.875

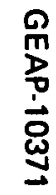




\subsubsection{Metallographic Examination of Rod Sections (R. E. Smith, D. L. Orton)}

\subsubsection{Procedure and Scope}

Sections of the irradiated SA-1 fuel rods were examined during both phases of the examination program. The metallographic procedures used in the final phase examinations were as follows. Fuel rod sections between $\sim 1.3$ and $\sim 2.5 \mathrm{~cm}(\sim 1 / 2$ and $\sim 1$ in.) long were obtained from selected locations by transversely cutting the rods with a silicon carbide cut-off wheel. Care was taken to retain both the axial and radial orientations of a specimen with respect to those of the rod from which it came. The specimens were inserted into hollow Bakelite mounts and vacuum potted with epoxy resin to fill the cracks and voids. The mounted specimens were placed in an oven $\left(49^{\circ} \mathrm{C}\left[120^{\circ} \mathrm{F}\right]\right.$ for 24 hours) to cure the resin. A Buehler automet was employed to grind the specimens on 240-grit silicon carbide papers until a full cross section was obtained. The grinding was then continued on 400-and 600-grit papers. Each specimen was macrographed at $5 \mathrm{X}$. The rough polishing was accomplished in two steps by rotating the specimens on nylon cloths charged with 9- and 6-micrometer diamond compounds using a Buehler Whirlimet polisher. The final polishing was accomplished with 0.5-micrometer diamond compound on a short-nap cloth attached to a Syntron vibratory polisher. Kerosene was used to lubricate the specimens during the grinding and polishing operation. The specimens were cleaned ultrasonically in xylene between each grinding and polishing operation.

Longitudinal specimens were prepared by mounting a full cross-section sample and grinding parallel to its axis until the desired surface was attained.

The specimens were examined at magnifications up to $500 \mathrm{X}$. All specimens were examined in the final polished condition. The thicknesses of the deposited crud (if it had not been removed) and of the $\mathrm{ZrO}_{2}$ on the outside and inside tubing surfaces were measured by means of a filar eyepiece with the specimens in the as-polished condition. In making these measurements on a transverse specimen, the prepared face was divided into octants and an average thickness determined for each octant. Since the external corrosion layers consisted of even films and intermittant thicker patches of oxide, the average thicknesses and proportions of each oxide form were determined for each octant. This allowed the calculation of an overall circumferential-average $\mathrm{ZrO}_{2}$ thickness for a specimen by taking a weighted average of the two forms for each octant, summing these values, and dividing by eight.

The etched $\mathrm{UO}_{2}$ microstructures of selected specimens were examined after examining them in the as-polished condition. The fuel was etched by swabbing with a solution of $10 \mathrm{ml} \mathrm{HNO}-20 \mathrm{ml} \mathrm{H}_{2} \mathrm{O}_{2}(30 \%)-70 \mathrm{ml} \mathrm{H} \mathrm{O}_{2}$ for 45 seconds. The cladding microstructure and hydride distribution were examined in all specimens. To accomplish this the cladding was etched by swabbing for about 20 seconds with a fresh solution of $45 \mathrm{ml} \mathrm{HNO}_{3}-45 \mathrm{ml} \mathrm{H}_{2} \mathrm{O}_{2}(30 \%)$ - $4 \mathrm{ml} \mathrm{HF}$ and viewing the specimens under polarized and normal lighting. Estimates of hydrogen content were made by comparing the specimens with photographic standards.

Some of the procedures used in the initial phase of the program differed to some extent from those just described. In the initial phase:

a) The radial orientation of a specimen was not always maintained.

b) Rough polishing was accomplished in a single step with the 6-micrometer diamond compound.

c) Water was used as the lubricant during grinding and polishing.

d) In measuring the external corrosion layer on a specimen, the relative amounts of even film-and patch-type $\mathrm{ZrO}_{2}$ were not determined for each octant. A statistical method was employed to estimate these proportions for the specimen as a whole.

e) Some of the $\mathrm{UO}_{2}$ was examined in a light (3-second) etched condition in addition to the standard (45-second) etched condition.

Specimens from five of the fuel rods removed from Assembly SA-1 at the end of reactor Cycle No. 4 and from thirteen rods that operated to the end of reactor Cycle No. 6 were examined. Most of the specimens were transverse sections selected to determine the general form and extent of cladding corrosion and zirconium hydride precipitation, and the natures of the cladding and $\mathrm{UO}_{2}$ microstructures. To investigate the condition of the cladding, specimens were obtained from various axial and radial locations in the assembly and, to some extent, from rods clad with tubing from the five different lots. Most specimens were obtained from near the peak burnup locations, which gamma scanning indicated were 25 to $30 \mathrm{~cm}$ (10 to $12 \mathrm{in.)}$ from the short end plug shoulders of both the " $A$ " and " $B$ " rods (see Section 5.3). While there was some variation in the burnup of the $\mathrm{UO}_{2}$ examined, the main emphasis was placed on the relatively higher exposure fuel in each group of rods. The form of the crud was examined, and its thickness was determined over the various sectors of the rod periphery on those specimens on which chemical removal had not previously been carried out. 
Some specimens were selected to further investigate special features noted in other portions of the examination. Examples of these are an area of unusual crud spalling, contact areas between spacer springs and fuel rods, a dark spot on a neutrograph, and regions that showed peaks in rod diameter profile traces.

\subsubsection{Results}

\subsection{Cladding}

Examples of the cladding microstructure are shown in Figures 58 through 61. Typical areas of a transverselyoriented specimen (No. 9957) and of a longitudinally-oriented specimen (No. 9956) from rod A41, which was removed from the assembly after two cycles in Dresden, are shown in the first two figures. There is no marked difference between the two orientations with respect to the distribution and concentration of zirconium hydride platelets. The microstructures of specimens from rods that operated through four cycles appeared very similar to those of the specimens examined during the initial phase of the program. Examples of transverse specimens from the more highly exposed rods are shown in Figures 60 and 61. The cladding grain size was estimated to be between ASTM No. 7 and No. 8, essentially the same as that determined on samples of unirradiated material. In general, very few hydride platelets were observed, but those that were present appeared to be uniformly distributed. Cladding samples adjacent to some of the metallography specimens were analyzed for hydrogen by the hot vacuum extraction technique (see Section 5.1.7). The highest $\mathrm{H}_{2}$ concentrations (129 to $146 \mathrm{ppm}$ ) were shown by samples adjacent to specimen No. A594 from rod A-49 (Figure 61).

Figure 62 indicates the type of corrosion that typically occurred on the outside surfaces of the SA-1 cladding, i.e., the formation of a relatively thin and even $\mathrm{ZrO}_{2}$ film in combination with a pitting attack, represented by the intermittent thicker patches of $\mathrm{ZrO}_{2}$. These oxide patches, which vary in concentration, length, and thickness, are thus responsible for the roughness observed over various portions of the rod surfaces during the visual examinations. $\mathrm{ZrO}_{2}$ thickness measurements made on an octant-by-octant basis on the transverse specimens are given in Table 13. In the case of the initial phase specimens obtained from rods that operated between 1175 and 1218 days in the VBWR and Mresden, the selestion of Octant No, 1 was arbitrary. With the later specimens, from rods that operated between 1767 and 1846 total days, Octant No. 1 represents the 0-degree orientation of each rod, where said orientation was taken as that point on the circumference directed toward the "identification mark" side of its subassembly (see Figure 16). Thus, it was possible to record variations in corrosion behavior about the specimen circumference and attempt to relate these to the orientation of the rod in the subassembly during operation. In addition to those made on transverse specimens, $\mathrm{ZrO}_{2}$ thickness measurements made on two longitudinally-oriented specimens that were examined during the initial phase are given in Table 14.

Among the initial phase specimens, the even film-type oxide typically showed circumferential-average thicknesses between 10 and $12 \mu(0.0004$ and $0.0005 \mathrm{in}$.). The circumferential-average patch-type oxide thicknesses ranged from 26 to $54 \mu$ ( 0.0010 and $0.0021 \mathrm{in}$.) and had a mean value of $40 \mu$ (0.0016 in.).

The estimated propnrtion of rod circumference covered by the patch-type $\mathrm{ZrO}_{2}$ ranged from 0.1 to 0.7 among the different specimens. Among the final phase specimens, the circumferential-average thickness of the even films typically ranged from 8 to $35 \mu$ ( 0.0003 to $0.0014 \mathrm{in}$.) and had a mean value of $15 \mu(0.0006 \mathrm{in}$.). That of the patches ranged from 23 to $110 \mu$ ( 0.0009 to $0.0043 \mathrm{in}$.) and averaged $64 \mu$ ( $0.0025 \mathrm{in}$.). The proportion of the rod circumference covered by the patch-type $\mathrm{ZrO}_{2}$ ranged from $<0.1$ to 0.5 and had an average value of 0.2 . The thickest single patch of oxide observed on any of the specimens was $160 \mu$ (0.0063 in.). It represents a metal penetration of $\sim 20$ percent of the 0.056-cm (0.022-in.) cladding wall.

Abnormally thick, fairly even layers of $\mathrm{ZrO}_{2}$ were observed over 45 to 90 degrees of specimens from rods B50 (A609 and A625), B83 (A611), and B85 (A592), which operated four cycles in Dresden, and from rod A46 (9956), which operated just two cycles. A portion of such a region on specimen No. 611 is shown in Figure 63(b). The corrosion layer on specimen No. A592 reached an octant-average thickness of $119 \mu$ (0.0047 in.).

Most of the other specimens also showed noticeable variations in the form and extent of external corrosion over different portions of their peripheries, particularly those that showed the comparatively greater circumferential-average corrosion. This kind of variation is illustrated in Figures 64 and 65. (However, the specimen chosen as an example is somewhat exceptional in that its overall corrosion was comparatively low.) With these specimens the orientation of maximum overall corrosion was determined largely by the proportion and thickness of patch-type oxide, which, in turn, generally increased together. The orientation of the thickest even film also generally corresponded to that of maximum overall corrosion, but the maximum thickness often was $\leqslant 5 \mu$ greater than the minimum. One rather notable exception was specimen No. A594 from rod A49 where the even film in one octant was $20 \mu$ thick compared to 9 to 


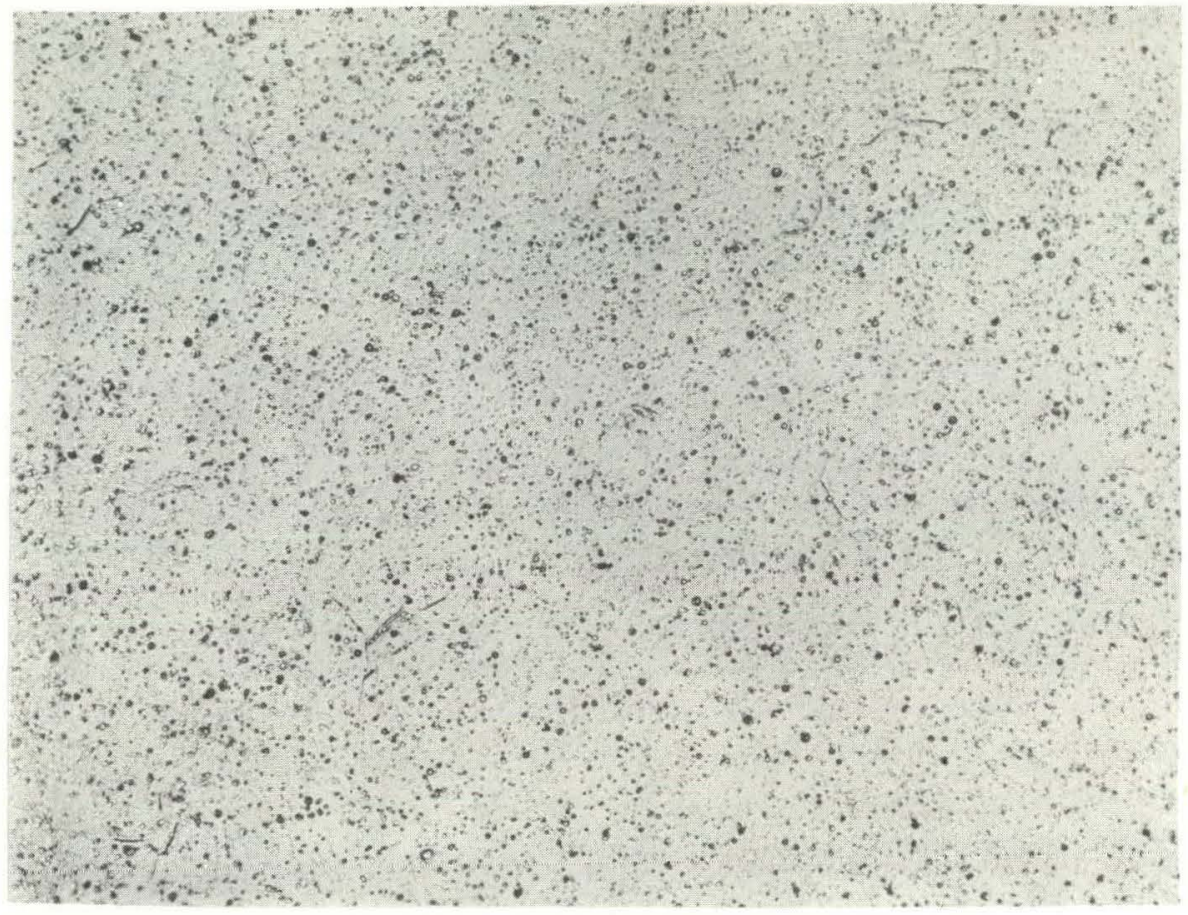

(a) CLADDING ETCHED

$250 x$

PHOTOGRAPHED UNDER NORMAL LIGHT

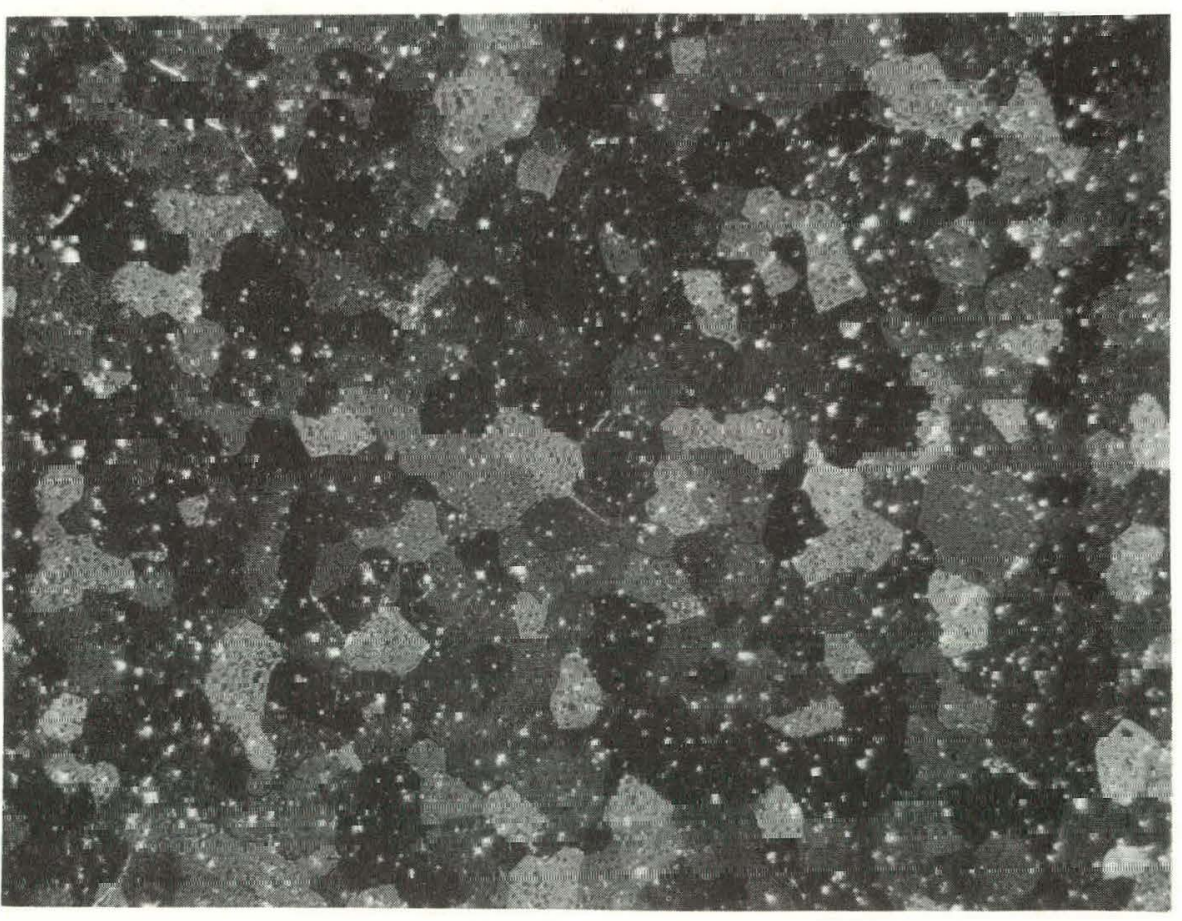

(b) CLADDING ETCHED

$250 x$

PHOTOGRAPHED UNDER POLARIZED LIGHT

Figure 58. Cladding Microstructure of Transversely-Oriented Specimen No. 9957 from Fuel Rod A41 


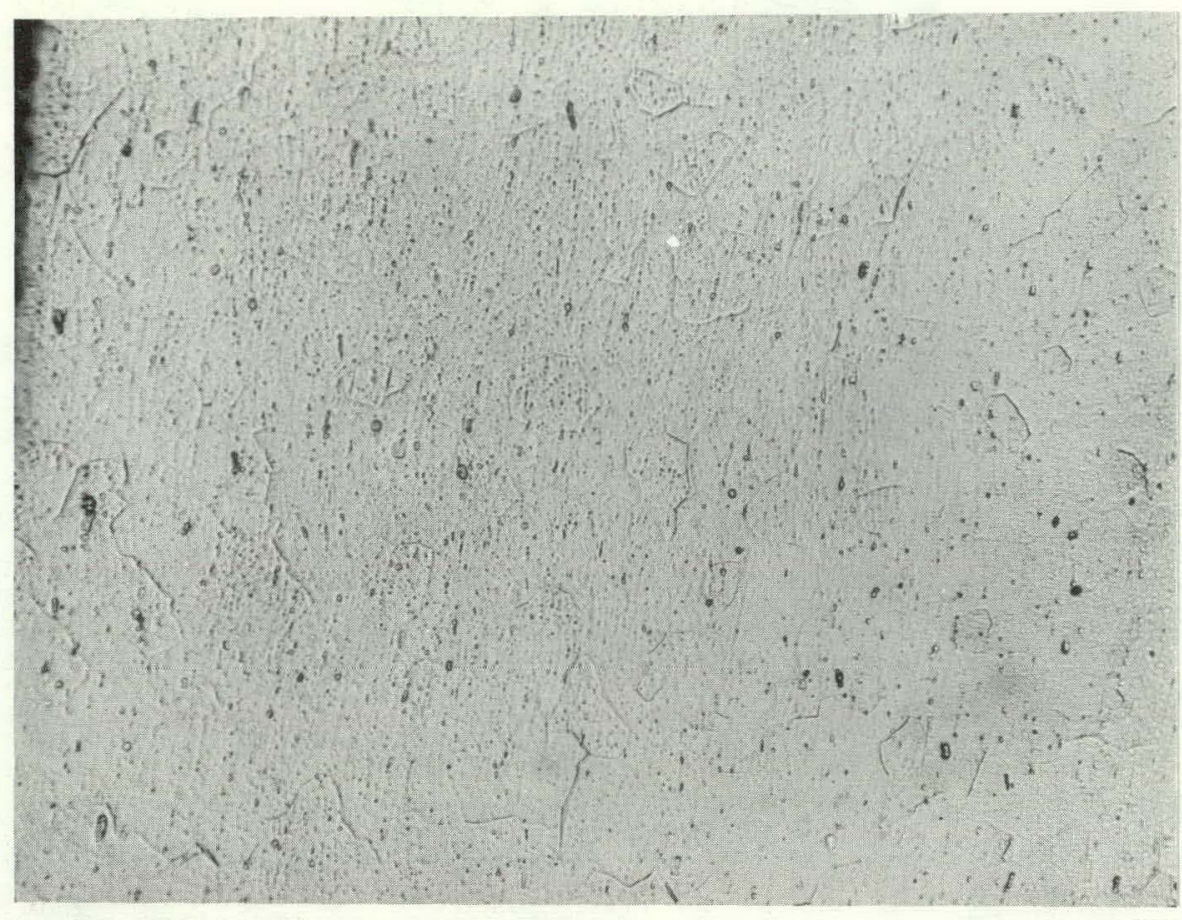

(a) CLADDING ETCHED

$250 X$

PHOTOGRAPHED UNDER NORMAL LIGHT

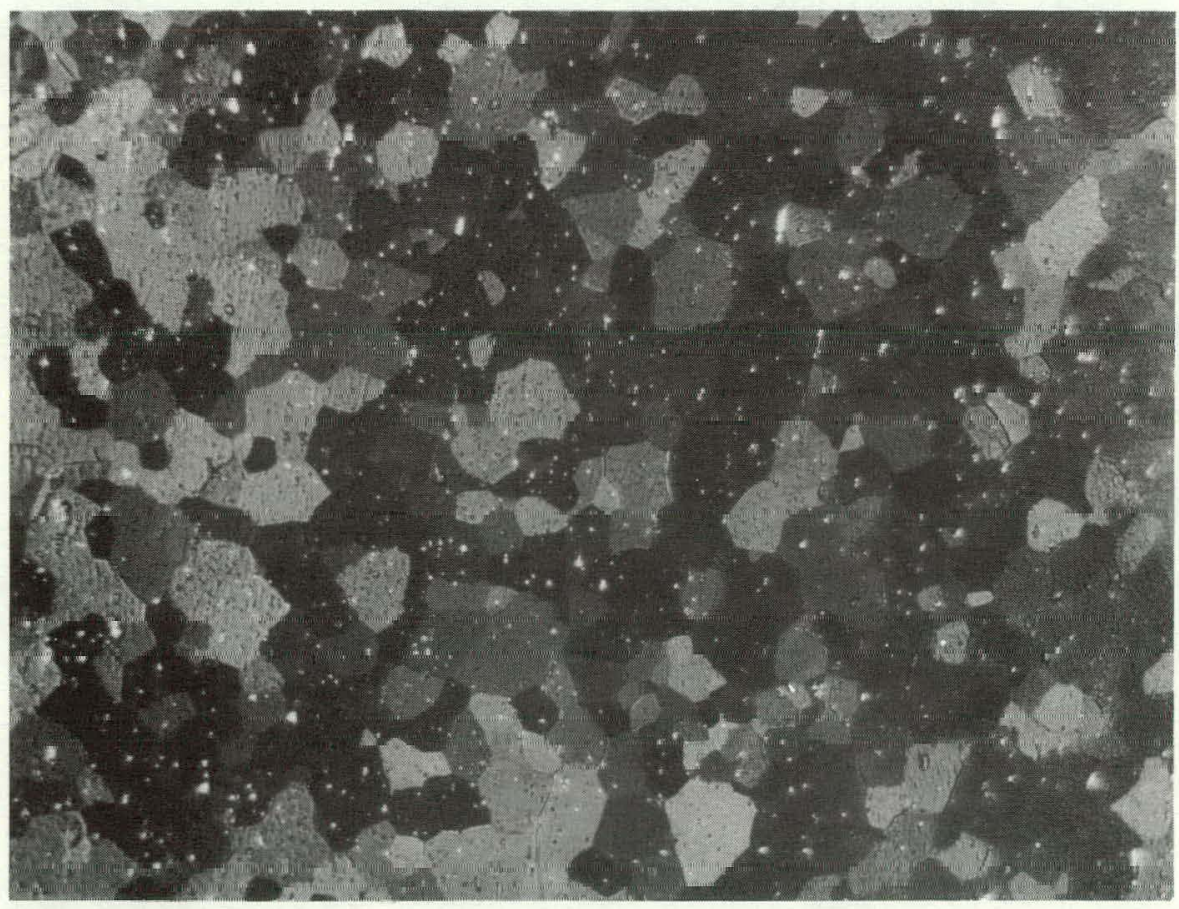

(b) C.I ADMING FTR.HFI

$250 x$

PHOTOGRAPHED UNDER POLARIZED LIGHT

Figure 59. Cladding Microstructure of Longitudinally-Oriented Specimen No. 9956 from Fuel Rod A41. 

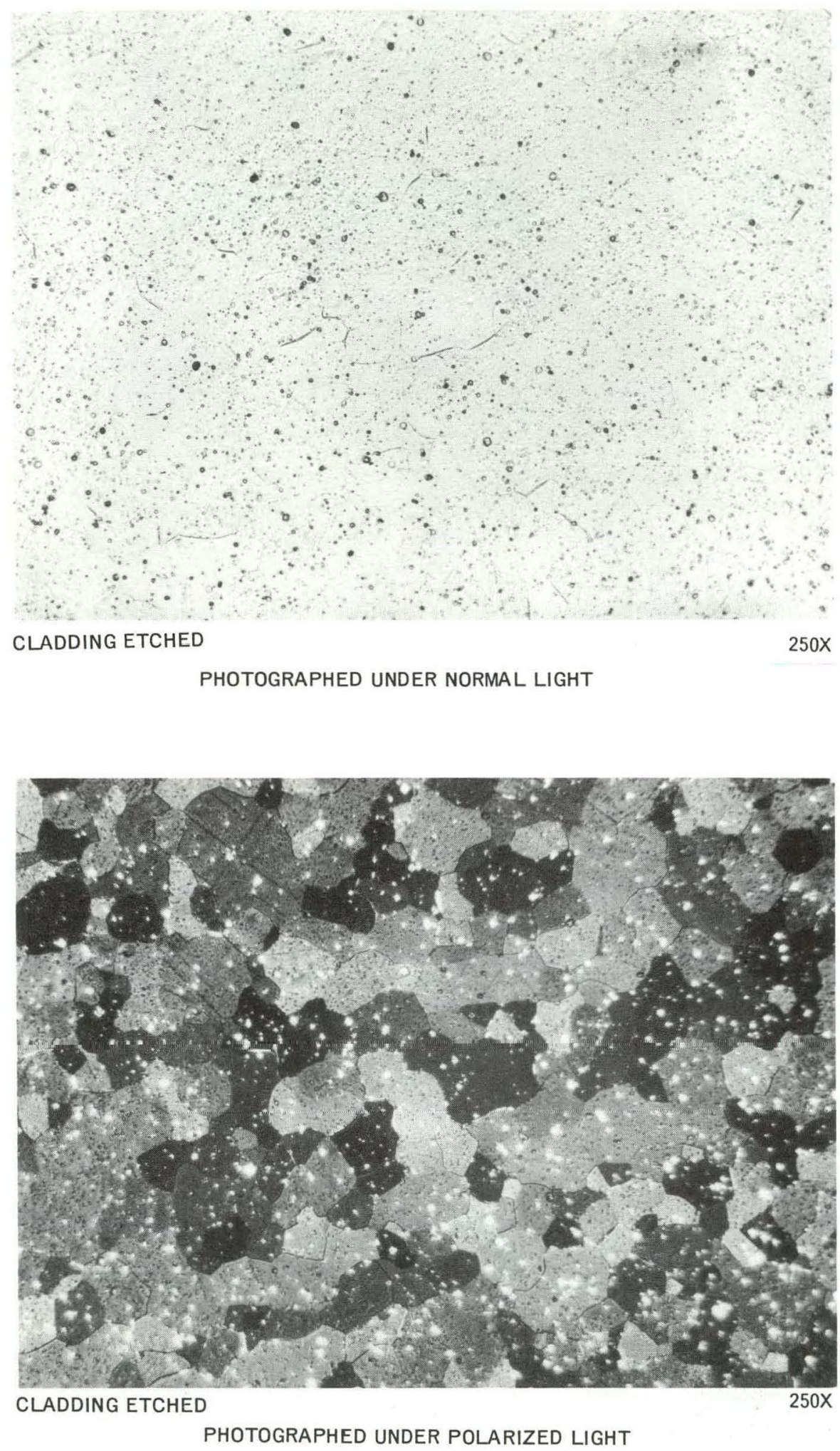

(b)

Figure 60. Cladding Microstructure of Transversely-Oriented Specimen No. A580 from Rod A37 


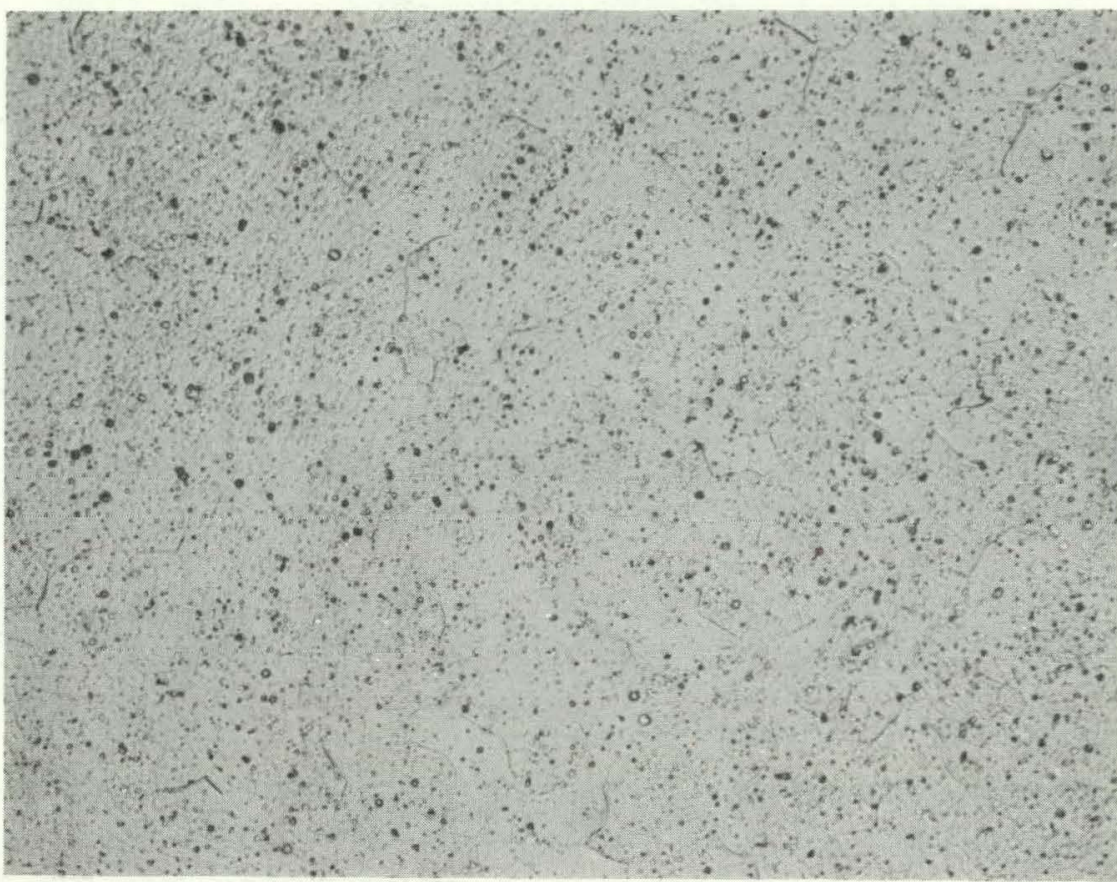

(a) CLADDING ETCHED

$250 x$

PHOTOGRAPHED UNDER NORMAL LIGHT

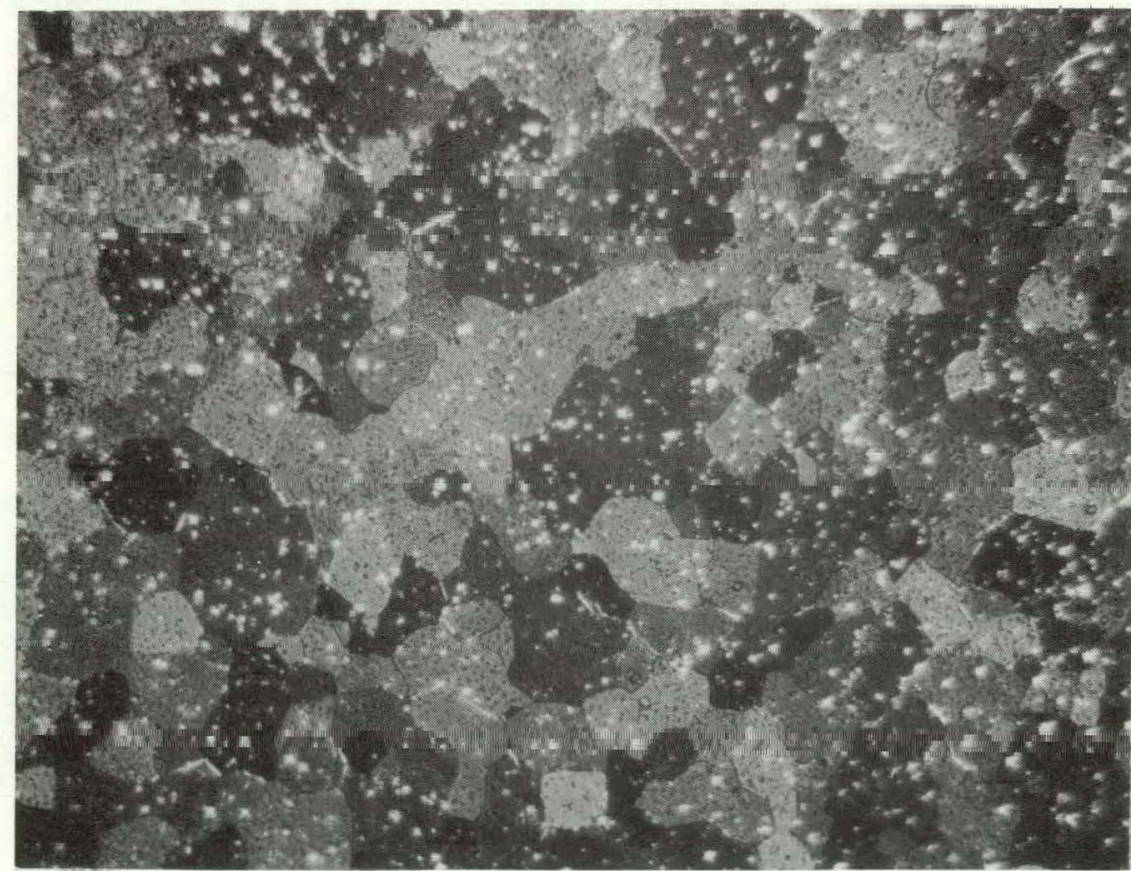

(b) CLADDING ETCHFO

$250 x$

PHOTOGRAPHED UNDER POLARIZED LIGHT

Figure 61. Cladding Microstructure of Transversely-Oriented Specimen No. A594 from Rod A49 

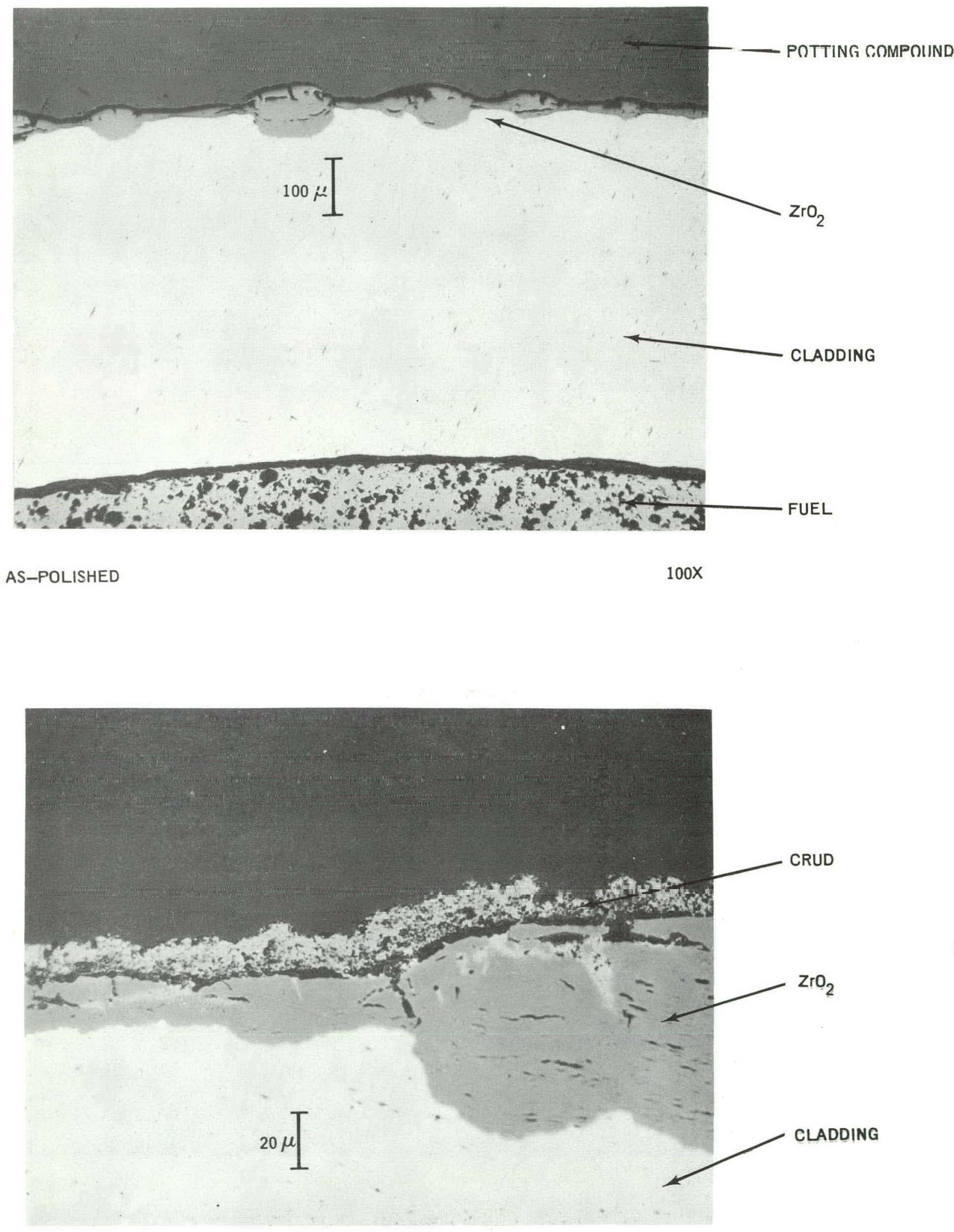

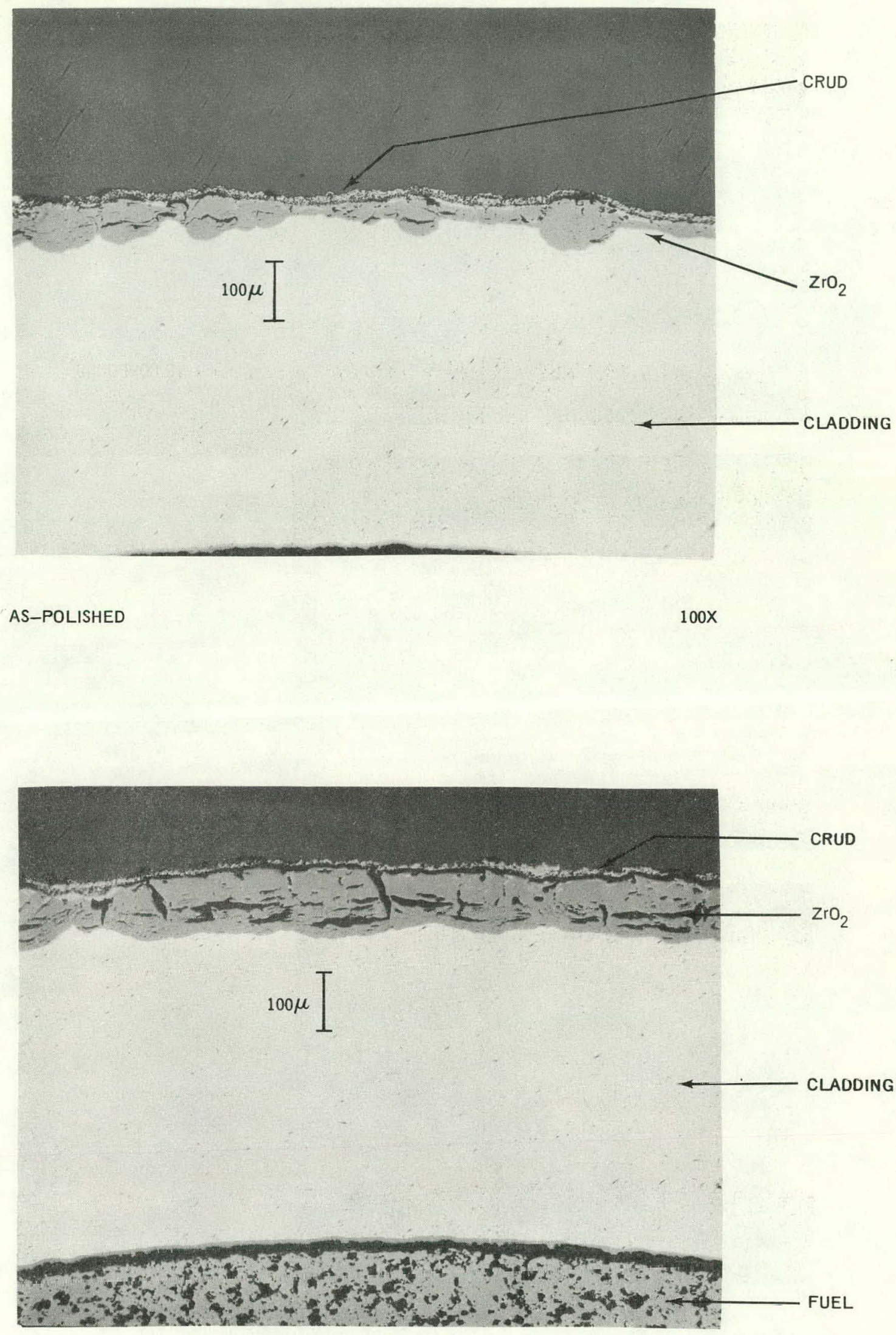
(a)

AS-POLISHED

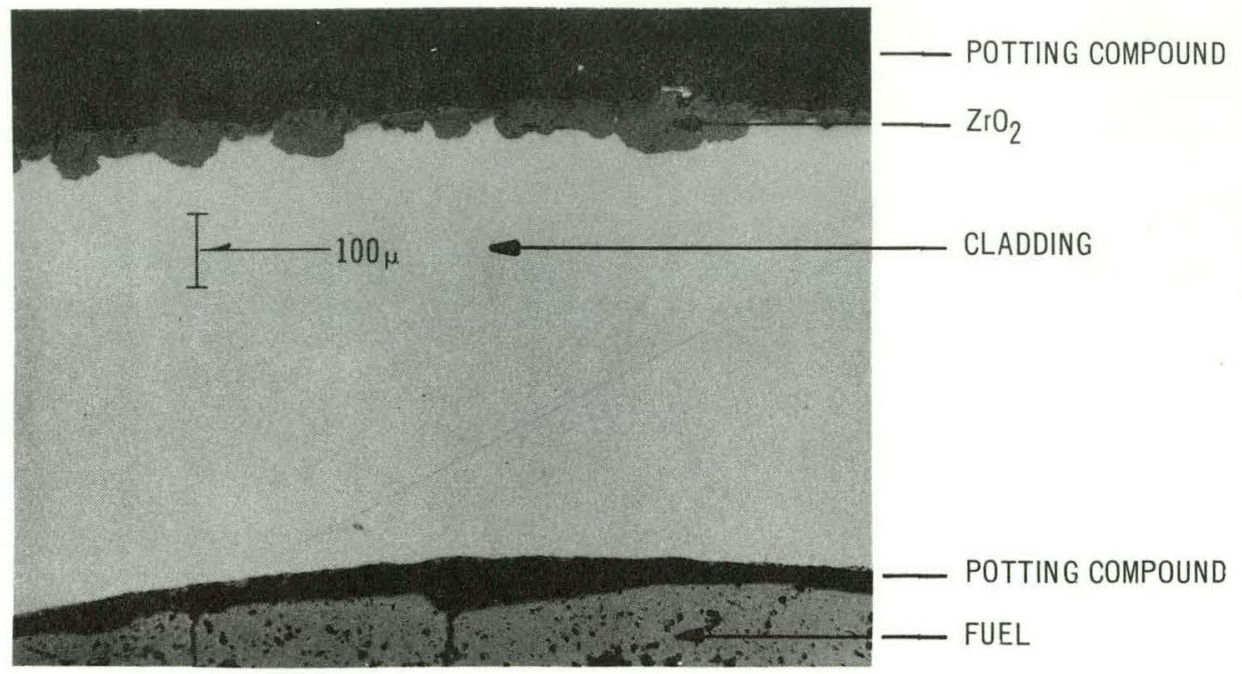

(b)

AS-POLISHED

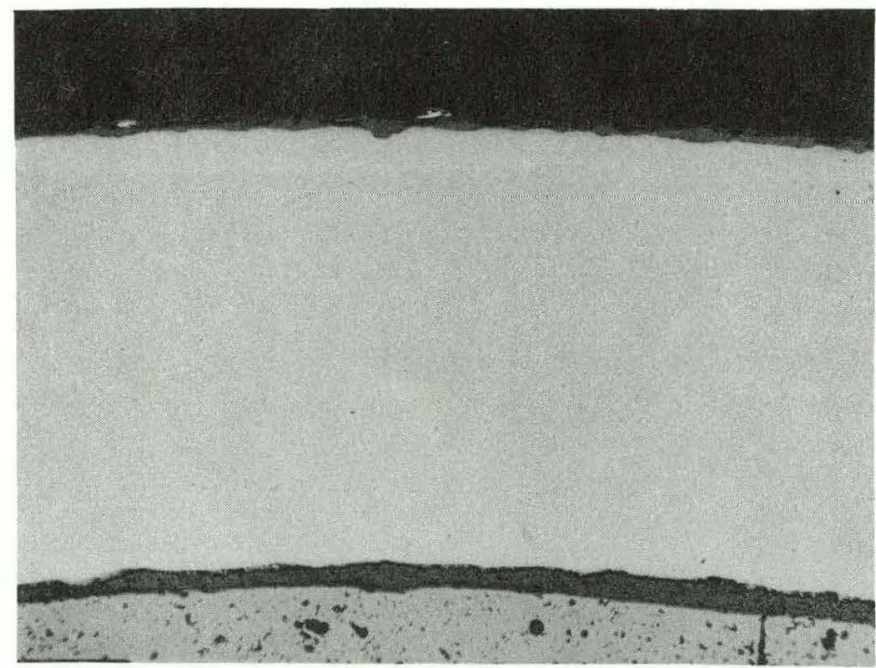

(c)

AS-POLISHED

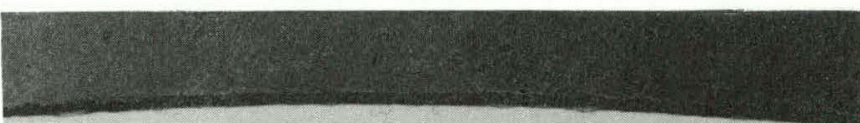

Figure 64. External $\mathrm{ZrO}_{2}$ at Different Locations of Specimen No. 9954 (See Figure 65) 


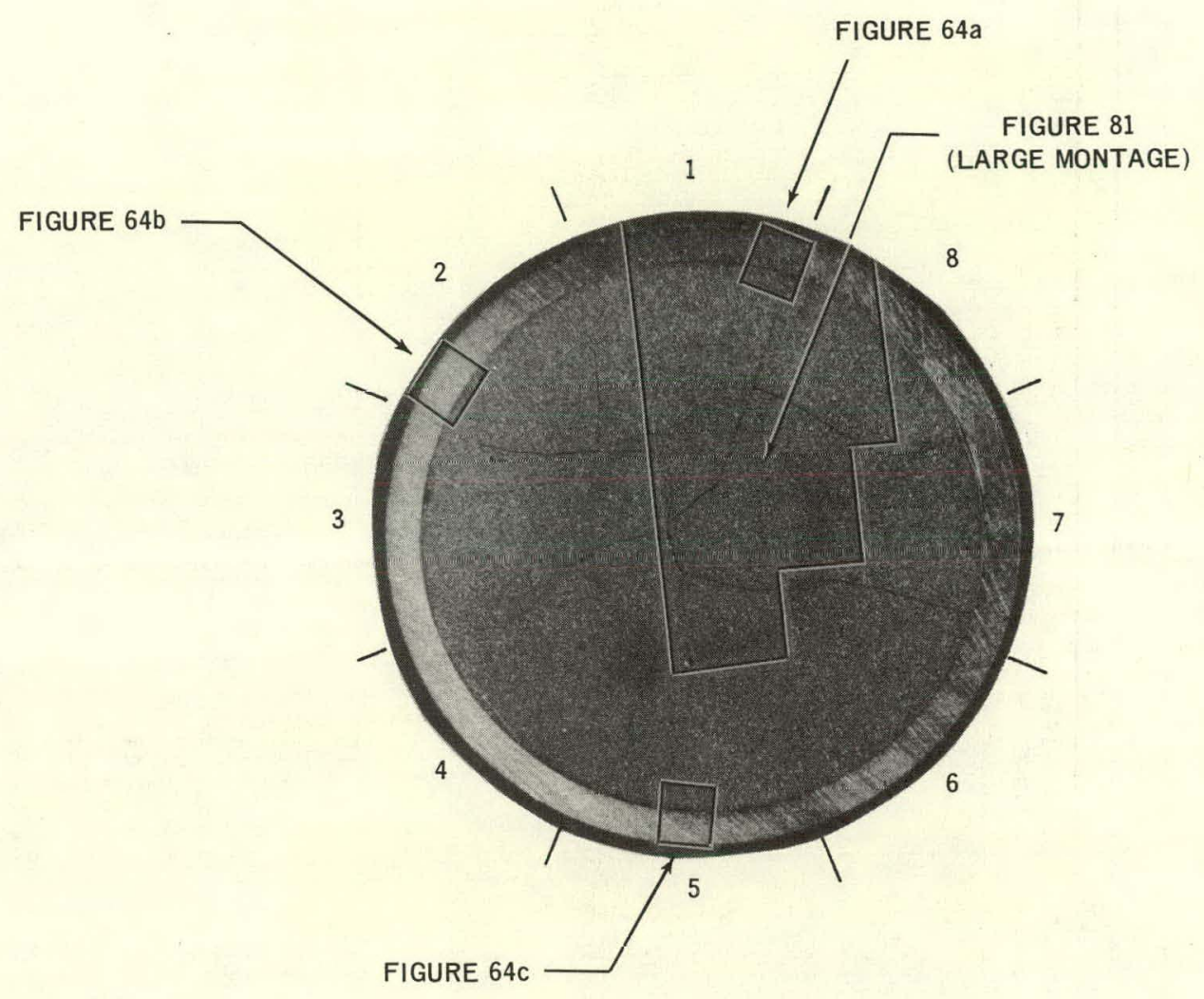

Figure 65. Macrograph of Specimen No. 9954 from Rod A13 (As-Ground- 6X Magnification). Locations of Micrographs and Octants (Listed in Table 13) are Indicated. 
Table 13

THICKNESS OF CRUD AND $\mathrm{ZrO}_{2}$ ON THE CLADDING OF TRANSVERSE METALLOGRAPHY SPECIMENS

Initial Phase

Rod Designation

Specimen Number, Location,

Operation, and

Tubing Lot Number*

\begin{abstract}
A13 9954
\end{abstract}
a) $27.9(11)$

b) $126.0(49-5 / 8)$

c) 1204

d) $8.1(29,700)$

e) $52(166,000)$

f) $129(410,000)$

g) $\mathrm{CA}-2$
$\mathrm{ZrO}_{2}$ on Outside Surface

\begin{tabular}{cr}
\hline $\begin{array}{c}\text { Even Film } \\
\text { Average } \\
\text { Thickness } \\
\text { (microns) }\end{array}$ & $\begin{array}{c}\text { Avera } \\
\text { Thickn } \\
\text { (micro }\end{array}$ \\
13 & 55 \\
14 & 35 \\
11 & 19 \\
10 & 15 \\
10 & 20 \\
10 & 22 \\
11 & 37 \\
16 & 79
\end{tabular}

12

35

0.1

\begin{tabular}{lc}
\multicolumn{2}{c}{ Overall } \\
\hline Average & Weight \\
Thickness & Gain \\
(microns) & $\left(\mathrm{mg} / \mathrm{dm}^{2} \mathrm{O}_{2}\right)^{* *}$
\end{tabular}

Crud

Average

Thickness

(microns)

Crud

chemically

removed

Not

measured
$\mathrm{ZrO}_{2}$ on Inside Surface Average

Thickness (microns)
A41 9957
a) 48.3 (19)
b) $105.7(41-5 / 8)$
c) 1204
d) $7.2(26,400)$
e) $46(147,000)$
f) $117(370,000)$
g) $\mathrm{CA}-4$

through 
Table 13 (Continued)

Initia Phase

Rod Designation Specimen $N$.mber,

$$
\text { Location, }
$$

Operation, and

Tubing Lot Number*

A46 9958

a) $25.1(9-7 / 8)$

b) $128.9(5(-3 / 4)$

C) $\mathbf{1 2 1 8}$

d) $6.9(25,300)$

e) $44(141,000)$

f) $91(290,000)$

g) $\mathrm{CA}-2$

Octa

\section{1 through}

$$
8
$$

\section{A46}

$\$ 959$

a) $92.1(36-1 / 4)$

b) $61.9(24-\Xi / 8)$

C) 1218

d) $4.6(16,9 \mathrm{CO})$

e) $30(94,000)$

f) $54(170,000)$

g) CA-2
$\mathrm{ZrO}_{2}$ or Outside Surface

\begin{tabular}{cr}
\hline $\begin{array}{c}\text { Even Film } \\
\text { Average } \\
\text { Thickness } \\
\text { (microns) }\end{array}$ & $\begin{array}{c}\text { Averag } \\
\text { Thickn } \\
\text { (microns }\end{array}$ \\
10 & 27 \\
10 & 20 \\
11 & 44 \\
12 & 75 \\
12 & 54 \\
14 & 85 \\
12 & 76 \\
10 & 53
\end{tabular}

11

54

0.3

24

\begin{tabular}{lc}
\hline \multicolumn{2}{c}{ Overall } \\
\hline $\begin{array}{c}\text { Average } \\
\text { Thickness } \\
\text { (microns) }\end{array}$ & $\begin{array}{c}\text { Weight } \\
\text { Gain } \\
\left(\mathrm{mg} / \mathrm{dm}^{2} \mathrm{O}_{2}\right)^{* *}\end{array}$
\end{tabular}

Crud
Average
Thickness
(microns

$\mathrm{ZrO}_{2}$ on

Inside Surface

Average

Thickness

(microns)

8

8

9

6

8

6

7

8

370

$\begin{array}{lrl}1 & g & 46 \\ 2 & 8 & 36 \\ 3 & 8 & 26 \\ 4 & 31 & 53 \\ 5 & 64 & 72 \\ 6 & 41 & 59 \\ 7 & 8 & 42 \\ 8 & 7 & 33\end{array}$

$\begin{array}{ll}3 & 1 / 2 \text { to } 1 \\ 3 & \\ 3 & \\ 3 & \\ 3 & \\ 2 & \\ 2 & \\ 3 & <1 \\ 3 & \end{array}$


Table 13 (Continued)

Initial Phase

Rod Designation Specimen Number, Location.

Operation, and

Tubing Lot Number

B70

a) $35.6(14)$

b) $190.8(75-1 / 8)$

c) 1175

d) $6.5(23,900)$

e) $42(132,000)$

f) $107(340,000)$

g) $\mathrm{CA}-5$
$\mathrm{ZrO}_{2}$ on Outside Surface

\begin{tabular}{cr}
\hline $\begin{array}{c}\text { Even Film } \\
\text { Average } \\
\text { Thickness } \\
\text { (microns) }\end{array}$ & $\begin{array}{c}\text { Avera } \\
\text { Thickn } \\
\text { (micro }\end{array}$ \\
10 & 50 \\
9 & 34 \\
10 & 49 \\
10 & 40 \\
10 & 46 \\
10 & 45 \\
9 & 46 \\
9 & 55 \\
&
\end{tabular}

1 through

Patches

$$
\begin{aligned}
& 50 \\
& 34 \\
& 49 \\
& 40 \\
& 46 \\
& 45 \\
& 46 \\
& 55
\end{aligned}
$$

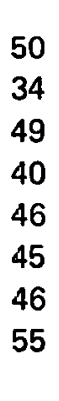

Average

Ahickness

Relati

Relative

Amount
46

0.1

\begin{tabular}{lc}
\hline \multicolumn{2}{c}{ Overall } \\
\hline Average & Weight \\
Thickness & Gain \\
(microns) & $\left(\mathrm{mg} / \mathrm{dm}^{2} \mathrm{O}_{2}\right)^{* *}$
\end{tabular}

Crud

Average

Thickness

(microns)

220
$\mathrm{ZrO}_{2}$ on Inside Surface

Average

Thickness

(microns)
$897 \quad 9962$
a) $23.5(9-1 / 4)$
b) $178.8(70-3 / 8)$
c) 1218
d) $7.3(26,600)$
e) $46(147,000)$
f) $117(370,000)$
g) $\mathrm{CA}-2$

1

1
2

3

3
4
5

6

7

8

$$
8
$$

B97 9963

a) 73.7 (29)

b) $228.9(90-1 / 8)$

c) 1218

d) $5.1(18,500)$.

e) $32(102,000)$

f) $57(180,000)$

g) $\mathrm{CA}-2$

1
2
3
4
5
6
7
8
1 through
8

10

31

22

.20

24

32

39

55

46

34

0.4

20

$\begin{array}{cl} & 4 \\ \text { Crud } & 3 \\ \text { chemically } & 5 \\ \text { removed } & 3 \\ & 3 \\ & 4 \\ & 3 \\ & 3\end{array}$

4

3

3

3

4

3

$\begin{array}{rl}10 & 3 \\ 11 & 5 \\ 9 & 1\end{array}$

10

34

34
44

54

54

59

59
56

59

36

49

0.6

34

530

310 
Table 13 (Continued)

Final Phase

Rod Designation Specimen Number,

\section{Location.}

Operation, and

Tubing Lot Number *

A1 1

a) $20.217-1$

b) $133.8(52.11 / 16)$

c) $i 832$

d) $9.9(36,20 \mathrm{C})$

e) $41(31,000$.

f) $110(350,000)$

g) $\mathrm{CA}-4$

\section{A15}

a) $25.7(10-1 / 3)$

b) $128.3(50-1 / 2$

c) 1767

d) $9.1(33,100(1)$

e) $40(127,003)$

f) $\subseteq 8(310,000)$

g) CA-5

A15 ․ A591

a) $80.9(35-3 / 8)$

b) $64.1(25-1 / 4)$

c) 1767

d) $6.8(24,900$

e) $33(95,000)$

f) $44(140,00(1)$

g) $\mathrm{CA}-5$

\begin{tabular}{r}
\hline Even F \\
Avera \\
Thickn \\
Imicro \\
10 \\
11 \\
14 \\
11 \\
10 \\
11 \\
10 \\
10 \\
11 \\
13 \\
11 \\
11 \\
11 \\
11 \\
10 \\
10 \\
11 \\
11 \\
8 \\
8 \\
7 \\
8 \\
7 \\
7 \\
\\
8 \\
11
\end{tabular}

$\mathrm{ZrO}_{2}$ on Outside Surface

Octant
$\left.110^{\circ}\right)$
2
3
4
5
6
7
8
1 through

Patches

Average

Relative

(microns)

Relative

Amount

\begin{tabular}{lc}
\multicolumn{2}{c}{ Overall } \\
\hline Average & Weight \\
Thickness & Gain \\
(microns) & $\left(\mathrm{mg} / \mathrm{dm}^{2} \mathrm{O}_{2}\right) * *$
\end{tabular}

Crud

Average

Thickness

10

25
41
72
63
34
25
23
23

0.04

0.19

0.71

0.53

0.10

0.02

0.03

0.03

11

11

55

55
39

12

12
11

10

1 through

8

60

0.21

21

330

106

106 - 1.00

$68 \quad 0.15$

$41 \quad 0.02$

0.02
0.08

0.17

0.06

0.04

0.44

0.24

0.05

0.12

0.08

0.12

0.18

0.19

0.23

0.13

0.14

33

through
8

$2 \mathrm{rO}_{2}$ on Inside Surface Average Thickness (microns)

$$
9 \text { : }
$$

9
9

10

9

9$$
9
$$

$12 \mu$ to $1 / 2 \mu$ spots

$$
\text { -to-trace }
$$<smiles>C1CCCCC1</smiles>

8

trace with scattered spots

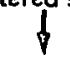

low

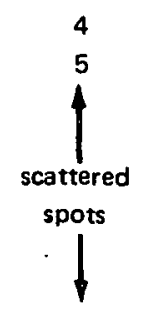

$4(0.25)$ ** 


\section{Table 13 (Continued)}

Final Phase

Even Film
Average
Thicknes
(microns

11
10
10
10
10
11
11
11

\begin{tabular}{ll}
\hline \multicolumn{2}{c}{ Patches } \\
\hline Average & \\
Thickness & Relative \\
(microns) & Amount
\end{tabular}

\begin{tabular}{lc}
\multicolumn{2}{c}{ Overall } \\
\hline Average & Weight \\
Thickness & Gain
\end{tabular}

Crud

Average

Thickness

mg/dm $\left.\mathrm{O}_{2}\right)^{\cdots} \quad$ (microns)

$\stackrel{9}{N}$

Rod Designation

Specimen Number

Location.

Operation, and

Tubing Lot Number *

A32 A610

a) $26.7(10-1 / 2)$

b) $127.3(50-1 / 8)$

c) 1832

d) $9.3(33,900)$

e) $39(123,000)$

f) $123(390,000)$

g) $\mathrm{CA}-4$

\begin{abstract}
A37 A580
\end{abstract}
a) $20.2(7-15 / 16)$

b) $133.8(52-11 / 16$

c) 1832

d) $10.1(37,000)$

e) $42(134,000)$

f) $117(370,000)$

g) $\mathrm{CA}-1$
0.02

0.03

0.03

0.05

0.05

0.05

0.04

0.01

1 through$$
8
$$

11

0.04

23

0.37

$\left.110^{\circ}\right)$

(microns)

$$
\begin{aligned}
& 11 \\
& 10 \\
& 10 \\
& 11 \\
& 11 \\
& 11 \\
& 11 \\
& 11
\end{aligned}
$$$$
11
$$

170

$\begin{array}{ll}47 & 0.37 \\ 45 & 0.28 \\ 23 & 0.06 \\ 21 & 0.05 \\ 21 & 0.05 \\ 24 & 0.20 \\ 17 & 0.13 \\ 23 & 0.08\end{array}$

$$
35
$$

A47

a) $25.7(10-1 / 8)$

b) $128.3(50-1 / 2)$

c) 1846

d) $9.1(33,100)$

e) $38(121,000)$

f) $107(340,000)$

g) CA-2

$\left.110^{\circ}\right)$

2

3

4

5

6

7

1 through
9

11
11

11

12

11
11

11

11

11

66
65
75
72
58
54
79
64

0.23

0.16

0.44

0.40

0.26

0.22

0.17

0.12

24
19
12
11
9
11
9
11

13

24
20
39
36
23
20
23
17

25

200

0.25

$$
\begin{aligned}
& 8 \\
& 8 \\
& 8 \\
& 8 \\
& 9 \\
& 8 \\
& 8 \\
& 9 \\
& 8
\end{aligned}
$$

$\mathrm{ZrO}_{2}$ on

Inside Surface Average

Thickness

(microns)

$$
7
$$

8

7

$\cdot 10$

8

$$
8
$$

8

Crud

chemically

removed

68

25

390

$\begin{array}{rc}9 & 7 \\ 8 & 8 \\ 9 & 7(0.2) \\ 13 & 8(0.5) \\ 12 & 7(0.3) \\ 9 & 7(0.3) \\ 10 & 8 \\ 10 & 7(0.54) \cdots\end{array}$


Table 13 (Con: inued)

Final Phase

Rod Designati on Specimen Number,

$$
\text { Location. }
$$

Operation, and

Tubinz Lot Number *

A49

A5734

a) $76.8(30-1 / 4)$

b) $77.2(30-3 / 8)$

c) 1846

d) $7.7(28,100$

e) $32(102,000)$

f) $73(230,000)$

g) CA-2

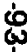

$\begin{array}{lc}\text { B50 A609 } & 1\left(0^{\circ}\right) \\ \text { a) } 74.9(29-1 / 2) & 2 \\ \text { b) } 230.2(90-5 / 8) & 3 \\ \text { c) } 1846 \quad & 4 \\ \text { d) } 7.4(27,100) & 5 \\ \text { e) } 31(99,000) & 6 \\ \text { f) } 47(150,000) & 7 \\ \text { g) CA.2 } & 8 \\ & 1 \text { through } \\ \text { B57 A6:3 } & 8 \\ \text { a) } 25.7(10-1 / 8) & 1\left(0^{\circ}\right) \\ \text { b) } 181.0(71-1 / 4) & 2 \\ \text { c) } 1846 \quad & 3 \\ \text { d) } 8.8(32,000) & 4 \\ \text { e) } 37(117,000) & 5 \\ \text { f) } 82(260,000) & 6 \\ \text { g) CA-1 } & 7 \\ & 8\end{array}$

$\mathrm{ZrO}_{2}$ on Outsice Surface

\begin{tabular}{|c|c|c|c|c|c|c|}
\hline \multirow{3}{*}{$\begin{array}{l}\text { Even Film } \\
\text { Average } \\
\text { Thicknes: } \\
\text { Imicrons: }\end{array}$} & \multicolumn{2}{|c|}{ Patches } & \multicolumn{2}{|c|}{ Overall } & \multirow{3}{*}{$\begin{array}{l}\text { Crud } \\
\text { Average } \\
\text { Thickness } \\
\text { (microns) }\end{array}$} & \multirow{3}{*}{$\begin{array}{c}\text { Inside Surface } \\
\text { Average } \\
\text { Thickness } \\
\text { (microns) }\end{array}$} \\
\hline & Average & & & Weight & & \\
\hline & $\begin{array}{l}\text { Thickness } \\
\text { (microns) }\end{array}$ & $\begin{array}{l}\text { Relat ve } \\
\text { Amount }\end{array}$ & $\begin{array}{l}\text { Thickness } \\
\text { (microns) }\end{array}$ & $\begin{array}{l}\text { Gain } \\
\left(\mathrm{mg} / \mathrm{dm}^{2} \mathrm{O}_{2}\right) \cdots *\end{array}$ & & \\
\hline 8 & 106 & 0.34 & 41 & & & trace with 4 to \\
\hline 9 & 46 & 0.16 & 15 & & & $10 \mu$ spots \\
\hline 9 & 74 & $0.1:$ & 20 & & & 0 \\
\hline 9 & 85 & 0.35 & 36 & & $\begin{array}{c}\text { Crud } \\
\text { - chemically }\end{array}$ & $\begin{array}{l}0(0.5) \\
6(0.5)\end{array}$ \\
\hline 20 & 96 & 0.52 & 60 & & removed & $\begin{array}{l}0(0.5) \\
7(0.5)\end{array}$ \\
\hline 9 & 116. & $0.6<$ & 77 & & & $\begin{array}{l}0(0.6) \\
6(0.4)\end{array}$ \\
\hline 11 & 108 & $0.7 \xi$ & 82 & & & $\begin{array}{l}0(0.5) \\
7(0.5)\end{array}$ \\
\hline 9 & 121 & $0.9<$ & 114 & & & 6 \\
\hline 10 & 105 & $0.4 \varepsilon$ & 56 & 870 & & $6(0.36)^{* \ldots}$ \\
\hline 10 & 61 & $0.2 E$ & 23 & & & 4 \\
\hline 11 & 64 & 0.51 & 38 & & & trace to \\
\hline 12 & 69 & $0.4 E$ & 38 & & Crud & $6 \mu$ spots \\
\hline 13 & 88 & $0.3 \subseteq$ & 42 & - & chemically & 1 \\
\hline 94 & 89 & 0.37 & 92 & & removed & $5(0.6)$ \\
\hline 105 & - & $0.0 \mathrm{C}$ & 105 & & & $7(0.5)$. \\
\hline $78(0.1)$ & $-(0.1)$ & $0.0 \mathrm{C}(0.1)$ & 43 & & & $5(0.2)$ \\
\hline $14(0.5)$ & $78(0.9)$ & $0.37(0.9)$ & & & & \\
\hline 11 & 68 & 0.39 & 33 & & & spatty \\
\hline 40 & 74 & 0.34 & 52 & 810 & & $6(0.16) * \ldots$ \\
\hline 12 & 81 & 0.35 & 36 & & 19 & $5(0.3)$ \\
\hline 12 & 84 & 0.29 & 33 & & 19 & trace with \\
\hline 13 & 65 & 0.26 & 27 & . & 18 & spots up to \\
\hline 12 & 73 & 0.38 & 35 & & 18 & $9 \mu$ \\
\hline 12 & 48 & 0.22 & 20 & & 17 & $8(0.5)$ \\
\hline 12 & 45 & 0.12 & 16 & & 17 & $7(0.6)$ \\
\hline 10 & 37 & 0.07 & 12 & & 15 & 8 \\
\hline 12 & 56 & 0.21 & 21 & & 16 & $7(0.6)$ \\
\hline 12 & 68 & 0.24 & 25 & 390 & 17 & $7(0.38) \cdots$ \\
\hline
\end{tabular}


Table 13 (Continued)

Final Phase

Rod Designation

Specimen Number,

$$
\text { Location. }
$$

Operation, and

Tubing Lot Number *

B62

A581

a) $24.6 \cdot(9-11 / 16)$

b) $179.9(70-13 / 16)$

c) 1832

d) $10.2(37,400)$

e) $43(136,000)$

f) $126(400,000)$

g) $\mathrm{CA}-1$

A611

a) $26.7(10-1 / 2)$

b) $181.9(71-5 / 8)$

c) 1846

d) $8.5 \cdot(31,100)$

e) $36(113,000)$

f) $98(310,000)$

g) $\mathrm{CA}-3$

$885 \quad \therefore$

a) $25.7(10.1 / 8)$

b) $181.0(71.1 / 4)$

c) 1803

d) $9.0(33,000)$

e) $39(123,000)$

f) $98(310,000)$

g) $\mathrm{CA}-5$
$\mathrm{ZrO}_{2}$ on Outside Surfice

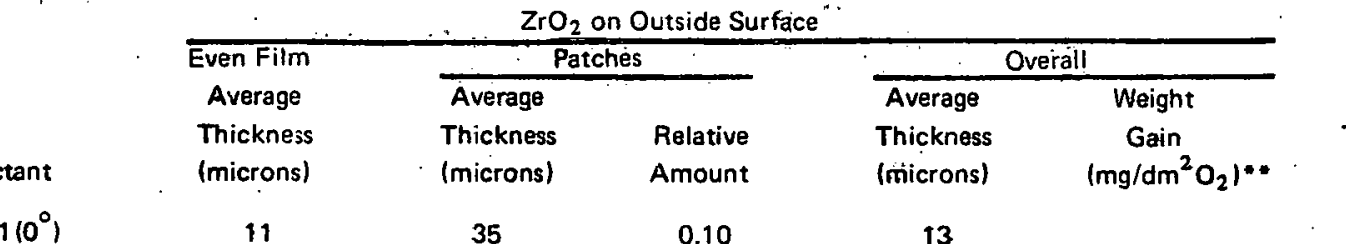

$1\left(0^{\circ}\right)$

4

4

5

6

8

1 through

8

$1\left(0^{\circ}\right)$

$$
\begin{aligned}
& 2 \\
& 3
\end{aligned}
$$

4

$$
\begin{aligned}
& 4 \\
& 5 \\
& 6
\end{aligned}
$$$$
6
$$$$
7
$$$$
8
$$

through

$$
8
$$

$1\left(0^{\circ}\right)$$$
2
$$

$$
3
$$

4

5

6

7
8

1 through

8

11
11
12
12
12
11
11
10

35
33
30
28
20
20
28
46

0.10
0.14
0.16
0.06
0.01
0.01
0.09
0.14

13
14
15
13
12
11
13
15

200

$\begin{array}{lll}34 & 0.09 & 13\end{array}$

\section{5}

\section{3}

1710.8
6110.2

45

0.17

$\begin{array}{lll}71(0.8) & 0.20 & 20 \\ -70.2) & 23\end{array}$

$\begin{array}{lll}71(0.8) & 0.26(0.8) & 37\end{array}$

6110
99

87

16

20

16

42

$-(0.2)$

$0.00(0.2)$

$\begin{array}{ll}- & 0.00 \\ - & 0.00\end{array}$

$-\quad 0.00$

0.49

$\begin{array}{ll}65 & 0.38 \\ 63 & 0.37\end{array}$

$65 \quad 0.23$

730

119

25

$-$

0.00

0.52

119

107

0.72

$\begin{array}{ll}128 & 0.72 \\ 124 & 0.43\end{array}$

$98 \quad 0.20$

91

72

$100(0.5)$

$-(0.5)$.

0.29
0.25

$0.70(0.5)$

108(0.5)

$0.00(0.5)$

49

110

0.34

71

1110

$\begin{array}{cc}\mathrm{ZrO}_{2} \text { on } \\ \text { Crud } & \text { Inside Surface } \\ \text { Average } & \text { Average } \\ \text { Thickness } & \text { Thickness } \\ \text { (microns) } & \text { (microns) }\end{array}$

14
15
16
16
16
16
16
15

$7(0.82) * * *$ 
Table 13 (C.ontinued)

Finat Phase

Rod Designation Specimen Number.

$$
\text { Locatior. }
$$

Operation, and

Tubing Lot Number *

$885 \quad A 593$
a) $89.9(35-3.8)$
b) $245.1(96-\cdot / 2)$
c) 1803
d) $5.7(20,700)$
e) $24(77,0000$
f) $38(120,000)$
gl CA.5

$\mathrm{ZrO}_{2}$ on Outside Surface

\begin{tabular}{|c|c|c|c|c|}
\hline \multirow{3}{*}{$\begin{array}{l}\text { Even Frim } \\
\text { Average } \\
\text { Thickness } \\
\text { (microns) }\end{array}$} & \multicolumn{2}{|c|}{ Patches } & \multicolumn{2}{|c|}{ Overall } \\
\hline & Average & & Average & Weight \\
\hline & $\begin{array}{l}\text { Thickness } \\
\text { (microns) }\end{array}$ & $\begin{array}{l}\text { Relative } \\
\text { Amount }\end{array}$ & $\begin{array}{l}\text { Thickness } \\
\text { (microns) }\end{array}$ & $\begin{array}{c}\text { Gain } \\
\left(\mathrm{mg} / \mathrm{dm}^{2} \mathrm{O}_{2}\right)^{* *}\end{array}$ \\
\hline 21 & 39 & 0.36 & 27 & \\
\hline 35 & 73 & 0.40 & 50 & \\
\hline 44 & 105 & 0.40 & 68 & \\
\hline 37 & 66 & 0.37 & 48 & \\
\hline 29 & 48 & 0.01 & 29 & \\
\hline 19 & 45 & 0.05 & 20 & \\
\hline 17 & - & 0.00 & 17 & \\
\hline 21 & 58 & 0.03 & 22 & \\
\hline 26 & 70 & 0.20 & 35 & 550 \\
\hline
\end{tabular}

$\mathrm{ZrO}_{2}$ on Inside Surface Average

Thickness

(microns)

$\begin{array}{ll}0(0.5) & \\ 16(0.5) & \\ 18 & \\ 16 & \text { trace and scattered } \\ 17 & \text { spots up to } \\ 16 & 8 \mu \\ 19(0.1) & \\ 0(0.9) & \\ 0 & \\ 0(0.5) & \\ 15(0.5) & \\ 17(0.64) \cdots \cdots & \text { low }\end{array}$




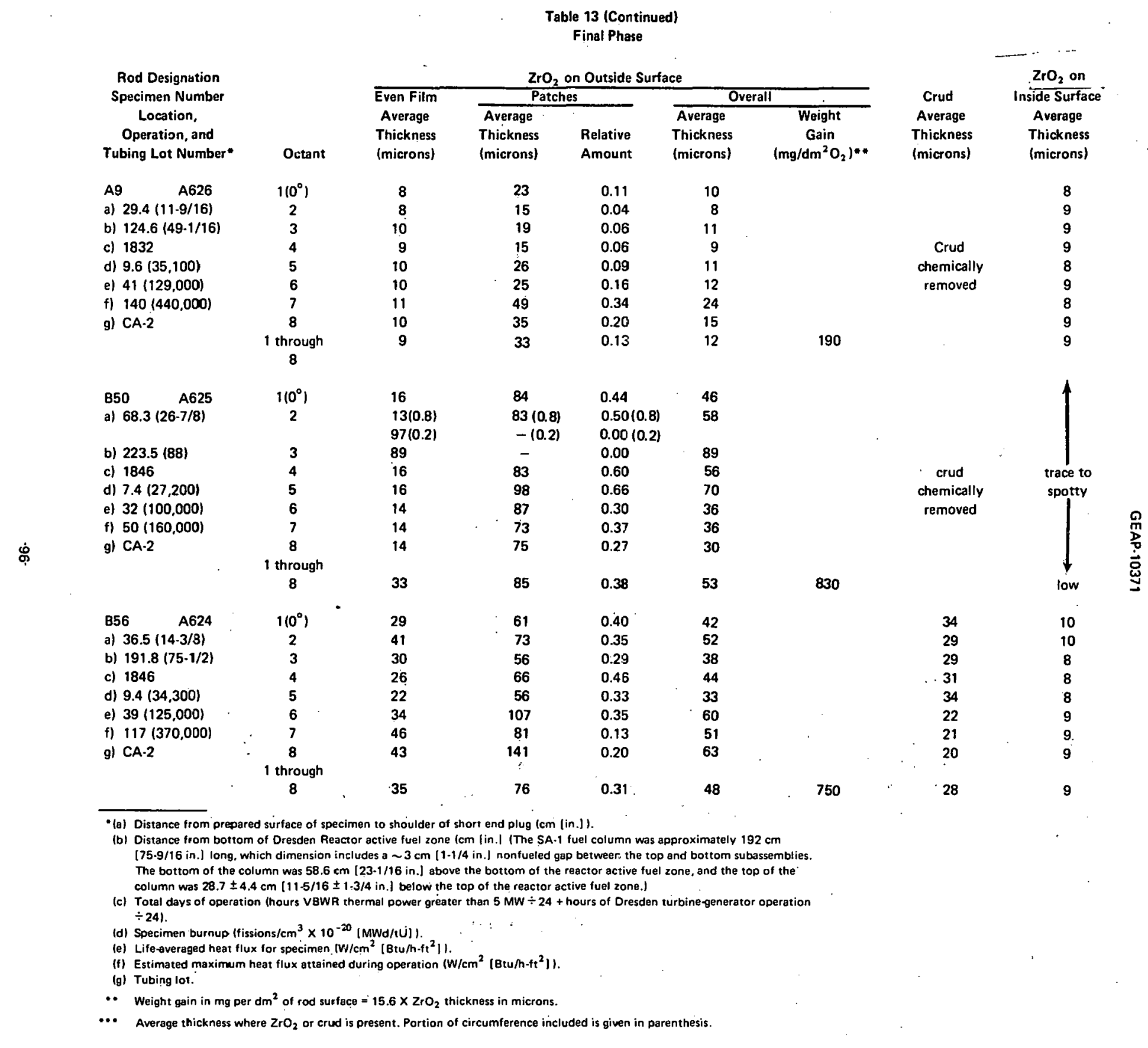


Table 14

\section{THICKNESS OF $\mathrm{ZrO}_{2}$ ON THE CLADDING OF LONGITUDINAL METALLOGRAPHY SPECIMENS}

Rod Designation

Specimen Number, Location.

Operation, and

Tubing Lot Number*

A41

9955

a) $21.6-25.1(8-1 / 2-9-7 / 8)$

b) $128.9-132.4(50-3 / 4-52.1 / 8)$

c) 1204

d) $7.7(28,300)$

e) $50(157,000)$

f) $123(390,000)$

g) $\mathrm{CA}-4$

$B 70$

9961

a) $50.8 \sim 54.3(20-21-3 / 8)$

b) $206.1-209.6(81-1 / 8-82-1 / 2)$

c) 1175

d) $6.0(22,100)$

e) $38(121,000)$

f) $98(310,000)$

g) CA-5

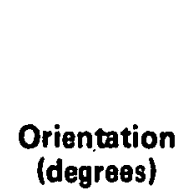

$\frac{\mathrm{ZrO}_{2} \text { on Outside Surface }}{\frac{\text { Even Film }}{\text { Average Thickness }} \underset{\text { Patches }}{\text { (microns) }}} \frac{\begin{array}{c}\text { Estimated } \\ \text { Overall } \\ \text { Weight Gain } \\ \left(\mathrm{mg} / \mathrm{dm}^{2} \mathrm{O}_{2}\right)^{*}\end{array}}{\text { * * }}$

10

17

11

43

$\begin{array}{lll}970 & 11 & 43\end{array}$

$\mathrm{ZrO}_{2}$ on Inside Surface Average Thickness (microns)

4

6

210

\begin{tabular}{|c|c|c|c|}
\hline 90 & 21 & 65 & 4 \\
\hline 270 & 15 & 57 & $\sim 1-1 / 2$ \\
\hline
\end{tabular}

"(a) Distance from prepared surface of specimen to shoulder of short end plug (cm [in.]).

(b) Distance from bottom of Dresden Reactor active fuel zone (cm [in.]). (The SA-1 fuel column was apnrnximately $192 \mathrm{~cm}$ [75.9/16 in.] long, which dimension includes a $\sim 3 \mathrm{~cm}$ [1-1/4 in.] nonfueled gap between the top and bottom subassemblies. The bottom of the column was $58.6 \mathrm{~cm}[23-1 / 16 \mathrm{in}$.] above the bottom of the reactor active fuel zone, and the top of the column was $28.7 \pm 4.4 \mathrm{~cm}[11-5 / 16 \pm 1-3 / 4 \mathrm{in}$.] below the top of the reactor active fuel zone.)

(c) Total days of operation (hours VBWR thermal power greater than $5 \mathrm{MW} \div 24+$ hours of Dresden turbine-generator operation $\div 24$ ).

(d) Specimen burnup (fissions $/ \mathrm{cm}^{3} \times 10^{-20}[\mathrm{MWd} / \mathrm{tU}]$ ).

(e) Life-averaged heat flux for specimen $\left(W / \mathrm{cm}^{2}\left[B t u / h-\mathrm{ft}^{2}\right]\right)$.

(f) Estimated maximum heat flux attained during operation $\left(\mathrm{W} / \mathrm{cm}^{2}\left[\mathrm{Btu} / \mathrm{h}-\mathrm{ft} \mathrm{t}^{2}\right]\right.$ )

(g) Tubing lot.

* Weight gain in $\mathrm{mg}$ per $\mathrm{dm}^{2}$ of rod surface $=15.6 \times \mathrm{ZrO}_{2}$ thickness in microns. 
$11 \mu$ over the remainder. The octant of maximum film thickness was 135 degrees away from that of maximum overall corrosion.

Among the specimens that showed the most significant variations in overall corrosion about the circumference, corner rod specimens No. A594 (rod A49) and No. A609 (rod B50) showed the most corrosion on those portions toward the corresponding channel corner (and, of course, also toward the corner of the adjacent stainless steel subassembly structural angle). In three other cases; the orientation of heaviest corrosion was directed toward the water gap caused by the removal of an adjacent rod at the end of Dresden Cycle No. 4 (specimens No. A582 [rod A11], * No. A590 [rod A15], and No. A592 [rod B85]). However, specimen No. A593 from near the top of the rod B85 fuel column showed the thickest $\mathrm{ZrO}_{2}$ toward the adjacent corner rod instead of toward the rod vacancy, and the maximum corrosion on specimen No. A611 from rod B83 also occurred 90 degrees from the direction of the rod vacancy water gap.

The corrosion weight gains, determined by multiplying the overall circumferential-average $\mathrm{ZrO}_{2}$ thicknesses by 15.6 ranged from 210 to $610 \mathrm{mg} / \mathrm{dm}^{2}$ and averaged $340 \mathrm{mg} / \mathrm{dm}^{2}$ among initial phase specimens. The weight gains shown by the final phase specimens ranged from 170 to $1110 \mathrm{mg} / \mathrm{dm}^{2}$ and had an average value of $510 \mathrm{mg} / \mathrm{dm}^{2}$. The weight gain values presented in Table 13 give full weight to all octants of every transverse specimen and thus include those regions which might be considered abnormally corroded.

The post-transition corrosion weight gain of the SA-1 cladding is shown as a function of exposure time in Figure 66. The 365-day data were obtained from like fuel rods irradiated in the VBWR under the AEC Fuel Cycle Program. The average weight gain for these specimens was $125 \mathrm{mg} / \mathrm{dm}^{2}$ (Ref. 3). In some cases among those rods that operated in Assembly SA-1, two specimens were prepared from a single rod. In such cases, the average weight gain of the two was plotted as a single value.

Where two specimens were taken from a fuel rod that operated four cycles in Dresden (rods A15 and B85), the specimen nearer the bottom or top of the full assembly showed a lower weight gain than that nearer the middle of the assembly in the maximum power region. On the other hand, the specimens from rods A49 and B50 also were taken from within $20 \mathrm{~cm}(8 \mathrm{in}$.) of the ends of the total SA-1 fuel column, and thus operated at powers somewhat below the averages of the respective rods. The diameter profiles of these rods indicate that the specimens were located in regions of maximum increase in diameter over pre-irradiation measurements; this fact suggests that the corrosion weight gains shown by the specimens were near the maximum values for the rods. Measurements made on specimens from rods A46 and B97 during the initial phase also indicate that the "corrosion profile" for a given rod does not necessarily correspond to the burnup profile. On the average, specimens from the B rods (top subassembly) showed larger weight gains than did those from the $A$ rods (bottom subassembly); however, there is considerabte overlapping in the ranges of values obtained on specimens from both groups. With the exceptions of rods B83 and B70, specimens from interior rods showed lower weight gains than did those from rods with outside locations in assembly SA-1.

Representative cross-sectional views of deposited crud are shown in Figures 62(b) and 63. The circumferentialaverage crud thickness measured on metallography specimens from rods that operated in Dresden 840 days ranged from 3 to $10 \mu(0.0004 \mathrm{in}$.) and had a mean value of $9 \mu(0.00035 \mathrm{in}$.). The crud thicknesses measured on specimens from rods that operated in Dresden 1468 days ranged from 4 to $28 \mu(0.0002$ to 0.0011 in.) and had a mean value of $14 \mu$. The . lowest deposition was measured on specimens located near the bottom of the SA-1 fuel column. The crud thicknesses measured on the metallography specimens agree reasonably well with those determined from diameter profiles run on rods that operated in Dresden for the same lengths of time. It may be recalled that the rod-average crud thicknesses measured by profilometry in the initial phase of the program showed mean and maximum values of $9 \mu$ and $12 \mu$, while the corresponding values for measurements made in the final phase were $12 \mu$ and $17 \mu$. The maximum circumferentialaverage thickness measured with the profilometer at any axial location of any rod that operated to the end of Cycle No. 6 was $28 \mu$ (rod A7), i.e., the same as the maximum measured on any metallography specimen.

Like the corrosion layers, the thickness of the crud deposit also varied considerably about the periphery of some specimens in the final phase group. In such cases, the crud was generally thickest, or at least thicker than average, in the orientation of heaviest corrosion. However, specimen A624 (rod B56) and A592 (rod B85) represent exceptions to this relationship. The crud on these specimens was thinnest over the octants of maximum overall corrosion; however, on the latter specimen it was thickest over the octant with the greatest average patch-type $\mathrm{ZrO}_{2}$ thickness. In other instances, the variation in crud thickness was rather small compared to that in $\mathrm{ZrO}_{2}$ thickness (e.g., specimen $\mathrm{A611}$ [rod $\mathrm{B} 83$ ])

*Between Cycle Nos. 4 and 5, rod A11 was moved to its final assembly position from the adjacent rod vacancy position (see Figure 16). Its orientation during Cycle Nos. 3 and 4 is unknown. The other final phase rods listed in Table 13 were not removed from their original subassembly locations until their examination at Vallecitos Nuclear Center (VNC). 


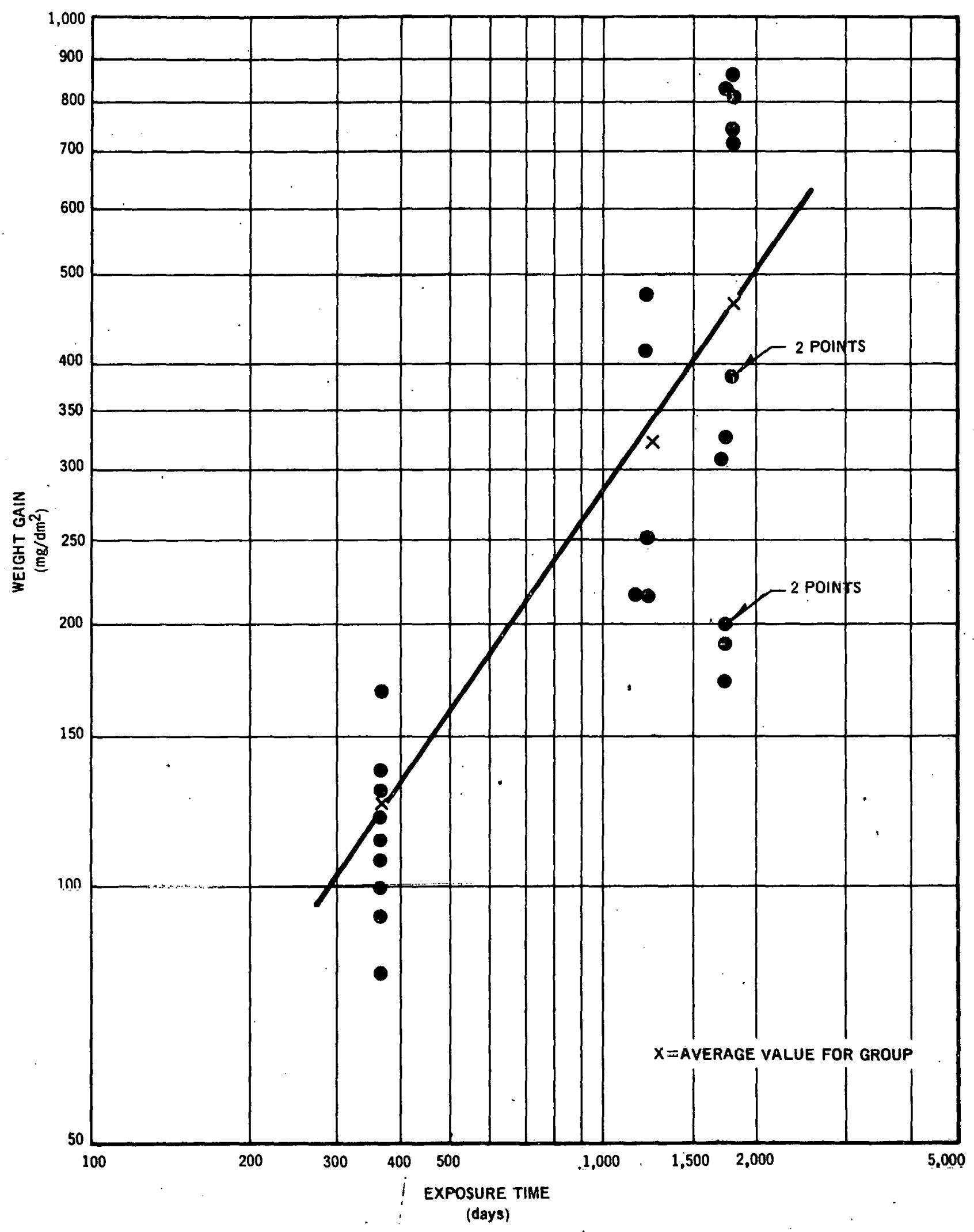

Figure 66. Oxide Weight Gain for SA-1 Cladding as a Function of Fuel Rod Operating Time 
and all of the specimens on which crud measurements were made in the initial phase. The crud on rod B56 had spalled down to a continuous white $\mathrm{ZrO}_{2}$ surface at several locations (see Figure 26). A portion of the crud and $\mathrm{ZrO}_{2}$ layers are shown in cross-sectional view in Figure 67. The average thickness of crud on this specimen was $28 \mu(0.0011$ in.); i.e., the maximum measured on any specimen and approximately twice the average thickness measured on the final phase specimens taken as a group. The weight gain shown by specimen No. A624 was $230 \mathrm{mg} / \mathrm{dm}^{2}$ greater than the average for all 16 specimens, but it was still lower than the weight gains shown by 4 of these specimens.

The reason(s) for the wide variation in corrosion behavior shown by the external surfaces of the specimens is not clear. For each group of specimens, the maximum exposure time is only 4 percent greater than the minimum, and over this narrow range the relationship between exposure time and weight gain is quite random. Large differences in weight gains were determined on specimens with approximately the same circumferential-average crud thicknesses. The degree of corrosion does not correlate well with heat flux within the range of values attained. The limited sampling represented by the group of specimens makes it difficult to ascertain any consistent differences in corrosion behavior among the five lots of tubing. The weight gains varied considerably among specimens from the same lot, particularly with lots CA-2 and CA-5. The corrosion of specimens from lots CA-1 and CA-4 was generally somewhat lower than that of specimens from the other lots. Only one specimen from lot CA-3 was examined, and it showed a greater than average weight gain. Chemical analyses of unirradiated samples from the various lots do not appear to offer any clues that might help to explain differences in corrosion behavior of specimens from different lots. ${ }^{2}$

During the visual examinations of the fuel rods, markings frequently were noted near points of contact with the SA-1 subassembly spacer springs. Some of the most prominent markings of this type, at least on decrudded rods, were observed at $36 \mathrm{~cm}(14 \mathrm{in.})$ from the short end plug of rod B70, which was one of those removed from SA-1 after two cycles of operation (see Figure 41). B70 was located in an outside non-corner position in Assembly SA-1; it was in contact at each spacer with three springs and the peripheral spacer band at 90-degree intervals. The band contacted the rod near the top and bottom edges of the $2.5-\mathrm{cm}(1-\mathrm{in}$.) high spacer; spring contact was at the midpoint. The rod was sectioned transversely and ground so that the plane through the center of the spacer spring marks could be examined. These marks can be seen on the macrograph of 'Figure 68 as regions of increased cladding corrosion. One of these regions showed a layer of $\mathrm{ZrO}_{2} 0.14 \mathrm{~cm}(0.055 \mathrm{in}$.) across and 70 to $100 \mu(\sim 0.003$ to 0.004 in.) thick (Figure 69). In general, as Table 13 indicates, the external $\mathrm{ZrO}_{2}$ around the circumference of specimen No. 9960 took the form of a $10 \mu$ film, with intermittent patches 40 to $50 \mu$ (0.0015 to 0.002 in.) thick.

The most prominent spring contact area markings among decrudded rods that operated four cycles in Dresden were shown by corner rod B50. In general, the external corrosion layer around specimen No. A625 consisted of an $\sim 15 \mu$-thick film with numerous intermittent oxide patches 60 to $90 \mu$ thick. A relative increase in corrosion was noted in the vicinity of the prominent contact area in octant 3 and part of octant 2 (see Table 13). In this region the external $\mathrm{ZrO}_{2}$ layer was continuous and 90 to $100 \mu(0.0035$ to 0.004 in.) thick. The prepared surface of specimen No. A625 included a second spring-rod contact area 90 degrees from the one just discussed. This second region showed some enhancement of corrosion, but not to the degree shown by the first contact area. Thus, although rod B50 operated 1468 days in Assembly SA-1, compared with 840 days for rod B70, the corrosion shown by rod B50 in the spring contact region was not much greater than that shown by rod B70. No evidence of mechanical wear of the cladding was detected in either of these spring contact regions.

Like most of the other SA-1 fuel rods, rod B70 did show evidence of cladding wear near midlength, which was caused during VBWR operation by contact with the wire-type spacers (see Figure 42(a)). All of the rods that were scanned for diameter profiles exhibited local diameter peaking at the VBWR spacer locations. In the case of B70, this increase in diameter was $0.009 \mathrm{~cm}(0.0035 \mathrm{in}$.$) . A pronounced localized increase in surface roughness occurred in the$ vicinity of the VBWR spacer location (see. Figure 42(a)). A longitudinal section that passed through a wear groove in the cladding of rod B70 was examined metallographically. The $0.005-$ to $0.008-\mathrm{cm}(0.002$ - to 0.003 -in.)-deep groove is shown in Figure 70 (where it is barely discernible) and in Figure 71. A buildup of $\mathrm{ZrO}_{2} 50$ to $100 \mu 10.002$ to 0.004 in.) thick was observed within the groove and for a distance of about $0.3 \mathrm{~cm} \mathrm{(1/8} \mathrm{in.)} \mathrm{on} \mathrm{either} \mathrm{side} \mathrm{of} \mathrm{it} \mathrm{("a"} \mathrm{in}$ Figure 70). Elsewhere on the "groove side" of specimen No. 9961, the external oxide consisted of an even 9-micron film with a few intermittent patches 14 to 75 microns $(0.0006$ to 0.003 in.) thick. On the opposite (270-degree) side of the specimen, the external $\mathrm{ZrO}_{2}$ generally consisted of an $\sim 10$-micron film with intermittent patches 28 to 103 microns $(\sim 0.001$ to 0.004 in.) thick distributed over the entire length. Over that portion designated "d" in Figure 70, however, a fairly continuous layer of oxide that built up to a maximum thickness of 75 microns $(0.003$ in.) was noted. A part of region " $d$ " is shown at a higher magnification in Figure 72. This particular region may have been close to another spacer wire contact point, although no evidence of wear was observed in the plane examined. The gap 
between the two pellets of specimen No. 9961 probably did not exist during the irradiation of rod B70, but was formed during specimen preparation. The neutron radiograph taken of the rod did not show such a gap at this location.

As was mentioned earlier, the stationary, "decrudded" diameter profiles of some rods showed peaks at pelletlength intervals during both the initial and final phases of the examination program. In an attempt to learn more about the mechanism(s) responsible for diameter increases of this type, a longitudinal specimen was taken from rod A41 at the location indicated in Figure 73. A macrograph of the specimen is shown in Figure 74. The distribution of the external $\mathrm{ZrO}_{2}$ along the two sides of the specimen is shown.

It will be noted that the degree of corrosion is significantly different at different locations on the specimen. The patch-type oxide and, to a lesser degree, the even film-type are thicker on one side (270-degree) than on the other. On both sides, the patch-type $\mathrm{ZrO}_{2}$ is thicker over the whole pellet portion of the specimen than over the ends. In fact, essentially no pitting corrosion took place over the ends of the 90-degree side. (This observation suggests a possible explanation for the "smooth rings" noted at pellet length intervals on the surfaces of some rods (see Figure 40). The variations in diameter along the specimen that one might expect from differences in $\mathrm{ZrO}_{2}$ thickness are of about the same magnitude as the variations over the corresponding portion of the profile scan, but the relationship in regard to distribution is not well defined. It is difficult to say whether or not cladding deformation has occurred at locations of local diameter increase.

It was of interest to consider the possible contribution made by the external corrosion layers to diameter increases and to values of o.d.max-o.d.min. For this purpose the layers of $\mathrm{ZrO}_{2}$ and crud (when present) on five specimens from initial phase rods (Nos. 9954 [Rod A13], 9957 [Rod A41], 9958 [Rod A46], 9962 and 9963 [rod B97]) and six specimens from final phase rods (Nos. A626 [Rod A9] , A582 [Rod A11] , A580 [Rod A37] , A594 [Rod A49], A609 and A625 [Rod B50]) were compared with the diameter profiles of these rods at the specimen locations. Reactor exposure effected a diameter increase that ranged from 0.0013 to $0.0038 \mathrm{~cm}$ (0.0005 to $0.0015 \mathrm{in}$.) and averaged $0.0025 \mathrm{~cm}(0.001 \mathrm{in}$.) among the initial phase specimens and that ranged from less than $0.0013 \mathrm{~cm}$ to $0.0076 \mathrm{~cm}(0.003 \mathrm{in}$.$) and averaged 0.0051 \mathrm{~cm}(0.002 \mathrm{in}$.$) among the final phase specimens. The values of$ o.d.max -o.d.min ranged from 0.0025 to $0.0051 \mathrm{~cm}$ for both groups. The average values were approximately $0.0051 \mathrm{~cm}$ for the first group and $0.0038 \mathrm{~cm}$ for the second.

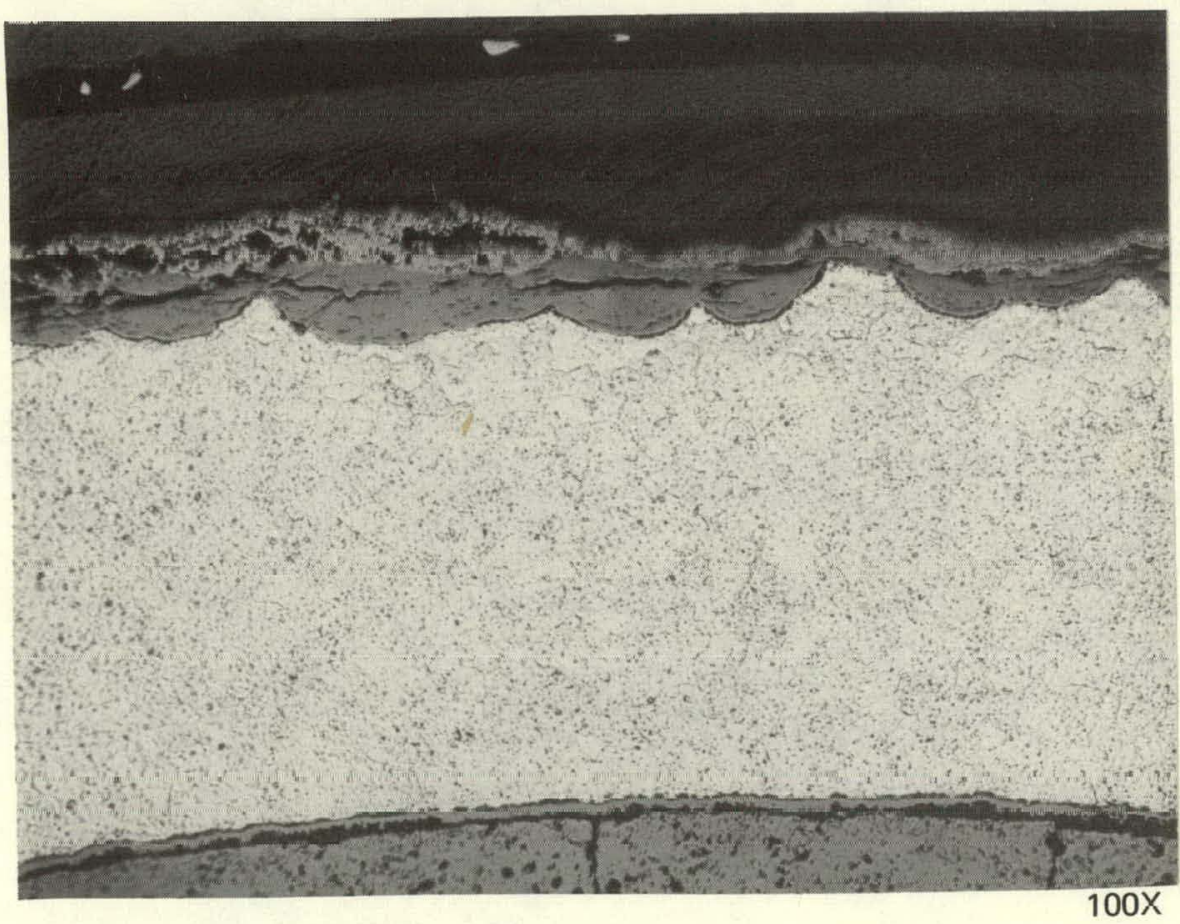

Figure 67. Portion of Rod B56 Cladding Showing Thick Crud and External $\mathrm{ZrO}_{2}$ (Specimen No. A624) 


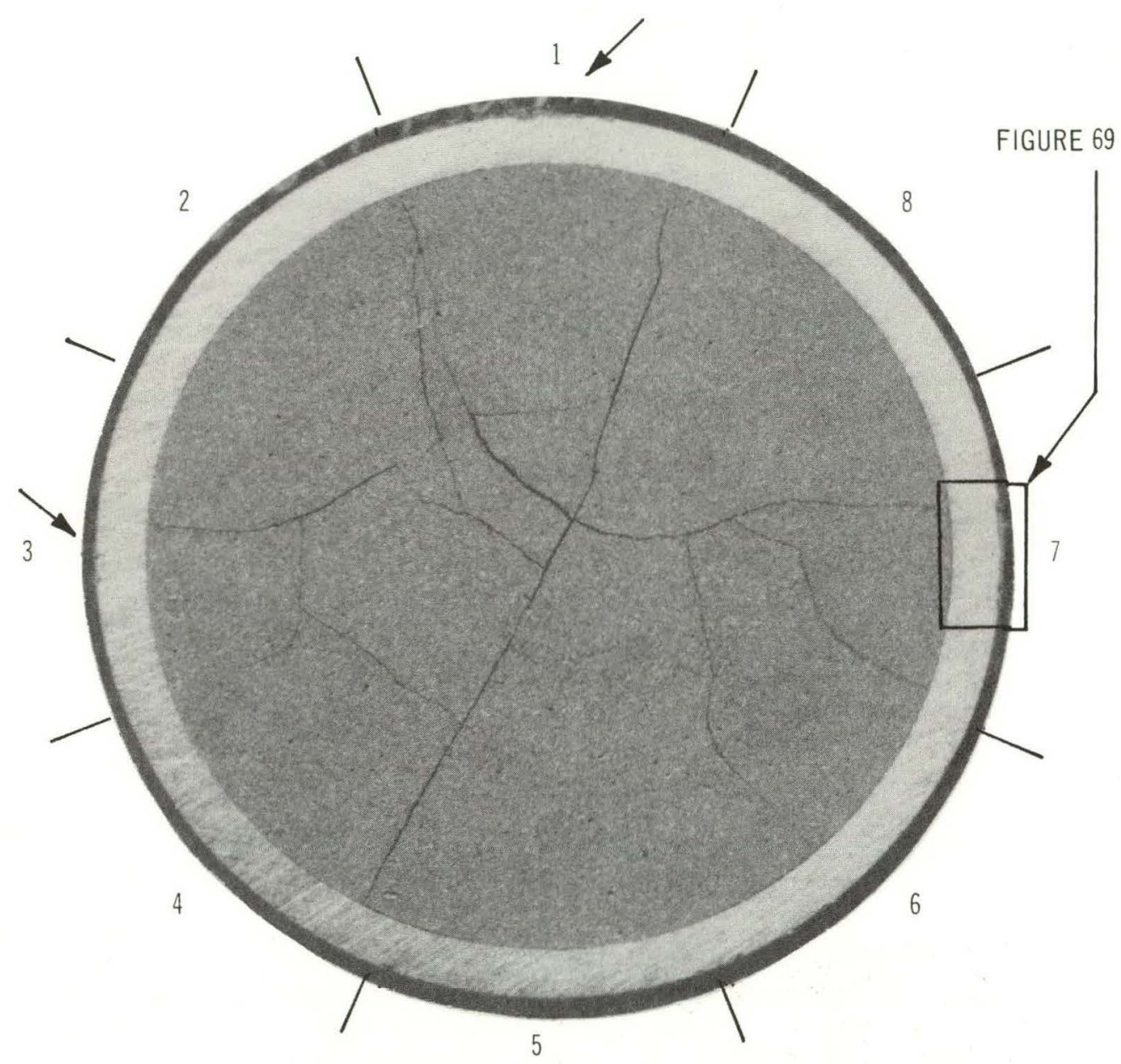

a. HIGH CORROSION REGIONS ARE INDICATED BY ARROWS.

b. LOCATIONS OF OCTANTS LISTED IN TABLE 13 ARE INDICATED BY NUMBERS ABOUT CIRCUMFERENCE.

Figure 68. Macrograph of Specimen No. 9960 (As-Ground-10X Magnification) 


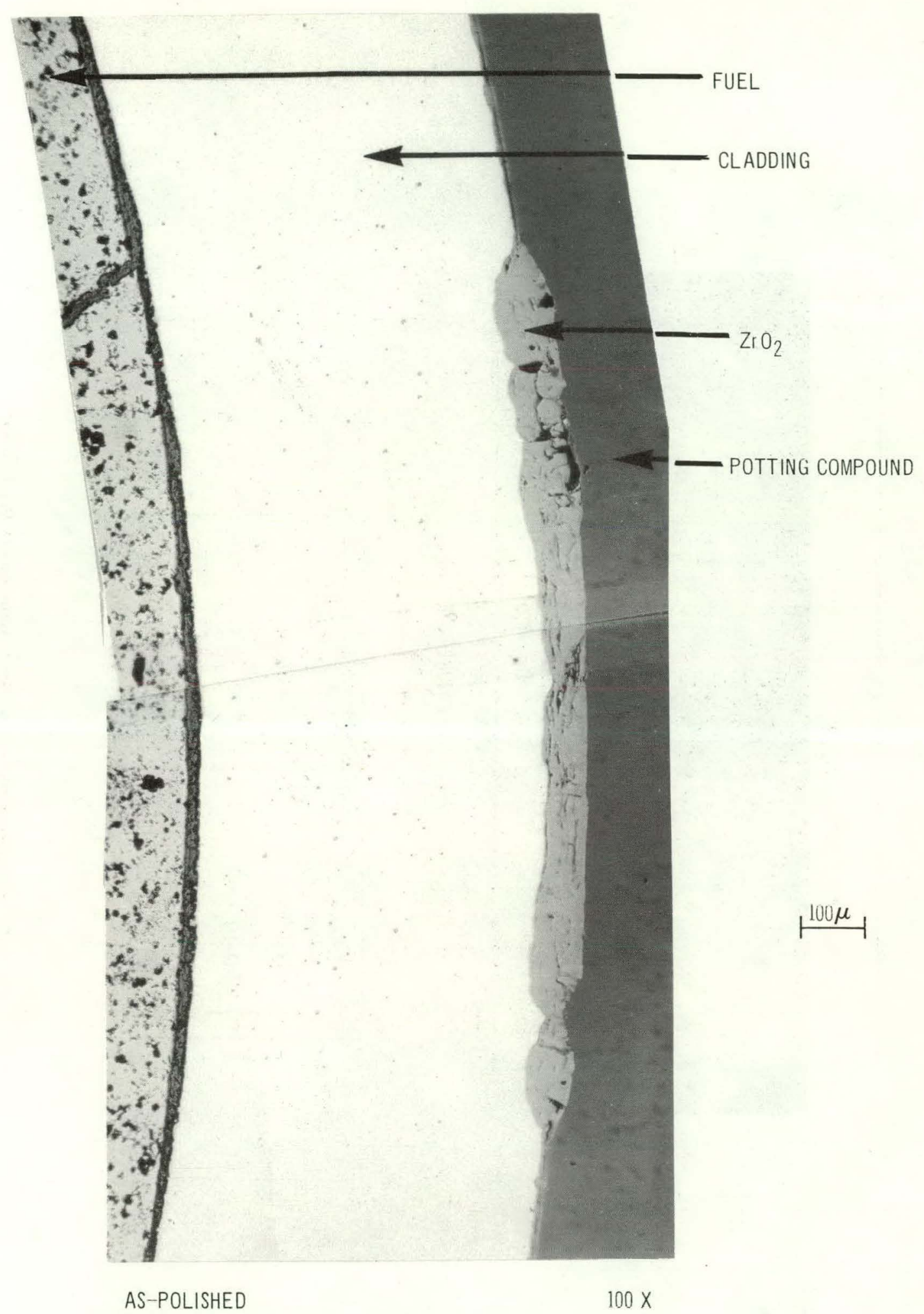

Figure 69. Thick $\mathrm{ZrO}_{2}$ Layer on Cladding in Spacer Spring Contact Area (Rod B70, Specimen No. 9960) 


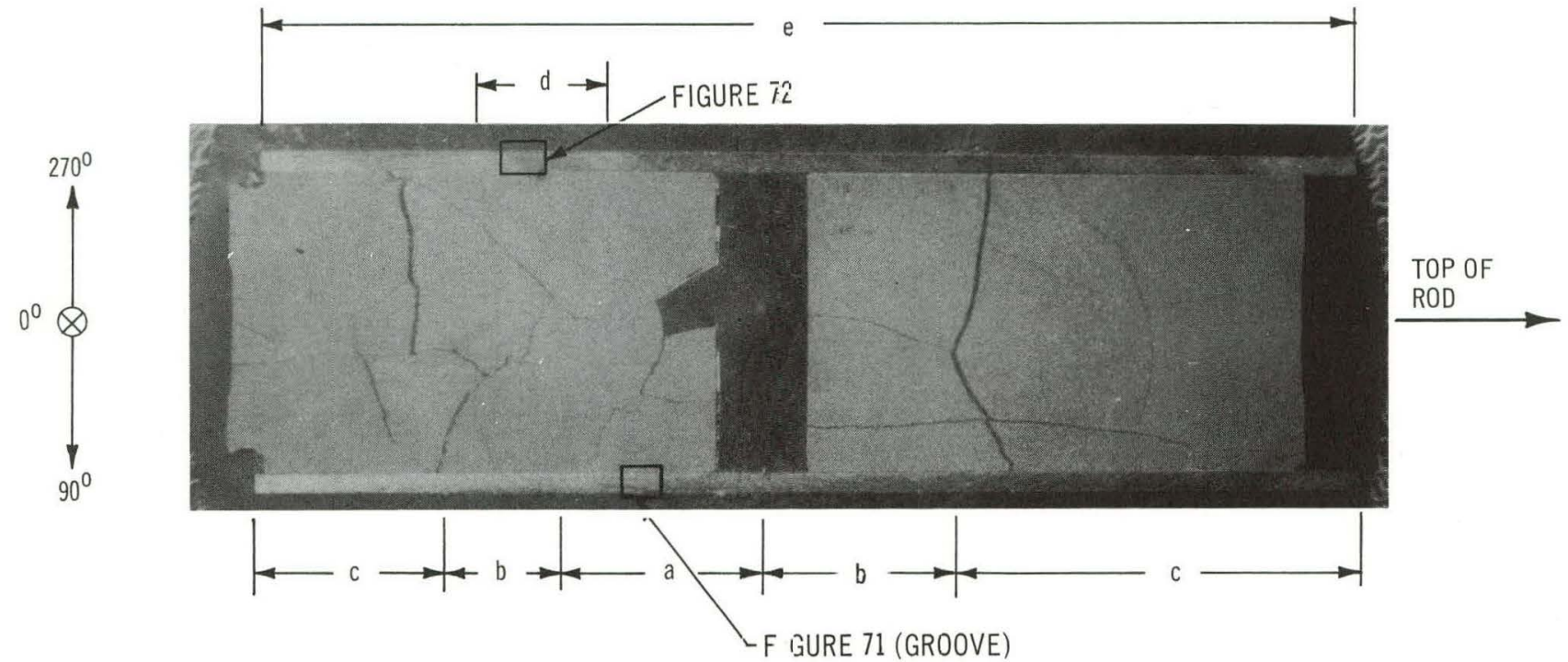

\begin{tabular}{|c|c|c|}
\hline \multirow[b]{2}{*}{ REGIONS } & \multicolumn{2}{|c|}{ EXTERNAL ZT 02 THICKNESS IN M CRONS } \\
\hline & $\begin{array}{l}\text { CONTINUOUS FILM } \\
\text { AVERAGE (RANGE) }\end{array}$ & $\begin{array}{l}\text { INT } \text { ZRMITTENT PATCHES } \\
\text { IVERAGE (RANGEE }\end{array}$ \\
\hline a & $60(56-66)$ & $84(75-94)$ \\
\hline b & & $50(14-75)$ \\
\hline c & $y(4-11)$ & VONE \\
\hline d & $46(19-75)$ & - \\
\hline e & $10(8-14) *$ & $57(28-103)$ \\
\hline
\end{tabular}

* DOES NOT INCLUDE REGION d

Figure 70. Macrograph of Specimen No. 9961 (As-Ground 4X Magnification) External $\mathrm{ZrO}_{2}$ Thickness in l'arious Locations is Shown. 


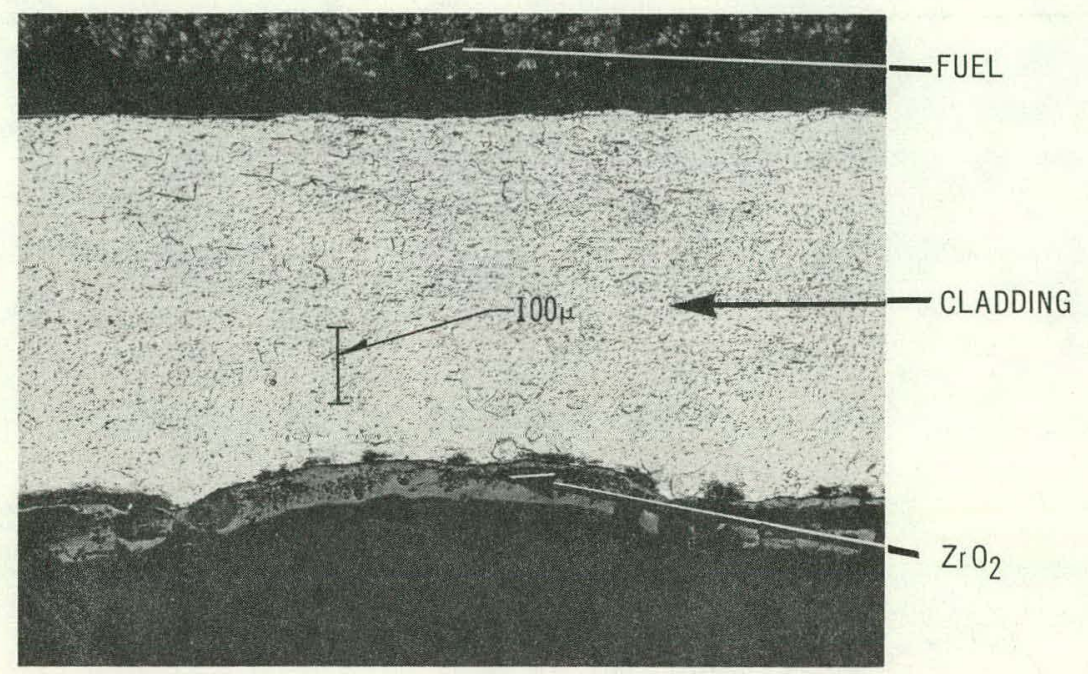

CLADDING ETCHED

Figure 71. Highly Corroded Groove Worn into Cladding of Rod B70 by VBWR Spacer Wire (Specimen No. 9961)

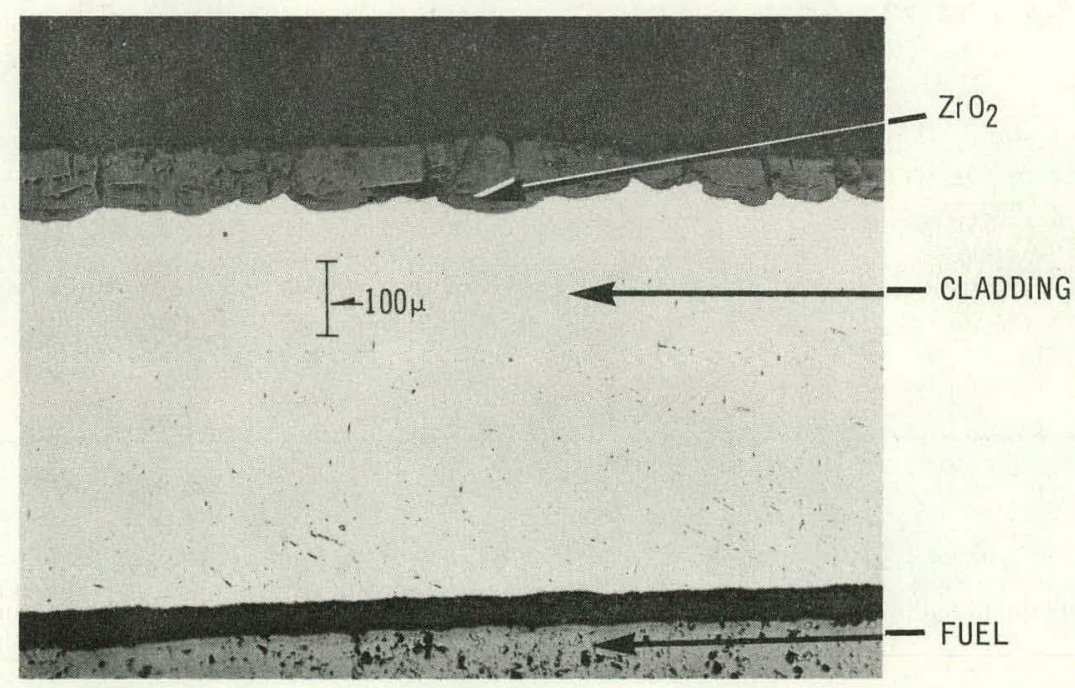

AS-POLISHED

Figure 72. Thick External ZrO., Layer in Region d of Specimen No. 9961. (See Figure 70) 


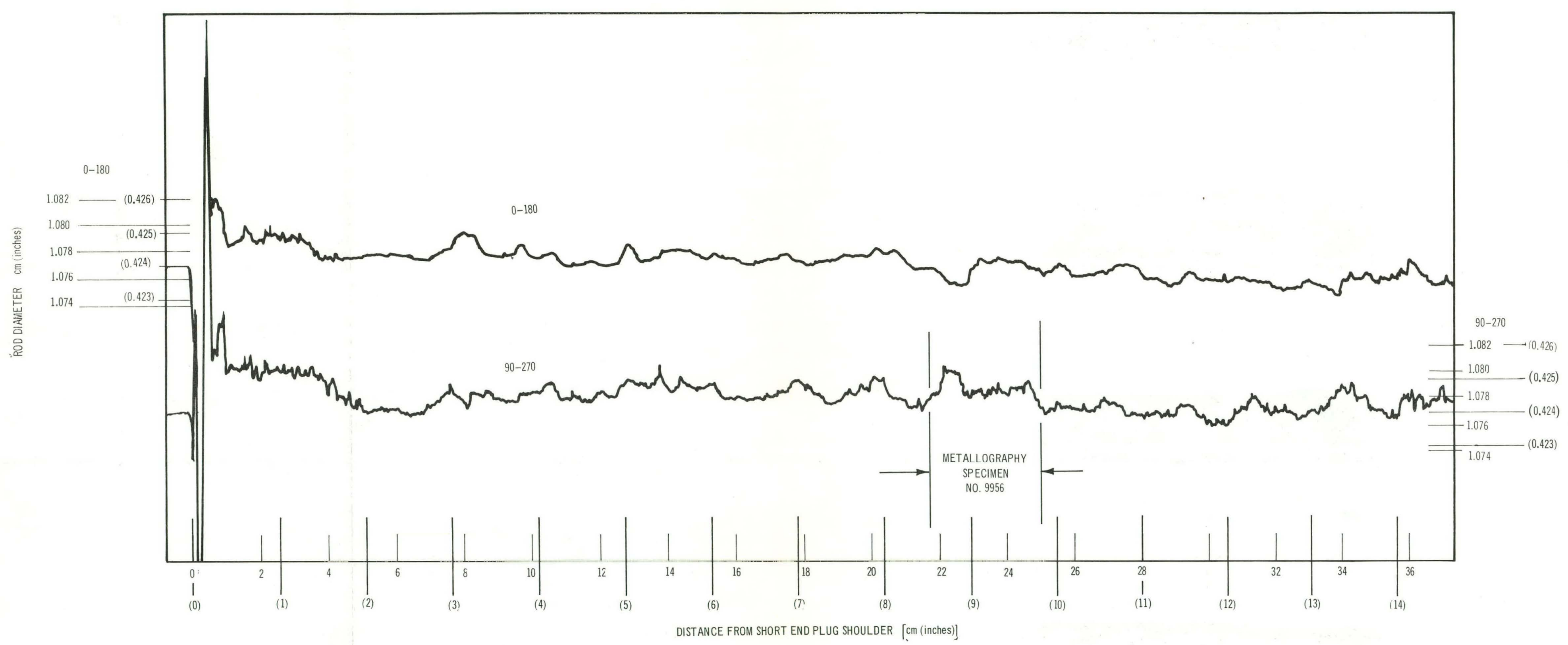

Figure 73. Diameter Profile Traces Over-Part of Rod A41

at O-180-degree and 90-270-degree Orientations.

is Indicated. 


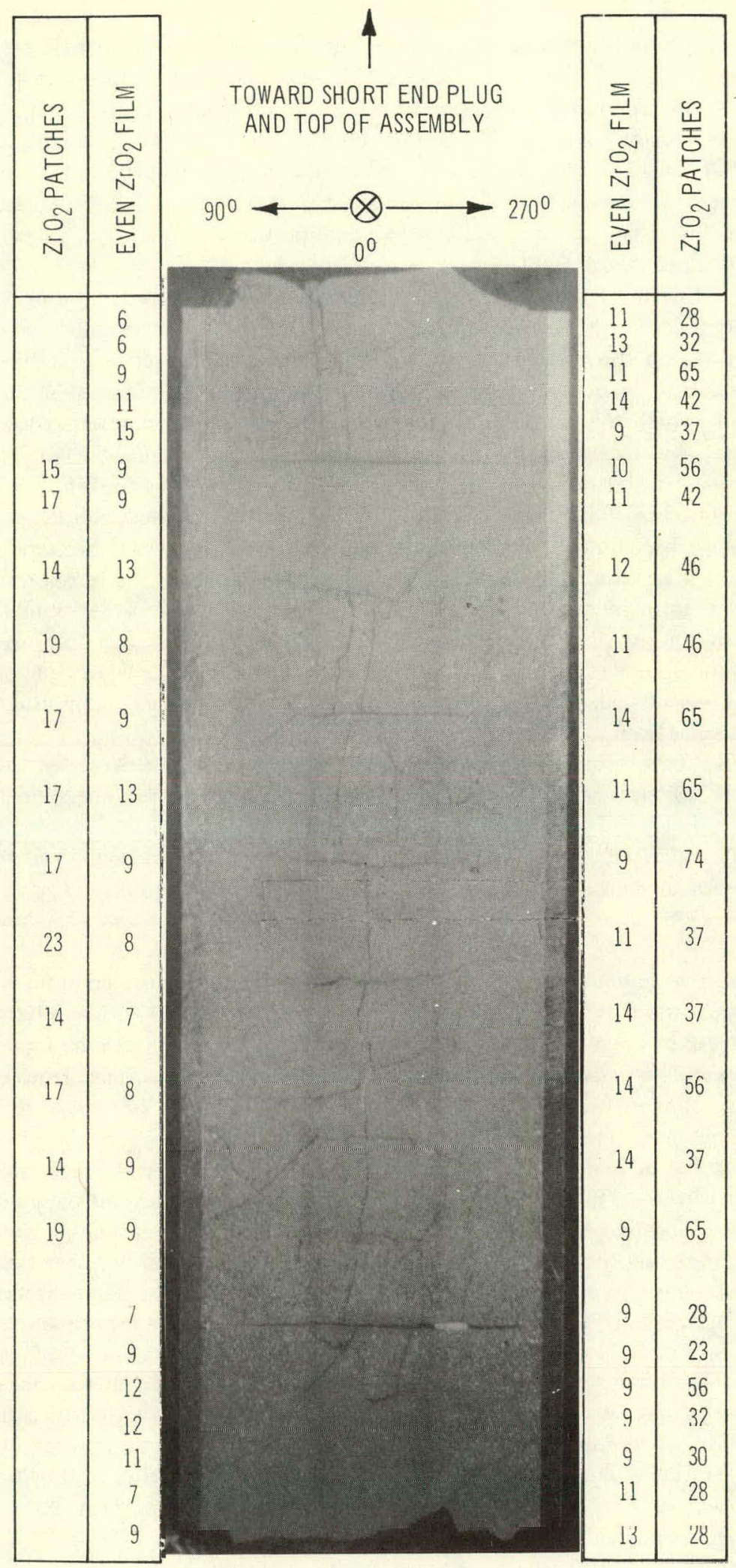

Figure 74. Macrograph of Specimen No. 9956 (As-Ground-5X Magnification). Thickness of Patch-Type and Even-Film-Type $\mathrm{ZrO}_{2}$ on External Cladding Surface is Shown in Microns. 
Subtracting out the estimated contribution of the $\mathrm{ZrO}_{2}$ reduced the diameter increases by as much as 0.0038 to $0.0051 \mathrm{~cm}$ in some instances. With the effects of the corrosion and crud layers taken into account, the diameter changes with respect to pre-irradiation ranged from 0 to $+0.0012 \mathrm{~cm}(0.0005 \mathrm{in.})$ for the initial group and from 0 to $+0.0038 \mathrm{~cm}(0.0015 \mathrm{in}$.) for the second. The rods that operated four cycles in Dresden showed an average increase in diameter of $\sim 0.0025 \mathrm{~cm}(0.001 \mathrm{in}$.) at the specimen locations. Specimen Nos. A594 and A609 were chosen specifically because of the large diameter increases shown by the A49 and B50 profiles at their respective locations $10.0076 \mathrm{~cm}$ or 0.003 in.). After subtracting out the estimated contribution of the $\mathrm{ZrO}_{2}$, both specimens showed increases between 0.0025 and $0.0038 \mathrm{~cm}(0.001$ to $0.0015 \mathrm{in}$.$) .$

The average values of o.d.max - o.d.min were decreased to $\sim 0.0025 \mathrm{~cm}$ for both groups of specimens. The range was 0.0013 to $0.0038 \mathrm{~cm}$ for the initial group and 0 to $0.0038 \mathrm{~cm}$ for the second.

The $\mathrm{ZrO}_{2}$ films on the internal cladding surfaces were quite even and continuous in some cases (Figures 75 and 77) and were spotty in others (Figure 76). It is possible that portions of some of these films were lost during sample preparation. Where the films were continuous, the average thicknesses ranged from less than 1 to $5 \mu$ among specimens from rods that were removed from the assembly at the end of Cycle No. 4 and had a mean value of 3 to $4 \mu$. The thinnest continuous films were shown by the two specimens from rod A46. The internal films on the specimens from rods that operated to the end of Cycle No. 6 were generally thicker than the films on those in the initial group. Those with the longer exposure showed circumferential-average thicknesses that ranged from 4 to $9 \mu$ and had a mean value of $8 \mu$. In some areas of specimens from both groups, fuel, either in the form of individual "globules," as shown in Figure 75, or in the form of rather extensive layers (Figures 77 and 78), was bonded to the $\mathrm{ZrO}_{2}$ film. Particularly where the layers of fuel existed, a layer of a darker material, perhaps a reaction product, was observed between the $\mathrm{ZrO}_{2}$ and fuel layers. A similar phenomenon was noted during the destructive examinations of Fuel Cycle Program fuel rods conducted at the conclusion of VBWR operation. ${ }^{3}$ The thicknesses of the internal and external $\mathrm{ZrO}_{2}$ were not related in any particular way.

Specimen No. A626 from rod A9 was prepared, to examine a possibly defective area in the cladding of the rod. The area showed on a neutron radiograph print as an $\sim 0.1-\mathrm{cm}(\sim 0.04-\mathrm{in}$.) -long spot slightly darker than the surrounding background (see Figure 45). Metallographic examination failed to reveal any reason for the spot. As was mentioned earlier, nothing unusual was noted during the earlier visual examinations of the rod surface or on the diameter profile traces, and analyses of the contained gases indicated that the rod was sound.

\subsection{Fuel}

The $\mathrm{UO}_{2}$ of the following specimens was examined in the etched condition by light microscopy: No. 9954 $(\operatorname{rod} A 13)$, Nos. 9956 and $9957(\operatorname{rod} A 41)$, Nos. 9958 and $9959(\operatorname{rod} A 46)$, Nu. $9960(\operatorname{rod} B 70)$ from the initial group and No. A580 (rod A37), No. A581 (rod B62), and No. A582 (rod A11) from the final group.

Most of the specimens showed no significant radial variation in grain size. However, specimen No. 9956 from the initial group and specimen Nos. A581 (Figure 79(b)) and A582 (Figure 80) from the final group did show evidence of equiaxed central grain growth to varying degrees.

Precipitates were observed within the $\mathrm{UO}_{2}$ grains near the outside surfaces of the pellets in all specimens (Figures $79,80,81$, and 82 ). The lowest concentration of these precipitates was shown by that specimen with the lowest burnup and power rating (No. 9959). With the exception of the three specimens with the lowest exposures (Nos. 9958, 9959, and 9960), intragranular precipitates could be seen at interior locations of the etched fuel as well. With specimen No. 9957 of the initial group and No. A581 of the final group, these interior precipitates were most pronounced at the pellet center as illustrated in Figures $79(\mathrm{~b})$ and $82(\mathrm{a})$. With the remaining specimens that showed interior precipitates, the maximum concentrations were attained at mid-radial locations (Figures 79(a), 80, and 81).

Differences with respect to the distribution of precipitates within the central grains also were noted. In those cases where the precipitates were concentrated at the center, distribution over the grains was quite even as indicated in Figures 79 (b) and 82 (a). In most cases where the maximum concentration occurred at mid-radial locations, the central grains showed precipitate-free bands extending inward from the boundaries as shown in Figure 79(a). However, in the case of specimen No. A582 from rod A11, the precipitates in the central grains are more highly concentrated next to the boundaries than in the grain centers (Figure 80). 


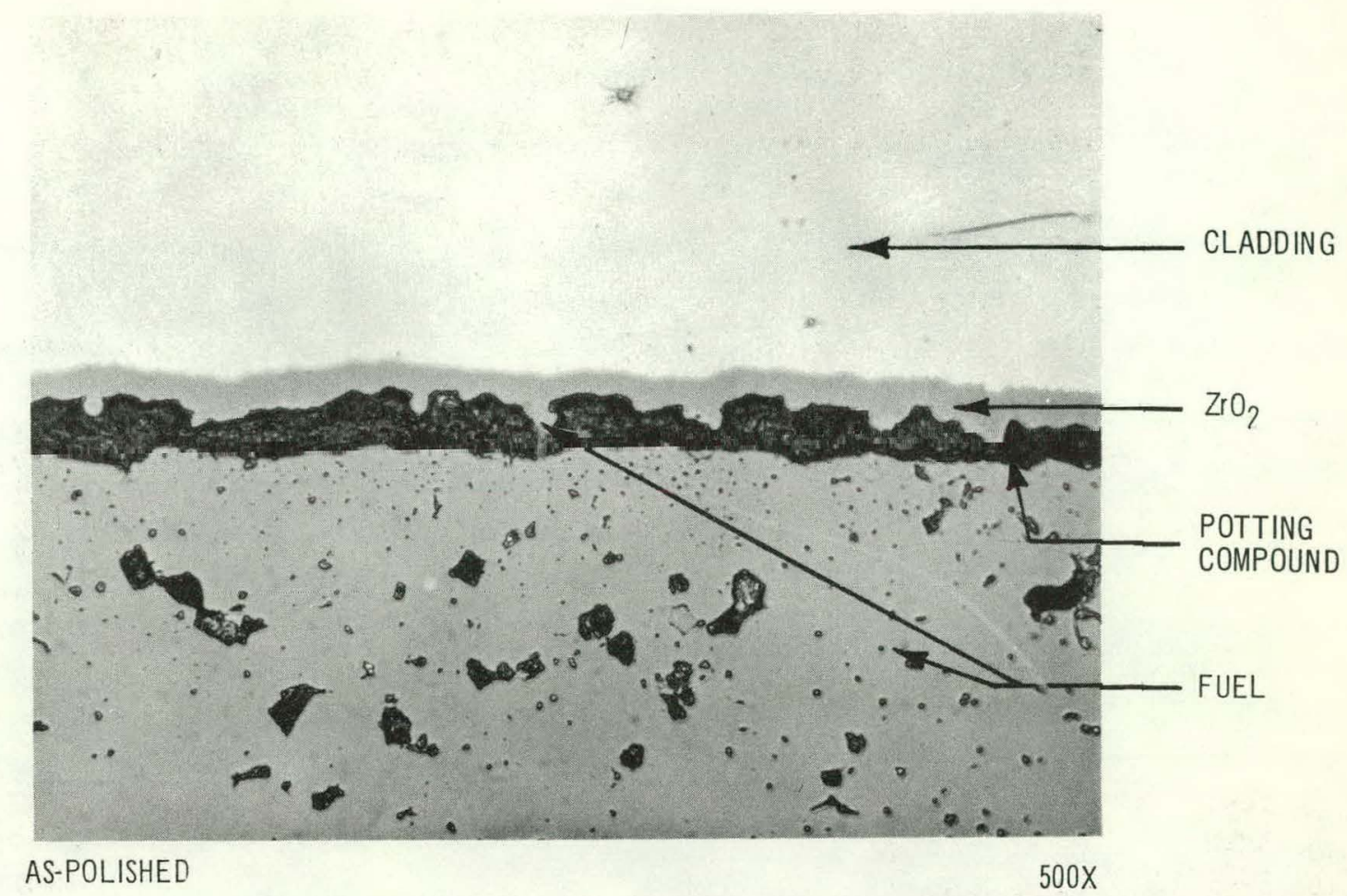

Figure 75. Fuel Particles Attached to Thick Interior $\mathrm{ZrO}_{2}$ Film-Specimen No. 9954

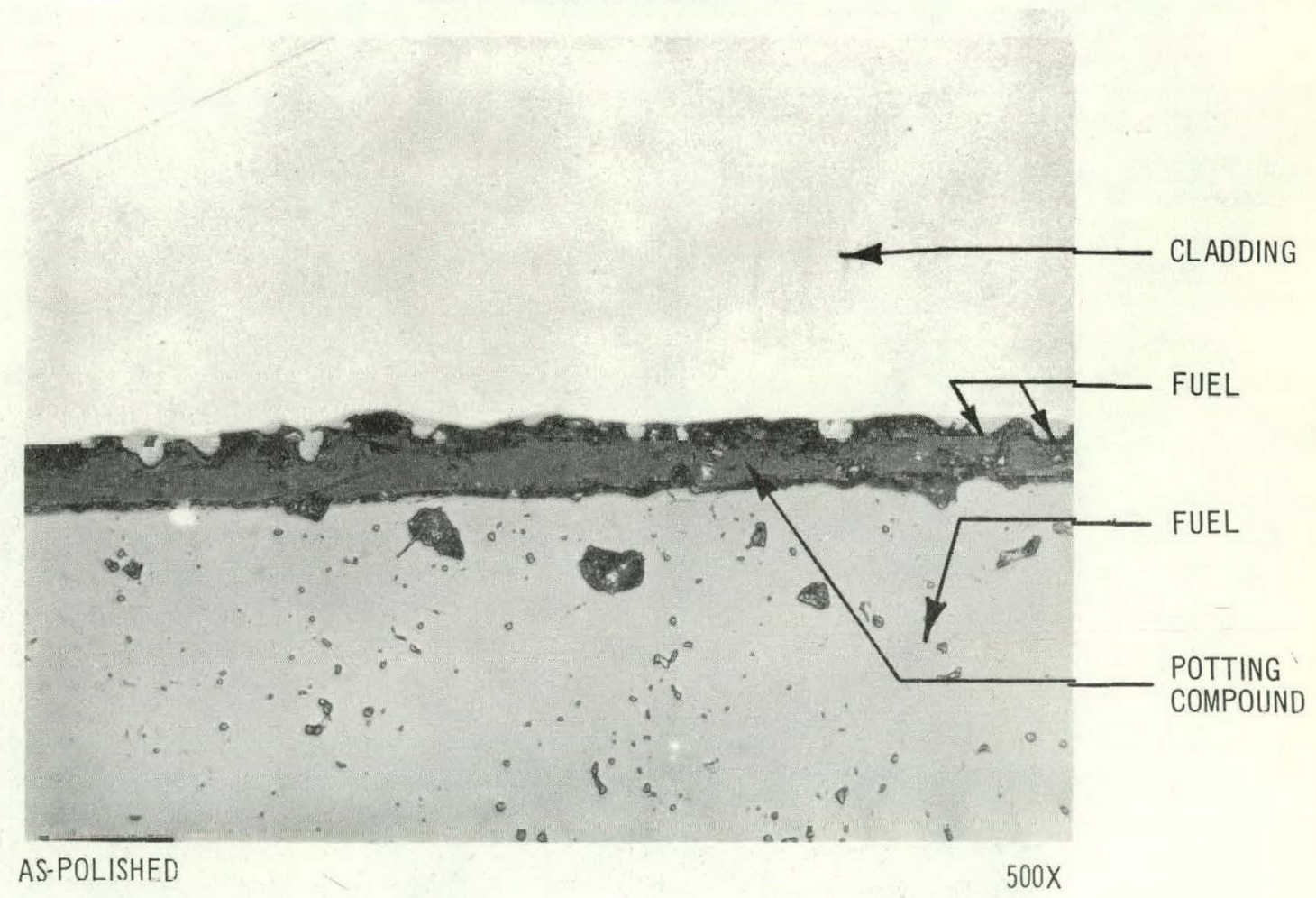

Figure 76. Fuel Particles Attached to Inside Cladding Surface and/or Thin Interior $\mathrm{ZrO}_{2}$ Film-Specimen No. 9958 


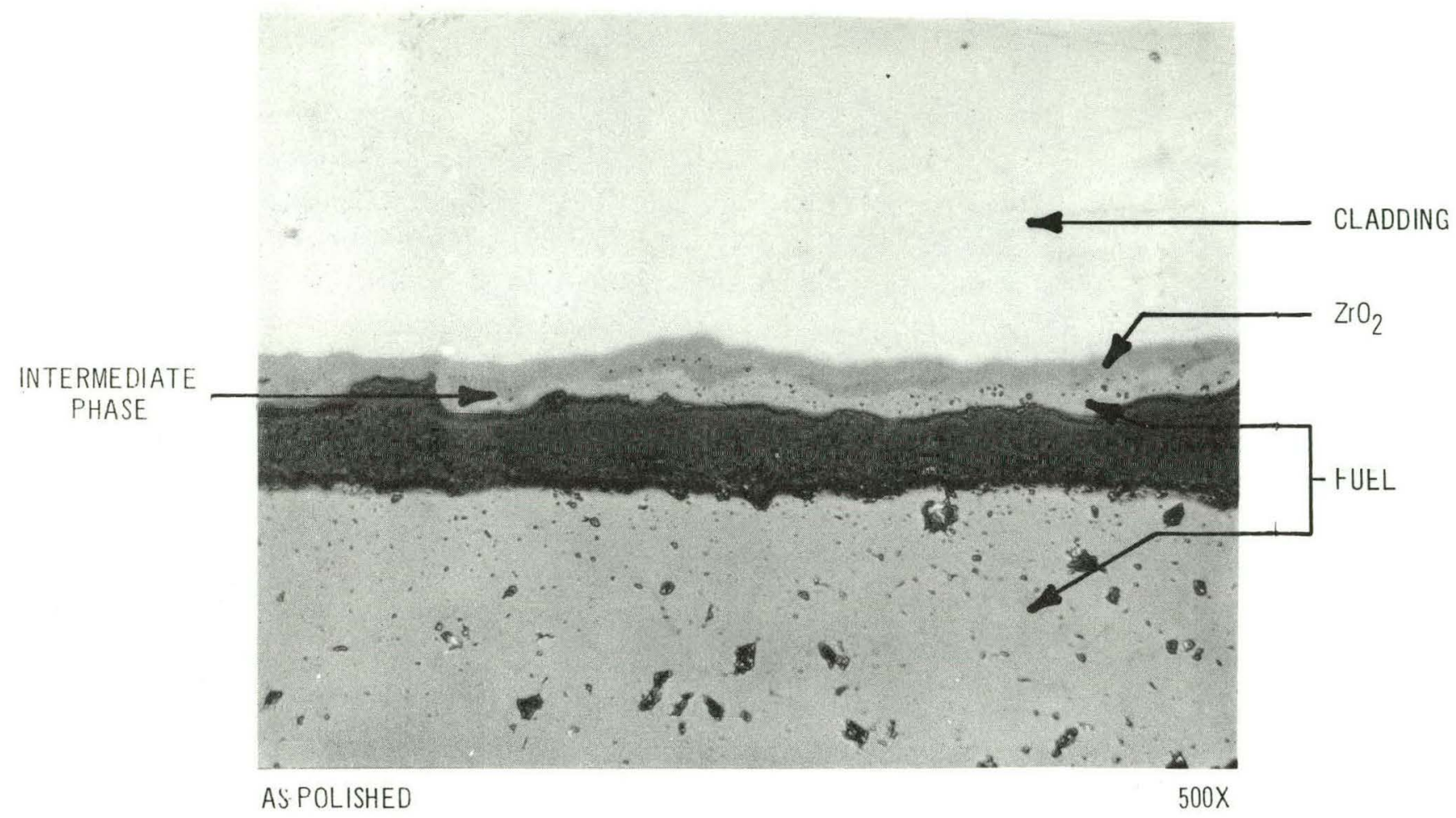

Figure 77. Layer of Fuel Attached to Thick Interior $\mathrm{ZrO}_{2}$ Film and Intermediate Darker Phase

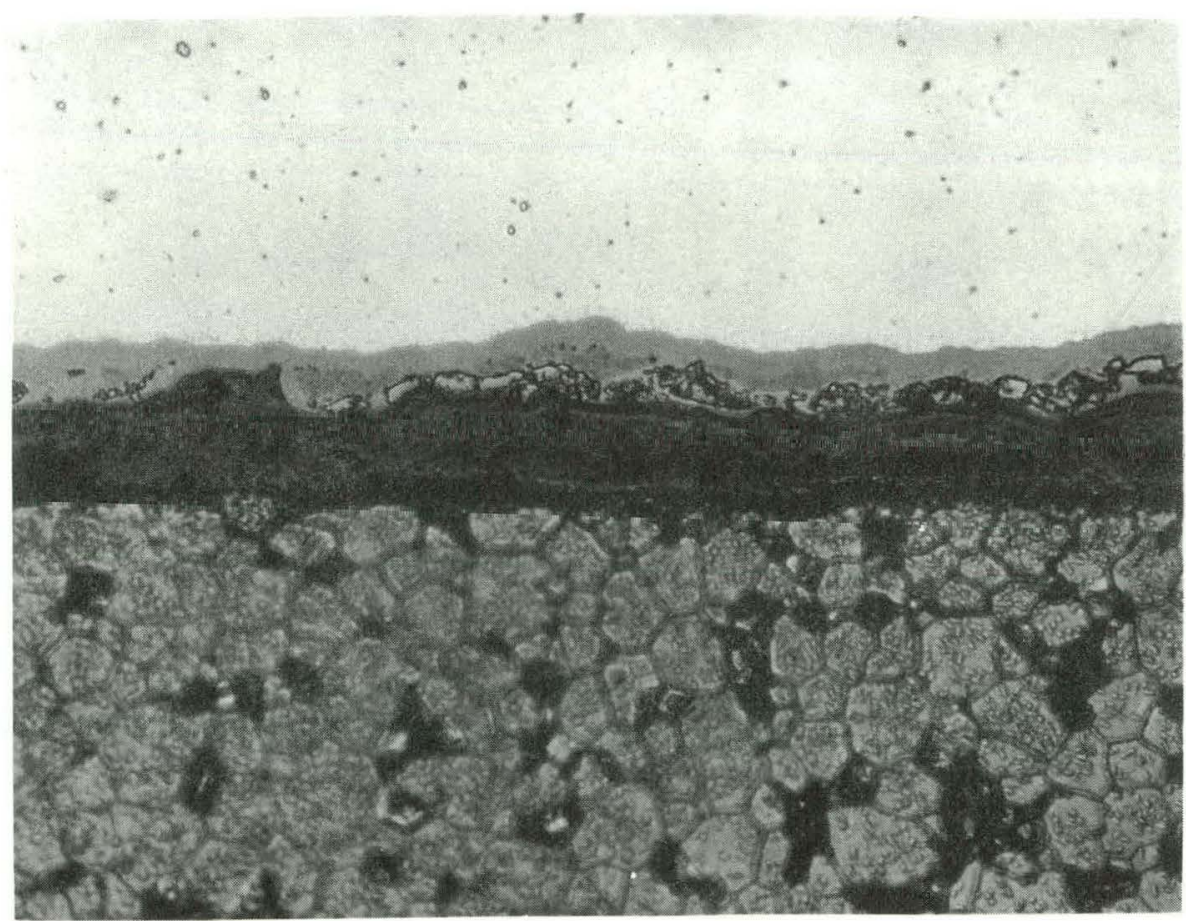

Figure 78. Area Shown in Figure 77 with Fuel in Etched Condition 

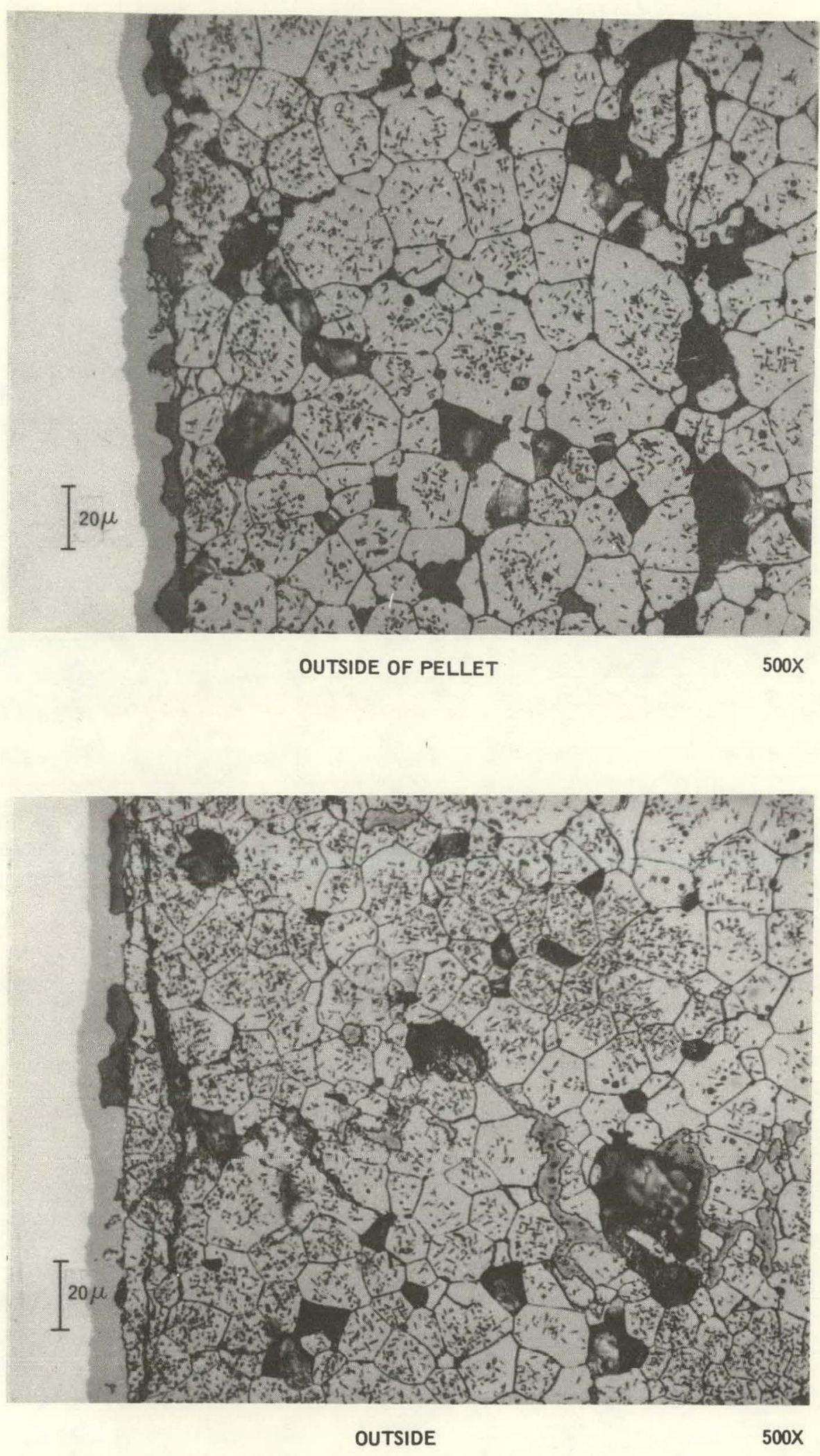

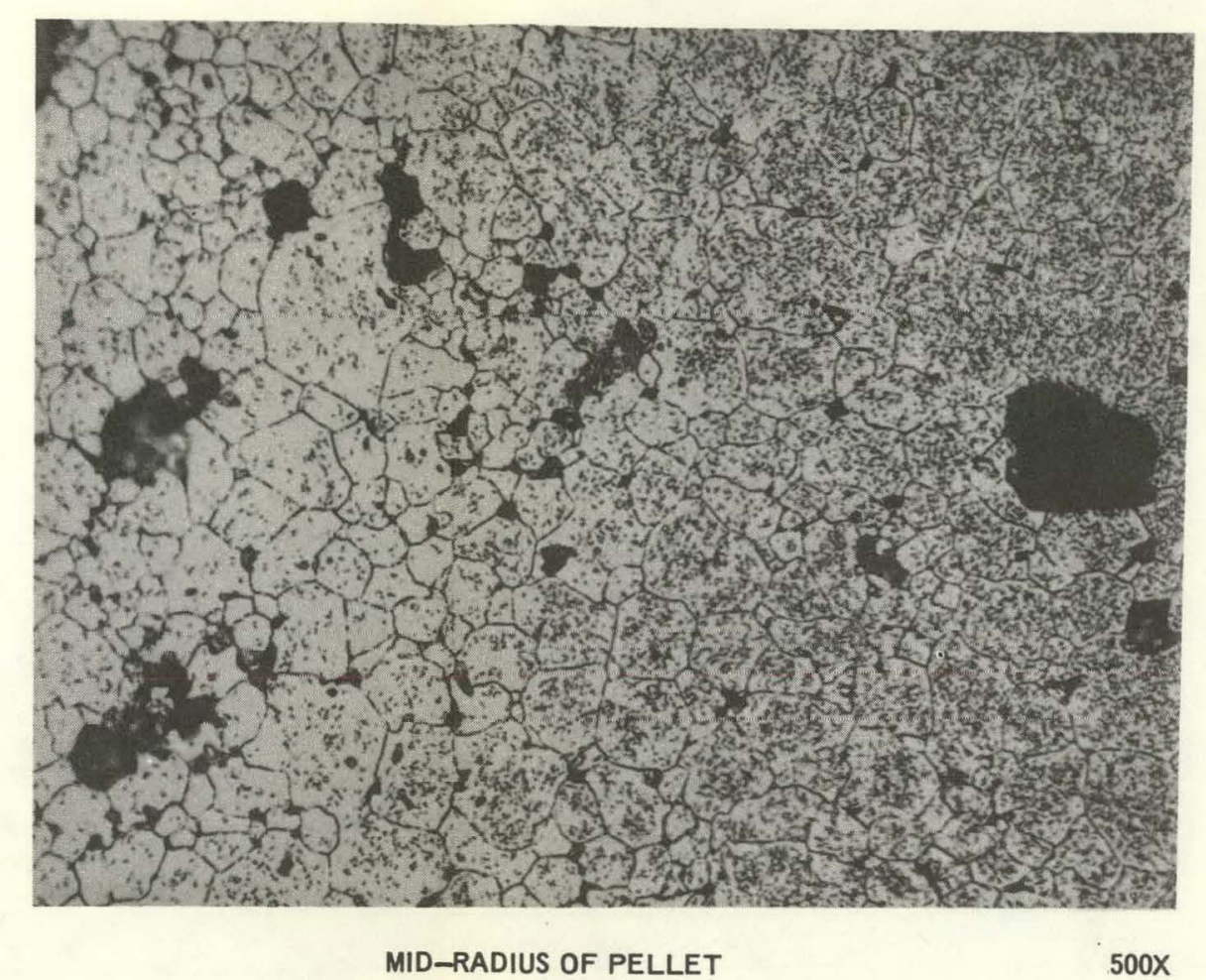

$500 x$

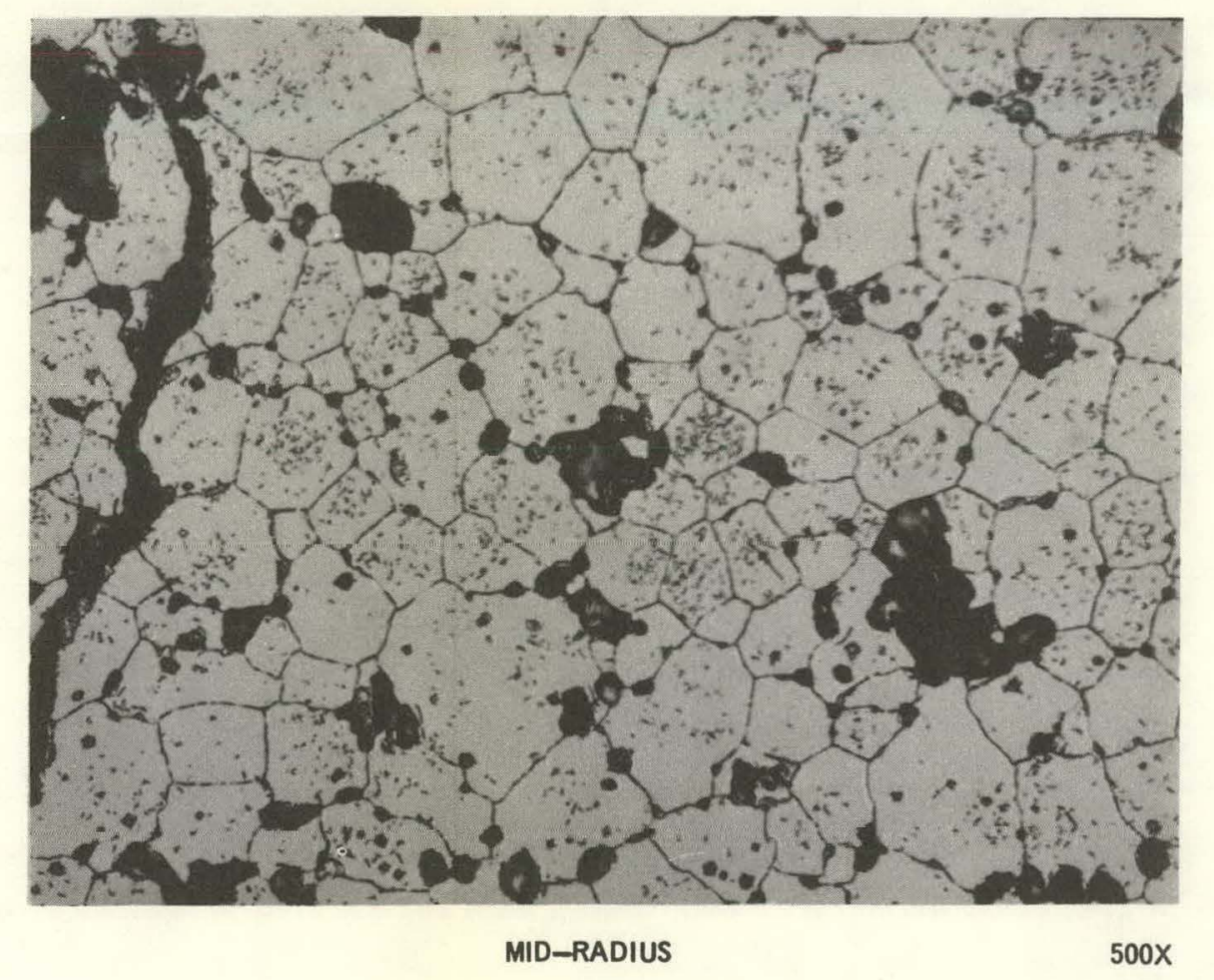

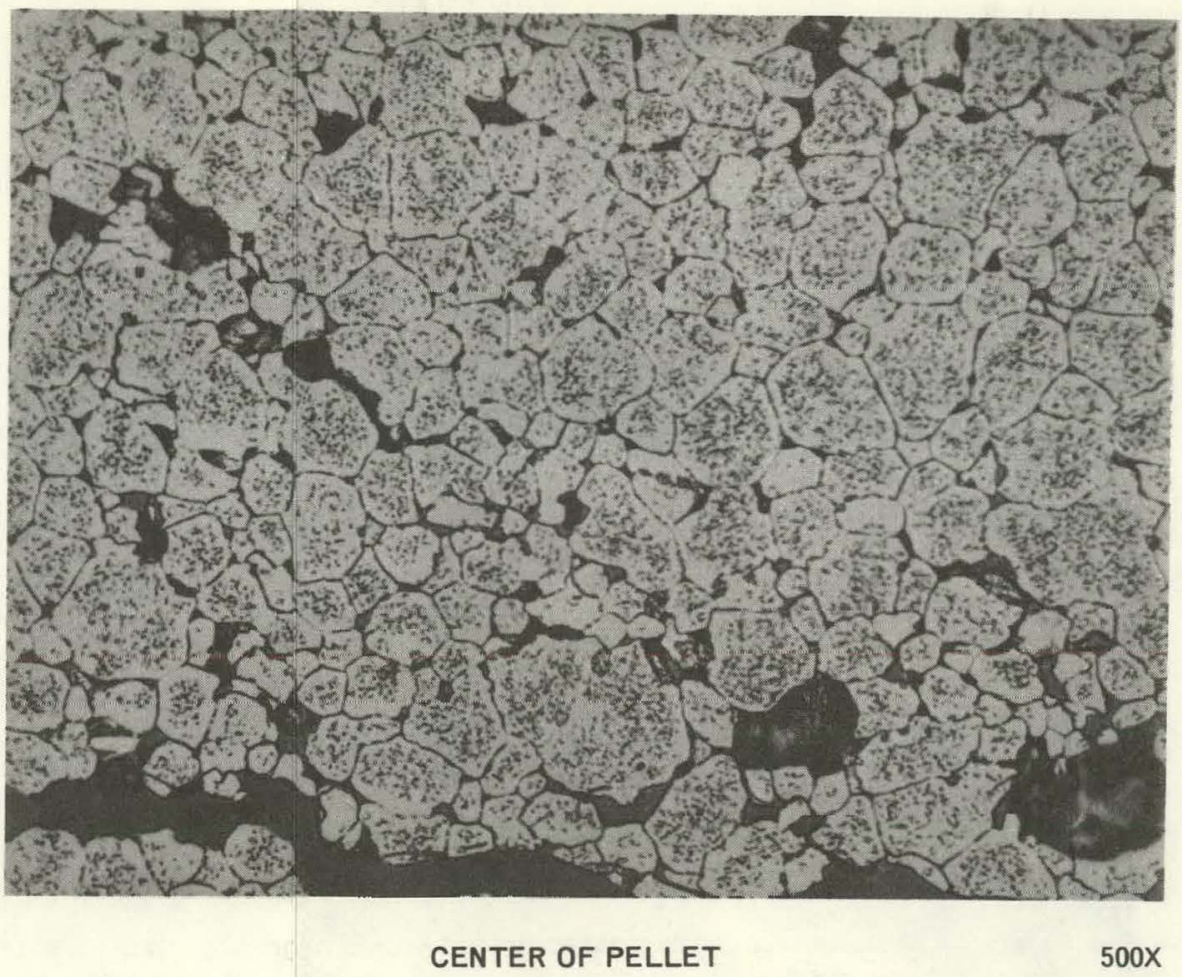

CENTER OF PELLET

$500 x$

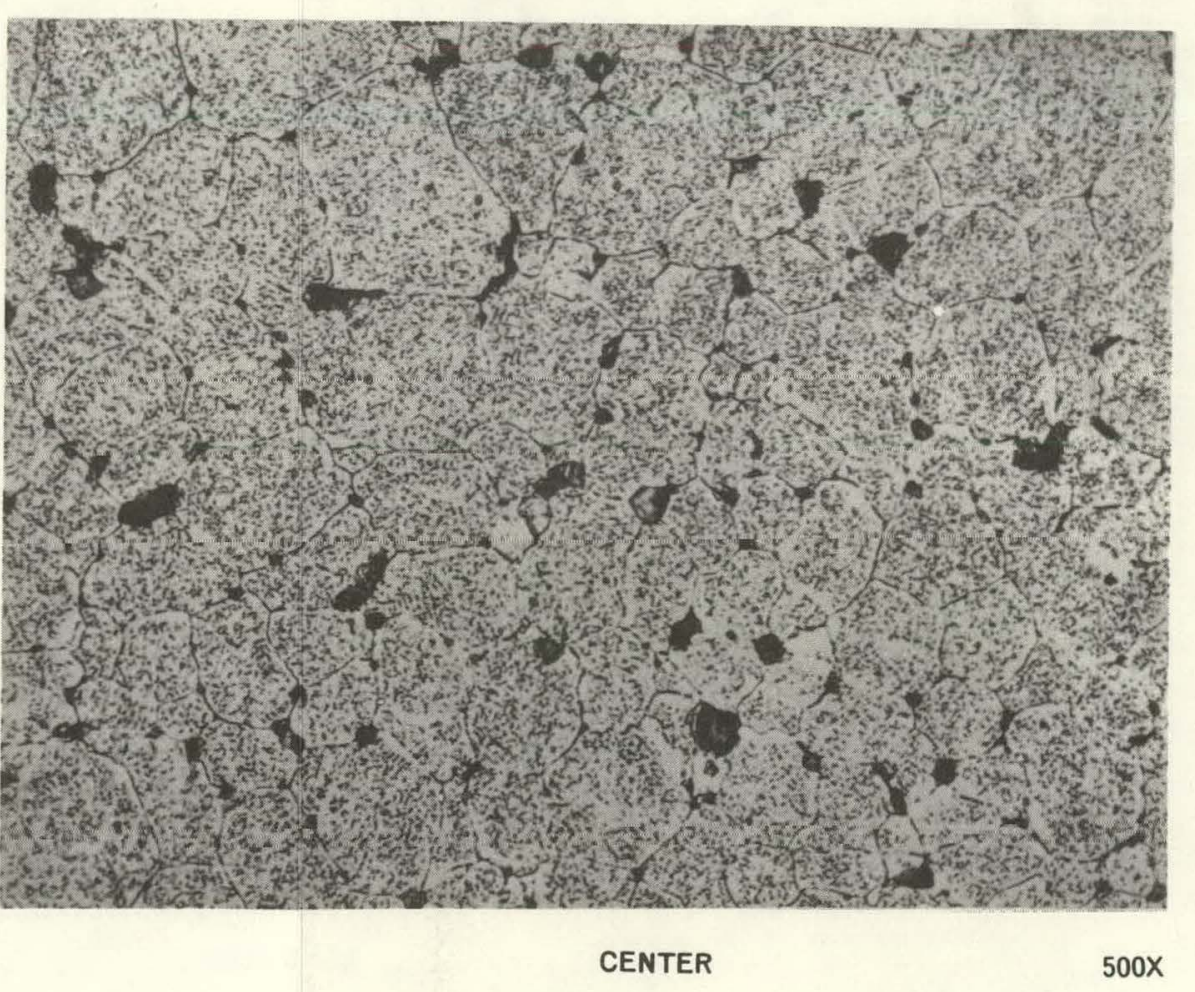

Figure 79. $\mathrm{UO}_{2}$ Microstructures of (a) Specimen No. A580 (Rod A37) and (b) Specimen
No. A581 (Rod B62) (Fuel Etched). 


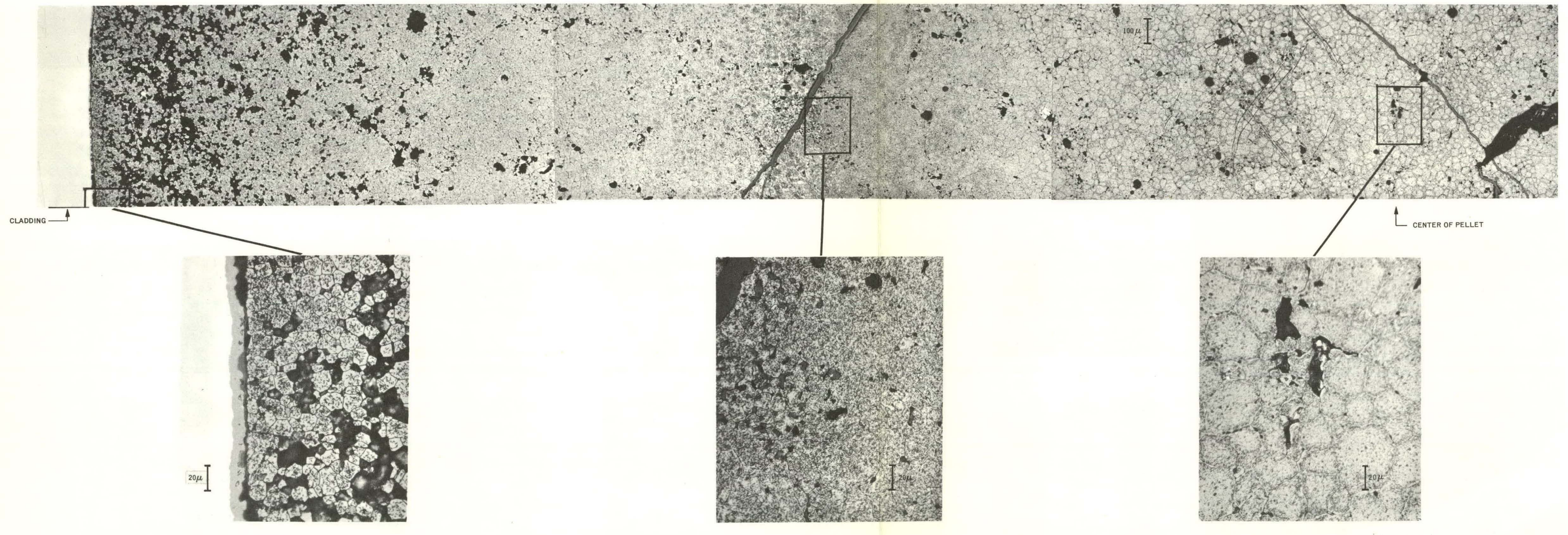




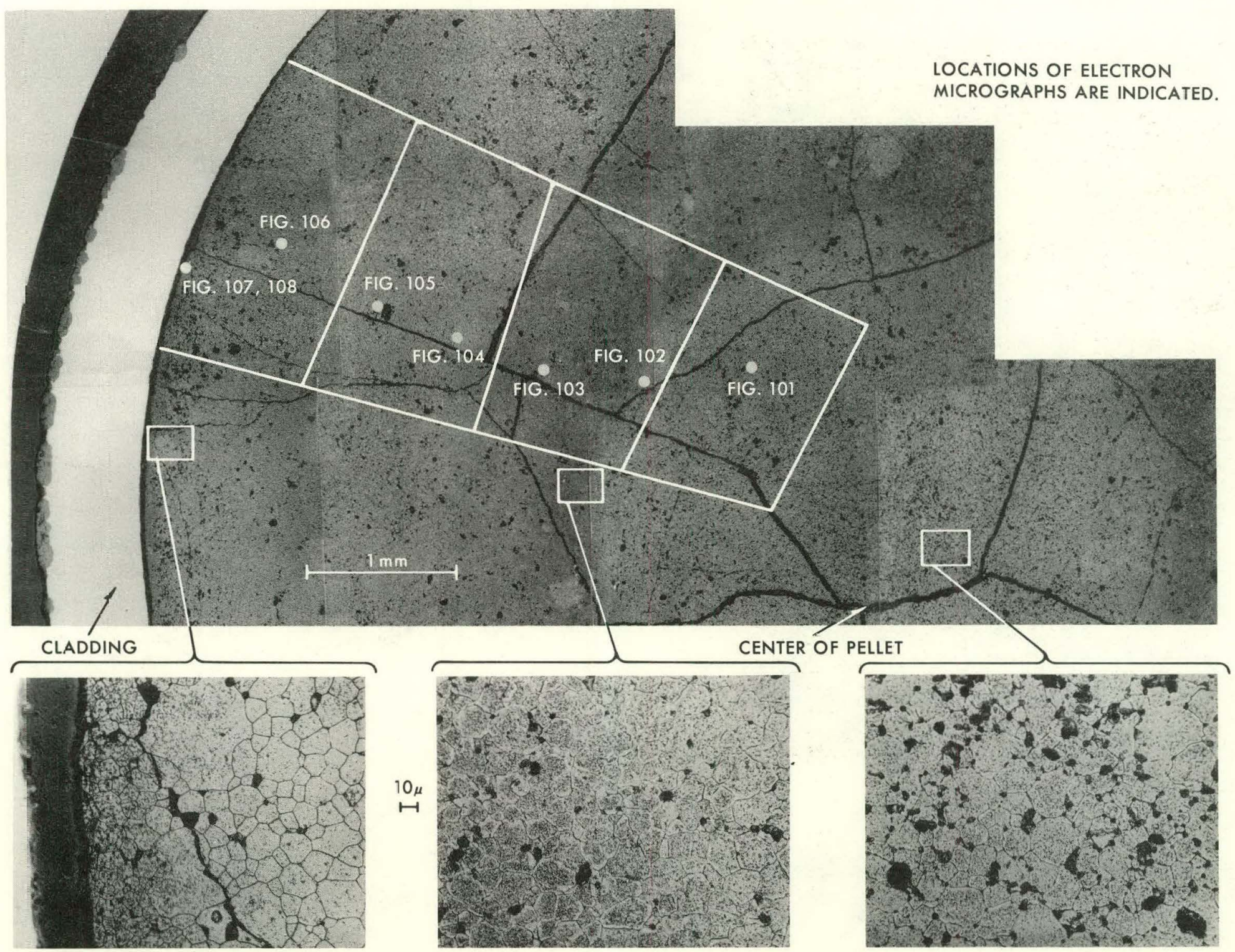

Figure 81. $\mathrm{UO}_{2}$ Microstructure of Specimen No. 9954 from Rod A13 (Fuel Etched).

Area Later Examined by Replication Electron Microscopy Is Outlined (See Subsection 5.2.1). 


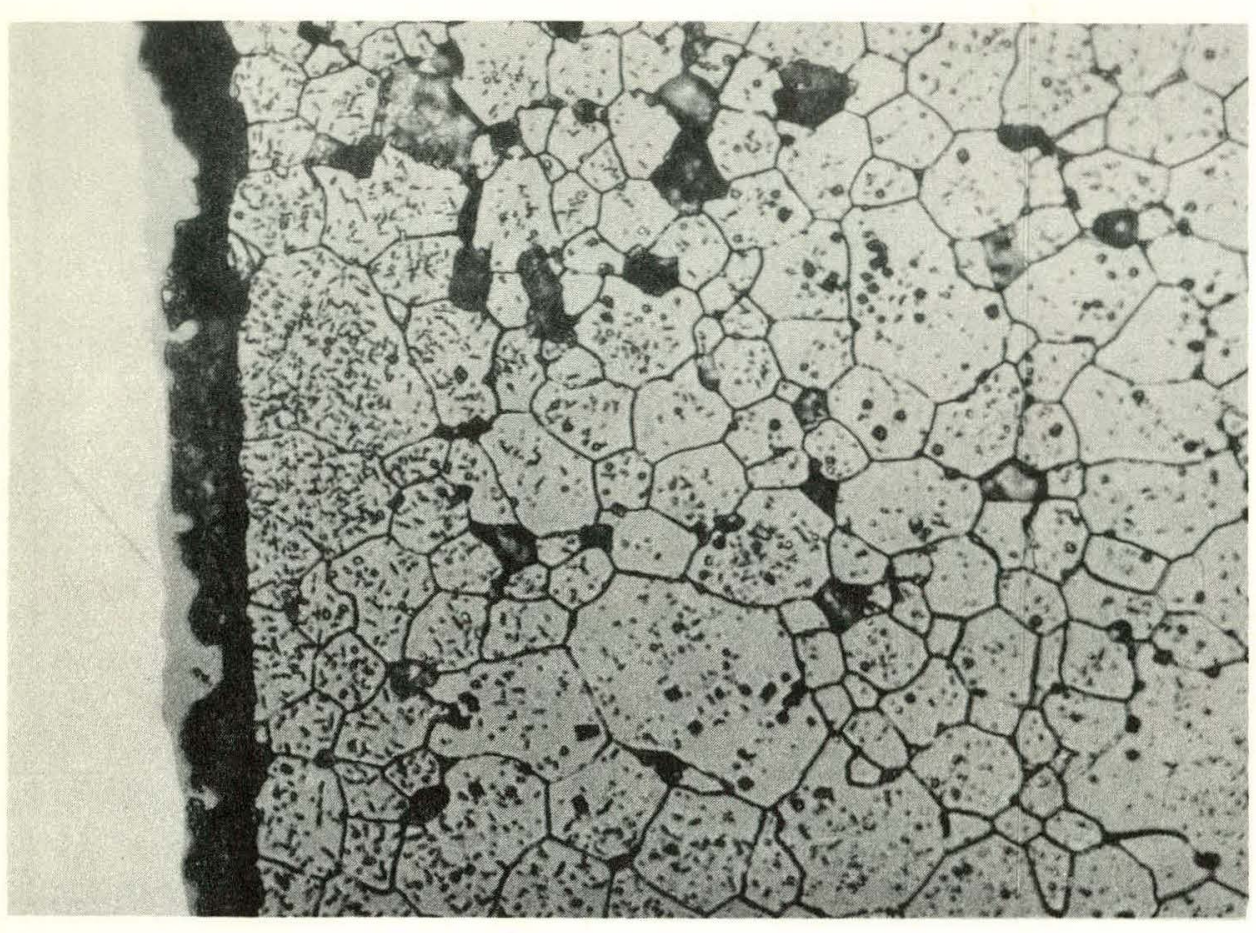

OUTSIDE OF PELLET

$500 x$

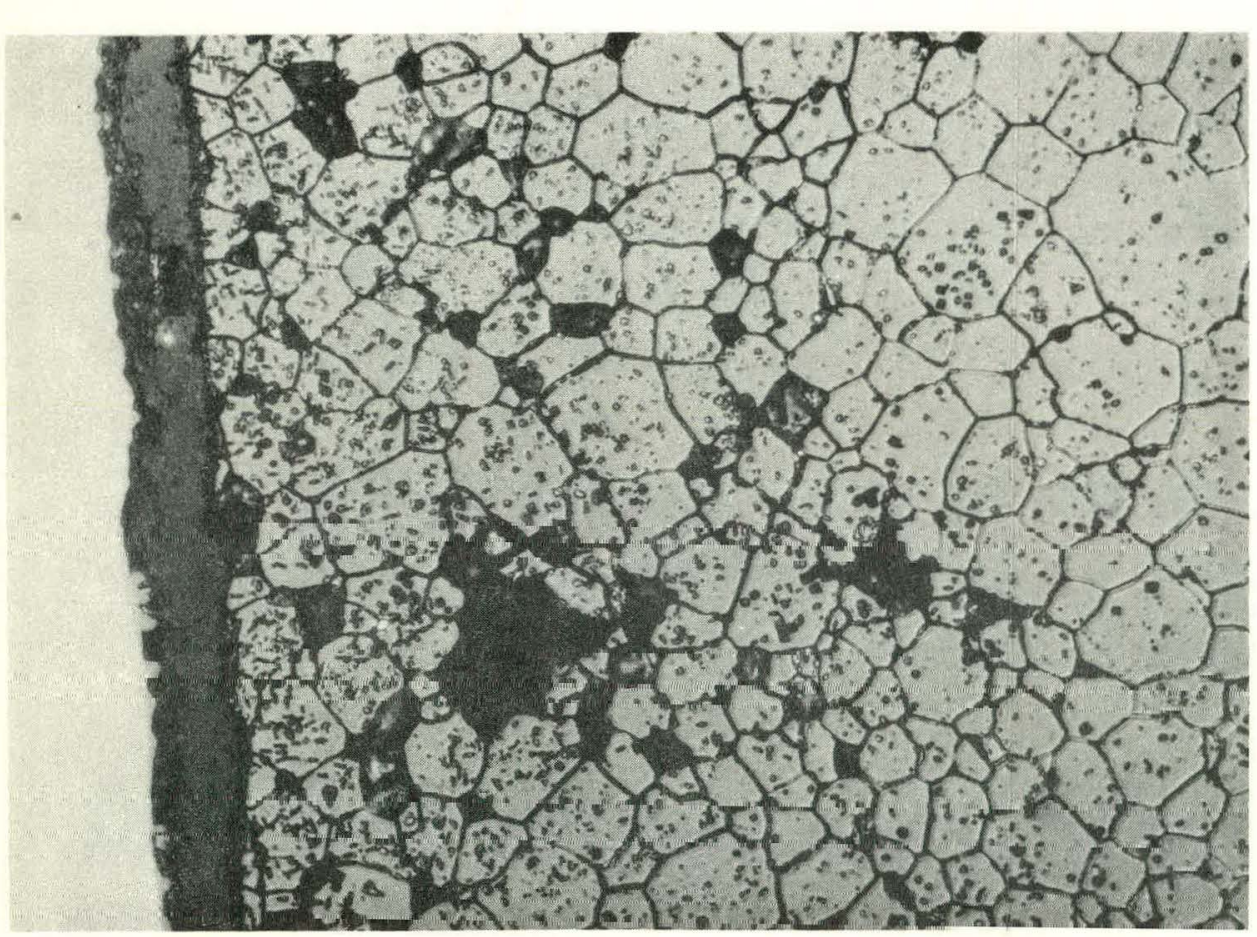

OUTSIDE

Figure 82. $\mathrm{UO}_{2}$ Microstructures of (a) Specimen No. 9957 and (b) Specimen No. 9958-Fuel Etched 45 seconds

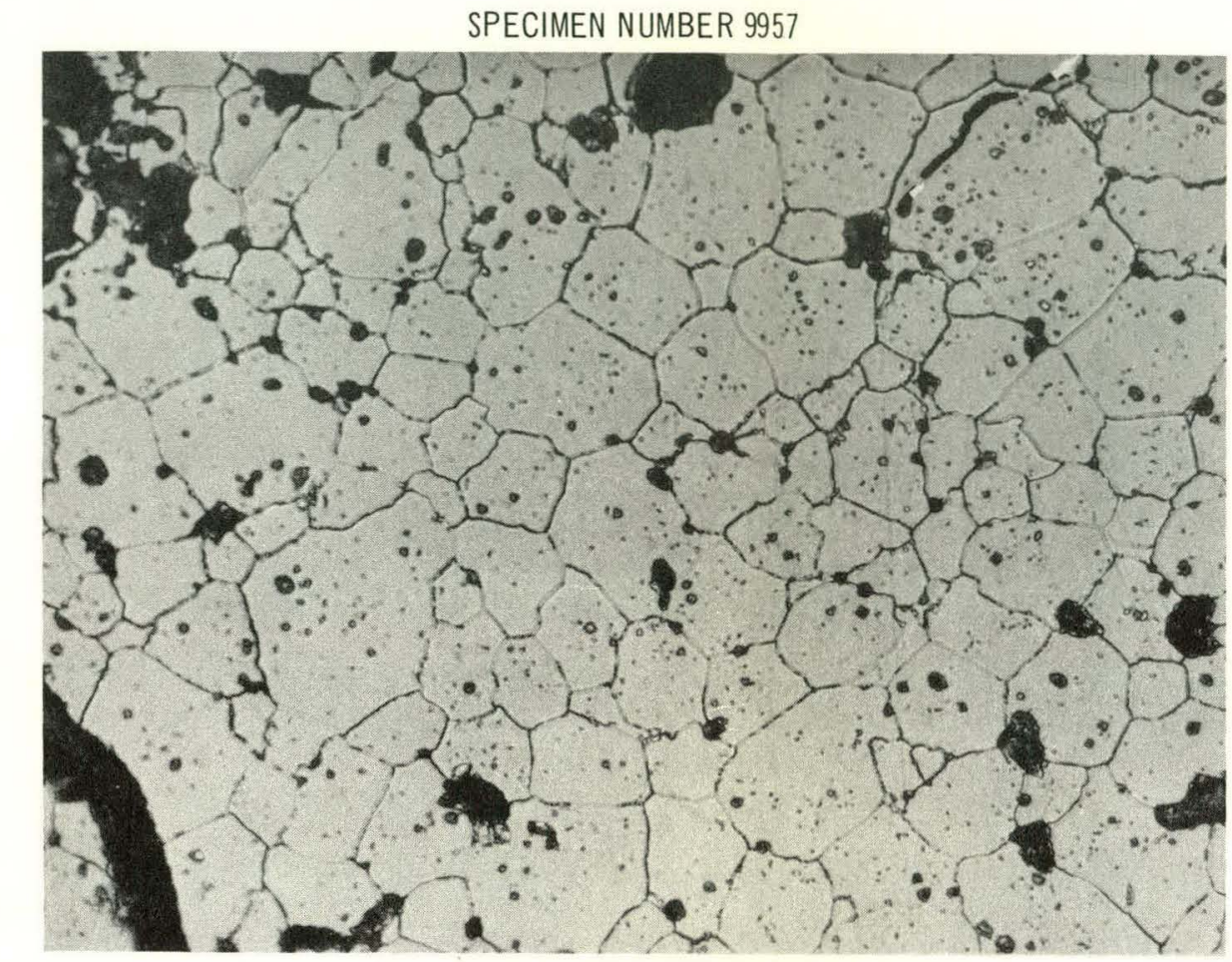

MID-RADIUS OF PELLET

$500 x$

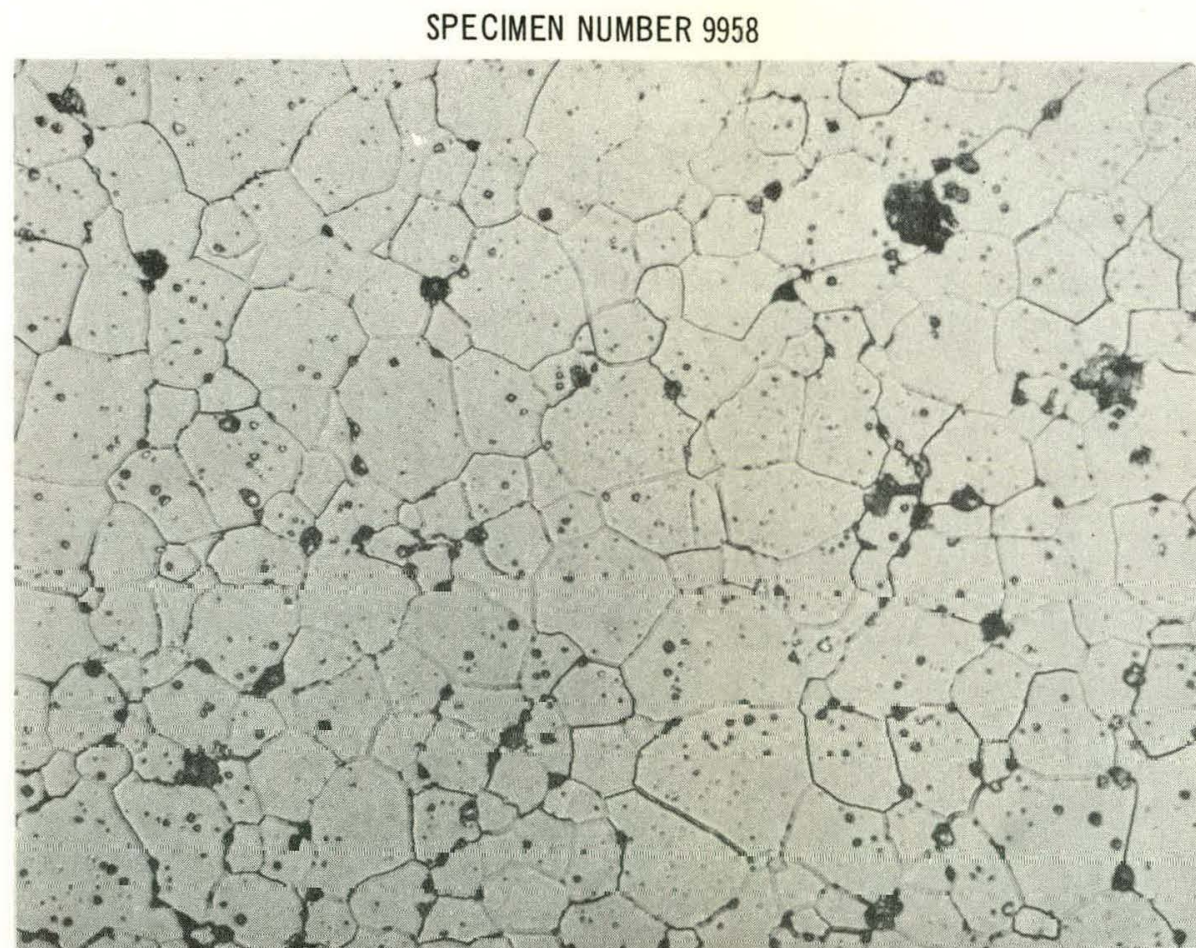

MID-RADIUS

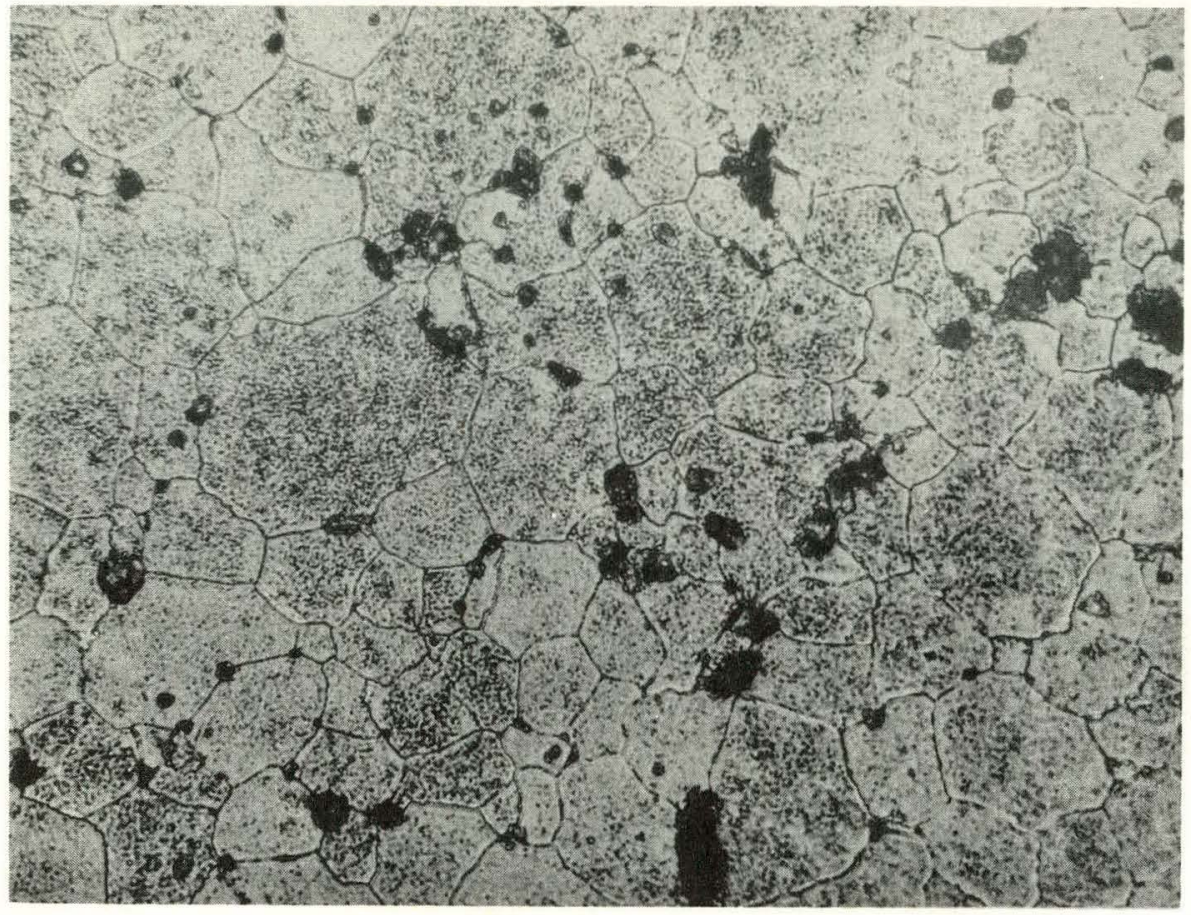

CENTER OF PELLET

$500 x$

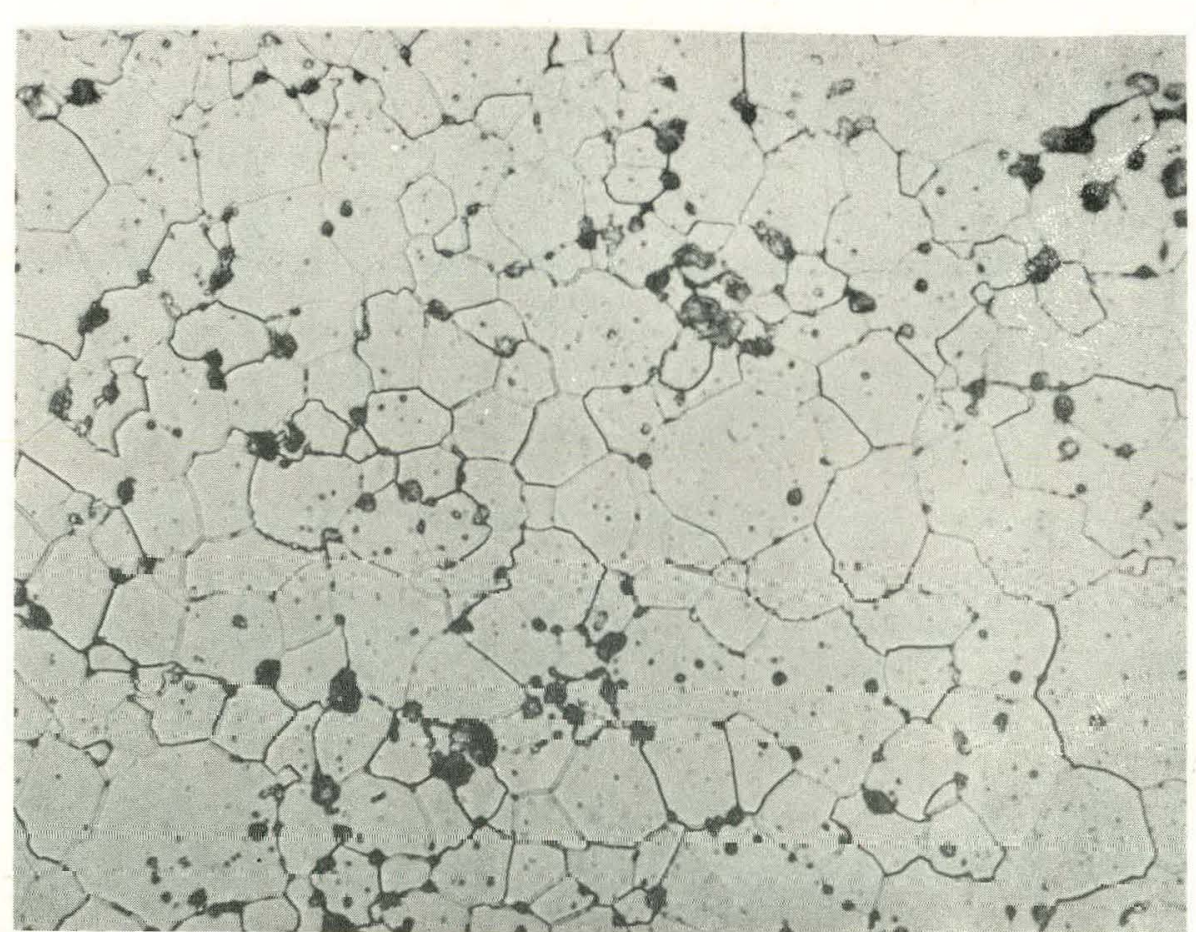




\subsubsection{Electron Microscopic Examination of SA-1 Cladding Samples}

(H. S. Rosenbaum, U. E. Wolff, W. H. Kimball)

\subsubsection{Procedure and Scope}

Thin foils of unirradiated archive cladding were prepared for transmission electron microscopic examination by first slitting a tube section longitudinally and flattening the resulting half rings. The pieces were ground on both sides to remove the oxide and then prethinned chemically to a thickness of about 0.013 to $0.025 \mathrm{~cm}(0.005$ to 0.010 in.). Discs $3 \mathrm{~mm}$ in diameter were punched from these pieces. Finally, the centers of the discs were thinned electrolytically in a twin-jet electro-polisher.

Samples of SA-1 cladding that had been exposed to a fast neutron fluence of approximately $5 \times 10^{21}$ nvt $>1 \mathrm{MeV}$ in 1204 days of VBWR and Dresden operation were prepared by first slitting and straightening sections of tubing from fuel rod $\mathrm{A} 13$ and punching $3 \mathrm{~mm}$ diameter discs from these sections in a hot cell. The discs then were prethinned by hand grinding and finally thinned with the twin-jet electro polisher.

Examinations of the thinned material were performed with a $100 \mathrm{kV}$ electron microscope.

\subsubsection{Results}

Structures typical of the unirradiated Zircaloy are shown in Figure 83, and representative areas of the irradiated material are shown in Figure 84. Evidence of long dislocations can be seen in both the unirradiated and irradiated material. No evidence of radiation-induced voids was observed.

\subsubsection{Analysis of Cladding Samples for Total Hydrogen and for Tritium (D. E. Rey)}

\subsubsection{Procedure and Scope}

Samples of the SA-1 cladding, both from fuel rods that were removed from the assembly at the end of reactor Cycle No. 4 and from rods that operated to the end of Cycle No. 6, were analyzed for total hydrogen and other gaseous species. In addition, some of the samples from the first group of rods were analyzed for tritium content. Tritium, which is produced by the ternary fission of uranium and plutonium, decays by beta emission to ${ }^{3} \mathrm{He}$. The degree to which it enters and is trapped by the Zircaloy cladding is of interest from the standpoint of both reactor operation and spent fuel reprocessing. *

Sample Preparation. Fuel rod segments, each $0.95 \mathrm{~cm}$ (3/8 in.) wide, were sectioned in duplicate from the desired axial locations in a hot cell of the Radioactive Materials Laboratory. Most of the segments came from the peak burnup regions of the rods; however, some were taken from locations near the top and bottom of the SA-1 fuel column. The bulk fuel was removed, and the cladding segments were leached with nitric acid and then rinsed thoroughly with distilled water. After drying, a cladding segment was split longitudinally into three pieces of equal length. These pieces were placed in appropriately labeled screw-cap glass vials and were shipped to Chemistry in a $110-\mathrm{kg}$ (250-Ib) cask.

In the lead fort of the Physical Chemistry Laboratory, the pieces of cladding were removed from the vials, visually inspected with mirrors, and then weighed. Each weighed piece of cladding was carried in a lead pig to the shielded vacuum outgassing apparatus and inserted into the loading arm. **

Outgassing. The vacuum system was pumped down overnight. The tungsten crucible then was degassed at a temperature between $1800^{\circ} \mathrm{C}$ and $1900^{\circ} \mathrm{C}$. (The crucible was heated by induction with a $10 \mathrm{KVA} \mathrm{LEPEL}$ RF generator.) With the system at a final base pressure of less than $10^{-7}$ torr, each cladding piece was dropped into the crucible and heated for a period of 30 minutes at $1300^{\circ} \mathrm{C}$. Evolved gases were moved rapidly from the furnace area by two mercury diffusion pumps working in tandem. The transfer of gases to the measuring section was completed by an automatic toepler pump. At the end of a run, the sample was dumped into the spent sample reservoir by lifting the crucible bail with a magnet. Blanks were run by heating the empty crucible for 30 minutes at $1300^{\circ} \mathrm{C}$.

\footnotetext{
*The investigation of tritium in fuel rods was carried further in a separate program under Project Agreement 41 , "Tritium Distribution in Zircaloy-Clad Fuel Rods."

** Some of the first samples prepared went through degreasing steps with an organic solvent both immediately before the weighing and after the distilled water rinse in the hot cell.
} 


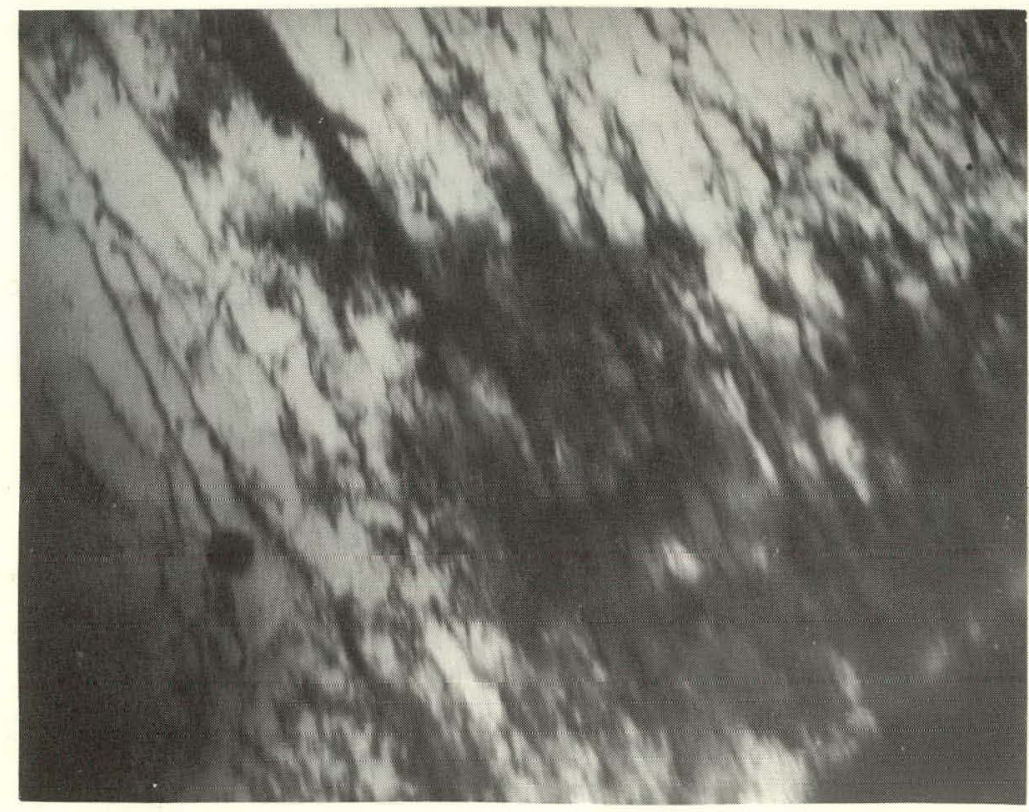

(a)

$10,500 x$

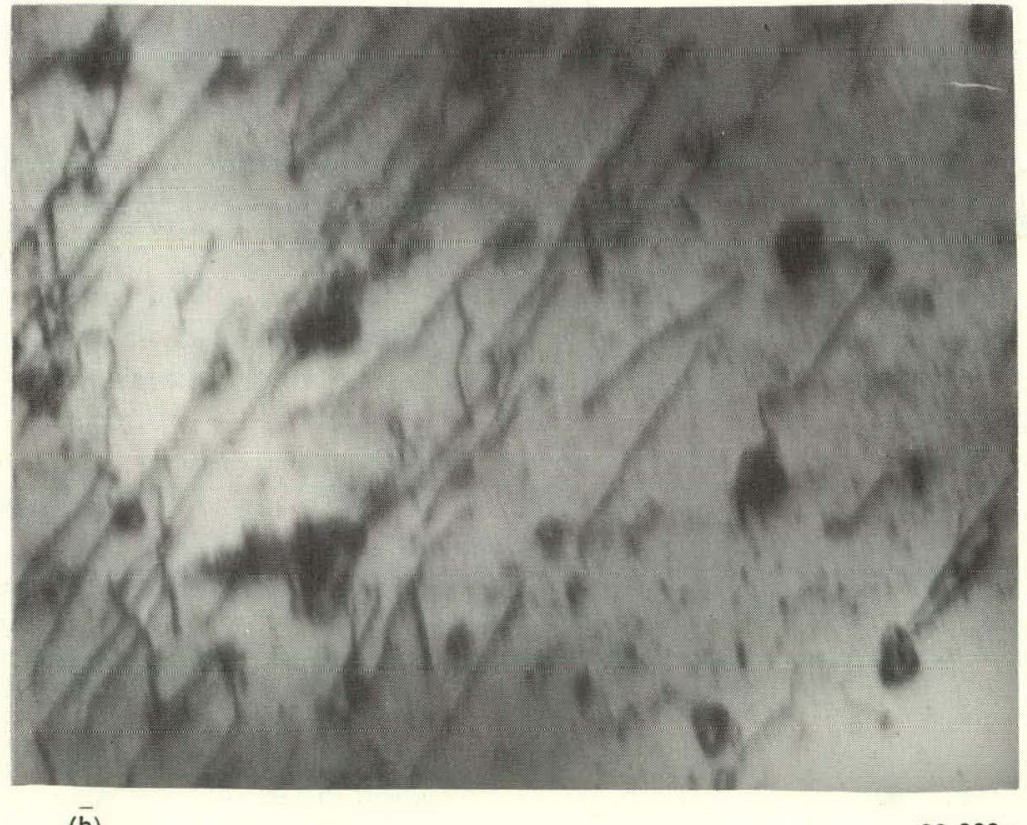

(b)

$30,000 x$

Figure 83. Unirradiated SA-1 (Fuel Cycle Program) Archive Cladding Material 


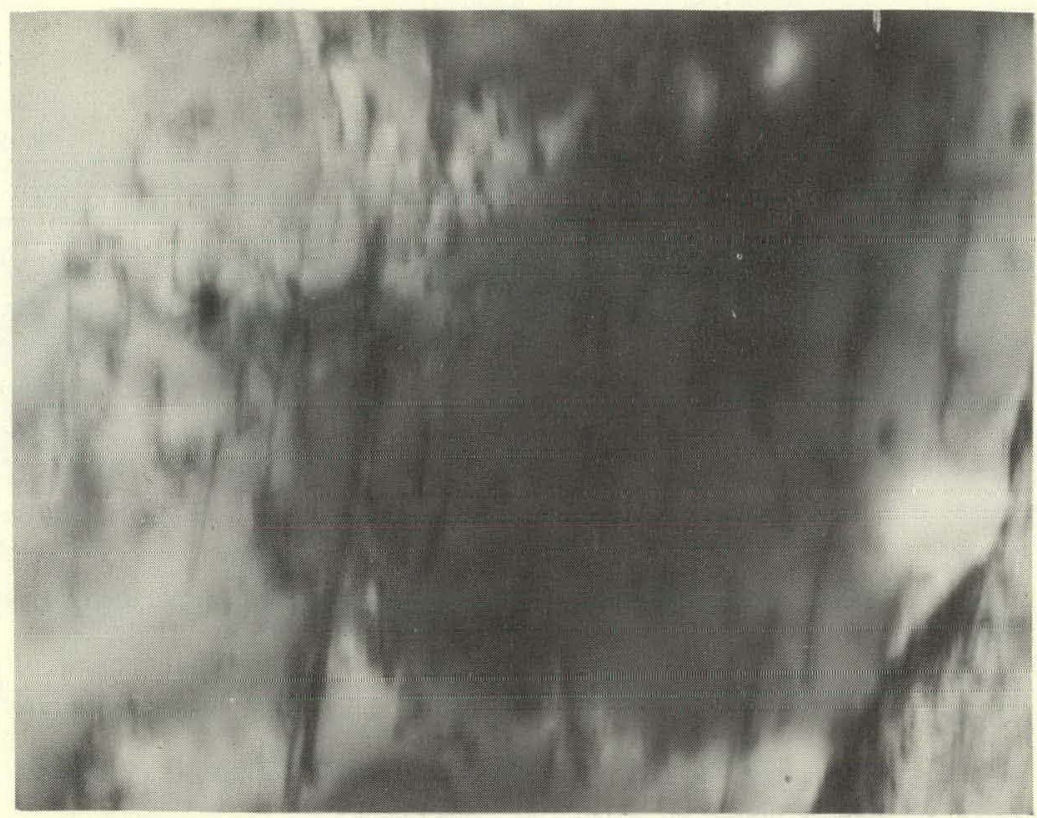

(a)

$30,000 x$

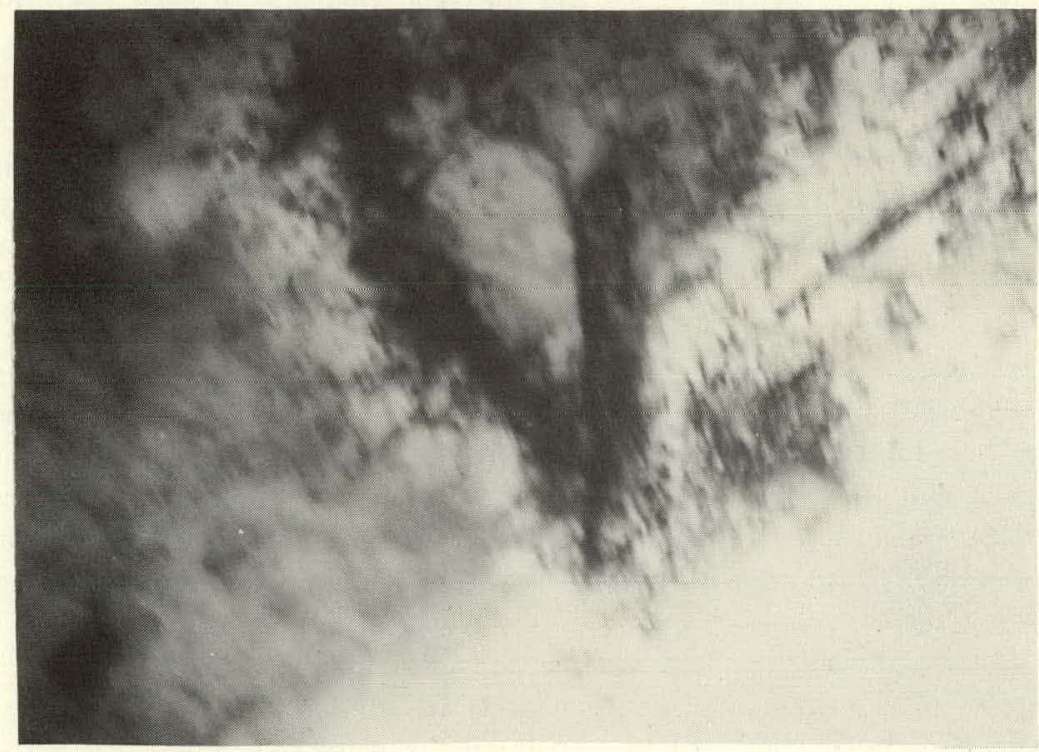

(b)

$30,000 x$

Figure 84. SA-1 Fuel Rod Cladding Exposed to Approximately $5 \times 10^{21} \mathrm{nvt}>1 \mathrm{MeV}$ 
Analysis. The total gas release from each sample of cladding was measured by means of a multirange McLeod gage. Constituent analysis was performed by gas chromatography. Some of the earlier analyses were carried out with a molecular sieve column. Later, the gas chromatographic scans were obtained by temperature programming a a $6.1-\mathrm{m}$ (20-ft) Porapak QS column from $-60^{\circ} \mathrm{C}$ to $+75^{\circ} \mathrm{C}$, using helium as carrier gas.

When a sample was to be analyzed for tritium as well as total composition, the gas was aliquoted after volume determination so that about one-third of the total collected was available for tritium analysis. The aliquot was first scanned for $\mathrm{Kr}-85$ by gamma spectrometry (primarily to qualitatively determine the detectability of this isotope in cladding samples), and then sent to the Metallurgy Mass Spectrometry Laboratory for conversion of hydrogen/tritium to water products $\left(\mathrm{H}_{2} \mathrm{O}, \mathrm{HTO}, \mathrm{T}_{2} \mathrm{O}\right)$ and residual gas analysis. The conversion was done by addition of a carefully measured amount of oxygen and subsequent combustion with a heated filament. The products of combustion were frozen out with a dry-ice acetone bath and then taken up with scintillator fluid for tritium counting.

Samples from seven locations of five rods were analyzed by chromatography during the initial phase of the program. Two pieces from the first set of seven cladding segments were analyzed. Then, at a later date, one piece from each corresponding adjacent segment was analyzed. The tritium analyses were performed on aliquots of gas extracted from the pieces of cladding from this second set of segments.

During the final phase of the program, samples from six locations of four rods were analyzed by chromatography for total composition only.

\subsubsection{Results}

\subsection{Chromatographic Analyses}

The results of the analyses performed on samples from rods that operated between 1175 and 1218 days in the VBWR and Dresden are given in Table 15, and Table 16 gives the results on samples from rods that operated between 1767 and 1846 days.

For the first group of samples, the total volumes of gas collected ranged from approximately 500 to 1100 microliters per gram of sample and averaged about 800. For a given pair of samples, these volumes generally were within 100 microliters per gram of each other, and the total volumes collected from the samples of one set were neither predominately larger nor smaller than the volumes collected from the corresponding duplicates. Sample B70F, however, contained 250 to 275 microliters per gram, or approximately one-third, more gas than sample B70E.

The chromatographic analyses showed total hydrogen contents of 84 to 95 percent, carbon monoxide contents of 1 to 12 percent, and carbon dioxide contents of 0.3 to 6 percent. The samples also contained up to 3.4 percent nitrogen, up to 0.6 percent oxygen, and up to 0.2 percent methane. In terms of parts per million, the total hydrogen contents ranged from 45 to 89 . The absorption of corrosion-generated hydrogen ranged from 1 to 7 percent and averaged 4 percent.

With the exception of the sample pair, B97C and B97D, the corresponding percentages of total hydrogen were within $\sim 5$ points of each other. The combined differences in total gas volumes and percentages of hydrogen then resulted in differences in cladding hydrogen contents that ranged from about 3 to 11 parts per million in six of the seven pairs of samples. The total hydrogen content of B70F was 21 to $22 \mathrm{ppm}$ greater than that of B70E.

In the first set of samples no oxygen and generally low-amounts of nitrogen were measured. The presence of oxygen and the correspondingly higher quantities of nitrogen measured in pieces from the adjacent cladding segments suggest that air contamination occurred during the extra manipulations required in taking aliquots for the tritium determinations.

For the final phase samples, the total volumes of gas collected ranged from a minimum of approximately 700 microliters per gram to a maximum of approximately 2200 , twice the content of any initial phase sample. The average gas content of the samples from rods that operated to the end of reactor Cycle No. 6 was 1200 microliters per gram.

The analyses showed total hydrogen contents of 72 to 96 percent, carbon monoxide contents of 5 to 24 percent, and carbon dioxide contents of 0.3 to 2 percent. The samples also contained up to 0.6 percent nitroyen and oxygen, and up to 0.05 percent methane. The total hydrogen contents in parts per million ranged from 46 to 146 and were somewhat higher, in general, than the hydrogen contents of samples from rods that were removed from SA-1 at the end of Cycle No. 4. The maximum percent absorption did not increase, however. Cladding samples from fuel rods of the same type as the SA-1 rods showed a maximum hydrogen content of about $60 \mathrm{ppm}$ and a maximum absorption of somewhat less than 7 percent after 365 days of operation. ${ }^{3}$ 
15

CHROMATOGRAPHIC ANALYSIS OF GASES EVOLVED FROM FUEL ROD CLADDING SAMPLES

Initial Phase

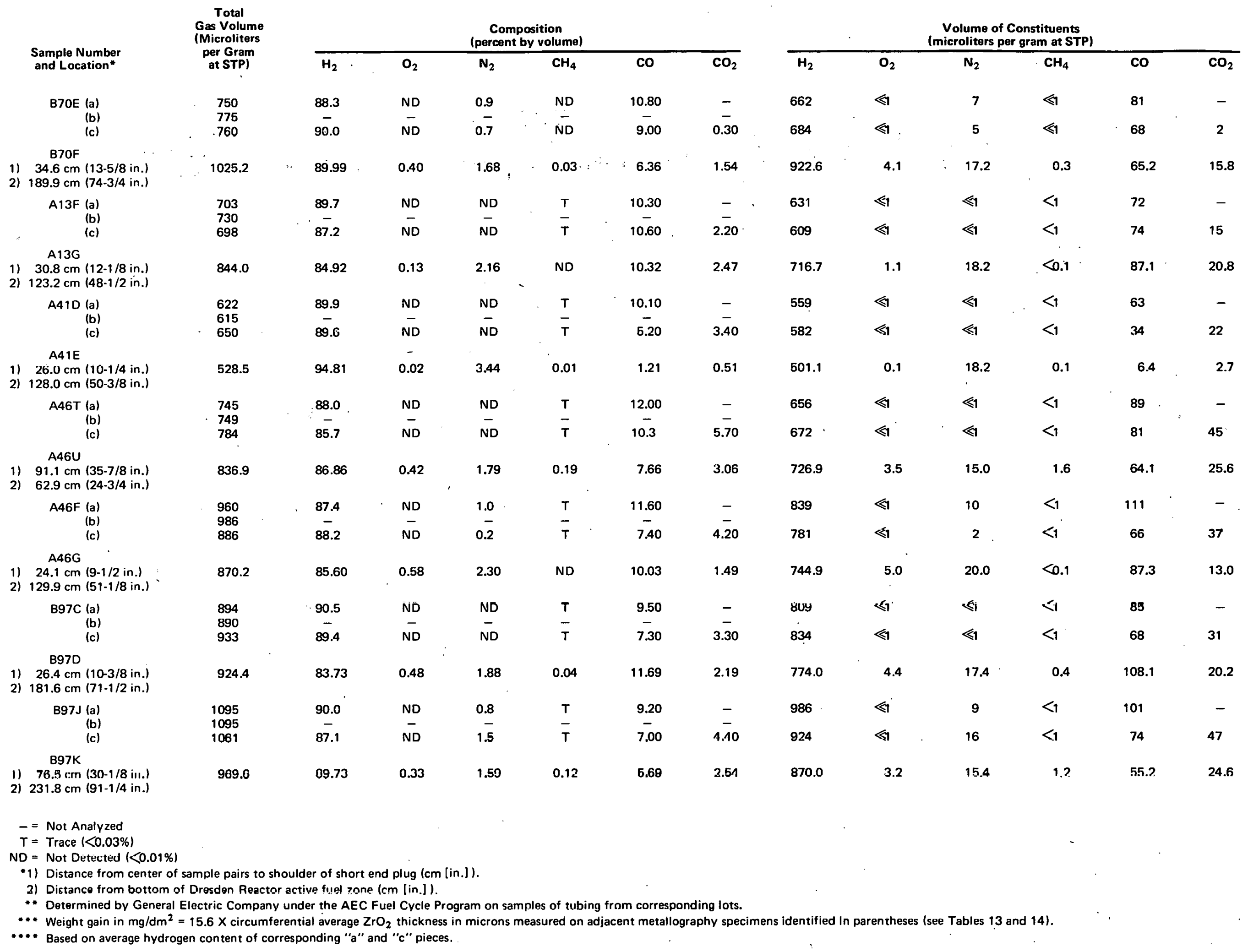

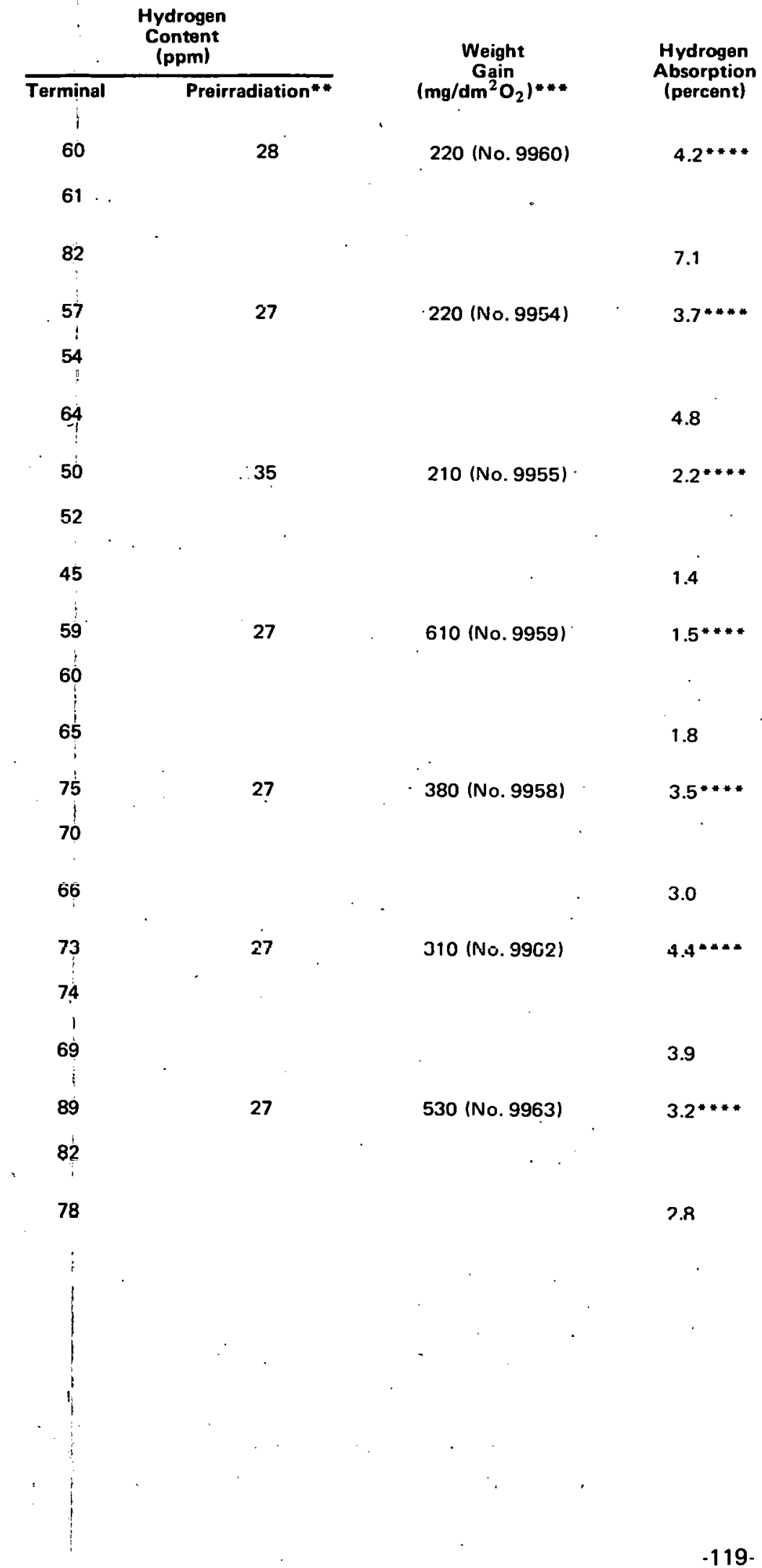


Table 16

CHROMATOGRAPHIC ANALYSIS OF GASES EVOLVED FROM FUEL ROD CLADDING SAMPLES

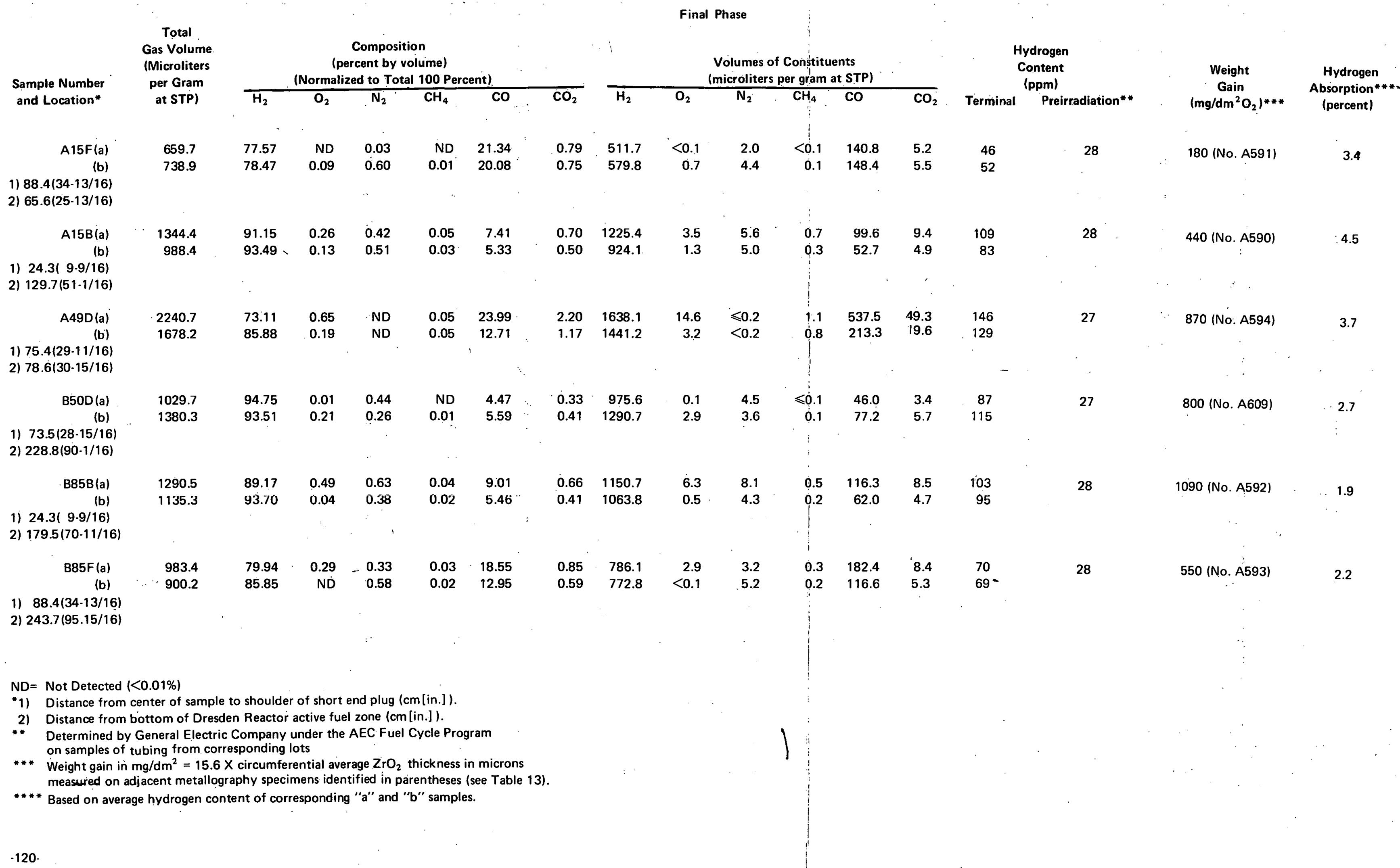


The maximum percent $\mathrm{CO}$ value was about twice the maximum value determined on any of the initial phase specimens, but it was no greater than some of those obtained in the analysis of samples from rods that saw only VBWR operation. Investigators under the Fuel Cycle Program suggested that the $\mathrm{UO}_{2}$ may have been the source of the $\mathrm{CO}$ and $\mathrm{CO}_{2}$ in the irradiated cladding. ${ }^{3}$ However, the wide variation in the CO content of the SA-1 cladding samples-even between two pieces from the same segment [A49D (a) and (b), for example] -seems difficult to explain. It is possible that contamination from some unknown source was at least partly responsible for the evolution of $\mathrm{CO}_{\text {and }} \mathrm{CO}_{2}$.

The source of the oxygen in the final phase samples is also uncertain. The low nitrogen contents of some of these samples indicate that air contamination was not responsible for the oxygen evolved in these cases.

\subsection{Tritium Analysis}

The tritium analyses are presented in Table 17, and data on the operation of the different rods in the two reactors are given in Table 18. The tritium content of the cladding ranged from approximately 5 to 58 parts per bitlion, equivalent to about 2 to 16 percent of the tritium generated during operation. The burnup of the fuel corresponding to the cladding samples analyzed for tritium ranged from $5 \times 10^{20}$ to $8 \times 10^{20}$ fissions $/ \mathrm{cm}^{3}(17,000$ to $30,000 \mathrm{MWd} / \mathrm{t})$, and the time-averaged power values ranged from about 30 to $50 \mathrm{~W} / \mathrm{cm}^{2}$ (100,000 to $\left.160,000 \mathrm{Btu} /-\mathrm{ft}^{2}\right)$. The maximum power of any rod at a sample location while in Dresden is estimated to have been $98 \mathrm{~W} / \mathrm{cm}^{2}$ or $310,00 \mathrm{Btu} / \mathrm{h}-\mathrm{ft}{ }^{2}$. This power was attained relatively early in Dresden operation. The cladding tritium content correlates quite well with the fuel burnup or average power rating over the total operating time. It will be noted that the ratio of cladding tritium content to burnup and time-averaged power increased rather markedly with increasing burnup and power both among samples from different rods and between two samples from an individual rod.

The values of tritium generation were approximated as follows: The distribution of fissions among U-235, Pu-239, Pu-241, and U-238 were obtained from chemical isotopic analyses: This information was directly obtainable for samples A13G, A41E, and A46G from analysis of adjacent fuel samples (see subsection 5.3). Fission distributions for the other four samples were estimated from curves of atom percent fission versus burnup generated from the SA-1 data and other chemically determined isotopic data. Yield values of $1.3 \times 10^{-4}$ for U-235 and U-238 and $2.3 \times 10^{-4}$ for Pu-239 and $\mathrm{Pu}-\mathbf{2 4 1}$ were then applied to estimate the production of tritium.

\subsubsection{Cladding Mechanical Properties Testing (G. P. Ferguson)}

The tests and measurements performed to determine the mechanical properties of the irradiated SA-1 fuel rod cladding included the following:

a. Tensile tests on longitudinally-oriented miniature coupon specimens

b. "Ring-on-mandrel" tensile tests on transverse cladding sections

c. Burst tests on rod sections

d. Microhardness measurements on the cladding wall of transversely and longitudinally-oriented metallography specimens

The burst tests were carried out only on cladding samples from rods that operated in Dresden to the end of Cycle No. 6. The other tests and measurements were performed only on samples from rods that operated to the end of Cycle No. 4.

\subsubsection{Tensile Tests on Longitudinal Coupon Specimens}

\subsection{Procedure and Scope}

Longitudinally-oriented tensile coupon specimens were obtained from the cladding of four irradiated fuel rods (A13, A41, A46, and B97). To prepare a specimen, the fuel rod was sectioned transversely to the desired length with a thin, abrasive cutting wheel. This section was then slit longitudinally to obtain two tensile coupon blanks. A hot cell-adapted Tensilkut machine and special holding fixtures were used to machine a reduced gauge length region on each coupon blank. A sketch of a tensile specimen is shown in Figure 85 . The gauge width and cladding thickness of each specimen were measured with a micrometer.

Similar specimens were prepared from unirradiated archive tubing to provide comparative data. Some of these specimens were prepared remotely, while others were prepared out-of-cell with either a Tensilkut machine or milling machine. 
Table 17

TRITIUM CONTENT OF CLADDING SAMPLES

\begin{tabular}{|c|c|c|c|c|c|c|c|}
\hline \multirow[b]{2}{*}{$\begin{array}{l}\text { Sample Number } \\
\text { and Location }\end{array}$} & \multirow{2}{*}{$\begin{array}{c}\text { Gas Volume } \\
\text { iMicroliters } \\
\text { per Gram } \\
\text { at STP) }\end{array}$} & \multicolumn{3}{|c|}{ Tritium Content ${ }^{c}$} & \multirow{2}{*}{$\begin{array}{c}\text { Approximate } \\
\frac{\mathrm{gm}^{3} \mathrm{H}_{2}}{\mathrm{gm} \mathrm{UO_{2 }}} \\
\text { generated } \\
\left(\mathrm{X} \mathrm{10^{9 } )}\right.\end{array}$} & \multirow[b]{2}{*}{$\begin{array}{l}\text { Percent } \\
\text { Tritium } \\
\text { in Cladding }\end{array}$} & \multirow[b]{2}{*}{$\begin{array}{l}\text { Krypton-85 } \\
\frac{\mathrm{dpm}}{\mathrm{gm}} \times 10^{-6}\end{array}$} \\
\hline & & $\frac{\mu \mathrm{Ci}}{\text { gm Cladding }}$ & $\begin{array}{c}\text { ppb } \\
\text { Cladding }\end{array}$ & $\frac{\text { gm in Cladding }}{\text { gm UO }}$ & & & \\
\hline
\end{tabular}

B70E

1) $35.1 \mathrm{~cm}(13-13 / 16 \mathrm{in.})$

1025.2

242.4

24.9

3.99

50

8

12

A13G

1) $31.3 \mathrm{~cm}(12.5 / 16 \mathrm{in}$.)

2) $122.7 \mathrm{~cm}(48-5 / 16 \mathrm{in.})$

844.0

561.4

57.8

9.25

61

15

16

A41E

1) $26.5 \mathrm{~cm}(10.7 / 16 \mathrm{in}$.

2) $127.5 \mathrm{~cm}(50-3 / 16 \mathrm{in.})$

528.5

553.4

56.9

9.14

57

16

NA

836.9

43.3

4.5

0.71

33

2

0.75

2) $62.4 \mathrm{~cm}(24-9 / 16 \mathrm{in}$.)

$$
\text { A46G }
$$

1) $24.6 \mathrm{~cm}(9-1.1 / 16 \mathrm{in.})$

2) $129: 4 \mathrm{~cm}(50-15 / 16 \mathrm{in}$.) B97D

1) $26.8 \mathrm{~cm}(10.9 / 16 \mathrm{in.})$

2) $182.1 \mathrm{~cm}(71-11 / 16 \mathrm{in.})$ B97K

- 1) $77.0 \mathrm{~cm}(30.5 / 16 \mathrm{in}$.)

2) $232.3 \mathrm{~cm}(91.7 / 16 \mathrm{in}$.

\section{2}

246.4

25.4

$4.02-$

53

32.1

5.14

969.6

311.6

92.7

9.5

1.53

36

\footnotetext{
NA = Not Analyzed.

(a) 1) Distance from center of sample to shoulder of short end plug (cm [in.]). 2) Distance from bottom of Dresden Reactor active fuel zone (cm [in.]).

(b) Not corrected for either coünting efficiency or decay. Analyzed in July 1970.

(c) Corrected to date of discharge (January 13, 1967).
} 
Table 18

ROD OPERATING DATA

\begin{tabular}{|c|c|c|c|c|c|c|c|c|c|c|c|c|}
\hline & \multirow{3}{*}{$\begin{array}{l}\text { Rod or } \\
\text { Sample }\end{array}$} & \multirow{3}{*}{$\begin{array}{l}\text { Initial } \\
\text { En-ichment } \\
\text { Uveight } \\
\text { percent } \\
\text { U-235) }\end{array}$} & \multirow{2}{*}{\multicolumn{2}{|c|}{$\begin{array}{c}\text { Burnup } \\
\text { Rod:Average, or Sample } \\
\end{array}$}} & \multirow{3}{*}{$\begin{array}{l}\text { Days of } \\
\text { Operationa }\end{array}$} & \multirow{3}{*}{$\begin{array}{c}\text { Time: } \\
\text { Averaged } \\
\text { VBWR } \\
\text { + Dresden }\end{array}$} & \multirow{3}{*}{$\begin{array}{c}\text { VBWR Operation } \\
\text { At Maximum } \\
\text { Reactor Power } \\
\text { Rod-Average } \\
\text { or Sample }\end{array}$} & \multirow{3}{*}{$\begin{array}{l}\text { Time-Averaged } \\
\text { Cycles } 3 \text { and } 4 \\
\text { Rod-Average } \\
\text { or Sample }\end{array}$} & \multicolumn{4}{|c|}{ Dresden Operation } \\
\hline & & & & & & & & & \multicolumn{4}{|c|}{$\begin{array}{l}\text { At Maximum Reactor Power } \\
\text { Average for Rod or Sample }\end{array}$} \\
\hline & & & $\begin{array}{c}\text { Fissions/cm } \\
\times 10^{-20}\end{array}$ & MWD/tU & & & & & $B O C 3^{C}$ & $E O C 3^{c}$ & BOC 4 & EOC 4 \\
\hline & B70 & 2.76 & 5.5 & 20,200 & 1,175 & $35.1(111)$ & $74(230)$ & $34(110)$ & $69(220)$ & & & \\
\hline & B $70 F$ & & 6.5 & 23,900 & & $41.5(132)$ & - & $40(130)$ & $73(230)$ & $48(150)$ & $55(170)$ & $41(130)$ \\
\hline \multirow{4}{*}{$\dot{\vec{\psi}}$} & A13 & 3.49 & 7.0 & 25,600 & 1,204 & $45.1(143)$ & $88(280)$ & $41(130)$ & $79(250)$ & - & - & - \\
\hline & A130 & & 8.1 & 29,700 & & $52.1(166)$ & $129(410)$ & $47(150)$ & $82(260)$ & $53(170)$ & $61(190)$ & $46(150)$ \\
\hline & A41 & 3.49 & 6.6 & 24,000 & 1,204 & $42.0(133)$ & $88(280)$ & $36(110)$ & $82(260)$ & - & - & - \\
\hline & $A 41 E$ & & 7.7 & 28,300 & & 49.5 (157) & $123(390)$ & $43(140)$ & $98(310)$ & $64(200)$ & $73(230)$ & $55(170)$ \\
\hline & A46 & 2.76 & 6.0 & 22,000 & 1,218 & $38.7(123)$ & $63(200)$ & $40(130)$ & $73(230)$ & -- & - & - \\
\hline & A46U & & 4.6 & 16,900 & & $29.7(94)$ & - & $30(100)$ & $54(170)$ & $35(110)$ & $41(130)$ & $30(90)$ \\
\hline & A46G & . & 6.9 & $25,30 \mathrm{C}$ & & $44.5(141)$ & $91(290)$ & $46(150)$ & $88(280)$ & $57(180)$ & $66(210)$ & $49(150)$ \\
\hline & B97 & 2.76 & 6.1 . & 22,200 & 1,218 & $38.6(122)$ & $82(260)$ & $36(110)$ & $76(240)$ & - & - & $\cdots$ \\
\hline & B97D & & 7.3 & 26,600 & & $46.3(147)$ & $117(370)$ & $43(140)$ & $88(280)$ & $57(180)$ & $66(210)$ & $49(150)$ \\
\hline & B97K & & 5.1 & 18,500 & & $32.2(102)$ & - & $30(100)$ & $57(180)$ & $37(120)$ & $43(140)$ & $32(100)$ \\
\hline
\end{tabular}

Estimated Heat Flux in W/cm ${ }^{2}$ (Btu/h- $\left.\mathrm{ft}^{2} \times 10^{-3}\right)^{\mathrm{b}}$

(a) Total days of operation, 840 days of which were in Dresden in all cases.

Days of operation in the VBWR is defined as hours al temperature (reactor thermal power $>5$ MW) divided by 24.

Days of operation in Dresden is defined as hours of turbine-generator operation divided by 24 .

(b) To obtain thear power in $\mathrm{kW} / \mathrm{ft}$ of rod length, multiply $\mathrm{W} / \mathrm{cm}^{2}$ by 0.103 .

(c) BOC $=$ Beginning of Cycle. EOC $=$ End of Cycle. 


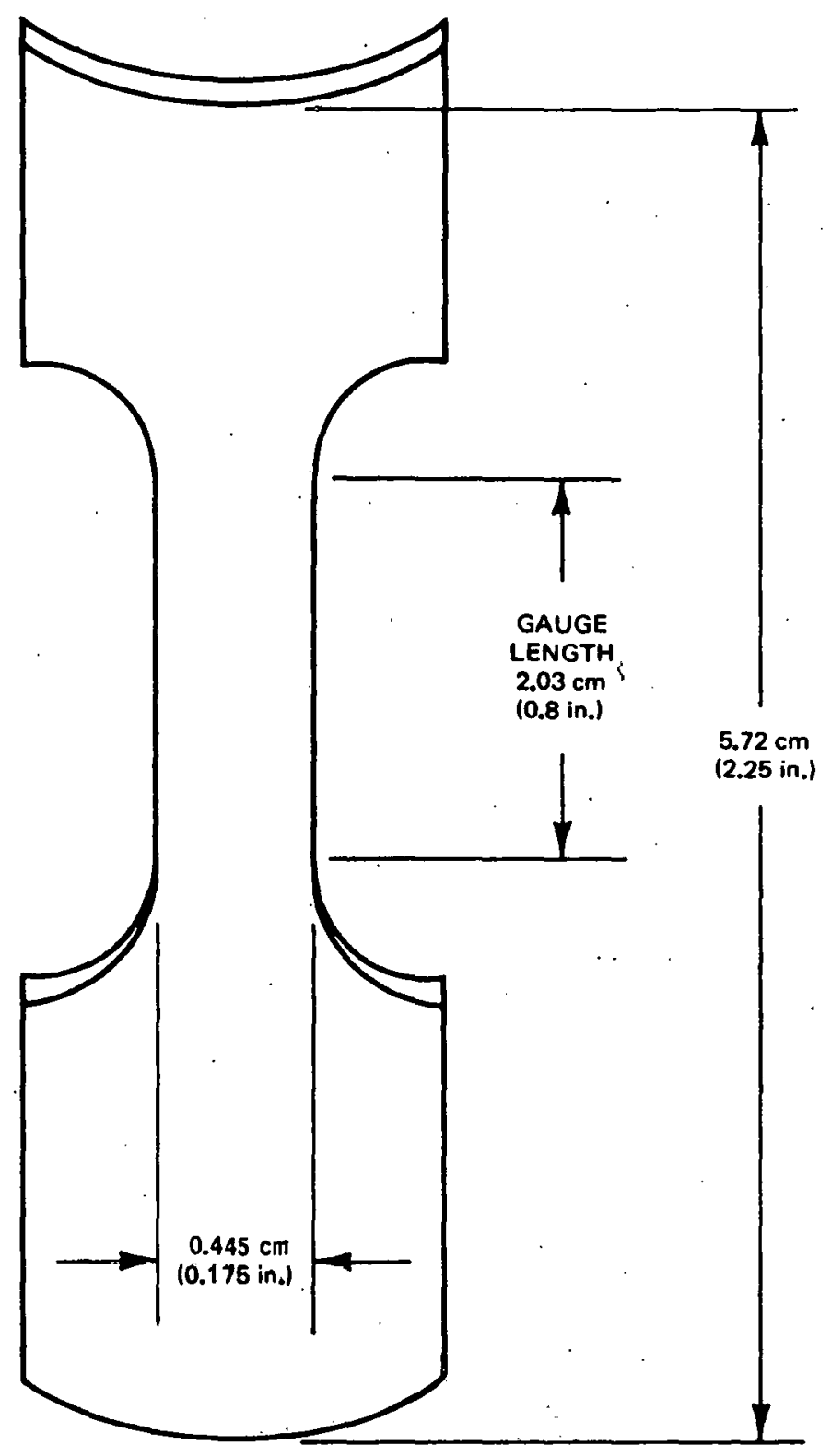

Figure 85. Schematic Diagram of Tensile Specimens Obtained from SA-1 Fuel Cladding 
All of the irradiated specimens and some of the unirradiated specimens were tested with an instron Model TT.C-L hot cell tensile testing machine. All specimens were pulled at a strain rate of either 0.02 or $0.025 \mathrm{~cm} / \mathrm{cm} / \mathrm{min}$. The uniform and total extension values on the remotely tested specimens were determined from traces of load versus time and the crosshead speed of the testing machine.

Specimens were tested at room temperature, $343^{\circ} \mathrm{C}\left(650^{\circ} \mathrm{F}\right), 399^{\circ} \mathrm{C}\left(750^{\circ} \mathrm{F}\right)$, and $454^{\circ} \mathrm{C}\left(850^{\circ} \mathrm{F}\right)$. The specimens were normally held at the testing temperature 15 minutes before tension was applied. However, several specimens were held at temperature for longer periods, up to $16-1 / 2$ hours.

The integrated fast flux exposure for the irradiated material is estimated to be between $3.5 \times 10^{21}$ and $6 \times 10^{21} \mathrm{nvt}>1 \mathrm{MeV}$.

\subsection{Results}

The test results are presented in Table 19. Examples of specimens that were tested at the various temperatures are shown in Figures 86(a) through 86(d). As expected, the irradiated material showed significantly increased strength and decreased ductility compared to the unirradiated Fuel Cycle Program archive material. The least effect of irradiation on yield strength, ultimate strength, and total elongation was shown at $454^{\circ} \mathrm{C}\left(850^{\circ} \mathrm{F}\right)$.

At room temperature $\left(22^{\circ} \mathrm{C}\right.$ or $\left.72^{\circ} \mathrm{F}\right)$ the average yield and ultimate strengths of the irradiated specimens were $6900 \mathrm{~kg} / \mathrm{cm}^{2}$ (97 kpsi) and $7700 \mathrm{~kg} / \mathrm{cm}^{2}(110 \mathrm{kpsi})$, and the uniform and total elongations were about 1 percent and 3 percent. Among the specimens that were held at temperature for the normal period, the high temperature ultimate strengths ranged from about $5000 \mathrm{~kg} / \mathrm{cm}^{2}(70 \mathrm{kpsi})$ at $343^{\circ} \mathrm{C}\left(650^{\circ} \mathrm{F}\right)$ to about $3000 \mathrm{~kg} / \mathrm{cm}^{2}(40 \mathrm{kpsi})$ at $454^{\circ} \mathrm{C}$ $\left(850^{\circ} \mathrm{F}\right)$. The differences between ultimate strength and yield strength were generally $\leqslant 70 \mathrm{~kg} / \mathrm{cm}^{2}(1 \mathrm{kpsi})$ in the high temperature tests, although there were some exceptions at $343^{\circ} \mathrm{C}$. The uniform elongations were typically 0.5 percent or less. Total elongations were 1 to approximately 1.5 percent at $343^{\circ} \mathrm{C}$, up to 2 percent at $399^{\circ} \mathrm{C}\left(750^{\circ} \mathrm{F}\right)$, and ranged from 5 to 12 percent at $454^{\circ} \mathrm{C}$.

Holding specimens at $343^{\circ} \mathrm{C}\left(650^{\circ} \mathrm{F}\right)$ for up to $16-1 / 2$ hours had no significant effect on any of the $343^{\circ} \mathrm{C}$ tensile properties. [The maximum wall-average operating temperature of the cladding is estimated to have been between $329^{\circ} \mathrm{C}$ and $343^{\circ} \mathrm{C}\left(625^{\circ}\right.$ and $650^{\circ} \mathrm{F}$.] The ultimate and yield strengths of one specimen held at $399^{\circ} \mathrm{C}\left(750^{\circ} \mathrm{F}\right)$ for 7 hours before testing at that temperature were, respectively, about $800 \mathrm{~kg} / \mathrm{cm}^{2}(11 \mathrm{kpsi})$ and $850 \mathrm{~kg} / \mathrm{cm}^{2}(12 \mathrm{kpsi})$ lower than the minimum values obtained on specimens tested at $399^{\circ} \mathrm{C}$ after the normal soaking period. The elongations did not change. A specimen held for $16-1 / 2$ hours at $399^{\circ} \mathrm{C}$ showed ultimate and yield strengths approximately $950 \mathrm{~kg} / \mathrm{cm}^{2}$ $(13.5 \mathrm{kpsi})$ and $1200 \mathrm{~kg} / \mathrm{cm}^{2}(17 \mathrm{kpsi}) \cdot$ lower than any specimen tested by the normal procedure and, in addition, it showed somewhat greater uniform and total elongations (1.2 percent and 3.6 percent). The $454^{\circ} \mathrm{C}$ tensile properties of the irradiated cladding apparently were not affected significantly by increasing the soaking time at that temperature to 1 hour. The ultimate strengths of three irradiated specimens held at $454^{\circ} \mathrm{C}$ for $16-1 / 2$ hours before testing approached that of the unirradiated material. One of the three showed increased uniform elongation and ultimate-yield strength differential, while another showed a total elongation at least as high as those of the unirradiated specimens and was of relatively high strength. There are no certain reasons for these differences in behavior.

\subsubsection{Ring-on-Mandrel Tensile Tests}

The tensile properties of irradiated fuel cladding in the transverse direction are of interest because of the possibility of mechanical interaction between the fuel and the cladding during the course of operation. It is expected that for a given fuel rod power level, the likelihood (or degree) of interaction will increase with time through the mechanism. of fission-product-induced fuel swelling. With the objective of determining some of the transverse tensile properties, particularly ductility, several ring-on-mandrel tests were performed on SA-1 cladding samples. This type of test had been carried out previously under the Fast Ceramic Reactor Development Program (Contract AT(04-3)-189, Project Agreement 10] on 'samples of irradiated stainless steel cladding. ${ }^{6}$

\subsection{Procedure and Scope}

The specimen in this test was a transverse cladding section, generally somewhat less in length than the inside diamoter of the cladiling This ring of rladding was placed over and centered on a metal cylinder that was somewhat longer than the ring, and of a diameter slightly smaller than the inside diameter of the cladding. The diameter of the ring was increased to the point of fracture by compressing the ends of the cylindrical mandret. Pressure was applied to the mandrel by means of a compression cage device used in conjunction with an Instron Model TT-C- $L$ tensile testing machine. The diameter or circumference of the ring at fracture was measured, and the value $\Delta D / D_{i}$ was calculated. 
Table 19

TENSILE TESTS ON LONGITUDINAL COUPON CLADDING SPECIMENS

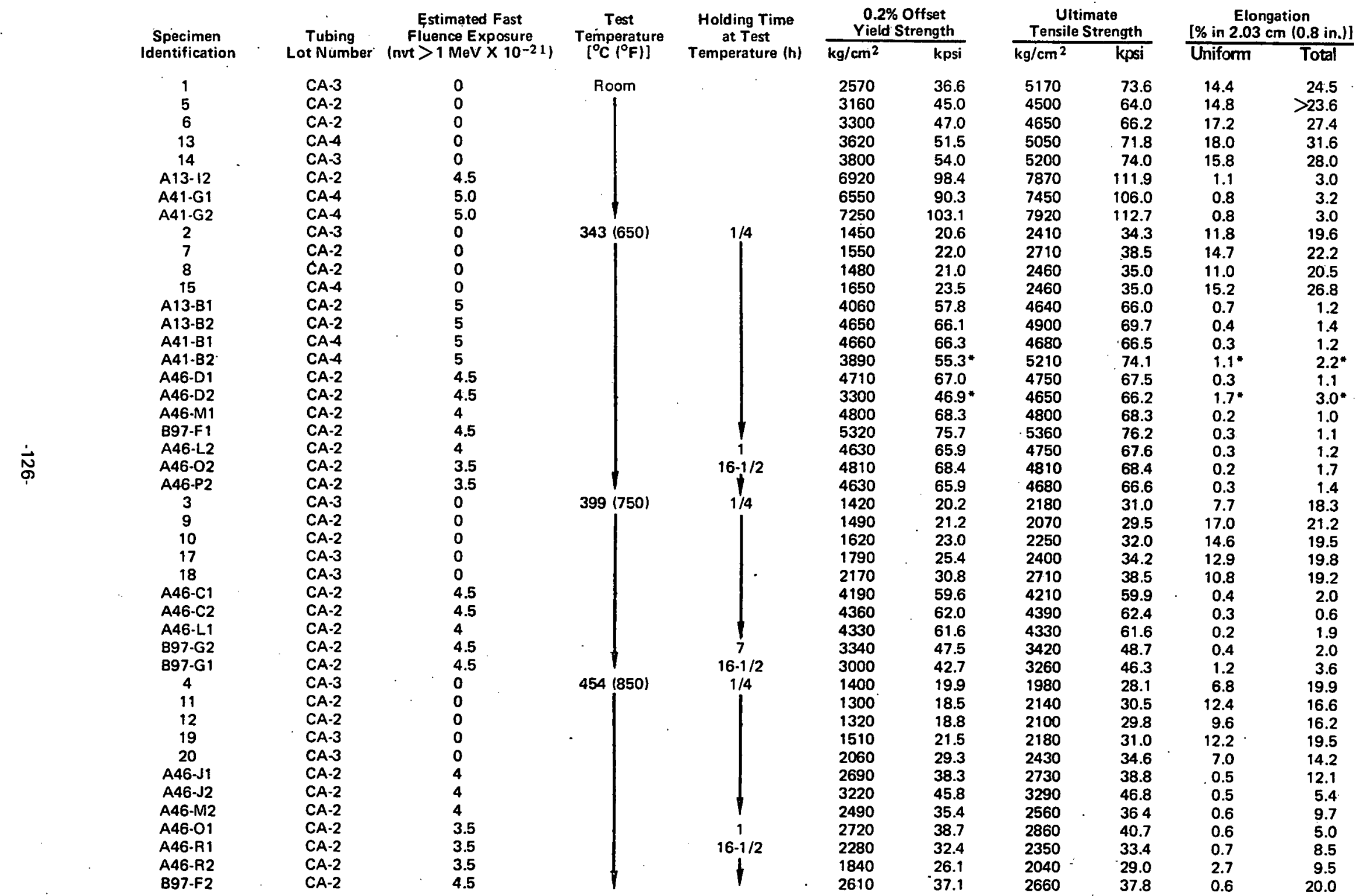

*Accuracy of these values is in doubt. Specimens may have slipped in grips.

NOTE: Unirradiated specimens 1 through 4 were prepared out of cell with a Tensilkut machine and were tested in cell.

Specimens 5 through 12 were prepared out of cell with a milling machine and were tested out of cell.

Specimens 13 through 15, and 17 through 20 were prepared in cell with a Tensilkut machine and were tested out of cell. 


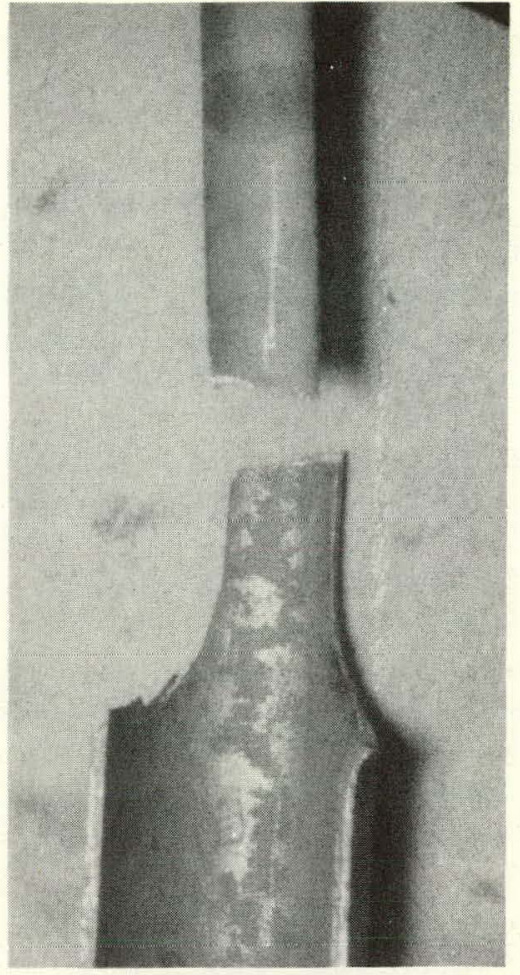

(a) ROOM TEMPERATURE SPECIMEN A41-G1

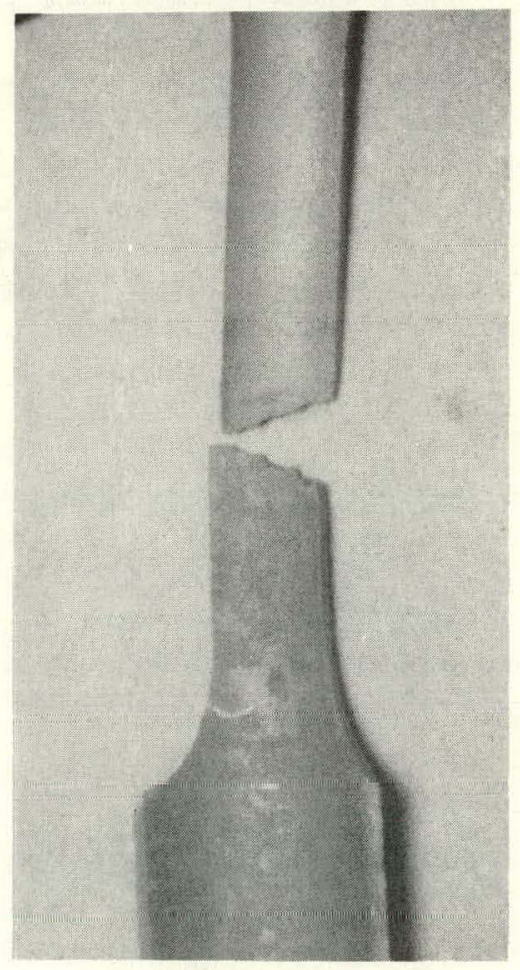

(c) $399^{\circ} \mathrm{C}\left(750^{\circ} \mathrm{F}\right)$ SPECIMEN A46-C1

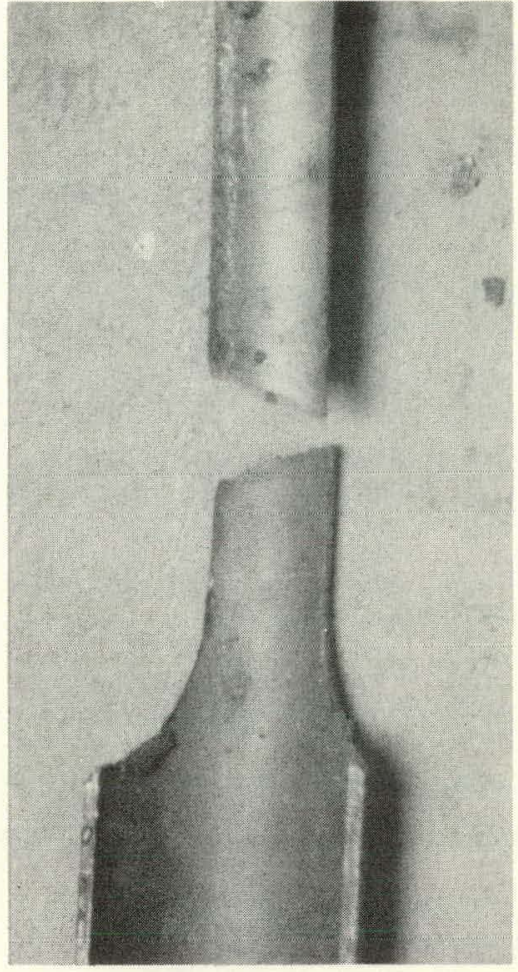

(b) $343^{\circ} \mathrm{C}\left(650^{\circ} \mathrm{F}\right)$ SPECIMEN B97-F1

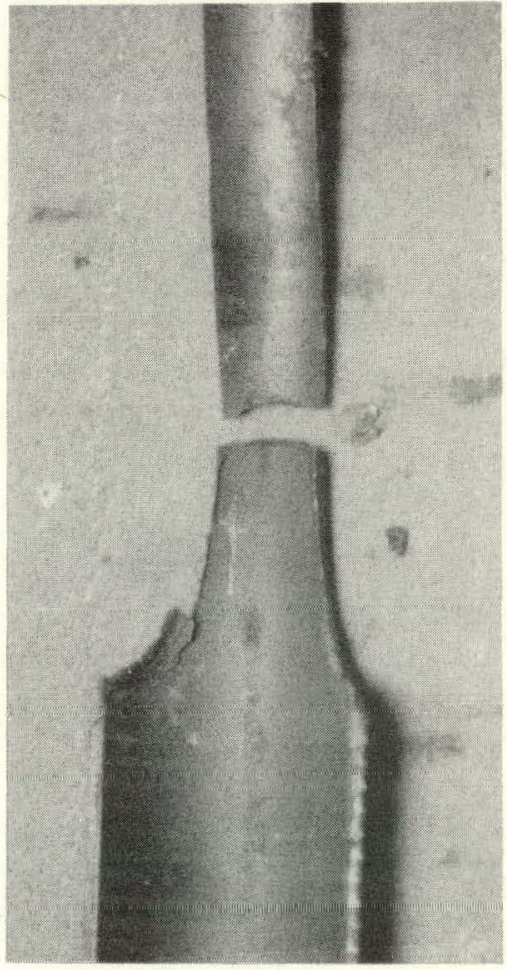

(d) $454^{\circ} \mathrm{C}\left(850^{\circ} \mathrm{F}\right)$ SPECIMEN A46-J1

Figure 86. Appearance of Irradiated Longitudinal Coupon Specimens Tested at Various Temperatures 
A ring width of $0.445 \mathrm{~cm}(0.175 \mathrm{inch})$ was selected for the present series of tests. This width was the same as the width of the reduced section in the aforementioned longitudinal tensile coupons. [The nominal inside diameter and wall thickness of the SA-1 cladding were $0.965 \mathrm{~cm}(0.380 \mathrm{in.})$ and $0.056 \mathrm{~cm}(0.022 \mathrm{in}$.), respectively.]

The irradiated ring specimens were prepared from two $\sim 15-\mathrm{cm}$ (6-inch)-long sections of fuel rods $\mathrm{A} 13$ and $\mathrm{A} 41$. The fast fluence exposure was estimated to be approximately $5 \times 10^{21} \mathrm{nvt}>1 \mathrm{MeV}$ for all specimens tested. The ring specimens were cut from the tubing with an abrasive wheel. The fuel was removed from the rod sections by dissolving it in nitric acid before cutting these sections into rings. The external surfaces of rods A13 and A41 were treated earlier with hydrochloric acid to remove the crud deposits.

Different specimens were tested at room temperature, $343^{\circ} \mathrm{C}\left(650^{\circ} \mathrm{F}\right)$, and $454^{\circ} \mathrm{C}\left(850^{\circ} \mathrm{F}\right)$. In the hightemperature tests, the specimens were held at temperature for 15 minutes before the load was applied to the mandrels.

Most of the tests were performed with a machine crosshead speed of $0.025 \mathrm{~cm}(0.01$ in.) per minute, which generally resulted in average specimen strain rates of 0.01 to $0.02 \mathrm{~cm}$ per $\mathrm{cm} / \mathrm{min}$. A few tests were run with crosshead speeds of $0.0025 \mathrm{~cm}$ or $0.005 \mathrm{~cm}$ (0.001 in. or $0.002 \mathrm{in.})$ per minute and correspondingly lower average strain rates. The average specimen strain rate was determined by dividing $\left(D_{f}-D_{i}\right) / D_{i}$ by the total test time. The values of $\Delta D / D_{i}$ were determined by measuring the diameters with a micrometer.

A trace of load on the mandrel versus time was made for each ring test. A given test was run to the point of specimen failure-indicated by a drop in load on the strip chart-to the $4500-\mathrm{kg}(10,000-\mathrm{lb})$ machine load limit, or to a point where the mandrel was estimated to have been compressed to a height only $0.050 \mathrm{~cm}(\sim 0.020 \mathrm{in}$.) or so greater than the ring width.

Several mandrel materials (Zircaloy, stainless steel, aluminum, and brass) and different mandrel heights were tried in an attempt to obtain successful tests at all temperatures.

\subsection{Results}

Some difficulty was encountered in expanding the ring specimens to fracture, particularly in tests carried out at $343^{\circ} \mathrm{C}\left(650^{\circ} \mathrm{F}\right)$. With a mandrel made of a relatively high strength material, such as Zircaloy-2, the load capacity of the Instron machine sometimes was reached before the specimen was expanded to fracture. Mandrels made of softer materials, on the other hand, tended to buckle or fold over the edges of a specimen, and these tendencies increased with increasing mandrel height.

The test results are given in Table 20. Strains to fracture $\left(\Delta D / D_{j} \times 100\right)$ of 13 to $27 \%$ were obtained at room temperature on the irradiated specimens. Two of these specimens are shown in Figure 87 after testing. Evidence of a slight amount of folding of the mandrel over the edges, or wall, of the specimen can be seen. An unirradiated specimen prepared from SA-1 (Fuel Cycle Program) archive tubing was strained 50\% without fracture in a room temperature test.

Specimens from rod $A 41$ were increased in diameter as much as 69 percent without fracturing when tested with normal mandrels at $343^{\circ} \mathrm{C}\left(650^{\circ} \mathrm{F}\right)$. Specimen $A 41-13\left(\Delta D / D_{i}=69 \%\right)$ is shown after testing, in Figure 88 , with a typical unirradiated specimen that has not been tested. A specimen from rod $A 13$ tested at $343^{\circ} \mathrm{C}$ fractured at a $\Delta D / D_{i}$ of 69 percent. However, because the ring was not centered on the mandrel, it underwent an abnormal deformation, and at the end of the test one edge of the ring was flush with the flat surface of the mandrel. These conditions may have caused premature fracturing.

A specimen from rod $\mathrm{A} 41$ tested at $343^{\circ} \mathrm{C}$ on a mandrel that contained a longitudinal groove in its cylindrical surface was expanded 55 percent before breaking at the location of the groove. The groove was intended to simulate a radial crack in a fuel pellet. The ring and mandrel are shown at the end of the test, in Figure 89. The groove shows considerable deformation. It was not possible to observe what changes in form the groove may have undergone while the test was in progress, but it is believed that an unsupported circumferential increment was maintained across the width of the ring.

Two specimens from rod $\mathrm{A} 41$ tested at $454^{\circ} \mathrm{C}\left(850^{\circ} \mathrm{F}\right)$ fractured at strains of 34 percent and 45 percent. One of these specimens, A41-4, is shown in Figure 90. It appeared that no folding of the Zircaloy mandrels over the specimen edges had occurred in these tests.

The strains to fracture for specimens from rod A13 were considerably lower than those for specimens from rod A41, in tests at room temperature. The operating histories of these two fuel rods in terms of exposure time, power, and integrated neutron exposure, and such effects of operation as corrosion and increased hydrogen content, were quite similar. The cladding for the two rods was fabricated from two different lots of tubing, but whether some difference(s) between the two lots was responsible for the differences in room temperature ductility was not established. No valid comparison of $343^{\circ} \mathrm{C}\left(650^{\circ} \mathrm{F}\right)$ ductility between specimens from the two rods can be made. 
Table 20

SA-1 CLADDING RING TESTS

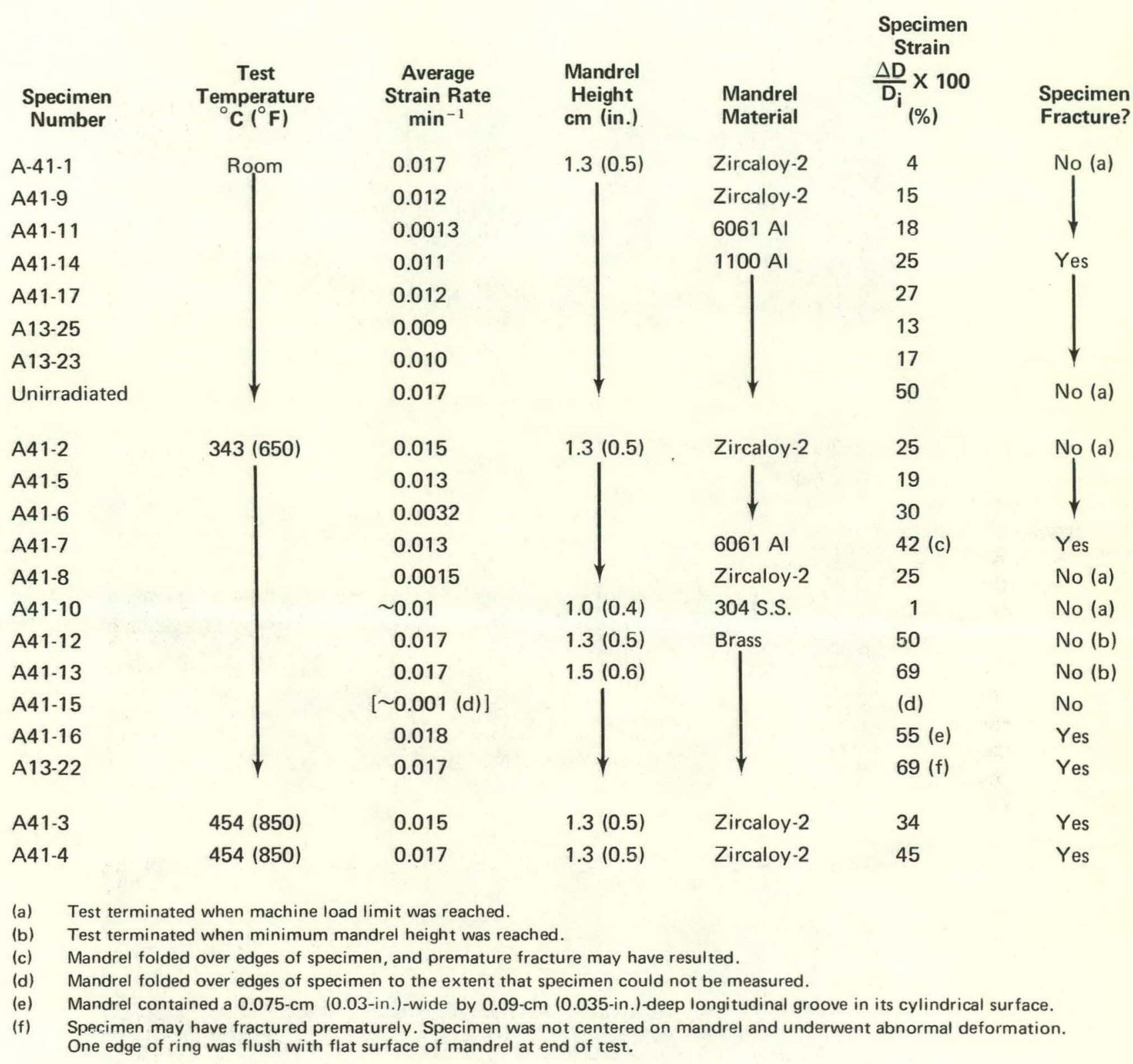



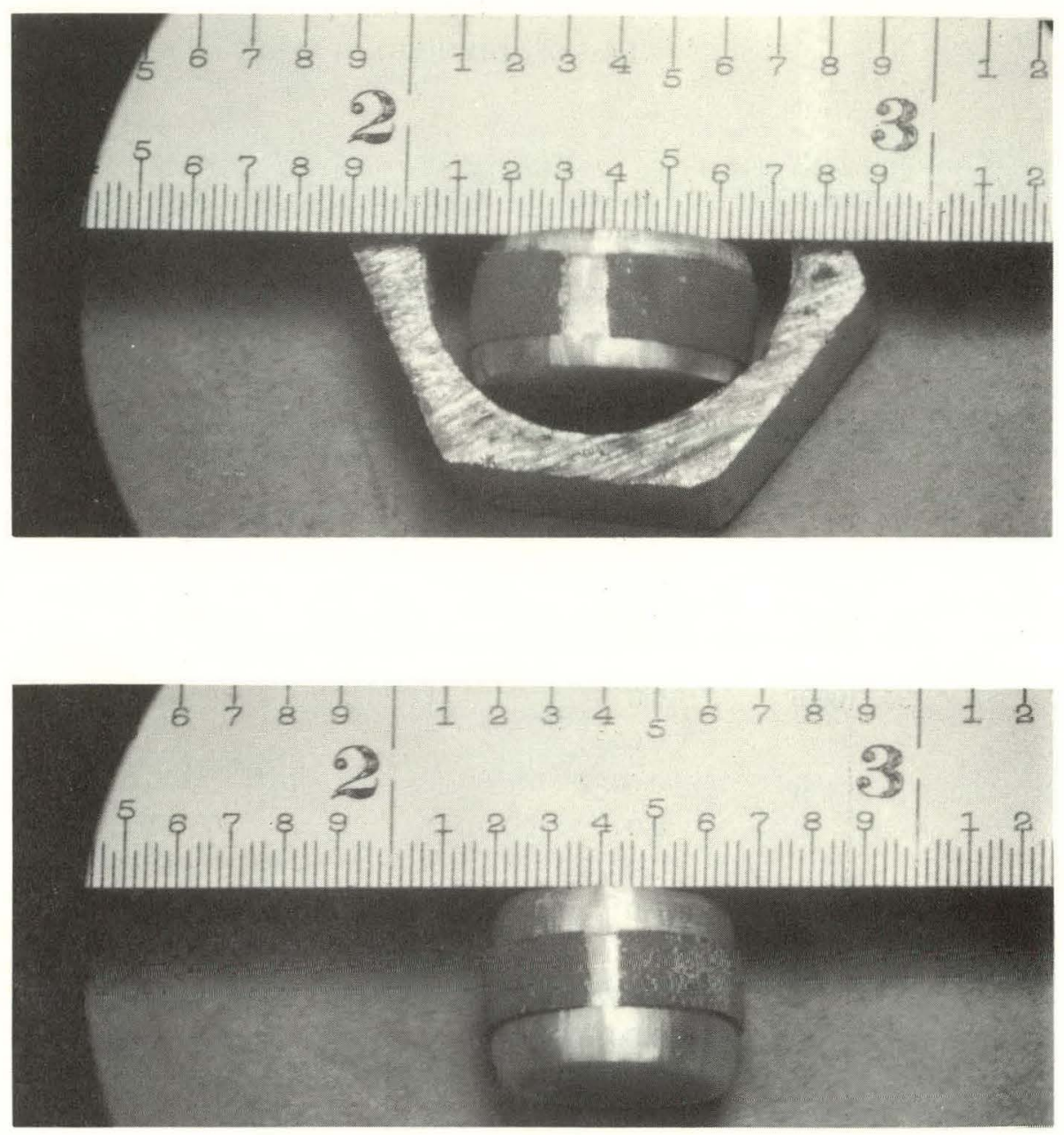

(b)

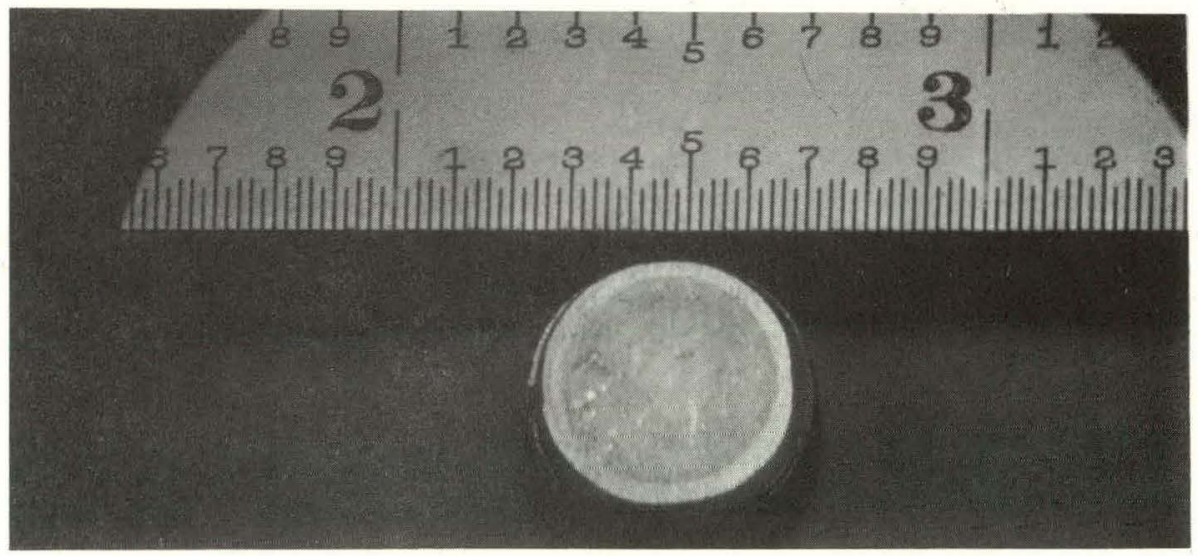

(c)

Figure 87. Ring Specimens and Mandrels After Testing at Room Temperature:

(a) Specimen A41-14 (Side View),

(b) Specimen A13-25 (Side View)

(c) Specimen A13-25 (Top View). 


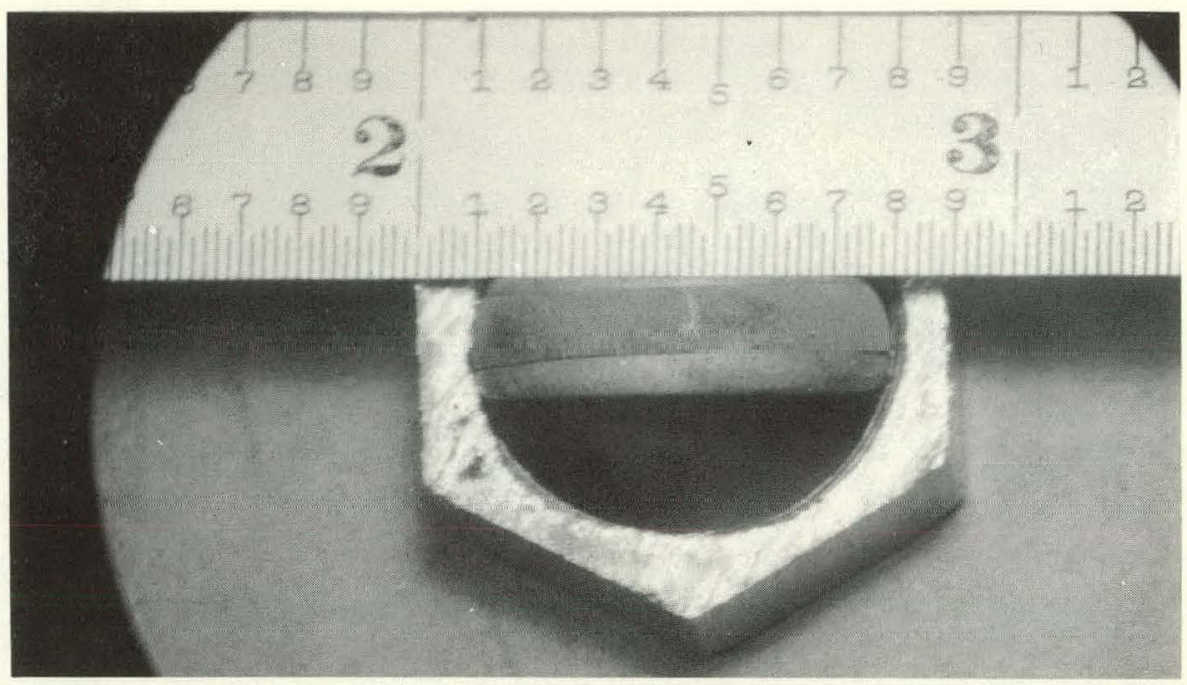

(a)

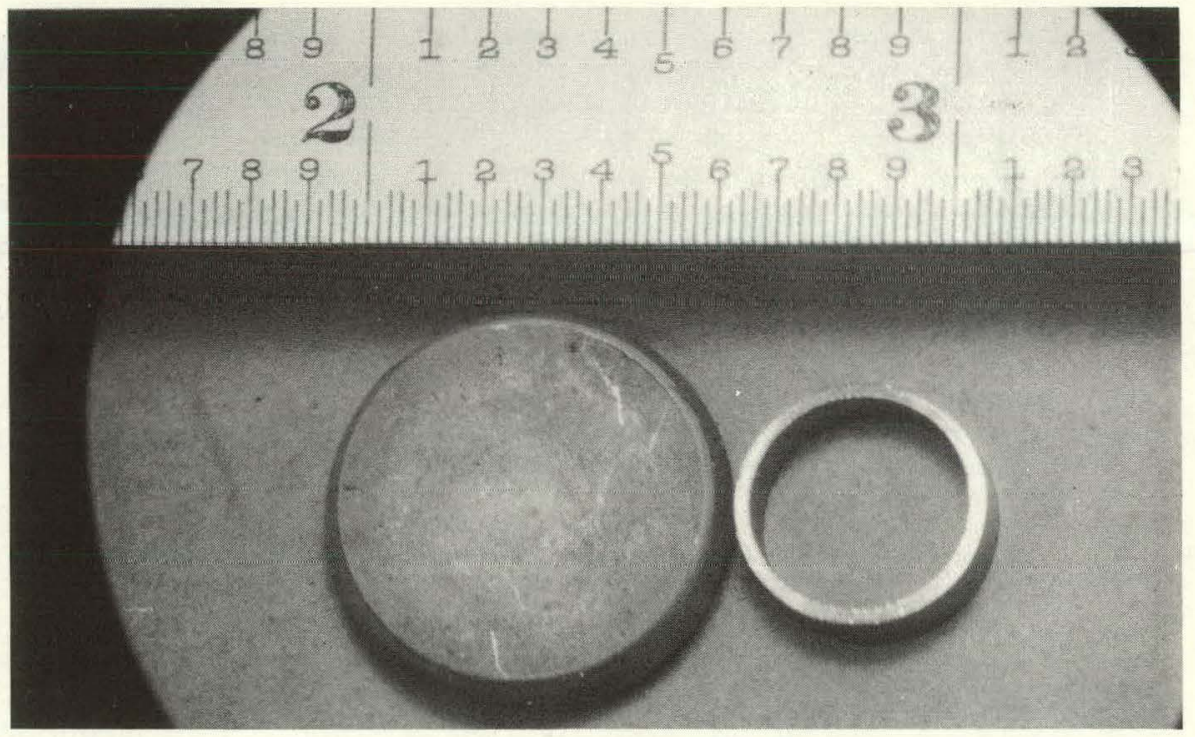

(b)

Figure 88. Specimen A41-13 After Testing at $343^{\circ} \mathrm{C}\left(650^{\circ} \mathrm{F}\right)$ :

(a) Side View, and (b) Top View, Shown with an

Unirradiated Specimen That Has Not Been Tested. 

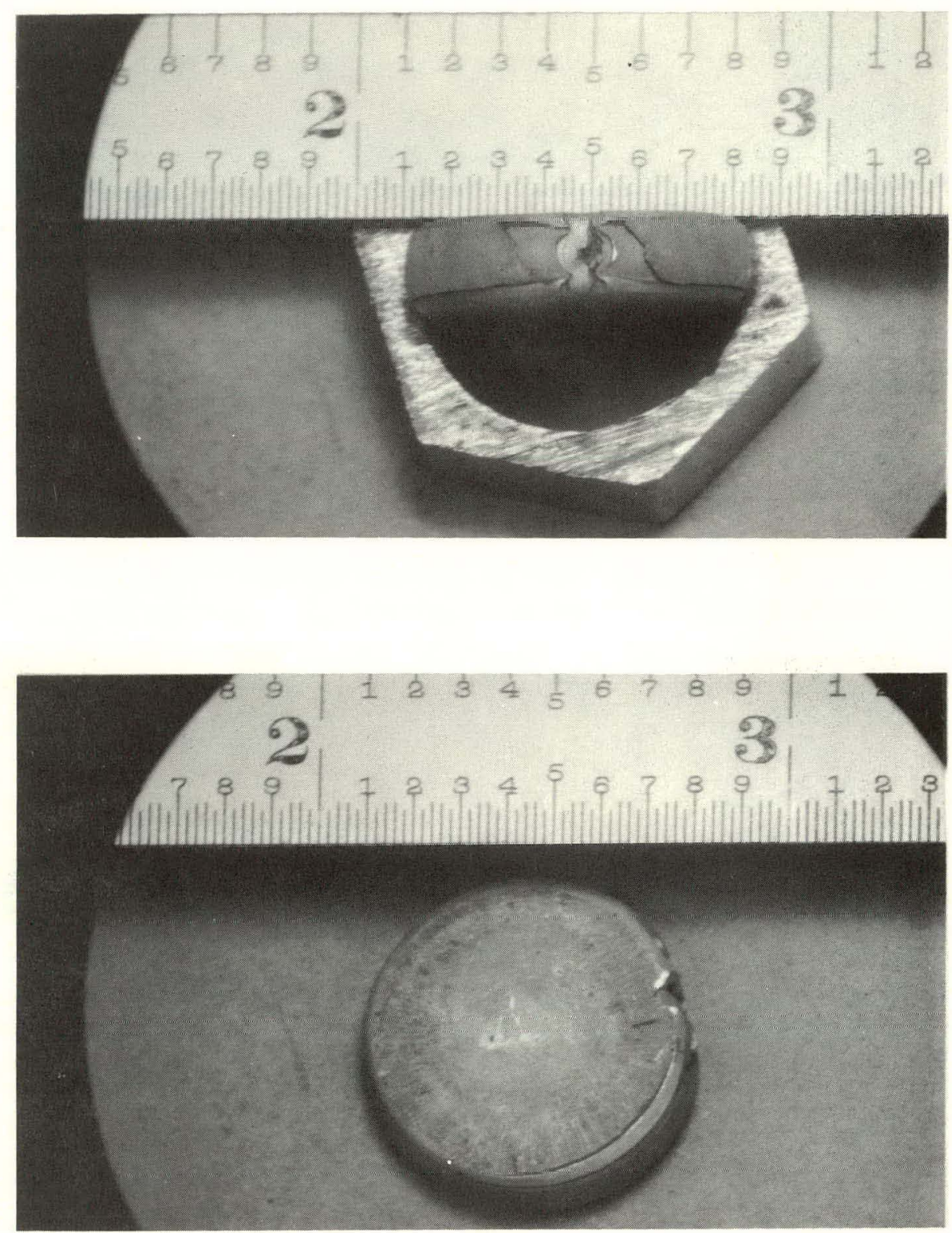

Figure 89. Specimen A41-16 After Testing at $343^{\circ} \mathrm{C}\left(650^{\circ} \mathrm{F}\right)$ with Grooved Mandrel 


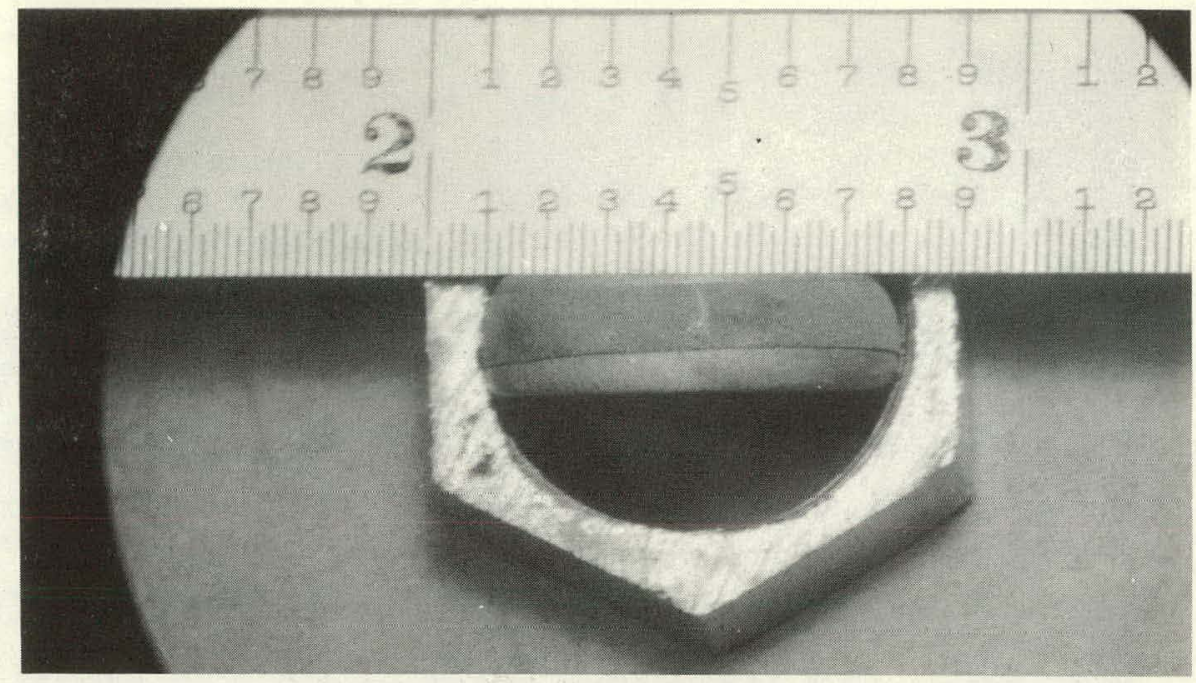

(a)

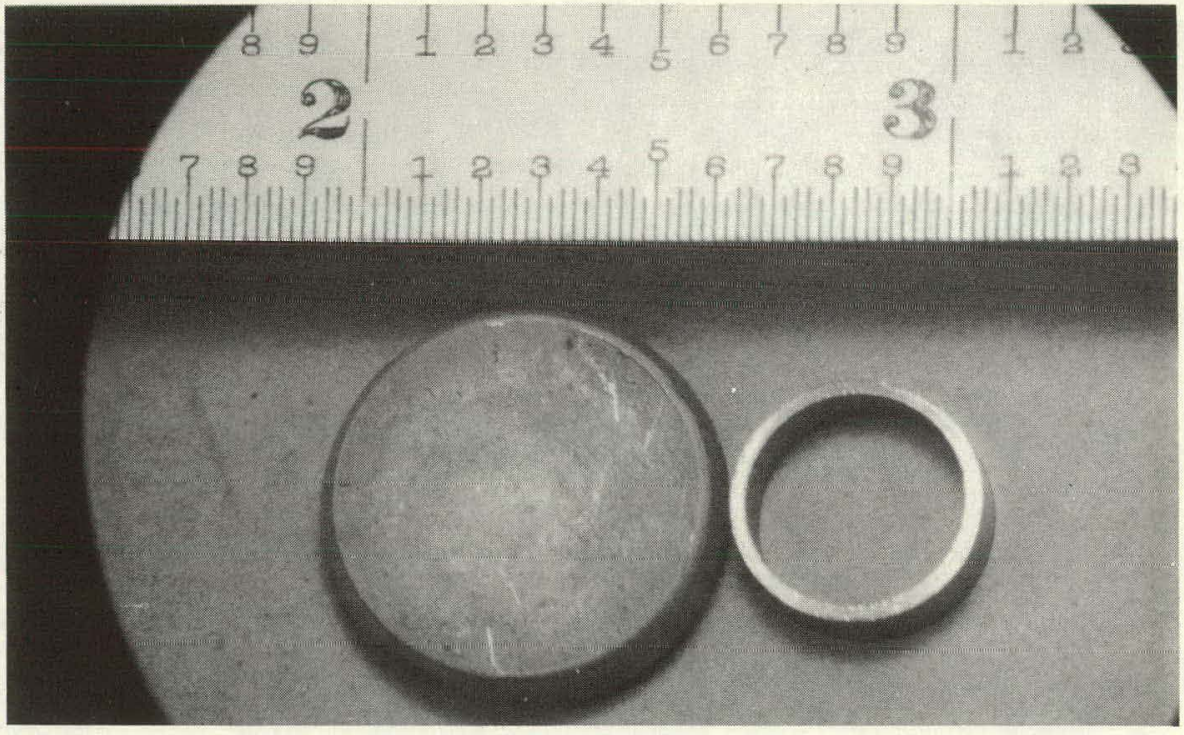

(b)

Figure 88. Specimen A41-13 After Testing at $343^{\circ} \mathrm{C}\left(650^{\circ} \mathrm{F}\right)$ :

(a) Side View, and (b) Top View, Shown with an

Unirradiated Specimen That Has Not Been Tested. 

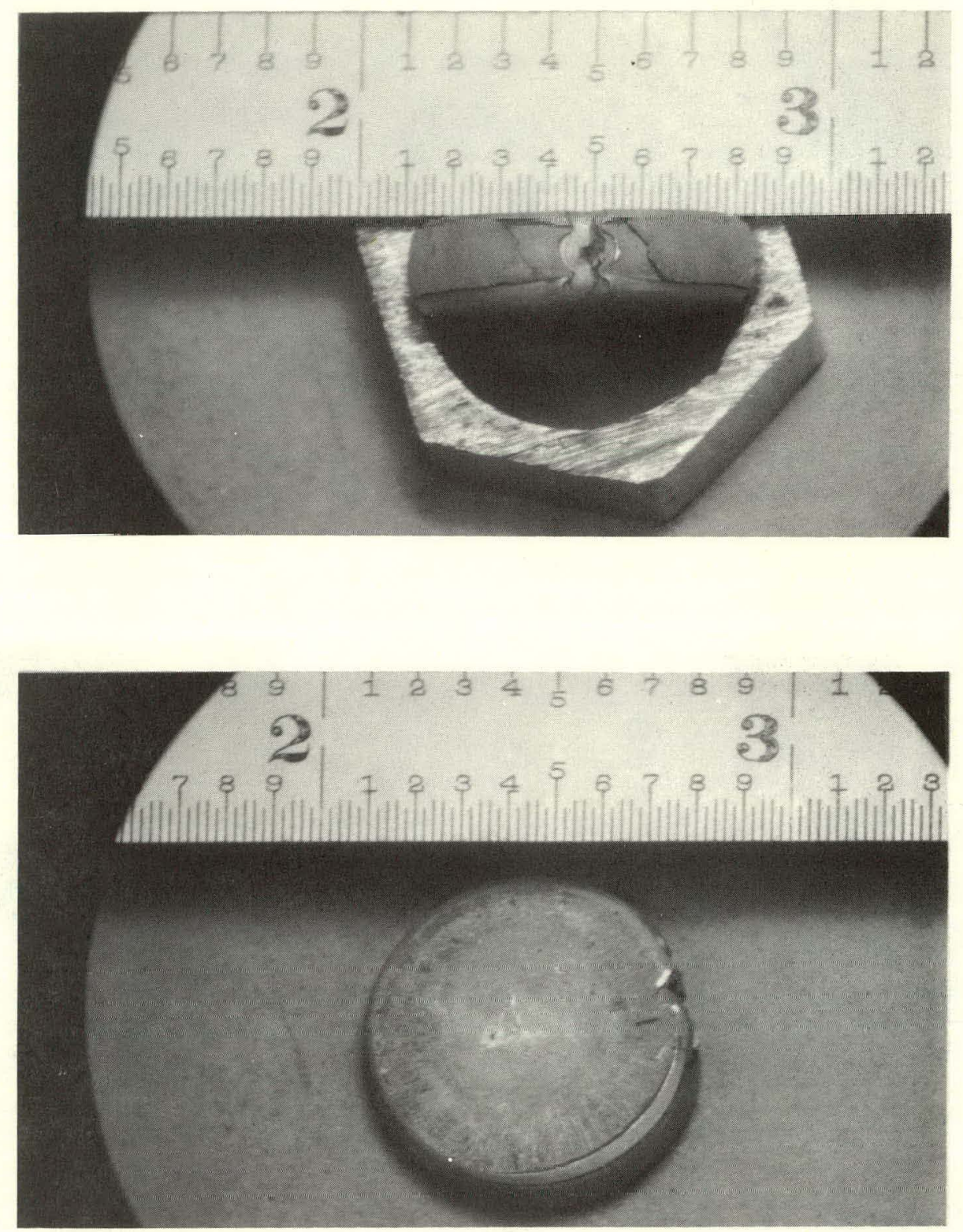

Figure 89. Specimen A41-16 After Testing at $343^{\circ} \mathrm{C}\left(650^{\circ} \mathrm{F}\right)$ with Grooved Mandrel 

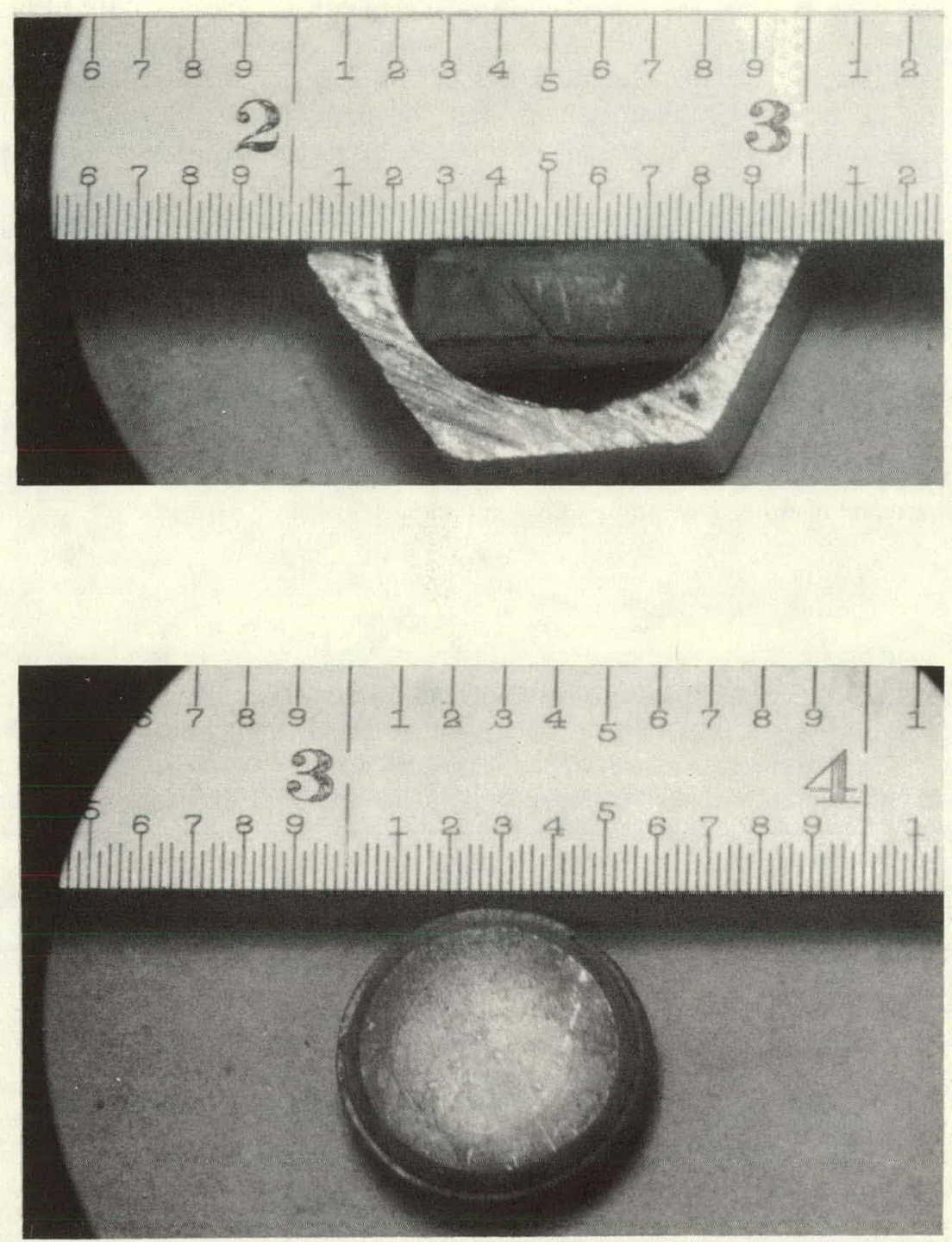

Figure 90. Specimen A41-4 After Testing at $454^{\circ} \mathrm{C}\left(850^{\circ} \mathrm{F}\right)$ 
The effect of strain rate is uncertain. The greatest strains were realized in some of the highest strain rate tests, but none of the tests performed at one of the lower rates was carried out to specimen fracture.

Investigators with the Fast Ceramic Reactor Development Program, who used the ring-on-compressed-cylinder test to measure the tensile ductility of irradiated Types-304 and $-316 \mathrm{~L}$ stainless steel cladding, pointed out that in this type of test the friction between the mandrel and the ring develop surface shear forces which support the entire gage length of the specimen and thus suppress localized necking. When mechanical interaction occurs during reactor operation, the fuel may support the cladding in a manner similar to the support provided the ring test specimens by the mandrels, but the relative extents of support are uncertain. In any event, it was expected that the strains to fracture obtained from ring tests would be greater than both the total elongations obtained from tensile tests in which the gage region was not supported, and the circumferential deformations to fracture obtained from burst tests in which necking instabilities were similarly unsupported. ${ }^{6}, 7$ However, the single ring test of the present series that was run at $343^{\circ} \mathrm{C}$ with a grooved mandrel apparently indicates that the presence of an unsupported increment which is small with respect to the total length over which deformation is occurring does not necessarily "drastically reduce" the strain to fracture of the specimen. Additional, more refined tests of this general type would have to be run, however, before the effects and significance of "notched mandrels" could be fully evaluated.

\subsubsection{Burst Tests}

\subsection{Procedure and Scope}

Samples of cladding that had been exposed to estimated fast fluences of $6 \times 10^{21}$ to $7 \times 10^{21}$ nvt ( $\mathrm{E}>1 \mathrm{MeV}$ ) were obtained for burst testing by sectioning out $20-\mathrm{cm}$ (8-in.)-lengths from selected fuel rods. All of the irradiated cladding samples came from tubing lot CA-2. One-half of the SA-1 rods were clad with tubing from this lot; hence it was the most representative and afforded the best selection of samples. For comparison, unirradiated control samples were cut from Type J Zircaloy-2 Fuel Cycle Program tubing that had been autoclaved. All of the control samples came from tubing lot CA-3; unfortunately, only tubing from this lot was in sufficient supply to prepare the required number. The unirradiated samples were tested in the hot cell according to the same procedure used on the irradiated samples.

Before an irradiated sample was tested, the crud and some of the external $\mathrm{ZrO}_{2}$ were removed from $\sim 2 \mathrm{~cm}$ $(\sim 3 / 4$ in.) of each end with emery cloth. Most of the fuel was left intact within the cladding; approximately 0.6 to $1.0 \mathrm{~cm}(1 / 4$ to $3 / 8 \mathrm{in}$.) was removed from one end so that wall thickness measurements could be made with a micrometer. The outside diameter of each sample was measured with a micrometer at the middle and at $5.1 \mathrm{~cm}(2 \mathrm{in}$.) from each end in two orientations 90 degrees apart. One end of the sample was sealed with a stainless steel Swagelok cap-type tube fitting. The other end was connected to a $1400 \mathrm{~kg} / \mathrm{cm}^{2}(20,000 \mathrm{psi})$ air-driven gas booster through $0.6 \mathrm{~cm}$ ( $1 / 4 \mathrm{in.}$ ) o.d. by $0.21 \mathrm{~cm}$ (0.083 in.) wall high-pressure tubing which was joined to the sample by means of another stainless steel Swagelok tube fitting. The length of sample between the fittings was approximately $16 \mathrm{~cm}$ (6-1/4 in.). The sample was placed in the center of a $3.8 \mathrm{~cm}(1-1 / 2 \mathrm{in.})$ i.d. by $0.6 \mathrm{~cm}(1 / 4 \mathrm{in}$.$) wall by \sim 25 \mathrm{~cm}(10 \mathrm{in}$.) long steel shroud tube which was capped at each end (see Figure 91).

The sample then was pressurized to failure with arqon at a rate of $53 \pm 21 \mathrm{kq} / \mathrm{cm}^{2}-\mathrm{min}(750 \pm 300 \mathrm{psi} / \mathrm{min})$. [However, the rate at the time of rupture was unintentionally increased to $320 \mathrm{~kg} / \mathrm{cm}^{2}-\mathrm{min}(4600 \mathrm{psi} / \mathrm{min}$ ) in the case of sample B98C-1, and to $89 \mathrm{~kg} / \mathrm{cm}^{2}-\min (1260 \mathrm{psi} / \mathrm{min})$ in the case of the unirradiated $454^{\circ} \mathrm{C}\left(850^{\circ} \mathrm{F}\right) \mathrm{control}$ sample.] The pressure was measured by both a Bourdon tube gage and a transducer. The transducer output was fed into a strain gage signal conditioner, and the readout was continuously recorded in terms of pressure on a strip chart recorder.

Tests were performed at nominal temperatures of $343^{\circ} \mathrm{C}\left(650^{\circ} \mathrm{F}\right), 399^{\circ} \mathrm{C}\left(750^{\circ} \mathrm{F}\right)$, and $454^{\circ} \mathrm{C}\left(850^{\circ} \mathrm{F}\right)$, in addition to room temperature. To carry out the high-temperature tests, the shrouded sample was placed in an electric resistance tube furnace. The sample temperature was measured by means of three chromel-alumel thermocouples located at the middle and at $5.1 \mathrm{~cm}(2 \mathrm{in}$.) from each end of the sample. The middle thermocouple was connected to a saturable reactor temperature controller. The sample was brought to the test temperature and held there $1 / 2$ hour. It was then pressurized to failure. The temperature at the middle of the sample was somewhat higher than at the other locations measured. The three temperature readings were generally within $5-1 / 2^{\circ} \mathrm{C}$ to $8-1 / 2^{\circ} \mathrm{C}\left(10^{\circ} \mathrm{F}\right.$ to $\left.15^{\circ} \mathrm{F}\right)$ of each other throughout the test. In the case of the unirradiated $454^{\circ} \mathrm{C}$ control sample, the temperature at one end was $\sim 17^{\circ} \mathrm{C}$ $\left(30^{\circ} \mathrm{F}\right)$ lower than at the middle.

The diameter of a tested sample was measured with the micrometer at locations just outside of the burst region and, in most cases, at locations somewhat removed from the burst region as well. The measurements were made in two orientations, 90 degrees apart. 


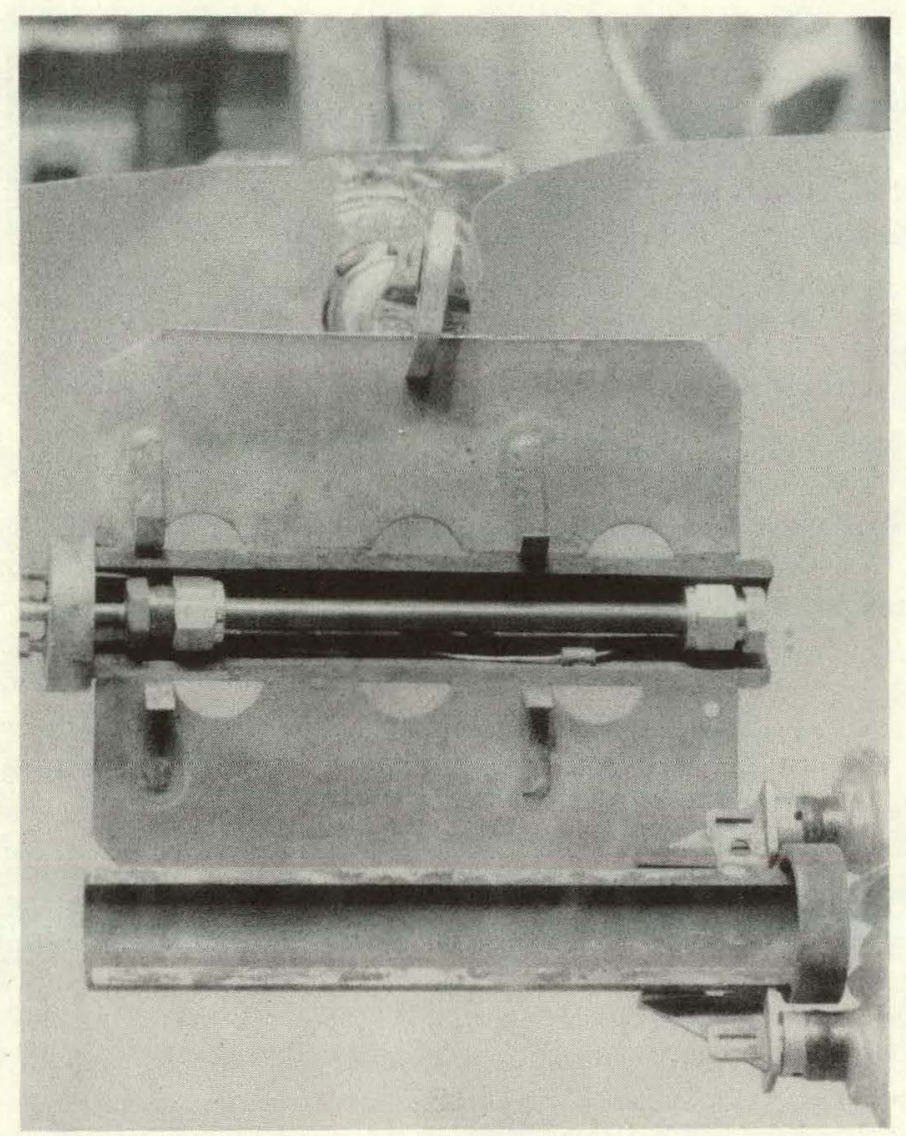

Figure 91. Unirradiated Sample Positioned in Open Shroud Tube Prior to Burst Testing 
In addition to the foregoing measurements, the distance around a tested sample from one edge of the primary (longitudinal) fracture to the other was measured by using strips of $0.0025-\mathrm{cm}(0.001$-in.)-thick stainless steel foil, $0.16 \mathrm{~cm}(1 / 16 \mathrm{in.})$ to $0.32 \mathrm{~cm}(1 / 8 \mathrm{in}$.) wide by approximately $25 \mathrm{~cm}$ (10 in.) long. While the sample was held in a horizontal position, one of these foil strips-with small lead weights attached to each end-was wrapped around the fracture region at the location of apparent maximum circumferential elongation. Pulling the strip taut about the sample resulted in a crimping of the strip at the edges of the fracture. The distance between the crimp marks $\left(C_{f}\right)$ was then measured out of cell by means of a scale and magnifying glass. The measured distances between crimp marks on duplicate foil strips were found to be within 0.025 to $0.05 \mathrm{~cm}(0.01$ to $0.02 \mathrm{in}$.) of each other on each of the irradiated samples and on the room-temperature control sample. Reproducibility was poorer on the high-temperature control samples due to the irregular nature of the fractures shown by these samples.

\subsection{Results}

The control and irradiated samples are shown, after testing, in Figures 92 through 96, and the values of burst pressure, hoop stress at rupture, and percent strain to fracture are listed in Table 21 . The $\Delta D / D_{i}$ values in the table were calculated from selected post-test diameter measurements made near the burst regıons and the corresponding pre-test measurements. The locations at which these values were determined for the high test temperature samples are indicated in Figures 97 through 99. $\Delta D / D_{i}$ values determined at locations away from the burst regions also are designated. The circumferential elongation values $\left(\mathrm{C}_{f}-\mathrm{C}_{i}\right) / \mathrm{C}_{i} \times 100$ in Table 21 were calculated from measurements made on the foil strips and the corresponding pre-test diameter measurements.

The average stresses at rupture for irradiated samples tested at room temperature and at nominal temperatures of $343^{\circ} \mathrm{C}, 399^{\circ} \mathrm{C}$, and $454^{\circ} \mathrm{C}$, were $8000 \mathrm{~kg} / \mathrm{cm}^{2}(114 \mathrm{kpsi}), 5100 \mathrm{~kg} / \mathrm{cm}^{2}$ (72 kpsi), $4900 \mathrm{~kg} / \mathrm{cm}^{2}(69 \mathrm{kpsi})$, and $4400 \mathrm{~kg} / \mathrm{cm}^{2}(62 \mathrm{kpsi})$, respectively. Based on these average values for each pair of irradiated samples, the largest difference between irradiated and unirradiated control samples was shown in the $343^{\circ} \mathrm{C}$ tests $\left(1800 \mathrm{~kg} / \mathrm{cm}^{2} \mathrm{or} 25 \mathrm{kpsi}\right)$ and the smallest difference was shown in the room temperature and $454^{\circ} \mathrm{C}$ tests $\left(1400 \mathrm{~kg} / \mathrm{cm}^{2}\right.$ or $19 \mathrm{kpsi}$ ).

It should be pointed out that while one of the room temperature samples was tested in a normal manner, the second was held at the highest test temperature investigated in the current series (i.e., $454^{\circ} \mathrm{C}$ ) for the standard holding time before being pressurized at room temperature. Although the stress at rupture shown by the second sample was somewhat lower than that of the first, the difference in values probably was no greater than one might expect to obtain between two comparable non-heat-treated samples. However, as Figure 93 shows, the samples appeared quite different after testing. Sample B98A-2 split longitudinally in two separate orientations approximately 180 degrees apart.

Most of the strain to fracture values shown by the unirradiated high test temperature samples were considerably greater than those shown by the room temperature test sample. However, irradiation markedly decreased the strains to fracture among the high temperature samples; it showed a comparatively small effect at room temperature. The percent strain to fracture did not show any clear temperature dependence between $343^{\circ} \mathrm{C}$ and $454^{\circ} \mathrm{C}$.

It is of interest to note in Figures 97 through 99 that diametral expansions of 2 to 7 percent occurred at locations removed from the burst regions on the various irradiated high test temperature samples.

\subsubsection{Microhardness Measurements on Metallography Specimens}

\subsection{Procedure and Scope}

Measurements of diamond pyramid hardness (DPH) were made on the cladding of two transverse and one longitudinal fuel rod section metallography specimens. Three-by-three arrays of indentations were made on each specimen at two locations approximately 180 degrees apart, or on opposite wall sections in the case of the longitudinal specimen. A typical array of indentations is shown in Figure 100.

\subsection{Results}

The DPH values obtained are given in Table 22. The average hardnesses were 217 and $223 \mathrm{DPH}$ for the transverse specimens and $246 \mathrm{DPH}$ for the longitudinal specimen. The measurements on the two specimens from Rod A41 indicate a directional difference in hardness, since the exposures were approximately the same.

The present measurements are probably most significant when compared with data on lower exposure and unirradiated Fuel Cycle Program cladding. The microhardness of an unirradiated transverse specimen was $158 \mathrm{DPH}$, and that of a longitudinal specimen was $195 \mathrm{DPH}$. Hardness measurements made on several transverse cladding sections exposed in the VBWR to between $1 \times 10^{21}$ and about $1.5 \times 10^{21} \mathrm{nvt}>1 \mathrm{MeV}$ showed a maximum value of $201 \mathrm{DPH}$ and an overall average value of $193 \mathrm{DPH}^{3}$ 


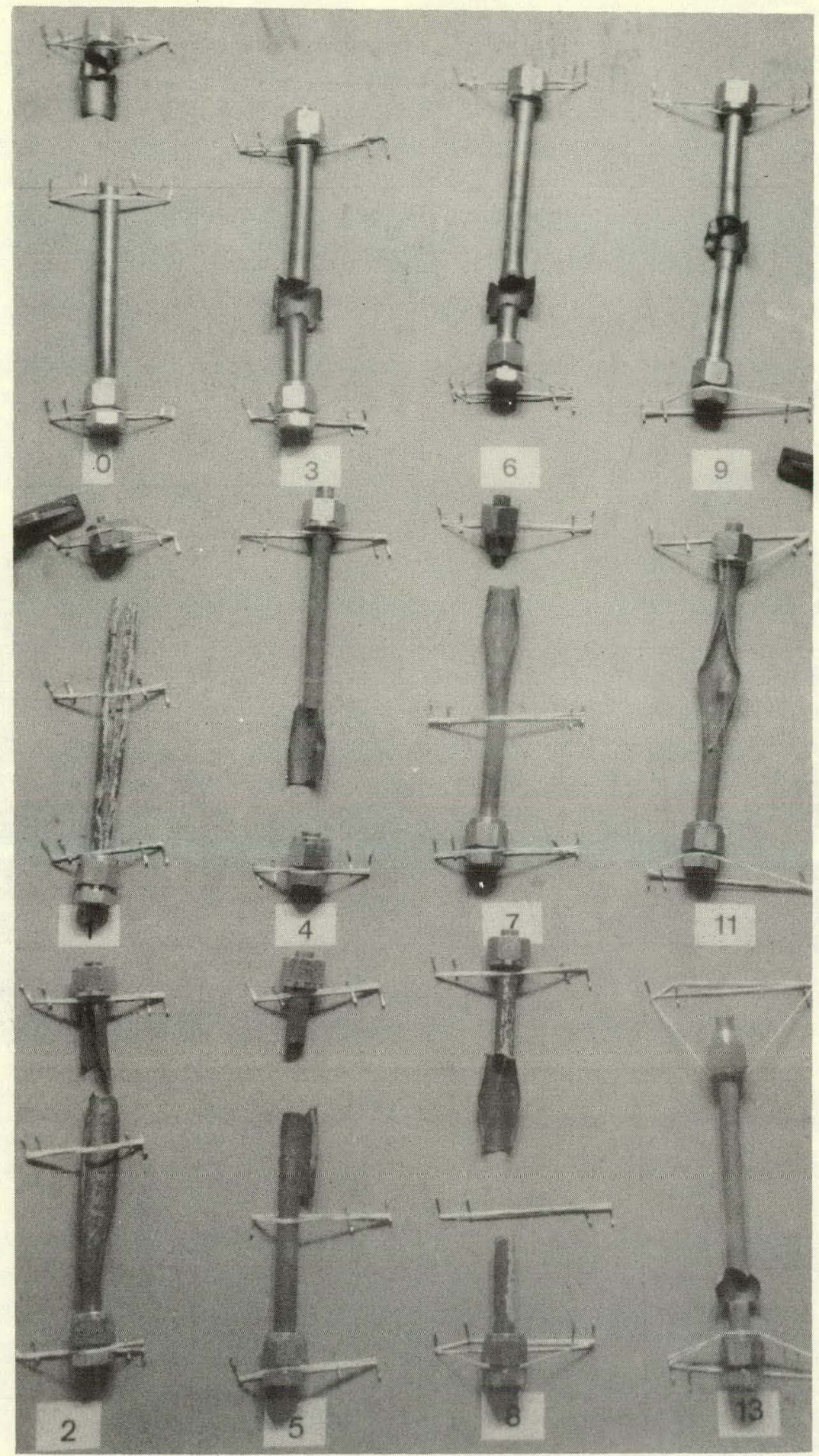

Figure Y2. SA-1 C'laddıng Samples Atter Burst lesting (See Table 21 for Key to Sample Designation) 


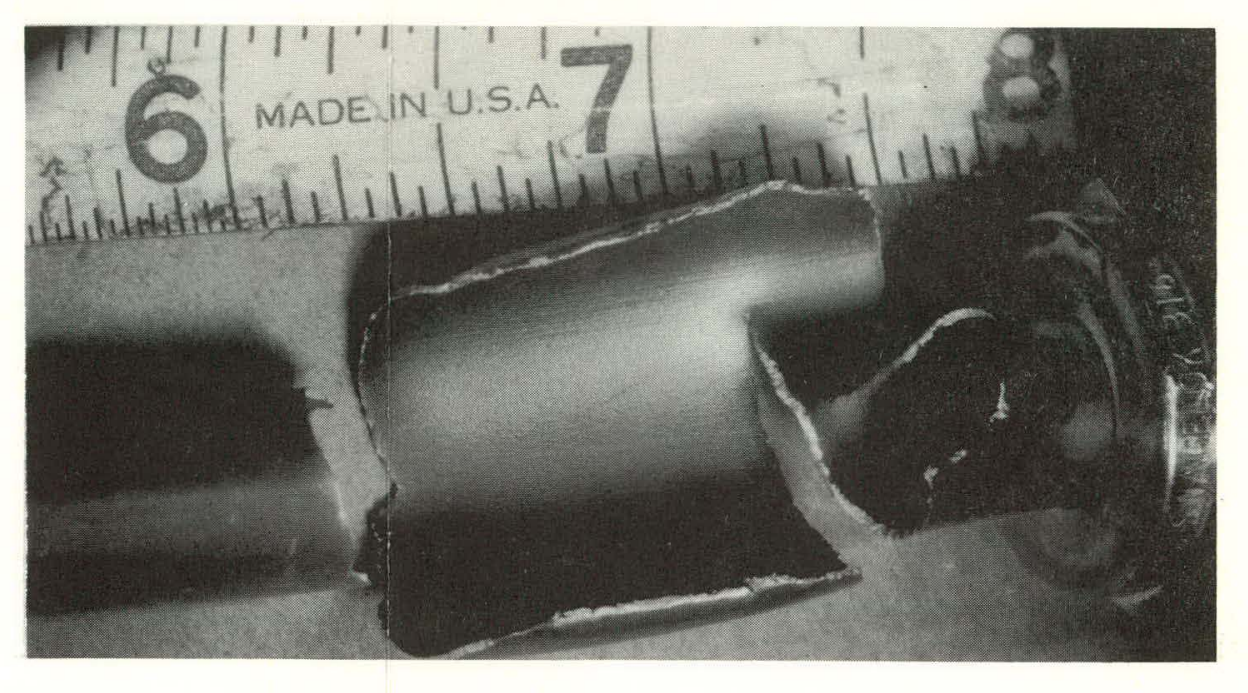

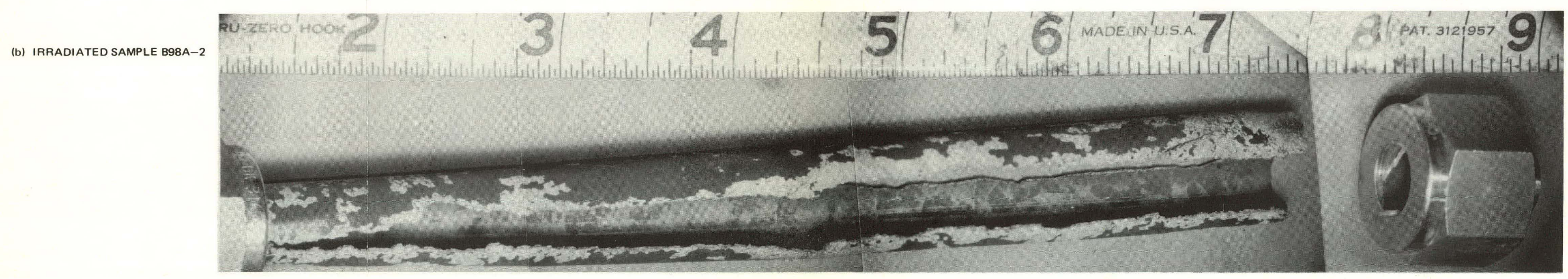

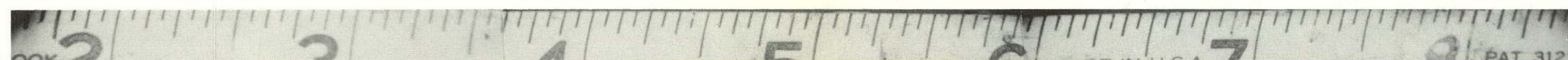
(c) IRRADIATED SAMPLE A42C-1 DOK
(HELL AT 454 C $8550^{\circ}$ F) FOR

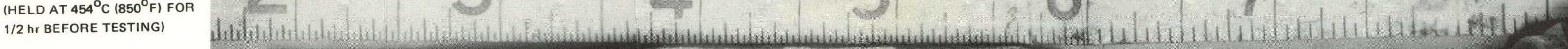





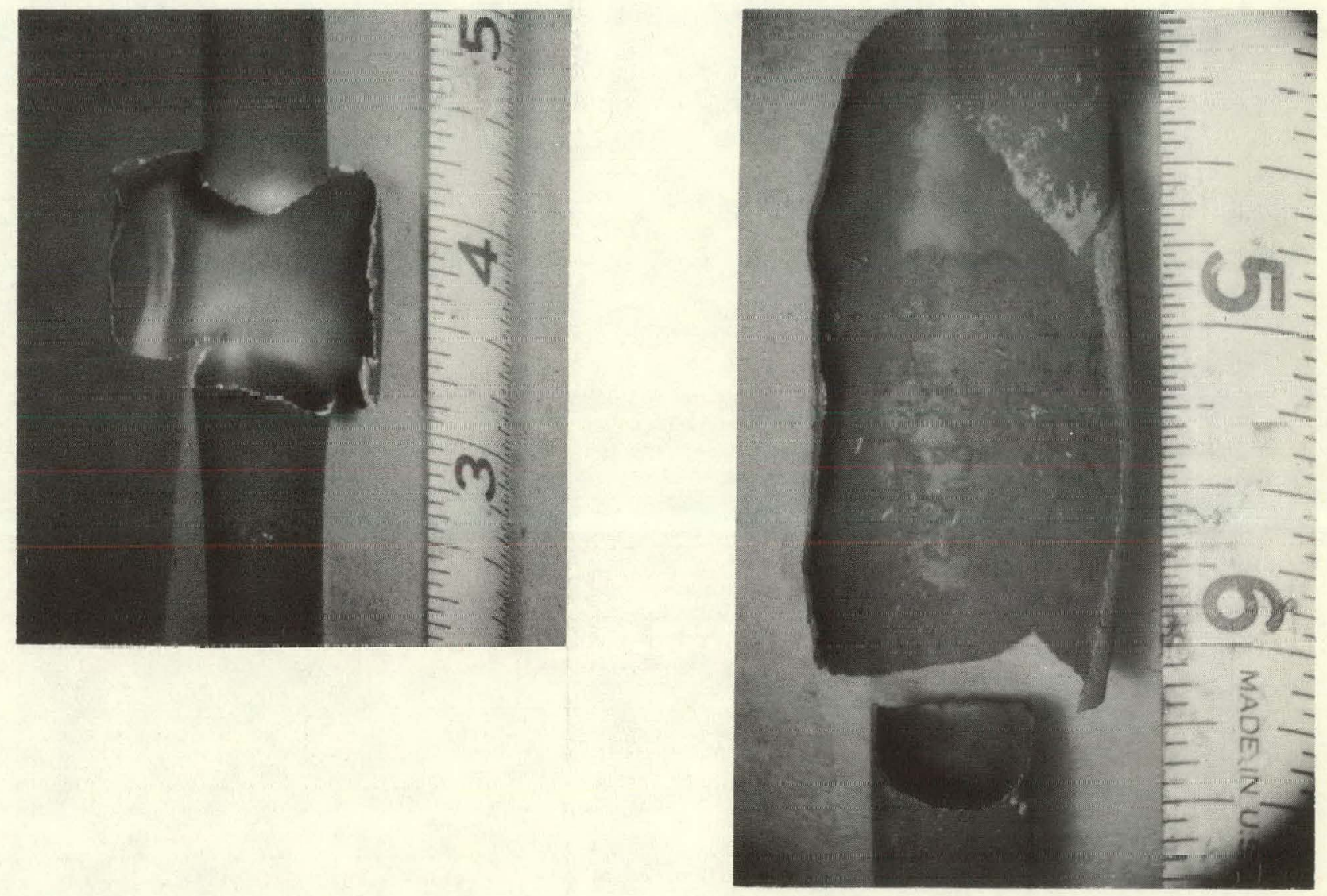

Figure 94. Burst Samples Tested at $\sim 343^{\circ} \mathrm{C}\left(650^{\circ} \mathrm{F}\right)$ :

Inirradiated Sample No. 3 (left);

Irradiated Sample A47D-2 (right) 


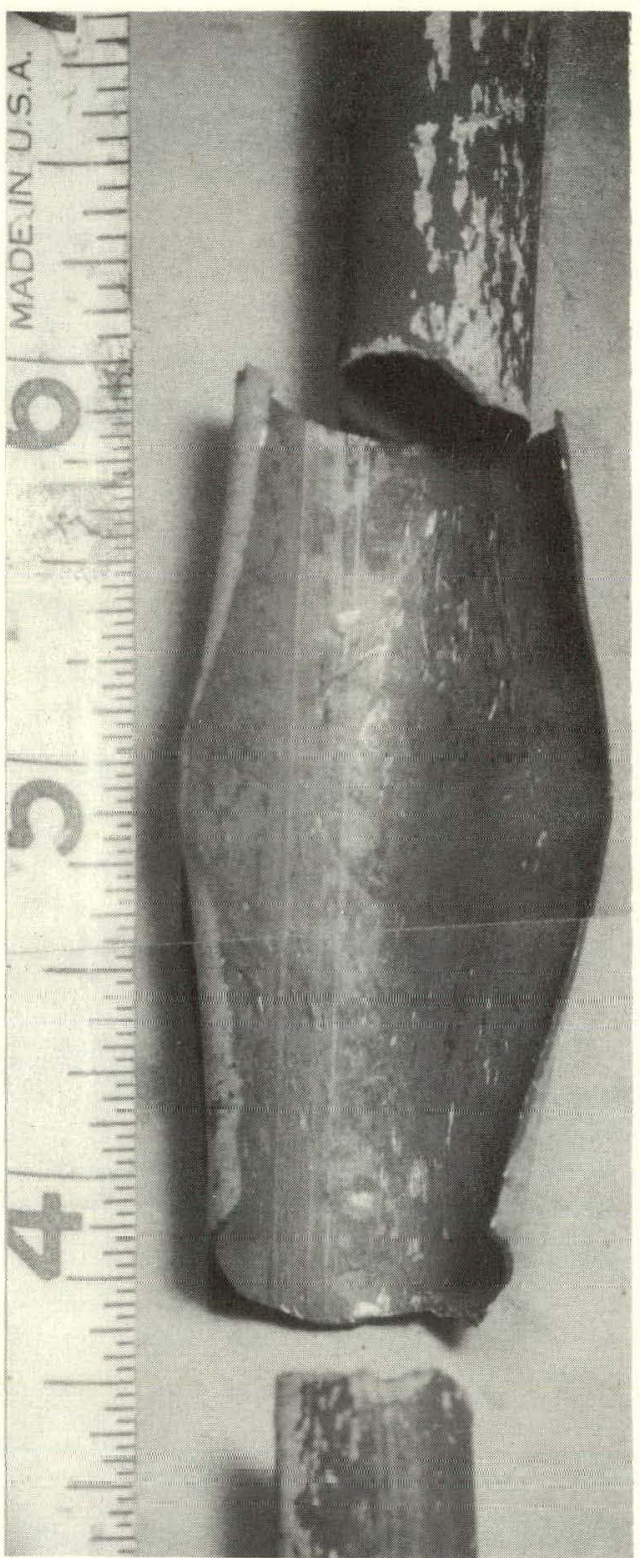

Figure 95. Burst Samples Tested at $\sim 399^{\circ} \mathrm{C}\left(750^{\circ} \mathrm{F}\right)$ : Unirradiated Sample No. 6 (left);

Irradiated Sample B98C-1 (right) 


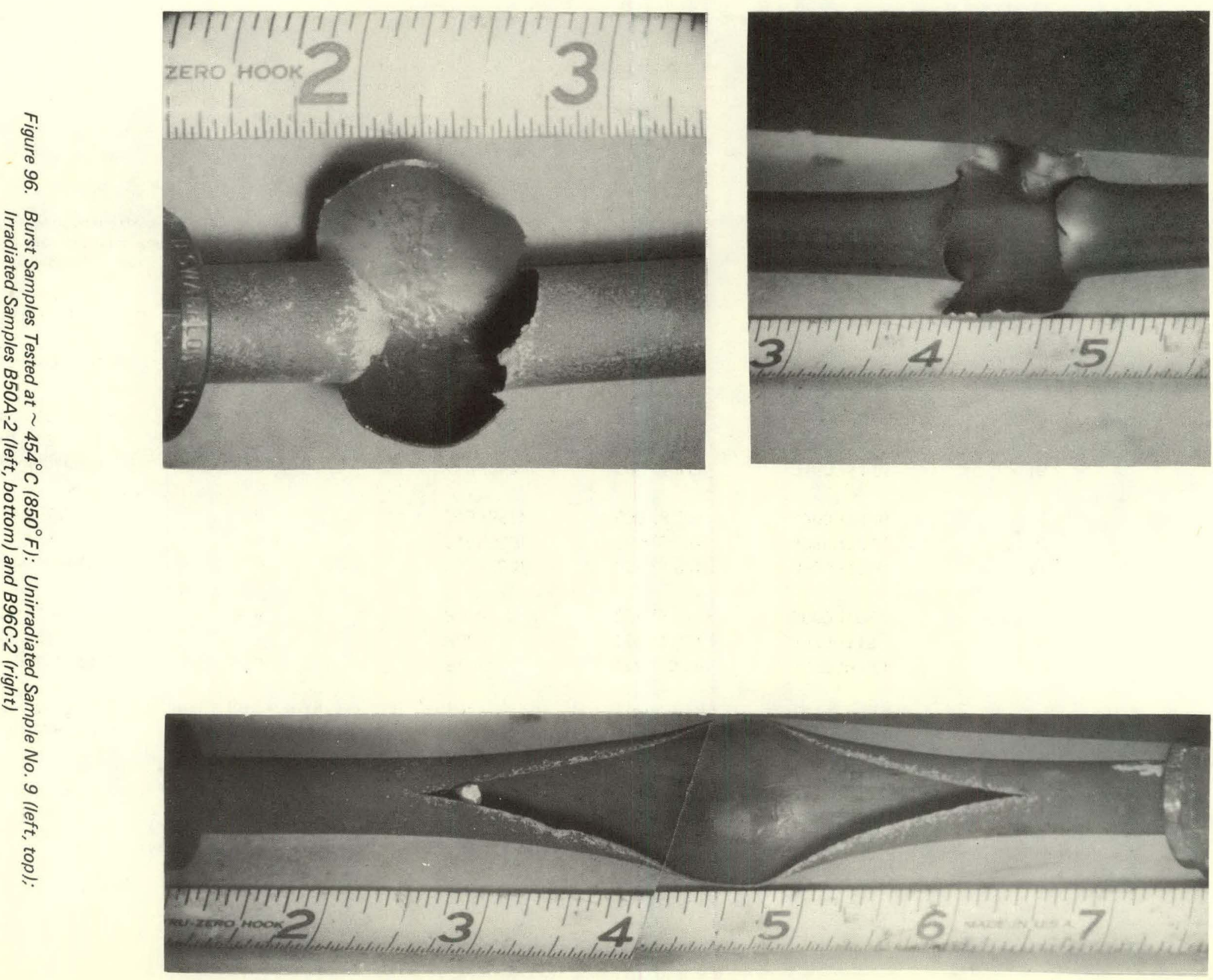


Table 21

BURST TESTS ON SA-1 CLADDING SAMPLES

\begin{tabular}{|c|c|c|c|c|c|c|}
\hline & \multirow[b]{2}{*}{$\begin{array}{c}\text { Estimated Fast } \\
\text { Fluence Exposure } \\
\left(\text { nvt }>1 \mathrm{MeV} \times 10^{-21}\right)\end{array}$} & \multirow[b]{2}{*}{$\begin{array}{c}\text { Test } \\
\text { Temperature } \\
{ }^{\circ} \mathrm{C}\left({ }^{\circ} \mathrm{F}\right)\end{array}$} & \multirow[b]{2}{*}{$\begin{array}{l}\text { Burst Pressure } \\
\mathrm{kg} / \mathrm{cm}^{2} \text { (kpsi) }\end{array}$} & \multirow[b]{2}{*}{$\begin{array}{l}\text { Hoop Stress } \\
\mathrm{kg} / \mathrm{cm}^{2} \text { (kpsi) }\end{array}$} & \\
\hline $\begin{array}{l}\text { Sample } \\
\text { Number* }\end{array}$ & & & & & $\frac{\overline{D_{f}-D_{i}}}{D_{i}} \times 100$ & $\begin{array}{l}\text { Circumferential } \\
\text { Elongation }\end{array}$ \\
\hline Unirradiated (0) & 0 & Room & $716(10.19)$ & $6650(94.6)$ & 9 & 8 \\
\hline B98A-2 (1) & 7 & Room & $792(11.27)$ & $8320(118.4)$ & - & 8 \\
\hline$A 42 C-1$ (2) & 6 & Room** & $828(11.77)$ & $7660(109.0)$ & - & 6 \\
\hline Unirradiated (3) & 0 & $343(650)$ & $356(5.07)$ & $3330(47.3)$ & 27 & $\geqslant 30$ \\
\hline B96A-2 (4) & 6.5 & $348(659)$ & $564(8.02)$ & $4980(70.8)$ & 4 & 3 \\
\hline A47D-2 (5) & 6 & 348 (659) & $586(8.34)$ & $5200(74.0)$ & 8 & 7 \\
\hline Unirradiated (6) & 0 & $403(757)$ & $338(4.81)$ & $3150(44.8)$ & 16 & $\geqslant 12$ \\
\hline B96C-1 (7) & 6.5 & $403(758)$ & $533(7.58)$ & $4960(70.6)$ & $3-4$ & 5 \\
\hline B98C-1 (8) & 6.5 & $393(740)$ & $532(7.56)$ & $4770(67.8)$ & 4 & 5 \\
\hline Unirradiated (9) & 0 & $454(850)$ & $315(4.48)$ & $3010(42.8)$ & 23 & $\geqslant 16$ \\
\hline B96C-2 (11) & 6 & $454(850)$ & $488(6.94)$ & $4490(63.8)$ & $2-4$ & 4 \\
\hline B50A-2 (13) & 6 & $459(859)$ & $478(6.80)$ & $4270(60.7)$ & 6 & 6 \\
\hline
\end{tabular}

* Numbers in parentheses refer to sample designations used in Figure 92.

* * Sample was held at $454^{\circ} \mathrm{C}$ for 30 minutes, cooled to room temperature and pressurized to failure.

- = Could not be measured. 


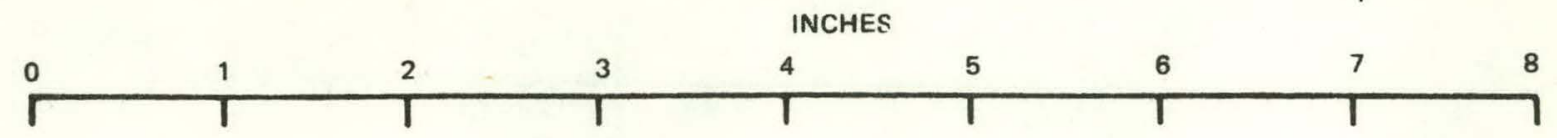
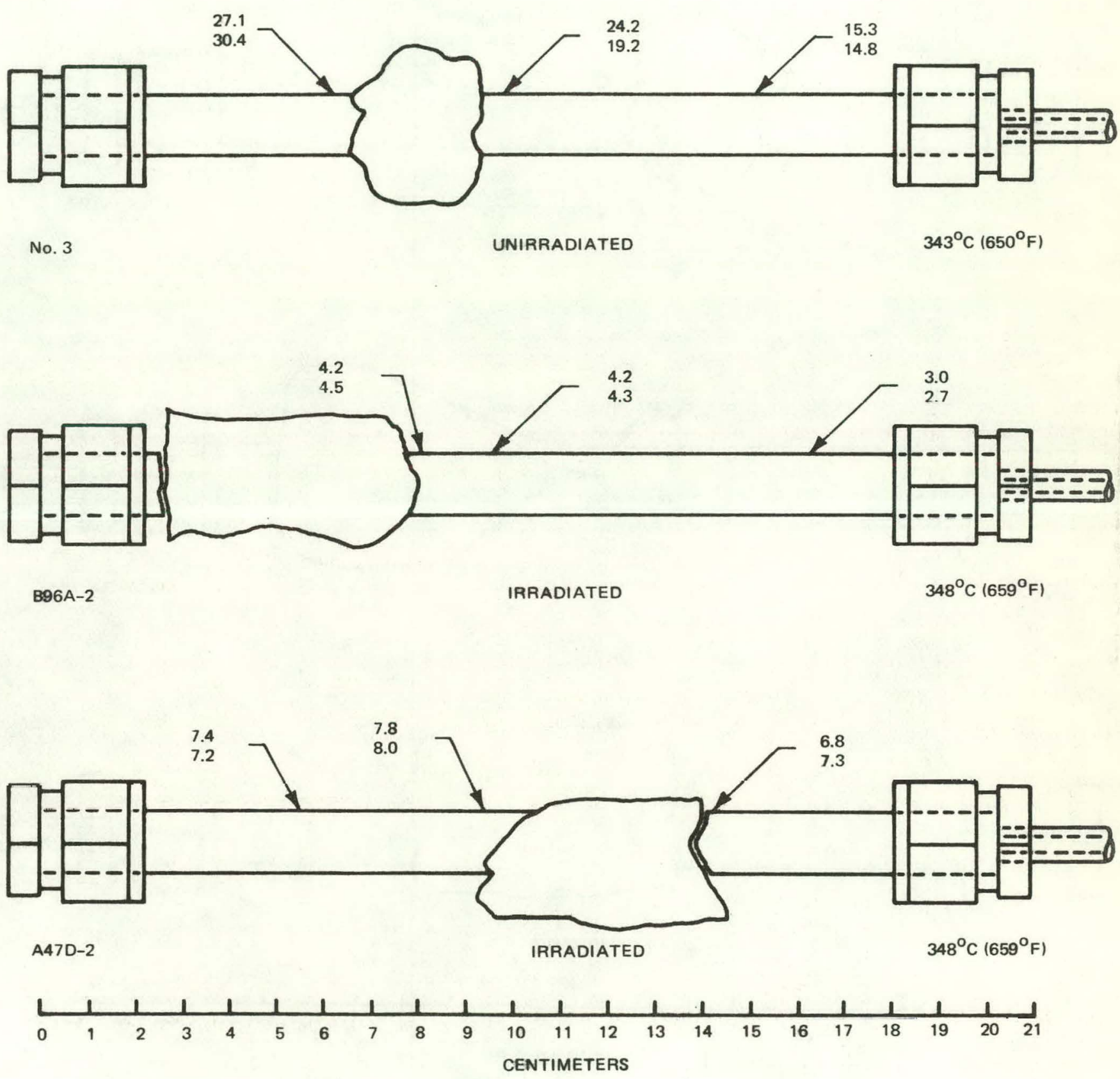

Figure 97. Values of $\left(D_{f}-D_{j}\right) / D_{i} \times 100$ at Various Points Along Samples Tested at a Nominal Temperature of $343^{\circ} \mathrm{C}\left(650^{\circ} \mathrm{F}\right)$. (Two determinations 90 degrees apart were made at each axial location indicated.) 
INCHES

\begin{tabular}{lllllllll}
0 & 1 & 2 & 3 & 4 & 5 & 6 & 7 & 8 \\
\hline & & 1 & & & & & &
\end{tabular}
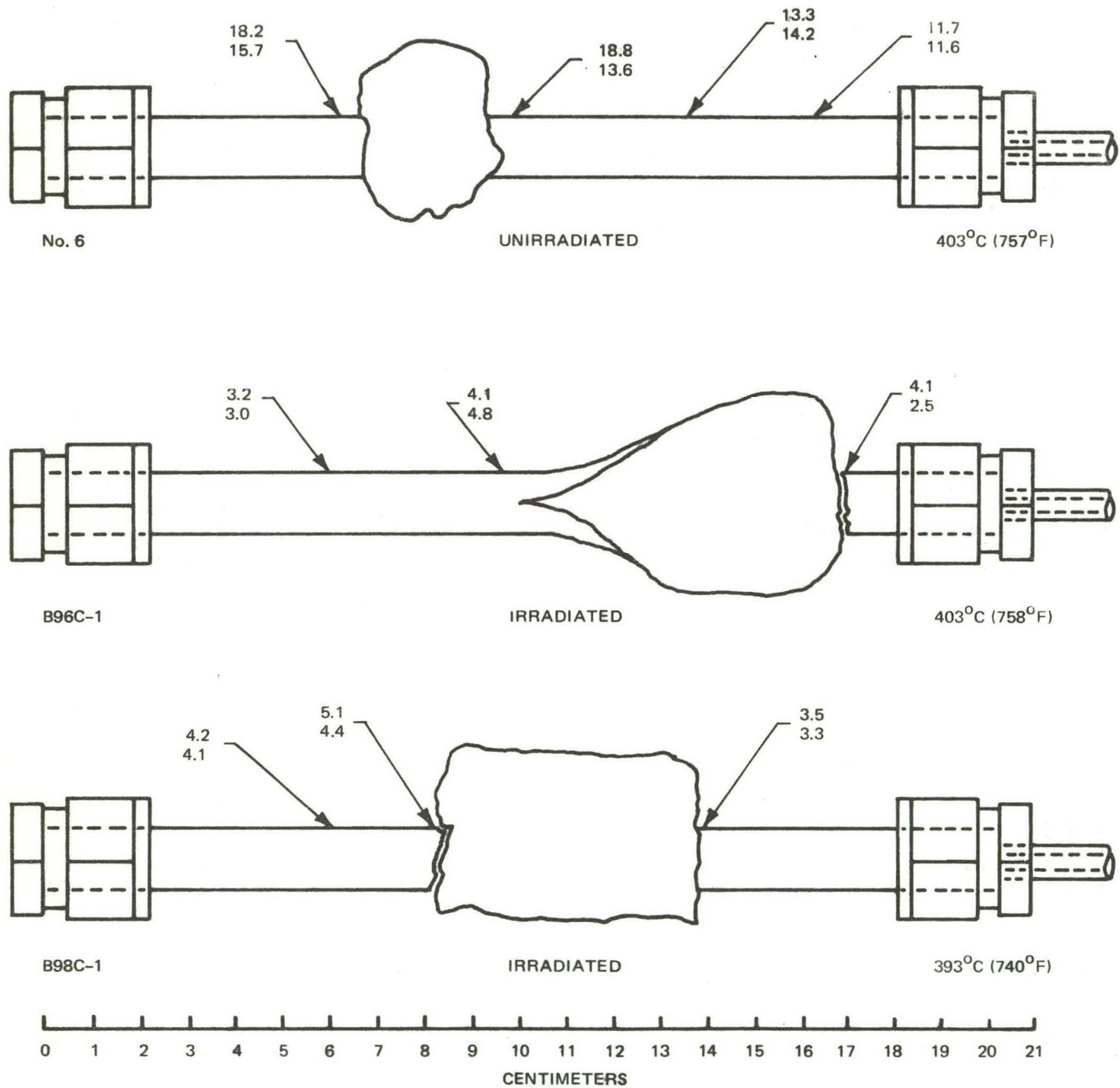

Figure 98. Values of $\left(D_{f}-D_{j}\right) / D_{i} \times 100$ at Various Points Along Samples Tested at a Nominal Temperature of $399^{\circ} \mathrm{C}\left(750^{\circ} \mathrm{F}\right)$ 

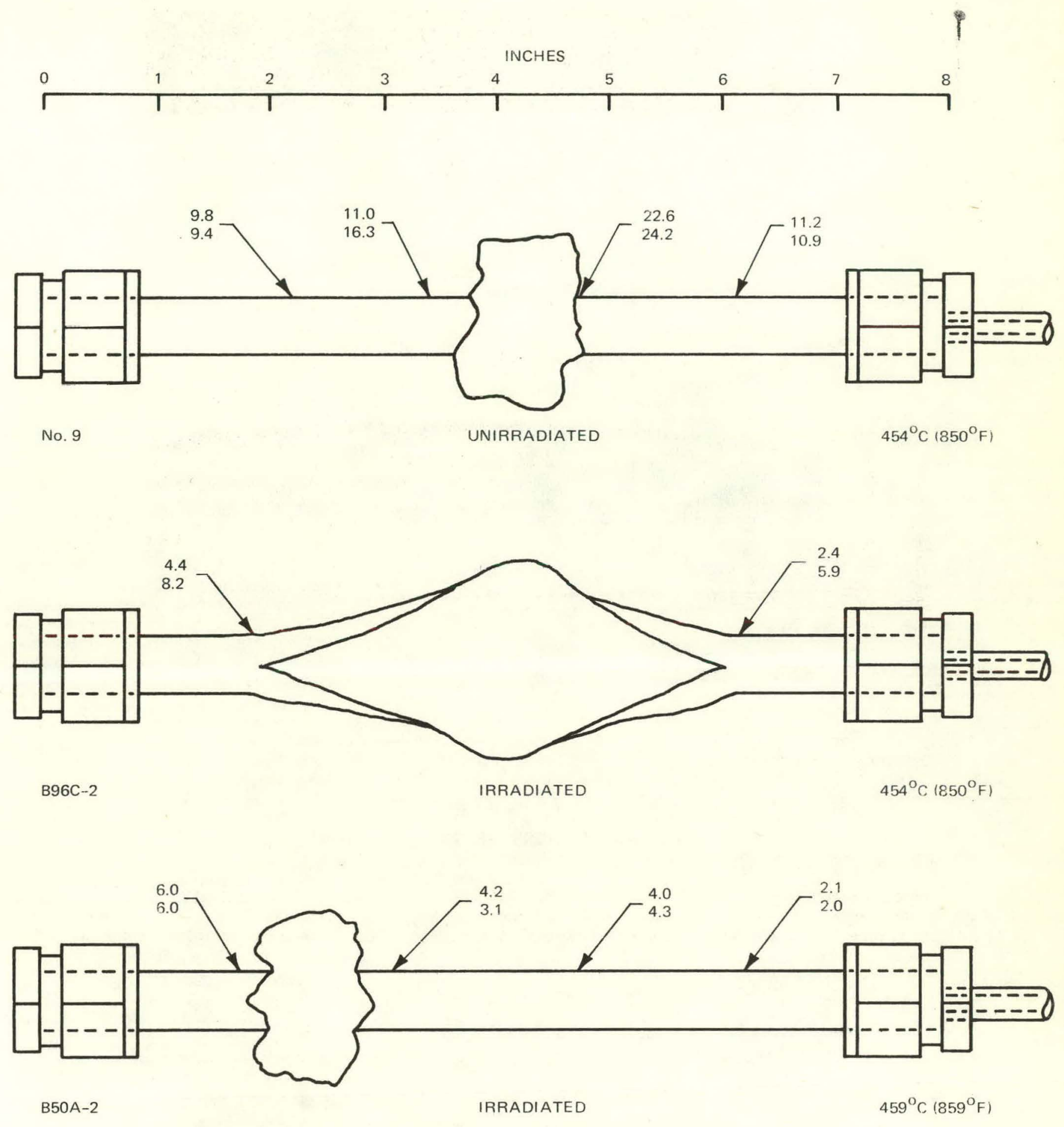

Figure 99. Values of $\left(D_{f}-D_{i}\right) / D_{i} \times 100$ at Various Points Along Samples Tested at a Nominal Temperature of $454^{\circ} \mathrm{C}\left(850^{\circ} \mathrm{F}\right)$ 


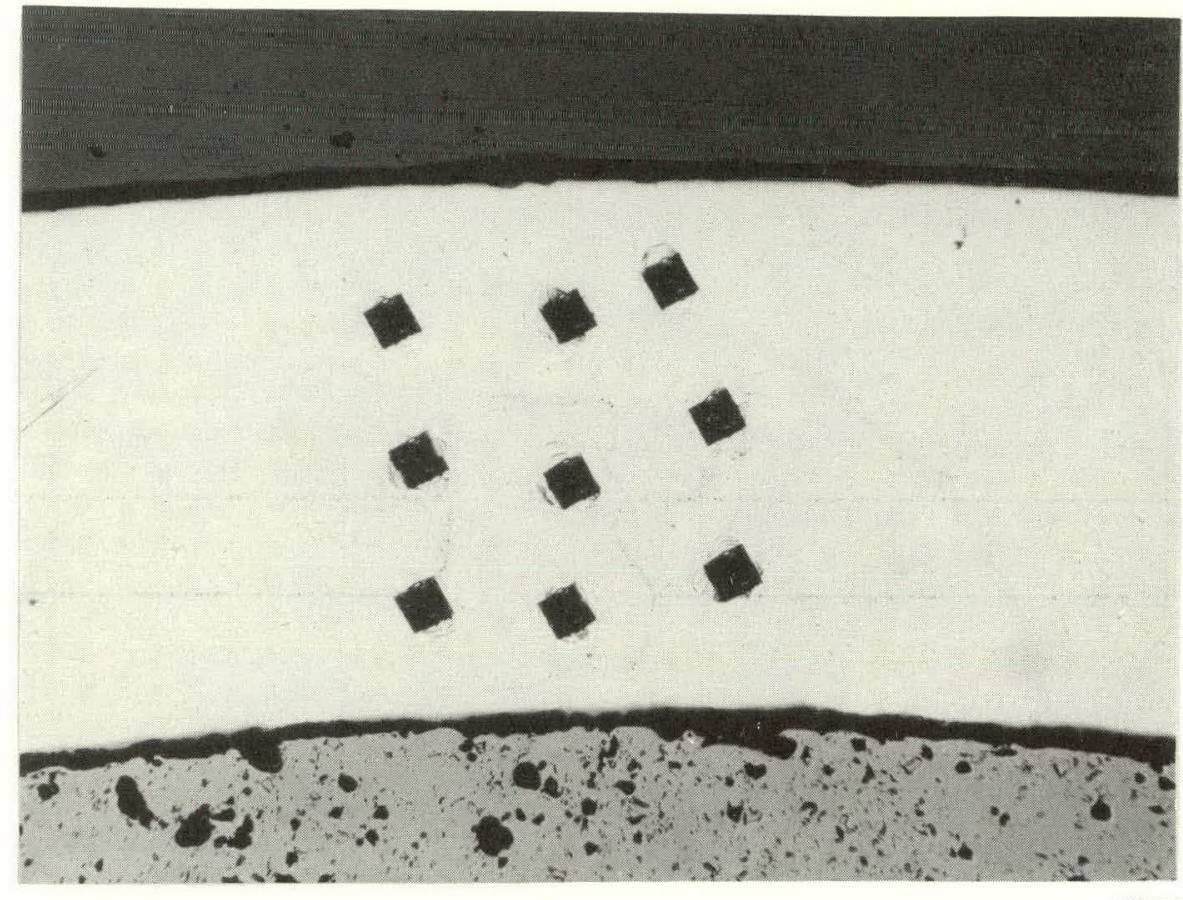

$100 \times$

Figure 100. Typical Array of Diamond Pyramid Hardness Indentations (Specimen No. 9957)

Table 22

MICROHARDNESS OF SA-1 CLADDING

\begin{tabular}{|c|c|c|c|c|c|c|c|c|}
\hline \multirow[b]{2}{*}{$\begin{array}{l}\text { Fuel } \\
\text { Rod }\end{array}$} & \multirow{2}{*}{$\begin{array}{l}\text { Metallography } \\
\text { Specimen } \\
\text { Number }\end{array}$} & \multirow[b]{2}{*}{ Orientation } & \multirow{2}{*}{$\begin{array}{c}\text { Estimated Fast } \\
\text { Fluence Exposure } \\
\text { nvt }>1 \mathrm{MeV} \times 10^{-21}\end{array}$} & \multirow[b]{2}{*}{ Location } & \multicolumn{4}{|c|}{ DPH, $0.5 \mathrm{~kg}$ Load } \\
\hline & & & & & $\begin{array}{l}\text { Outside } \\
\text { Diameter }\end{array}$ & Center & $\begin{array}{c}\text { Inside } \\
\text { Diameter }\end{array}$ & Average \\
\hline \multirow[t]{2}{*}{ A41 } & 9956 & Longitudinal & 5 & 1 & 240 & 246 & 228 & 240 \\
\hline & & & & 2 & 253 & 246 & 254 & 251 \\
\hline \multirow[t]{2}{*}{ A41 } & 9957 & Transverse & 5 & 1 & 218 & 224 & 221 & 221 \\
\hline & & & & 2 & 228 & 226 & 222 & 225 \\
\hline \multirow[t]{2}{*}{ A46 } & 9958 & Transverse & 4.5 & 1 & 219 & 219 & 213 & 217 \\
\hline & & & & 2 & 219 & 214 & 217 & 217 \\
\hline
\end{tabular}


No general difference in microhardness was noted with respect to the outside, center, and inside locations of the cladding wall. With the possible exception of the longitudinal specimen, the hardnesses measured at the two locations of a given specimen were about the same. However, the locations of the arrays of indentations with respect to the orientation of the rods in the fuel assembly during operation are not known.

\subsubsection{General}

The ultimate hoop stresses shown by the SA-1 burst samples were generally somewhat greater than the ultimate strengths shown by the somewhat lower exposure longitudinal coupon specimens, and the strain to fracture values of the burst samples were generally somewhat higher than the total elongations shown by the longitudinal specimens. The difference in strengths increased and the difference in elongations decreased with increasing test temperature.

The average $343^{\circ} \mathrm{C}\left(650^{\circ} \mathrm{F}\right)$ ultimate strength of the SA-1 coupon specimens was about $700 \mathrm{~kg} / \mathrm{cm}^{2}(10 \mathrm{kpsi})$ greater than the average $343^{\circ} \mathrm{C}$ ultimate strength of comparable specimens irradiated in the VBWR under the Fuel Cycle Program to $\sim 1 \times 10^{21}$ nvt $>1 \mathrm{MeV}$, and the total elongations were only $\sim 0.3$ percent lower. However, burst samples that were irradiated to $\sim 1 \times 10^{21}$ nvt, and were pressurized to failure with a liquid medium at room temperature, showed strains to fracture of 13 to 16 percent, i.e., about two times the elongations shown by the more highly exposed SA-1 samples. ${ }^{3}$

\subsubsection{Crud Analysis (W. Lim)}

\subsubsection{Procedure and Scope}

During the initial phase of the program the crud, i.e., the corrosion products deposited from the coolant, were removed from the surfaces of fuel rods A4, A13, A28, A41, B70, and B76 and chemically analyzed. These rods had operated in Dresden 840 days.

Removal of the crud was carried out in the following manner. The fuel rod was placed in a 1000 -ml buret that contained a known quantity of concentrated hydrochloric acid. The quantity of acid used was such that approximately one-half of the rod was immersed when it was placed in the buret. The remainder of the rod extended through a hole in a stopper which was inserted in the top of the buret. By means of heating tape wrapped around the buret, the acid was heated to approximately $70^{\circ} \mathrm{C}$ and held at this temperature for 4 hours. The resulting solution was allowed to cool and then was drawn off into a plastic bottle. The rod was removed from the buret and rinsed with sodium carbonate solution and clear water. The portion of the rod from which the crud had been removed was measured for length.

The above procedure was then repeated on the other half of the rod with fresh acid. Bottom subassembly rods $A 4$ and $A 13$, also $A 28$ and $A 41$, were combined into pairs for crud removal. Top subassembly rods $B 70$ and $B 76$ were de-crudded separately. The resulting eight solutions were analyzed for metallic elements by wet chemical techniques.

During the final phase of the program, the crud was chemically removed from rods A7, A9, A22, A37, A49, and B50. A somewhat different procedure was used on these later rods. The burets were replaced with tubes long enough to accommodate the full length of the rods. Each rod was placed in a separate tube and enough concentrated $\mathrm{HCl}$ was added to completely cover the rod. The acid was brought to the desired temperature (somewhat higher than the $70^{\circ} \mathrm{C}$. temperature used on the earlier rods), held at that temperaturc for a pei iod of time, cooled to room temperature and drained uff. Each rod was then inverted in its tube, and the procedure was repeated with fresh acid. The acid temperatures and holding times are listed below for the different rods.

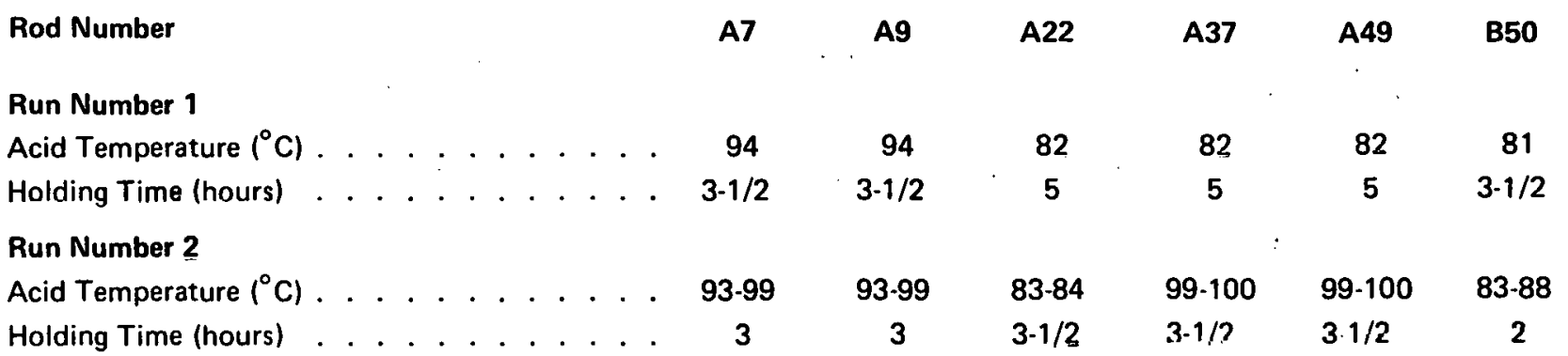

The solutions obtained from the above rods were not analyzed. 


\subsubsection{Results}

Analyses of the solutions, given in Table 23, indicated that nickel, iron, copper, and chromium were the principal metallic elements present in the crud. Nickel constituted approximately 65 to 75 percent of the combined weight of these four elements, which is expressed in terms of milligrams deposited per square decimeter of fuel rod surface. The data in Table 23 are presented in the form of a full-assembly profile. These profiles indicate that in the upper three-fourths of the assembly the deposition of $\mathrm{Ni}, \mathrm{Fe}, \mathrm{Cu}$, and $\mathrm{Cr}$ was, on the average, somewhat greater than $300 \mathrm{mg} / \mathrm{dm}^{2}$, while in the lower one-fourth the deposition of these elements was approximately $100 \mathrm{mg} / \mathrm{dm}^{2} . \mathrm{The}$ relative concentrations of the elements did not vary widely with elevation, although it appears that the relative concentration of copper increased somewhat at mid-assembly, while the relative concentration of iron increased slightly at the top and bottom of the assembly.

The nearly solid black surface coloration of the initial phase rods after decrudding and the dark brown color of portions of the final phase rods are not what one would expect in view of the rather thick layers of $\mathrm{ZrO}_{2}$ revealed by subsequent metallographic examinations of rod sections. It is possible that a very thin film of crud still remained on the surfaces after the dissolution operation. Some crud was, in fact, observed on a metallography specimen of one final phase rod (B50) that had been treated with hydrochloric acid. However, no evidence of remaining crud was detected on the several additional specimens examined.

\subsubsection{Neutron Fluence Analysis (C. P. Ruiz, J. P. Peterson, Jr., F. R. Smith)}

\subsubsection{Procedure and Scope}

The thermal and fast neutron fluences were measured on selected fuel and cladding samples by two methods. For the fuel samples, a thermal fluence was derived in the BURNUP program ${ }^{8}$ based on the U.235 depletion. A fast fluence was also obtained from the same data set, based on the U-238 fission contribution to the total fission inventory, and by use of a fast fission cross section of $310 \mathrm{mb}$. The cladding at some of the same locations, and at some additional ones of interest, was also analyzed for these two quantities. For these measurements, Co-60 and Mn-54 were utilized for the thermal and fast fluences, respectively.

The technique utilized with the cladding involved leaching an approximately 0.2 gram sample in concentrated $\mathrm{HCl}$, removal of external deposits, weighing, and dissolution in HF. After complexing of the fluoride with borıc acid, the solution was diluted to a known volume and aliquoted for the radiochemical determination which was performed directly by means of a high resolution $\mathrm{Ge}(\mathrm{Li})$ detector system. The iron and cobalt were measured by atomic absorption. The appropriate combination of the resultant data vielded the specific activity relative to the particular element. The fluence was obtained by describing the irradiation history in terms of time steps each of which was set equal to a given cycle of reactur operation. The exposure obtained in each cycle was weighted with respect to the power level of reactor operation. A cross section of $60 \mathrm{mb}$ was used for the fast cross section.

During the initial phase of the program, the fuel, but not the cladding, of four burnup samples from different rods was analyzed for thermal and fast neutron fluences. In the final phase, ten cladding samples from six rods were analyzed, and fuel burnup samples from six of the ten locations were analyzed for neutron fluence. For the four locations in which a burnup analysis had not been performed, the burnup was detcrmined from gamma scan data by utilizing the Cs-137 activity, and by estimating the corresponding fluences.

\subsubsection{Results}

The sample locations and the corresponding data are given in Table 24 with the exception of the thermal fluence derived from the cladding. The total fast fluence values ranged from $6 \times 10^{21}$ to $1 \times 10^{22} \mathrm{nvt}$ (E >0.005 MeV. The fluence $>1 \mathrm{MeV}$ is approximately 0.7 of the total fast fluence.) The largest values were measured at those locations nearest the middle of the assembly on rods that operated to the end of Dresden Reactor Cycle No. 6. The fast fluence data obtained on the final phase samples by the two methods of measurement compare well, especially on consideration of the fact that a 300-day half-life monitor was used to obtain flux integrated over an 8-vear period.

The magnitude of the thermal fluence for each sample based on U-235 depletion ranged from $2 \times 10^{21}$ to $3.5 \times 10^{21}$ nvt and follows the fast fluence variations. The data obtained from analysis of the cladding were found to be erratic. This could have been due to failure to remove the last traces of cobalt in the cladding deposition prior to dissolution. This contention is supported by widely varying apparent cobalt contents in the cladding, i.e., from 6.7 ppm to $19 \mathrm{ppm}$, which range is significantly larger than the range of error for the cobalt measurement by atomic absorption. 
Table 23

CHEMICAL ANALYSIS OF CRUD SOLUTIONS

\begin{tabular}{|c|c|c|c|c|c|c|c|c|c|c|}
\hline \multirow[b]{2}{*}{ Food } & \multirow[b]{2}{*}{$\begin{array}{l}\text { Distance frorr. } \\
\text { Botom of Reactor } \\
\text { Active Fuel Zone } \\
\text { [cm (in.)] }\end{array}$} & \multicolumn{2}{|c|}{$\mathbf{F e}$} & \multicolumn{2}{|c|}{$\mathrm{Cu}$} & \multicolumn{2}{|c|}{$\mathrm{Ni}$} & \multicolumn{2}{|c|}{ a } & \multirow[b]{2}{*}{$\begin{array}{c}\mathrm{Fe}, \mathrm{Cu}, \mathrm{Ni}, \mathrm{Cr} \\
\text { Total } \\
\text { Deposition } \\
\left(\mathrm{mg} / \mathrm{dm}^{2}\right)\end{array}$} \\
\hline & & $\begin{array}{l}\text { Deposition } \\
\left(\mathrm{mg} / \mathrm{dm}^{2}\right)\end{array}$ & $\begin{array}{c}\text { Relative } \\
\text { Concentration } \\
(\%)\end{array}$ & $\begin{array}{l}\text { Deposition } \\
\left(\mathrm{mg} / \mathrm{dm}^{2}\right)\end{array}$ & $\begin{array}{c}\text { Relative } \\
\text { Concentration } \\
\text { (\%) }\end{array}$ & $\begin{array}{l}\text { Deposition } \\
\left(\mathrm{mg} / \mathrm{dm}^{2}\right)\end{array}$ & $\begin{array}{c}\text { Pelative } \\
\text { Concentration } \\
(\%)\end{array}$ & $\begin{array}{l}\text { Deposition } \\
\left(\mathrm{mg} / \mathrm{dm}^{2}\right)\end{array}$ & $\begin{array}{c}\text { Retative } \\
\text { Concentration } \\
\text { (\%) }\end{array}$ & \\
\hline E70 & $2: 4.3$ to 260.0 & 69 & 18.8 & 18 & 4.9 & 274 & 74.7 & 6 & 1.6 & 367 \\
\hline 806 & $(84-3 / 8$ to $102-3 / 8)$ & 72 & 23.1 & 14 & 4.5 & 226 & 72.4 & $<1$ & - & 312 \\
\hline 870 & 15.9 to 214.3 & 34 & 13.9 & 14 & 5.7 & 187 & 76.3 & 10 & 4.1 & 245 \\
\hline B:6 6 & $(61-3 / 8$ to $84-3 / 8)$ & 61 & 14.8 & 50 & 12.2 & 295 & 71.8 & 5 & 1.2 & 411 \\
\hline $\begin{array}{l}\text { A4 } \\
+ \\
A ; 3\end{array}$ & 103.9 to 154.6 & 44. & 17.1 & 34 & 13.2 & 176 & 68.5 & 3 & 1.2 & 257 \\
\hline $\begin{array}{c}A=8 \\
+ \\
A 41\end{array}$ & $(42-i / 8$ to $60-7 / 8)$ & 71 & 17.8 & 69 & 17.2 & 255 & 63.8 & $: 5$ & 1.2 & 400 \\
\hline $\begin{array}{l}\text { A4 } \\
+ \\
\text { A13 }\end{array}$ & 50.5 to 108.9 & 24 & 18.9 & 6 & 4.7 & 94 & 74.0 & 3 & .2 .4 & 127 \\
\hline $\begin{array}{c}\text { A28 } \\
+ \\
\text { A4. }\end{array}$ & $(19.7 / 8$ to $42.7 / 8)$ & 22 & 22.0 & 8 & 8.0 & 69 & 69.0 & 1 & 1.0 & 100 \\
\hline
\end{tabular}


Table 24

\section{FAST AND THERMAL NEUTRON FLUENCE}

\begin{tabular}{|c|c|c|c|c|}
\hline \multirow{2}{*}{$\begin{array}{l}\text { Sample } \\
\text { Number }\end{array}$} & \multirow{2}{*}{$\begin{array}{l}\text { Location* } \\
\text { (cm [in.]) }\end{array}$} & $\begin{array}{r}\text { Total } \\
\text { Invt } \times 10^{-21} \\
\end{array}$ & Total Fast Fluence & \multirow{2}{*}{$\begin{array}{r}\text { Thermal Flu } \\
\text { from U-2 } \\
\text { Inv } t \times 10\end{array}$} \\
\hline & & From U-238 & From $M n-54$ & \\
\hline & & Initial Pha & & \\
\hline A13-67 & $\begin{array}{l}\text { a) } 27.3(10-3 / 4) \\
\text { b) } 126.7(49-7 / 8)\end{array}$ & 8 & - & 2.3 \\
\hline A41-68 & $\begin{array}{l}\text { a) } 27.6(10-7 / 8) \\
\text { b) } 126.4(49-3 / 4)\end{array}$ & 8 & - & 2.4 \\
\hline A46-69 & $\begin{array}{l}\text { a) } 27.6(10-7 / 8) \\
\text { b) } 126.4(49-3 / 4)\end{array}$ & 7 & - & 2.4 \\
\hline B70.70 & $\begin{array}{l}\text { a) } 26.4(10-3 / 8) \\
\text { b) } 181.6(71-1 / 2)\end{array}$ & 7 & - & 2.3 \\
\hline & $\cdot$ & Final Pho & & . \\
\hline A11G-4 & $\begin{array}{l}\text { a) } 80.3(31-11 / 16) \\
\text { b) } 73.5(28-15 / 16)\end{array}$ & $7^{\dagger}$ & 7 & $2.6^{\dagger}$ \\
\hline A11E-2 & $\begin{array}{l}\text { a) } 25.2(9-15 / 16) \\
\text { b) } 128.6(50-11 / 16)\end{array}$ & 9 & 9 & 3.5 \\
\hline A33A-3 & $\begin{array}{l}\text { a) } 25.2(9.15 / 16) \\
\text { b) } 128.6(50.11 / 16)\end{array}$ & 7 & 8 & 2.9 \\
\hline $\mathrm{A} 37 \mathrm{H}-2$ & $\begin{array}{l}\text { a) } 25.2(9-15 / 16) \\
\text { b) } 128.6(50-11 / 16)\end{array}$ & 9 & 7 & 3.5 \\
\hline A47D-3 & $\begin{array}{l}\text { a) } 81.8(32-3 / 16) \\
\text { b) } 72.2(28-7 . / 16)\end{array}$ & $6^{\dagger}$ & 7. & $2.1^{\dagger}$ \\
\hline A47D-1 & $\begin{array}{l}\text { a) } 27.5(10-13 / 16) \\
\text { b) } 126.5(49-13 / 16)\end{array}$ & 8 & 10 & 3.5 \\
\hline B62H-2 & $\begin{array}{l}\text { a) } 28.3(11-1 / 8) \\
\text { b) } 183.5(72-1 / 4)\end{array}$ & 9 & 9 & 3.5 \\
\hline B62J-4 & $\begin{array}{l}\text { a) } 81.8(32-3 / 16) \\
\text { b) } 237.0(93-5 / 16)\end{array}$ & $7^{\dagger}$. & 9 & $2.7^{\dagger}$ \\
\hline B96A-3 & $\begin{array}{l}\text { a) } 28.3(11-1 / 8) \\
\text { b) } 183.5(72-1 / 4)\end{array}$ & 9 & 10 & 3.5 \\
\hline B96C-4 & $\begin{array}{l}\text { a) } 81.8(32-3 / 16) \\
\text { b) } 237.0(93-5 / 1.6)\end{array}$ & $6^{\dagger}$ & $\therefore 7$ & $1.8^{\dagger}$ \\
\hline
\end{tabular}

* a) Distance from center of specimen to shoulder of short end plug. b) Distance from bottom of Dresden Reactor active fụel zone.

* To obtain the fluence $>1 \mathrm{MeV}$, these values may be multiplied by 0.7 .

$t$ These values were derived from Cs-137 gamma scan data. 


\subsection{IRRADIATED UO 2 CHARACTERIZATION STUDIES (H. S. Rosenbaum, Technical Director; U. E. Wolff)}

The irradiated $\mathrm{UO}_{2}$ fuel in some of the SA-1 rods was examined by several techniques in addition to that of optical (light) metallography (subsection 5.1.5). Replication electron microscopy was employed to investigate the microstructure of a metallographically prepared cross section at higher magnifications, and thin slivers of $\mathrm{UO}_{2}$ extracted from a rod section were examined by thin foil transmission electron microscopy. Fracture surfaces were examined by replication electron microscopy. Fuel particles extracted from different radial locations of a rod cross section were analyzed by $x$-ray diffraction primarily to determine any relative changes in lattice parameter.

\subsubsection{Examination of Metallography Specimens by Replication Electron Microscopy} (U. E. Wolff, W. H. Kimball)

\subsubsection{Procedure and Scope}

In conjunction with the earlier light metallographic examination of specimen No. 9954 from fuel rod A13, cellulose acetate replicas were made of the polished $\mathrm{UO}_{2}$ surface in both a light (3-second) etched condition and the standard (45-second) etched condition. Chromium-shadowed carbon replicas then were prepared from the plastic replicas and examined by electron microscopy with $80-\mathrm{kV}$ electrons. The direction of shadowing was from the center of the fuel toward the cladding. The regions of the $\mathrm{UO}_{2}$ examined are indicated on the light micrograph of figure 81.

Rod A13 was the most highly exposed rod removed from SA-1 at the end of Dresden Reactor Cycle No. 4. The transverse section examined had an average burnup of $8.1 \times 10^{20}$ fissions $/ \mathrm{cm}^{3}(29,700 \mathrm{MWd} / \mathrm{tU})$.

\subsubsection{Results}

It was found that the standard etch revealed much more structure than did the light etch. There was no evidence of grain growth.

The interior of the grains in the central region of the specimen contained many small precipitates (see Figures 101, 102, and 103). These were also observed by light microscopy. Figure 81 shows that their concentration seemed to increase with distance from the center and then at a certain radius, $0.24 \mathrm{~cm}(0.094 \mathrm{in}$.) from the fuel periphery, dropped off sharply to form a ring. The concentration of precipitates was relatively low between the ring and a location about $0.01 \mathrm{~cm}(0.004 \mathrm{in}$.) from the pellet periphery (Figures 104, 105, and 106). Between the latter location and the periphery the concentration of precipitates was sharply increased. The intragranular precipitates adjacent to the cladding were apparently somewhat larger than those in the interior of the fuel (Figures 107 and 108 ). At all radial locations they appeared to have a crystallographic relationship to the mother grain.

The grain boundaries near the periphery of the $\mathrm{UO}_{2}$ were more heavily etched than the centrally located grain boundaries, and they contained numerous precipitates which finally appeared to merge into continuous sheets covering the grain boundary surfaces (see Figures 105, 106, and 107). The radial distribution of the grain boundary precipitates and variation in the severity of grain boundary etching apparently correlate with the fuel burnup which increases toward the periphery (see subsection 5.3). Berman presented evidence that the heavy grain boundary attack in irradiated $\mathrm{UO}_{2}$ coincided with the presence of fission products in the grain boundaries. ${ }^{9}$ It is therefore very likely that the grain boundary precipitates in specimen No. 9954 are fission products.

The volume fraction of the intragranular precipitates, as seen in the etched condition, had a bimodal radial distribution with one peak at the location of the darkly etched ring and the other peak at the fuel-cladding interface.

\subsubsection{Examination of Thin Particles by Transmission Electron Microscopy (U. E. Wolff, E. S. Darlin)}

\subsubsection{Procedure and Scope}

Since the resolution limit of replicas is about $100-200 \AA$, irradiation-induced defects smaller than that could not be detected by this method. Such defects can only be studied by transmission electron microscopy of thin foils.

The foils were obtained by extracting thin slivers of $\mathrm{UO}_{2}$ from the fractured surface of a transverse metallography specimen. Hardness indentations were made with a $5000 \mathrm{~g}$ load at four different distances from the cladding to fracture the specimen surface. About 20 five-mm-diameter replicas wore then made fiun all portions of this surface with the replicating material "Technovit." This is a self-curing methyl methacrylic ester which adheres tenaciously to the replicated surface. Consequently, on separation, large and $\mathrm{small}_{\mathbf{U}} \mathrm{O}_{2}$ particles were pulled out of the surface. Carbon replicas of about two-mm diameter were made from the Technovit replicas by maskiny uff the unwanted portions (i.e., those containing large $\mathrm{UO}_{2}$ particles). The thin slivers embedded in the final replicas were examined with either the 100 $\mathrm{kV}$ microscope at VNC or with the $650 \mathrm{kV}$ microscope at the University of California at Berkeley.

The particles examined were extracted from metallography specimen No. 9954 frnm rod A13. 


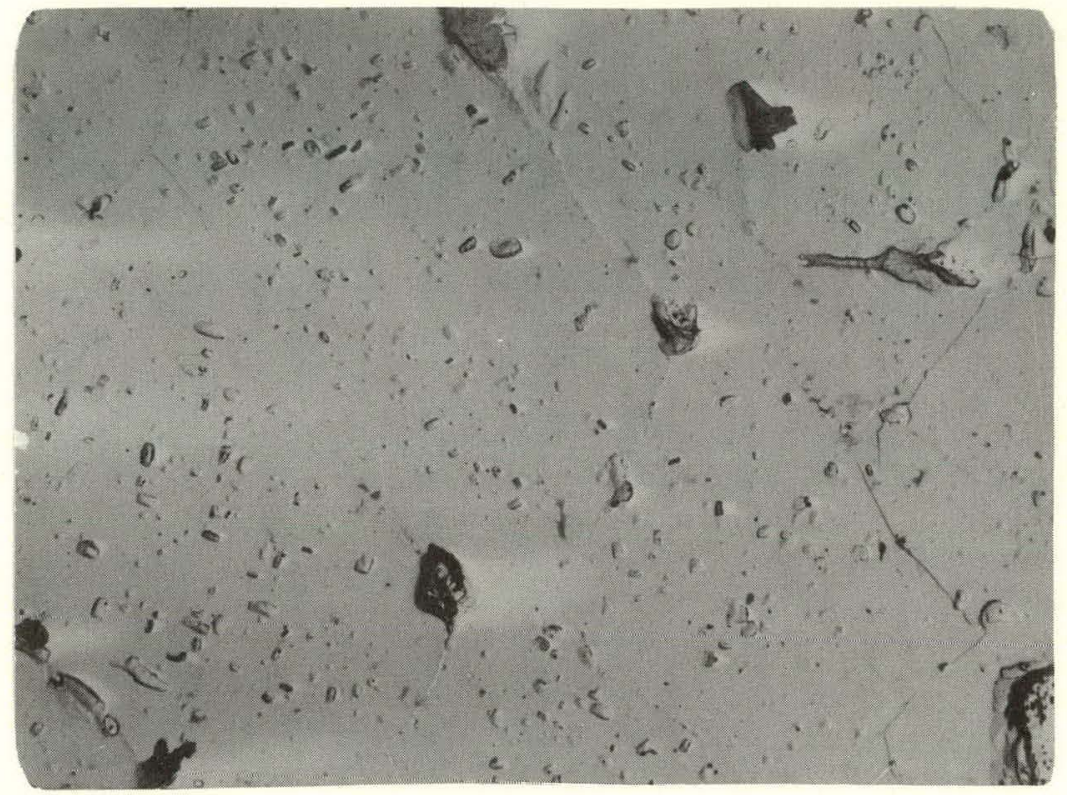

ETCHED 45 SECONDS

$3000 x$

Figure 101. Center Region of Irradiated Fuel After Standard Etch, Showing Some Precipitates and Light Grain Boundary Attack. [0.36 cm (0.14 in.) from Pellet Periphery] (Specimen No. 9954)

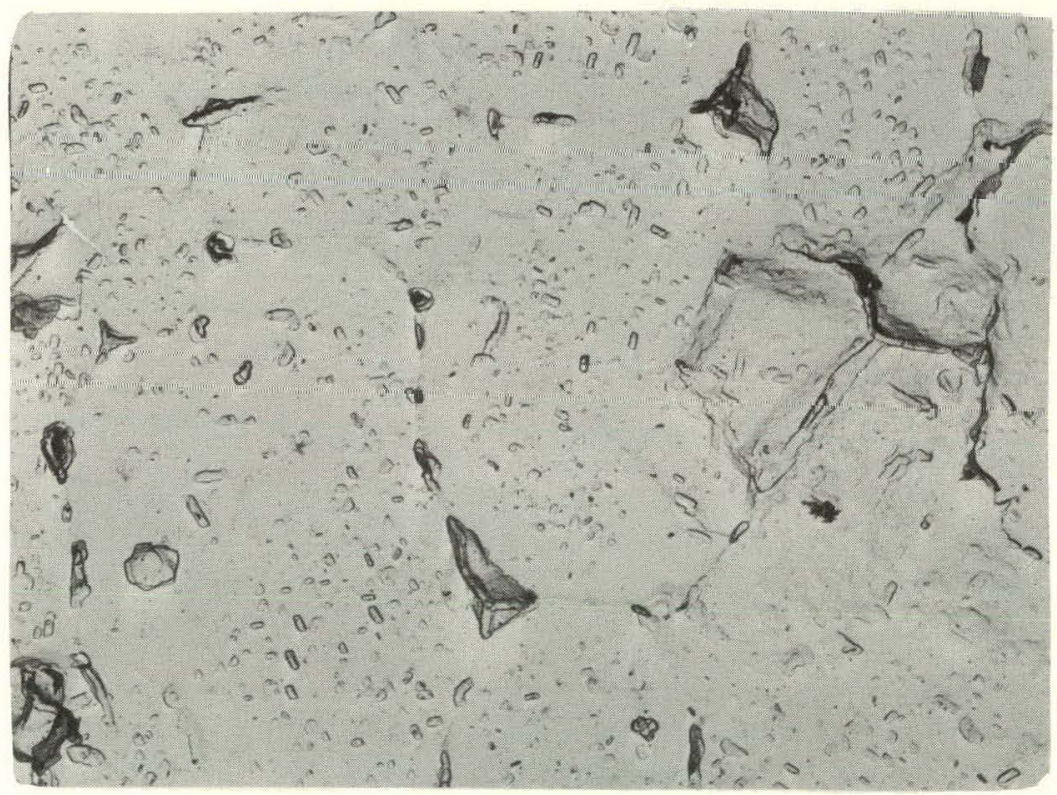

ETCHED 45 SECONDS

$3000 \times$

Figure 102. Ring Region $0.30 \mathrm{~cm}$ (0.12 in.) from Pellet Periphery. Note Numerous Precipitates. (Specimen No. 9954) 


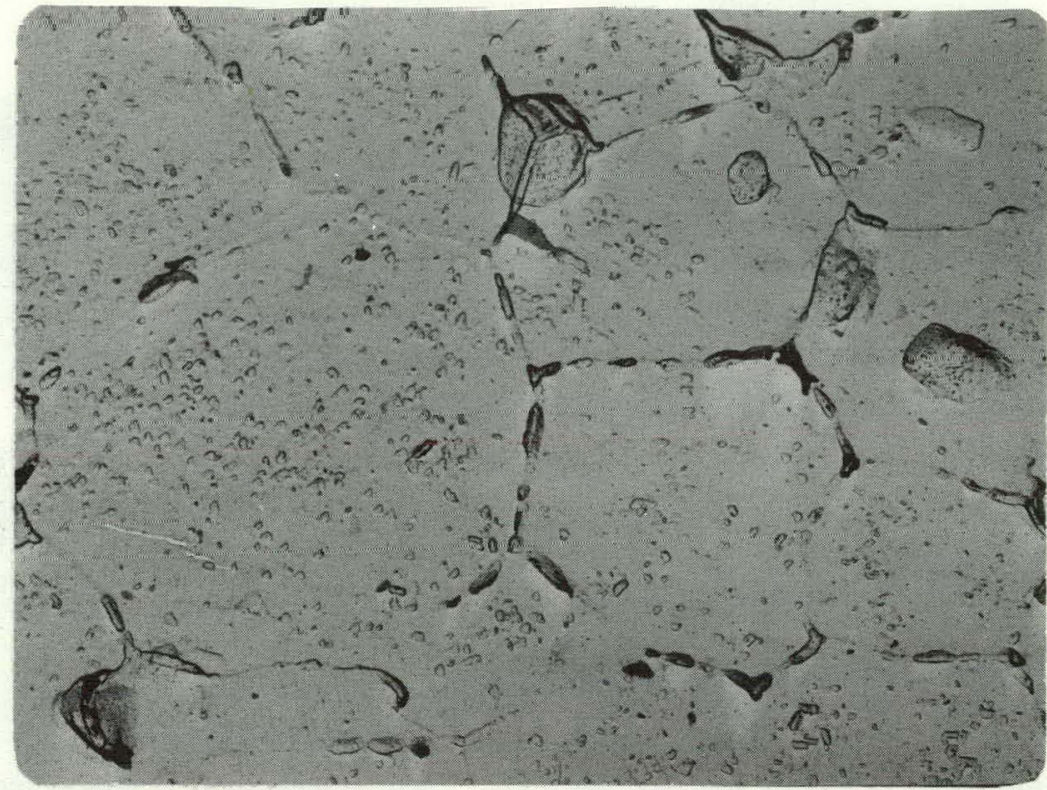

ETCHED 45 SECONDS

Figute 103. Ring Region $0.24 \mathrm{~cm}$ (0.09 in.) from Pellet Periphery (Specimen No. 9954)

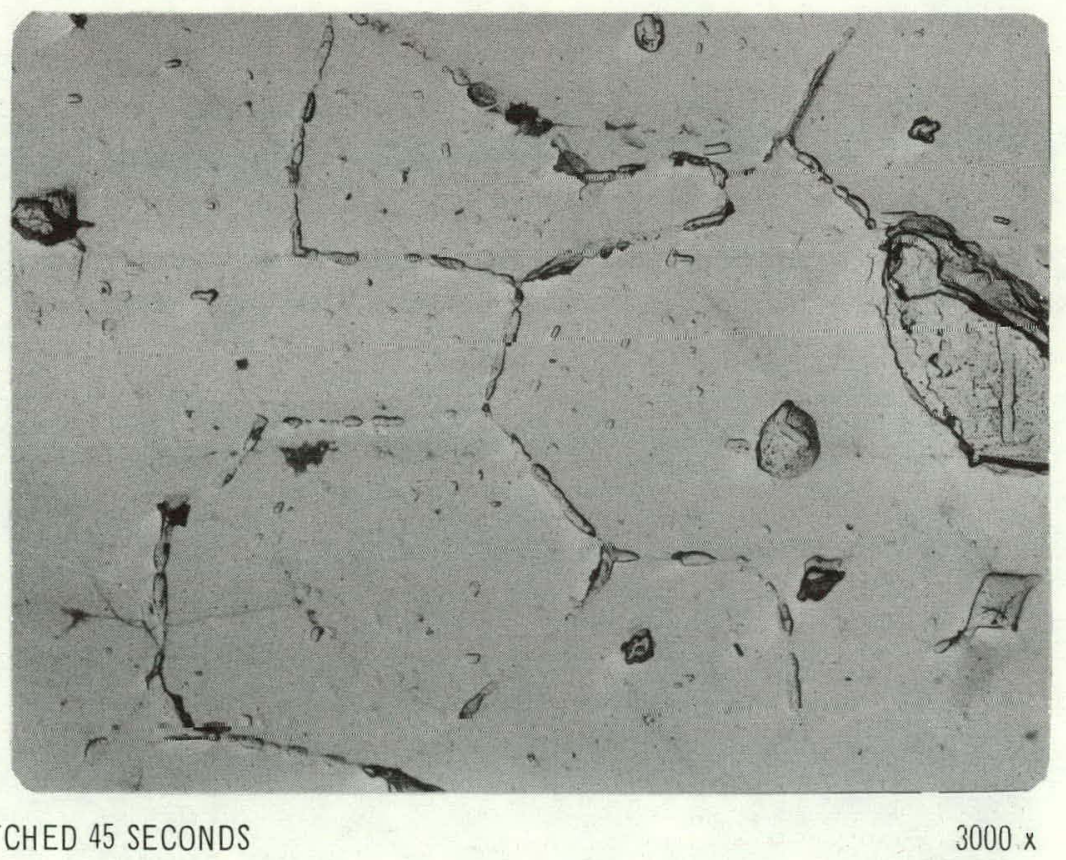

Figure 104. Qutside of Ring Region $0.18 \mathrm{~cm} 10.07 \mathrm{in}$.) trom Pellet Periphery. Note Lack of Precipitates. (Specimen No. 9954) 


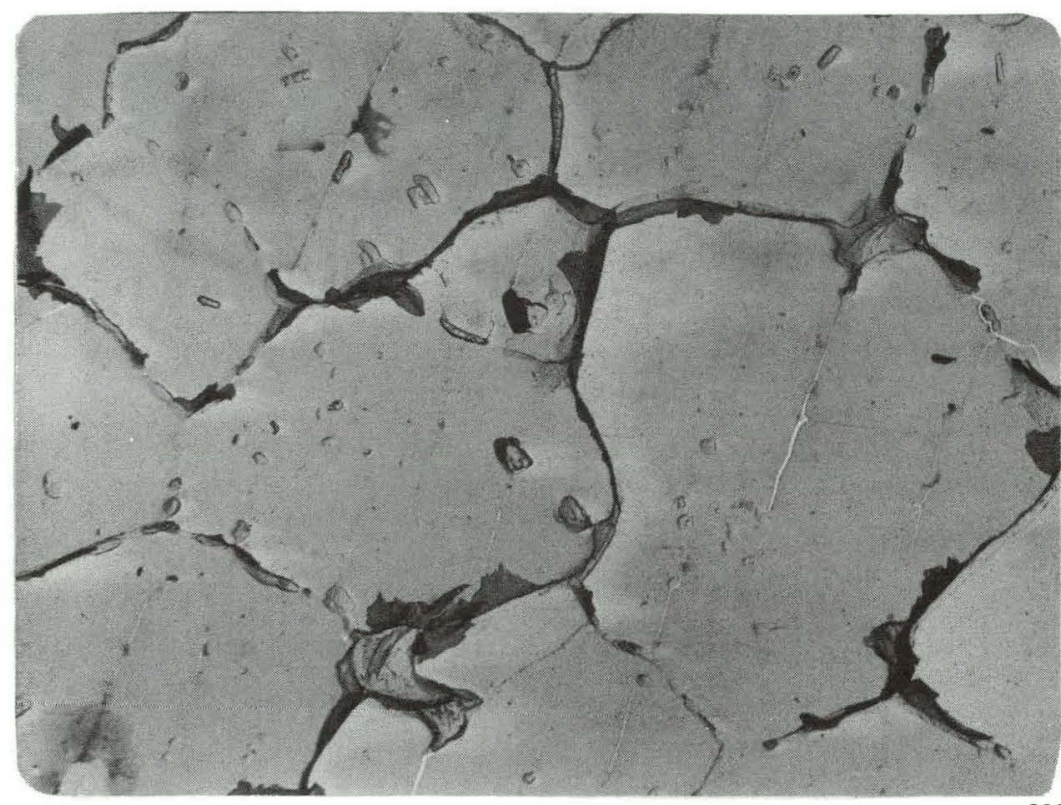

$3007 \times$

ETCHED 45 SECONDS

Figure 105. $\quad 0.13 \mathrm{~cm}$ (0.05 in.) from Pellet Periphery, Where Increased Grain Boundary Attack Appears (Specimen No. 9954)

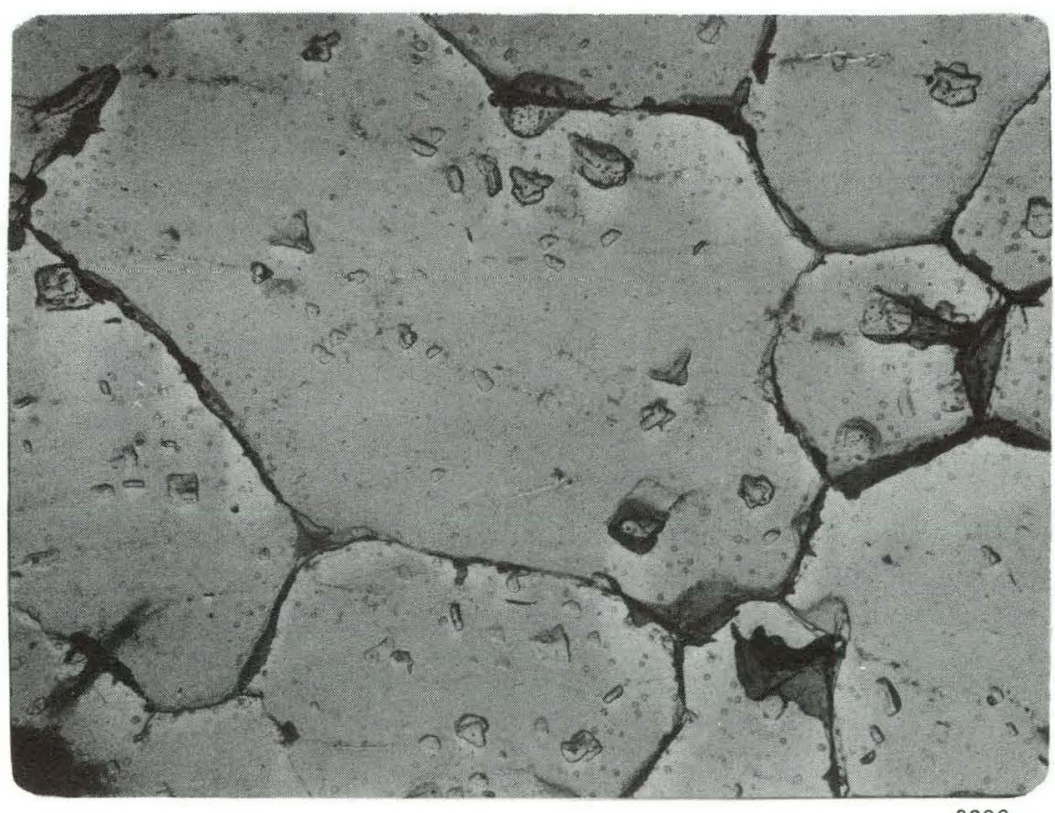

ETCHED 45 SECONDS

$3000 x$

Figure 106. $0.06 \mathrm{~cm}$ (0.02 in.) from Pellet Periphery, Where Large Precipitates Start to Appear. (Specimen No. 9954) 


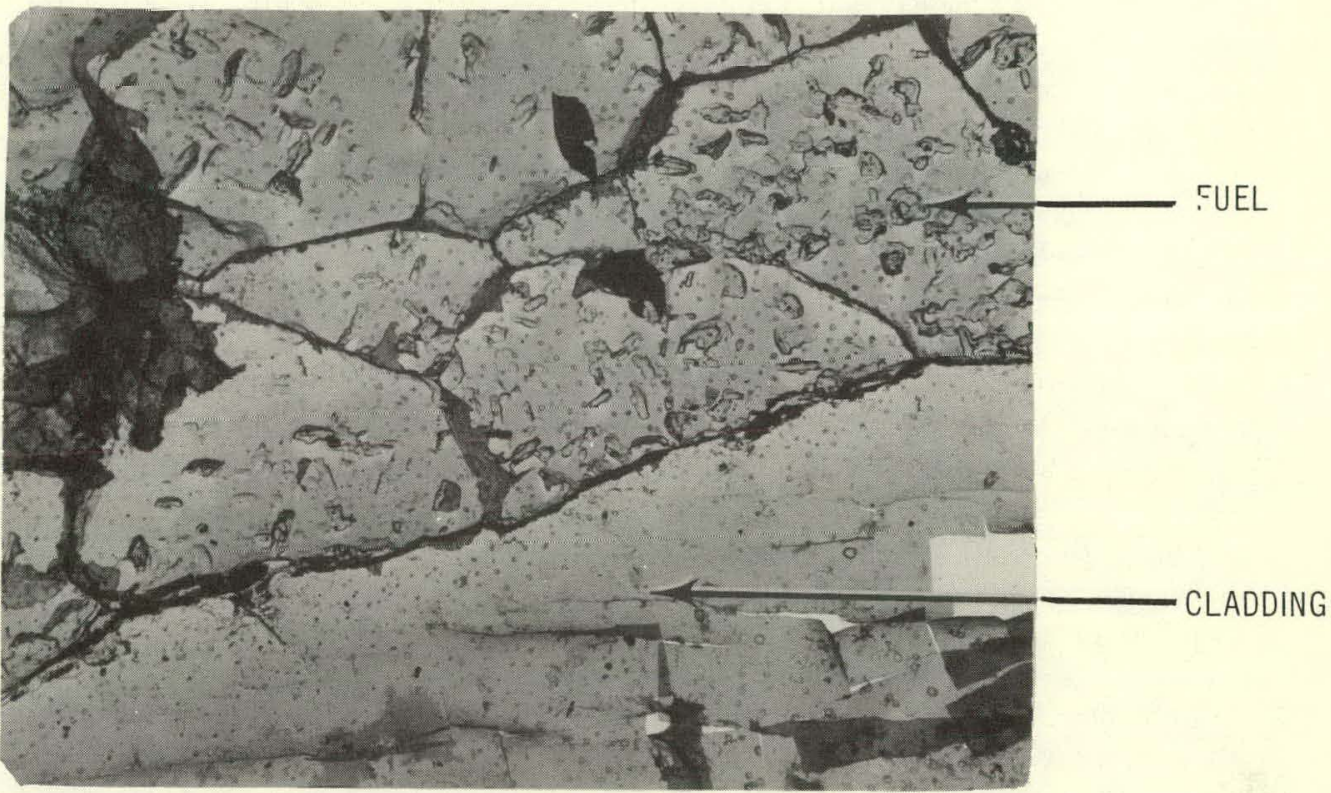

ETCHED 45 SECONDS ( UO, ETCHANT)

$3000 \times$

Figure 107. Fuel-Cladding Interface Region. Note Numerous Large Precipitates in $\mathrm{UO}_{2}$ (Specimen No. 9954)

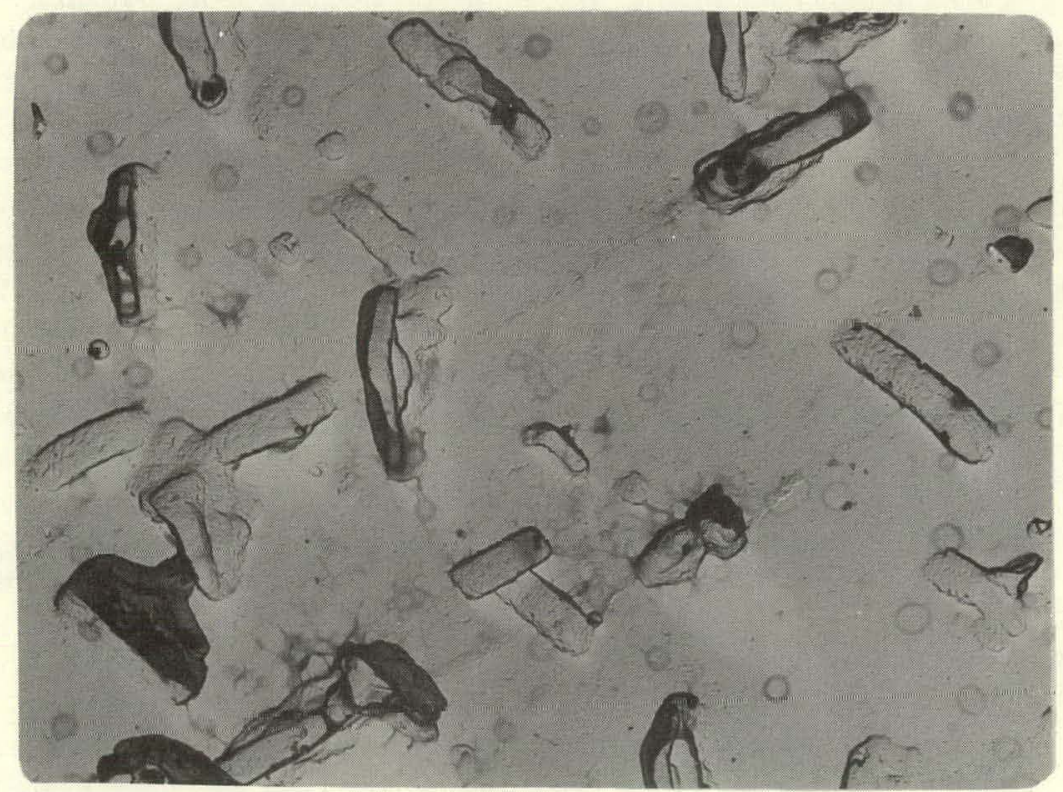

ETCHED 45 SECONDS

Figure 108. Large Intragranular Precipitates of Figure 107 Shown at Higher Magnification. Note Orientation. 


\subsubsection{Results}

Some of the slivers had edges thin enough for electron microscopy with 100-kV electrons. Figure 109 shows such a thin edge. Dislocation loops and several small pores are visible.

A number of replicas were examined with $650-\mathrm{kV}$ electrons.

a. Area near cladding:

Figure 110 shows the edge of a sliver with numerous defects. These defects show up as dark spots in the bright field image and as spots with white-black contrast in the dark fieldeimage. In Figure 111 some rod or plate shaped inclusions are visible. These appear to have the same size and shape as those seen in replicas of the same general location (see Figure 108).

b. Area about $1.3 \mathrm{~mm}$ (0.05 in.) from cladding:

A small chip (Figure 112) was transparent in its entirety to $650 \mathrm{kV}$ electrons. A dense dispersion of defects is seen in bright and dark field. Similarly, Figure 113 shows the edge of a sliver in bright field and dark field with two different diffraction vectors. The numerous spot defects are apparent. In addition a few long dislocations are present.

c. Area near fuel center, about $3.8 \mathrm{~mm}(0.15 \mathrm{in.})$ from cladding:

Two small chips are shown in Figure 114. In the bright field image only a few defects are visible. In the dark field image, on the other hand, the structure of the larger chip looks severely disrupted.

\subsubsection{Examination of Fracture Surfaces by Replication Electron Microscopy}

\section{(U. E. Wolff, W. C. Oh, E. S. Darlin)}

\subsubsection{Procedure and Scope}

This investigation was undertaken to gain more insight into the grain boundary structure of highly irradiated $\mathrm{UO}_{2}$ fuel than could be obtained from the two previously described electron microscopic techniques. Since irradiated $\mathrm{UO}_{2}$ is very brittle and apparently fractures intergranularly, such fracture surfaces appeared to be suitable for grain boundary examination at the high magnifications obtainable by electron microscopy of replicas.

The starting material was specimen No. A584 from the peak burnup region of rod A11. This rod operated to the end of Cycle No. 6 and attained a peak burnup of $10.0 \times 10^{21}$ fissions $/ \mathrm{cm}^{3}(36,600 \mathrm{MWd} / \mathrm{tU})$. The section prepared was the surface mating with metallography specimen No. A582. The microstructure of the latter showed platelet precipitates with maximum density near the cladding and again in a ring at about mid-radius (see Figure 80 ). It was very similar to the structure observed in previously mentioned specimen No. 9954 from rod A13. Specimen No. A584 was polished without using water in order to retain water-soluble fission products.

Particles of $\mathrm{UO}_{2}$ were pulled from the fuel cross section at selected locations again with the aid of Technovit replicating material, but applied in this case with a small mold. This mold is a patented device made of plastic called a T\&B "Ty-Rap" (used by electricians to harness electrical cables) and contains a 5-mm diameter hole. The device also has a $\sim 18-\mathrm{cm}(7-\mathrm{in}$.$) tail and, therefore, can be handled remotely rather easily (see Figure 115). The Ty-Rap was$ secured to the desired area of the fuel cross section with double-backed masking tape. In some cases, the opening was restricted to a diameter smaller than $5 \mathrm{~mm}$ by cutting an appropriately smaller hole into the masking tape. The Technovit replicating material was poured into the hole and allowed to cure. After curing, the Technovit plug adhered tenaciously to the $\mathrm{UO}_{2}$. When the Ty-Rap was lifted off the $\mathrm{UO}_{2}$, particles of $\mathrm{UO}_{2}$ were pulled off with the Technovit. The particles firmly adhered to the Technovit and presented fresh $\cup_{2}$ fracture surfaces for further replication. Because of the brittleness of the irradiated $\mathrm{UO}_{2}$ it was not necessary in this case to make hardness indentations as a means of producing fractures.

To correlate each Technovit plug with its original position on the $\mathrm{UO}_{2}$ cross section, a photograph was taken of the section with the empty mold in place (Figure 116[a]), another one after removal of the Technovit plug (Figure $116[\mathrm{~b}]$ ), and a third of the stripped plug with the embedded $\mathrm{UO}_{2}$ particles (Figure 116 [c]). By comparison of the $\mathrm{UO}_{2}$ crack pattern on these photographs, the location of the replica with respect to the $\mathrm{UO}_{2}$ cross section could be determined. Such groups of photographs were taken for each Technovit plug.

Up to this stage all operations were done remotely. Next, the plastic molds with the Technovit were removed from the hot cell, the Technovit plugs were pressed out of the mold, and carbon was evaporated at 45 and 90 degrees onto the surface containing the $\mathrm{UO}_{2}$ particles. The Technovit was dissolved in acetone leaving the carbon replicas, usually in several pieces, floating in the acetone. These carbon replicas contained embedded the majority of the $\mathrm{UO}_{2}$ particles. Since the particles were large and not transparent to electrons, they were dissolved by immersion of the replicas in diluted $(1: 1)$ nitric acid for about one week. After washing the replicas in several changes of a solution of 


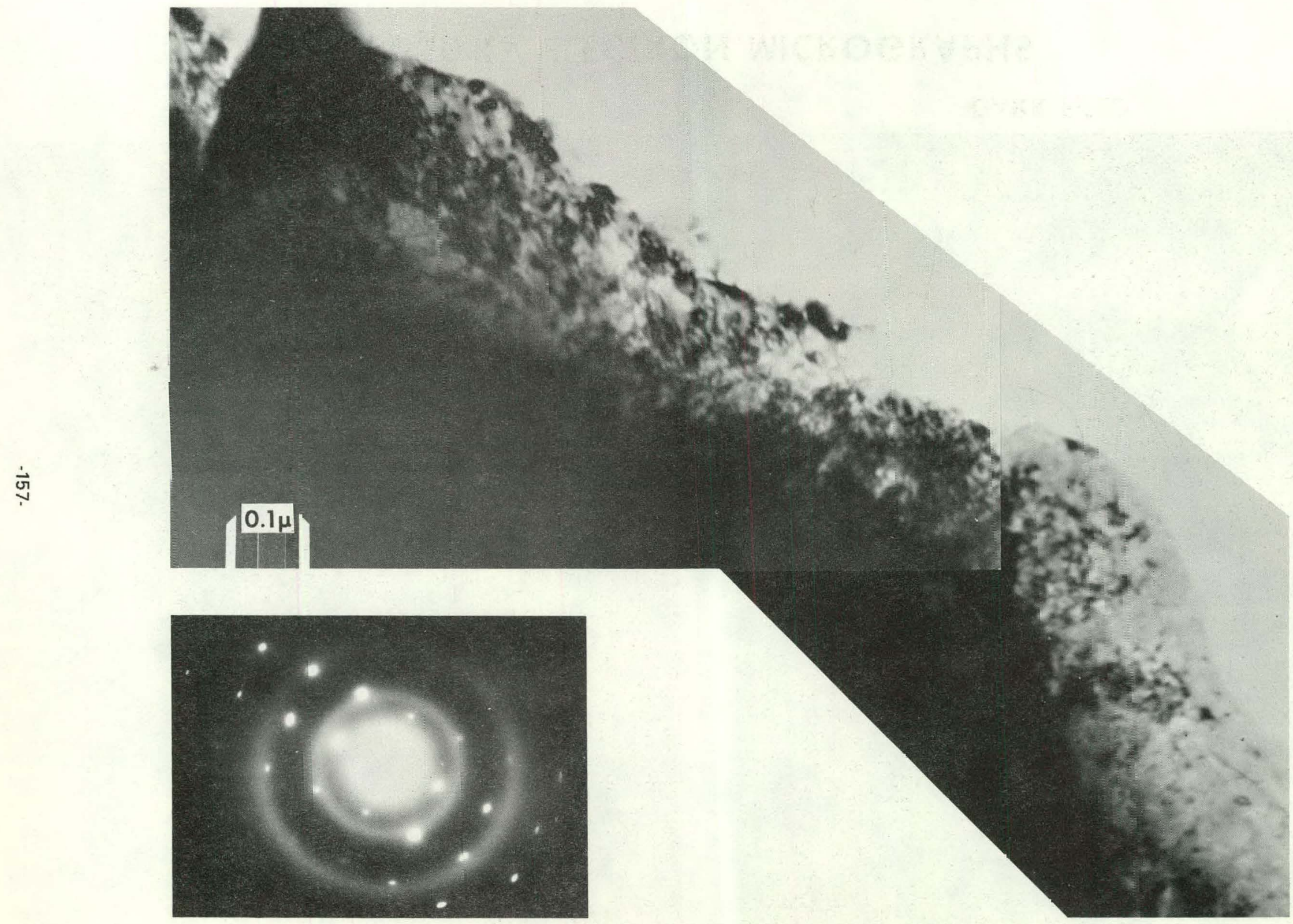




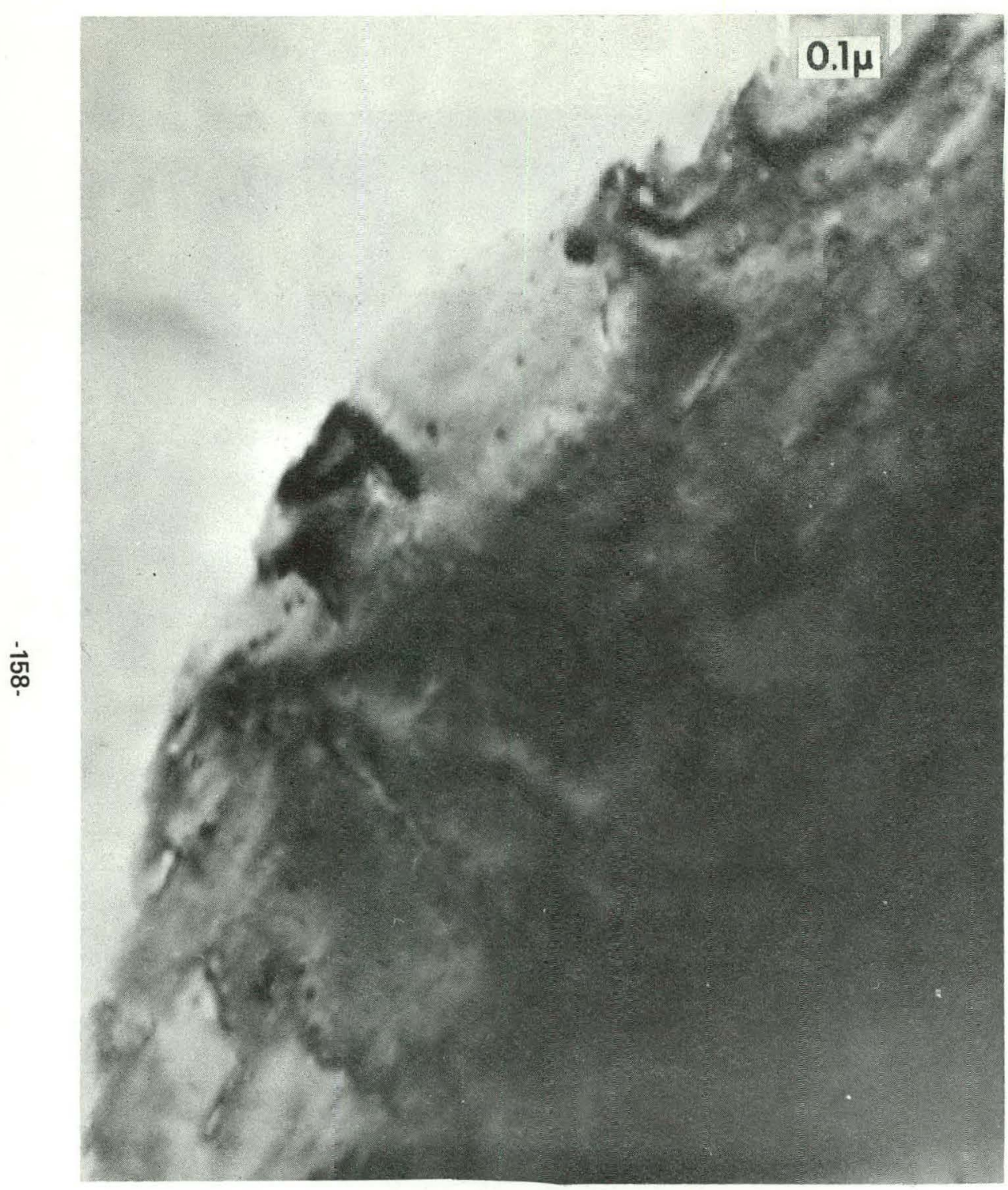

BRIGHT FIELD

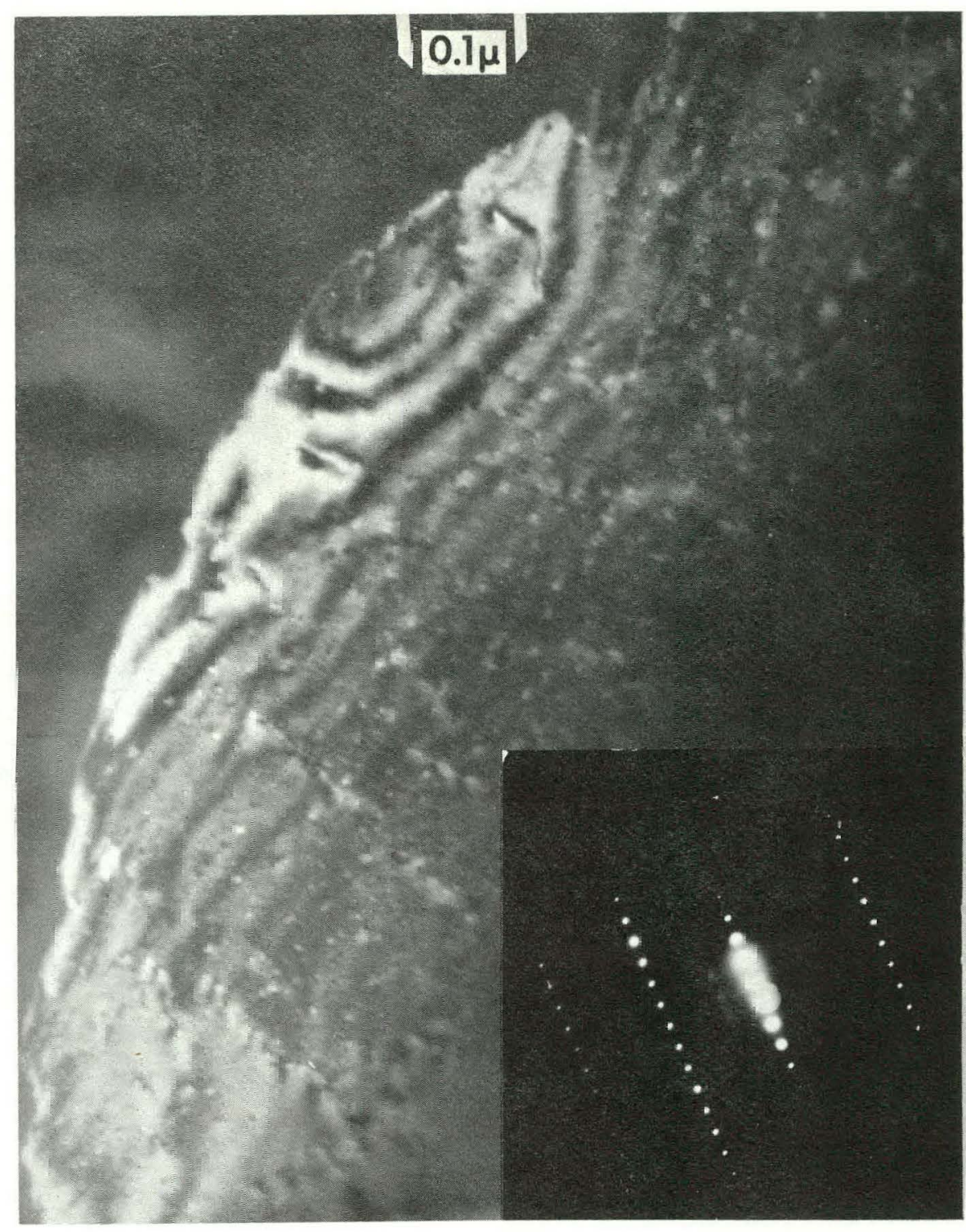

DARK FIELD

650 KV ELECTRON MICROGRAPHS

Figurs 110. Irradiated $\mathrm{NO}_{2}, 8 \times 10^{20}$ Fissions $/ \mathrm{cm}^{3} 0.2_{-0.2}^{+0.7} \mathrm{~mm}$ frem. Cladding 


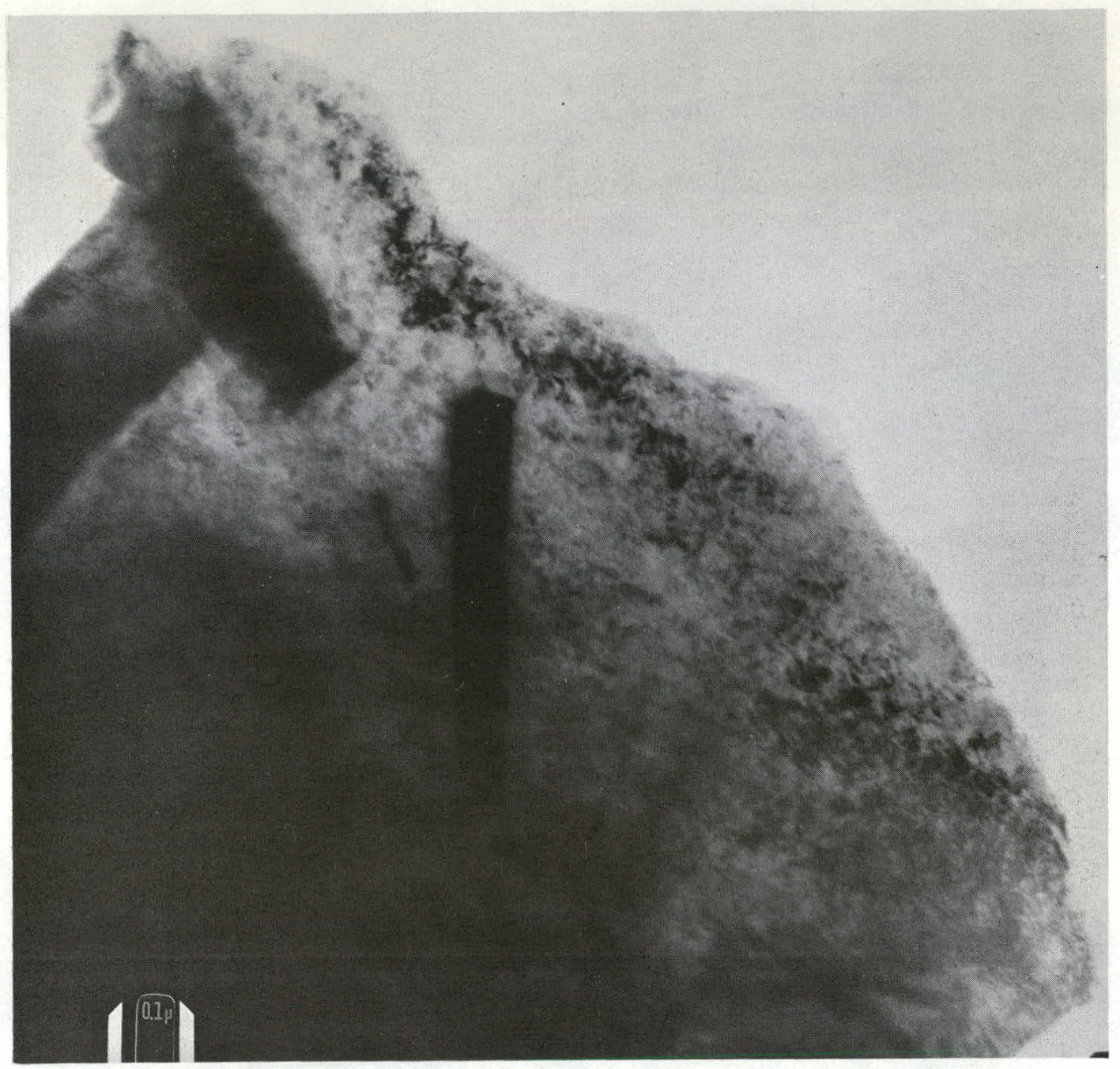

650 KV ELECTRON MICROGRAPH

$75,000 x$

Figure 111. Irradiated $\cup_{2}, \sim 0.2 \mathrm{~mm}$ from Cladding. Platelet Precipitates in Matrix 


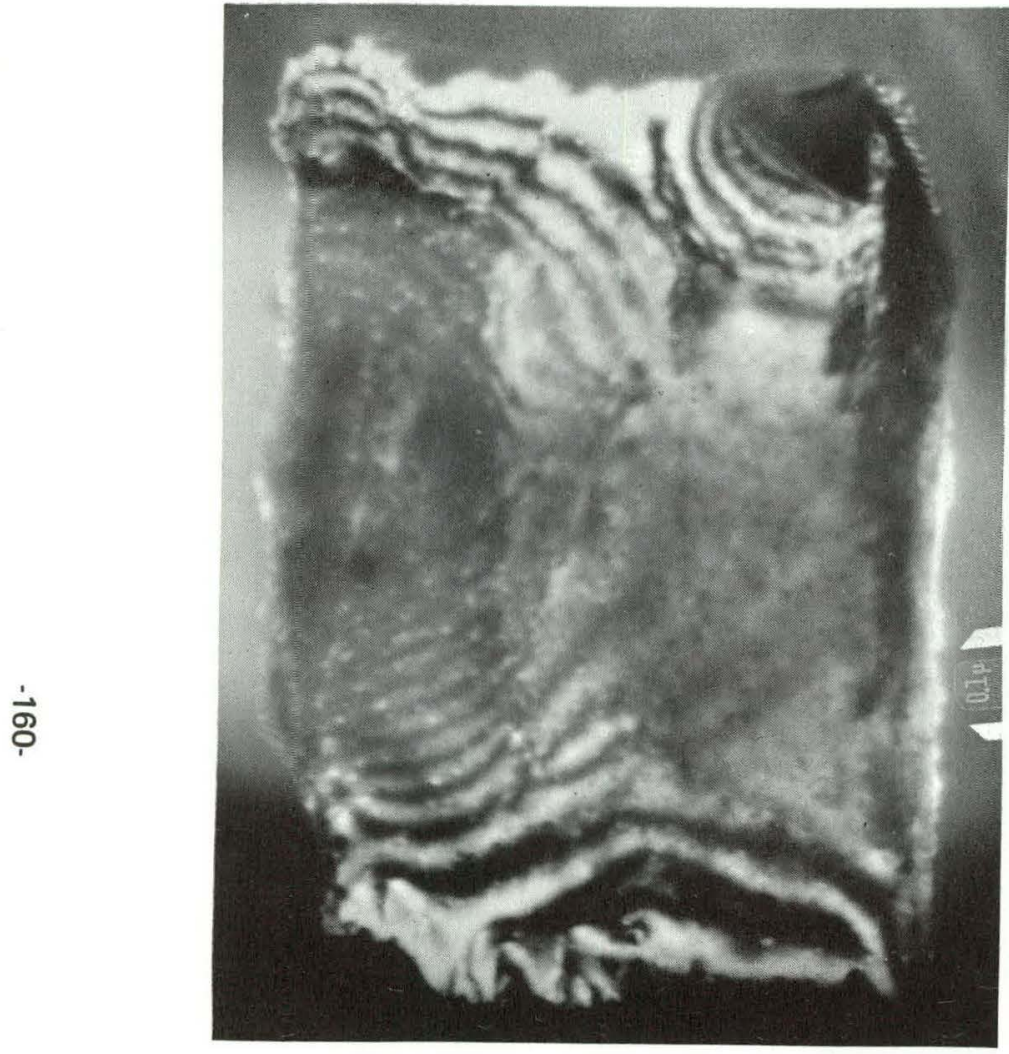

DARK FIELD
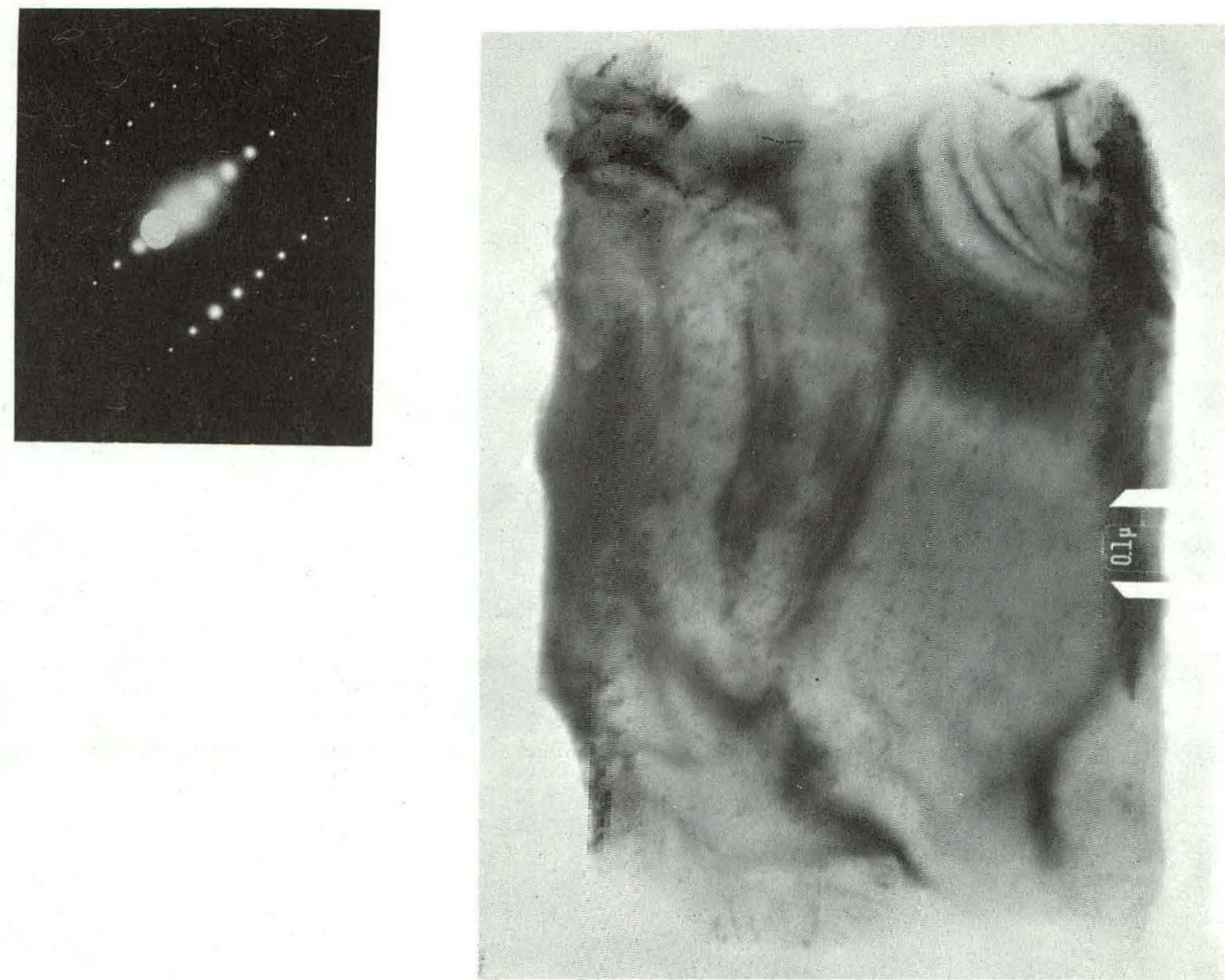

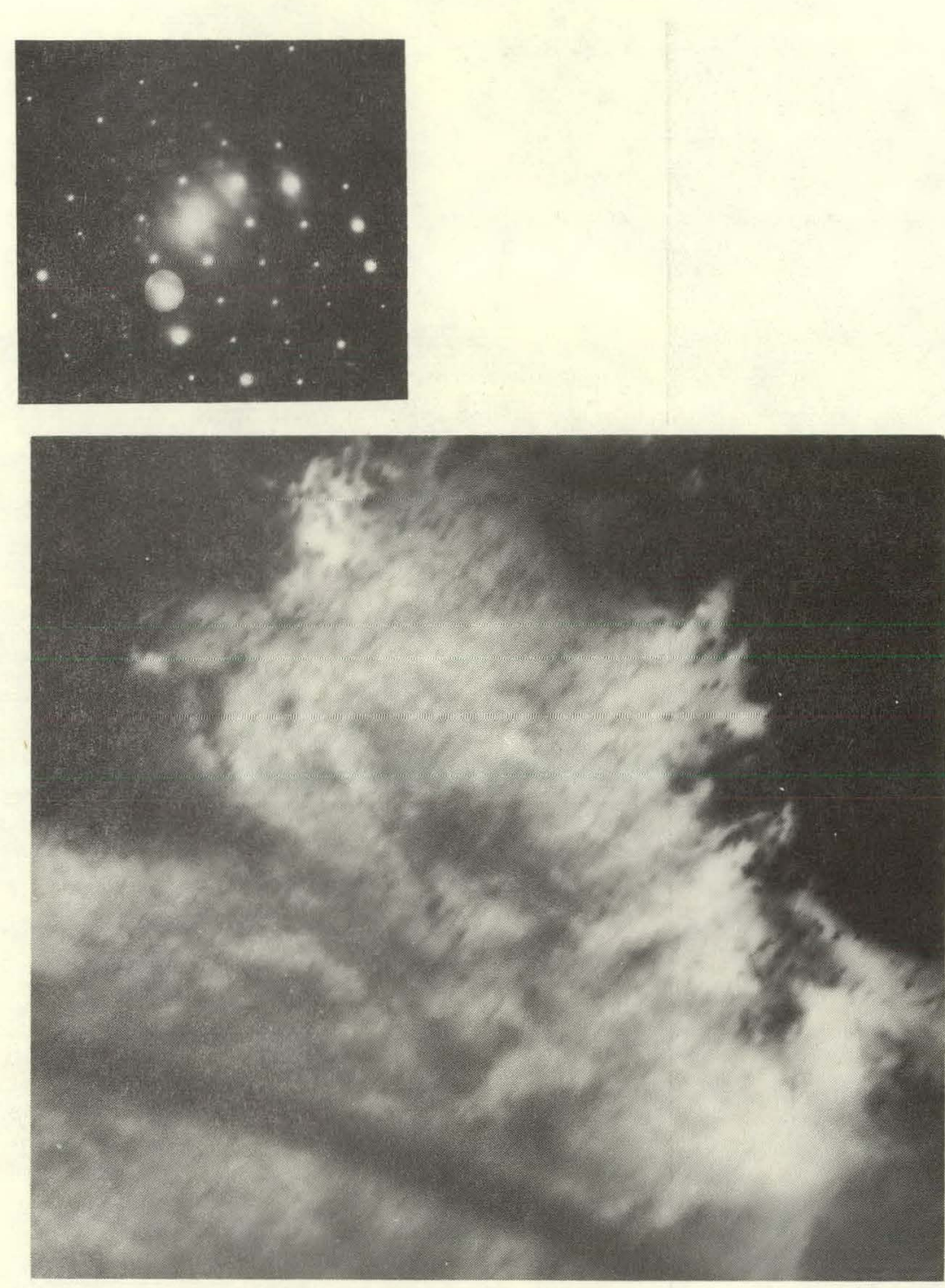

DARK FIELD
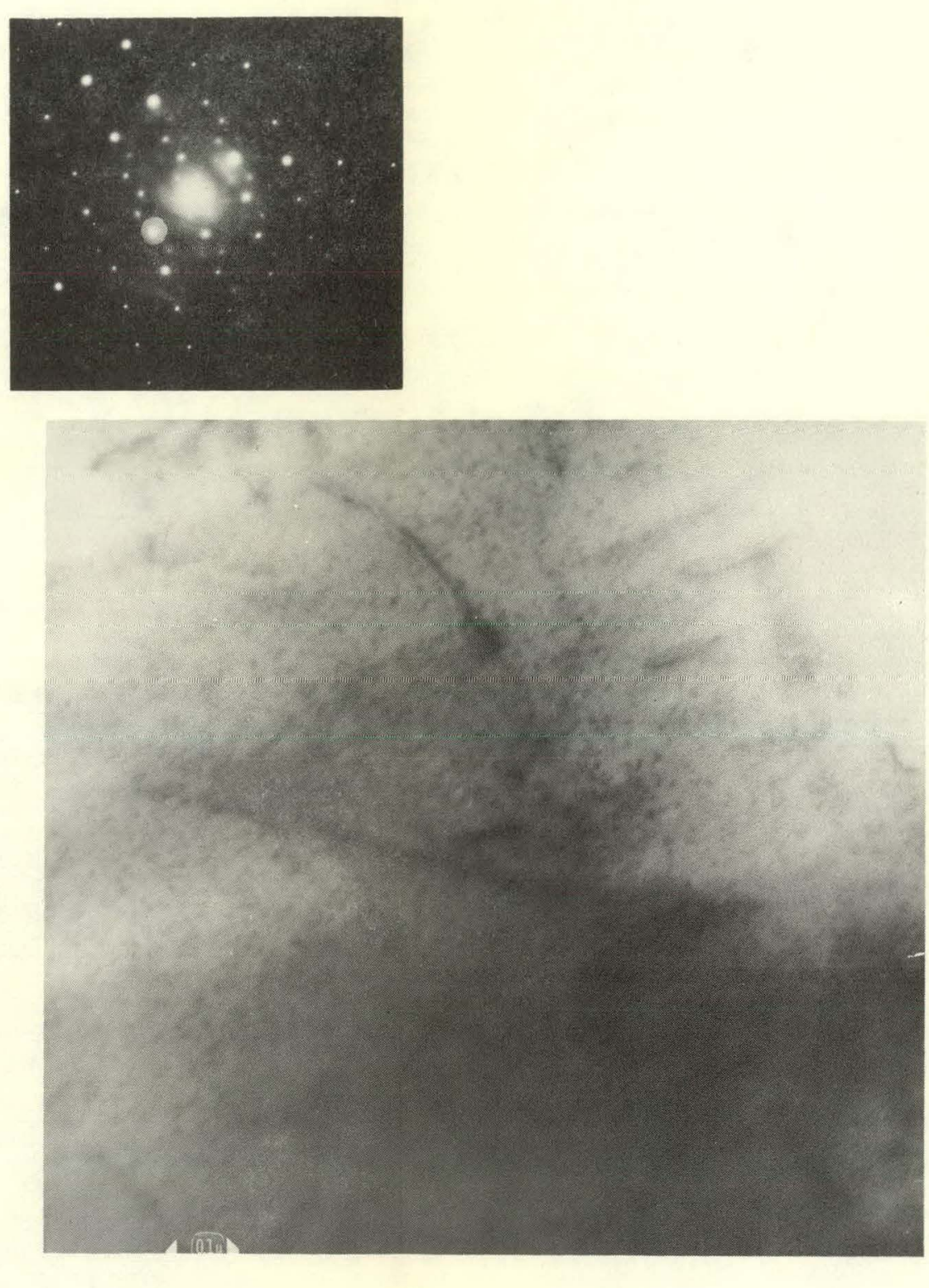

BRIGHT FIELD
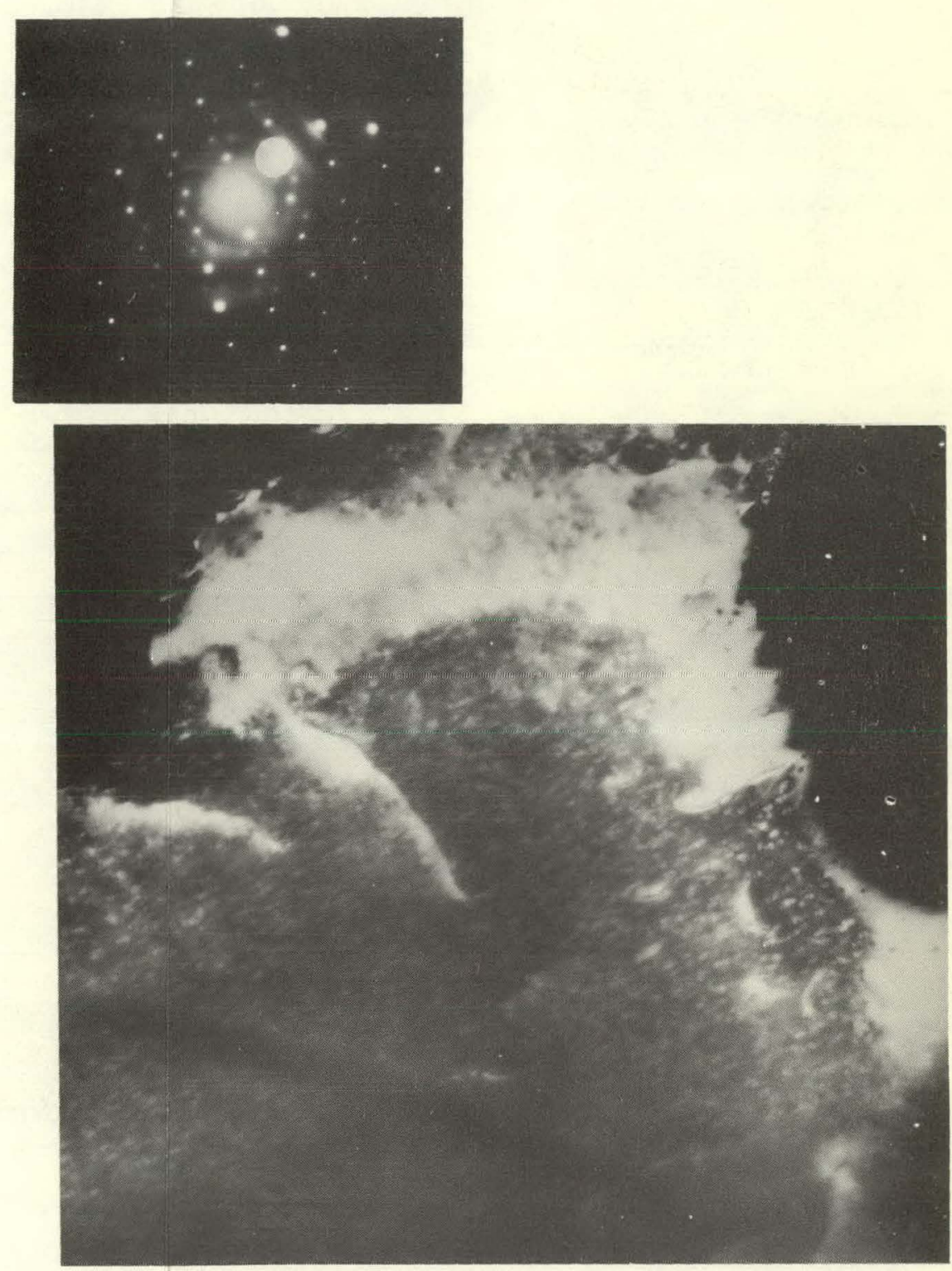

DARK FIELD 


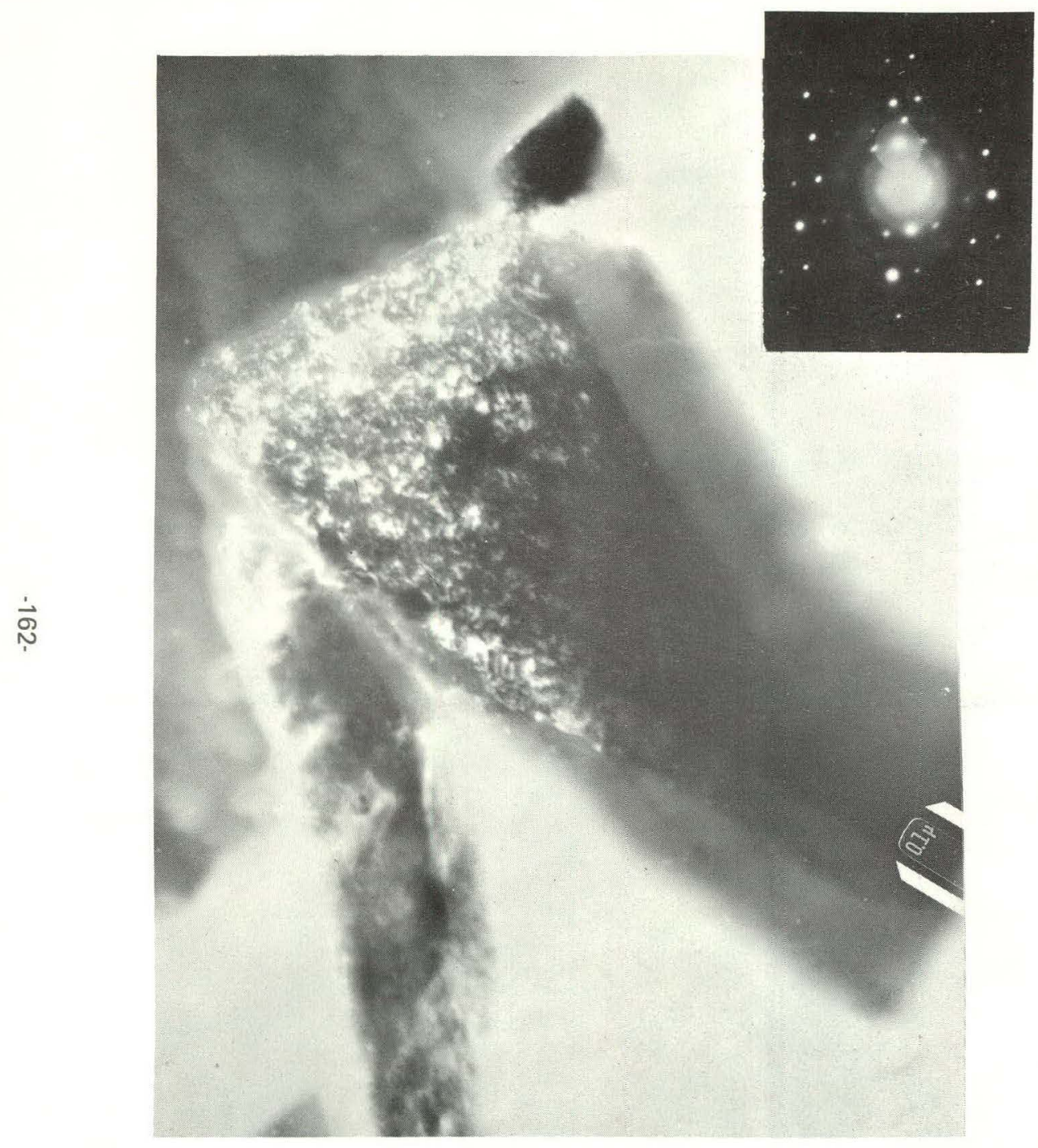

DARK FIELD

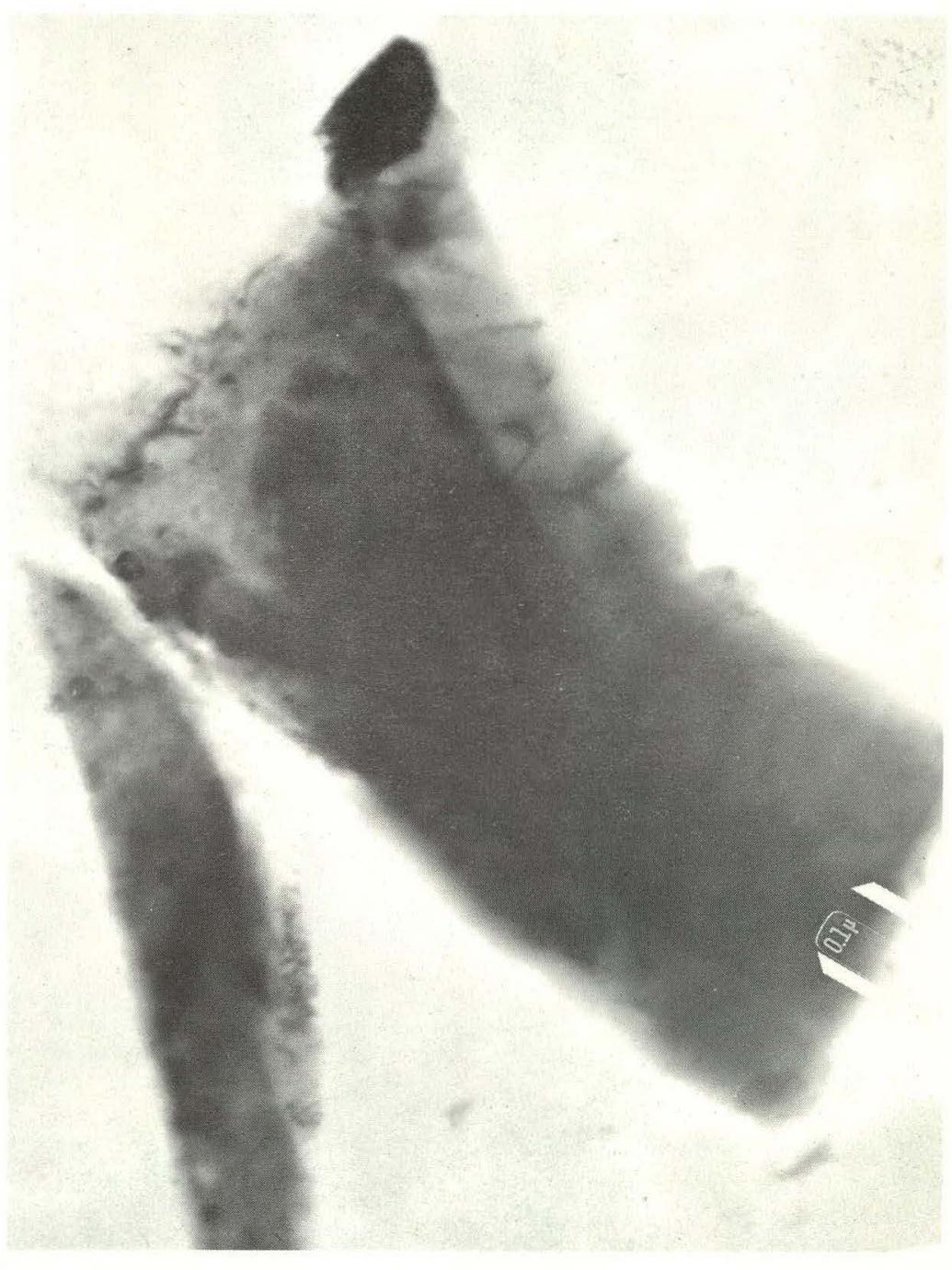

BRIGHT FIELD

$75,000 x$

Figure 114. Irradiated $\mathrm{UO}_{2}$, Near Fuel Center 


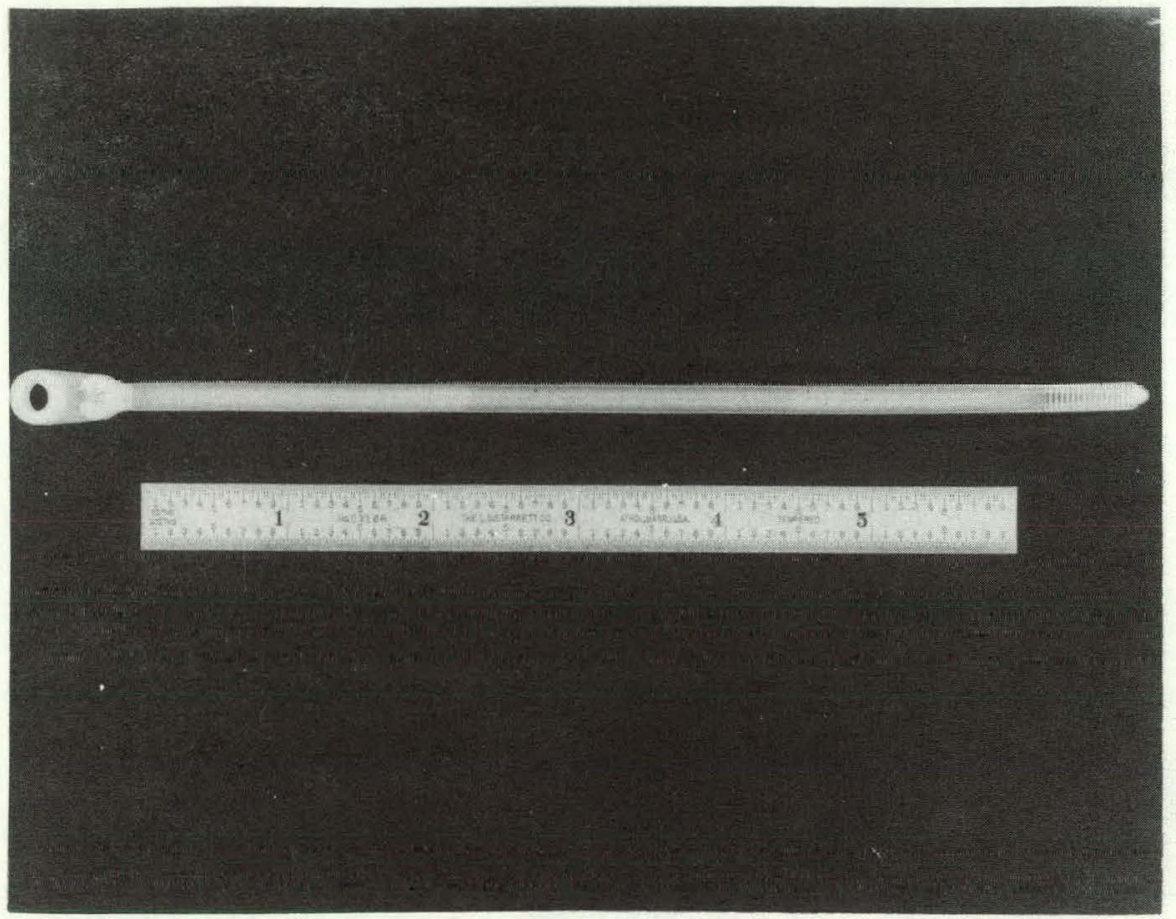

(a) OVERALL VIEW

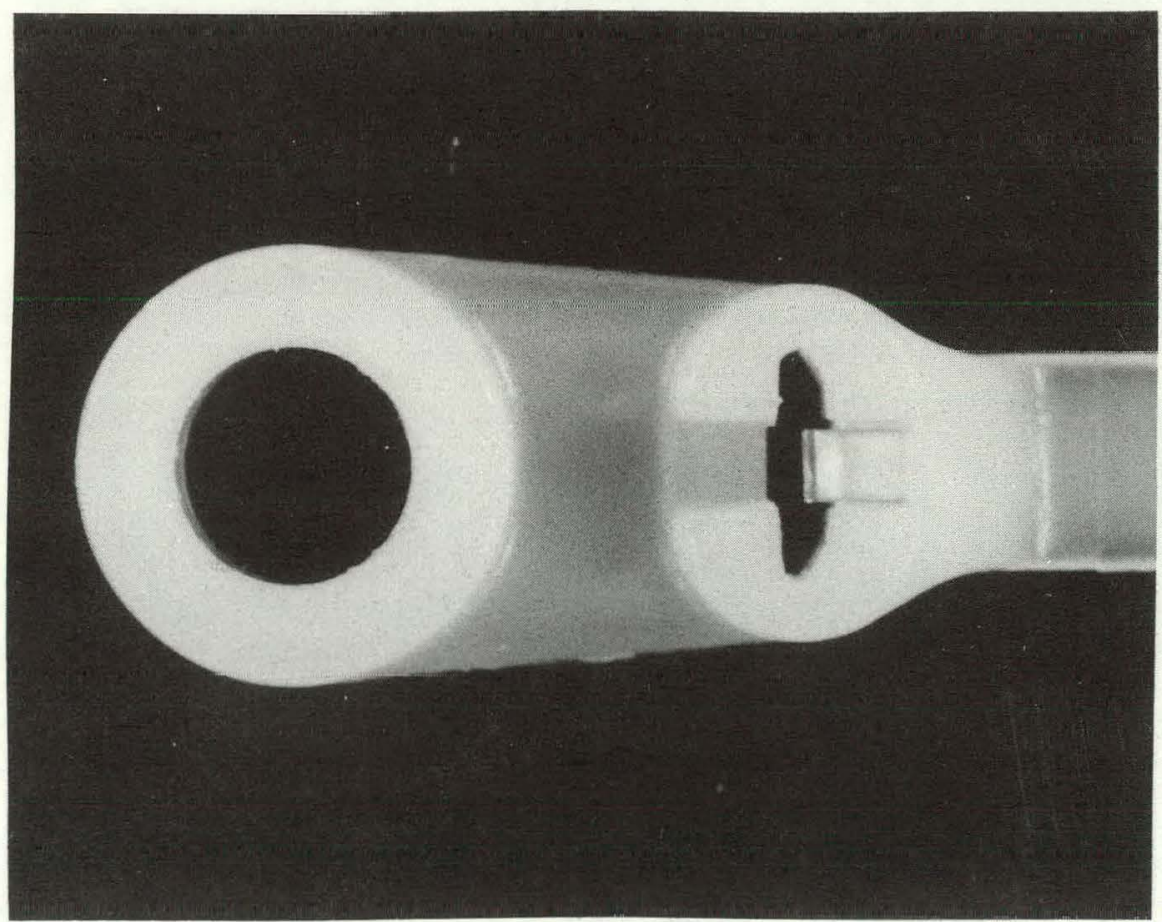

(b) ENLARGED DETAIL

Figure 115. Plastic Mold for Replicating Resin 


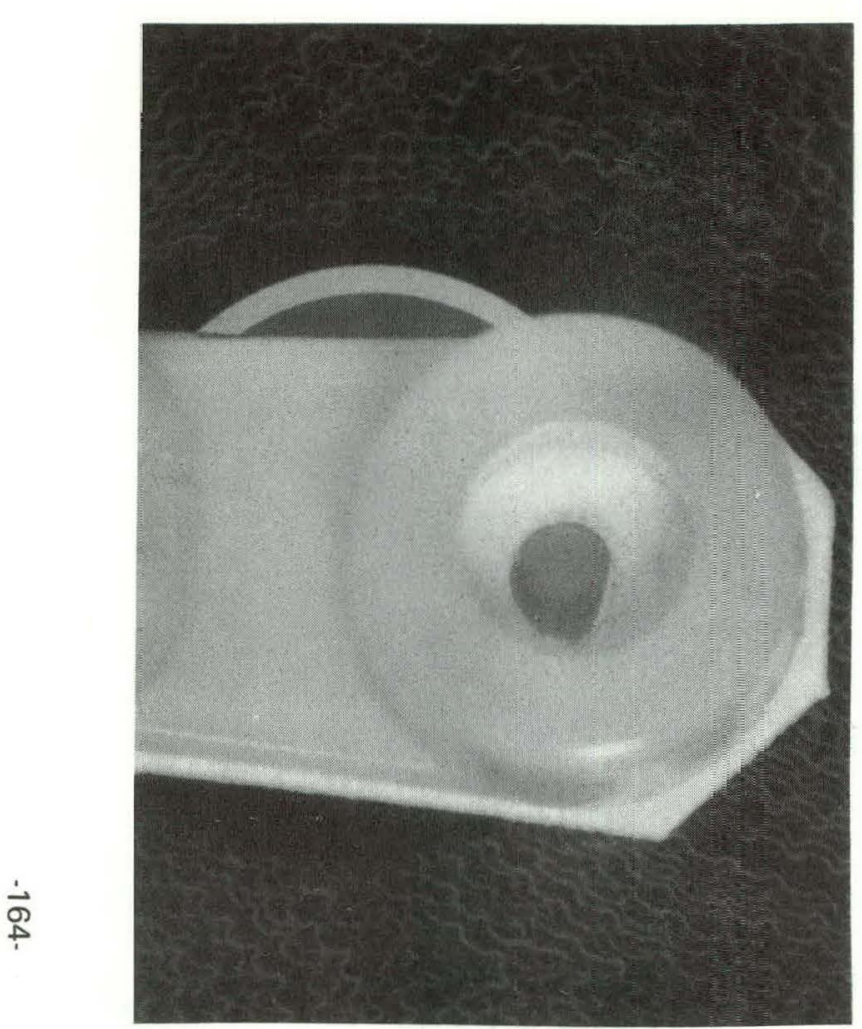

(a) MOLD FASTENED ON FUEL CROSS-SEC-IJN.

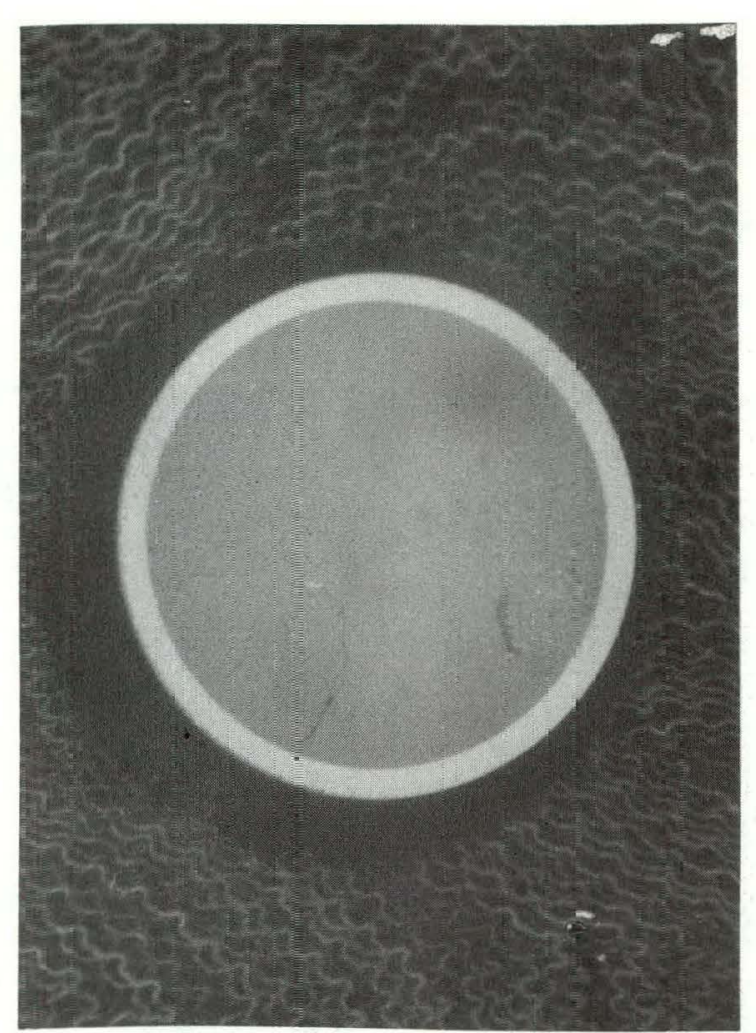

b) FUEL CROSS-SECTION AFTER STFIFPING OF TECHNOVIT; ROUGH SURFACE A ZEA INDICATES STRI PPED FUEL.

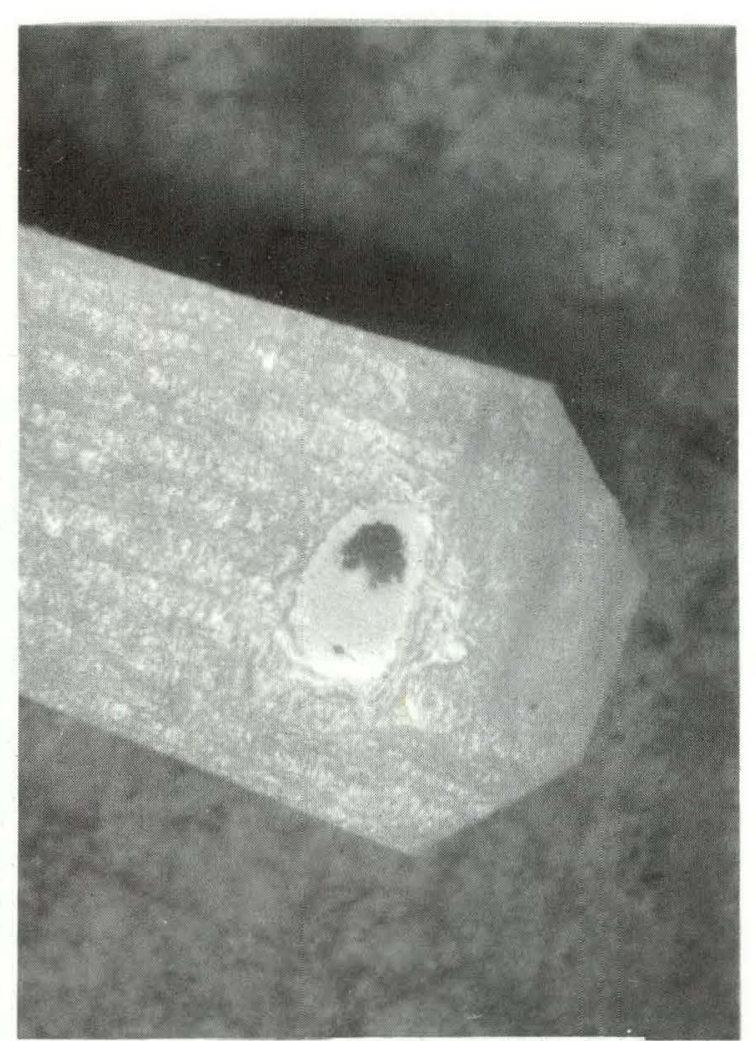

(c) TECHNOVIT IN MOLD WITH STRIPPED $\mathrm{UO}_{2}$ IN PLACE. 
1 part methanol in 5 parts of water, they were examined by transmission electron microscopy. All micrographs were taken as stereo pairs to aid in interpretation. However, only single micrographs are included in this report.

In the series of strippings, the first few Technovit plugs were only about $1 \mathrm{~mm}$ in diameter. These had not pulled out observable $\mathrm{UO}_{2}$ particles. The first plug with appreciable amounts of $\mathrm{UO}_{2}$ was replica No. 7 (Figure 116). This plug had a diameter of about $2 \mathrm{~mm}$ and came from the periphery of the fuel. Part of the cladding is visible on Figure 116(a).

As the preparation of additional Technovit plugs proceeded, more and more $\mathrm{UO}_{2}$ particles were removed from the polished surface. Each new Technovit plug, therefore, replicated some old fracture surfaces in addition to pulling out fresh $\mathrm{UO}_{2}$ particles. Consequently, the final carbon replicas may have contained some areas of two-stage replication and some of one-stage replication of $\mathrm{UO}_{2}$ fracture surfaces as indicated in Figure 117.

Replica No. 16 was one of the later 5-mm-diameter Technovit plugs from the fuel periphery (Figure 118), and No. 18 was a $5-\mathrm{mm}$-diameter plug from the center of the fuel (Figure 119).

\subsubsection{Results}

\subsection{Replicas No. 7 and No. 16 (Near Cladding)}

Two grains, about 10 to $15 \mu \mathrm{m}$ across, had been pulled out with Replica No. 7 (Figure 120). One grain is a nearly perfect cube; the other one shows five facets. Both have fairly smooth surfaces with a few "bumps." It appears that the five-facet grain contains an inclusion which in turn has a smooth pore on its surface (longer arrow in Figure 120). Another pore is seen on another facet (short arrow). A different type of particle is shown in Figure 121. It appears to have four facets. However, two of them have river markings and might, therefore, not be grain boundaries. The junctions of the facets are rough. At the apex of the particle a short flat split is seen (arrow).

Areas where previously $\mathrm{UO}_{2}$ particles had been pulled out of the specimen surface are shown in Figure 122 from Replica No. 16. The fracture is intergranular, and both micrographs contain several grains with their junctions. In Figure 122(a), a round second-phase particle is visible near the most prominent junction. The grain boundary surfaces on Figure 122(b) contain a number of large pores (with white "shadows") and a second-phase particle (arrow). Also, a small angular $\mathrm{UO}_{2}$ particle has been pulled with this replica (double arrow).

\subsection{Replica No. 18 (Near Fuel Center)}

The fracture surfaces in the fuel center have an appearance quite different from that at the fuel periphery. Figure 123 shows ripples, grooves, and a cell-like structure on the grain boundaries. Similar ripples are seen in Figure 124(a). In addition, the fracture surfaces contain numerous small, uniformly dispersed "bumps" (Figure 124) the nature of which is not clear at present. The bumps might be evidence of small second-phase or fission product particles.

Another feature of Replica No. 18 is the occurrence of fairly flat structures about 5 to $10 \mu \mathrm{m}$ across (Figures 124(a) and 125). It appears probable that these flats are manifestations of second-phase particles which either have cleaved or parted at the particle-matrix interface. The flat split in Figure 121 might be the same kind of feature. In the optical metallography, no comparable structural details were observed which could be correlated directly with the observed plate-structure. The plates are definitely much larger than the overall platelet precipitation observed within the grains (see Section 5.2.1).

\subsection{Summary}

The features observed on the $\mathrm{UO}_{2}$ grain boundaries cannot readily be interpreted. Few pores were seen, but the resolution of replicas is not good enough to detect pores of less than about 100 to $200 \AA$ diameter. The platelets seen in the grain interiors by optical metallography and by replication electron microscopy of cross sections were not present on the grain boundary surfaces. This, of course, could be expected since the platelets had never been observed in grain boundaries. However, the grain boundaries might contain continuous second-phase coatings. If so, it would be difficult to detect such phases on replicas of fracture surfaces. Second phases can more readily be seen if they are discontinuous. The "bumps" observed might be such second phases. However, they do not correspond to anything seen in the cross sections.

\subsubsection{Lattice Parameter Measurements (J. E. Lewis, J. L. Lakner)}

\subsubsection{Procedure and Scope}

X-ray diffraction analyses were performed on three fuel samples from specimen No. 584 trom rod A11, 1.e., the same specimen used for the examination of fracture surfaces (subsection 5.2.3). The samples were taken from the center, mid-radius, and periphery of the polished fuel cross section. 


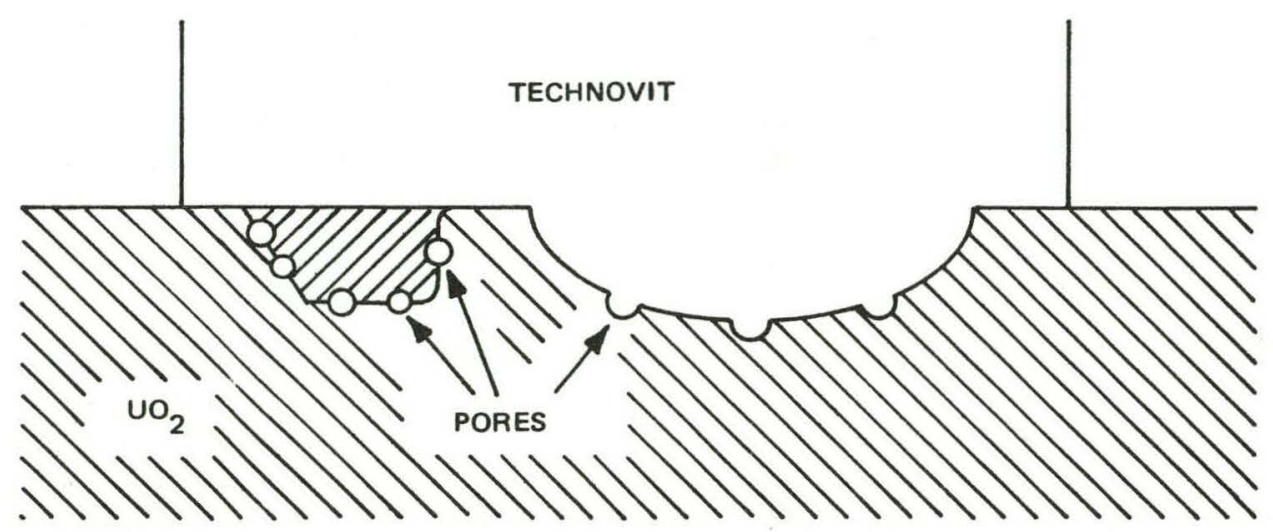

(a) FIRST STEP: TECHNOVIT APPLIED TO UO ${ }_{2}$ SURFACE WITH PARTICLE ALREADY PULLED OUT BY PREVIOUS REPLICA.

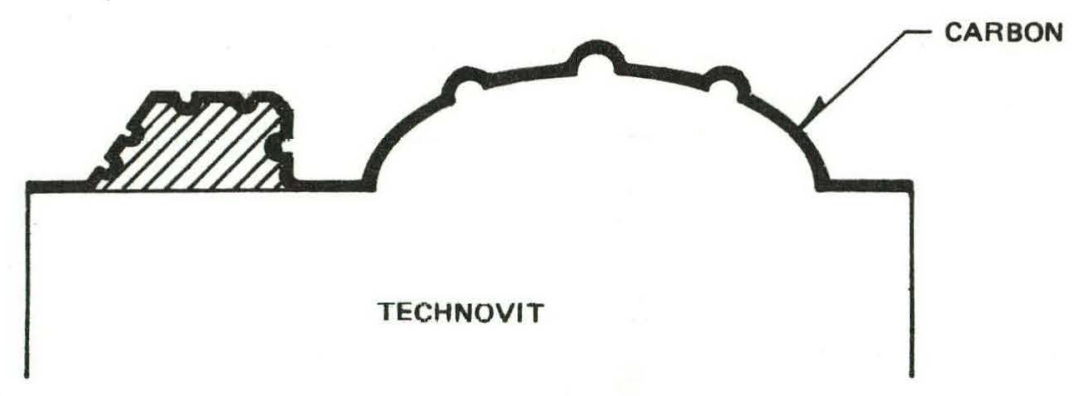

(b) SECOND STEP: TECHNOVIT HAS PULLED OUT ANOTHER UO 2 PARTICLE. CARBON COATING PRODUCES REPLICA THAT IS ONE-STAGE OVER THE FRESHLY PULLED PARTICLE AND TWO-STAGE OVER THE REST OF THE SURFACE.

Figure 117. Schematic Representation of Replication 


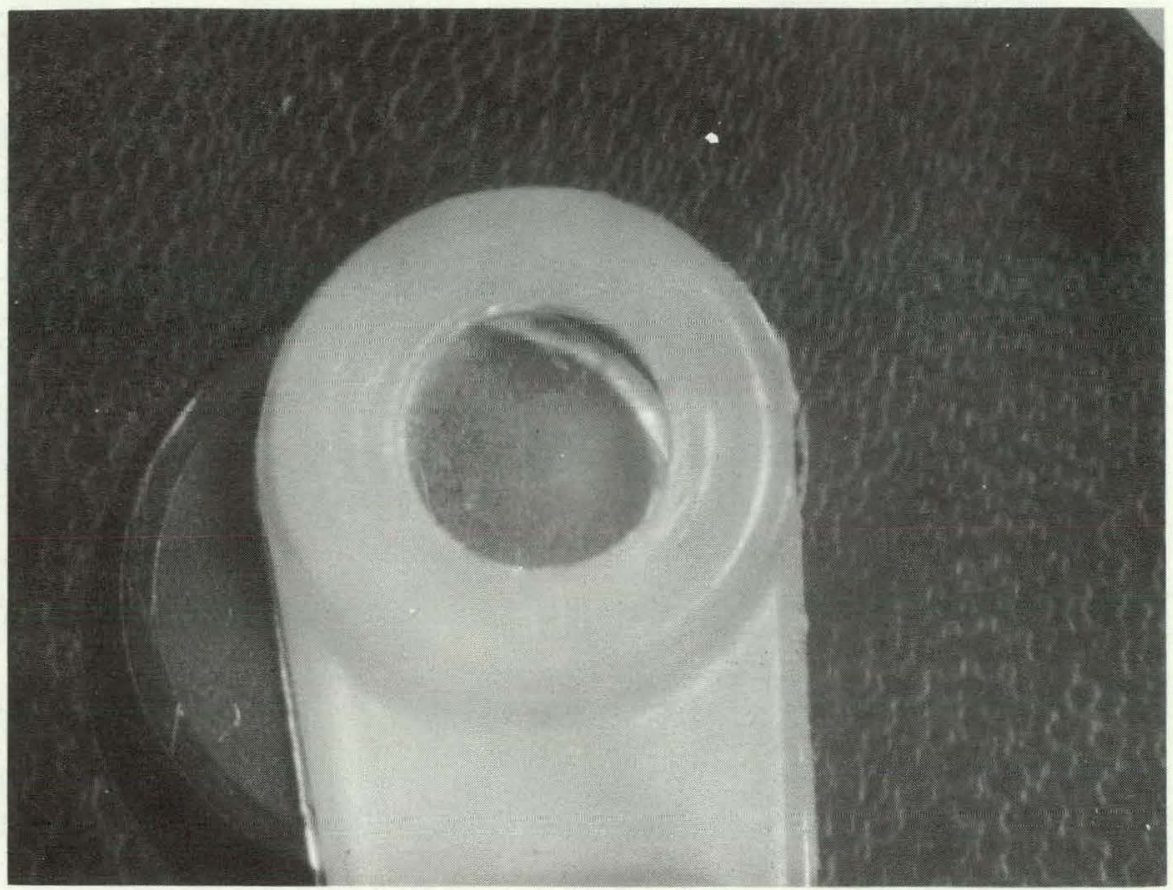

(a) MOLD PLACED ON FUEL CROSS-SECTION

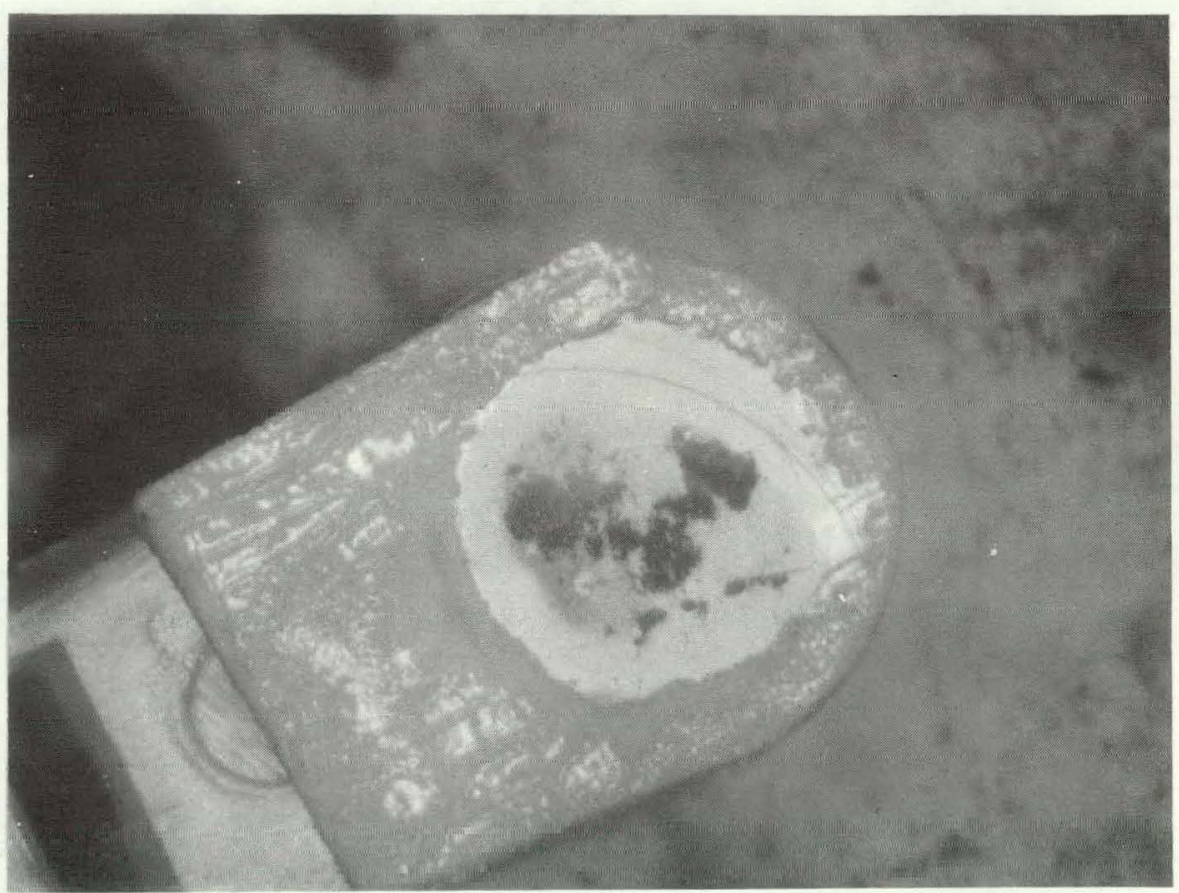

(b) STRIPPED TECHINŨVII PLUG WI I H EXIRACIIEU UU ${ }_{2}$

Figure 118. Technovit Replica No. 16 


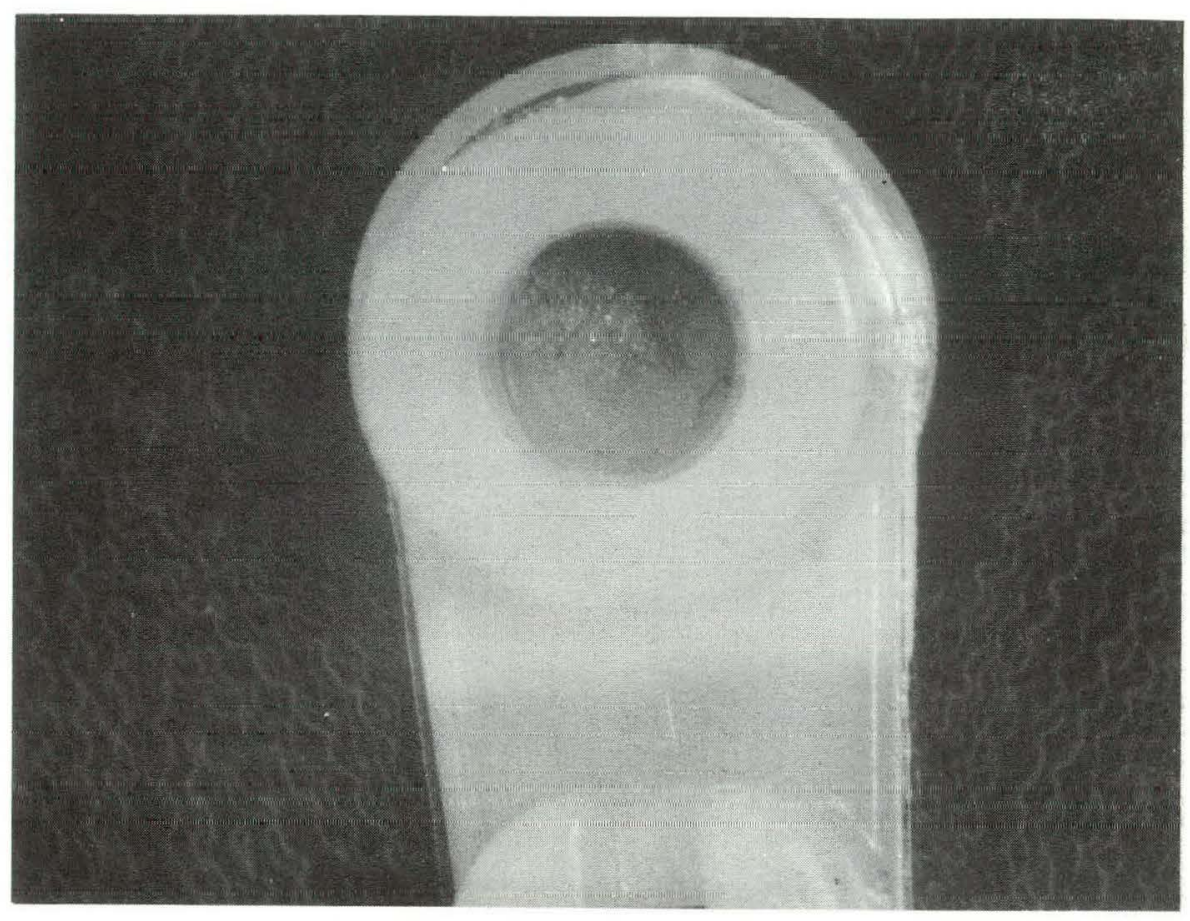

(a) MOLD PLACED ON CENTER OF FUEL CROSS-SECTION

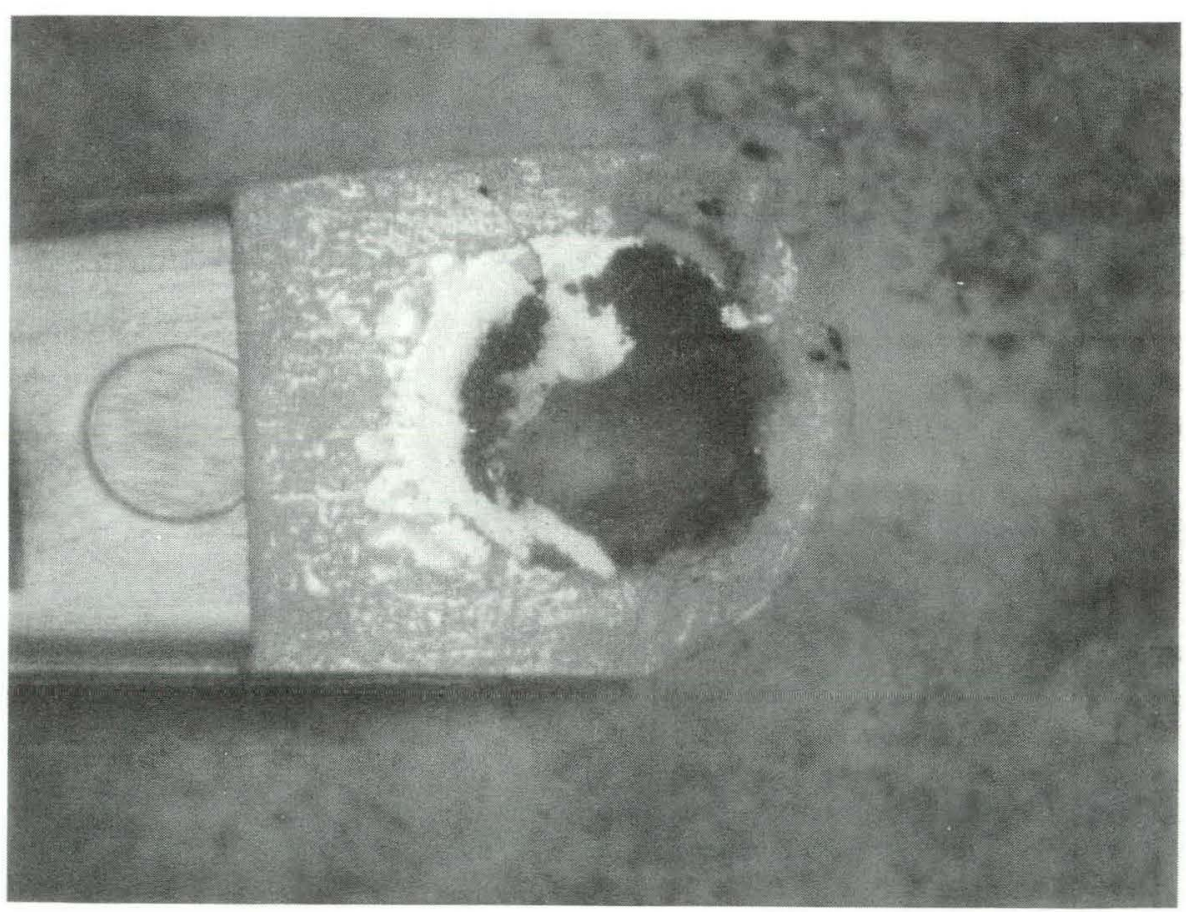

(b) STRIPPED TECHNOVIT PLUG WITH EXTRACTED UO ${ }_{2}$

Figure 119. Technovit Replica No. 18 


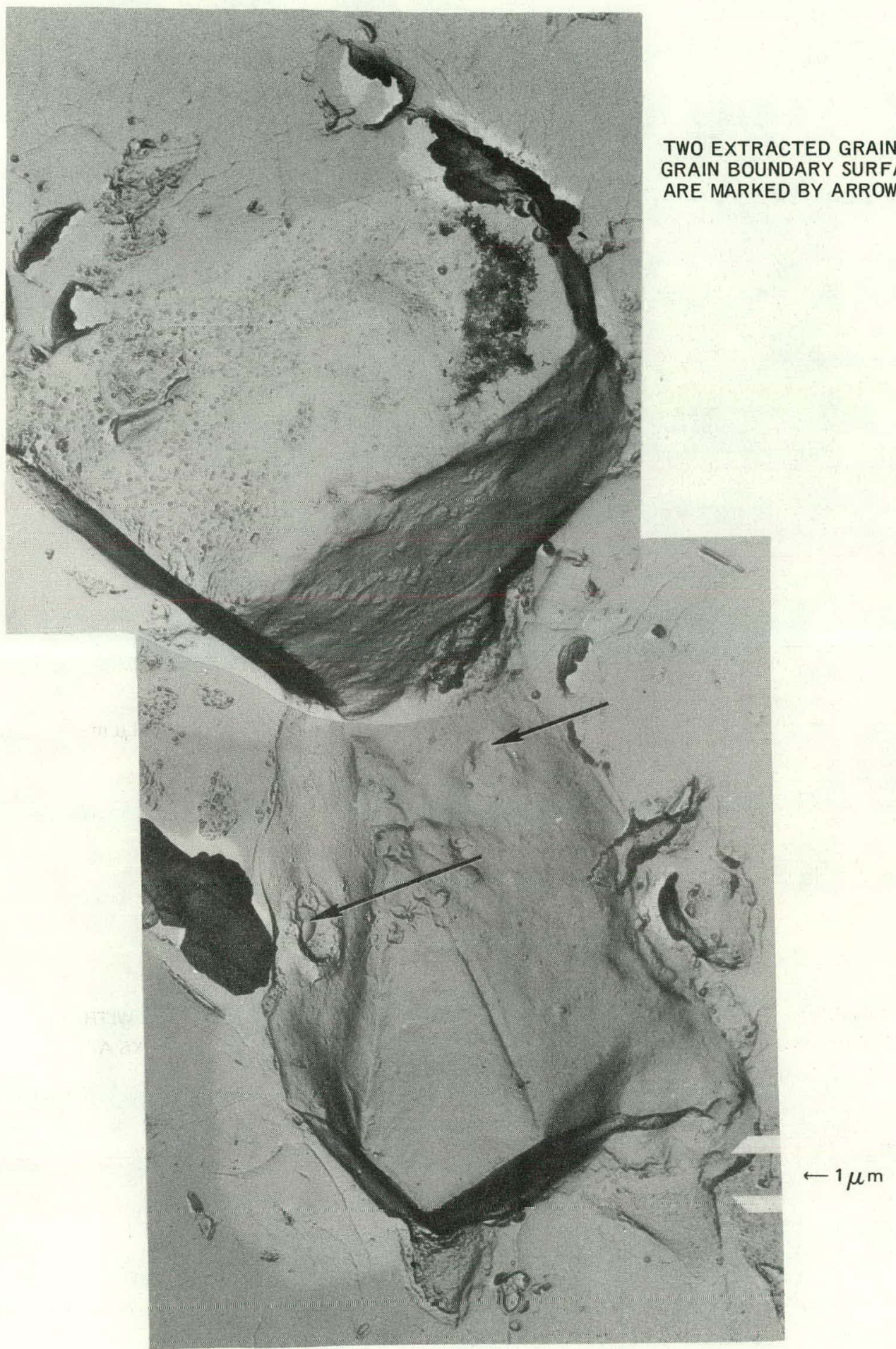

Figure 120. Carbon Replica No. 7 from Near Fuel-Cladding Interface 


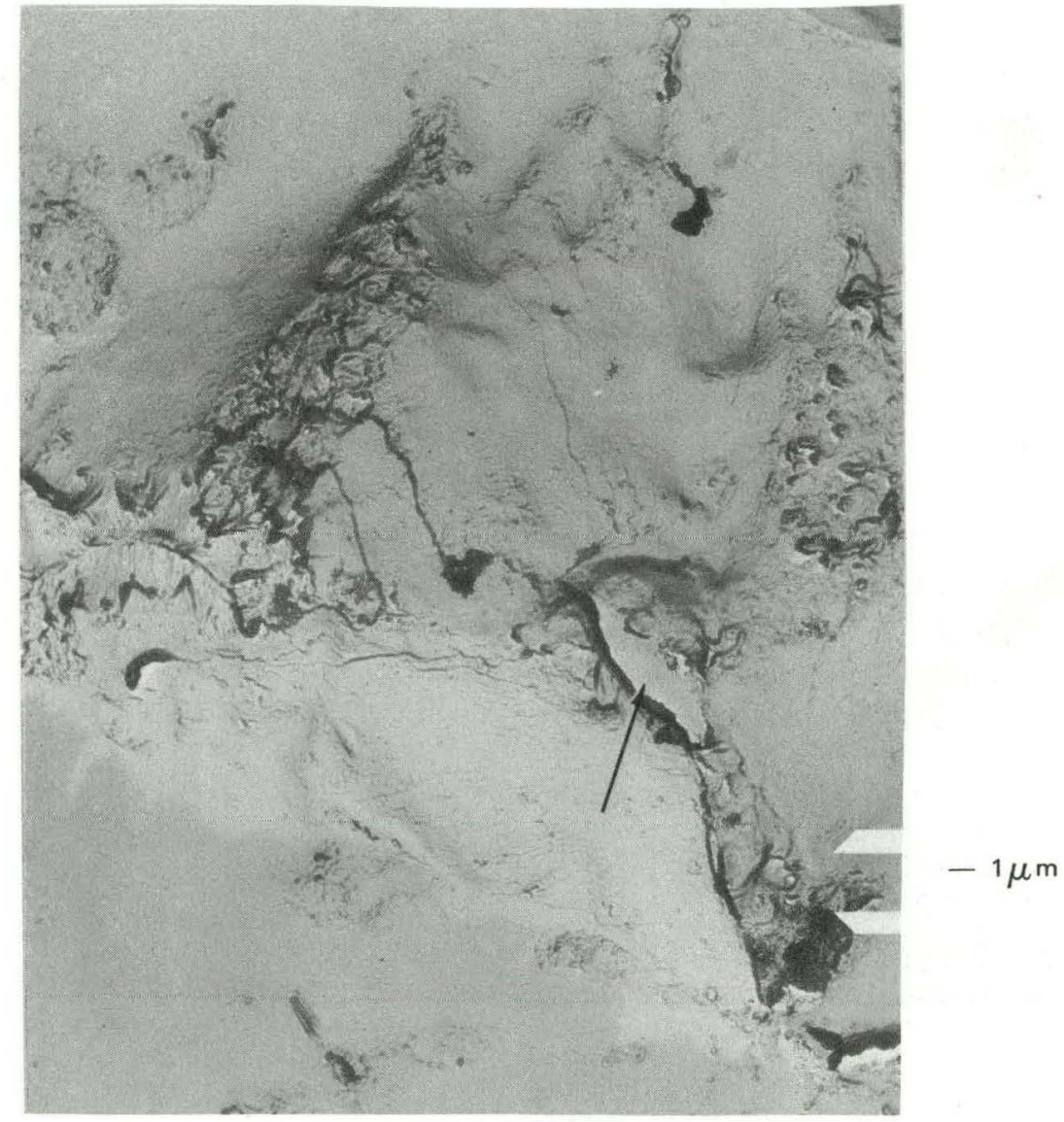

EXTRACTED UO ${ }_{2}$ PARTICLE HAS SOME SMOOTH SURFACES AND SOME SURFACES WITH RIVER MARKINGS. THE JUNCTIONS BETWEEN FACETS ARE ROUGH. ARROW MARKS A FLAT SPLIT IN THE UO ${ }_{2}$.

Figure 121. Carbon Replica No. 7 


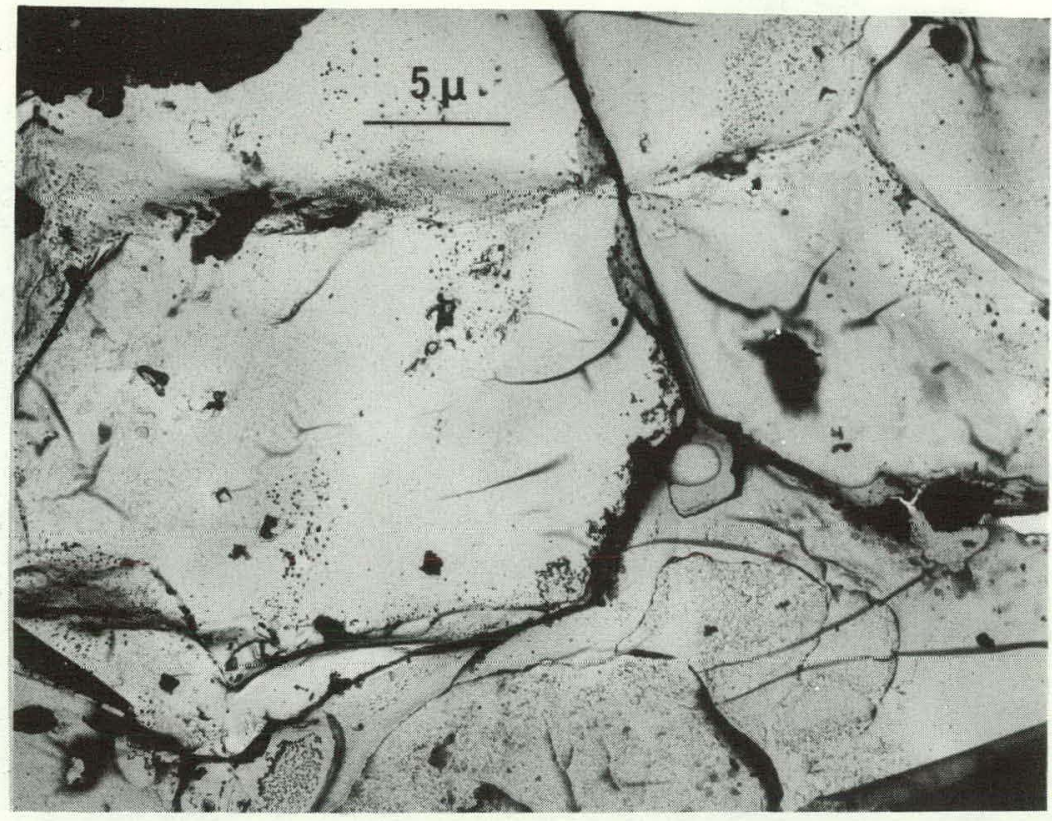

(a) ROUND SECOND PHASE PARTICLE NEAR MOST PROMINENT JUNCTION (BLACK SPOTS ARE ARTIFACTS OR UNDISSOLVED $\mathrm{UO}_{2}$,)

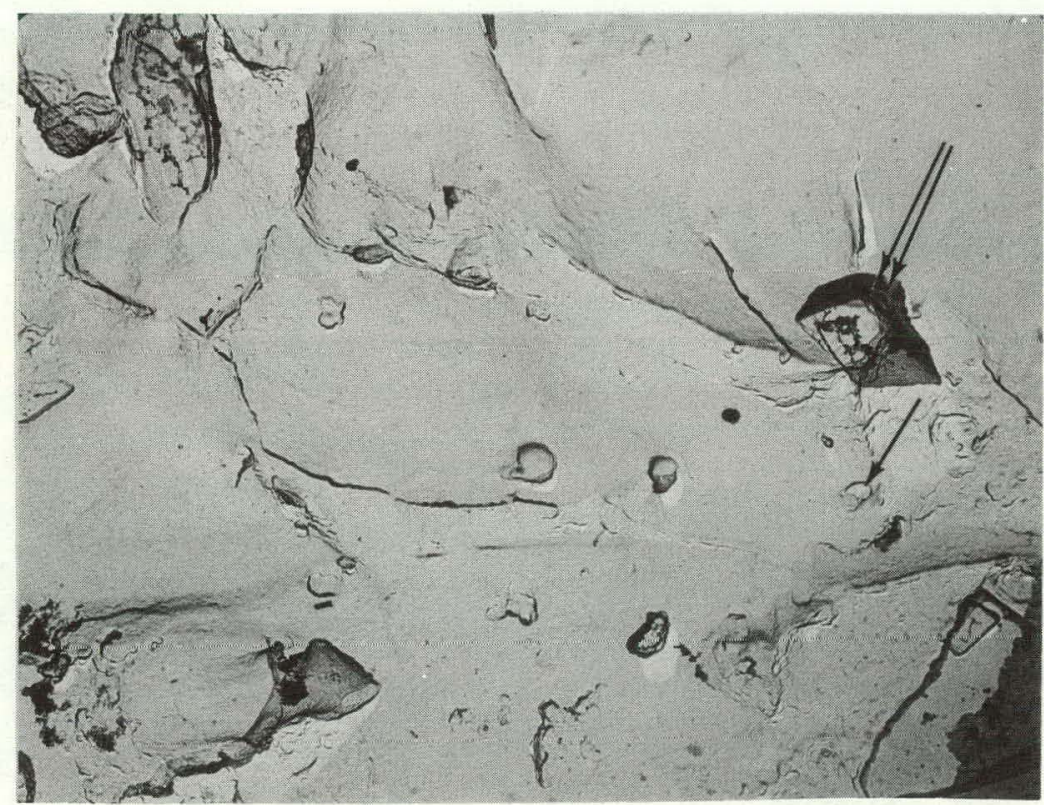

(b) SEVERAL PORES (WITH WHITE "SHADOWS") AND AN INCLUSION (ARROW). 


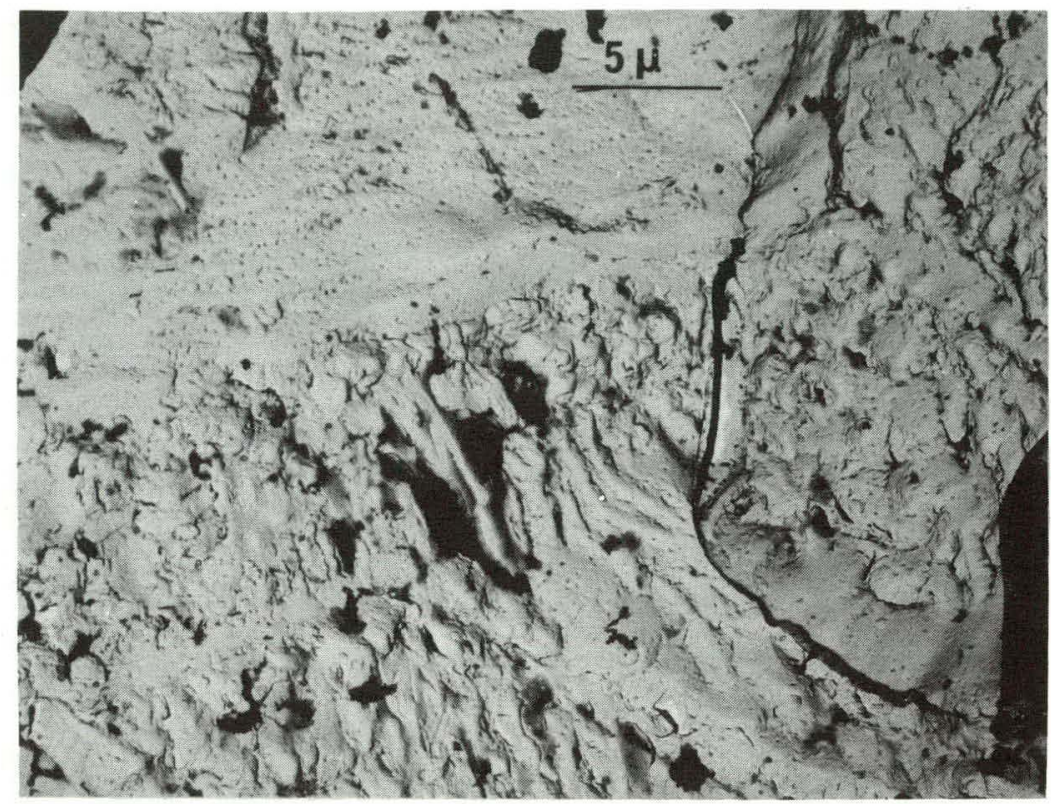

(a)

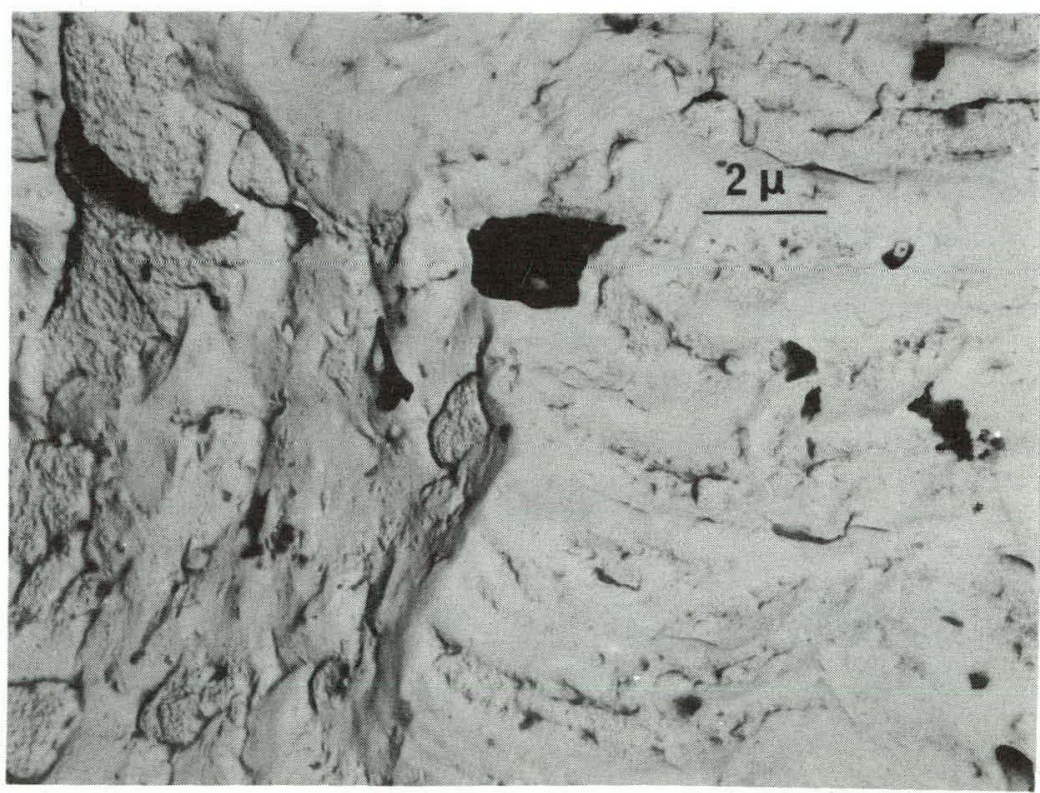

(b)

GRAIN BOUNDARY SURFACES WITH RIPPLES AND GROOVES

Figure 123. Carbon Replica No. 18 from Center of Fuel 


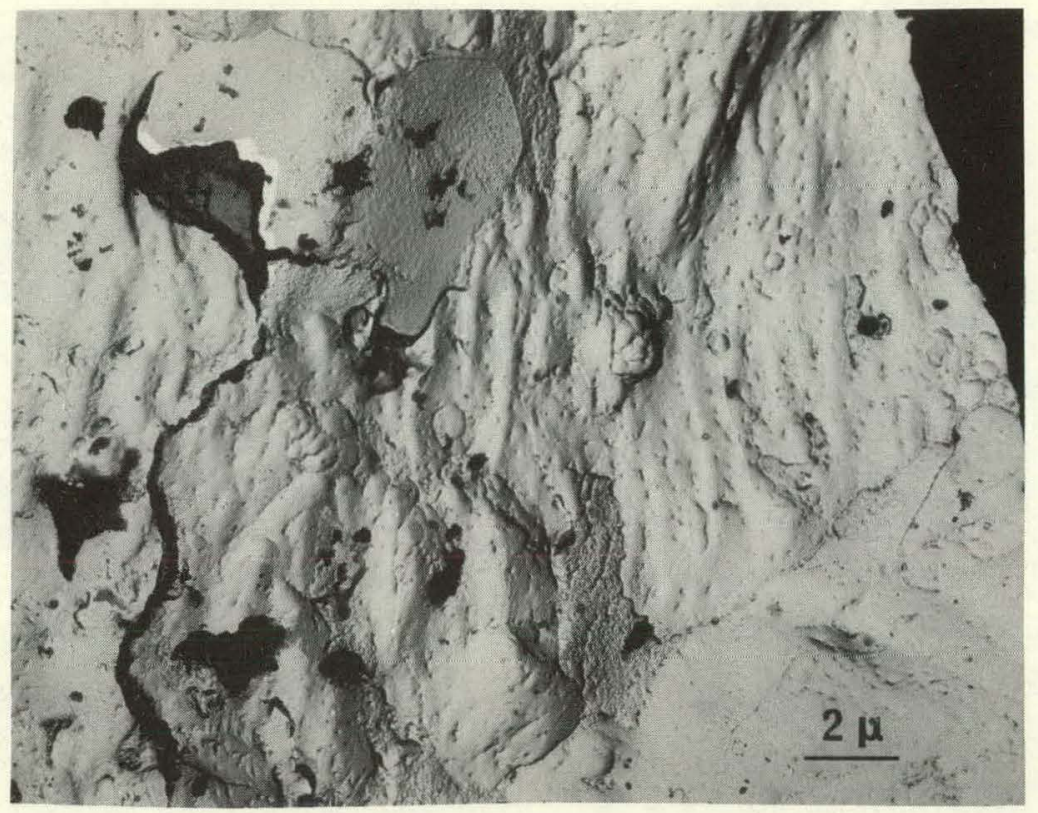

(a)

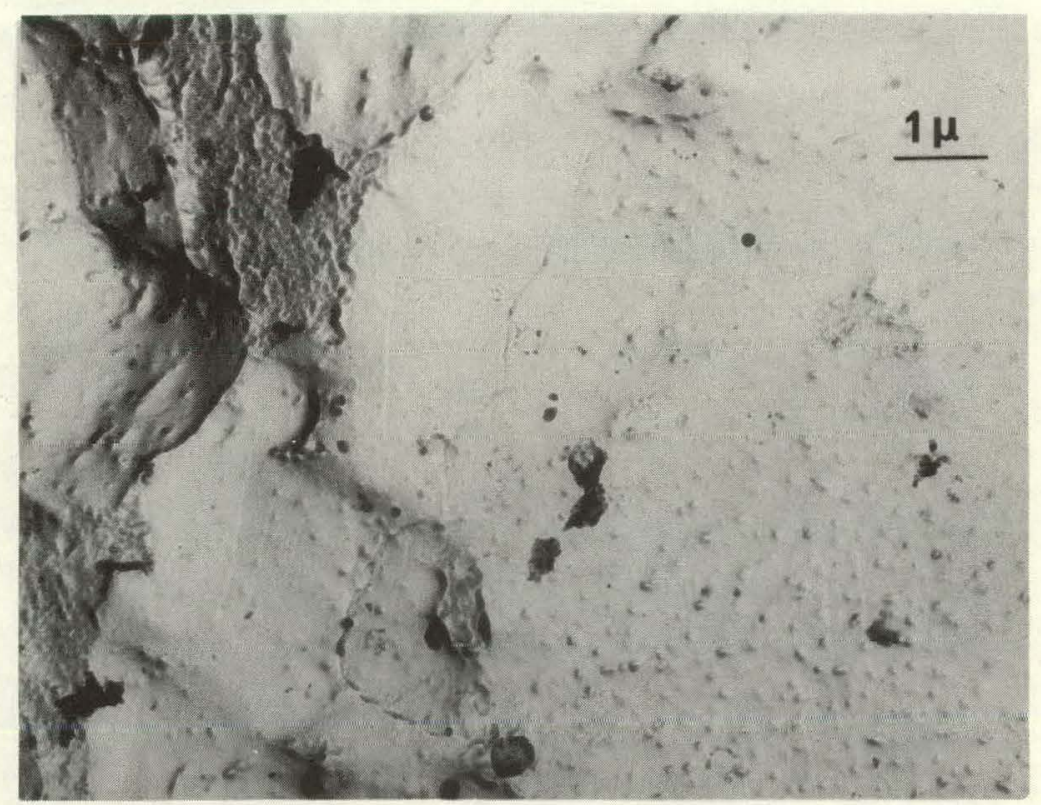

(b)

GRAIN BOUNDARY SURFACES WITH A UNIFORM DISPERSION OF "BUMPS" TLAT ARCAS IN (a) ARE POSSIBLE SELUINU HHASES.

Figure 124. Carbon Replica No. 18 


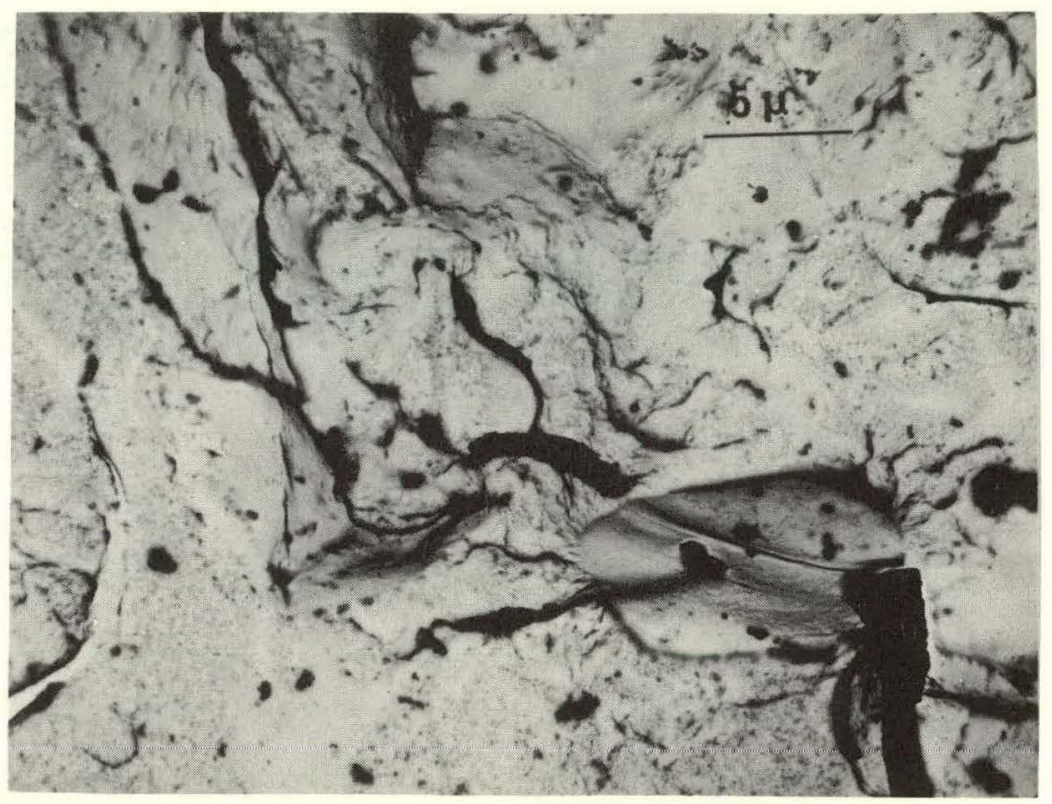

(a)

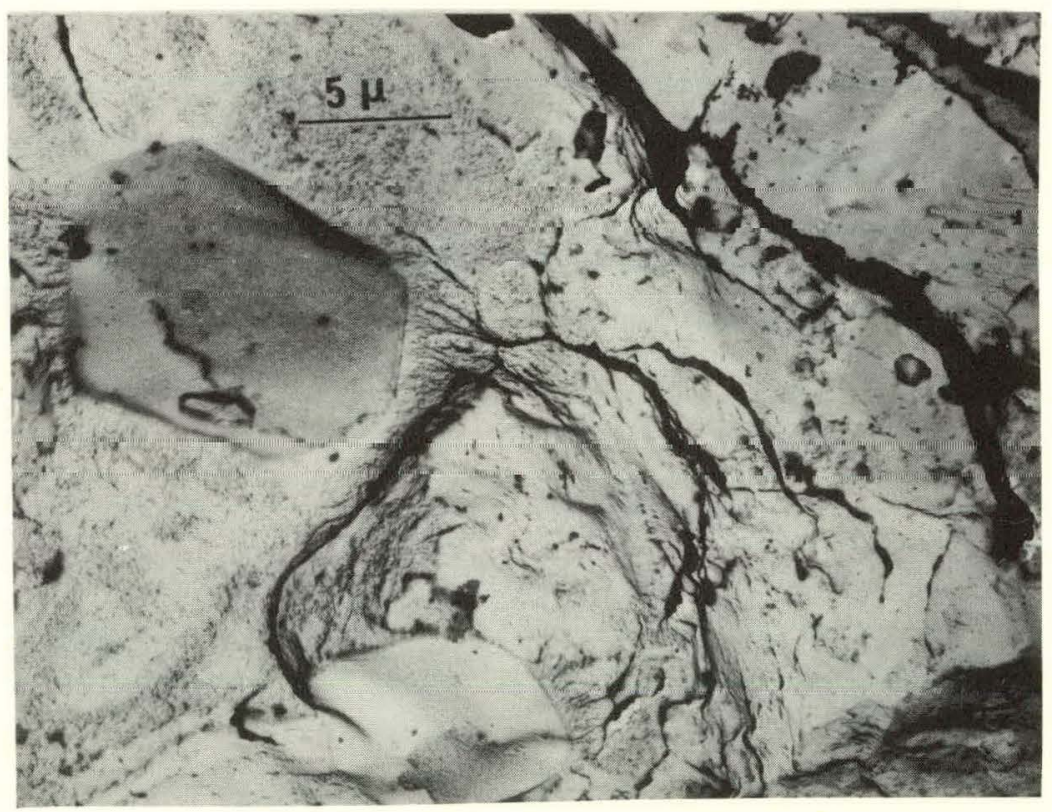

(b)

IRREGULAR SURFACES WITH CRACKS, PROBABLY GRAIN BOUNDARY SURFACES. FLAT AREAS ARE POSSIBLE SECOND PHASES.

Figure 125. Carbon Replica No. 18 
This analysis was primarily performed in an attempt to measure the oxygen-to-metal ratio by observing relative changes in the $\mathrm{UO}_{2}$ fuel unit cell dimension. In addition, checks were made for other crystallographic phases, such as $\mathrm{U}_{4} \mathrm{O}_{2}$ and fission products and for irradiation damage effects.

Unfiltered Cu x-rays were used with the 114.6- $\mathrm{mm}$ diameter Debye-Scherrer powder cameras for the analysis. The $x$-ray diffraction analysis was performed using a rotating anode $x$-ray generator system operated at $50 \mathrm{kV}$ and $100 \mathrm{~mA}$. The $\mathrm{UO}_{2}$ lattice parameter, $\mathrm{a}_{0}$, for each powder camera film was calculated from all readable diffraction lines, including those caused by the $\mathrm{CuK} \beta_{1}$ wavelength component, with diffraction angle $2 \theta$ more than 90 degrees. These data were extrapolated by means of the Nelson-Riley function ${ }^{10}$ to obtain the corrected values. The standard deviation from the least squares fit of the data to the Nelson-Riley function was taken as the probable error associated with each parameter.

The particle extraction technique described in subsection 5.2.3 was employed to obtain samples for the $\mathrm{x}$-ray diffraction measurements. The size of the hole in the double-backed masking tape used to secure the mold to the specimen was about $2 \mathrm{~mm}$ in diameter.

Figure 126 shows the fuel particles attached to the Technovit, and the circles indicate from which area of the replicas the particles were taken. The particles were removed using a microscope and fine steel probe. They were transferred to the end of a $0.12 \mathrm{~mm}(0.005-\mathrm{in}$.) diameter glass fiber coated with petroleum jelly which was used as the adhesive for the fuel particles. The glass fibers were held with modeling clay in brass powder camera mounts.

The $x$-ray diffraction exposure time was predetermined by placing the sample and film in the cameras for various times to determine the maximum permissible background fogging to the film from radiation emitted by the sample.

The radiation level of the prepared powder camera samples as measured with a C.P. meter at contact were as follows:

\begin{tabular}{lrrrr}
\multicolumn{1}{c}{ Sample } & Radiation Level $(\mathrm{mR} / \mathrm{h})$ & $\beta-\gamma$ & $\begin{array}{c}\text { Maximum Film } \\
\text { Exposure Time (hr) }\end{array}$ \\
Center of Pellet & $\gamma$ & 1 & 19 & 2.5 \\
Mid-Radius & 18 & 115 & 0.75 \\
Periphery of Pellet & 2 & 19 & 2.5
\end{tabular}

\subsubsection{Results}

No phases other than the $\mathrm{UO}_{2}$ fuel could be detected. The particles of fuel examined were not removed exactly from the area of highest second-phase concentration, but close enough to the area so that some of the second phase should have been in the $\mathrm{x}$-ray samples. Apparently the concentration of this phase is too small to be observable.

The results of the $\mathrm{UO}_{2}$ lattice parameter measurements were rather significant. The lattice parameter of the irradiated $\mathrm{UO}_{2}$, averaged over all three radial positions, is 0.10 percent larger than that of the unirradiated control specimen. This increase can be attributed to irradiation damage, ${ }^{11}$ since the fuel specimen was not run at a temperature high enough $\left(1650^{\circ} \mathrm{C}\right)$ to anneal out the irradiation damage. (The maximum centerline temperature was approximately $1650^{\circ} \mathrm{C}\left(3000^{\circ} \mathrm{F}\right)$ and was attained early in the period of operation.) The lattice parameter measurements are presented in Table 25.

A small difference in the lattice parameter between the center and the periphery was also noted. However, because of the confidence limits that must be placed on these measurements, the difference may not be significant. If significant, however, this change would indicate an average increase in the lattice parameter of approximately 0.04 percent from the center to the periphery of the fuel. This change, if attributed to an oxygen-metal ratio change based on the $\mathrm{UO}_{2}$ lattice parameter, would correspond to a difference of approximately 1.3 percent from the center to the periphery.

\subsection{FUEL BURNUP AND ISOTOPIC COMPOSITION ANALYSES \\ (C. P. Ruiz, Technical Director; J. P, Peterson, Jr., F. R. Smith)}

\subsubsection{Analysis of Fuel Samples}

\subsubsection{Procedure and Scope}

Full cross-section samples of fuel and cladding $1.3 \mathrm{~cm}(1 / 2 \mathrm{in.})$ long were cut from four rods that operated to the end of Dresden Reactor Cycle No. 4 and from 16 rods that operated to the end of Cycle No. 6 . Samples were taken 


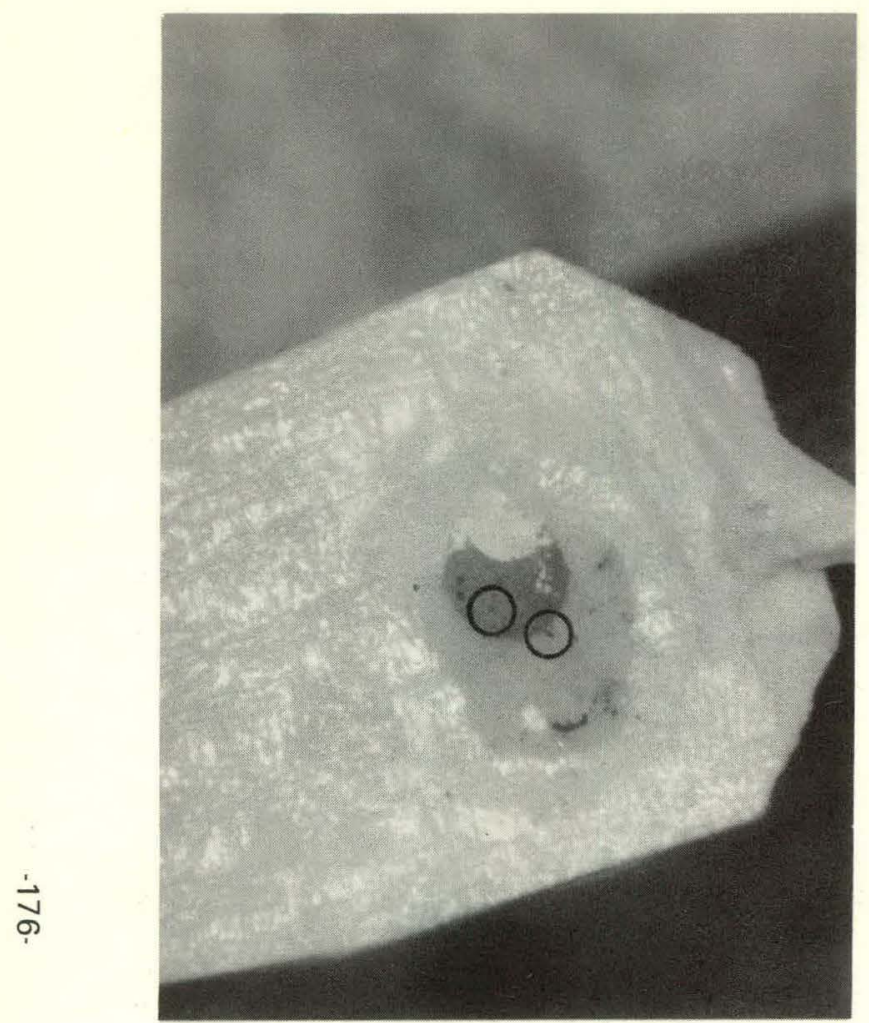

(a) CENTER OF FUEL PELLET

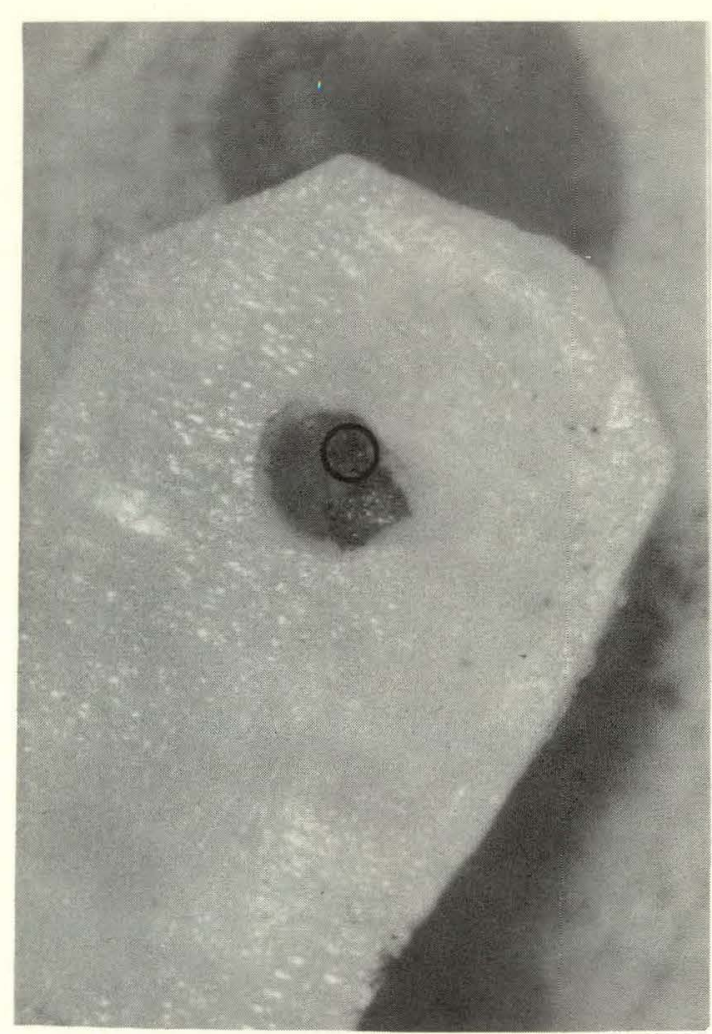

(b) MID-RADIUS APPROXIMATELY $3 \mathrm{~mm}$ $(\sim 0.1$ in.) FROM FUEL CENTER

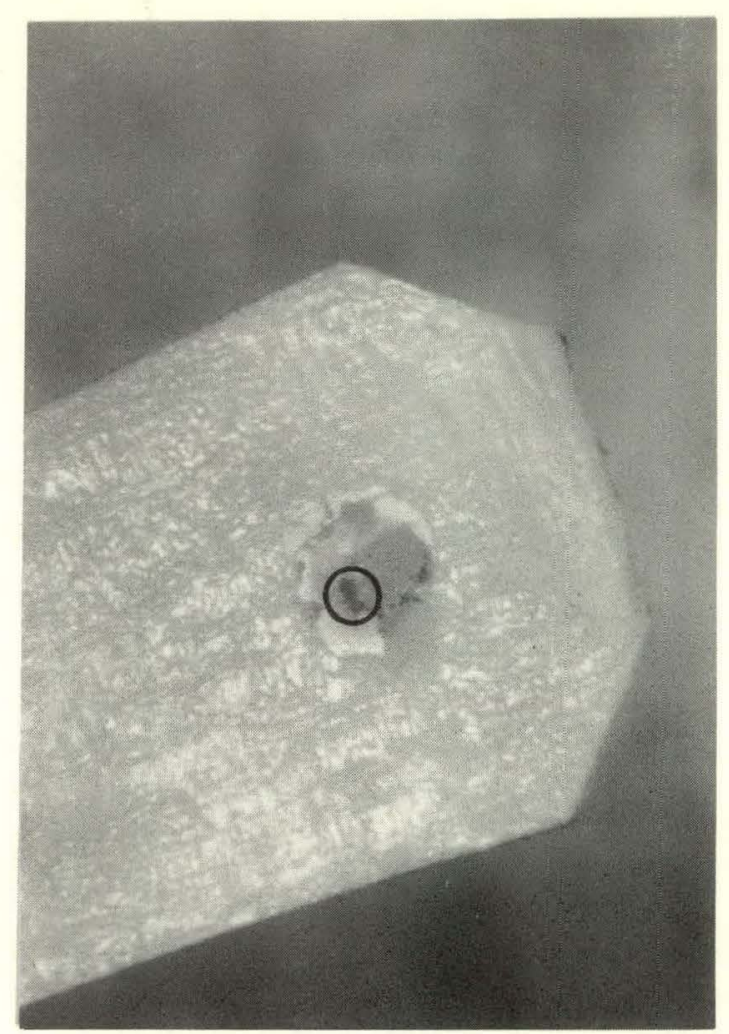

(c) PERIPHERY OF FUEL APPROXIMATELY $0.5 \mathrm{~mm}(\sim 0.02$ in.) FROM FUELCLADDING INTERFACE

PARTICLES WITHIN CIRCLES WERE USED FOR X-RAY DIFFRACTION ANALYSIS.

Figure 126. Technovit Replicas in Molds with Embedded $\mathrm{UO}_{2}$ Particles Extracted from Fuel Section A-584 
Table 25

LATTICE PARAMETER OF IRRADIATED $\mathrm{UO}_{2}$

\author{
Sample \\ Unirradiated Control \\ Specimen No. A584 \\ Center \\ Mid-Radius \\ Periphery
}

Average Increase
$a_{0}(\AA)$

Increase in

$a_{0}(\%)$

$5.470 \pm 0.001$

$5.475 \pm 0.001$

$5.475 \pm 0.002$

$5.477 \pm 0.001$

0.09

0.09

0.13

0.10

from rods located in both subassemblies; however, more samples were taken from the bottom subassembly (A-1) than from the top (B-1). Most of the samples were taken from locations of maximum burnup 25 to $30 \mathrm{~cm}$ (10 to $12 \mathrm{in}$.) from the short end plug shoulders. However, in the final phase of the program eight additional samples were taken from axial locations near the ends of the highest exposure " $A$ " rod and " $B$ " rod, primarily to monitor the reliability with which Cs-137 could be used to measure burnup under the operating conditions of this fuel. (Gamma scanning, which is discussed in the following section, was actually performed before the sample cutting to aid in selecting the samples.)

The fuel of each of the above samples was dissolved at ambient temperature in 8 molar nitric acid for a period in excess of 24 hours. A small sample was transferred from the hot cells to the Radiochemical Laboratory for analysis.

In addition to the full cross-section samples, sets of fuel samples were obtained in the initial phase of the program from the maximum burnup locations of two rods to determine burnup and isotopic composition as a function of radial location. The samples were removed by grinding one end of a $4.5-\mathrm{cm}(2-\mathrm{in}$.) rod length toward the center in steps as the piece was rotated. Ten samples were taken from each rod. Figure 127 shows the end of a rod length at the completion of sampling.

Mass spectrometry was employed to measure burnup by the $\mathrm{Nd}-148$ method and measure uranium and plutonium. ${ }^{12}$ These data provided the input to the computer program BURNUP. ${ }^{8}$ In addition to yielding the burnup and isotopic composition, the program yields the fraction of fissions from each of the four primary fissionable species, $\mathrm{U}-235, \mathrm{Pu}-239, \mathrm{Pu}-241$, and $\mathrm{U}-238$, and a set of effective cross sections consistent with the isotopic abundance measured with the burnup, and with the thermal neutron fluence, based on the $U-235$ depletion. As was discussed earlier, a fast fluence can be estimated from the U-238 fission fraction.

In addition to the uranium and plutonium isotopes usually measured, $\mathrm{Pu}-236, \mathrm{Pu}-238$, and the isotopic concentrations of americıum and curium were determined on selected samples from both the initial and final-phase rod groups. U-232 was measured on some samples from rods that operated to the end of Cycle No. 6; Np-237 and the fission products Cs-137, Cs-134, Ru-106, and Ce-144 were measured on most of the samples from rods that were removed from SA-1 at the end of Cycle No. 4.

The measurement of the U-232, Pu-236 and Pu-238, and the americium and curium were obtained by alpha particle spectroscopy by use of solid-state detectors, after suitable separations. For U-232 analysis this involved multiple passes through a Dowex-1 anion exchange column using both aqueous $\mathrm{HCl}$ and $\mathrm{HNO}_{3}$ media to selectively separate the uranium from plutonium, the most troublesome alpha active contaminant. After final purification, the uranium was electroplated onto platinum discs for alpha pulse-height analysis from which the U-232 was measured relative to the $\mathrm{U}-236$, which in turn was related to the $\mathrm{U}-238$ by means of the mass spectrometric analysis. The alpha particle spectra of the plutonium-fraction, available from the separation for mass spectrometric analysis, was the basis of the Pu-236 and Pu-238 data. The americium and curium were measured in the initial effluent from the aqueous $\mathrm{IINO}_{3}$ Duvvex-1 culuıIı fıum which the uranium and plutonıum had been separated by adsorption on the column.

The above procedure provided data on the abundances of Am-241, Am-243 and Cm-242, Cm-244. With some of the earlier samples anion exchange chromatography of the residual solutions was performed by use of methanolic $\mathrm{HNO}_{3}$ to separate the americium from the curium and from fission products. The abundances of $\mathrm{Am}-242 \mathrm{and} \mathrm{Cm}-243$, Cm-245, Cm-246 were then obtained by mass spectrometry. 

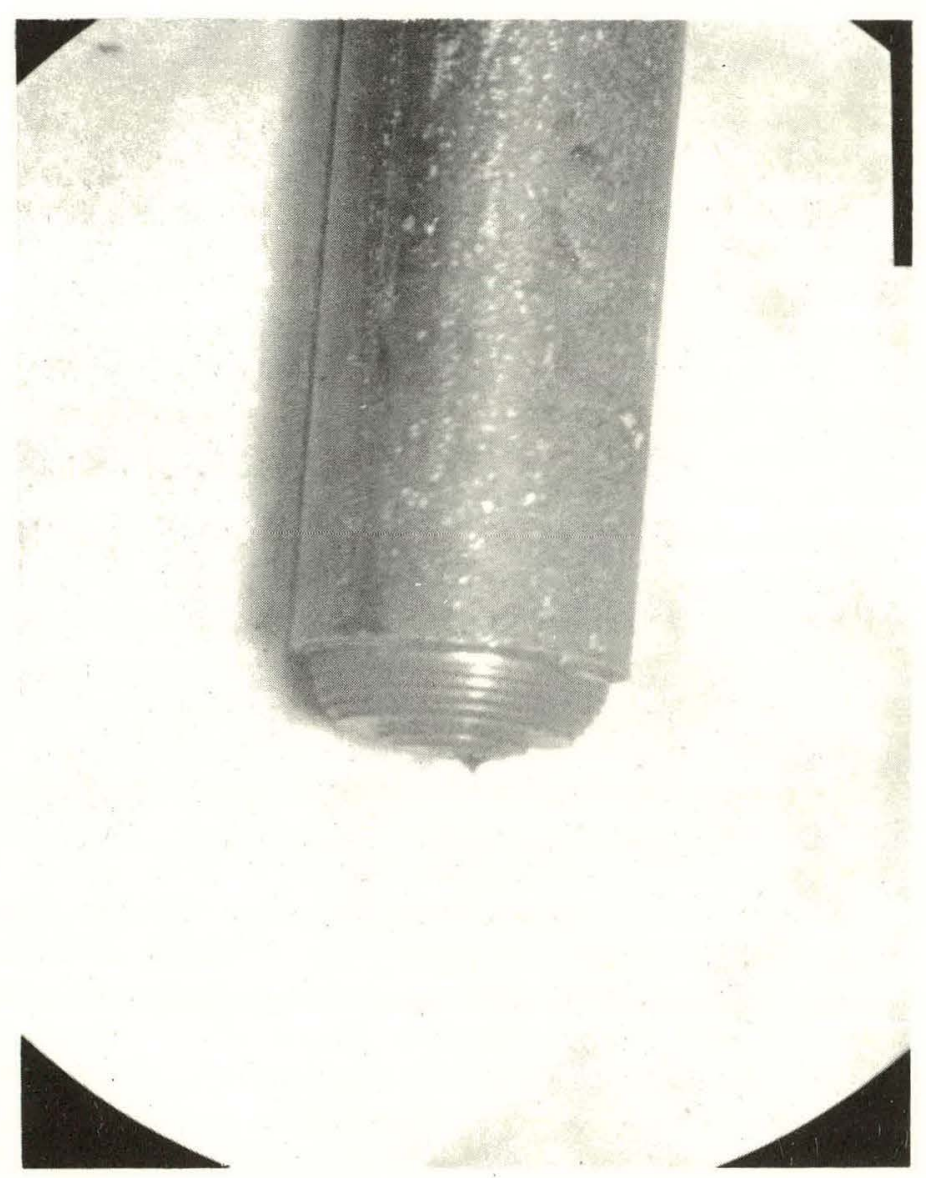

Figure 127. Appearance of Portion of Fuel Rod B70 After Samples Had Been Removed from Different Radial Locations 
The Np-237 was analyzed radiochemically. In brief, the procedure consisted of blending a measured volume of original sample solution with a known.amount of tracer $\mathrm{Np}-239$. Isotopic exchange was obtained by reduction to the tetravalent state in $\mathrm{HNO}_{3}$, and the neptunium was separated from the other heavy elements and fission products by anion exchange in a reducing media. The neptunium fraction was mounted and gross alpha counted. The fraction of alpha counts due only to neptunium was determined by pulse-height analysis, and the chemical yield determined by comparative gamma pulse-height analysis using the $106 \mathrm{keV}$ peak of $\mathrm{Np}-239$. These data, combined with a knowledge of the plutonium concentration, yielded the $\mathrm{Np}-237 / \mathrm{U}-238$ atom ratios.

\subsubsection{Results}

The results of the measurements made on full cross-section samples in both the initial and final phases of the program are given in Tables 26, 27, and 28. Table 26 gives the plutonium and uranium concentrations for the more abundant isotopes and the burnup based on the $\mathrm{Nd}-148$ method. The highest exposure was achieved by sample 116 from rod B62 for which a burnup of $10.4 \times 10^{20}$ fission $/ \mathrm{cm}^{3}(37,900 \mathrm{MWd} / \mathrm{tU})$ was measured. The axial locations of the 10 samples obtained from rods $A 37$ and $B 62$ are indicated with respect to the Dresden reactor active fuel zone in Figure 128. Single samples from other " $A$ " rods were obtained from axial locations approximately the same as that of sample 105 from rod $A 37$, and single samples from other " $B$ " rods were obtained from axial locations near that of sample 116 from rod $B 62$.

Table 27 gives the isotopic abundances of the less abundant isotopes of uranium and plutonium, as well as those of americium and curium for the nine samples analyzed. All the data have been corrected for growth or decay to the time of fuel discharge where appropriate. These data are useful in defining the magnitude of the various nuclides found in BWR fuel irradiated in these high neutron fluences. Based on these data and appropriate calculations, the effect of these low abundance nuclides can be determined with somewhat greater accuracy; for example, the effect of relatively high levels of U-232 on uranium handling. It is to be noted that in all cases, the specification limit of $110 \mathrm{ppb}$ of U-232 relative to U-235 for reenrichment is exceeded (not only by virtue of U-232 but also because of the low residual abun. dance of $\mathrm{U}-235) .^{13}$ The relatively high levels of $\mathrm{Pu}-236$ and $\mathrm{Pu}-238$ must be considered in working with plutonium separated from high exposure fuel. Finally, these measurements provide some data on the quantities of americium and curium available in high exposure fuel which are useful in defining more precisely the heavy element isotopic inventory, of interest in fuel cycle considerations.

The results of the fission product analyses performed on full cross-section samples are given in Table 28.

Fuel samples were taken from different radial positions from the maximum burnup locations of rods $A 13$ and B70, which had' cross-sectional average burnups of $8.1 \times 10^{20}$ fissions $/ \mathrm{cm}^{3}$ and $6.9 \times 10^{20}$ fissions $/ \mathrm{cm}^{3}, \mathrm{respectively}$. Presented in Tables 29 and 30 as functions of radial location are burnup, uranium and plutonium isotopic compositions, and the atom ratios relative to U-238 of Np-237, Pu-238, Am-241 and Am-243, Cm-242 and Cm-244, and the fission products $\mathrm{Nd}-148, \mathrm{Cs}-137$ and $\mathrm{Cs}-134, \mathrm{Ru}-106$, and $\mathrm{Ce}-144$. The marked radial dependence of burnup, of plutonium content, and of the concentrations of some other heavy elements and fission products can be noted.

The distributions of fissions among U-235, Pu-239, Pu-241, and U-238 are given for the various full cross-section and radial samples in Appendix D.

\subsubsection{Fuel Rod Gamma Scan Data}

\subsubsection{Procedure and Scope}

Axial traverses of gamma-ray activity were made on the 10 rods removed from Assembly SA-1 after two cycles of operation in Dresden and on 41 rods that operated through four cycles. The following procedure and system (Figure 129) were used in the final phase of the program. A $40 \mathrm{cc}$ detector was placed in front of a collimator slit which penctrated throught the $91-\mathrm{cm}(\overline{3} \overline{6}-\mathrm{in}$.$) hot cell wall. Thus, as the fuel rod was drawn past the appropriate end of the$ slit (located against the interior of the cell wall), the detector received a collimated gamma ray beam.

The pulses from the detectur were passed through a solid-state preamplifier, amplifier, and base line restorer. At this point, the pulses were routed to a 1024 multichannel analyzer and to two single-channel analyzers. One of the single-channel analyzers was set to accept pulses at the energy corresponding to gamma rays from a particular fission pivduci llucllele of Interest, while the other single-channel analyzer was set to accept pulses at a slightly higher energy for a measure of the Compton and background distribution. The output pulses from each of these analyzers were fed to scalers and also to two linear count rate meters, from which the signals were fed to a strip chart recorder, such that the backgrüund sigrial cuulit rate was subtracted from the total count rate to yield only a net count rate. 
Table 26

BURNUPS AND URANIUM AND PLUTONIUM ISOTOPIC COMPOSITIONS OF FULL CROSS SECTION SAMPLES

Rod $\quad \begin{array}{cc}\text { Nominal } \\ \text { Cold } \\ \text { Enrichment }\end{array} \quad \begin{gathered}\text { Distance } \\ \text { From Short } \\ \text { End Plug } \\ \text { Shoulder }\end{gathered}$

$\begin{array}{ll}\text { Enrichment } & \text { Shoulder } \\ \text { lat.\% U-235) } & \text { [cm (in.)] }\end{array}$

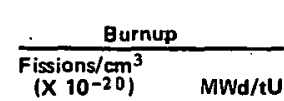

Atom Percent (Normalized to Total 100\%)

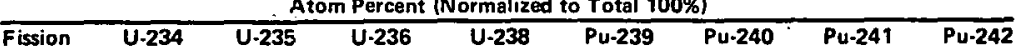

Initial Phase

A46,
B70.
A41
A13

$$
2.79
$$

$27.6(10-7 / 8)$ $26.4(10-3 / 8)$

$27.6(10-7 / 8)$

6.9
6.9
7.8
8.1

25,300

25,300

2.894

2.889

3.266

0.012 0.012

0.015

0.62

0.382 $0.736 \quad 0.48$

Final Phase

$\begin{array}{cc}\text { A35 } & 104 \\ \text { A43 } & 112 \\ \text { A42 } & 111 \\ \text { A47 } & 113 \\ \text { A48 } & 114 \\ \text { A49 } & 115 \\ 896 & 122 \\ 891 & 121 \\ \text { B98 } & 123 \\ \text { A34 } & 103 \\ \text { A33 } & 102 \\ \text { A40 } & 110 \\ \text { A9 } & 100 \\ \text { A11 } & 101 \\ \text { A37 } & 105 \\ & 106 \\ & 107 \\ & 108 \\ & 109 \\ \text { 862 } & 116 \\ & 117 \\ & 118 \\ & 119 \\ & 120\end{array}$

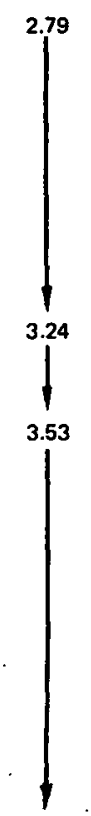

30,780
31,980
33,050
33,060
33,560
33,590
32,080
32,420
33,250
32,230
32,875
33,790
35,080
36,650
37,330
36,400
32,190
26,510
29,130
37,900
36,130
32,370
22,620
25,460
3.510

$\begin{array}{llll}3.510 & 0.010 & .0 .312 & .0 .395 \\ 3.655 & 0.012 & 0.450 & 0.454\end{array}$

\begin{tabular}{lllll}
3.850 & 0.010 & 0.243 & 0.405 \\
\hline
\end{tabular}

$\begin{array}{llll}3.768 & 0.009 & 0.260 & 0.402\end{array}$

$\begin{array}{llll}3.825 & 0.009 & 0.245 & 0.404\end{array}$

$\begin{array}{llll}3.828 & 0.009 & 0.212 & 0.408\end{array}$

$\begin{array}{llll}3.658 & 0.009 & 0.279 & 0.398\end{array}$

$\begin{array}{llll}3.696 & 0.009 & 0.272 & 0.415\end{array}$

$\begin{array}{llll}3.789 & 0.009 & 0.224 & 0.403\end{array}$

$\begin{array}{llll}.3 .789 & 0.009 & 0.224 & 0.403 \\ 3.683 & 0.011 & 0.431 & 0.459\end{array}$

$\begin{array}{llll}3.683 & 0.011 & 0.431 & 0.459\end{array}$

$3.760 \quad 0.013$

$\begin{array}{llll}3.850 & 0.009 & 0.230 & 0.403\end{array}$

$\begin{array}{llll}4.010 & 0.011 & 0.422 & 0.486\end{array}$

$\begin{array}{llll}4.188 & 0.012 & 0.373 & 0.500\end{array}$

$\begin{array}{llll}4.188 & 0.012 & 0.373 & 0.500 \\ 4.264 & 0.012 & 0.359 & 0.500\end{array}$

$\begin{array}{llll}4.264 & 0.012 & 0.359 & 0.500 \\ 4.160 & 0.012 & 0.301 & 0.497\end{array}$

$\begin{array}{llll}3.684 & 0.013 & 0.517 & 0.485\end{array}$

$\begin{array}{llll}3.040 & 0.013 & 0.859 & 0.445\end{array}$

$\begin{array}{llll}3.339 & 0.014 & 0.651 & 0.472\end{array}$

$\begin{array}{llll}3.339 & 0.014 & 0.651 & 0.472 \\ 4.328 & 0.011 & 0.365 & 0.505\end{array}$

$\begin{array}{llll}4.131 & 0.012 & 0.329 & 0.502\end{array}$

$\begin{array}{llll}3.704 & 0.013 & 0.532 & 0.479 \\ 2.596 & 0.015 & 1.118 & 0.403\end{array}$

$\begin{array}{llll}2.596 & 0.015 & 1.118 & 0.403 \\ 2.920 & 0.014 & 0.944 & 0.434\end{array}$ 
Tabie 27

ABUNDANCES OF U-232, Np-237, Pu-236, Pu-238, Am AND Cm ISOTOPES IN FULL CROSS SECTION FUeL SAMPLES

\begin{tabular}{|c|c|c|c|c|c|c|c|c|c|c|c|c|c|c|c|}
\hline \multirow{3}{*}{$\begin{array}{l}\text { Rod and } \\
\text { Sample } \\
\text { Numbers }\end{array}$} & \multirow{2}{*}{\multicolumn{2}{|c|}{ Burnup }} & \multicolumn{13}{|c|}{ Atom Ratios (Corrected to time of fuel discharge) } \\
\hline & & & U.232 & U-232 & p-237 & Pu-236 & Pu-238 & Am-241 & Am-242 & Am-243 & $\mathrm{Cm}_{\mathrm{m}-242}$ & $C_{m-243}$ & $\mathrm{Cm} \cdot \mathbf{2 4 4}$ & $\mathrm{Cm}_{\mathrm{m}-245}$ & Cm-246 \\
\hline & $\begin{array}{c}\text { Fissions/cm } \\
\left(\times 10^{-20}\right)\end{array}$ & $\overline{M W d / t U}$ & $\begin{array}{c}\overline{U-238} \\
\left(X 10^{9}\right)\end{array}$ & $\begin{array}{l}\overline{U .2 .35} \\
\text { (pph) }\end{array}$ & $\begin{array}{c}\overline{U-238} \\
\left(\times 10^{4}\right)\end{array}$ & $\begin{array}{c}\overline{U .238} \\
\left(\times 10^{10}\right)\end{array}$ & $\begin{array}{c}\overline{U .238} \\
\left(X 10^{4}\right)\end{array}$ & $\begin{array}{l}\overline{U .238} \\
\left(x 10^{5}\right)\end{array}$ & $\begin{array}{l}-238 \\
\left(X 10^{7}\right)\end{array}$ & $\begin{array}{c}\overline{U .238} \\
\left(X 10^{5}\right)\end{array}$ & $\begin{array}{l}0.238 \\
\left(\times 10^{5}\right)\end{array}$ & $\begin{array}{c}U .238 \\
\left(\times 10^{7}\right)\end{array}$ & $\begin{array}{l}U .238 \\
\left(\times 10^{5}\right)\end{array}$ & $\begin{array}{l}U-238 \\
\left(\times 10^{7}\right)\end{array}$ & $\begin{array}{l}U .238 \\
\left(\times 10^{8}\right)\end{array}$ \\
\hline
\end{tabular}

\begin{tabular}{|c|c|c|c|c|c|c|c|c|c|c|c|c|c|c|}
\hline A46.69 & 6.9 & 25,300 & $N_{A}^{N A}$ & $N A$ & NA & 3.8 & 0.87 & 2.7 & 4.4 & 4.8 & 1.11 & 2.33 & 0.93 & 2.81 \\
\hline $870-70$ & 6.9 & 25,300 & & & 2.8 & 2.5 & 0.70 & 3.2 & 3.9 & 4.1 & 1.17 & 2.27 & 1.01 & 3.35 \\
\hline A $41-68$ & 7.8 & 28,500 & & & 3.4 & 5.5 & 1.06 & 5.5 & 5.3 & 5.6 & 1.52 & 3.32 & 1.48 & 5.59 \\
\hline A1367 & 8.1 & 29,700 & & & 3.4 & 4.9 & 1.14 & 6.5 & NA & NA & 1.58 & NA & 1.62 & NA \\
\hline
\end{tabular}

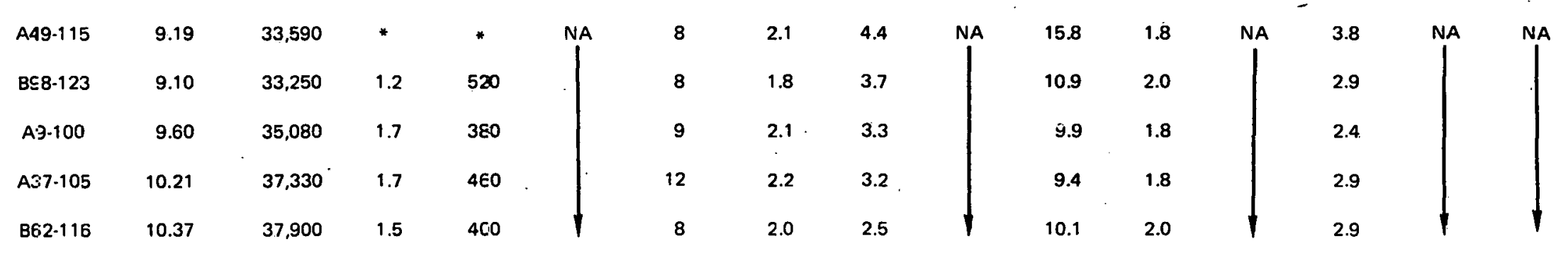

NOTES:

NA $=$ No: Analyzed.

Nominal nitial uran um enrichments were 2.79 at.\% for rods $A 46, B 70, A 49$, and $B 98$

and 3.53 at.\% for rods $A 41, A 13, A 9, A 37$, and $B 62$.

These data for sample 115 appeared to be un:easonably high and, hence are not reported. 
GEAP-10371

Table 28

FISSION PRODUCT ANALYSES ON FULL CROSS SECTION FUEL SAMPLES

\begin{tabular}{|c|c|c|c|c|c|c|c|}
\hline \multirow{3}{*}{$\begin{array}{l}\text { Rod and } \\
\text { Sample } \\
\text { Numbers }\end{array}$} & & & \multicolumn{5}{|c|}{ Atom Ratios Relative to U-238* } \\
\hline & \multicolumn{2}{|c|}{ Burnup } & \multirow{2}{*}{$\begin{array}{l}\frac{N d-148}{U-238} \\
\left(X \quad 10^{3}\right)\end{array}$} & \multirow{2}{*}{$\begin{array}{l}\frac{\text { Cs-137 }}{U-238} \\
\left(\times 10^{3}\right)\end{array}$} & \multirow{2}{*}{$\begin{array}{l}\frac{C s-134}{U \cdot 238} \\
\left(\times 10^{3}\right)\end{array}$} & \multirow{2}{*}{$\begin{array}{l}\frac{R u \cdot 106}{U-238} \\
\left(\times 10^{3}\right)\end{array}$} & \multirow{2}{*}{$\begin{array}{l}\frac{C e-144}{U-238} \\
\left(X 10^{3}\right)\end{array}$} \\
\hline & $\begin{array}{c}\text { Fissions } / \mathrm{cm}^{3} \\
\left(\times 10^{-20}\right)\end{array}$ & $M W d / t U$ & & & & & \\
\hline A46-69 & 6.9 & 25,300 & 0.522 & 1.9 & 0.13 & 0.17 & 0.31 \\
\hline 870-70 & 6.9 & 25,300 & 0.507 & 1.7 & 0.12 & 0.14 & 0.34 \\
\hline A41-68 & 7.8 & 28,500 & 0.573 & 2.3 & 0.16 & 0.15 & 0.42 \\
\hline A13-67 & 8.1 & 29,700 & 0.606 & 2.4 & 0.18 & 0.16 & 0.41 \\
\hline
\end{tabular}

"Corrected to time of fuel discharge.

The energy region for the single-channel analyzer was set by operating the multichannel analyzer in the coincidence mode. The gating signal was supplied from a given single-channel analyzer. The width of the energy region was set to accept the total photopeak for the signal. A corresponding number of channels was set for the background single-channel analyzer.

A typical gamma-ray spectrum is shown in Figure 130. Of primary interest was Cs-137 to provide relative burnup data. Data were obtained on all 41 rods scanned by using the signal at $0.662 \mathrm{MeV}$ with the background region set at $0.680 \mathrm{MeV}$. To obtain some information on the relative amounts of Pu-239 fission some of the rods were scanned for Ru-106, which by virtue of its fission yield shows a $\sim 10$-fold enhancement over that for U-235 fission. In addition; data were obtained for Ce-144 (285 days half-life) and Zr-95 (65 days half-life) to provide data on more recent relative rod burnups. For the $\mathrm{Ru}-106, \mathrm{Ce}-144$, and $\mathrm{Zr}-95$, the signal gating regions were $0.515,2.19(\mathrm{Pr}-144)$, and $0.765 \mathrm{MeV}$ $(\mathrm{Zr}+\mathrm{Nb}-95)$ with the background gating regions set at $0.530,2.30$, and $0.820 \mathrm{MeV}$, respectively.

In the scanning, the rods from both subassemblies were oriented axially as they had operated in Dresden so that the relative gamma activity could be recorded as a function of increasing distance from the bottom of the active fuel zone of that reactor. The rods were pulled past the slit at $6.4 \mathrm{~cm}(2-1 / 2 \mathrm{in.})$ per minute; the speed of the recorder was $1.3 \mathrm{~cm}(1 / 2 \mathrm{in.})$ per minute. The linear count rate meters had a time constant of two seconds. The number of pulses passed by each single-channel analyzer was accumulated by a scaler for the whole axial traverse. The difference in the scaler counts thus vielded the integral count rate for the data obtained on the chart recorder.

For the Ru-106, Cs-137, and Zr-95, a $0.157 \cdot \mathrm{cm}(0.062-\mathrm{in}$.) collimator slit-height was used. Because of the relatively weak intensity of the high energy Pr-144 line, the slit was opened to $0.64 \mathrm{~cm}(0.25$ in.). To limit the count rate to $5 \times 10^{4} \mathrm{cps}$, a $0.64-\mathrm{cm}$ lead filter was used with $0.102-\mathrm{cm}(0.040-\mathrm{in}$.$) cadmium interposed between the lead and$ the detector. The width of the slits used in both cases was $1.90 \mathrm{~cm}(0.75 \mathrm{in}$.$) .$

To obtain data on the reproducibility of the scans, rod A37 was selected as a standard rod which was scanned at least once a day throughout the scan period. In general, the reproducibility was within 3 percent.

In the initial phase of the program Cs-137 was the only fission product nuclide measured individually. A 4-cc $\mathrm{Ge}(\mathrm{L} i)$ detector was used in conjunction with a 256-channel analyzer. A Nal(TI) detector system, shown schematically in Figure 129, provided a gross gamma scan simultaneously. In the scanning, all 10 rods were oriented axially as they had operated in the VBWR, rather than in Dresden, with the net result that the traces of " $A$ " rods made in the initial phase are reversed with respect to the traces of " $A$ " rods made in the final phase. 
Table 29

ANALYSES OF FUEL SAMPLES FROM DIFFERENT RADIAL LOCATIONS, FUEL ROD A13

Distance

From

Sample Periphery

Number $\mathrm{cm}$ (inch).

$82 \quad 0.000-0.005$ (0.000-0.002)

$83 \div 0.005-0.010$ (0.002-0.004)

$84 \quad 0.010-0.018$ (0.004.0.007)

$85: 0.018-0.025$ $(0.007-0.010)$

$86 \cdot 0.025-0.038$ $(0.010-0.015)$

$87 \quad 0.038-0.051$ (0.015-0.020)

$88 \quad 0.051-0.076$ (0.020-0.030)

$89 \quad 0.076-0.127$ $(0.030 .050)$

$0.127 \cdot 0.254$ (0.050-0:100)

91 "0.254-center" Notes:

$N A=$ not analyzed

Nominal Initial uranium enrichment for rod A13 was 3.53 atom $\%$.

*Nominal pellet radius $=0.478 \mathrm{~cm}(0.188 \mathrm{inch})$

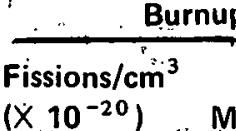

$9.1 \quad 33,400$

$8.6 \quad 31,600$

8.3

30,400

$3.49 \quad 0.019$

7.8

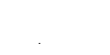

8

7.9

28,800

3.3

\section{Atom Ratios Relative to ${ }^{238} \mathrm{U}$ (Corrected to time of fuel discharge)} \begin{tabular}{l} 
Fissions/cm ${ }^{3}$ \\
$\left(X 10^{-20}\right)$ \\
\hline
\end{tabular}

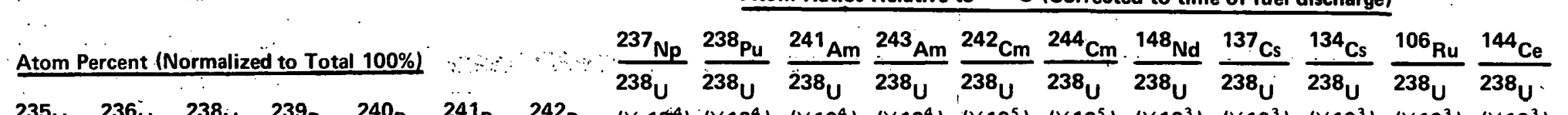
$\begin{array}{llllllllllllllllllllll}11.6 & 42,500 & 4.84 & .0 .015 & 0.728 & 0.453 & 92.577 & 0.742 & 0.362 & 0.187 & 0.097 & 5.4 & 1.59 & 0.88 & \text { NA } & 3.00 & 3.33 & 0.850 & 3.1 & 0.23 & 0.60 & 0.46\end{array}$ $\begin{array}{llllllllllllllllllllllll}10.6 & 38,600 & 4.39 & 0.015 & 0.716 & 0.454 & 93.314 & 0.598 & 0.293 & 0.147 & 0.074 & 4.5 & 1.39 & \text { NA } & 2.0 & 2.75 & 3.26 & 0.780 & 3.2 & 0.17 & 0.46 & 0.42\end{array}$

$\begin{array}{lllllllllllllllllllllll}9.2 & 33,700 & 3.85 & 0.013 & 0.720 & 0.467 & 94.097 & 0.461 & 0.228 & 0.110 & 0.055 & 4.3 & 1.26 & 0.74 & 1.1 & 1.93 & 1.89 & 0.681 & 2.7 & 0.20 & 0.27 & 0.40\end{array}$

$\begin{array}{llllllllllll}3.83 & 0.015 & 0.726 & 0.465 & 94.274 & 0.372 & 0.189 & 0.086 & 0.042 & 3.9 & 1.16 & 0.80\end{array}$

$\begin{array}{llllllllll}3.61 & 0.015 & 0.737 & 0.459 & 94.488 & 0.369 & 0.189 & 0.092 & 0.041 & 40\end{array}$

$\begin{array}{ll}1.29 & 0.52\end{array}$

$1.0 \quad 1.74 \quad 1.83$

$0.742 \quad 0.45$

95394

$0.346 \quad 0$

$\begin{array}{lll}0.076 & 0.036 & 3.9\end{array}$

$1.18 \quad 0.58$

0.5

$41 \quad 1.4$

$\begin{array}{lllllll}0.656 & 2.4 & 0.18 & 0.13 & 0.38\end{array}$

$\begin{array}{llllllllll}3.27 & 0.015 & 0.758 & 0.456 & 94.925 & 0.312 & 0.166 & 0.066 & 0.031 & 3.5\end{array}$

$0.92 \quad 0.40$

0.4

1.25

$\begin{array}{lllll}0.640 & 2.3 & 0.17 & 0.13 & 0.33\end{array}$

$\begin{array}{llllllllll}3.17 & 0.015 & 0.758 & 0.454 & 95.043 & 0.301 & 0.161 & 0.065 & 0.031 & 3.6\end{array}$

$1.02 \quad 0.32$

$0.5 \quad 1.10$

$\begin{array}{llllllllll}3.42 & 0.015 & 0.771 & 0.443 & 94.757 & 0.321 & 0.173 & 0.068 & 0.031 & 3.5\end{array}$

$\begin{array}{llllllllll}0.015 & 0.842 & 0.443 & 94.796 & 0.329 & 0.179 & 0.066 & 0.030 & 3.2\end{array}$

$1.14 \quad 0.58$

$\begin{array}{llllllll}0.5 & 1.16 & 1.07 & 0.555 & 1.5 & 0.11 & 0.11 & 0.23\end{array}$

$\begin{array}{llllllll}0.5 & 1.3 & 1.1 & 0.593 & 1.5 & 0.13 & 0.15 & 0.28\end{array}$

$\begin{array}{llllllll}0.6 & 0.98 & 1.00 & 0.566 & 1.8 & 0.11 & 0.17 & 0.35\end{array}$ 
Table 30

ANALYSES OF FUEL SAMPLES FROM DIFFERENT RADIAL LOCATIONS, FUEL ROD B7O

\begin{tabular}{|c|c|c|c|c|c|c|c|c|c|c|c|c|c|c|c|c|c|c|c|c|c|c|c|}
\hline \multirow[b]{3}{*}{$\begin{array}{l}\text { Sample } \\
\text { Number } \\
\end{array}$} & \multirow{3}{*}{$\begin{array}{c}\text { Distance } \\
\text { From } \\
\text { Pellet } \\
\text { Periphery } \\
{[\mathrm{cm}(\text { inch)] }}\end{array}$} & & \multicolumn{8}{|c|}{ Atom Ratios Relative to ${ }^{238} \mathrm{U}$ (Corrected to time of fuel discharge) } & \multirow{3}{*}{$\frac{106}{238_{u}}$} & \multirow{3}{*}{$\begin{array}{l}\frac{144}{C e} \\
\frac{238_{U}}{\left(\times 10^{3}\right)} \\
\end{array}$} \\
\hline & & Bur & nup & & & Atom D & ercent 1 & I rmalizo & C to Tn & 100-Por & rcentl & & ${ }^{237}{ }_{\mathrm{Np}}$ & $238 \mathrm{Pu}$ & & & ${ }^{242} \mathrm{Cm}$ & ${ }^{244} \mathrm{Cm}$ & ${ }_{\mathrm{Nd}}^{148}$ & ${ }^{137}$ cs & ${ }^{134} \mathrm{cs}$ & & \\
\hline & & $\begin{array}{l}\text { Fissions/cm }{ }^{3} . \\
\left(\times 10^{-20}\right) \\
\end{array}$ & $\mathrm{MWd} / \mathrm{tU}$ & Fission & ${ }^{234} \mathrm{U}$ & ${ }^{235} \mathrm{U}$ & $236 \mathrm{u}$ & $\underline{238} \mathrm{U}$ & ${ }^{239} \mathrm{P}_{\mathrm{Pu}}$ & ${ }^{240} \mathrm{Pu}_{\mathrm{Pu}}$ & ${ }^{241} \mathrm{Pu}$ & ${ }^{242} \mathrm{Pu}$ & $\begin{array}{l}238 \mathrm{U} \\
\times\left(\times 10^{4}\right) \\
\end{array}$ & $\begin{array}{l}238 \mathrm{U} \\
\left(\times 10^{4}\right) \\
\end{array}$ & $\begin{array}{l}238 \mathrm{U} \\
\left(\times 10^{4}\right) \\
\end{array}$ & $\begin{array}{l}238 \mathrm{U} \\
\left(\times 10^{4}\right) \\
\end{array}$ & $\begin{array}{l}238 u \\
\left(\times 10^{5}\right) \\
\end{array}$ & $\begin{array}{l}238 u \\
\left(x 10^{5}\right) \\
\end{array}$ & $\begin{array}{l}238 \mathrm{U} \\
\left(\underline{x} 10^{3}\right) \\
\end{array}$ & $\begin{array}{l}238, \underline{u} \\
\left(x 10^{3}\right) \\
\end{array}$ & $\begin{array}{l}238 \mathrm{u} \\
\left(\times 10^{3}\right) \\
\end{array}$ & & \\
\hline 93 & $\begin{array}{c}0.000-0.005 \\
(0.000-0.002)\end{array}$ & 10.2 & 37,400 & 4.25 & 0.010 & 0.724 & 0.342 & 93.234 & 0.770 & 0.373 & 0.198 & 0.099 & NA & 1.68 & 0.76 & 0.6 & 2.92 & 3.34 & 0.763 & 3.1 & 0.24 & 0.28 & 0.54 \\
\hline 94 & $\begin{array}{c}0.005-0.010 \\
(0.002-0.004)\end{array}$ & 9.1 & 33,300 & 3.79 & 0.012 & 0.569 & 0.375 & 94.082 & 0.634 & 0.305 & 0.158 & 0.074 & 4.5 & 1.26 & 0.67 & 0.5 & 2.47 & 2.28 & 0.691 & 2.7 & 0.19 & 0.33 & 0.45 \\
\hline 95 & $\begin{array}{c}0.010-0.018 \\
(0.004-0.007)\end{array}$ & 7.8 & 28,600 & 3.25 & 0.012 & 0.572 & 0.375 & 94.962 & 0.450 & 0.219 & 0.107 & 0.051 & 3.1 & 1.01 & 0.46 & 0.3 & 1.46 & 1.44 & 0.593 & 2.1 & 0.15 & 0.21 & 0.37 \\
\hline 96 & $\begin{array}{c}0.018-0.025 \\
(0.007-0.010)\end{array}$ & 7.1 & 25,900 & 2.96 & 0.012 & 0.572 & 0.371 & 95.348 & 0.397 & 0.199 & 0.093 & 0.048 & 3.6 & 1.08 & 0.35 & .0 .5 & .1 .25 . & 1.26 & 0.543 & 2.1 & 0.15 & 0.18 & 0.34 \\
\hline 97 & $\begin{array}{c}0.025-0.038 \\
(0.010-0.015)\end{array}$ & 6.9 & 25,100 & 2.87 & 0.012 & 0.574 & 0.361 & 95.519 & 0.360 & 0.181 & 0.083 & 0.039 & 2.8 & 1,01 & 0.33 & 0.3 & 1.15 & 1.14 & 0.511 & 2.1 & 0.15 & 0.26 & 0.35 \\
\hline 98 & $\begin{array}{c}0.038-0.051 \\
(0.015-0.020)\end{array}$ & 6.5 & 23,900 & 2.74 & 0.012 & 0.593 & 0.369 & 95.718 & 0.307 & 0.158 & 0.070 & 0.033 & NA & 0.95 & NA & 0.2 & 1.04 & 0.73 & 0.487 & 1.7 & 0.14 & 0.14 & 0.28 \\
\hline 99 & $\begin{array}{c}0.051-0.076 \\
(0.020-0.030)\end{array}$ & 6.8 & 25,000 & 2.86 & 0.012 & 0.597 & 0.367 & 95.598 & 0.310 & 0.160 & 0.066 & 0.031 & 3.4 & 0.96 & 0.16 & 0.2 & 1.12 & 0.88 & 0.513 & 1.9 & 0.14 & 0.13 & 0.30 \\
\hline 100 & $\begin{array}{c}0.076-0.127 \\
(0.030-0.050)\end{array}$ & 6.8 & 24,900 & 2.85 & 0.012 & 0.607 & 0.361 & 95.513 & 0.355 & 0.188 & 0.075 & 0.038 & 3.3 & $1: 01$ & 0.18 & 0.2 & 0.92 & 0.81 & 0.464 & 2.0 & 0.14 & 0.15 . & 0.32 \\
\hline 101 & $\begin{array}{c}0.127-0.254 \\
(0.050-0.100)\end{array}$ & 6.7 & 24,400 & 2.79 & 0.012 & 0.621 & 0.360 & 95.625 & 0.322 & 0.173 & 0.066 & 0.031 & 3.1 & 0,88 & 0.28 & 0.2 & 0.89 & 0.84 & 0.073 & 2.0 & 0.14 & 0.28 & 0.33 \\
\hline 102 & $\begin{array}{l}\text { 0.254-center* } \\
\text { (0.100-center) }\end{array}$ & 6.2 & 22,600 & 2.59 & 0.012 & 0.636 & 0.364 & 95.834 & 0.306 & 0.166 & 0.063 & 0.029 & 2.4 & $0: 79$ & 0.20 & 0.2 & 0.77 & 0.68 & 0.458 & 1.5 & 0.11 & 0.12 & 0.25 \\
\hline
\end{tabular}




\section{4}

$29.4 \pm 5.1 \mathrm{~cm} \mathrm{(11-9/16 \pm 2} \mathrm{in.)}$ FUEL ZONE
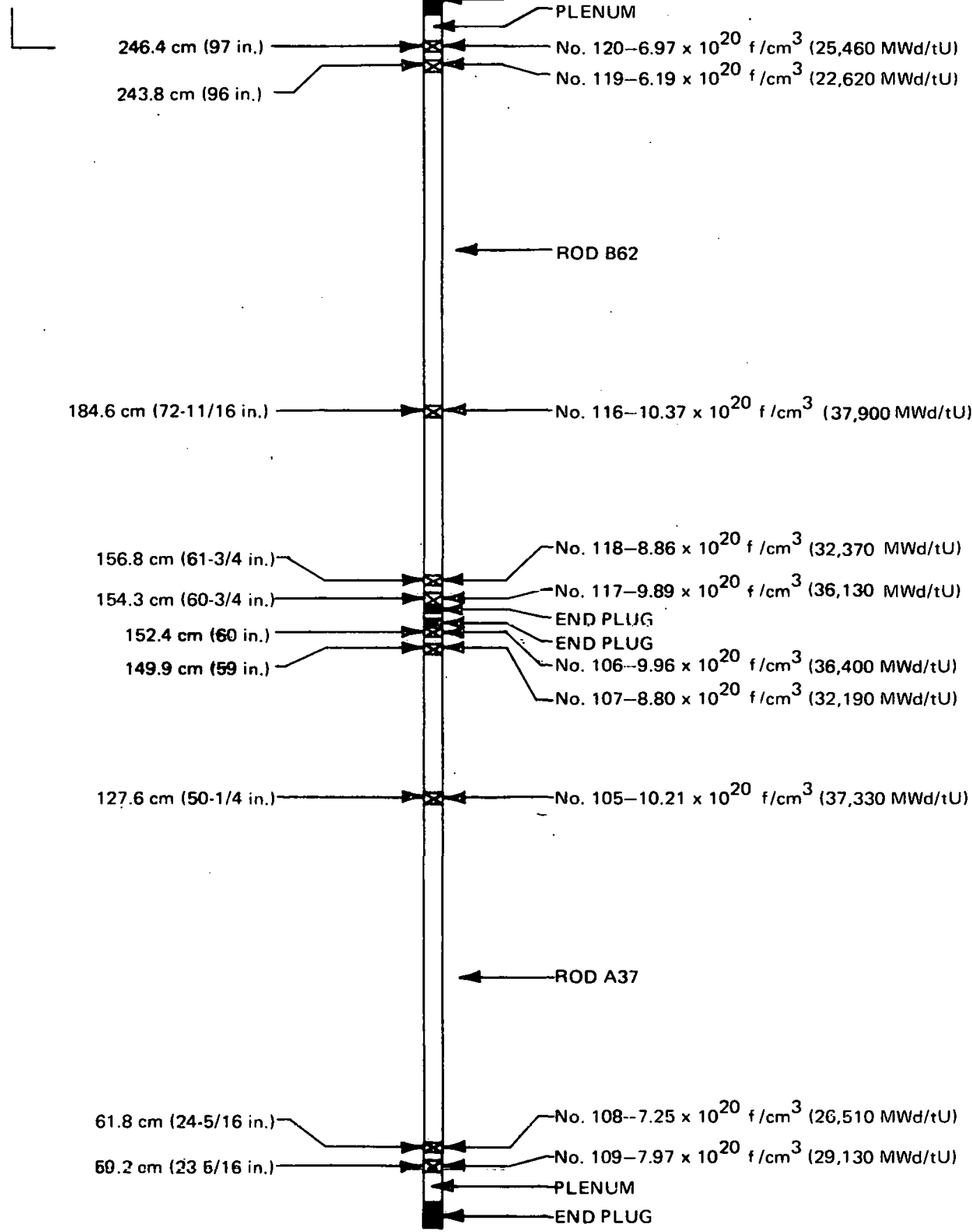

Figure 128. Locations of Burnup and Isotopic Composition Samples from Rods A37 and B62 in Terms of Distance from the Bottom of the Reactor Active Fuel Zone 


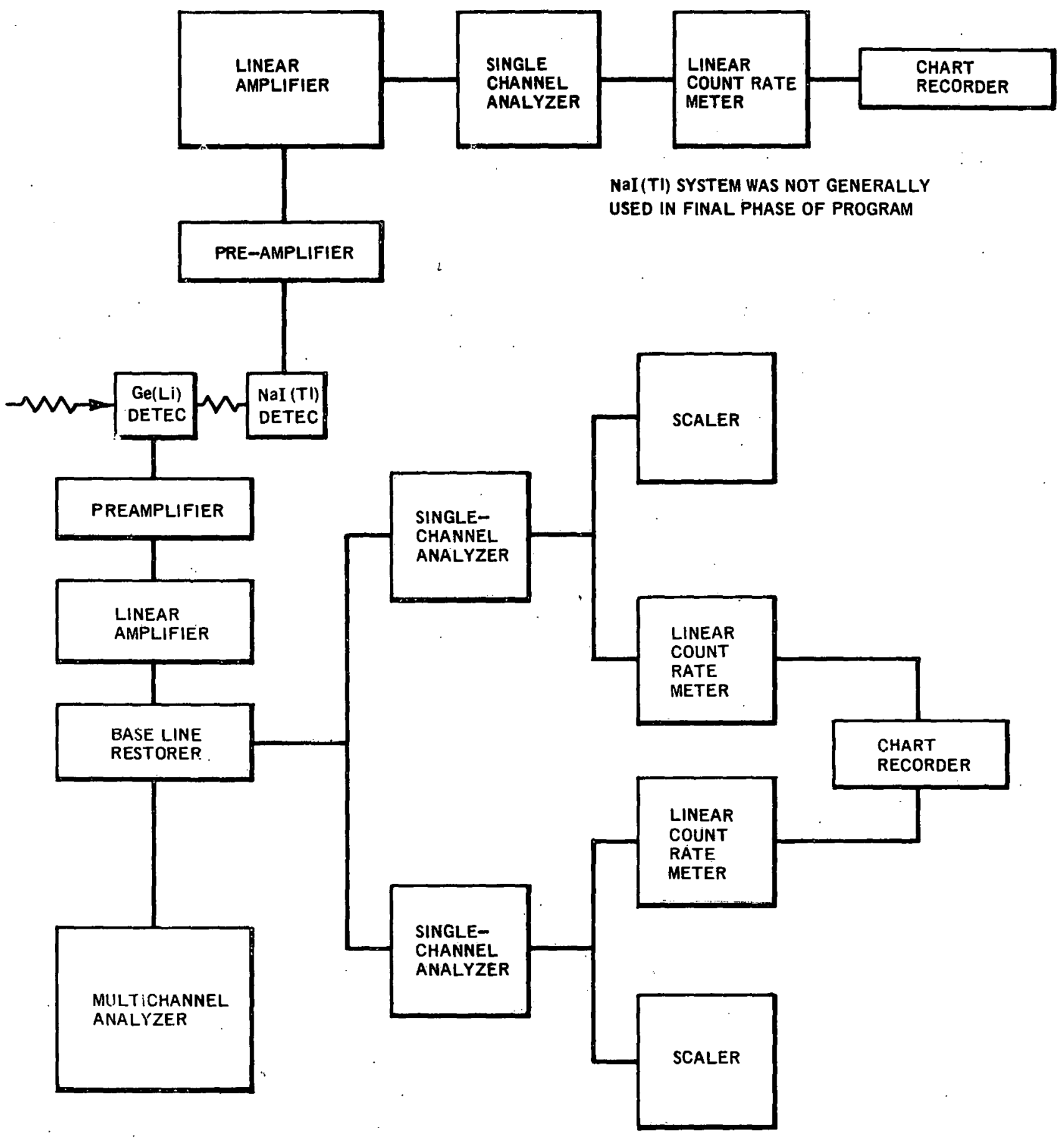

Figure 129. Schematic Drawing of Ge(Li) and Nal(TI) Gamma Scanning Systems 
$10^{5}$

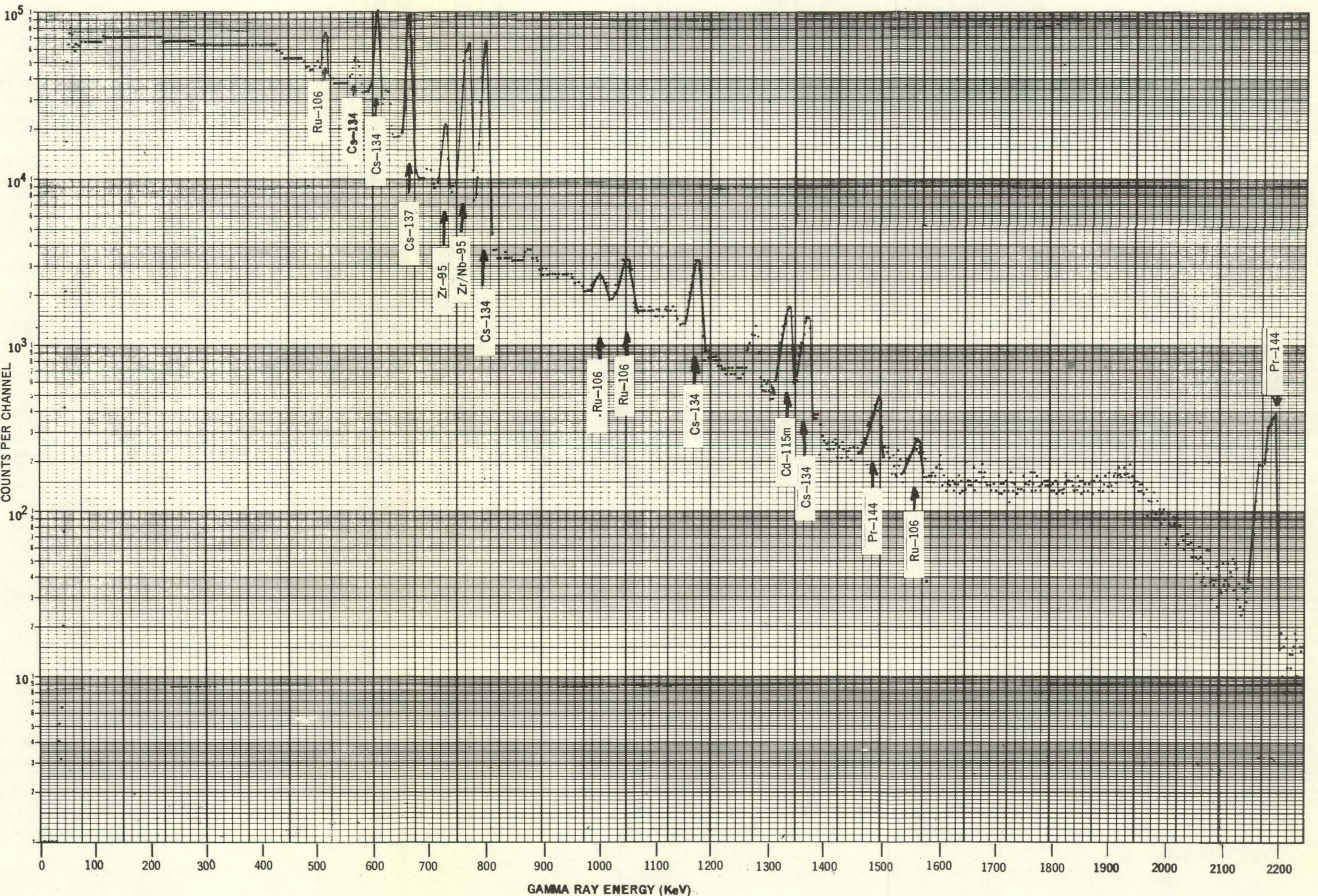




\subsubsection{Results}

Gross gamma scan traces of an " $A$ " rod and a " $B$ " rod that were removed from SA-1 at the end of Cycle No. 4 and of rod A37, which operated to the end of Cycle No. 6, are shown in Figures 131 through 133. Gamma scan traces for Cs-137 are shown in Figures 134 through 136 for rods representative of those that operated to the end of Cycle No. 6. Table 31 gives the ratios of peak-to-average gamma activity along the length of each rod scanned, based on gross activity with the initial phase rods and on Cs-137 with the final phase rods. It is seen that the values are slightly higher for the top subassembly than for the bottom subassembly. The ratios are relatively lower, in general, for the final phase rods of both subassemblies. The average burnups for those rods from which burnup samples were obtained were determined by applying the gross or Cs-137 gamma scan data to the sample burnup, determined from neodymium. The integral Cs-137 data provided relative burnup values on the remaining rods that had been scanned, so that by comparing these relative values with the burnup of one rod selected as a standard, rod-average and peak burnup values could be determined for all scanned rods. These burnup values are listed in Section 4 (Table 2).

The adequacy of gamma scan data in providing information on relative burnup is indicated by a comparison of the relative burnup values based on Cs-137 obtained from fuel rod scanning with the values obtained by use of the Nd-148 method. The comparison as presented in Figures 134, 135, 137, and 138 where the Cs-137 values given are those measured at the same axial position as the samples taken tor burnup analysis by the INd-148 method. All data have been normalized to sample 105, which was obtained from the maximum flux position of rod A37. Slight corrections of the Cs-137 data have been made to allow for the differences in fission yield from the contributing tissionable species.

The data show that under these irradiation conditions, and the exceptionally long exposure period, the relative Cs-137 intensities are in good agreement with the burnups based on the $\mathrm{Nd}-148$ method. This is true not only at the more central locations for each rod, given in Figures 137 and 138, but also at the various axial positions measured, which include the end points of the fuel columns (Figures 134 and 135). Thus axial redistribution of the Cs-137 under the irradiation conditions of this fuel is not significant. Therefore, Cs-137 is an adequate burnup monitor for use in gamma scanning in spite of the fact that radial migration has undoubtedly occurred. (Compare radial distributions of Cs-137 and $\mathrm{Nd}-148$ in samples of Tables 29 and 30.)

Gamma scan traces for each of the three remaining fission products investigated are shown for rods A37 and B86 in Figures 139 through 144. It is seen that significant differences appear on comparisons of the traces obtained from the four fission products. The traces for Zr-95 show the axial rod power distribution during the last period of exposure by virtue of its 65-day half-life. Apparent differences between the count rates of the $A$ and $B$ rods shown by the tour sets of traces are not significant because of source detector geometry changes. The slight depressions seen in the traces are due to the spacers. In the final phase of the program all data were ohtained using A37 as a standard rod; hence, this rod was used for normalization. The integrals of the conınt rate curves for all rods in which gamma scan measurements were made are given in Figures 145 and 146. Although trends are somewhat perturhed hy the varying enrichments and rod vacancies within the subassemblies, the relative burnup (based on Cs-137) is still seen to correlate with the enrichment and position of the rods within the bundles. A somewhat different pattern emerges based on the other fission products, which can be interpreted qualitatively in the same way as previously described with regard to the axial traces. The error in each of the values is estimated to be $\pm 2 \%(1 \sigma)$. The reason for the relatively low value for the Ru 106 and high value of Ce 111 for rod $A-17$ is not understood.

Since Ru-106 has a fission yield for plutonium which is about 10 times higher than that for U-235, the possibility exists of using this information, which can be obtained in gamma scanning to measure the plutonium fission rate relative to that of uranium. ${ }^{14,15}$ Since Ru-106 has a 1 -year half-life, the Pu-239, Pu-241 fission rate is being monitored during only the later stages of exposure for this fuel, which has a relatively long irradiation history. Since Ce-144 has a comparable half-life, i.e., 285 days, and a fission yield which is roughly the same for the four principal fissioning species, the ratio of Ru-106 to Ce-144 activity is proportional to the ratio of fissions due to Pu-239, Pu-241 to the total fissions during the same exposure period. The gamma scan data obtained for Ru-106 and for Ce-144 and their ratio at the five burnup sample locations for rod $\mathrm{A}-37$ are given in Figure 147. For comparison, the fission ratio of $\mathrm{Pu} /(\mathrm{U}+\mathrm{Pu})$ was estimated from the measured isotopic data of Table 26 utilizing the fission cross sections obtained from the program BURNIJP and by making the simplifying assımptinn that the isntopic distribution was invariant over the exposure period monitored by the two fission products. All the data have been normalized to the highest exposure location. It is seen in this crude comparison, the fission product ratio is responsive to the ratio of plutonium-to-total fission in this very high exposure fuel. Thus, gamma scan data have the potential for yielding this type of information but, obviously, further work is required to refine the data analysis. 
Table 31

RATIOS OF AXIAL PEAK TO ROD-AVERAGE GAMMA RAY INTENSITIES

\begin{tabular}{cc}
\multicolumn{2}{c}{ Subassembly A-1 } \\
$\begin{array}{c}\text { Rod } \\
\text { Number }\end{array}$ & $\begin{array}{c}\text { Peak-to- } \\
\text { Average Ratio }\end{array}$
\end{tabular}

$\frac{\text { Subassembly B-1 }}{\begin{array}{c}\text { Rod } \\ \text { Number }\end{array}} \begin{gathered}\text { Peak-to- } \\ \text { Average Ratio }\end{gathered}$

Rod Removed from SA-1 at the End of Cycle No. 4

(Data Based on Gross Gamma Activity)

$\begin{array}{rlll}\text { A4 } & 1.18 & B 70 & 1.25 \\ \text { A13 } & 1.16 & B 76 & 1.30 \\ \text { A28 } & 1.13 & B 88 & 1.25 \\ \text { A41 } & 1.19 & B 97 & 1.20 \\ \text { A45 } & 1.16 & & \\ \text { A46 } & 1.15 & & \end{array}$

Rods That Operated to the End of Cycle No. 6

(Data Based on Cs-137)

\begin{tabular}{|c|c|c|c|}
\hline A1 & 1.06 & B50 & 1.13 \\
\hline A7 & 1.11 & B52 & 1.10 \\
\hline $\mathrm{A} 9$ & 1.09 & B56 & 1.12 \\
\hline A11 & 1.10 & B57 & 1.11 \\
\hline A15 & 1.11 & B58 & 1.16 \\
\hline A18 & 1.12 & B60 & 1.16 \\
\hline A22 & 1.09 & B61 & 1.10 \\
\hline A26 & 1.09 & B62 & 1.14 \\
\hline $\mathrm{A} 27$ & 1.11 & B83 & 1.08 \\
\hline A32 & 1.11 & B85 & 1.12 \\
\hline А33 & 1.07 & B86 & 1.13 \\
\hline A34 & 1.07 & B89 & 1.06 \\
\hline A35 & 1.07 & B91 & 1.15 \\
\hline A37 & 1.10 & B92 & 1.16 \\
\hline A38 & 1.08 & B93 & 1.15 \\
\hline A39 & 1.08 & B95 & 1.11 \\
\hline A40 & 1.09 & B96 & 1.15 \\
\hline A42 & 1.08 & B98 & 1.17 \\
\hline A43 & 1.06 & & \\
\hline A47 & 1.11 & & \\
\hline A48 & 1.09 & & \\
\hline A49 & 1.08 & & \\
\hline R.9n & 1.13 & & \\
\hline
\end{tabular}




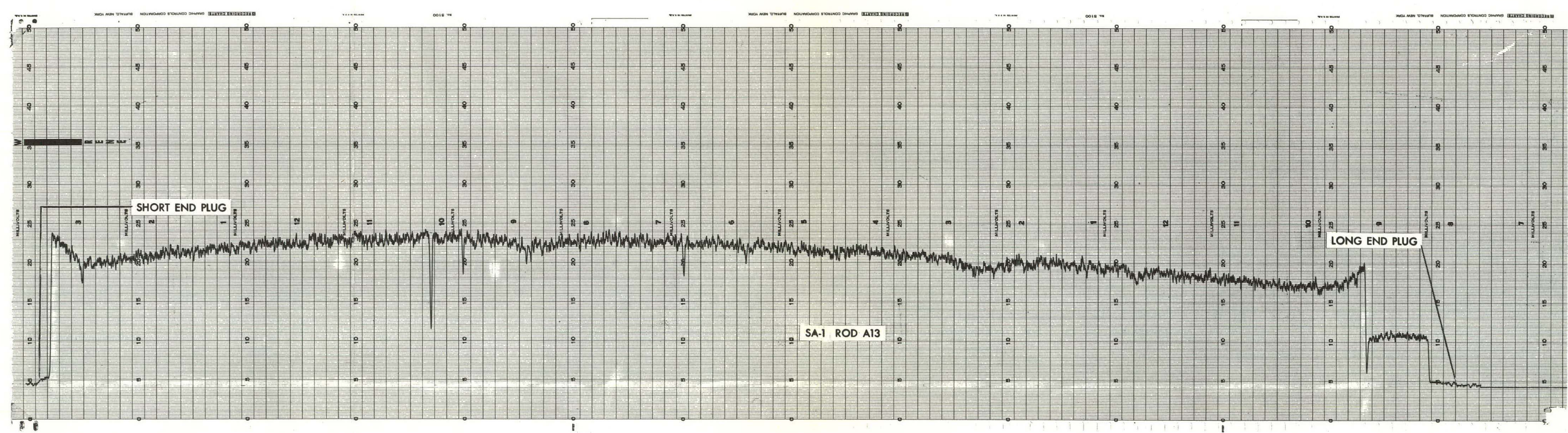




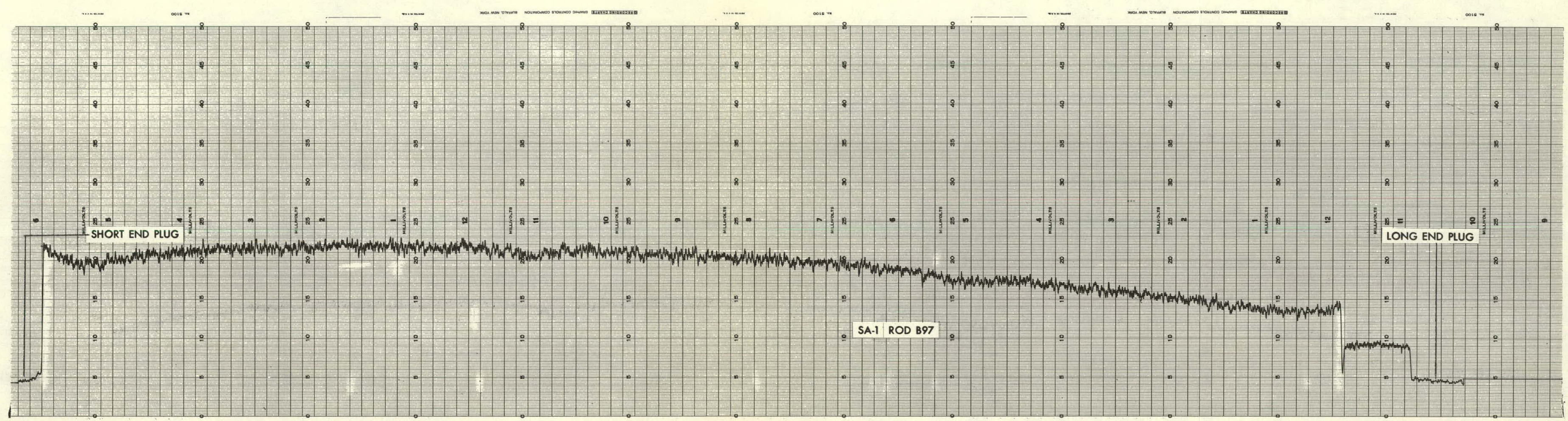




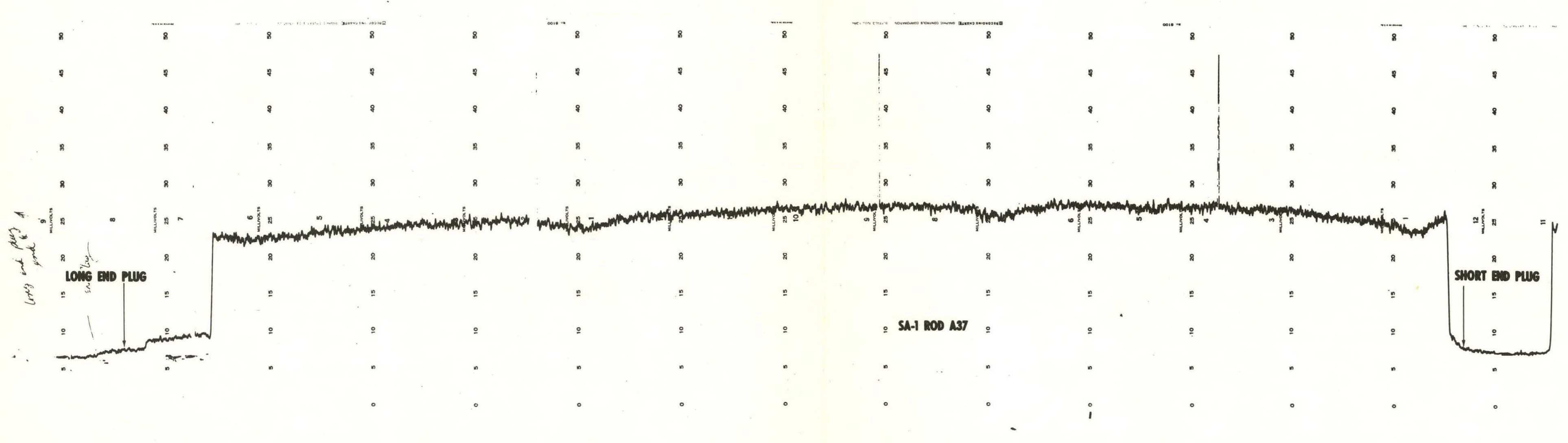




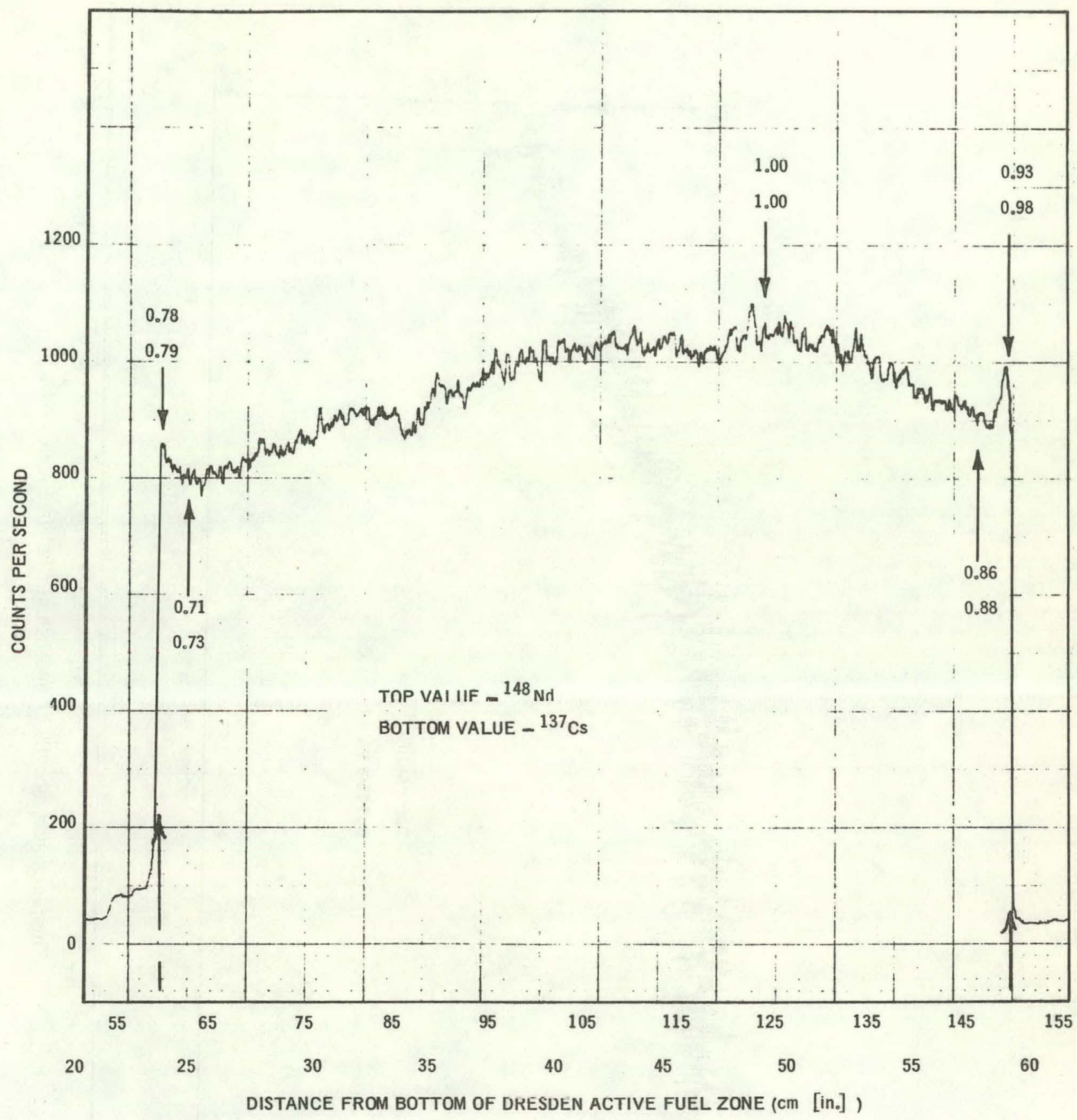

Figure 134. Comparison of Relative Burnups at Various Axial Locations by Cs-137 from the Rod Scan with Values Obtained by Nd-148 Method for Rod A-37 


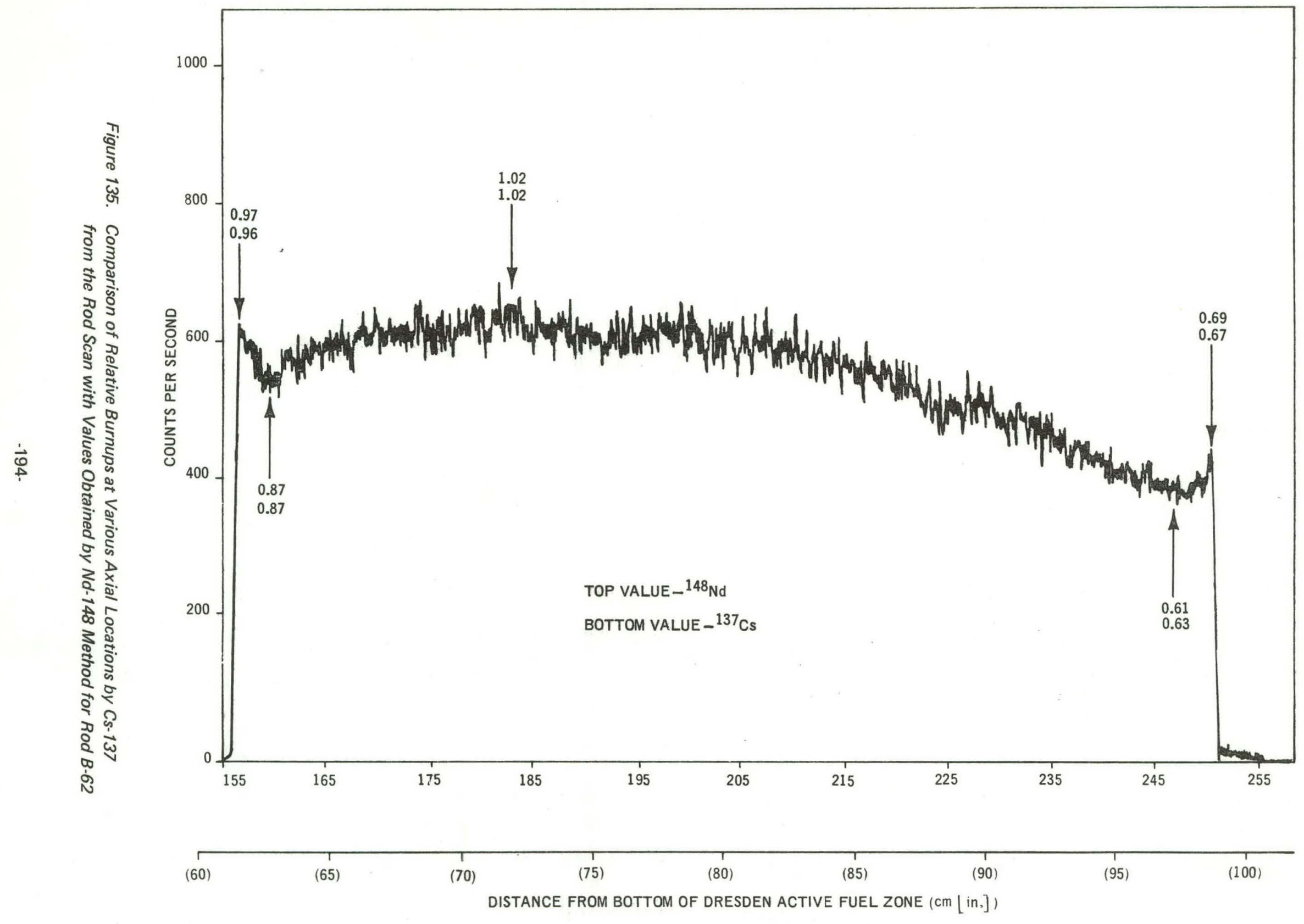




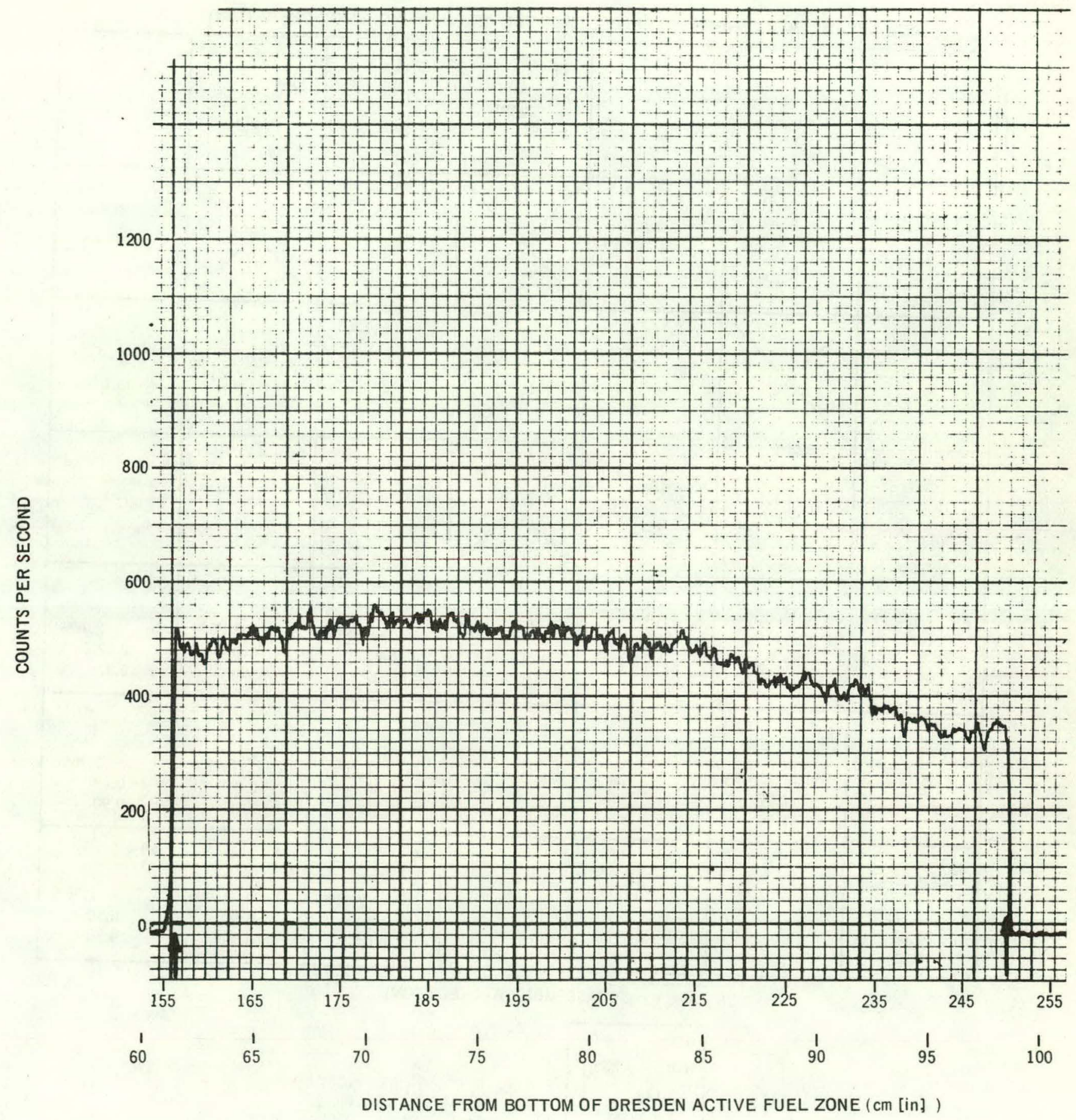

Figure 136. Gamma Scan of Rod B86 for Cs-137 


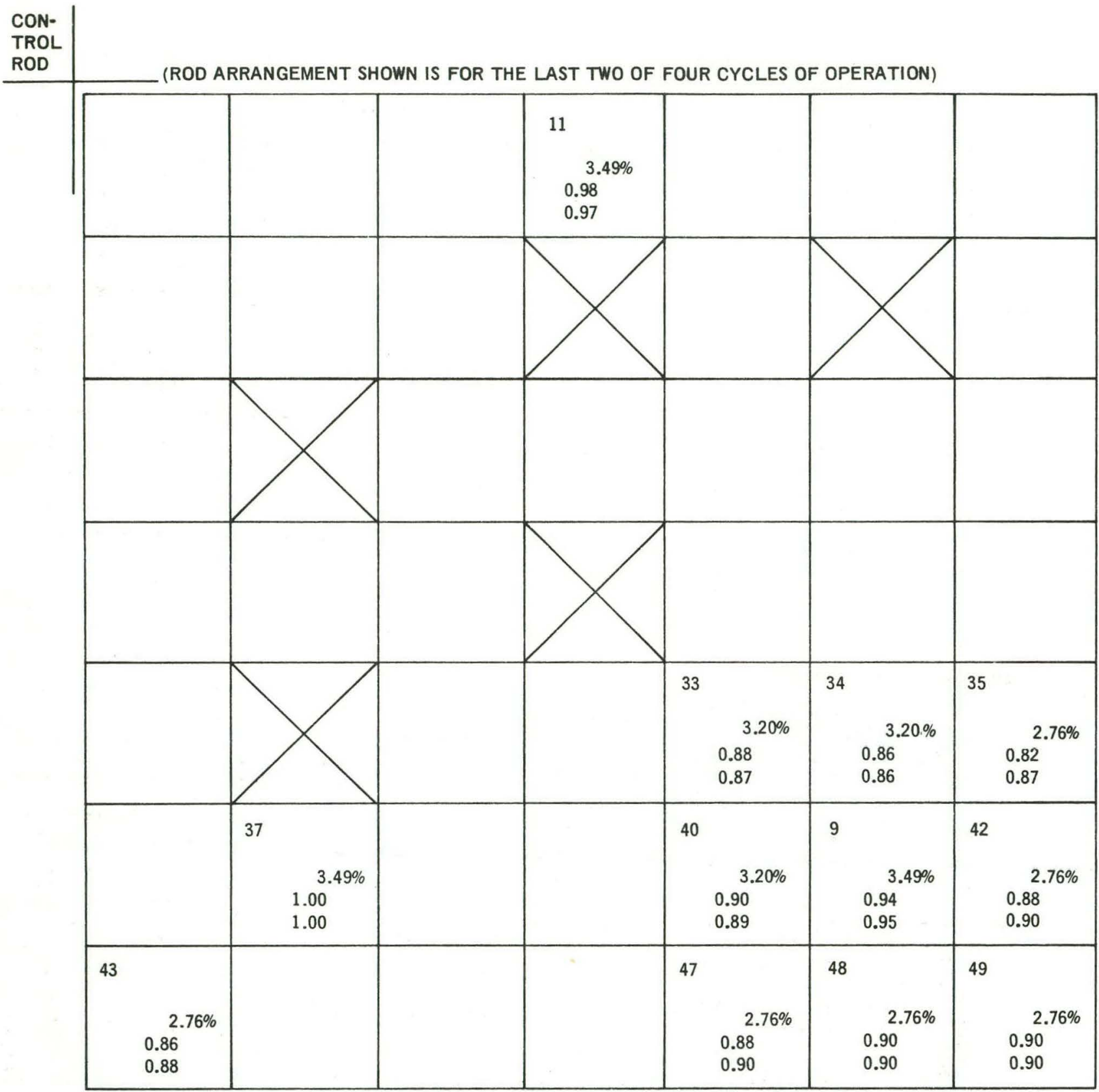

SUBASSEMBLY A-1 (BOTTOM)

\begin{tabular}{|lr|}
\hline ROD & WT\% \\
NO: & $235 \mathrm{U}$ \\
\multicolumn{2}{|c|}{${ }^{148} \mathrm{Nd}$} \\
\multicolumn{2}{|c|}{${ }^{137} \mathrm{Cs}$} \\
\hline
\end{tabular}

Figure 137. Comparison of Relative Burnups by Cs-137 from Rod Gamma Scan Data at Specific Axial Locations with Those Obtained by the Nd-148 Method at the Same Locations for Subassembly A-1. Data are Normalized to the Sample Point from Rod A-37. 


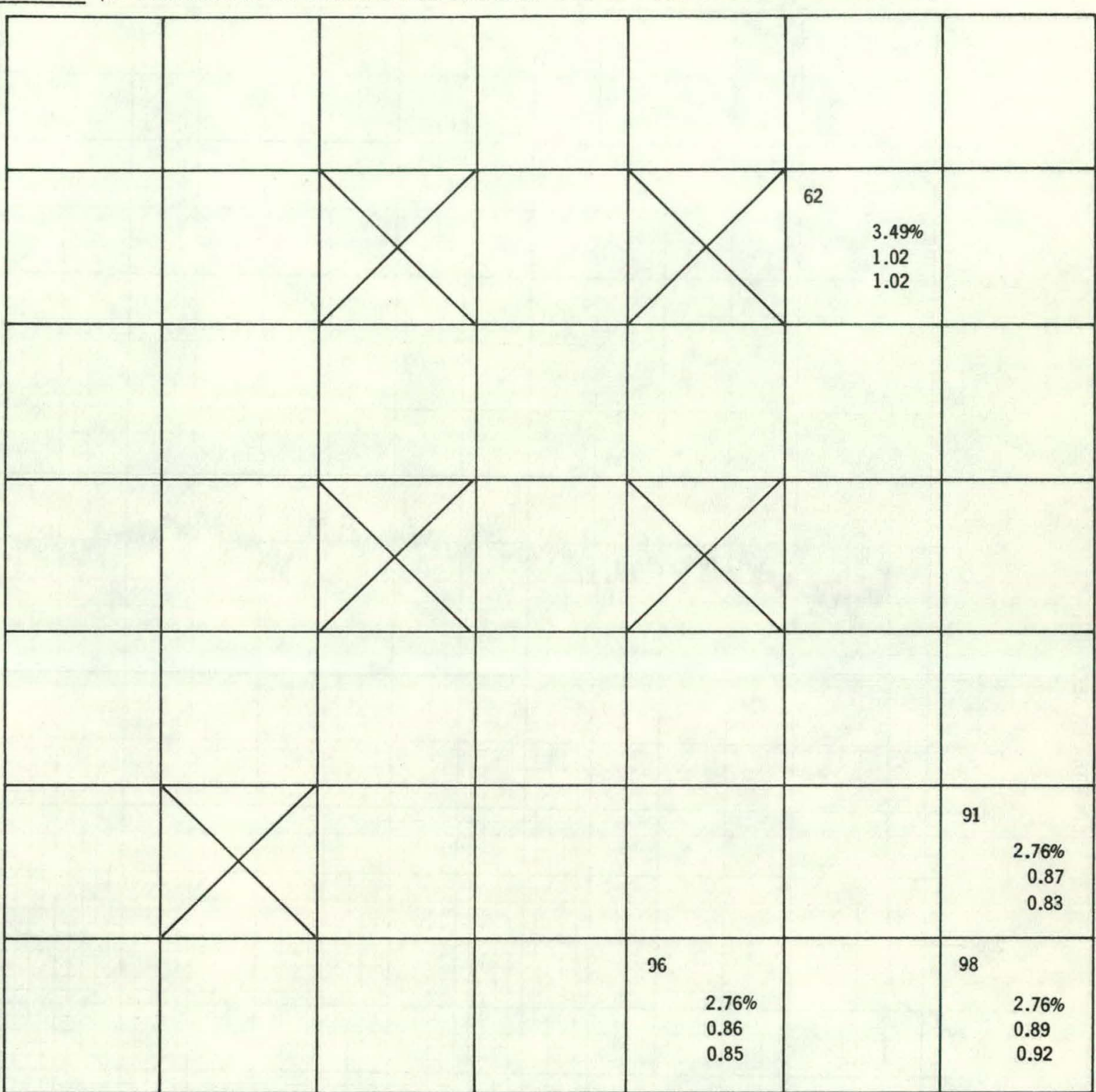

SUBASSEMBLY B-1 (TOP)

ROD Wt\%

NO. $235 \mathrm{U}$

$148 \mathrm{Nd}$

${ }^{137} \mathrm{Cs}$

Figure 138. Comparison of Relative Burnups by Cs-137 from Rod Gamma Scan Data at Specific Axial Locations with Those Obtained by the Nd-148 Method at the Same Locations for Subassembly B-1. Data are Normalized to the Sample Point from Rod A-37. 


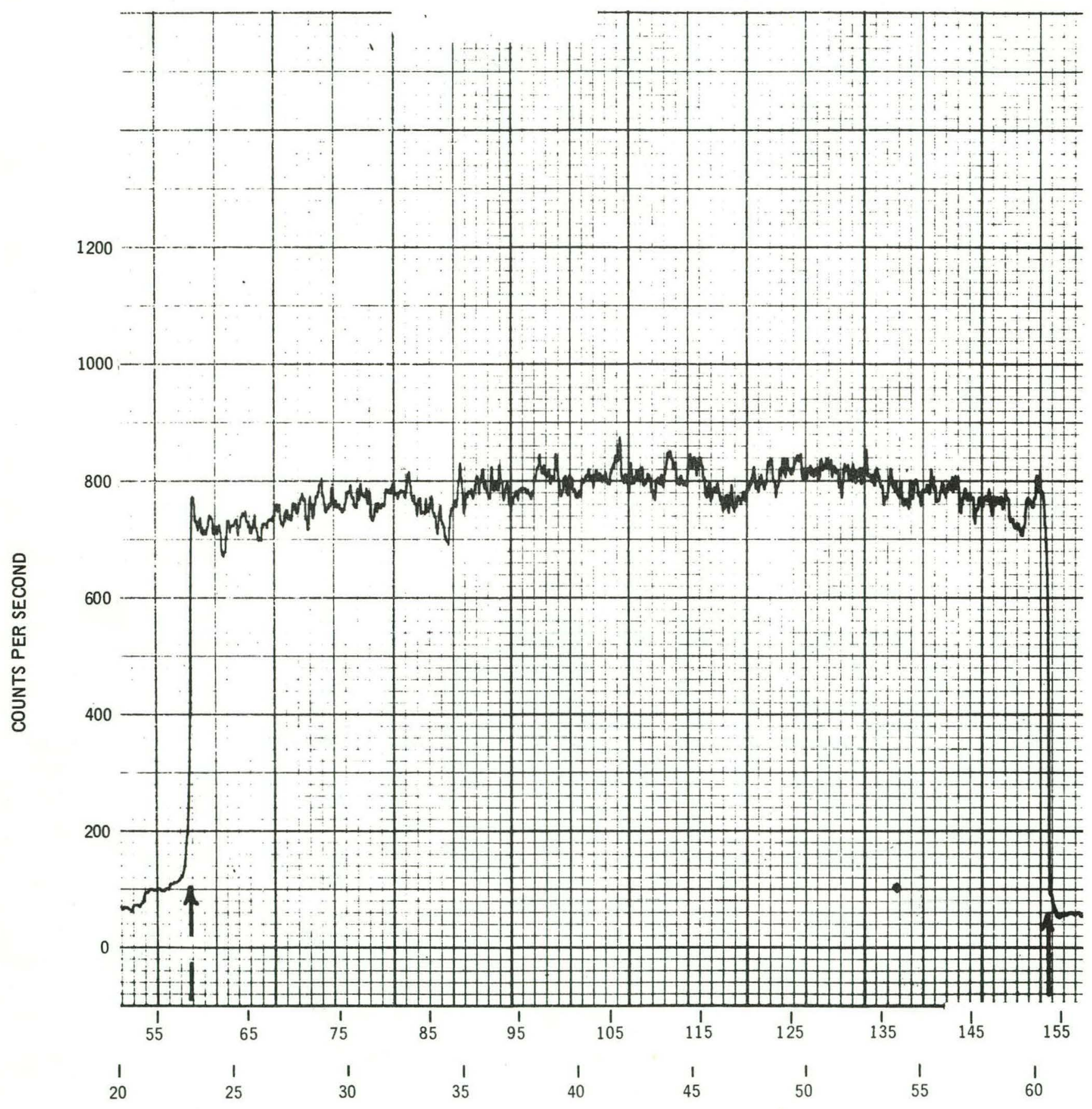

DISTANCE FROM BOTTOM OF DRESDEN ACTIVE FUEL ZONE (cm [in.] )

Figure 139. Gamma Scan of Rod A37 for Ru-106 


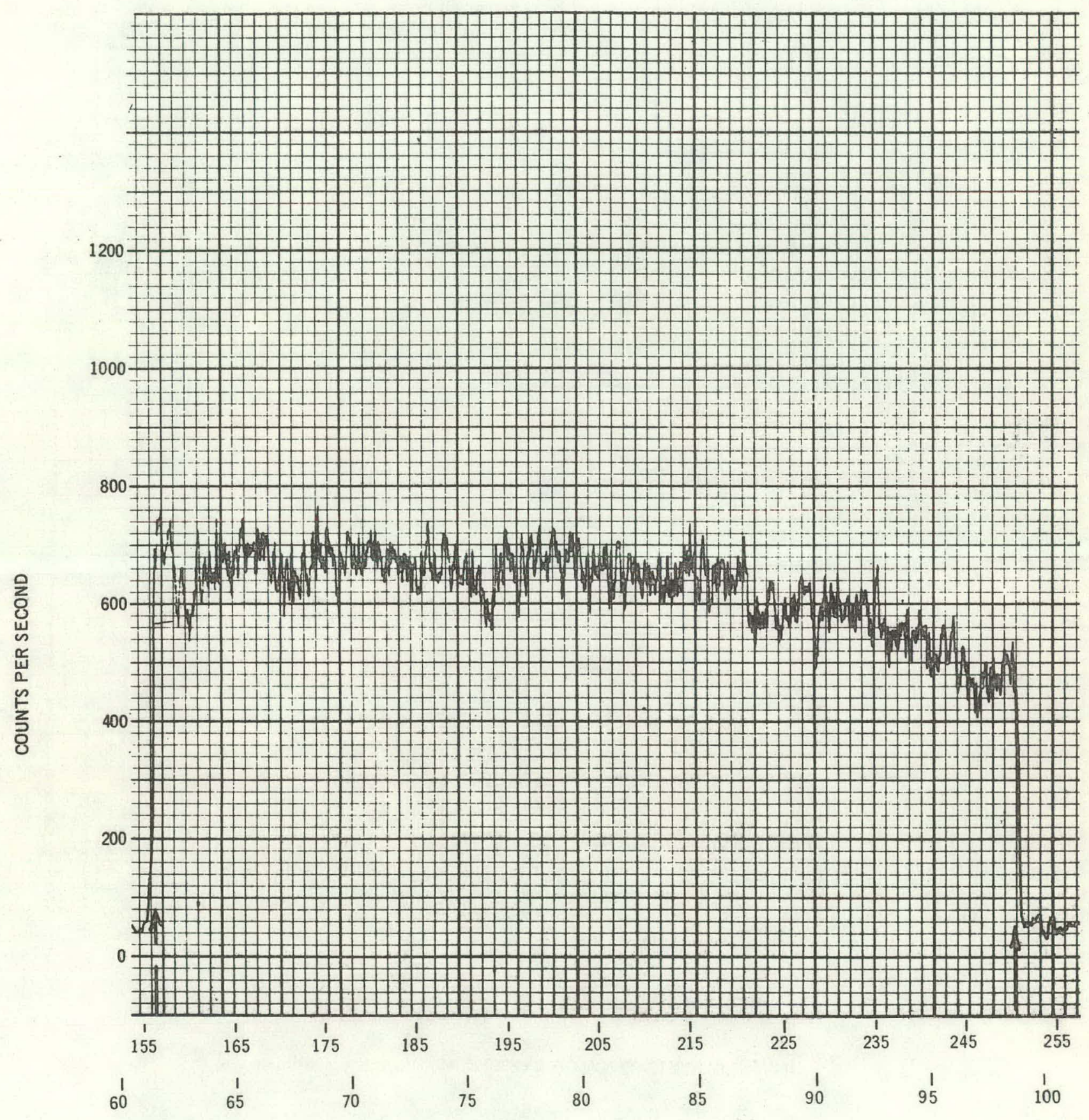

UIS I ANLL F RUM BUITOM OF DRESDEN ACTIVE FUEL ZONE (cm [in] )

Figure 140. Gamma Scan of Rod B86 for Ru-106 


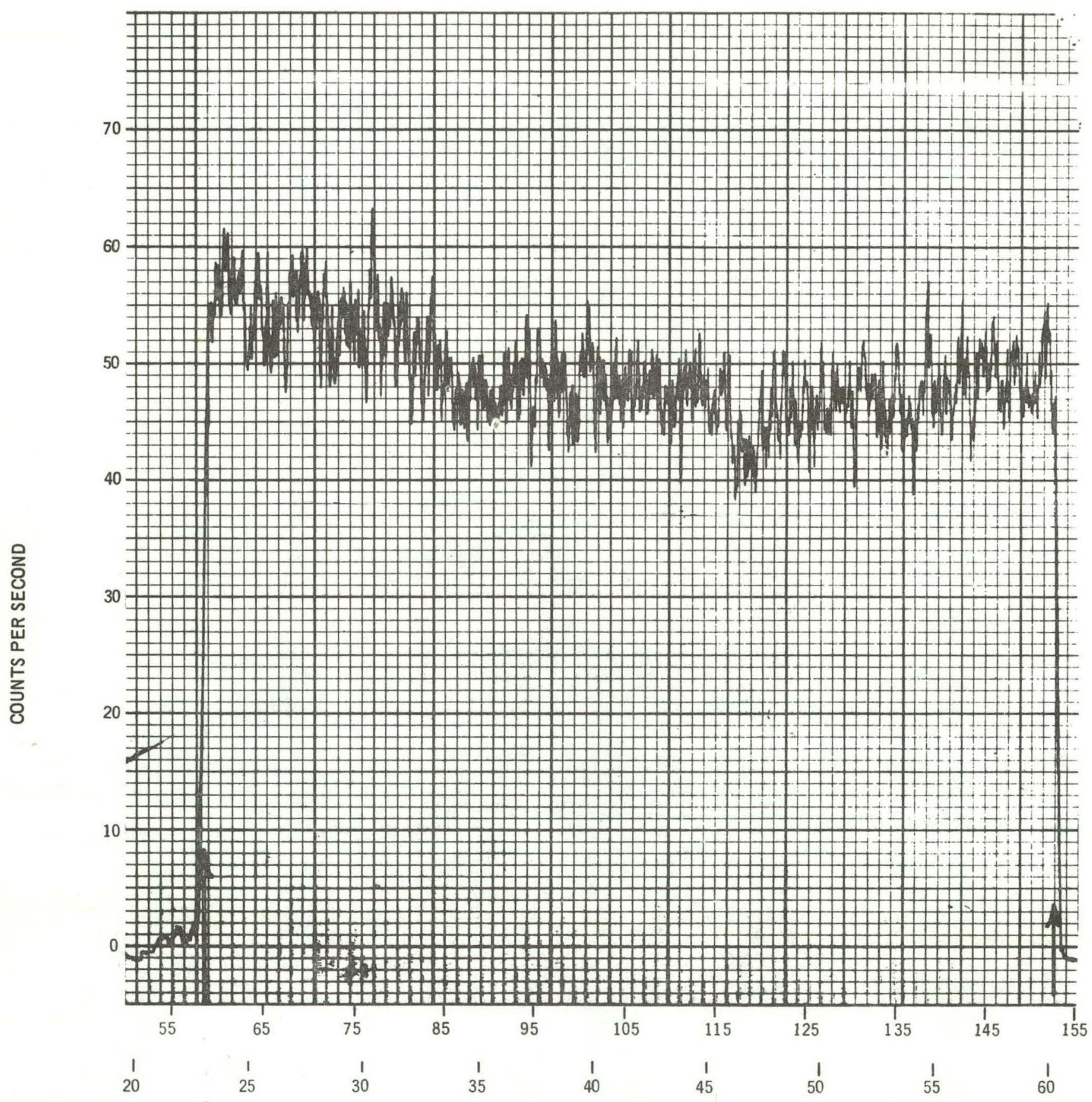

DISTANCE FROM BOTTOM OF DRESDEN ACTIVE FUEL ZONE (cm [in.] )

Figure 141. Gamma Scan of Rod A37 for Pr-144 


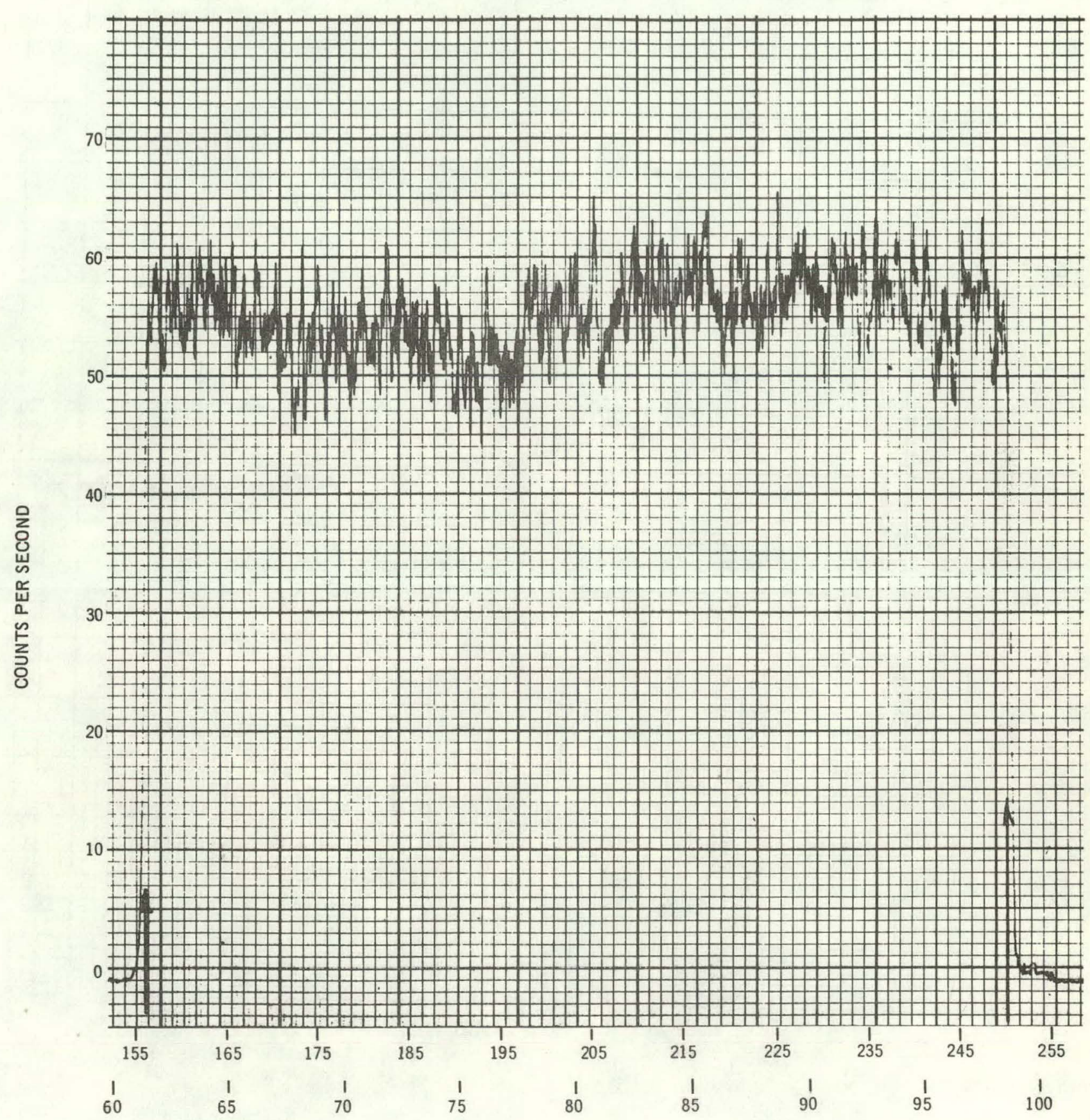

DISTANCE FROM BOTTOM OF DRESDEN ACTIVE FUEL ZONE (cm [in] )

Figure 142. Gamma Scan of Rod B86 for Pr-144 


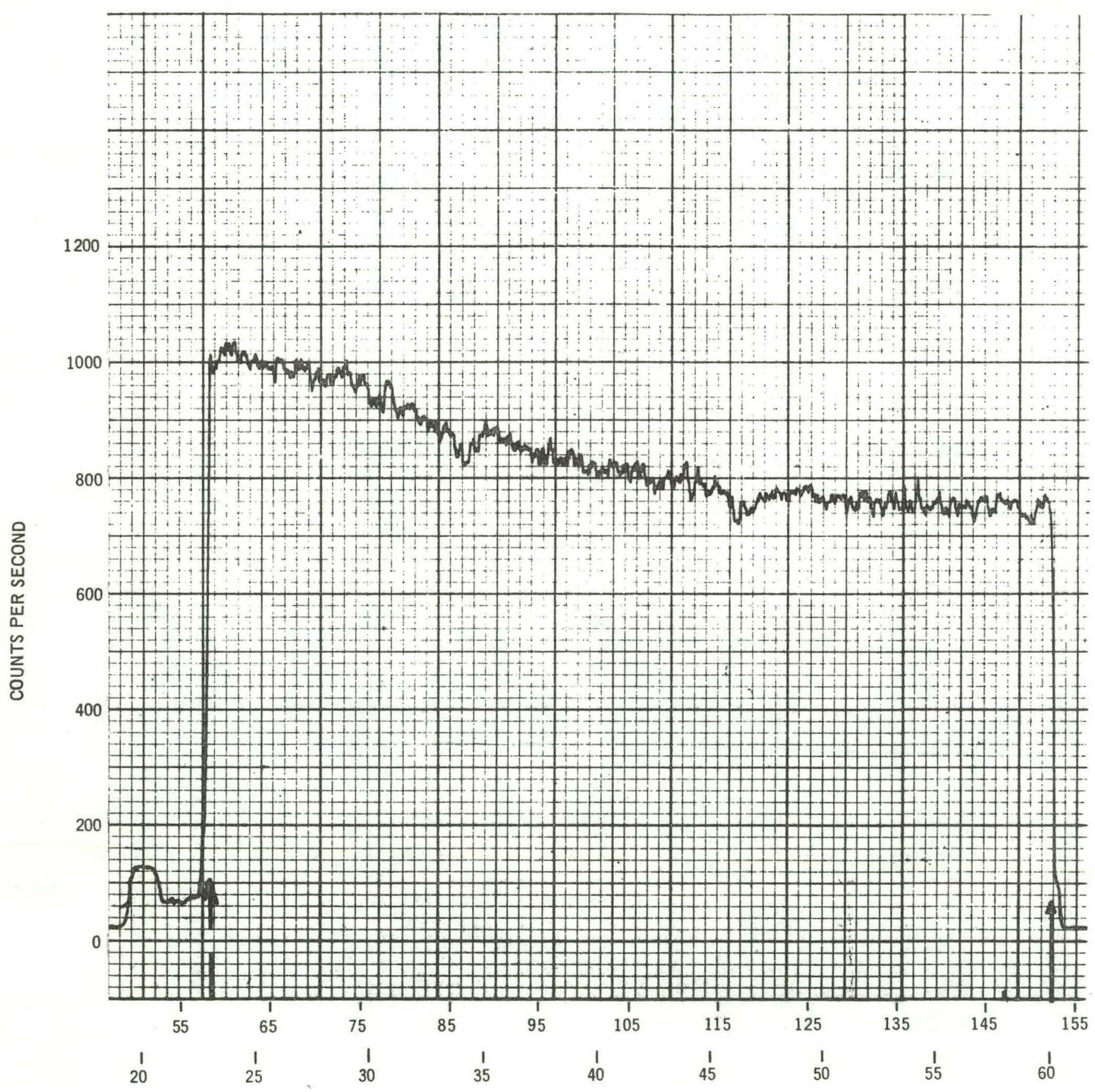

DISTANCE FROM BOTTOM OF DRESDEN ACTIVE FUEL ZONE (cm [in.] )

Figure 143. Gamma Scan of Rod A37 for Zr/Nb-95 


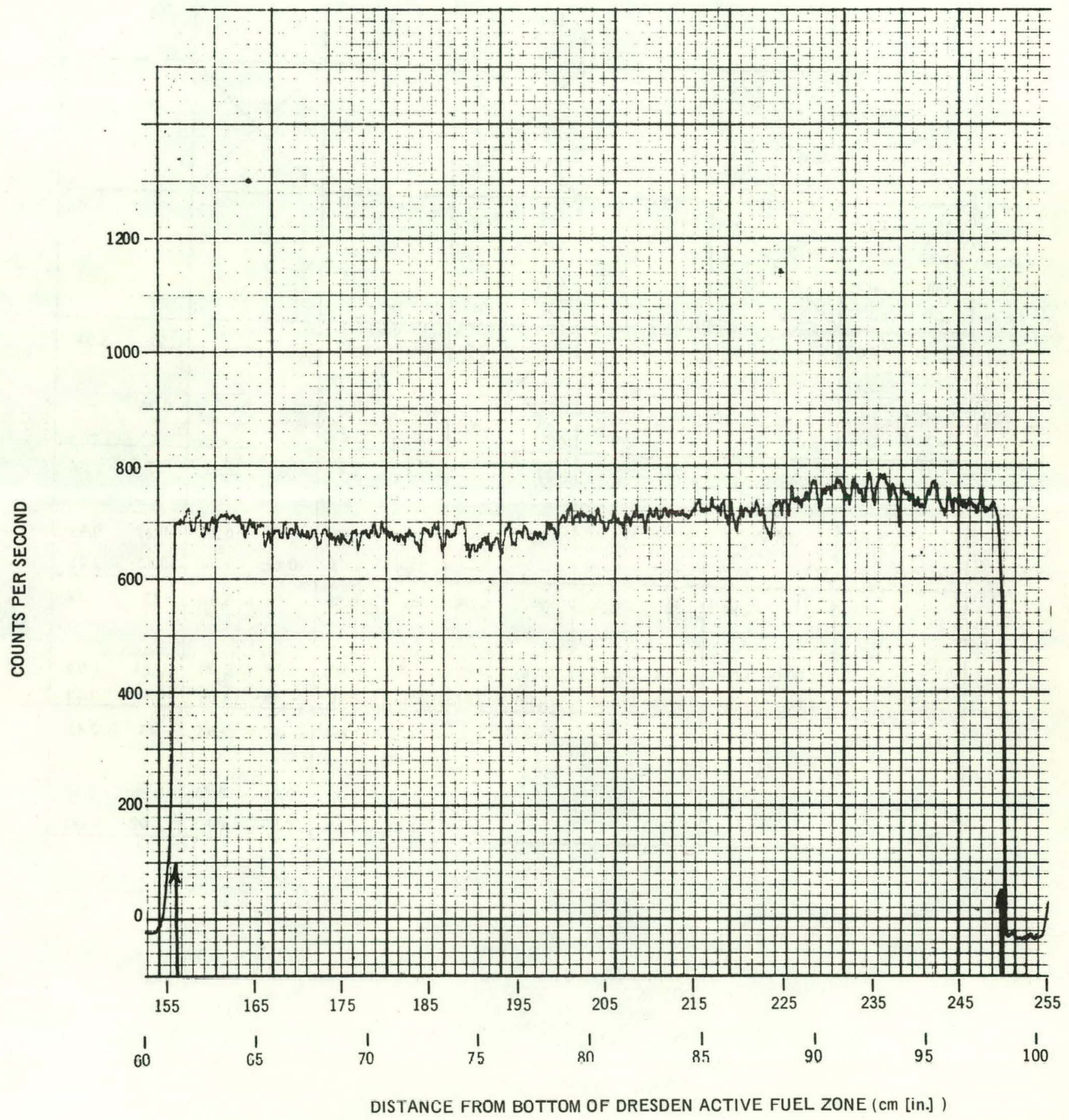

Figure 144. Gamma Scan of Rod B86 for Zr/Nb-95 


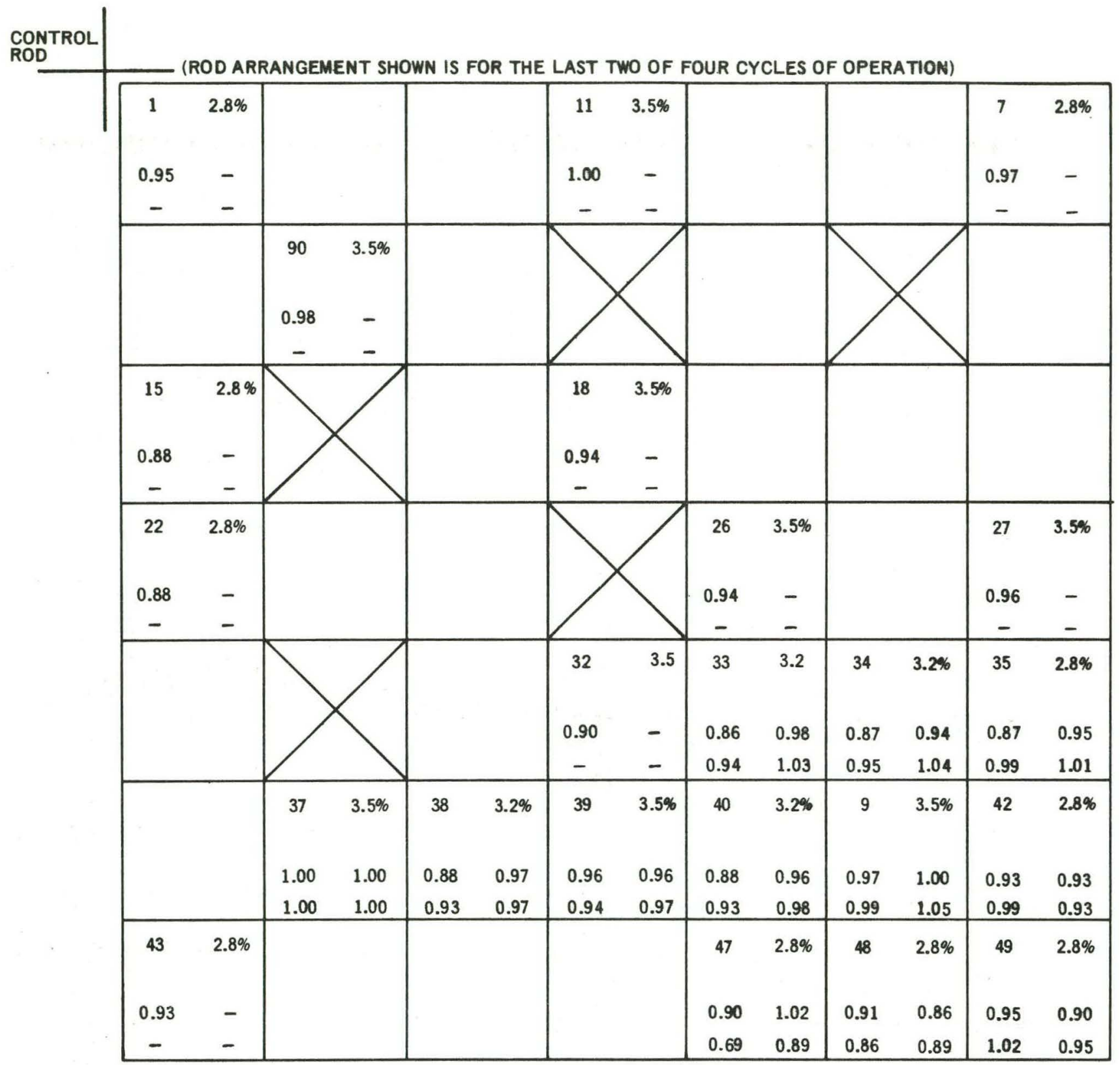

$$
\begin{array}{|cc}
\text { ROD NO. } \\
\text { W/O } \\
{ }^{235} \mathrm{U} \\
137 \mathrm{Cs} & { }^{144} \mathrm{Ce} \\
106 \mathrm{Ru} & { }^{95} \mathrm{Zr}
\end{array}
$$

Figure 145. Relative Rod-Average Fission Product Activity Values Obtained from Rods from Subassembly A-1 (Bottom) 
GEAP-10371

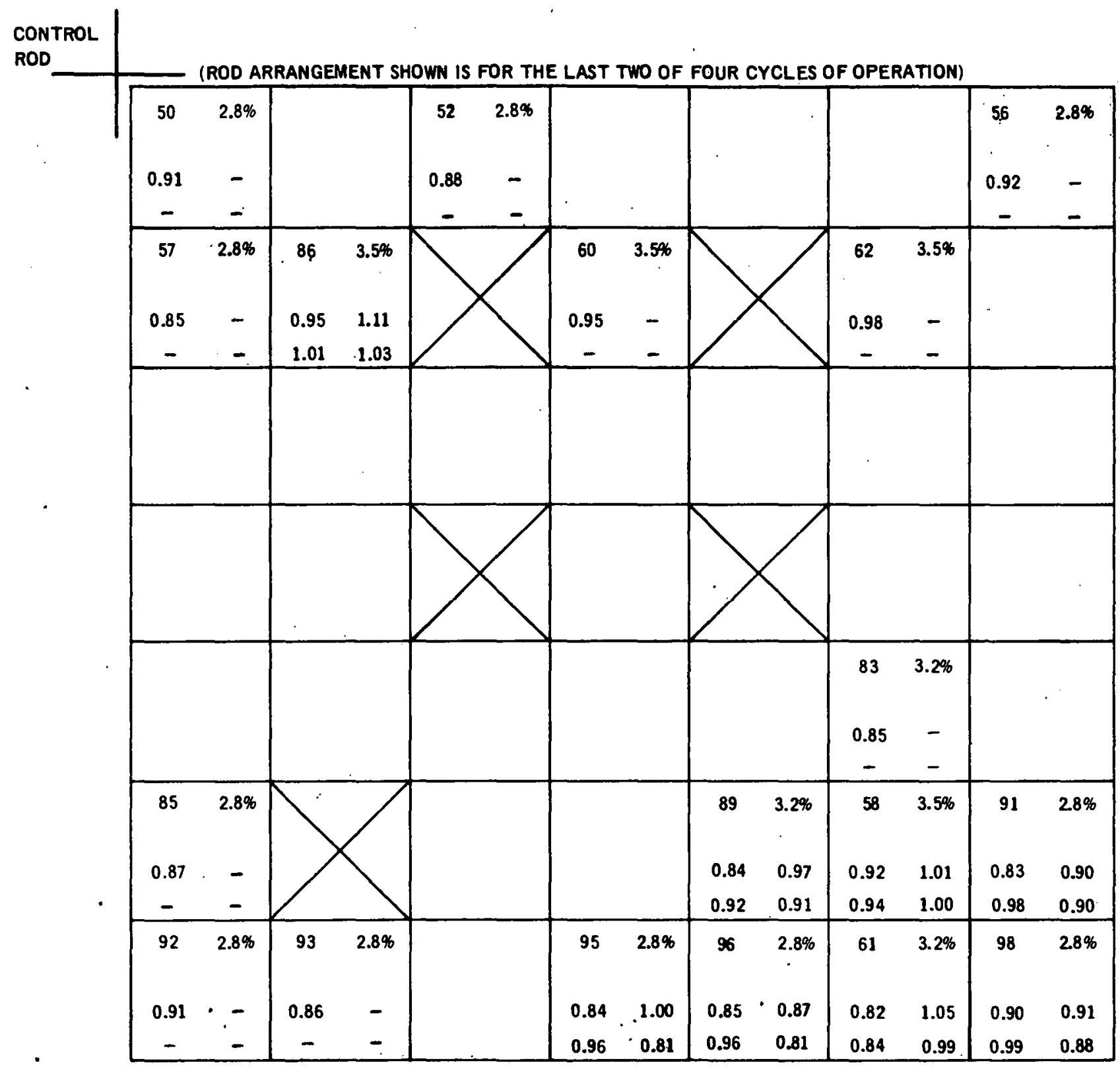

$$
\begin{aligned}
& \text { ROD NO. } 235 \mathrm{~W} \\
& { }^{137} \mathrm{Cs}{ }^{144} \mathrm{Ce} \\
& { }^{106_{\mathrm{Ru}}} \quad{ }^{95} \mathrm{Zr}
\end{aligned}
$$

Figure 146. Relative Rod-Average Fission Product Activity Values Obtained from Rods from Subassembly B-1 (Top) 


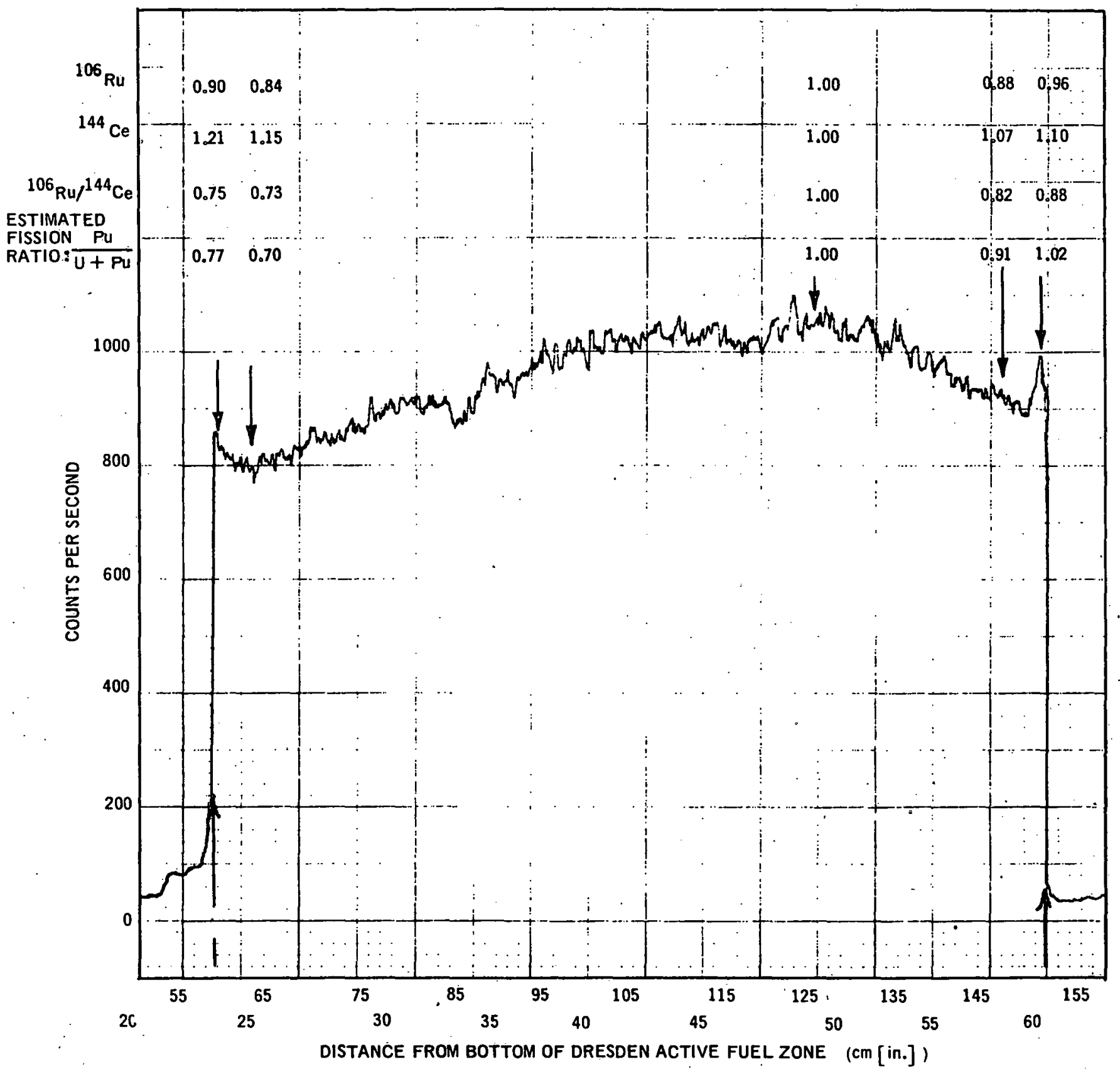

Figure 147. Comparison of the Ru-106/Ce-144 Ratio for an Estimate of the Pu/(U + Pu Fission Ratio for Rod A37 During /ts Most Recent Exposure History 


\section{ACKNOWLEDGMENTS}

The Zircaloy-Clad $\mathrm{UO}_{2}$ Fuel Rod Evaluation Program was sponsored by the United States Atomic Energy Commission, Division of Reactor Development and Technology, and was conducted by the Nuclear Energy Division of the General Electric Company. The program comprised three separate tasks: Fuel Rod Performance Evaluation, Irradiated $\mathrm{UO}_{2}$ Characterization Studies directed by $\mathrm{H}$. S. Rosenbaum, and Fuel Burnup and Isotopic Composition Analyses directed by C. P. Ruiz. The following individuals contributed to the performance and/or supervison of the examinations and analyses carried out during the course of the program:

Materials Investigation-Irradiation Processing Operation
G. P. Ferguson
R. E. Smith

Remote Handling Operations-Irradiation Processing Operation
G. Atchinson
D. G. Karris
D. C. Campuzano
D. L. Orton
N. J. Corege
L. L. Silva
L. C. Cronk
R. A. Tabor
R. C. Douglas
D. S. Vash
R. E. Jones
M. A. Vega

Nuclear Test Reactor-Irradiation Processing Operation
J. J. Haskins
W. J. Lowe
W. B. Johnson
J. E. Ward

Chemistry and Chemical Engineering Laboratory-Nucleonics Laboratory

$$
\text { C. P. Ruiz }
$$

Analytical Chemistry-Nucleonics Laboratory
M. A. Alper :
W. R. Silva
E. W. Butts
D. H. Simpson
J. P. Peterson, Jr.
F. R. Smith
D. E. Rey
E. B. Young

Reactonr Chemistry-Nuclennics Laboratory

W. Lim

Materials Structure and Properties-Nucleonics Laboratory
E. S. Darlin
W. C. Oh
W. H. Kimball
H. S. Rosenbaum
J. L. Lakner
U. E. Wolff

J. E. Lewis

Ceramic Development-Nucleonics Laboratory
M. M. Csicsery
L. N. Grossman

Fuel Development-Water Reactors-Nuclear Fuel Department

F. H. Megerth 
Thanks are due to Prof. Gareth Thomas, University of California at Berkeley, for making available the high-voltage electron microscope and for suggestions concerning interpretation of the electron micrographs.

The cooperation of the Commonwealth Edison Company, particularly of the people of the Dresden staff, in agreeing to operate Assembly SA-1 in Unit No. 1 to a high exposure level, in providing the extensive help required to prepare for the assembly's initial insertion in the core and to carry out subsequent leak tests, examinations, and fuel shipments, and in freely furnishing the reactor operating data essential to the evaluation of the assembly's performance is gratefully acknowledged.

\section{REFERENCES}

1. Baroch, C. J., Hoffmann, J.P., and Rous, W. C., AEC Fuel Cycle Program-Design and Fabrication of the Basic Fuel Assemblies, March 15, 1963 (GEAP-3653).

2. Design and Fabrication of Special Assembly SA-1, April 1971 (GEAP-10355).

3. Williamson, H. E., Baroch, C.J., Hoffmann,J.P., and Ikeuye, D. T., AEC Fuel Cycle Program-Examination of Zircaloy-Clad $\mathrm{UO}_{2}$ Fuel Rods Operated in the VBWR to 10,000 MWd/tU, March 15, 1965 (GEAP-4597).

4. Hoyt, J. L., Porter, C. E., and Wilkinson, C. D., “Neutron Radiography Applications at General Electric," American Nuclear Society Transactions, Vol. 10, No. 2, p. 446 (November 1967).

5. Grossman, L. N., and Hegland, J. O., Tritium Distribution in High Power Zircaloy Fuel Elements, June 1971 (GEAP-12205).

6. Sodium Cooled Reactors, Fast Ceramic Reactor Development Program, Twenty-Sixth Quarterly Report, February-April 1968, June 1968 (GEAP-5631).

7. Sodium Cooled Reactors, Fast Ceramic Reactor Development Program, Twenty-Eighth Quarterly Report, May-July 1968, November 1968 (GEAP-5700).

8. Rider, B. F., Ruiz, C.P., Peterson, J. P., Jr., and McLaughlin, T. V., BURNUP: A FORTRANIV Code for Computing $U$ and Pu Fuel Burnup from U, Pu, and Nd Mass Spectrometric Measurements Updated to Include Fast Reactor Fuels, January 1970 (GEAP-5355A).

9. Berman, R. M., "Fission Fragment Distribution in Irradiated $\mathrm{UO}_{2}, "$ Nuclear Science and Engineering 16. 315-328 (1963).

10. Barrett, C. S., and Massalski, T. B., Structure of Meta/s, McGraw-Hill, New York, N.Y., 1966, pp. $141-149$.

11. Belle, J., Uranium Dioxide: Properties and Nuclear Applications, U.S. Government Printing Office, July 1961, pp. $457-460$.

12. Standard Method of Test for Atom Percent Fission in Uranium and Plutonium Fuel Neodymium-148 Method, Part 30, ASTM, 1966 Race St., Philadelphia, Pa., 19103 (ASTM E321-69).

13. Federal Register, Vol. 31, No. 250, Wednesday, December 28, 1966.

14. Durham, R. W., Burnup of Ceramic Fuel by Gamma Ray Scanning, 1967 (AECL-2688).

15. Forsyth, R. S., and Blackadder, W. H., Use of Fission Product Ru-106 Gamma Activity as a Method for Estimating the Relative Number of Fission Events in U-235 and Pu-239 in Low Enrichment Fuel Elements, 1970 (AE-390). 


\section{APPENDIX A}

\section{LIST OF REPORTS ISSUED}

Prior reports to the U.S. Atomic Energy Commission under the Zircaloy-Clad $\mathrm{UO}_{2}$ Fuel Rod Evaluation Program (Project Agreement 41) comprise the following:

a. "Zircaloy-Clad $\mathrm{UO}_{2}$ Fuel Rod Evaluation Program, Quarterly Progress Report No. 1, November 1967-January 1968," March 1968 (GEAP-5598).

b. "Zircaloy-Clad $\mathrm{UO}_{2}$ Fuel Rod Evaluation Program, Quarterly Progress.Report No. 2, February 1968-April 1968," May 1968 (GEAP-5624).

c. "Zircaloy-Clad $\mathrm{UO}_{2}$ Fuel Rod Evaluation Program, Quarterly Progress Report No. 3, May 1968-July 1968," August 1968 (GEAP-5667).

d. "Zircaloy-Clad UO 2 Fuel Rod Evaluation Program, Quarterly Progress Report No. 4, August 1968-October 1968," November 1968 (GEAP-5702).

e. "Zircaloy-Clad $\mathrm{UO}_{2}$ Fuel Rod Evaluation Program, Quarterly Progress Report No. 5, November 1968--.January 1969," February 1969 (GEAP-5746).

f. "Zircaloy-Clad $\mathrm{UO}_{2}$ Fuel Rod Evaluation Program, Quarterly Progress Report Nos. 6 and 7, February-July 1969," August 1969 (GEAP-10079).

g. "Zircaloy-Clad $\mathrm{UO}_{2}$ Fuel Rod Evaluation Program, Quarterly Progress Report No. 8, August-October 1969," November 1969 (GEAP-10121).

h. "Zircaloy-Clad $\mathrm{UO}_{2}$ Fuel Rod Evaluation Program, Quarterly Progress Report No. 9. November 1969-January 1970," February 1970 (GEAP-10160).

i. "Zircaloy-Clad $\mathrm{UO}_{2}$ Fuel Rod Evaluation Program, Quarterly Progress Report No. 10, February-April 1970," May 1970 (GEAP-10204).

j. "Zircaloy-Clad $\mathrm{UO}_{2}$ Fuel Rod Evaluation Program, Quarterly Progress Report No. 11, May-July 1970," August 1970 (GEAP-10217).

k. "Zircaloy-Clad $\mathrm{UO}_{2}$ Fuel Rod Evaluation Program, Quarterly Progress Report No. 12, August-October 1970," November 1970 (GEAP-10287).

I. "Zircaloy-Clad $\mathrm{UO}_{2}$ Fuel Rod Evaluation Program, Progress Report No. 13, November 1970-March 1971," April. 1971 (GE^P.10363).

m. "Design and Fabrication of Special Assembly SA-1," April 1971 (GEAP-10355). 
GEAP-10371

APPENDIX B

VBWR OPERATING DATA ON SA-1 RODS 
Table B-1

VBWR OPERATING DATA ON STA-1 RODS

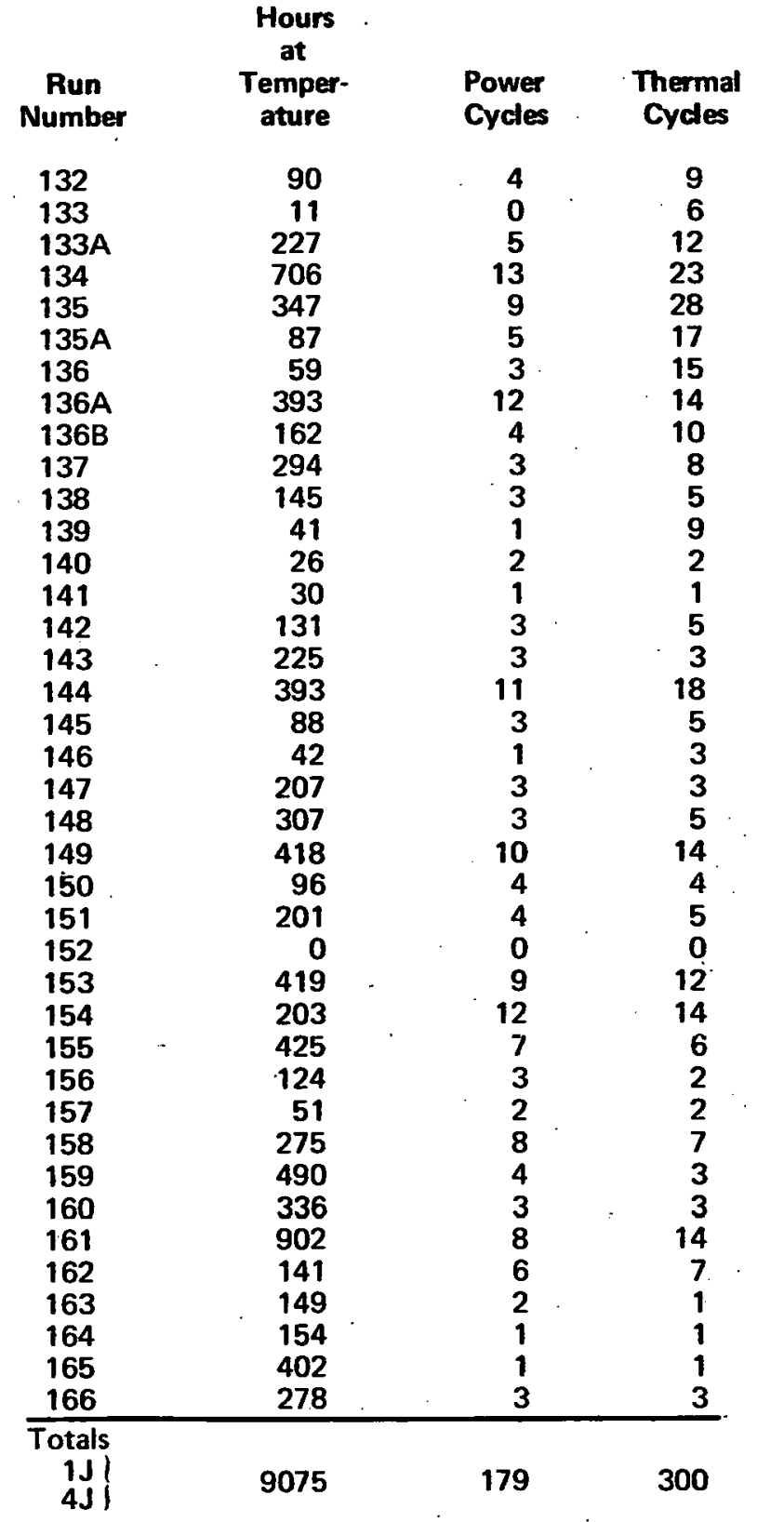

Assembly $1 \mathrm{~J}$.

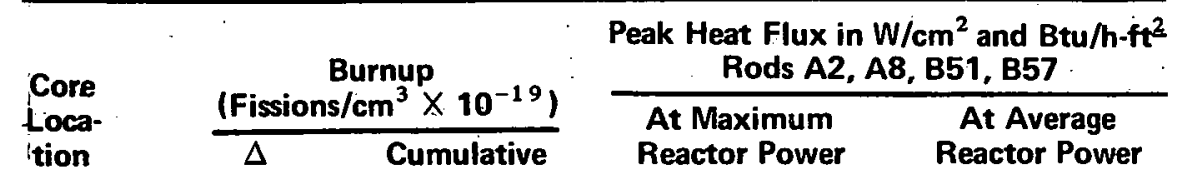

$\Delta \quad$ Cumulative

$\begin{array}{ll}0.126 & 0.12 \\ 0.008 & 0.14 \\ 0.342 & 0.476 \\ 1.308 & 1.784\end{array}$

$\begin{array}{ll}0.342 & 0.476 \\ 1.308 & 1.784 \\ 0.498 & 2.282 \\ 0.104 & 2.386\end{array}$

$\begin{array}{ll}0.498 & 2.282 \\ 0.104 & 2.386 \\ 0.055 & 2.441 \\ 0.561 & 3.002 \\ 0.189 & 3.191\end{array}$

$\begin{array}{ll}0.561 & 3.002 \\ 0.189 & 3.191 \\ 0.492 & 3.683 \\ 0.219 & 3.902 \\ 0.044 & 3.96\end{array}$

$\begin{array}{llll}0.492 & 3.683 & 59 & 187,000 \\ 0.219 & 3.902 & 53 & 167,000 \\ 0.044 & 3.946 & 49 & 156,000 \\ 0.030 & 3.976 & 47 & 150,000\end{array}$

$\begin{array}{llll}0.044 & 3.946 & 49 & 156,000 \\ 0.030 & 3.976 & 47 & 150,000 \\ 0.027 & 4.003 & 42 & 132,000\end{array}$

0.027

$\begin{array}{ll}0.282 & 4.285 \\ 0.525 & 4.810 \\ 0.077 & 5.787\end{array}$

$\begin{array}{ll}0.077 & 5.864 \\ 0.074 & -9.968\end{array}$

$\begin{array}{ll}0.413 & 6.321 \\ 0.487 & 6.808 \\ 0.752 & 7.560 \\ 0.170 & 7.730\end{array}$

$\begin{array}{ll}0.170 & 7.730 \\ 0.367 & 8.097\end{array}$

0.772

0.356
0.840

0.840
0.181
0.104
0.410

0.410

0.607

$\begin{array}{ll}0.161 & 13.600 \\ 0.183 & 13.761\end{array}$

$\begin{array}{ll}0.181 & 13.761 \\ 0.183 & 14.127 \\ 0.446 & 14.573 \\ 0.312 & 14.885\end{array}$

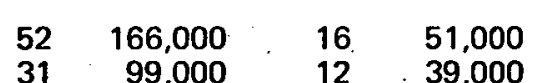

99,000
198,000

198,000
180,000

151,000

216,000
265,000
124,000

124,000
160,000

220,000

228,000

192,000

244,000

298,000
231,000

203,000

159,000

205,000
205,000

. 121,000

125,000
$37 . \quad 11,000$

. 125,000

$\begin{array}{rr}12 & 39,000 \\ 42 & 133,000 \\ 53 & 169,000 \\ 32 & 102,000 \\ 25 & 78,000 \\ 12 & 39,000 \\ 36 & 114,000 \\ 27 & 87,000 \\ 40 & 127,000 \\ 40 & 127,000 \\ 13 & 42,000 \\ 23 & 72,000 \\ 23 & 72,000 \\ 57 & 180,000 \\ 62 & 198,000 \\ 65 & 205,000 \\ 17 & 54,000 \\ 20 & 64,000 \\ 54 & 170,000 \\ 42 & 133,000 \\ 45 & 142,000 \\ 36 & 113,000 \\ 49 & 154,000 \\ & -14 \\ 44 & 141,000 \\ 48 & 152,000 \\ 60 & 190,000 \\ 42 & 133,000 \\ 52 & 165,000 \\ 43 & 13,000 \\ 61 & 193,000 \\ 58 & 185,000 \\ 39 & 124,000 \\ 31 & 98,000 \\ 36 & 183,000 \\ 35 & 11,000 \\ 35 & 111,000 \\ 30 & 96,000\end{array}$

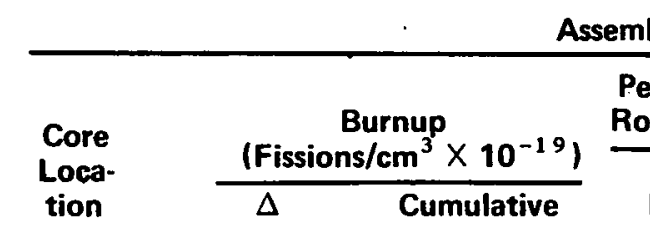

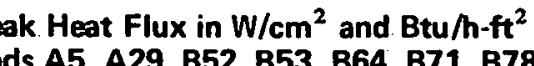

$\begin{array}{ll}\text { At Maximum } & \begin{array}{c}\text { At Average } \\ \text { Reactor Power }\end{array} \\ \text { Reactor Power } & \end{array}$

$\begin{array}{lllllll}0-6 & 0.137 & 0.137 & 56 & 178,000 & 17 & 55,000 \\ & 0.071 & 0.208 & 27 & 87,000 & 11 & 34,000 \\ & 0.315 & 0.523 & 55 & 175,000 & 37 & 118,000\end{array}$

$\begin{array}{llllll}0.071 & 0.208 & 27 & 87,000 & 11 & 34,000 \\ 0.315 & 0.523 & 55 & 175,000 & 37 & 118,000 \\ 1.204 & 1.727 & 55 & 175,000 & 47 & 149,000\end{array}$

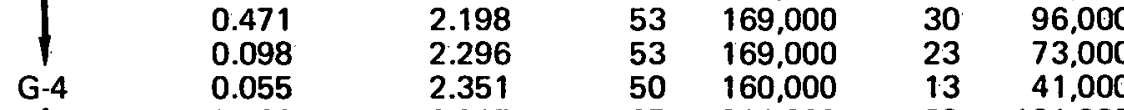

$\begin{array}{ccccccc}\text { G-4 } & 0.055 & 2.351 & 50 & 160,000 & 13 & 43,000 \\ & 0.566 & 2.917 & 67 & 214,000 & 38 & 121,000 \\ & 0.192 & 3.109 & 45 & 142,000 & 29 & 92,000\end{array}$

$\begin{array}{llllr}3.109 & 45 & 142,000 & 29 & 92,000 \\ 3.604 & 63 & 199,000 & 43 & 135,000\end{array}$

$\begin{array}{lllll}3.823 & 56 & 177,000 & 42 & 135,000 \\ 3.864 & 50 & 158,000 & 14 & 43,000\end{array}$

$\begin{array}{lllll}3.864 & 50 & 158,000 & 14 & 43,000 \\ 3.891 & 48 & 153,000 & 23 & 73,000\end{array}$

$\begin{array}{rrrrr}3.921 & 43 & 135,000 & 23 & 74,000 \\ 4.195 & 169 & 220,000 & 58 & 183,000\end{array}$

$\begin{array}{llllll}4.715 & 69 & 220.000 & 64 & 202,000 \\ 5664 & 86 & 272.000 & 67 & 211,000\end{array}$

$\begin{array}{rrrrr}5.664 & 86 & 272,000 & 67 & 211,000 \\ 5.749 & 43 & 136,000 & 19 & 59,000\end{array}$

$\begin{array}{rrrrr}5.796 & 55 & 176,000 & 22 & 70,000 \\ 6247 & 77 & 245,000 & 59 & 187,000\end{array}$

$\begin{array}{lllll}6.802 & 75 & 239,000 & 45 & 144,000 \\ 7.582 & 74 & 236,000 & 46 & 147,000\end{array}$

7.763

8.157

236,000

207,000

83262,000

215,000

251.000

223,000

225,000

225,000
154,000

112,000

$\begin{array}{ll}36 & 115,000 \\ 40 & 128,000\end{array}$

$\begin{array}{ll}38 & 122,000 \\ 52 & 166,000\end{array}$

$48 \quad 151,000$

\begin{tabular}{ll}
48 & 151,000 \\
35 & 110,000 \\
\hline & 207,000
\end{tabular}

$\begin{array}{ll}65 & 207,000 \\ 45 & 142,000\end{array}$

$\begin{array}{ll}55 & 176,000 \\ 46 & 146,000\end{array}$

$\begin{array}{ll}46 & 146,000 \\ 67 & 212,000 \\ 64 & 203,000\end{array}$

$\begin{array}{ll}64 & 223,000 \\ 37 & 118,000\end{array}$

$29 \quad 91,000$

$\begin{array}{rr}29 & 91,000 \\ 33 & 105,000\end{array}$

$\begin{array}{ll}32 & 102,000 \\ 38 & 122,000\end{array}$

NOTES:

Hours at temperature is defined as the number of hours the reactor power was greater than $5 \mathrm{MWt}$.

A power cycle is defined as a reactor core power variation from less than $5 \mathrm{MW}$ to greater than $20 \mathrm{MW}$ and returned to less than $5 \mathrm{MW}$. A thermal cycie is defined as a reactor core power variation from zero power to greater than $5 \mathrm{MW}$ and return to zero power. 
Table B-1 (Continued).

\begin{tabular}{|c|c|c|c|}
\hline $\begin{array}{l}\text { Run } \\
\text { Number }\end{array}$ & $\begin{array}{c}\text { Hours } \\
\text { at } \\
\text { atmper } \\
\text { ature }\end{array}$ & $\begin{array}{l}\text { Power } \\
\text { Cycles }\end{array}$ & $\begin{array}{c}\text { Thermal } \\
\text { Cycles }\end{array}$ \\
\hline 132 & 90 & 4 & 9 \\
\hline 133 & 11 & 0 & 6 \\
\hline $133 \mathrm{~A}$ & 227 & 5 & 12 \\
\hline 134 & 706 & 13 & 23 \\
\hline 135 & 347 & 9 & 28 \\
\hline $135 \mathrm{~A}$ & 87 & 5 & 17 \\
\hline 136 & 59 & 3 & 15 \\
\hline $136 \mathrm{~A}$ & 393 & 12 & 14 \\
\hline $136 \mathrm{~B}$ & 162 & 4 & 10 \\
\hline 137 & 294 & 3 & 8 \\
\hline 138 & 145 & 3 & 5 \\
\hline 139 & 41 & 1 & 9 \\
\hline 140 & 26 & 2 & 2 \\
\hline 141 & 30 & 1 & 1 \\
\hline 142 & 131. & 3 & 5 \\
\hline 143 & 225 & 3 & 3 \\
\hline 144 & 393 & 11 & 18 \\
\hline 145 & 88 & 3 & 5 \\
\hline 146 & 42 & 1 & 3 \\
\hline 147 & 207 & 3 & 3 \\
\hline 148 & 307. & 3 & 5 \\
\hline 149 & 418 & 10 & 14 \\
\hline 150 & 96 & .4 & $\begin{array}{ll}\cdots & 4\end{array}$ \\
\hline 151 & 201 & 4 & 5 \\
\hline 152 & 0 & 0 & 0 \\
\hline 153 & 419 & 9 & 12 \\
\hline 154 & 203 & 12 & 14 \\
\hline 155 & 425 & 7 & 6 \\
\hline 156 & 124 & 3 & 2 \\
\hline 157 & 51 & 2 & 2 \\
\hline 158 & 275 & 8 & 7 \\
\hline 159 & 490 & .4 & 3 \\
\hline 160 & 336 & 3 & 3 \\
\hline 161 & 902 & 8 & 14 \\
\hline 162 & 141 & 6 & $\quad 7$ \\
\hline 163 & 149 & 2 & 1 \\
\hline 164 & 154 & .1 & $\cdots 1$ \\
\hline 165 & 402 & 1 & 1 \\
\hline 166 & 278 & 3 & 3 \\
\hline \multicolumn{4}{|l|}{ Totals } \\
\hline $\left.\begin{array}{l}5 J \\
6 J\end{array}\right\}$ & 9075 & 179 & 300 \\
\hline
\end{tabular}

Assembly 5J

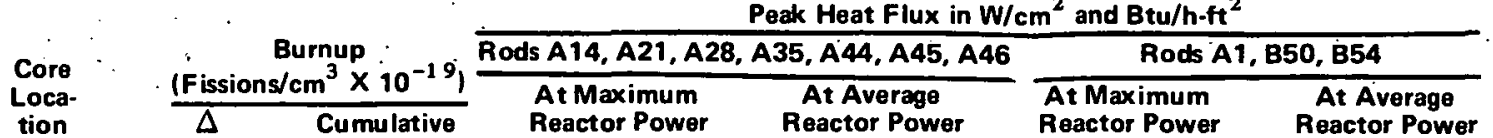

$\begin{array}{llllrlrrrrr}0.7 & 0.153 & 0.153 & 64 & 202,000 & 20 & 62,000 & 57 & 182,000 & 18 & 56,000 \\ & 0.008 & 0.161 & 30 & 95,000 & 12 & 37,000 & 27 & 86,000 & 11 & 34,000\end{array}$

$\begin{array}{llllllllll}0.353 & 0.514 & 60 & 189,000 & 40 & 127,000 & 54 & 170,000 & 36 & 114,000\end{array}$

$\begin{array}{llllllllll}1.354 & 1.868 & 60 & 189,000 & 51 & 161,000 & 54 & 170,000 & 46 & 145,000\end{array}$

$\begin{array}{llllllllll}0.520 & 2.388 & 37 & 182,000 & 32 & 103,000 & 52 & 164,000 & 29 & 93,000 \\ 0.109 & 2.497 & 57 & 182,000 & 25 & 79,000 & 52 & 164,000 & 22 & 71,000\end{array}$

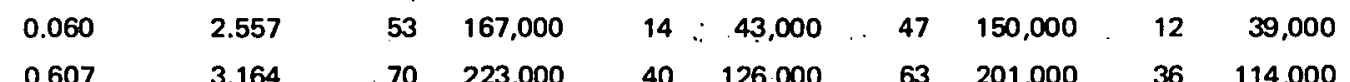

$0.607 \quad 3.164$

0.205

0.235

$0.049 \quad 4.187$

$0.036 \quad 4.256$

0.315

0.237
0.090

$0.052 \quad 6.379$

0.482

0.635

0.914

0.454

0.947

$0.441-10.460$

$1.034 \quad 11.494$

0.224

0.123

$0.490 \quad 12.331$

$0.714 \quad 14.120$

$\begin{array}{ll}1.702 & 15.822 \\ 0.191 & 16.013\end{array}$

$0.216 \quad 16.229$

$\begin{array}{ll}0.224 & 16.453 \\ 0.635 & 17.088\end{array}$

0.421

$\begin{array}{llll}63 & 201,000 & 36 & 114,000\end{array}$

$47 \quad 148,000 \quad 30: 96,000$

$\begin{array}{llll}42 & 133,000 & 27 & 86,000\end{array}$

$\begin{array}{llllllll}65 & 207,000 & 44 & 140,000 & 59 & 186,000 & 40 & 126,000\end{array}$

$\begin{array}{lllllllll}58 & 185,000 & 44 & 141,000 & 52 & 166,000 & =40 & 126,000\end{array}$

\begin{tabular}{llllllllll}
55 & 175,000 & 26 & 84,000 & 50 & 158,000 & $\ddots$ & 24 & 44,0000 \\
\hline
\end{tabular}

$\begin{array}{lllllllll}49 & 155,000 & 27 & 85,000 & 44 & 140,000 & 24 & \cdot 76,000\end{array}$

$\begin{array}{llllllll}80 & 253,000 & 67 & 211,000 & 72 & 228,000 & 60 & 190,000\end{array}$

$\begin{array}{llllllll}80 & 253,000 & 73 & 232,000 & 72 & 228,000 & 66 & 209,000\end{array}$

$\begin{array}{llllllll}4 & 135,000 & 19 & 59,000 & 38 & 122,000 & 17 & 53,000\end{array}$

$\begin{array}{llllllll}55 & 175,000 & 22 & 70,000 & 50 & 158,000 & 20 & 63,000\end{array}$

$\begin{array}{llllllll}77 & 244,000 & 59 & 186,000 & 69 & 220,000 & 5^{5} & 188,000\end{array}$

$\begin{array}{llllllll}850 & 255,000 & 49 & 154,000 & 73 & 230,000 & 44 & 139,000\end{array}$

$\begin{array}{llllllll}70 & 223,000 & 42 & 132,000 & 63 & 23,1000 & 46 & 146,000 \\ & & 38 & 119,000\end{array}$

$70 \quad 223,000$

$56 \quad 178,000$

$63 \quad 201,000 \quad 51 \quad 161,000$

$90 \quad 286,000$

$52 \quad 165,000$

$\begin{array}{llll}81 & 257,000 & 47 & 148,000\end{array}$

$\begin{array}{ll}69 & 220,000 \\ 81 & 256,000\end{array}$

$35 \quad 112,000$

$\begin{array}{llll}62 & 198,000 & 32 & 101,000 \\ 73 & 230,000 & 60 & 189,000\end{array}$

71. 225,000

$67 \quad 211,000$
$47 \quad 148,000$

$\begin{array}{llll}64 & 230,000 & 60 & 189,000 \\ 64 & 202,000 & 42 & 133,000\end{array}$

$73 \quad 232,000$

$\begin{array}{lr}48 & 183,000\end{array}$

$\begin{array}{llll}66 & 209,000 & 52 & 165,000\end{array}$

$\begin{array}{llllllll}55 & 176,000 & 48 & 152,000 & 50 & 158,000 & 43 & 137,000\end{array}$

$\begin{array}{lllll}70 & 209,000\end{array}$

$\begin{array}{ll}71 & 222,000 \\ 71 & 225,000\end{array}$

$63 \quad 201,000$

$63 \quad 200,000 \quad 59 \quad 188,000$

$\begin{array}{llllllll} & 175,000 & 36 & 17,0000 & 64 & 202,000 & 49 & 154,000\end{array}$

$\begin{array}{lllllllll}44 & 140,000 & 41 & 131,000 & 40 & 126,000 & 37 & 118,000\end{array}$

$\begin{array}{llllllll}47 & 150,000 & 42 & 133,000 & 43 & 135,000 & 38 & 119,000\end{array}$

$\begin{array}{lllllllll}17.088 & 50 & 157,000 & 47 & 150,000 & 44 & 141,000 & 42 & 134,000 \\ 17.509 & 50 & 157,000 & 38 & 121,000 & 44 & 141,000 & 34 & 109,000\end{array}$

\begin{tabular}{|c|c|c|c|c|c|c|c|c|c|c|}
\hline \multirow{4}{*}{$\begin{array}{l}\text { Core } \\
\text { Coca- } \\
\text { tion }\end{array}$} & & & \multirow{2}{*}{\multicolumn{8}{|c|}{ 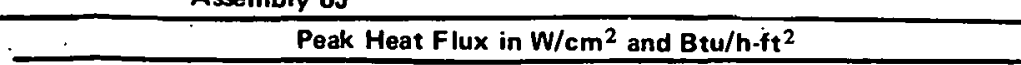 }} \\
\hline & & & & & & & & & & \\
\hline & \multirow{2}{*}{\multicolumn{2}{|c|}{$\begin{array}{c}\text { Burnup } \\
\left.\text { (Fissions/cm } / \mathrm{cm}^{3} \times 10^{-19}\right)\end{array}$}} & \multicolumn{4}{|c|}{ Rods A42, A48, A49, B56, B91, B97, B98 } & \multirow{2}{*}{\multicolumn{2}{|c|}{$\begin{array}{l}\text { Rods A47, } \\
\text { At aximum } \\
\text { Reactor Powar }\end{array}$}} & 14, B9? & \\
\hline & & $\frac{\left.m^{3} \times 10^{-19}\right)}{\text { Cumulative }}$ & \multicolumn{2}{|c|}{$\begin{array}{c}\text { At Maximum } \\
\text { Reactor Power }\end{array}$} & \multicolumn{2}{|c|}{$\begin{array}{c}\text { At Average } \\
\text { Reactor Power }\end{array}$} & & & \multicolumn{2}{|c|}{$\begin{array}{c}\text { At Average } \\
\text { Reactor Powe }\end{array}$} \\
\hline \multirow[t]{6}{*}{ D-11 } & 0.134 & 0.134 & 55 & 175,000 & 17 & 54,000 & 50 & 158,000 & 15 & 48,000 \\
\hline & 0.005 & 0.139 & 25 & 79.000 & 10 & 31,000 & 22 & 71,000 & 9 & 28,000 \\
\hline & 0.290 & 0.429 & 50 & 158,000 & 33 & 106,000 & 45 & 142,000 & 30 & 96,000 \\
\hline & 1.111 & 1.540 & 50 & 158,000 & 43 & 135,000 & 45 & 142,000 & 38 & 121,000 \\
\hline & 0.440 & 1.980 & 49 & 155,000 & 28 & 88,000 & 44 & 140,000 & 25 & 79,000 \\
\hline & 0.090 & 2.070 & 49 & 155,000 & 21 & 67,000 & 44 & 140,000, & 19 & 61,000 \\
\hline \multirow[t]{28}{*}{$G 6$} & 0.085 & 2.155 & 78 & 247,000 & 20 & 64,000 & 70 & 222,000 & 18 & 57,000 \\
\hline & 0.862 & 3.017 & 104 & 330,000 & 59 & 187,000 & 94 & 297,000 & 5.3 & 168,000 \\
\hline & 0.290 & 3.307 & 69 & 220,000 & 45 & 143,000 & 62 & 198,000 & 41 & 129,000 \\
\hline & 0.766 & 4.073 & 97 & 308,000 & 66 & 209,000 & 87 & 277,000 & 59 & 188,000 \\
\hline & 0.334 & 4.407 & 87 & 276,000 & 66 & 209,000 & 78 & 248,000 & 59 & 188,000 \\
\hline & 0.066 & 4.473 & 76 & 242,000 & 20 & 65,000 & 69 & 218,000 & 19 & 59,000 \\
\hline & 0.044 & 4.517 & 73 & 233,000 & 35 & 112,000 & 66 & 210,000 & 32 & 101,000 \\
\hline & 0.047 & 4.564 & 65 & 205,000 & 35 & 112,000 & 58 & 184,000 & 32 & 100,000 \\
\hline & 0.424 & 4.988 & 106 & 335,000 & 88 & 279,000 & 95 & 302,000 & 79 & 252,000 \\
\hline & 0.804 & 5.792 & 106 & 335,000 & 97 & 307,000 & 95 & 302,000 & 87 & 277,000 \\
\hline & 1.395 & 7.187 & 121 & 385,000 & 94 & 298,000 & 109 & 346,000 & 84 & 268,000 \\
\hline & 0.123 & 7.310 & 60 & 190,000 & 26 & 83,000 & 54 & 171,000 & 23 & 74,000 \\
\hline & 0,068 & 7.378 & 78 & 246,000 & 31 & 98,000 & 70 & 221,000 & 28 & 88,000 \\
\hline & 0.657 & 8.035 & 108 & 343,000 & 83 & 262,000 & 97 & 309,000 & 74 & 236,000 \\
\hline & 0.815 & 8.850 & 104 & 331,000 & 63 & 199,000 & 99 & 298,000 & 57 & 180,000 \\
\hline & 1.264 & 10.114 & 104 & 331,000 & 65 & 207,000 & 94 & 298,000 & 59 & 186,000 \\
\hline & 0.260 & 10.374 & 90 & 285,000 & 53 & 168,000 & 81 & $.256,000$ & 48 & 151,000 \\
\hline & 0.564 & 10.938 & 90 & 285,000 & 72 & 228,000 & 81 & 256,000 & 65 & 205,000 \\
\hline & - & 10.938 & & - & & - & & - & & - \\
\hline & 1.180 & 12.128 & 113 & 359,000 & 65 & 207,000 & 102 & 323,000 & 59 & 186,000 \\
\hline & 0.607 & 12.735 & 96 & 305,000 & 49 & 156,000 & 86 & 274,000 & 44 & 140,000 \\
\hline & 1.447 & 14.182 & 112 & 356,000 & 92 & 293,000 & 101 & 320,000 & 83 & 263,000 \\
\hline & 0.306 & 14.488 & 97 & 307,000 & 64 & 202,000 & 87 & 276.000 & 57 & 181,0חก \\
\hline & 0.167 & 14.655 & 100 & 317,000 & 79 & 250,000 & 90 & 285,000 & 71 & 224,000 \\
\hline & 0.722 & 15.377 & 76. & 241,000 & 66 & 208,000 & 68 & 217,000 & 59 & 187,000 \\
\hline & 1.480 & 16.857 & 91 & 288,000 & 85 & 271,000 & 82 & 259,000 & 77 & 243,000 \\
\hline & 0.993 & 17.850 & 91 & 288,000 & 82 & 260,000 & 82 & 259,000 & 74 & 234,000 \\
\hline & 2.306 & 20.156 & 93 & 294,000 & 71 & 225,000 & 84 & 265,000 & 64 & 202,000 \\
\hline \multirow{5}{*}{ H-13 } & 0.175 & 20.331 & 48 & 153,000 & 31 & 99,000 & 44 & 138,000 . & 28 & 89,000 \\
\hline & 0.197 & 20.528 & 38 & 122,000 & 36 & 114,000 & 35 & 110,000 & 32 & 103,000 \\
\hline & 0.189 & 20.717 & 37 & 117, חกח & 33 & 104,000 & 33 & 105,000 & 20 & 93,000 \\
\hline & 0.596 & 21.313 & 46 & 145,000 & 44 & 138,000 & 41 & 130,000 & 39 & 124,000 \\
\hline & 0.413 & 21.726 & 50 & 159,000 & 38 & 122,000 & 45 & 143,000 & 35 & 110,000 \\
\hline
\end{tabular}




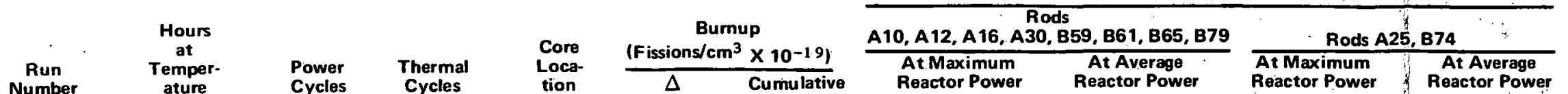

\begin{tabular}{|c|c|c|c|}
\hline 132 & 90 & 4 & 9 \\
\hline 133 & 11 & 0 & 6 \\
\hline $133 \mathrm{~A}$ & 227 & 5 & 12 \\
\hline 134 & 706 & 13 & 23 \\
\hline 135 & 347 & 9 & 28 \\
\hline $135 \mathrm{~A}$ & 87 & 5 & 17 \\
\hline 136 & 59 & 3 & 15 \\
\hline $136 \mathrm{~A}$ & 393 & 12 & 14 \\
\hline 1368 & 162 & 4 & 10 \\
\hline 137 & 294 & 3 & 8 \\
\hline 138 & 145 & 3 & 5 \\
\hline 139 & 41 & 1 & 9 \\
\hline 140 & 26 & 2 & 2 \\
\hline 141 & 30 & 1 & 1 \\
\hline 142 & 131 & 3 & 5 \\
\hline 143 & 225 & 3 & 3 \\
\hline 144 & 393 & 11 & 18 \\
\hline 145 & 88 & 3 & 5 \\
\hline 146 & 42 & 1 & 3 \\
\hline 147 & 207 & 3 & 3 \\
\hline 148 & 307 & 3 & 5 \\
\hline 149 & 418 & 10 & 14 \\
\hline 150 & 96 & 4 & 4 \\
\hline 151 & 201 & 4 & 5 \\
\hline 152 & 0 & 0 & 0 \\
\hline 153 & 419 & 9 & 12 \\
\hline 154 & 203 & 12 & 14 \\
\hline 155 & 425 & 7 & 6 \\
\hline 156 & 124 & 3 & 2 \\
\hline 157 & 51 & 2 & 2 \\
\hline 158 & 275 & 8 & 7 \\
\hline 159 & 490 & 4 & 3 \\
\hline 160 & 336 & 3 & 3 \\
\hline 161 & 902 & 8 & 14 \\
\hline 162 & 141 & 6 & 7 \\
\hline 163 & 149 & 2 & 1 \\
\hline 164 & 154 & 1 & 1 \\
\hline 165 & 402 & 1 & 1 \\
\hline 166 & 278 & 3 & 3 \\
\hline \multicolumn{4}{|l|}{ Totals } \\
\hline (8J 8 & 7347 & 164 & 280 \\
\hline
\end{tabular}

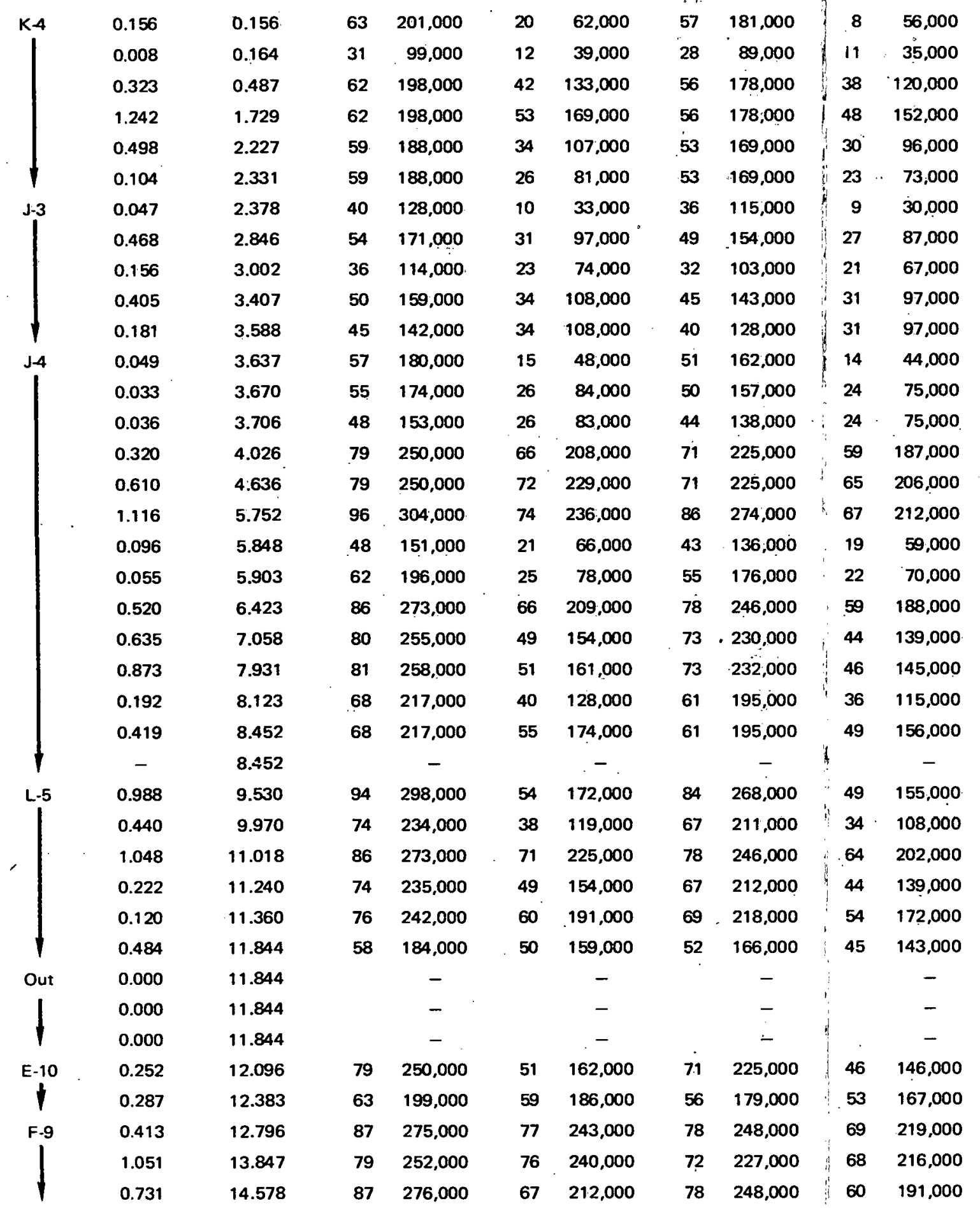

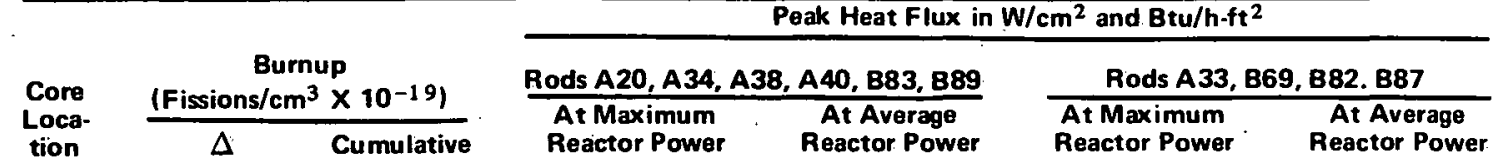

$\begin{array}{lll}\mathrm{J}-13 & 0.148 & 0.148 \\ & 0.008 & 0.156\end{array}$

$61 \quad 193,000$

$19 \quad 59,000$

$55 \quad 174,000$

35110,000

$14 \quad 43,000$

$31 \quad 99,000$

$17 \quad 53,000$ $0.364 \quad 0.520$

$1.398 \quad 1.918$

$\begin{array}{ll}0.572 & 2.490 \\ 0.118 & 2.608\end{array}$

$0.047 \quad 2.655$

$69 \quad 220,000$

$47 \quad 148,000$

$\begin{array}{ll}62 & 198,000 \\ 62 & 198,000\end{array}$

$\begin{array}{rr}12 & 39,000 \\ 42 & 133,000\end{array}$

$\begin{array}{llllllll}217,000 & 59 & 188,000 & 62 & 198,000 & 53 & 169,000\end{array}$

$\begin{array}{rrrrrrrr}68 & 217,000 & 30 & 94,000 & 61 & 195,000 & 26 & 84,000\end{array}$

$\begin{array}{llllllll}44 & 141,000 & 11 & 36,000 & 40 & 127,000 & 10 & 33,000\end{array}$

$\begin{array}{llllllll}59 & 188,000 & 34 & 107,000 & 53 & 169,000 & 30 & 96,000\end{array}$

$\begin{array}{llllllll}39 & 125,000 & 26 & 81,000 & 35 & 112,000 & 23 & 73,000\end{array}$

$55 \quad 175000 \quad 38 \quad 119,000 \quad 50 \quad 158,000 \quad 34 \quad 107,000$

$\begin{array}{llllllll}55 & 175,000 & 38 & 119,000 & 50 & 158,000 & 34 & 107,000\end{array}$

$\begin{array}{llllllll}56 . & 179,000 & 15 & 48,000 & 51 & 101,000 & 14 & 43,000\end{array}$

$\begin{array}{llllllll}55 & 173,000 & 26 & 83,000 & 49 & 156,000 & 24 & 75,000\end{array}$

$\begin{array}{lllllllll}55 & 173,000 & 26 & 83,000 & 49 & 156,000 & 24 & 75,000 \\ 57 & 181,000 & 31 & 99,000 & 51 & 163,000 & 28 & 89,000\end{array}$

$\begin{array}{llllllll}93 & 296,000 & 78 & 247,000 & 84 & 266,000 & 70 & 222,000\end{array}$

$\begin{array}{llllllll}93^{\circ} & 296,000 & 85 & 271,000 & 84 & 266,000 & 77 & 244,000\end{array}$

$\begin{array}{lllllllll}86 & 274,000 & 67 & 212,000 & 78 & 247,000 & 60 & 191,000\end{array}$

$\begin{array}{llllllll}45 & 142,000 & 20 & 62,000 & 40 & 128,000 & 18 & 56,000\end{array}$

$\begin{array}{llllllll}58 & 185,000 & 23 & 74,000 & 52 & 166,000 & 21 & 66,000\end{array}$

$81 \quad 256,000 \quad 62 \quad 196,000 \quad 73 \cdot 230,000 \quad 55 \quad 178,000$

$\begin{array}{llllllll}99 & 314,000 & 60 & 189,000 & 89 & 283,000 & 54 & 171,000\end{array}$

$\begin{array}{llllllll}88 & 280,000 & 55 & 175,000 & 79 & 252,000 & 50 & 157,000\end{array}$

$79 \begin{array}{llllllll}750,000 & 47 & 148,000 & 71 & 225,000 & 42 & 133,000\end{array}$

$\begin{array}{llllllll}79 & 250,000 & 63 & 200,000 & 71 & 225,000 & 57 & 180,000\end{array}$

$\begin{array}{llllllll}97 & 307,000 & 56 & 177,000 & 87 & 276,000 & 50 & 159,000\end{array}$

$\begin{array}{llllllll}72 & 229,000 & 37 & 117,000 & 65 & 206,000 & 33 & 105,000\end{array}$

$\begin{array}{llllllll}84 & 266,000 & 69 & 219,000 & 75 & 239,000 & 62 & 197,000\end{array}$

$\begin{array}{llllllll}71 & 225,000 & 47 & 148,000 & 64 & 202,000 & 42 & 133,000\end{array}$

$\begin{array}{llllllll}73 & 232,000 & 58 & 183,000 & 66 & 209,000 & 52 & 165,000\end{array}$

$\begin{array}{llllllll}55 & 176,000 & 48 & 152,000 & 50 & 158,000 & 43 & 137,000\end{array}$

$\begin{array}{llllllll}82 & 259,000 & 77 & 243,000 & 73 & 233,000 & 69 & 219,000\end{array}$

$\begin{array}{llllllll}82 & 259,000 & 74 & 234,000 & 73 & 233,000 & 66 & 210,000\end{array}$

$\begin{array}{llllllll}86 & 272,000 & 66 & 208,000 & 77 & 245,000 & 59 & 187,000\end{array}$

$\begin{array}{lllllllll}97 & 307,000 & 63 & 199,000 & 87 & 276,000 & 56 & 179,000\end{array}$

$\begin{array}{llllllll}77 & 245,000 & 72 & 229,000 & 69 & 220,000 & 65 & 206,000\end{array}$

$\begin{array}{llllllll}88 & 278,000 & 78 & 246,000 & 79 & 250,000 & 70 & 221,000 \\ 82 & 261,000 & 79 & 249,000 & 74 & 235,000 & 71 & 224,000\end{array}$

$\begin{array}{llllll:llll}87 & 276,000 & 67 & 212,000 & 78 & 248,000 & 60 & 191,000\end{array}$

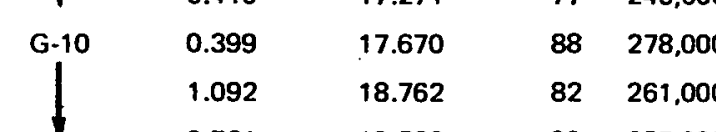

$81 \quad 256,000$

197,000 
Table B.1 (Continued).

\begin{tabular}{|c|c|c|c|}
\hline $\begin{array}{l}\text { Run } \\
\text { Number }\end{array}$ & $\begin{array}{l}\text { Hours } \\
\text { at } \\
\text { Temper- } \\
\text { aturre }\end{array}$ & $\begin{array}{l}\text { Power } \\
\text { Cycles }\end{array}$ & $\begin{array}{c}\text { Thermal al } \\
\text { Cycles }\end{array}$ \\
\hline 134 & 706 & 13. & 23 \\
\hline 135 & 347 & 9 & 28 \\
\hline $135 \mathrm{~A}$ & 87 & 5 & 17 \\
\hline 136 & 59 & 3 & 15 \\
\hline $136 \mathrm{~A}$ & 393 & 12 & 14 \\
\hline $136 \mathrm{~B}$ & 162 & 4 & 10 \\
\hline 137 & 294 & 3 & 8 \\
\hline 138 & 145 & 3 & 5 \\
\hline 139 & 41 & 1 & 9 \\
\hline 140 & 26 & 2 & 2 \\
\hline 141 & 30 & 1 & .1 \\
\hline 142 & 131 & 3 & 5 \\
\hline 143 & 225 & 3 & 3 \\
\hline 144 & 393 & 11 & 18 \\
\hline 145 & 88 & 3 & 5 \\
\hline 146 & 42 & 1 & 3 \\
\hline 147 & 207 & 3 & 3 \\
\hline 148 & 307 & 3 & 5 \\
\hline 149 & 418 & 10 & 14 \\
\hline 150 & 96 & 4 & 4 \\
\hline 151 & 201 & 4 & 5 \\
\hline 152 & 0 & 0 & 0 \\
\hline 153 & 419 & 9 & 12 \\
\hline 154 & 203 & 12 & 14 \\
\hline 155 & 425 & 7 & 6 \\
\hline 156 & 124 & 3 & 2 \\
\hline 157 & 51 & 2 & 2 \\
\hline 158 & 275 & 8 & 7 \\
\hline 159 & 490 & 4 & 3 \\
\hline 160 & 336 & 3 & 3 \\
\hline 161 & 902 & 8 & 14 \\
\hline 162 & $14 \uparrow$ & 6 & 7 \\
\hline 163 & 149 & 2 & 1 \\
\hline 164 & 154 & .1 & 1 \\
\hline 165 & 402 & 1 & 1 \\
\hline 1 1ศศ & 278 & 3 & 3 \\
\hline \\
\hline $\begin{array}{l}111 \\
12 J\end{array} \mid$ & 8747 & 170 & 273 \\
\hline
\end{tabular}

Assembly $11 \mathrm{~J}$

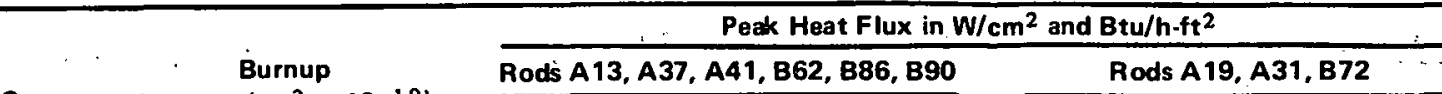
Rods A13, A37, A41, B62, B86, B90

Rods A 19, A31, B72

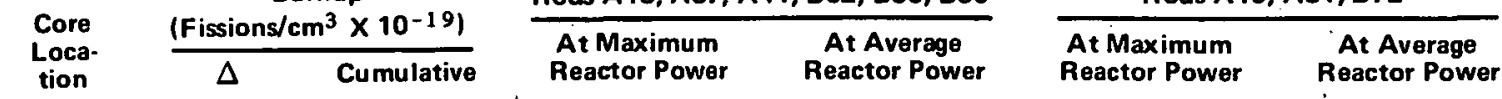
$\begin{array}{lllllllllll}\text { G.6. } & 2.301 & 2.301 & 103 & 327,000 & 88 & 279,000 & \therefore 93 & 294,000 & 79 & 251,000\end{array}$ $\begin{array}{lllllllllll}1.031 & 3.332 & 116 & 368,000 & 66 & 209,000 & 104 & 331,000 & .59 & 188,000\end{array}$ $\begin{array}{llllllllll}1.031 & 3.332 & 116 & 368,000 & .60 & 209,000 & 104 & 331,000 & 50 & 188,000 \\ 0.216 & 3.548 & .116 & 368,000 & 50 & 159,000 & 104 & 331,000 & 45 & 143,000\end{array}$

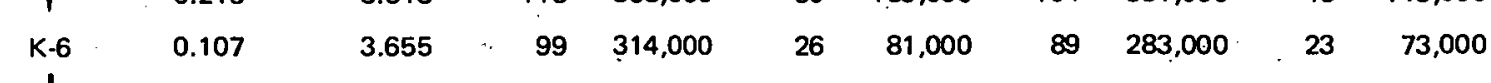
$\begin{array}{rrrrrrrrrr}1.042 & 4.697 & 132 & 418,000 & 75 & .237,000 & 119 & 376,000 & 67 & 213,000 \\ 0.361 & 5058 & 88 & 278,000 & 57 & 181,000 & 79 & 250,000 & 51 & 162,000\end{array}$ $\begin{array}{rrrrrrrrrrrr}0.361 & 5.058 & 88 & 278,000 & 57 & 181,000 & \ldots & 79 & 250,000 & 51 & 162,000 \\ 0.958 & 6.016 & 123 & 391,000 & 54 & 25,000 & 111 & 352,000 & 75 & 239,000\end{array}$ $\begin{array}{rrrrrrrrrr}0.419 & 6.435 & 110 & 349,000 & 84 & 265,000 & 111 & 352,000 & 75 & 239,000 \\ 0.060 & 69 & 314,000 & 75 & 239,000\end{array}$ $\begin{array}{lllllllllll}0.068 & 6.503 & 83 & 264,000 & 22 & 71,000 & 75 & 238,000 & 20 & 64,000\end{array}$ $\begin{array}{lllllllllllll}0.047 & 6.550 & 80 & 255,000 & 38 & 122,000 & .73 & 230,000 & 35 & 110,000\end{array}$ $\begin{array}{lllllllllllll}0.047 & 6.597 & 71 & 224,000 & \therefore & 38 & 122,000 & 64 & 202,000 & 35 & 110,000\end{array}$ $\begin{array}{llllllllllll}0.460 & \quad 7.057 & . . & 115 & 365,000 & 96 & 304,000 & 103 & 328,000 & 86 & 273,000\end{array}$ $\begin{array}{lllllllllll}0.867 & 7.924 & : 115 & 365,000 & 106 & 335,000 & 103 & .328,000 & 95 & 301,000\end{array}$ $\begin{array}{llllllllll}1.466 & 9.390 & 130 & 412,000 & 101 & 319,000 & 117 & 371,000 & .91 & 288,000\end{array}$ $\begin{array}{llllllllll}0.129 & 9.519 & 73 & 231,000 & 32 & 100,000 & 66 & 208,000 & .28 & 90,000\end{array}$ $\begin{array}{llllllllll}0.071 & 9.590 & 79 & 249,000 & 32 & 100,000 & 71 & 224,000 & 28 & 90,000\end{array}$ $\begin{array}{llllllllll}0.681 & 10.271 & 109 & 345,000 & 83 & 264,000 & 98 & 310,000 & 75 & 237,000\end{array}$ $\begin{array}{llllllllll}0.810 & 11.081 & 113 & 358,000 & 69 & 218,000 & 102 & 322,000 & 61 & 194,000\end{array}$

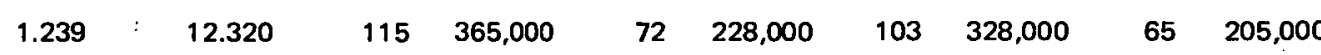
$\begin{array}{lllllllllll}0.276 & 12.596 & 96 & 303,000 & -56 & 179,000 & 86 & 273,000 & 51 & 161,000\end{array}$ $\begin{array}{llllllllll}0.596 & 13.192 & 96 & 303,000 & 76 & 242,000 & 86 & 273,000 & 69 & 218,000\end{array}$

$-13.192$

$\begin{array}{rrrrrrrrrr}1.338 & 14.530 & 127 & 402,000 & 73 & 232,000 & 114 & 362,000 & 66 & 209,000 \\ 0.572 & 15.102 & 91 & 289,000 & 46 & 147,000 & 82 & 260,000 & 42 & 133,000\end{array}$

$\begin{array}{llllllllll}1.357 & 16.459 & 106 & 337,000 & 87 & 277,000 & 96 & 303,000 & 79 & 249,000\end{array}$ $\begin{array}{llllllllll}0.306 & 16.765 & 100 & 316,000 & 66 & 208,000 & 90 & 284,000 & 59 & 187,000\end{array}$ $\begin{array}{llllllllll}0.167 & 16.932 & 103 & 326,000 & 81 & 257,000 & 92 & 293,000 & 73 & 231,000\end{array}$ $\begin{array}{llllllllll}0.673 & 17.605 & 78 & 248,000 & 67 & 214,000 & 70 & 222,000 & 61 & 192,000\end{array}$ $\begin{array}{llllllllll}1.767 & 19.372 & 114 & 360,000 & 107 & 338,000 & 102 & 324,000 & 96 & 305,000\end{array}$ $\begin{array}{llllllllll}1.185 & 20.557 & 114 & 360,000 & : 02 & 325,000 & 102 & 324,000 & .92 & 293,000\end{array}$ $\begin{array}{lllllllllll}2.109 & 22.666 & 99 & 315,000 & 76 & 241,000 & 90 & 284,000 & : & .68 & 217.000\end{array}$ $\begin{array}{llllllllll}0.383 & 23.049 & 99 & 315,000 & 64 & 204,000 & 90 & 284,000 & 58 & 184,000\end{array}$ $\begin{array}{lllllllllllll}0.435 & 23.484 & 79 & 249,000 & 73 & 233,000 & 71 & 224,000 & 66 & 209,000\end{array}$ $\begin{array}{llllllllll}0.451 & 23.935 & 85 & 270,000 & 75 & 239,000 & .77 & 243,000 & 68 & 215,000\end{array}$ $\begin{array}{ll}1.185 & 25.120\end{array}$ $\begin{array}{llll}.82 & 261,000 \quad 79 & 249,000\end{array}$

an 285, กחก $\quad 69 \quad 318,000$
109346,000

$10-348,000$

93. 295,000

Reactor Power

$98 \quad 311,000$ At Average
Reactor Power

348,000

$103 \quad 326,000$

$\begin{array}{rr}137 & 435,000 \\ 91 & 290,000\end{array}$

197,000

99313,000

84265,000

$28 \quad 406,000$

$26 \quad 84,000$

$\begin{array}{ll}99 & 313,000\end{array}$

$92 \quad 293,000$

78. 246,000

$24 \quad 392,000$

82. 261,000

$87 \quad 275,000$

15364,000

$15 \quad 365,000$

$103 \quad 328,000$

$90 \quad 284,000$

61. 194,000

216,000

237,000

388,000

$102 \quad 323,000$
112

67. 213,000

388,000

12356,000

$\begin{array}{ll}110 \quad 349,000 & 0\end{array}$

$110 \quad 349,000$

$\begin{array}{ll}114 & 361,000 \\ 57 & 181,000\end{array}$

$\begin{array}{ll}74 & 181,000 \\ 235,000\end{array}$

$88 \cdot 280,000$

$25 \quad 79,000$

$\begin{array}{ll}03 & 326,000\end{array}$

$30 \quad 94,000$

2325,000

$51 \quad 163,000$

$67 \quad 212,000$

$92 \quad 293,000$

$64 \quad 202,000$

$10 \quad 348,000$

$43 \quad 136,000$

$68 \quad 217,000$

54. 170,000

288,000

$73 \quad 230,000$

99313,000

$21 \quad 386,000$

$70 \quad$ 222,000

$32 \quad 259,000$

$\begin{array}{lll}307,000 & 50 & 157,000\end{array}$

$\begin{array}{ll}50 & 157,000 \\ 93 & 295,000\end{array}$

$109 \quad 346,000$
87

65 205,000

$102 \quad 322,000$

$80 \quad 254,000$

$102 \quad 322,000$

$\begin{array}{ll}63 & 140,000 \\ 44 & 14000\end{array}$

\begin{tabular}{ll}
$77 \quad 245,000$ \\
\hline
\end{tabular}

$67 \quad 212,000$

89281,000

$84 \quad 265,000$

$96 \quad 305,000$

$90 \quad 287,000$
87

305,000

$87 \quad 276,000$

$\begin{array}{lll}68 & 186.000\end{array}$

$\begin{array}{lll}309,000 & 74 & 236,000\end{array}$

$\begin{array}{ll}95 & 302,000\end{array}$

$\begin{array}{ll}74 & 236,000 \\ 62 & 196,000\end{array}$

$\begin{array}{ll}76 & 242,000\end{array}$

$\begin{array}{ll}79 & 251,000 \\ 83 & 264,000\end{array}$

71226,000

$70 \quad 222,000$

$79 \quad 251,000$

05 202,000

$\begin{array}{llll}86 & 274,000 & 81 & 258,000\end{array}$

$\begin{array}{lllll}86 & 274,000 & 78 & 248,000\end{array}$

$\begin{array}{llll}88 & 278,000 & 67 & 212,000\end{array}$

$\begin{array}{llll}86 & 272,000 & 55 & 176,000\end{array}$

$\begin{array}{llll}69 & 218,000 & 64 & 204,000\end{array}$

$\begin{array}{llll}71 & 226,000 & 63 & 200,000\end{array}$

$\begin{array}{llll}75 & 238,000 & 72 & 227,000\end{array}$

B) IYb, UUU 

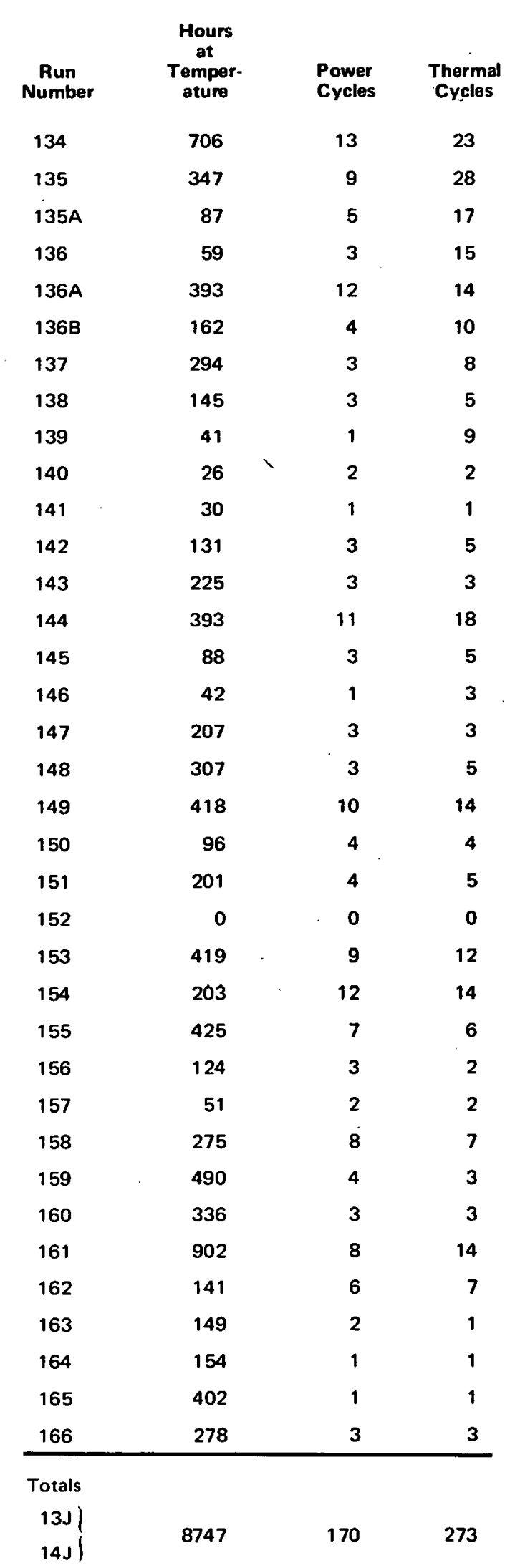

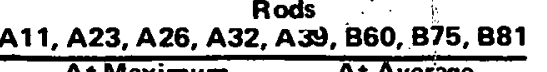

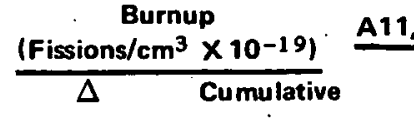

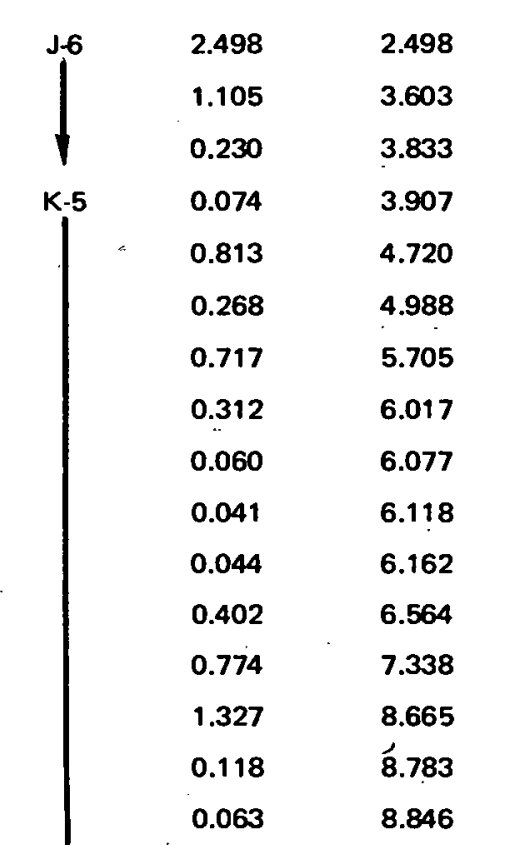

0.063

G.11 0.832

$0.260 \quad 11.891$

0.569

0.566

$\begin{array}{ll}1.330 & 15.606 \\ 0.309 & 15015\end{array}$

$0.309 \quad 15.915$

$\begin{array}{ll}0.167 & 16.082 \\ 0.673 & 16.755\end{array}$

$\begin{array}{ll}1.726 & 18.481 \\ 1.152 & 19.633\end{array}$

$2.315 \quad 21.948$

$0.347 \quad 22.295$

$0.386 \quad 22.681$

$0.410 \quad 23.09$

$\begin{array}{ll}1.078 & 24.167 \\ 0.747 & 24.916\end{array}$
112356,000

$127 \quad 402,000$

$127 \quad 402,000$

$\begin{array}{ll}72 & 229,000\end{array}$

96305,000

64204,000

285,000

80255,000

228,000

$69 \quad 219,000$

61193,000

99315,000

315,000

$55 \quad 175000$

$72 \quad 227,000$

$\begin{array}{ll}99 & 315,000\end{array}$

$118 \quad 373,000$

$120 \quad 381,000$

289,000

91289,000

$121 \quad 385,000$

$\begin{array}{rr}88 & 279,000 \\ 102 & 325,000\end{array}$

$94 \quad 297,000$

$96 \quad 306,000$

$73 \quad 233,000$

$\begin{array}{ll}113 & 358,000 \\ 113 & 358,000\end{array}$

$93 \quad 296,000$

$100 \quad 316,000$

$\begin{array}{ll}79 & 251,000 \\ 86 & 273,000\end{array}$

$\begin{array}{ll}86 & 272,000\end{array}$

$94,297,000$
At Average
Reactor Power

Rods B66. B73

228,000

$\begin{array}{ll}101 & 320,000 \\ 114 & 362,000\end{array}$

174,000

$\begin{array}{rr}19 & 59,000 \\ 55 & 173,000\end{array}$

$\begin{array}{llll}114 & 362,000 & 50 & 157,000\end{array}$

$42 \quad 133,000$

$\begin{array}{lllr}86 & 274,000 & 49 & 155,000\end{array}$

$\begin{array}{lllll}58 & 184,000 & 38 & 120,000\end{array}$

193,000

19. 61,000

$33 \cdot 105,000$

$\begin{array}{ll}33 & 105,000 \\ 83 & 262,000\end{array}$

$55 \quad 174,000$

65 $205,000-17-5,000$

$\begin{array}{llll}62 & 197,000 & 30 & 95,000\end{array}$

$\begin{array}{llllll}289,000 & 90 & 284,000 & 82 & 260,000\end{array}$

$65 \quad 207,000$

$24 \quad 76,000$

$\begin{array}{lr}76 & 241,000\end{array}$

240,000 की 186,000

$\begin{array}{llll}50 & 158,000 & 22 & 69,000\end{array}$

$\begin{array}{llll}50 & 158,000 & 22 & 69,000 \\ 64 & 204,000 & 26 & 82,000\end{array}$

$\begin{array}{rllll}90 & 284,000 & 68 & 217,000\end{array}$

$\begin{array}{llllll}71 & 225,000 & 106 & 336,000 & 64 & 203,000 \\ 75 & 238,000 & 108 & 343,000 & 67 & 214,000\end{array}$

$\begin{array}{lllllllllllll}54 & 171000 & 82 & 260,000 & 48 & 153000\end{array}$

73231,000

$70 \quad 222,000$

260,000

153,000

$\begin{array}{ll}45 & 142,000\end{array}$

$109 \quad 346,000$

$-$

$84 \quad 267,000$

$\begin{array}{lll}79 & 251,000\end{array}$

$\begin{array}{lll}40 \quad 128,000 & \end{array}$

195,000

$\begin{array}{lll}76 & 240,000\end{array}$

$76 \quad 241,000$

$\begin{array}{lllll}84 & 267,000 & 55 & 175,000\end{array}$

63201,000

87.000

$68 \quad 217,000$

\begin{tabular}{ll}
106 & 337,000 \\
\hline & 323,000
\end{tabular}

$\begin{array}{lll}102 & 322,000\end{array}$

57181,000

71226,000

$\begin{array}{llll}102 & 322,000 & 92 & 291,000\end{array}$

$\begin{array}{llllll}205,000 & 90 & 284,000 & 58 & 184,000\end{array}$

$\begin{array}{llllll}235,000 & 71 & 226,000 & 67 & 211,000\end{array}$

$76 \quad 242,000$

$78 \quad 246,000$

$\begin{array}{ll}72 & 229,000\end{array}$

$\begin{array}{ll}77 & 245,000 \\ 84 & 267,000\end{array}$

$\begin{array}{ll}69 & 218,000 \\ 73 & 233,000\end{array}$

$\begin{array}{ll}73 & 233,000 \\ 65 & 205,000\end{array}$

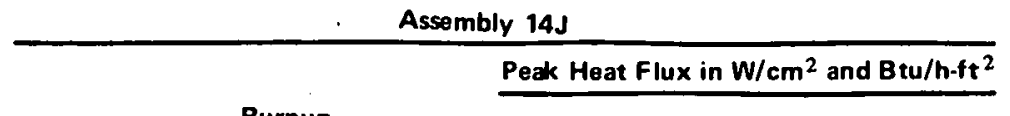

Core
$\begin{gathered}\text { Coca- } \\ \text { tion }\end{gathered}$$\quad \frac{\begin{array}{c}\text { Burnup } \\ \left(\text { Fissions } / \mathrm{cm}^{3} \times 10^{-19}\right)\end{array}}{\Delta \quad \text { Cumulative }}$

Rods A18, A24, B67

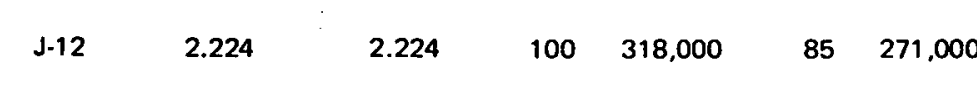

$\begin{array}{lllllll}\text { L.6 } & 0.224 & 2.224 & 100 & 318,000 & 85 & 271,000\end{array}$

$\begin{array}{llllll}0.186 & 3.332 & 114 & 360,000 & 49 & 156,000\end{array}$

$\begin{array}{llllll}0.085 & 3.417 & 81 & 256.000 & 21 & 66,000\end{array}$

$\begin{array}{llllll}0.873 & 4.290 & 108 & 341,000 & 61 & 193,000\end{array}$

$\begin{array}{llllll}0.287 & 4.577 & 72 & 227,000 & 47 & 148,000\end{array}$

$\begin{array}{llllll}0.774 & 5.351 & 100 & 318,000 & 68 & 216,000\end{array}$

\begin{tabular}{lllllll}
\hline & 0.331 & 5.682 & 90 & 284,000 & 68 & 216,000
\end{tabular}

$\begin{array}{lllllll}\text { E.10 } & 0.063 & 5.745 & 71 & 225,000 & 19 & 61,000\end{array}$

\begin{tabular}{|llllll}
0.041 & 5.786 & 68 & 216,000 & 33 & 104,000
\end{tabular}

$\begin{array}{llllll}0.047 & 5.833 & 60 & 191,000 & 33 & 104,000\end{array}$

$\begin{array}{llllll}0.389 & 6.222 & 98 & 312,000 & 82 & 260,000\end{array}$

$\begin{array}{llllll}0.750 & 6.972 & 98 & 312,000 & 90 & 286,000\end{array}$

\begin{tabular}{lllllll}
\hline-12 & 0.096 & 8.354 & 118 & 375,000 & 92 & 291,000
\end{tabular}

\begin{tabular}{|llllll}
0.052 & 8.502 & 61 & 195,000 & 25 & 78,000
\end{tabular}

$\begin{array}{lllllll} & 0.520 & 9.022 & 85 & 269,000 & 65 & 205,000 \\ M-11 & 0.711 & 9.733 & 98 & 310,000 & 59 & 187,000\end{array}$

\begin{tabular}{|llllll}
1.040 & 10.773 & 93 & 294,000 & 58 & 184,000
\end{tabular}

$\begin{array}{lllll}10.986 & 73 & 232,000 & 43 & 137,000\end{array}$

$\begin{array}{lll}11.451-73 \quad 232,000-59 & 186,000\end{array}$

11.451

\begin{tabular}{lllllll}
\hline & 0.988 & 12.439 & 98 & 311,000 & 57 & 180,000
\end{tabular}

$\begin{array}{lllllll}\text { N-8 } & 0.391 & 12.830 & 59 & 187,000 & 30 & 95,000\end{array}$

$\begin{array}{lllllll}M .8 & 1.220 & 14.050 & 89 & 283,000 & 73 & 233,000\end{array}$

$14,408 \quad 121 \quad 3850$

$\begin{array}{lllllll}14.408 & 121 & 305,000 & 80 & 253,000\end{array}$

$\begin{array}{lllll}14.605 & 125 & 306,000 & 98 & 312,000\end{array}$

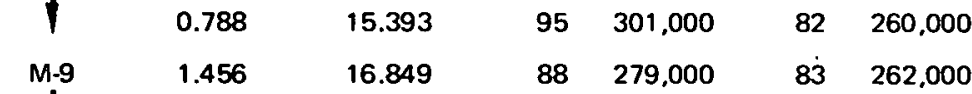

$\begin{array}{cllllll}\text { M.-9 } & 1.456 & 16.849 & 88 & 279,000 & 83 & 262,000 \\ & 0.974 & 17.823 & 88 & 279,000 & 79 & 252,000\end{array}$

$\begin{array}{llllll}20.387 & 98 & 311.000 & 75 & 237,000\end{array}$

$\begin{array}{lllll}20.628 & 69 & 219,000 & 45 & 142,000\end{array}$

$20.904 \quad 55 \quad 170,000-525155000$

$\begin{array}{lllll}21.985 & 57 & 182,000 & 55 & 173,000\end{array}$

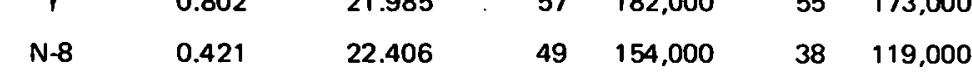


rable B-1 (Continued)

Assembly 16

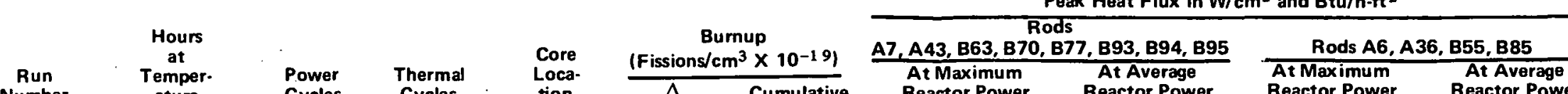

\begin{tabular}{|c|c|c|c|}
\hline & & & \\
\hline 135 & 347 & 9 & 28 \\
\hline $135 \mathrm{~A}$ & 87 & 5 & 17 \\
\hline 136 & 59 & 3 & 15 \\
\hline $136 \mathrm{~A}$ & 393 & 12 & 14 \\
\hline $136 \mathrm{~B}$ & 162 & 4 & 10 \\
\hline 137 & 294 & 3 & 8 \\
\hline 138 & 145 & 3 & 5 \\
\hline 139 & 41 & 1 & 9 \\
\hline $140^{\circ}$ & 26 & 2 & 2 \\
\hline 141 & 30 & 1 & 1 \\
\hline 142 & 131 & 3 & 5 \\
\hline 143 & 225 & 3 & 3 \\
\hline 144 & 393 & 11 & 18 \\
\hline 145 & 88 & 3 & 5 \\
\hline 146 & 42 & 1 & 3 \\
\hline 147 & 207 & 3 & 3 \\
\hline 148 & 307 & 3 & 5 \\
\hline 149 & 418 & 10 & 14 \\
\hline 150 & 96 & 4 & 4 \\
\hline 151 & 201 & 4 & 5 \\
\hline 152 & 0 & 0 & 0 \\
\hline 153 & 419 & 9 & 12 \\
\hline 154 & 203 & 12 & 14 \\
\hline 155 & 425 & 7 & 6 \\
\hline 156 & 124 & 3 & 2 \\
\hline 157 & 51 & 2 & 2 \\
\hline 158 & 275 & 8 & 7 \\
\hline 159 & 490 & 4 & 3 \\
\hline 160 & 336 & 3 & 3 \\
\hline 161 & 902 & 8 & 14 \\
\hline 162 & 141 & 6 & 7 \\
\hline 163 & 149 & 2 & 1 \\
\hline 164 & 154 & 1 & 1 \\
\hline 165 & 402 & 1 & 1 \\
\hline 166 & 278 & 3 & 3 \\
\hline \multicolumn{4}{|l|}{ Totals } \\
\hline $16 \mathrm{~J}$ & 8041 & 157 & 250 \\
\hline $17 \mathrm{~J}$ & 7168 & 137 & 192 \\
\hline
\end{tabular}

\begin{tabular}{|c|c|c|c|c|c|c|}
\hline \multirow{3}{*}{$\begin{array}{l}\text { Core } \\
\text { Loca- } \\
\text { tion }\end{array}$} & & \multicolumn{4}{|c|}{ Peak Heat Flux in W/cm² and Btu/h-ft } \\
\hline & \multicolumn{2}{|c|}{$\begin{array}{c}\left.\begin{array}{c}\text { Burnup } \\
\text { (Fissions/cm }\end{array} \mathrm{cm}^{3} \times 0^{-19}\right) \\
\end{array}$} & \multicolumn{4}{|c|}{ Rods A3, A4, A15, A22 } \\
\hline & $\Delta$ & Cumulative & & $\begin{array}{l}\text { I acaximum } \\
\text { actor Power }\end{array}$ & & $\begin{array}{l}\text { it Average } \\
\text { actor Power }\end{array}$ \\
\hline \multirow{2}{*}{ out } & 0.000 & 0.000 & & - & & . \\
\hline & 0.000 & 0.000 & & - & & - \\
\hline \multirow[t]{3}{*}{$F-5$} & 0.066 & 0.066 & 57 & 181,000 & 15 & 47,000 \\
\hline & .0 .673 & 0.739 & 76 & 242,000 & 43 & 137,000 \\
\hline & 0.227 & 0.966 & 51 & 161,000 & 33 & 105,000 \\
\hline \multirow{2}{*}{$\begin{array}{c}\text { Out: } \\
\dagger\end{array}$} & 0.000 & 0.966 & & - & & - \\
\hline & 0.000 & 0.966 & & - & & - \\
\hline \multirow{8}{*}{$\left.\right|^{F-5 i}$} & 0.052 & 1.018 & 59 & 187,000 & 16 & 50,000 \\
\hline & 0.033 & 1.051 & 57 & 180,000 & 27 & 86,000 \\
\hline & 0.033 & 1.084 & 50 & 159,000 & 27 & 87,000 \\
\hline & 0.328 & 1.412 & 82 & 260,000 & 68 & 217,000 \\
\hline & 0.627 & 2.039 & 82 & 260,000 & 75 & 238,000 \\
\hline & 1.146 & 3.185 & 100 & 317,000 & 78 & 246,000 \\
\hline & 0.098 & 3.283 & 49 & 155,000 & 21 & 67,000 \\
\hline & 0.057 & 3.340 & 63 & 200,000 & 25 & 80,000 \\
\hline \multirow{3}{*}{ 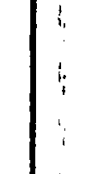 } & 0.534 & 3.874 & 87 & 277,000 & 67 & 212,000 \\
\hline & 0.624 & 4.498 & 86 & 273,000 & 52 & 165,000 \\
\hline & 0.958 & 5.456 & 87 & 275,000 & 54 & 172,000 \\
\hline & 0.219 & 5.675 & 74 & 236,000 & 44 & 139,000 \\
\hline \multirow[t]{3}{*}{ is } & 0.473 & 6.148 & 74 & 236,000 & 60 & 189,000 \\
\hline & - & 6.148 & & - & - & \\
\hline & 0.990 & 7.138 & 93 & 296,000 & 54 & 171,000 \\
\hline & 0.468 & 7.606 & 79 & 252,000 & 41 & 129,000 \\
\hline & 1.097 & 8.703 & 93 & 294,000 & 76 & 242,000 \\
\hline & 0.241 & 8.944 & 77 & 245,000 & 51 & 161,000 \\
\hline & 0.131 & 9.075 & 80 & 253,000 & 63 & 199,000 \\
\hline & 0.531 & 9.606 & 61 & 192,000 & 52 & 166,000 \\
\hline & 1.138 & 10.744 & 72 & 227,000 & 67 & 213,000 \\
\hline \multirow{2}{*}{$\vdots$} & 0.766 & 11.510 & 72 & 227,000 & 65 & 205.000 \\
\hline & 1.726 & 13.236 & 70 & 222,000 & 54 & 170,000 \\
\hline \multirow[t]{2}{*}{$i$} & 0.205 & 13.441 & 59 & 188,000 & 38 & 122,000 \\
\hline & 0.233 & 13.674 & 47 & 150,000 & 44 & 140,000 \\
\hline \multirow[t]{3}{*}{$d_{i}$} & 0.238 & 13.912 & 49 & 156,000 & 44 & 138,000 \\
\hline & 0.602 & 14.514 & 46 & 147,000 & 44 & 140,000 \\
\hline & 0.410 & $14.930^{\circ}$ & 51 & 161,000 & 39 & 124,000 \\
\hline
\end{tabular}


APPENDIX C

\section{DRESDEN REACTOR WATER CHEMISTRY}


Table C-1

DRESDEN REACTOR WATER CHEMISTRY ${ }^{\dagger}$

June
July
August
September
October
November
December

$\begin{array}{ll}6.7 & 7.5 \\ 6.6 & 7.3 \\ 6.4 & 7.4 \\ 6.4 & 7.7 \\ 6.7 & 7.5 \\ 6.5 & 7.4 \\ 7.2 & 7.7\end{array}$

8.2
8.4
8.2
8.9
8.5
8.7
8.8

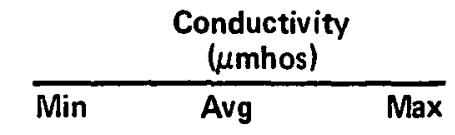

January

February March

Cycle Average

\section{Cycle No. 4-1965}

June
July
August
September
October
November
December

$\begin{array}{ll}6.9 & 7.5 \\ 7.1 & 7.5 \\ 7.3 & 7.7 \\ 7.6 & 8.3 \\ 6.7 & 7.7 \\ 6.8 & 8.0 \\ 7.1 & 7.5\end{array}$

1966

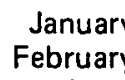

February

March

April

May

June
July

August

September

October

November

December

$\begin{array}{ll}7.2 & 8.0 \\ 6.8 & 7.9 \\ 6.6 & 7.8 \\ 6.5 & 7.8 \\ 6.9 & 7.7 \\ 6.0 & 7.2 \\ 6.6 & 7.6 \\ 4.2^{*} & 7.4 \\ 6.1 & 7.4 \\ 6.3 & 7.6 \\ 4.7^{*} & 7.7 \\ 6.4 & 7.5\end{array}$

8.7
8.4
8.8
8.5
8.1
8.2
8.5
8.3
8.1
8.2
8.5
8.3

1967

January

Cycle Average

$\begin{array}{lll}7.0 & 8.0 & 9.2 \\ 7.2 & 8.0 & 8.8 \\ 7.2 & 8.0 & 9.2 \\ 6.8 & 7.6 & 8.7\end{array}$

\subsection{6}

$\begin{array}{ll}0.41 & 0.98\end{array}$

$0.36 \quad 0.58$

$0.47 \quad 0.97$

0.49

0.48

0.28

0.40

0.92

\subsection{5}

0.30

0.27

\subsection{1}

0.46

0.43

0.45

\subsection{5}

0.44

0.38

0.38

0.42

0.39

0.44

0.59
0.59

0.62

0.73

0.30

0.29

0.65

0.59
.65

0.29

0.25
0.25

0.41

0.25
0.27

0.27

0.39

0.37

0.43

0.43

0.30

0.29

0.32

0.28

0.26

0.25

0.31

0.42

0.57

$0.43 \quad 0.74$

$\begin{array}{ll}0.43 & 0.74 \\ 0.38 & 0.62\end{array}$

0.44

1.30

$$
0.29
$$

0.28

$\begin{array}{ll}0.46 & 0.81 \\ 0.42 & 0.72\end{array}$

0.31
0.27
0.23
0.30
0.10
0.26
0.28

0.82
0.78
0.67
0.96

$\frac{\begin{array}{c}\text { Turbidity } \\ \text { (APHA Units) }\end{array}}{\text { Min } \quad \text { Avg Max }}$

1.2
4.2
5.2
3.2
2.4
2.6
3.0

6.6
11.0
14.1
8.0
6.1
5.0
5.2

22.0
30.0
24.4
40.0
10.0
9.2
8.4

2.4
1.8
1.2

\section{0}

3.8

4.6

9.2

8.4

26.0

18.8

\section{$0.41 \quad 0.73$}

\subsection{9}

3.0
2.6
2.4
1.8
4.0
1.8
2.6

6.2
5.3
4.0
4.7
15.2
3.9
5.3

14.0

14.0
10.2

7.0

7.0

95.0

7.4
10.2

$\begin{array}{ll}0.46 & 0.95 \\ 3.55^{*} & 72.00^{*}\end{array}$

$1.36^{*} \quad 28.50^{*}$

$\begin{array}{ll}3.0 & 7.3 \\ 3.0 & 6.0 \\ 3.0 & 5.4 \\ 2.2 & 4.8 \\ 2.8 & 6.6 \\ 1.0 & 3.5 \\ 1.8 & 3.5 \\ 2.4 & 6.8 \\ 4.8 & 7.5 \\ 2.6 & 6.2 \\ 2.2 & 7.3 \\ 2.2 & 7.8\end{array}$

22.0

22.0
12.6

18.0

8.0

15.4

11.2

5.0

20.4

14.4

19.2

44.0

2.0

2.6

\begin{abstract}
$4.7 \quad 12.0$
\end{abstract}
6.1

18.4

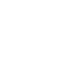

\begin{tabular}{lll} 
& $\begin{array}{c}\text { Chloride } \\
\text { (ppm) }\end{array}$ \\
\hline Min & Avg & Max
\end{tabular}

$\begin{array}{lll}0.001 & 0.029 & 0.030 \\ 0.007 & 0.034 & 0.05 \\ 0.023 & 0.037 & 0.10 \\ 0.001 & 0.047 & 0.17+ \\ 0.006 & 0.033 & 0.260 \\ 0.002 & 0.034 & 0.080 \\ 0.047 & 0.053 & 0.133\end{array}$

$\begin{array}{lll}0.026 & 0.041 & 0.100 \\ 0.017 & 0.069 & 0.192 \\ 0.020 & 0.043 & 0.118 \\ 0.015 & 0.042 & 0.138\end{array}$

$\begin{array}{rrl}0.004 & 0.031 & 0.084 \\ 0.001 & 0.038 & 0.189 \\ 0.008 & 0.032 & 0.083 \\ 0.014 & 0.041 & - \\ 0.02 & 0.05 & 0.30 \\ 0.010 & 0.043 & 0.150 \\ 0.001 & 0.038 & 0.189\end{array}$

$\begin{array}{rrr}0.018 & 0.081 & 0.138 \\ 0.010 & 0.037 & 0.107 \\ 0.001 & 0.039 & 0.082 \\ 0.005 & 0.031 & 0.061 \\ 0.005 & 0.045 & 0.106 \\ 0.008 & 0.040 & 0.070 \\ 0.02 & 0.05 & 0.160 \\ 0.014 & 0.06 C & 0.560^{*} \\ 0.016 & 0.038 & 0.064 \\ 0.017 & 0.033 & 0.049 \\ 0.005 & 0.028 & 0.043 \\ 0.010 & 0.040 & 0.084\end{array}$

$\begin{array}{rrr}0.01 & 0.032 & 0.044 \\ 0.010 & 0.041 & 0.111\end{array}$


Table C-1 (Continued)

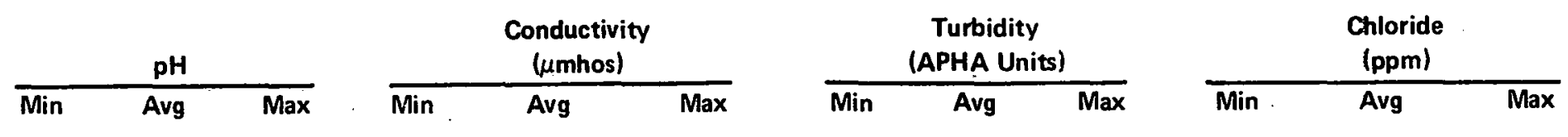

Cycle No. 5-1967

June
July
August
September
October
November
December

$\begin{array}{lll}6.4 & 7.4 & 8.2 \\ 6.8 & 7.5 & 8.8 \\ 6.3 & 7.2 & 8.8 \\ 6.2 & 7.4 & 8.4 \\ 6.3 & 7.2 & 8.3 \\ 6.2 & 7.4 & 8.3 \\ 5.8 & 7.0 & 8.9\end{array}$

$\begin{array}{lll}0.33 & 0.52 & 0.85 \\ 0.35 & 0.45 & 0.80 \\ 0.34 & 0.43 & 0.86 \\ 0.33 & 0.51 & 1.45 \\ 0.43 & 0.60 & 0.89 \\ 0.30 & 0.53 & 0.73 \\ 0.32 & 0.46 & 0.68\end{array}$

1.6
0.2
1.8
2.4
2.6
3.4
3.0

3.5
3.3
3.6
4.4
3.9
6.5
5.3

7.0
18.0
8.4
8.8
6.0
32.0
13.0

$\begin{array}{lll}0.014 & 0.032 & 0.057 \\ 0.014 & 0.048 & 0.280 \\ 0.023 & 0.041 & 0.117 \\ 0.021 & 0.039 & 0.110 \\ 0.024 & 0.034 & 0.046 \\ 0.020 & 0.038 & 0.092 \\ 0.020 & 0.038 & 0.160\end{array}$

1968

$\stackrel{\vec{N}}{\dot{N}}$

January
Cycle Average

$\begin{array}{ll}5.0 & 7.4 \\ 6.1 & 7.3\end{array}$

$8.7 \quad 0.32$

$\begin{array}{ll}0.45 & 0.64 \\ 0.51 & 0.86\end{array}$

1.8
2.1

$\begin{array}{ll}6.9 & 12.0 \\ 4.7 & 11.1\end{array}$

0.001

0.017

Cycle No. 6-1968

June
July
August
September
October
November
December

$\begin{array}{ll}6.3 & 7.2 \\ 6.0 & 6.8 \\ 6.5 & 7.2 \\ 5.8 & 7.1 \\ 7.0 & 7.7 \\ 6.1 & 7.2 \\ 6.1 & 6.8\end{array}$

8.7
7.9
8.2
8.1
8.4
8.2
8.5

$\begin{array}{ll}0.31 & 0.44 \\ 0.32 & 0.52 \\ 0.32 & 0.42 \\ 0.32 & 0.52 \\ 0.30 & 0.50 \\ 0.24 & 0.43 \\ 0.27 & 0.38\end{array}$

1.0
0.86
0.75
1.30
1.05
0.74
0.55

2.2
2.0
1.6
1.8
2.2
2.6
1.2

5.4
4.3
3.5
4.6
3.6
4.1
4.1

26.0
10.0
6.0
16.0
5.0
19.0
19.0

\subsection{1}

$$
0.000
$$

0.010

0.010
0.01

0.01
0.02
0.012

0.012
0.01

0.029

0.068

1969

January
February
March

$\begin{array}{lll}5.8 & 6.9 & 7.8 \\ 6.0 & 7.0 & 7.9 \\ 6.5 & 7.5 & 8.0 \\ 6.6 & 7.6 & 8.2 \\ 6.5 & 7.2 & 8.3 \\ 5.8 & 6.6 & 7.5 \\ 5.6 & 6.6 & 7.6 \\ 6.1 & 6.7 & 7.4\end{array}$

\subsection{6}

$\begin{array}{ll}0.35 & 0.49 \\ 0.41 & 0.60\end{array}$

2.2

4.0

4.0
5.2
3.9

0.41
0.41
0.47

0.60

2.2

0.29

0.30

0.28

$\begin{array}{ll}0.38 & 0.84 \\ 0.43 & 0.56\end{array}$

May

July

Cycle Average

$\begin{array}{lll}6.2 & 7.1 & 8.0\end{array}$

Four-Cycle Average

6.5

7.5

8.4

0.29

0.29

0.43

0.38

0.39

0.58

2.0
2.0

2.0

2.0
2.0

0.56

2.0

2.0

0.29

0.44

0.80

2.4

5.6

5.6
15.6

15.6
6.0

14.8

5.4

23.2

19.4

8.6

13.3

0.016

0.02

0.014

0.026

0.018

0.013

0.016

0.01

0.037

0.116

TData in this table were extracted from the monthly reports of the Commonwealth Edison Company on Dresden operation.

"These values were not included in the calculations of cycle averages. 
GEAP-10371

APPENDIX D

\section{DISTRIBUTION OF FISSIONS}

AMONO URANIUM ANU PLUTONIUM ISTOTOPES 
Table D-1

DISTRIBUTION OF FISSIONS AMONG URANIUM AND PLUTONIUM ISOTOPES

FOR FULL CROSS-SECTION FUEL SAMPLES

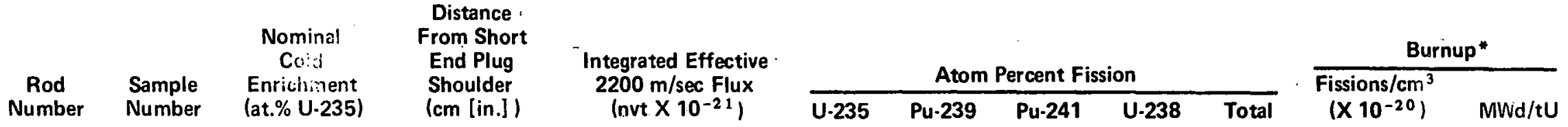

$\begin{array}{lll}\text { A46 } & 69 & 2.79 \\ \text { B70 } & 70 & 2.79 \\ \text { A41 } & 68 & 3.53\end{array}$

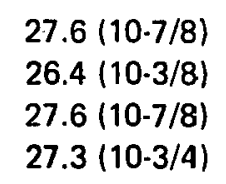

Initial Phase

$\begin{array}{llllllll}2.391 & 1.787 & 0.869 & 0.084 & 0.192 & 2.932 & 7.0 & 25,700 \\ 2.262 & 1.744 & 0.885 & 0.079 & 0.190 & 2.898 & 6.9 & 25,400 \\ 2.393 & 2.283 & 0.746 & 0.104 & 0.215 & 3.348 & 8.0 & 29,200 \\ 2.308 & 2.251 & 0.758 & 0.101 & 0.213 & 3.323 & 7.9 & 29,000\end{array}$

Final Phase

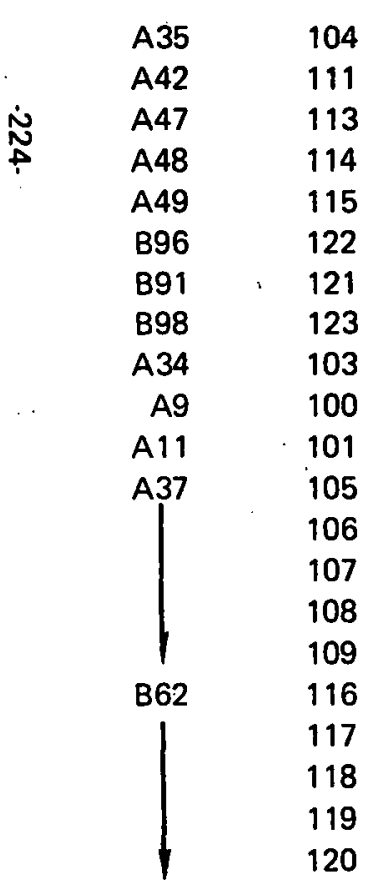
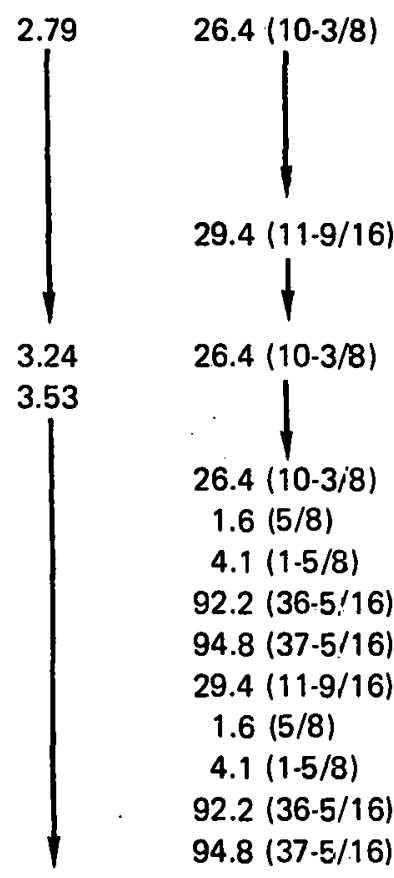

3.253
3.624
3.525
3.612
3.835
3.417
3.429
3.749
3.018
3.265
3.453
3.515
3.791
2.951
2.164
2.591
3.488
3.649
2.904
1.664
2.017

$\begin{array}{ll}2.032 & 1.076 \\ 2.089 & 1.191 \\ 2.075 & 1.196 \\ 2.087 & 1.226 \\ 2.116 & 1.224 \\ 2.059 & 1.138 \\ 2.061 & 1.161 \\ 2.087 & 1.218 \\ 2.300 & 0.994 \\ 2.546 & 1.038 \\ 2.588 & 1.107 \\ 2.600 & 1.145 \\ 2.648 & 1.045 \\ 2.468 & 0.858 \\ 2.184 & 0.596 \\ 2.356 & 0.681 \\ 2.596 & 1.190 \\ 2.624 & 1.040 \\ 2.455 & 0.864 \\ 1.912 & 0.481 \\ 2.115 & 0.549\end{array}$

$\begin{array}{lll}0.175 & 0.217 & 3.500 \\ 0.207 & 0.233 & 3.720 \\ 0.200 & 0.233 & 3.704 \\ 0.211 & 0.236 & 3.761 \\ 0.227 & 0.236 & 3.802 \\ 0.188 & 0.226 & 3.611 \\ 0.196 & 0.228 & 3.646 \\ 0.226 & 0.250 & 3.782 \\ 0.134 & 0.226 & 3.653 \\ 0.186 & 0.263 & 4.033 \\ 0.198 & 0.269 & 4.162 \\ 0.201 & 0.271 & 4.217 \\ 0.197 & 0.255 & 4.144 \\ 0.133 & 0.226 & 3.685 \\ 0.072 & 0.186 & 3.039 \\ 0.095 & 0.205 & 3.337 \\ 0.204 & 0.273 & 4.264 \\ 0.188 & 0.266 & 4.118 \\ 0.131 & 0.237 & 3.688 \\ 0.046 & 0.159 & 2.597 \\ 0.062 & 0.186 & 2.913\end{array}$

$\begin{array}{rr}8.39 & 30,680 \\ 8.93 & 32,630 \\ 8.89 & 32,490 \\ 9.03 & 33,000 \\ 9.13 & 33,360 \\ 8.66 & 31,670 \\ 8.75 & 31,980 \\ 9.08 & 33,180 \\ 8.74 & 31,960 \\ 9.65 & 35,280 \\ 9.97 & 36,430 \\ 10.10 & 36,910 \\ 9.92 & 36,250 \\ 8.81 & 32,200 \\ 7.25 & 26,500 \\ 7.96 & 29,110 \\ 10.22 & 37,340 \\ 9.86 & 36,020 \\ 8.82 & 32,220 \\ 6.19 & 22,630 \\ 6.95 & 25,390\end{array}$

From heav element data. 
Table D-2

DISTRIBUTION OF FISSIONS AMONG URANIUM AND FLUTONIUM ISOTOPES FOR FUEL SAMPLES FROM DIFFERENT RADIAL LOCATIONS

ROD A13

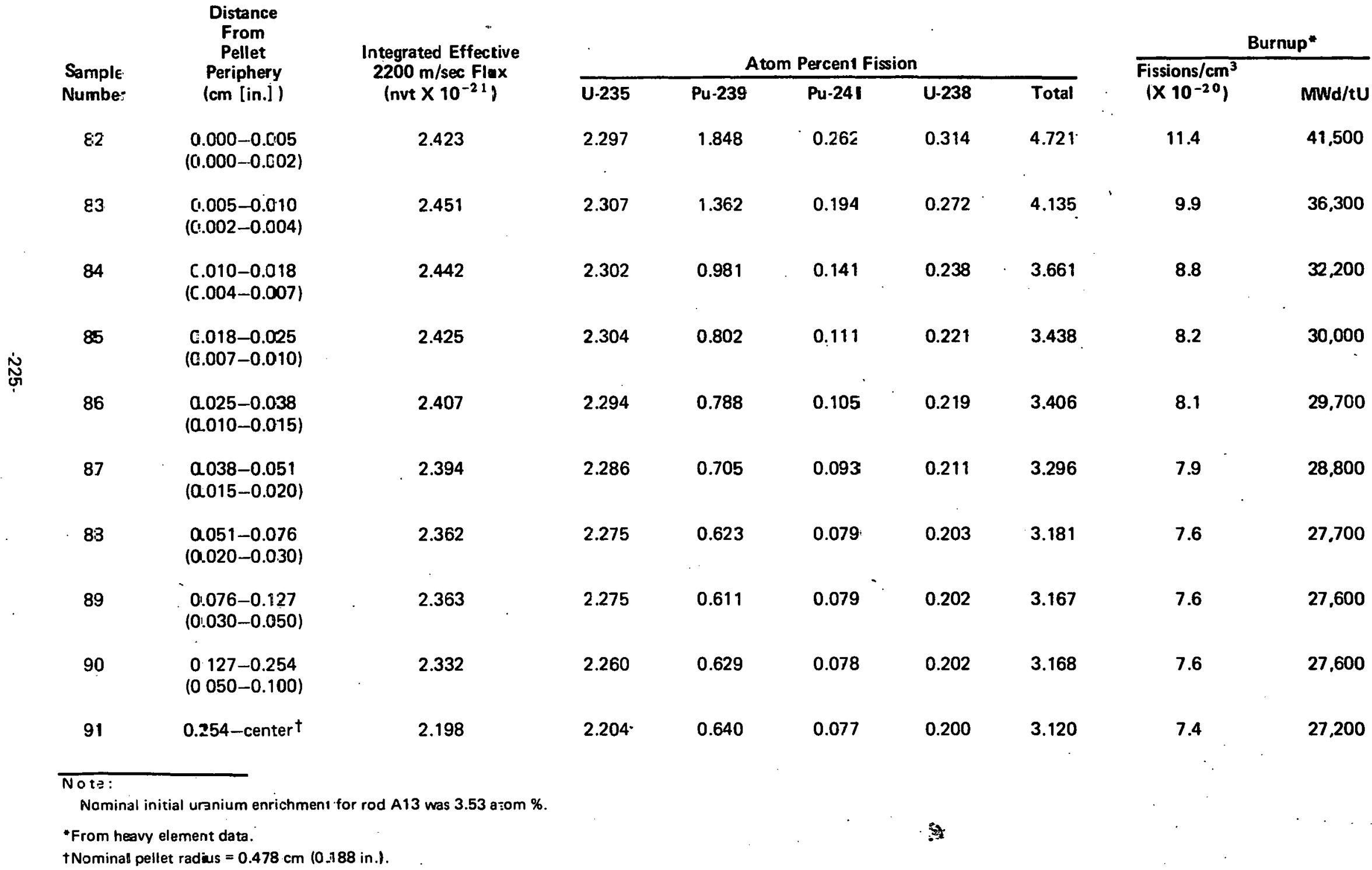


Table D-3

DISTRIBUTION OF FISSIONS AMONG URANIUM AND PLUTONIUM ISOTOPES

FOR FUEL SAMPLES FROM DIFFERENT RADIAL LOCATIONS

ROD B70

\begin{tabular}{|c|c|c|}
\hline $\begin{array}{l}\text { Sample } \\
\text { Number }\end{array}$ & $\begin{array}{l}\text { Distance } \\
\text { From } \\
\text { Pellet } \\
\text { Periphery } \\
\text { (cm [in.]) }\end{array}$ & $\begin{array}{l}\text { Integrated Effective } \\
2200 \mathrm{~m} / \mathrm{sec} \text { Flux } \\
\text { (nvt } \times 10^{-21} \text { ) }\end{array}$ \\
\hline 93 & $\begin{array}{c}0.000-0.005 \\
(0.000-0.002)\end{array}$ & 2.046 \\
\hline 94 & $\begin{array}{c}0.005-0.010 \\
(0.002-0.004)\end{array}$ & 2.418 \\
\hline 95 & $\begin{array}{c}0.010-0.018 \\
(0.004-0.007)\end{array}$ & 2.412 \\
\hline 96 & $\begin{array}{c}0.018-0.025 \\
(0.007-0.010)\end{array}$ & 2.415 \\
\hline 97 & $\begin{array}{c}0.025-0.038 \\
(0.010-0.015)\end{array}$ & 2.408 \\
\hline 98 & $\begin{array}{c}0.038-0.051 \\
(0.015-0.020)\end{array}$ & 2.356 \\
\hline 99 & $\begin{array}{c}0.051-0.076 \\
(0.020-0.030)\end{array}$ & 2.345 \\
\hline 100 & $\begin{array}{c}0.076-0.127 \\
(0.030-0.050)\end{array}$ & 2.323 \\
\hline 101 & $\begin{array}{c}0.127-0.254 \\
(0.050-0.100)\end{array}$ & 2.288 \\
\hline 102 & $\begin{array}{c}0.254-\text { center } t \\
(0.100 \text {-center })\end{array}$ & 2.237 \\
\hline
\end{tabular}

Note:

Nominal initial uranium enrichment for rod B70 was 2.79 at. $\%$.

*From heavy element data.

${ }^{\dagger}$ Nominal pellet radius $=0.478 \mathrm{~cm}(0.188 \mathrm{in}$.$) .$

\section{Atom Percent Fission}

U.235

Pu-239

Pu-241

1.680

1.901

0.267

1.822

1.467

0.200

0.140

$1.817 \quad 1.039$

0.919

0.121

1.815

1.809

0.824

0.107

0.701

0.089

1.797

0.682

0.084

1.795

1.783

0.811

0.102

0.189

1.776

0.706

0.083

0.173

2.738

1.736

0.667

0.076

0.172

2.652

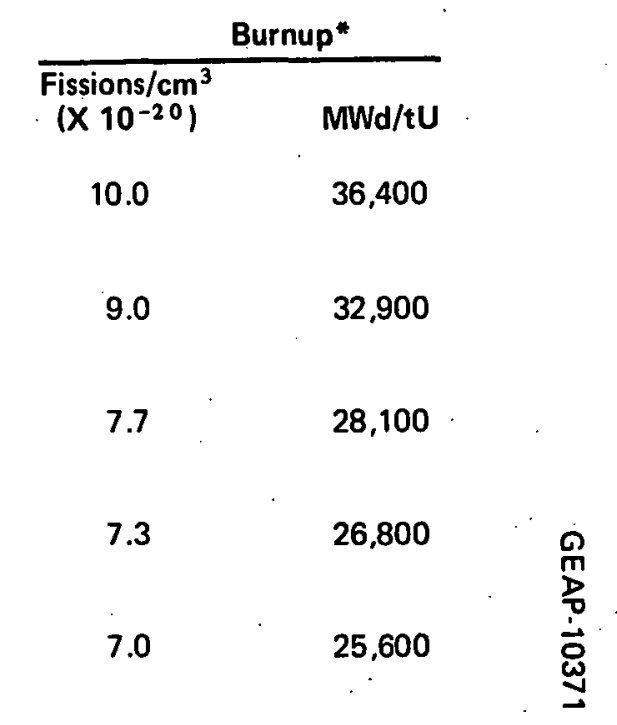

6.6

24,200

6.6

24,000

6.9

25,200

6.5

23,900

6.3

23,200 


\section{DISTRIBUTION}

Atomic Energy Commission San Francisco Operations Office 2111 Bancroft Way

Berkeley, California 94704

Arthur W. Larson

Site Representative

U.S. Atomic Energy Commission c/o General Electric Company 310 DeGuigne Avenue Sunnyvale, California 94086

U.S. Atomic Energy Commission Germantown, Maryland 20545

Attn: J.M. Simmons

U.S. Atomic Energy Commission Germantown, Maryland 20545

Attn: A. Van Echo

U.S. Atomic Energy Commission Germantown, Maryland 20545

Attn: J.A. Lieberman

U.S. Atomic Energy Commission Germantown, Maryland 20545

Attn: S.A. Szawlewicz

U.S. Atomic Energy Commission Germantown, Maryland 20545

Attn: M.A. Rosen

U.S. Atomic Energy Commission Germantown, Maryland 20545

Nttn: E.E. Kinluer

U.S. Atomic Energy Commission Germantown, Maryland 20545 Attn: D.E. Erb

U.S. Atomic Energy Commission Germantown, Maryland 20545

Attn: W.H. McVey

U.S. Atomic Energy Commission Germantown, Maryland 20545

Atttn: I.F. Tartman

U.S. Atomic Energy Commission Germantown. Maryland 20545 Attn: J.W. Vaughan
3

U.S. Atomic Energy Commission

Germantown, Maryland 20545

Attn: Document Library

U.S. Atomic Energy Commission

1 Chicago Operations Office 9800 South Cass Avenue Argonne, Illinois

Attn: M.E. Jackson, Senior Site Representative, ANL

U.S. Atomic Energy Commission

Oak Ridge Operations Office

Post Office Box E

Oak Ridge, Tennessee 37830

Attn: D.F. Cope, Senior Site Representative, ORNL

1 U.S. Atomic Energy Commission

Richland Operations Office

Richland, Washington

Attn: P.G. Holsted, Senior Site Representative, PNL

1

U.S. Atomic Energy Commission

20

Department of Technical Information Extension

Oak Ridge Operations Office

1 P.O. Box E

Oak Ridge, Tennessee 37830

Attn: R.L. Shannon

$1 \quad$ U.S. Atomic Energy Commission

Savannah River Operations Office

P.O. Box 8

Aiken, South Carolina 29801

1 Attn: N. Stetson

Ames Laboratory

lowa State University

2 Box 1129 ISU Station

Ames, lowa 50010

Attn: F.H. Spedding

1

Ames Lahoratory

lowa State University

Box 1129 ISU Station

Ames, lowa 50010

1 Attn: O.N. Carlson

Añies Laboratory 
Argonne National L_aboratory 9700 South Cass Avenue Argonne, lllinois 60440

Attn: R.C. Vogel

Argonne National Laboratory 9700 South Cass Avenue Argonne, Illinois 60440 Attn: M.V. Nevitt

Argonne National Laboratory 9700 South Cass Avenue Argonne, lllinois 60440

Attn: J.H. Kittel

Brookhaven National Laboratory Upton, New York 11973

Attn: Dey. Gurinsky

Los Alamos Scientific Laboratory P.O. Box 1663

Los Alamos, New Mexico 87544

Attn: D.E. Hall

Los Alamos Scientific Laboratory P.O. Box 1663

Los Alamos, New Mexico 87544

Attn: R.D. Baket

Oak Ridge National Laboratory Oak Ridge Operations Office P.O. Box E

Oak Ridge, Tennessee 37830 .

Attn: J.E. Cunningham

Oak Ridge National Laboratory

Oak Ridge Operations Office

P.O. Box E

Oak Ridge, Tennessee 37830

Attn: P. Patriarca

Oak Ridge National Laboratory

Oak Ridge Operations Office

P.O. Box E

Oak Ridge, Tennessee 37830

Attn: D.E. Ferguson

Oak Ridge National Laboratory

Oak Ridge Operations Office

P.O. Box E

Oak Ridge, Tennessee 37830

Attn: J.R. Weir
1 Pacific Northwest Laboratory

P.O. Box 999

Richland, Washington 99352

Attn: F.W. Albaugh

1 Pacific Northwest Laboratory P.O. Box 999

Richland, Washington 99352

Attn: J.J. Cadwell

1 Pacific Northwest Laboratory

P.O. Box 999

Richland, Washington 99352

Attn: A.L. Bement

1 Pacific Northwest Laboratory

P.O. Box 999

Richland, Washington 99352

Attn: E. Evans

Pacific Northwest Laboratory

P.O. Box 999

Richland, Washington 99352

Attn: R.L. Dillon

Pacific Northwest Laboratory

P.O. Box 999

Richland, Washington 99352

Attn: R.G. Wheeler

Atomics International

P.O. Box 301

Canoga Park, California 91304

Attn: S. Carniglia

Atomics International

1

1 P.O. Box 301

Canoga Park, California 91304

Attn: S. Arneson

Battelle Memorial Institute

505 King Avenue

1 Columbus, Ohio 43201

Attn: S. Paprocki

Battelle Memorial Institute

505 King Avenue

Columbus, Ohio 43201

Attn: D. Keller

1

Battelle Memorial Institute
505 King Avenue

Columbus, Ohio 43201

Attn: W. Berry 
Battelle Memorial Institute 505 King Avenue

Columbus, Ohio 43201

Attn: DMIC

Babcock \& Wilcox Company P.O. Box 1260

Lynchburg, Va. 24505

Attn: C. Baroch

Bobcock \& Wilcox Company P.O. Box 1260

Lynchburg, Va. 24505

Attn: L. Weissert

Babcock \& Wilcox Company P.O. Box 1260

Lynchburg, Va. 24505

Attn: J. Landis

Babcock \& Wilcox Company P.O. Box 1260

Lynchburg, Va. 24505

Attn: C. Johnson

Combustion Engineering, Inc. Naval Reactors Division

P.O. Box 400

Windsor, Connecticut 06095

Attn: W.P. Chernock

Combustion Engineering, Inc. Naval Reactors Division. P.O. Box 400

Windsor, Connecticut 06095

Attn: S.S. Christopher

Gulf General Atomics, Inc.

P.O. Box 608

San Diego, California 92112

Attn: S. Jaye

General Electric Company

KAPL

One River Road

Schenectady. N.Y.

Attn: A.E. Bibb

General Electric Company

NMPO

P.O. Box 132

Cincinnati, Ohio 45215

Attn: V.P. Calkins
1 General Electric Company

NMPO

P.O. Box 132

Cincinnati, Ohio 45215

Attn: C. Brassfield

1

General Electric Company

NMPO

P.O. Box 132

Cincinnati, Ohio 45215

1

Attn: J. McGurty

Savannah River Laboratory-du Pont

E.I. du Pont de Nemours \& Co.

Savannah River Plant

1 Aiken, South Carolina 29801

Attn: TIS Document Room

Battelle

1

Pacific Northwest Laboratories

Battelle Boulevard

- Richland, Washington 99352

Attn: R. P. Marshall

Westinghouse Electric Corporation

APD

P.O. Box 355

Pittsburgh, Pa. 15230

Attn: T. Stern

Westinghouse Electric Corporation

Bettis Atomic Power Plant

P.O. Box 79

West Mifflin, Pa. 15122

Attn: E.J. Kreigh

Westinghousc Elcctric Corporation

Bettis Atomic Power Plant

P.O. Box 79

West Mifflin, Pa. 15122

Attn: R.H. Fillnow

1 Westinghouse Electric Corporation

Bettis Atomic Power Plant

P.O. Box 79

West Mifflin, Pa. 1512 ?

Attn: B. Lustman

1 Westinghouse Electric Corporation 
Idaho Nuclear Corporation P.O. Box 1845

Idaho Falls, Idaho 83401

Attn: J.M. Beeston

Idaho Nuclear Corporation P.O. Box 1845

Idaho Falls, Idaho 83401

Attn: W. C. Francis
$1 \quad$ United Nuclear Library

\section{Elmsford, New York 10523}

